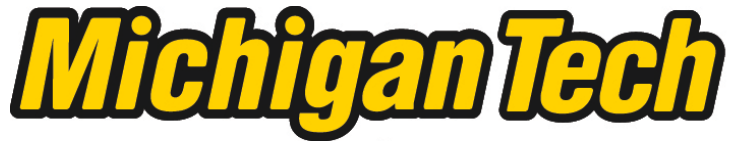 \\ Michigan Technological University Create the Future Digital Commons @ Michigan Tech
}

Dissertations, Master's Theses and Master's Reports - Open

Dissertations, Master's Theses and Master's

Reports

2005

Corrugated wood composite panels for structural decking

Wei Chiang Pang

Michigan Technological University

Follow this and additional works at: https://digitalcommons.mtu.edu/etds

Part of the Civil and Environmental Engineering Commons

Copyright 2005 Wei Chiang Pang

\section{Recommended Citation}

Pang, Wei Chiang, "Corrugated wood composite panels for structural decking", Dissertation, Michigan Technological University, 2005.

https://doi.org/10.37099/mtu.dc.etds/263

Follow this and additional works at: https://digitalcommons.mtu.edu/etds

3 Part of the Civil and Environmental Engineering Commons 


\title{
Corrugated Wood Composite Panels For Structural Decking
}

\author{
By: \\ WEI CHIANG PANG
}

\begin{abstract}
A DISSERTATION
Submitted in partial fulfillment of the requirements

for the degree of

DOCTOR OF PHILOSOPHY

Civil Engineering
\end{abstract}

MICHIGAN TECHNOLOGICAL UNIVERSITY

2005 
This dissertation, "Corrugated Wood Composite Panels for Structural Decking”, is hereby approved in partial fulfillment of the requirements for the degree of DOCTOR OF PHILOSOPHY in the field of Civil Engineering.

Department of Civil and Environmental Engineering

Dissertation Advisor:

Dr. L. Bogue Sandberg

Date

Department Chair:

Dr. C. Robert Baillod Date




\section{Acknowledgements}

I would like to express my gratitude to all who have helped me or supported me to complete this project. I'm especially thankful to my advisor Dr. L. Bogue Sandberg for giving me the opportunity to work with him on this research. I appreciate his advice and patience throughout my graduate study.

This project was supported by the National Research Initiative of the USDA Cooperative State Research, Education and Extension Service, grant number 200135504-10042. I'm grateful to the USDA for the funding.

My sincere appreciation also go to my dissertation committee, Dr William M. Bulleit, Dr. Theresa M. Ahlborn, and Dr. Peter E. Laks, for taking time to review this dissertation.

I would also like to thank John W. Forsman (Assistant Research Scientist) and William A. Yrjana (Research Associate) from the Forest Resources and Environmental Science Department for helping me in the production of the corrugated panels.

Last but not least, I would like to thank my family for giving me a great life and providing me the opportunity to study in the United States of America. 


\section{Abstract}

High flexural strength and stiffness can be achieved by forming a thin panel into a wave shape perpendicular to the bending direction. The use of corrugated shapes to gain flexural strength and stiffness is common in metal and reinforced plastic products. However, there is no commercial production of corrugated wood composite panels. This research focuses on the application of corrugated shapes to wood strand composite panels.

Beam theory, classical plate theory and finite element models were used to analyze the bending behavior of corrugated panels. The most promising shallow corrugated panel configuration was identified based on structural performance and compatibility with construction practices. The corrugation profile selected has a wavelength equal to 8”, a channel depth equal to $3 / 4$ ”, a sidewall angle equal to 45 degrees and a panel thickness equal to $3 / 8$ ".

16” 16 " panels were produced using random mats and 3-layer aligned mats with surface flakes parallel to the channels. Strong axis and weak axis bending tests were conducted. The test results indicate that flake orientation has little effect on the strong axis bending stiffness. The $3 / 8$ " thick random mat corrugated panels exhibit bending stiffness $\left(400,000 \mathrm{lbs}-\mathrm{in}^{2} / \mathrm{ft}\right)$ and bending strength $(3,000 \mathrm{in}-\mathrm{lbs} / \mathrm{ft})$ higher than ${ }^{23} / 32$ ” or 3/4" thick APA Rated Sturd-I-Floor with a 24” o.c. span rating. Shear and bearing test results show that the corrugated panel can withstand more than 50 psf of uniform load at 48” joist spacings. 
Molding trials on 16 ” 16 ” panels provided data for full size panel production. Full size 4'x8' shallow corrugated panels were produced with only minor changes to the current oriented strandboard manufacturing process. Panel testing was done to simulate floor loading during construction, without a top underlayment layer, and during occupancy, with an underlayment over the panel to form a composite deck. Flexural tests were performed in single-span and two-span bending with line loads applied at mid-span. The average strong axis bending stiffness and bending strength of the full size corrugated

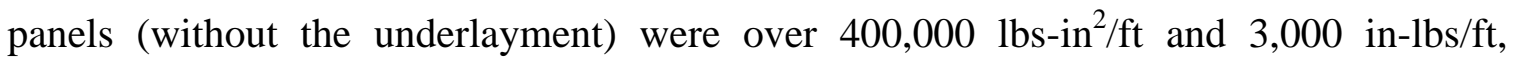
respectively. The composite deck system, which consisted of an OSB sheathing $\left({ }^{15} / 32\right.$ ” thick) nailed-glued (using 3d ringshank nails and AFG-01 subfloor adhesive) to the corrugated subfloor achieved about $60 \%$ of the full composite stiffness resulting in about 3 times the bending stiffness of the corrugated subfloor $\left(1,250,000 \mathrm{lbs}-\mathrm{in}^{2} / \mathrm{ft}\right)$. Based on the LRFD design criteria, the corrugated composite floor system can carry 40 psf of unfactored uniform loads, limited by the $\mathrm{L} / 480$ deflection limit state, at 48 ” joist spacings.

Four 10-ft long composite T-beam specimens were built and tested for the composite action and the load sharing between a 24" wide corrugated deck system and the supporting I-joist. The average bending stiffness of the composite T-beam was 1.6 times higher than the bending stiffness of the I-joist.

A 8-ft x 12-ft mock up floor was built to evaluate construction procedures. The assembly of the composite floor system is relatively simple. The corrugated composite floor system might be able to offset the cheaper labor costs of the single-layer Sturd-IFloor through the material savings. However, no conclusive result can be drawn, in terms 
of the construction costs, at this point without an in depth cost analysis of the two systems. The shallow corrugated composite floor system might be a potential alternative to the Sturd-I-Floor in the near future because of the excellent flexural stiffness provided. 


\section{Table of Contents}

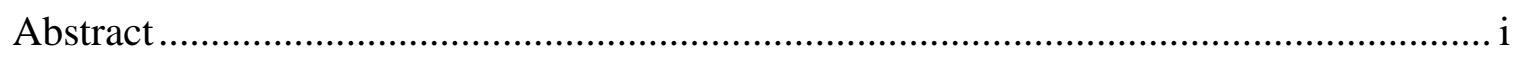

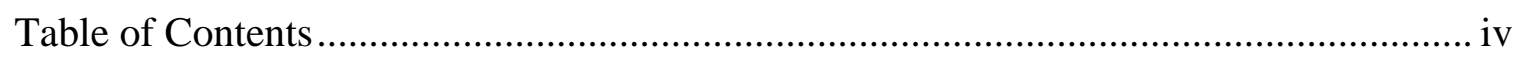

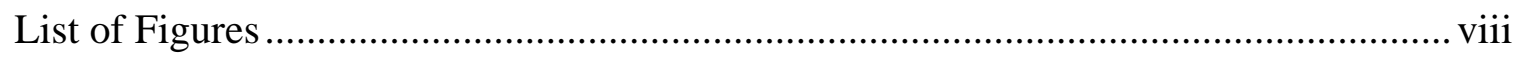

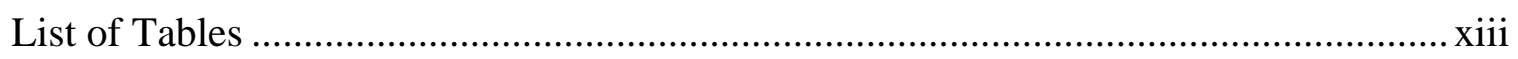

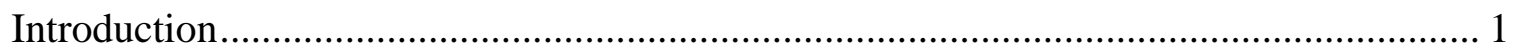

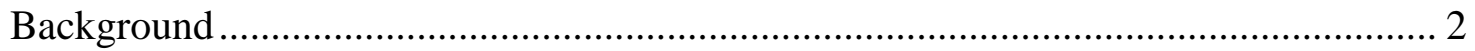

Research Objectives................................................................................................... 4

Research Approach …………………............................................................... 5

Preliminary Panel Geometry Studies .......................................................................... 8

Relative Stiffness and Relative Strength................................................................. 9

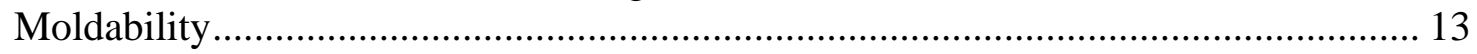

Corrugated Panel Profile for Molding Trials ............................................................. 15

Configuration of Composite Deck System .................................................................... 17

Mathematical Models................................................................................................ 18

Finite Element Model ............................................................................................... 20

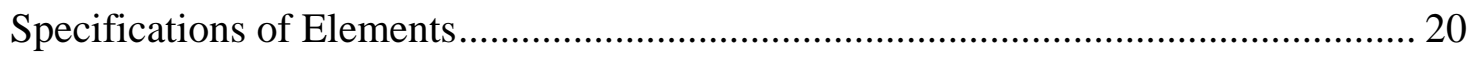

Boundary Conditions and Gap Elements ............................................................... 22

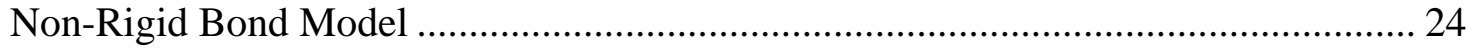

Orthotropic Plate Model ............................................................................................. 27

Trigonometric Series Expansion of Loads.................................................................. 29

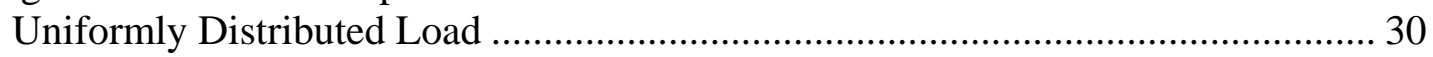

Uniform Line Load .......................................................................................... 32

Concentrated Load............................................................................................ 34

Free-Free and Simply Supported (FFSS) Plates ……….............................................. 35

Rayleigh-Ritz Method............................................................................................ 36

Approximate Function for FFSS Plates .................................................................. 37

Convergence studies of FFSS Plates......................................................................... 39

Anticlastic Effect ………................................................................................ 41

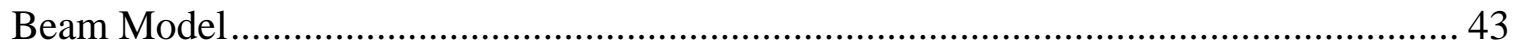

Shear Correction Coefficient .................................................................................. 43

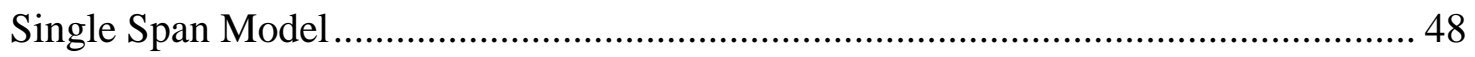

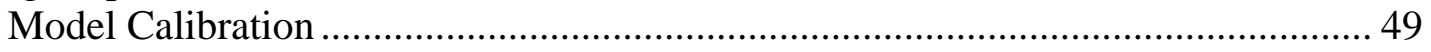

Two-span Model ......................................................................................................... 53 


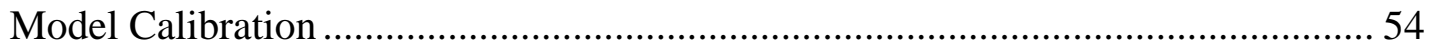

MOE and MOR of Corrugated Panels .................................................................... 56

Composite Deck Beam Model........................................................................... 57

Bending Stiffness of Partial Composite Deck ......................................................... 57

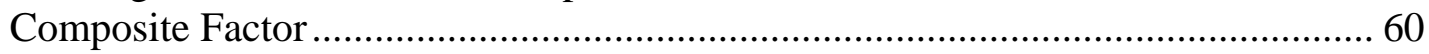

Shear Stiffness of Partial Composite Deck ………………....................................... 61

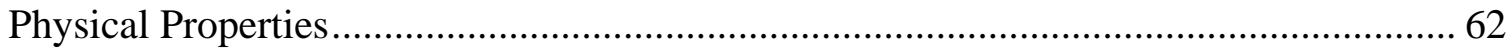

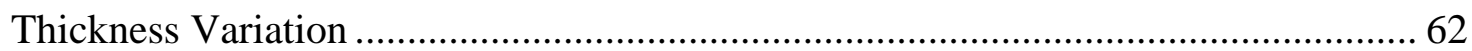

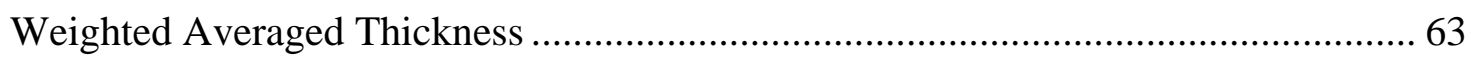

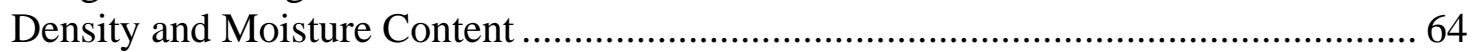

Manufacture of 16”x16" Corrugated Panels ......................................................................... 66

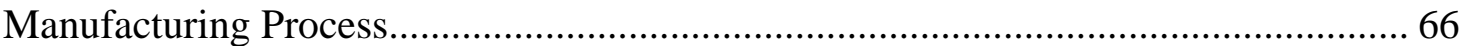

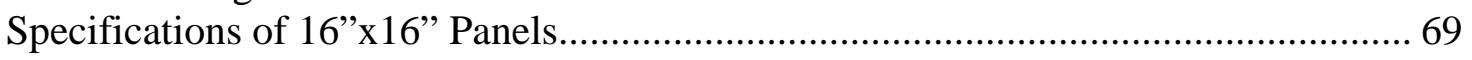

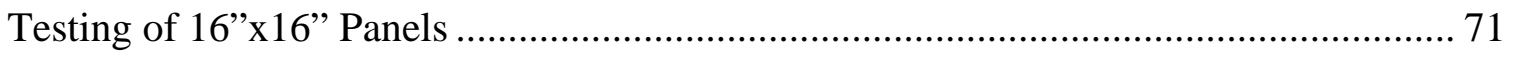

Weak Axis Bending Test ...................................................................................... 72

Test Procedures ......................................................................................... 72

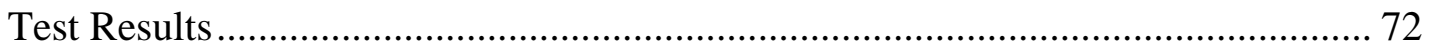

Finite Element Model ................................................................................. 74

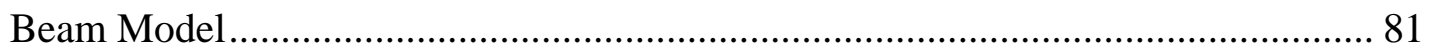

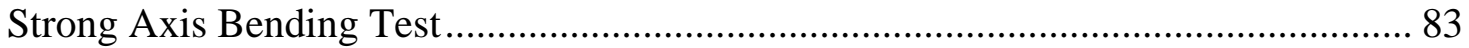

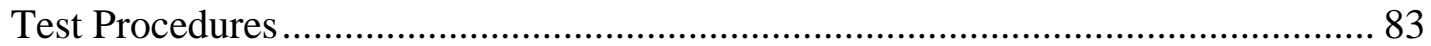

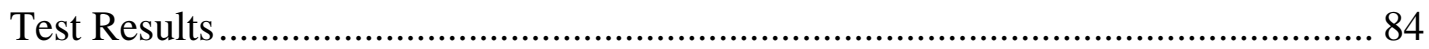

Finite Element Model ............................................................................................. 87

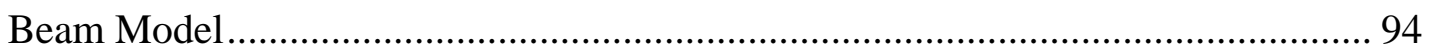

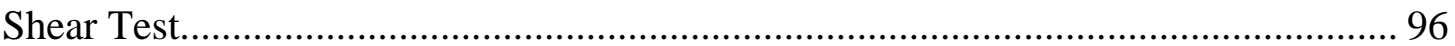

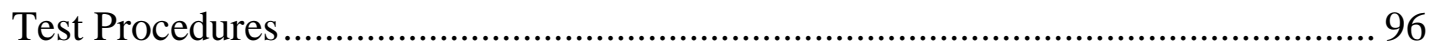

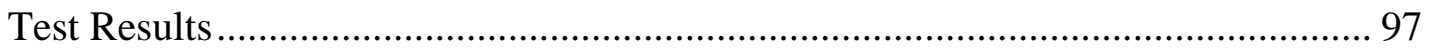

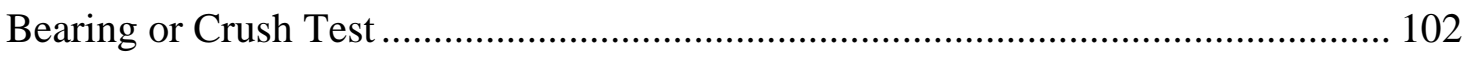

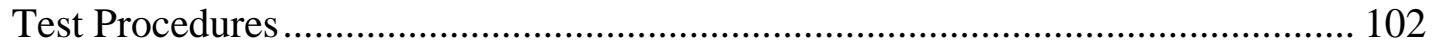

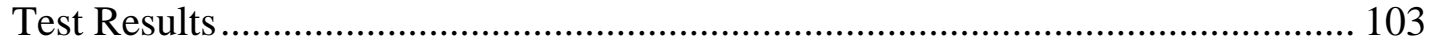

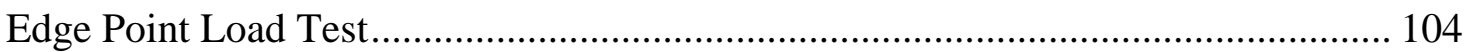

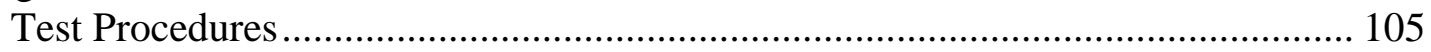

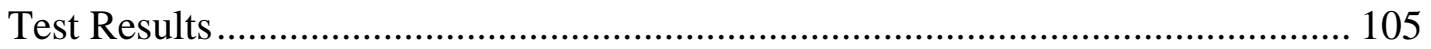

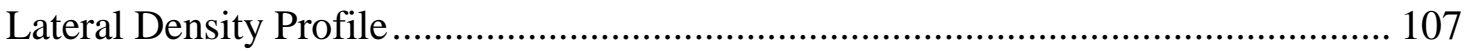

Comparison of Corrugated Panel and APA Rated Sturd-I-Floor ................................ 108

Manufacture of 4ft x 8ft Corrugated Panels ................................................................... 109

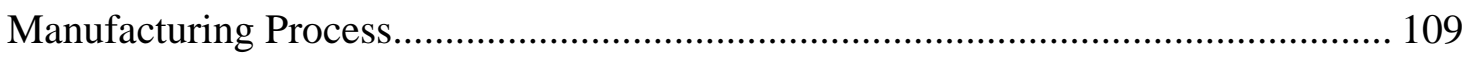

Full-Scale Panel Testing ................................................................................................. 113

Strength Axis Flexure Test of 4'x8' Corrugated Panels .............................................. 113

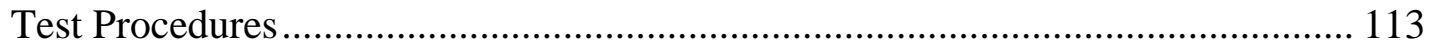

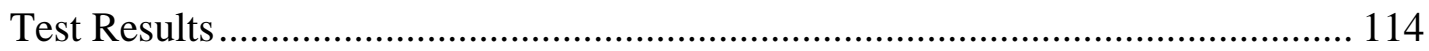

Strength Axis Static Bending of 2’ Wide Corrugated Panel........................................ 117 
Corrugated Panel Single Span Test........................................................................ 118

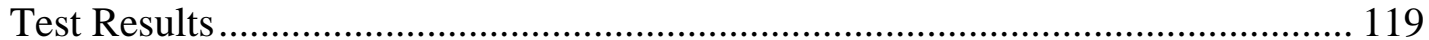

Corrugated Panel Two-Span Continuous Test...................................................... 123

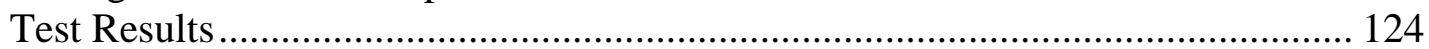

Strength Axis Static Bending of 2' Wide Partial Composite Deck .............................. 127

Single Span Partial Composite Deck Test ................................................................ 127

Composite Deck Two-Span Continuous Bending Test .......................................... 137

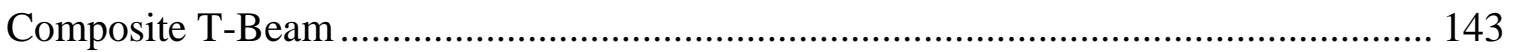

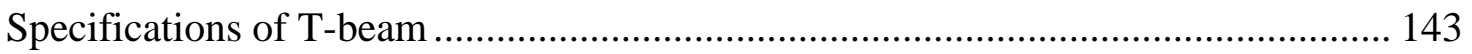

Experimental Procedures and Results....................................................................... 144

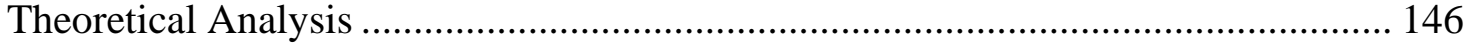

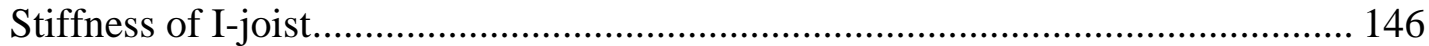

Stiffness of Partial Composite T-beam ................................................................. 148

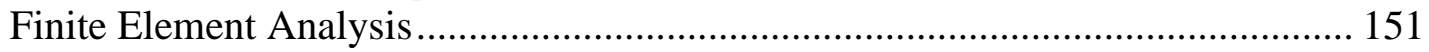

Comparison of FE and Beam Models ................................................................. 153

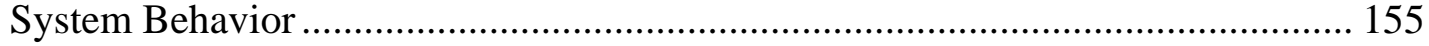

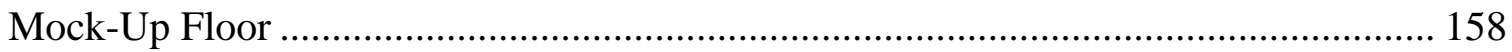

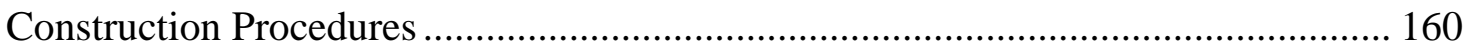

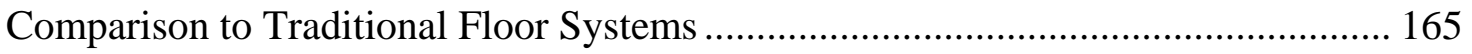

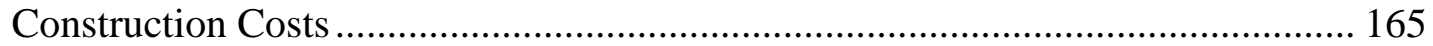

Flexural Performances ………………………………….................................. 166

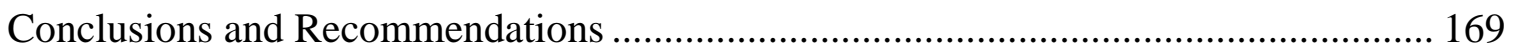

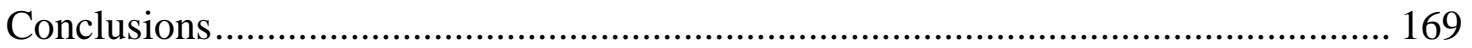

Recommendations for Future Work......................................................................... 170

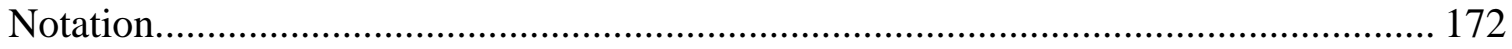

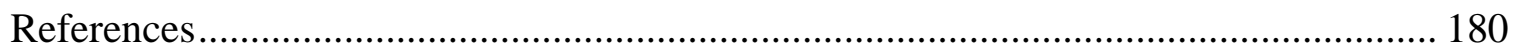

Appendix A. Moment of Inertia of Corrugated Panel ..................................................... 183

Appendix B. Moldability Factor ..................................................................................... 185

Appendix C. Cross-sectional Area of Corrugated Panel .................................................. 186

Appendix D. FFSS Plate Under Line Load for Matlab Program...................................... 187

Appendix E. Dimensions of Mid Surfaces ……………….......................................... 190

Appendix F. Test Data for 16”x16” Panels ........................................................................ 191

Appendix G. Test Data for 4’x8’ Panels......................................................................... 194

Appendix H. Lateral Density Profile Data...................................................................... 195 
Appendix I. 4'x8' Corrugated Panels Board Diagram............................................... 198

Appendix J. Test Data for 2' Wide Corrugated Panels and Composite Decks............... 202

Appendix K. Shear Modulus of I-Joist .................................................................. 207

Appendix L. Allowable Moment Estimation for Composite T-Beam........................... 209 


\section{List of Figures}

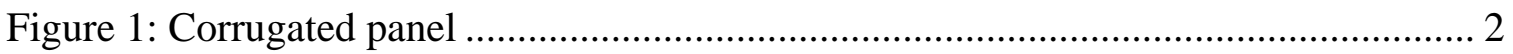

Figure 2: Geometric variables defining the corrugation profile. .................................... 8

Figure 3: Relative bending stiffness and relative bending strength of corrugated panels over flat panels with varying (a) wavelength, (b) channel depth, (c) sidewall angle,

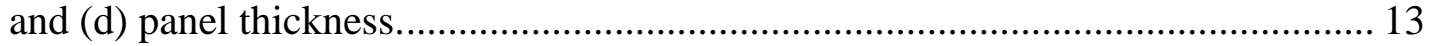

Figure 4: Moldability factor for corrugated panels with varying (a) wavelength, (b) channel depth, (c) sidewall angle, and (d) panel thickness................................... 15

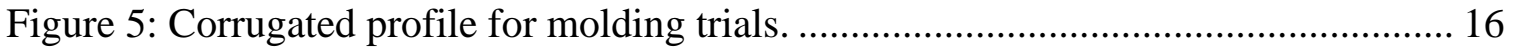

Figure 6: Composite deck system cross section view............................................... 17

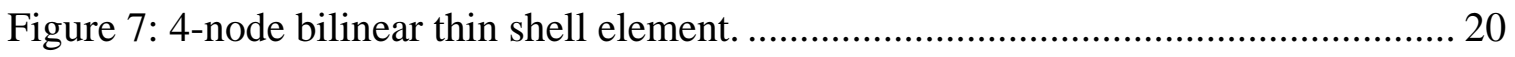

Figure 8: Typical 4-node thin shell elements mesh for corrugated panel........................ 22

Figure 9: Reaction forces and deformed shape of corrugated panel at the supports of finite

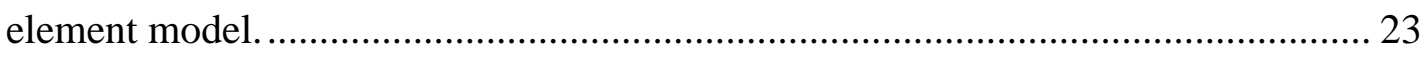

Figure 10: Typical mesh for composite deck FE model............................................. 24

Figure 11: Finite element model of corrugated panel-OSB partial composite joint......... 25

Figure 12: Non-rigid bond finite element model. ....................................................... 26

Figure 13: Equivalent orthotropic plate model of corrugated panel.............................. 27

Figure 14: Uniformly distributed load on rectangular plate. ........................................ 30

Figure 15: Fourier sine series approximation of uniformly distributed load................... 31

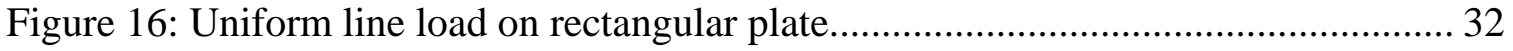

Figure 17: Fourier sine series approximation of uniform line load................................ 33

Figure 18: Concentrated point load on rectangular plate............................................ 34

Figure 19: A rectangular plate with simple supports at two opposite edges and free on the

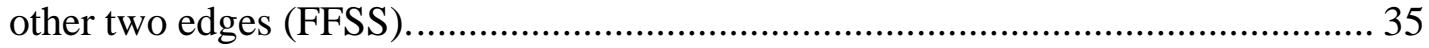

Figure 20: Rayleigh-Ritz approximate functions for FFSS plates................................ 38

Figure 21: Convergence plot of N-parameter Rayleigh-Ritz approximation of FFSS plate

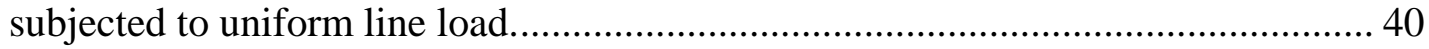


Figure 22: Convergence plot of M-load terms of FFSS plate subjected to uniform line load. 41

Figure 23: Anticlastic effect of FFSS plate model................................................... 42

Figure 24: Cross section of corrugated panel above the neutral axis. ........................... 45

Figure 25: First static moment of corrugated panel. .................................................... 45

Figure 26: Shear stress distribution through the thickness of corrugated panel. .............. 46

Figure 27: Shear correction coefficient of corrugated panels of varying panel skin

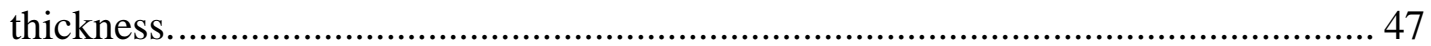

Figure 28: Simple beam with concentrated load at mid-span...................................... 48

Figure 29: Deflections of calibrated single-span and two-span beam models................. 52

Figure 30: Beam fixed at one end, support at other and concentrated load at mid-span.. 53 Figure 31: Effective axial stiffness of the partial composite deck system for beam model.

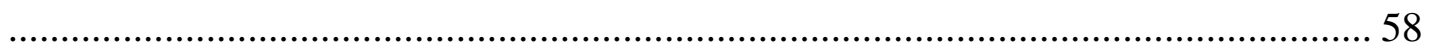

Figure 32: Neutral axis of the partial composite deck system. .................................... 59

Figure 33: Thickness variation of corrugated panel due to die closing gap. ................... 63

Figure 34: Weighted average thickness calculation.................................................... 64

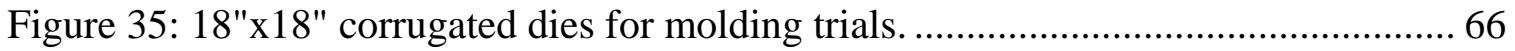

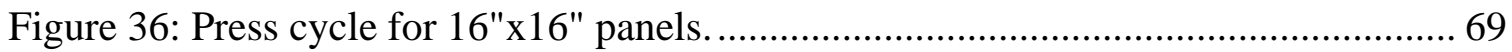

Figure 37: Weak axis bending test assembly for 3"x16" corrugated panels................... 72

Figure 38: Load-deflection curves for weak axis bending specimens............................. 74

Figure 39: Finite element model for 3"x16" weak axis bending test............................... 75

Figure 40: Poisson’s ratio sensitivity studies of 3"x16" weak axis bending specimens... 76

Figure 41: Panel skin thickness sensitivity studies of 3"x16" weak axis bending

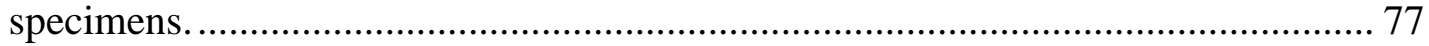

Figure 42: Shear modulus sensitivity studies of 3"x16" weak axis bending specimens. . 78

Figure 43: Modulus of elasticity sensitivity studies of 3"x16" weak axis bending

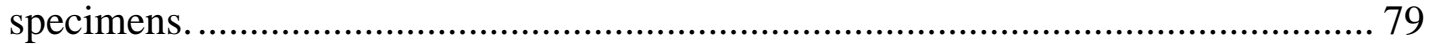

Figure 44: FE models and test data of 3”x16” weak axis bending test specimens.......... 80

Figure 45: Equivalent length of simple beam with concentrated load at mid-span.......... 81

Figure 46: Strong axis bending test assembly for 16"x16" corrugated panels. ................ 84

Figure 47: Linear regression for typical load-deflection curve. .................................... 86 
Figure 48: Load-displacement curves for strong axis bending specimens. ..................... 86

Figure 49: Finite element model for 16”x16” strong axis bending test........................... 87

Figure 50: Poisson's ratio sensitivity studies of 16"x16" strong axis bending specimens.

Figure 51: Panel skin thickness sensitivity studies of 16"x16" strong axis bending specimens.

Figure 52: Modulus of elasticity sensitivity studies of 16"x16" strong axis bending specimens. 90

Figure 53: Shear modulus sensitivity studies of 16"x16" strong axis bending specimens.

Figure 54: Determination of modulus of elasticity to shear modulus ratio. 92

Figure 55: FE models and test data of 16"x16" strong axis bending test specimens........ 93

Figure 56: Shear test assembly for 16”x16” corrugated panels..................................... 96

Figure 57: Load-displacement curves for shear test specimens................................... 97

Figure 58: Simple beam with concentrated load at any point....................................... 98

Figure 59: Estimation of the shear strength for 16”x16” corrugated panel using empirical equations; (a) maximum moment, (b) maximum load, and (c) maximum shear.... 101

Figure 60: Bearing or crush test assembly for 16"x16" panels..................................... 102

Figure 61: Load-deflection curves for crush test panels........................................... 103

Figure 62: Edge point load test assemblies for 16"x16" panels with (a) lower decks as

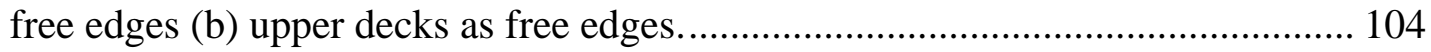

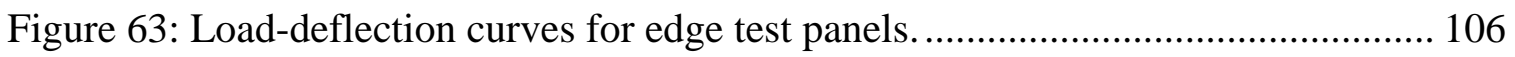

Figure 64: Lateral density profiles of corrugated panels. .......................................... 107

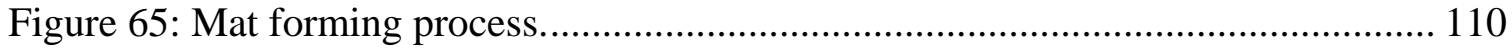

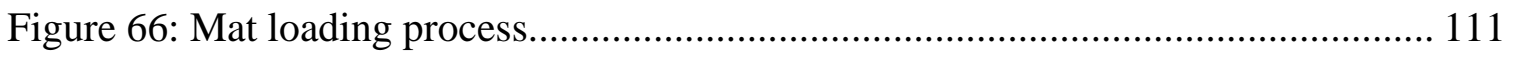

Figure 67: 4'x8' corrugated panel flexure test setup. ............................................... 114

Figure 68: Load-to-deflection ratio versus thickness of beam model, plate model and test

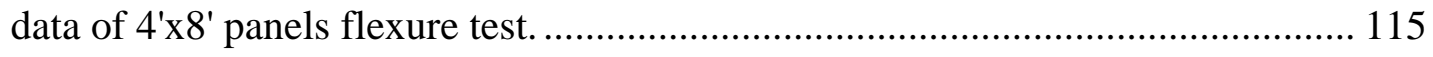

Figure 69: Bending stiffness versus panel density plot for 4'x8' corrugated panels....... 116

Figure 70: Bare panel single-span bending test assembly........................................ 119

Figure 71: Typical finite element model for 2’ wide single-span bending test. ............. 120 
Figure 72: Test results of bare corrugated panel single-span test for nominal (a) 24" and

(b) 32" nominal spans. 121

Figure 73: Test assembly for two-span continuous strong axis static bending test........ 123

Figure 74: Typical finite element model for 2' wide two-span continuous bending test.

Figure 75: Test results of bare corrugated panel double-span test for nominal (a) 24" and

(b) $32 "$ nominal spans. 126

Figure 76: $1 / 4$ " bead adhesive on corrugated panel. 128

Figure 77: Single-span composite deck test specimen. 128

Figure 78: Composite deck single-span bending test assembly.... 129

Figure 79: Typical finite element model for 2' wide single-span partial composite bending test. 130

Figure 80: Load-to-deflection versus adhesive shear modulus plots of the (a) 24” and (b) 32” single-span FE and beam models. 135

Figure 81: Composite deck two-span bending test assembly 137

Figure 82: Typical finite element model for 2' wide two-span partial composite bending test. 140

Figure 83: Load-to-deflection versus adhesive shear modulus plots of the (a) 24” and (b) 32” double-span FE and beam models.

Figure 84: Assembly of double-T-beam. 144

Figure 85: Composite T-beam test with two equal loads symmetrically placed. 145

Figure 86: Cross sectional view of prefabricated wood I-joist.

Figure 87: Cross sectional view of composite T-beam: (a) end view and (b) side view.149 Figure 88: Finite element model of partial composite T-beam; (a) isometric view, (b) side view, and (c) I-joist model. 152

Figure 89: Load-to-deflection versus adhesive shear modulus of the partial composite Tbeam. 154

Figure 90: Schematic of the composite corrugated floor system; (a) top view, (b) side view, and (c) front view. 159

Figure 91: Mock-up floor construction; four I-joists at 32" spacing. 160

Figure 92: Mock-up floor construction; 1/4” diameter AFG-01 adhesive on I-joist. 161 
Figure 93: Mock-up floor construction; nails schedule of corrugated subfloor.

Figure 94: Mock-up floor construction; application of adhesive on corrugated subfloor. 163

Figure 95: Mock-up floor construction; installation of underlayment.......................... 164

Figure 96: Corrugated composite floor system...................................................... 164 


\section{List of Tables}

Table 1: Input properties of FFSS plate for convergence studies.

Table 2: Deflection error of single-span original and corrected beam models from FE model.

Table 3: Deflection error of two-span original and corrected beam models from FE

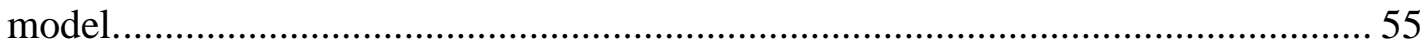

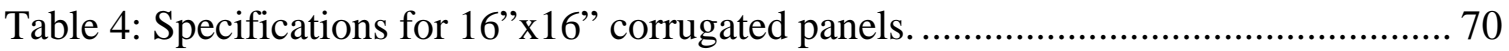

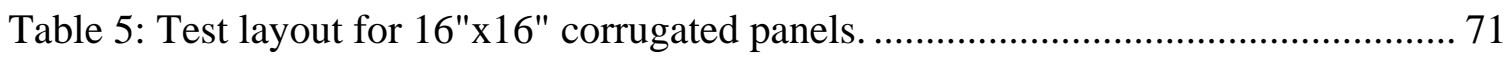

Table 6: Moisture content and density of weak axis bending test specimens. ................. 73

Table 7: Sensitivity studies of Poisson's’s ratio of 3"x16" weak axis bending specimens.

Table 8: Sensitivity studies of thickness of 3"x16" weak axis bending specimens.......... 76

Table 9: Sensitivity studies of shear modulus of 3"x16" weak axis bending specimens. 77

Table 10: Sensitivity studies of MOE of 3"x16" weak axis bending specimens.............. 78

Table 11: FE models for weak axis bending of 3"x16" specimens with different MOE and

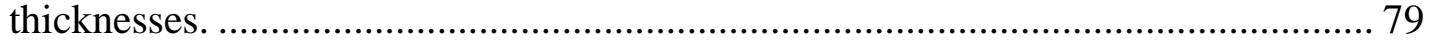

Table 12: MOE and weak axis bending stiffness of 3"x16” specimens estimated using FE

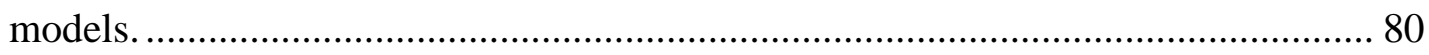

Table 13: MOE, bending stiffness and strength of weak axis bending tests, estimated

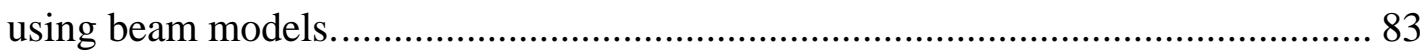

Table 14: Moisture content and density of strong axis bending test specimens............... 85

Table 15: Sensitivity studies of Poisson’s ratio of 16"x16" strong axis bending specimens.

Table 16: Sensitivity studies of thickness of 16"x16" strong axis bending specimens. ... 89

Table 17: Sensitivity studies of MOE of 16”x16" strong axis bending specimens.......... 90

Table 18: Sensitivity studies of shear modulus of 16"x16" strong axis bending specimens.

Table 19: FE models for strong axis bending of 16"x16" specimens with different MOE and thicknesses 
Table 20: MOE and strong axis bending stiffness of 16”x16” specimens estimated using

FE models.

Table 21: Bending stiffness and bending strength of strong axis bending test estimated using beam theory. 95

Table 22: Average moisture content and densities for the shear and end bearing tests specimens.

Table 23: Maximum shear and moment for the shear and strong axis bending tests....... 99

Table 24: Estimation of shear strength for 16"x16" corrugated panel. 100

Table 25: Uniform load capacities (psf) of the 16"x16” corrugated panel at 0.02 " of deformation under compression. 104

Table 26: Average moisture content and densities for edge test specimens 105

Table 27: Average stiffness and average maximum load for edge test specimens. 106

Table 28: Bending stiffness and strength of corrugated panel estimated from small specimen testing. 108

Table 29: Panel design bending stiffness and strength for APA Rated Sturd-I-Floor.... 108

Table 30: Flexure test results of 4'x8' corrugated panel................................................. 117

Table 31: Bare corrugated panel single span bending test results................................... 122

Table 32: Bare corrugated panel two-span continuous bending test results.................... 125

Table 33: Input parameters of the FE model for single-span partial composite deck bending test.

Table 34: Partial composite deck single-span bending test results. 136

Table 35: Input parameters of the FE model for two-span partial composite deck bending test. 140

Table 36: Partial composite deck double-span bending test results. 142

Table 37: Test results of composite T-beams. 145

Table 38: Material properties of the partial composite T-beam finite element mesh..... 153

Table 39: Comparison of partial composite T-beam FE and beam models. 154

Table 40: System effect of nailed-glued T-beam assembly with corrugated composite deck system. 157

Table 41: Section properties of corrugated panel. 166 
Table 42: Baseline flexural capacities of corrugated panel and composite deck system. 167

Table 43: Unfactored uniform load capacities (psf) of corrugated panel. ....................... 168 Table 44: Unfactored uniform load capacity (psf) of corrugated composite deck (with 15/32" rated 32/16 OSB sheathing as underlayment) .............................................. 168 


\section{Introduction}

Wood flake composite panels, such as oriented strandboard (OSB) or flakeboard, have gained more and more market share over plywood in the structural panel sector over the past 20 years. In 2001, OSB accounted for 53\% of structural panel consumption and is projected to remain above plywood consumption in the future [Howard 2001]. The decline of plywood production is primarily due to less availability of large diameter roundwood, which is essential for obtaining veneer for plywood production. On the other hand, wood flake composite panels can utilize young growth trees with smaller diameter. With the diminishing of large diameter roundwood, there is a need to improve the efficiency of composite panels in order to meet the market's demand and to fully utilize young growth forest resources.

In the past two decades, there has been a great deal of research to improve the mechanical properties of flat flakeboard and OSB by optimizing the resin content, flake geometry, flake alignment, additives, etc. It appears that the strength of flat composite panels has been pushed to the limit of current technology. One option to improve the strength of a panel would be to alter the shape of the panel into a more efficient geometry. Higher stiffness and flexural strength can be obtained by molding the flakeboard into a corrugated shape perpendicular to the direction of primary bending (Figure 1). The idea of using a corrugated panel is not new; it is very common in the plastic and sheet metal industries. Nevertheless there is currently no commercial production of corrugated wood panels as decking materials for floor or roof systems. 


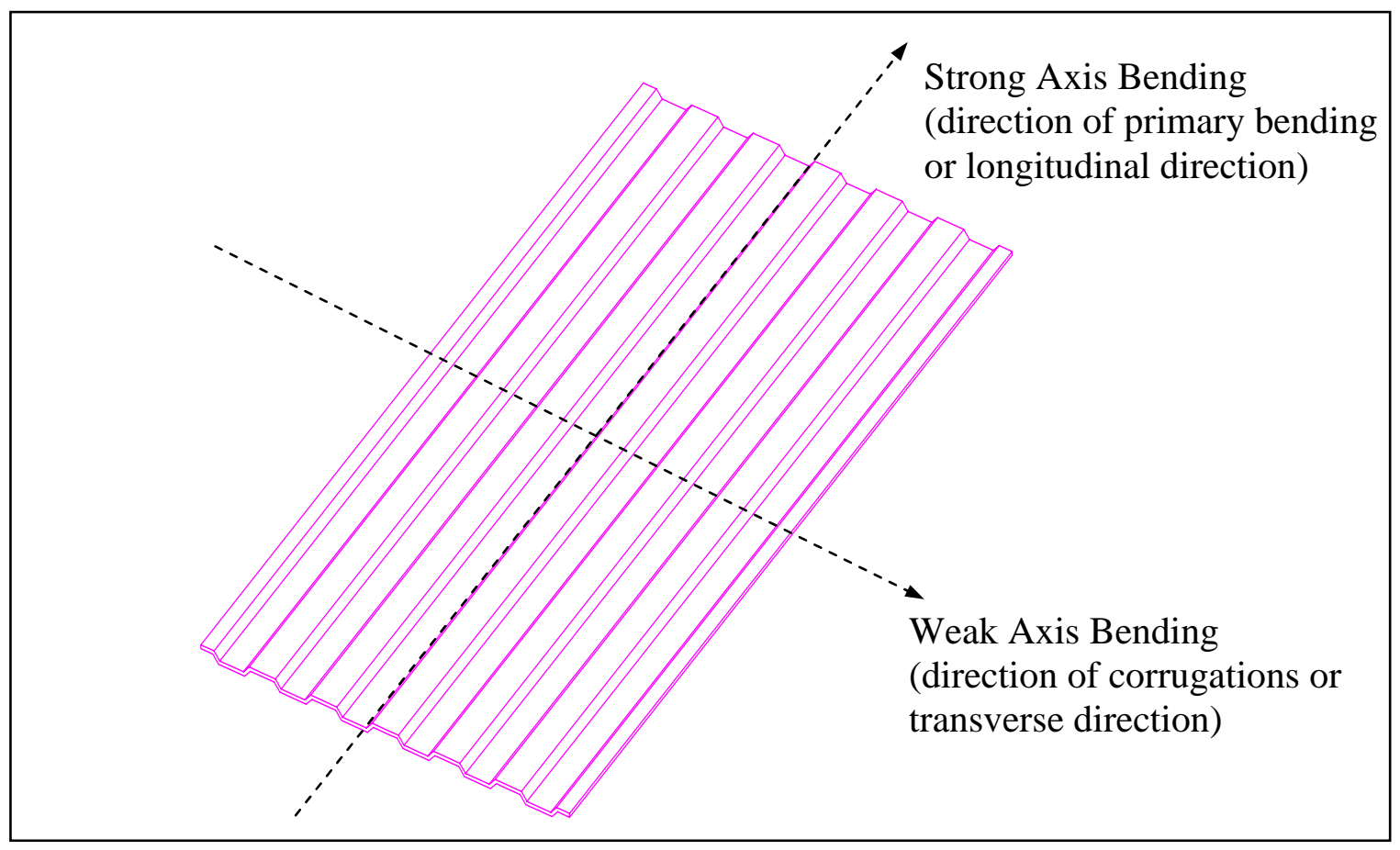

Figure 1: Corrugated panel

\section{Background}

In the mid 1970s, Price and Kesler [Price and Kesler 1974] molded relatively shallow small specimen corrugated panels (16”x18” trimmed size, 30-degree pitch with 5.63” period, 45-degree pitch with 4.00” period and 45-degree pitch with 5.63” period) by placing a flat wood flake mat on a set of fixed corrugated platens. The thickness of all

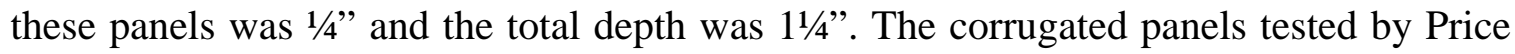
and Kesler did not exhibit good bending properties. Lower maximum stress and lower modulus of elasticity were reported for these panels compared to the flat boards with similar thickness. The lower strength properties reported may have been due to bad flow properties of the mat in the cross corrugation direction because the initial flat mat must elongate to assume the shape of the corrugated platens. This suggested that the molding 
process needed to be refined in order to produce corrugated boards with better strength properties.

Later in the 1980s, Michigan Technological University performed extended studies on the molding behavior of flat-top deep corrugation panels molded by using fixed corrugated platens [Baas 1989; Liptak 1989; Vandenbergh 1988]. These studies used painted grids on the ends of the mat to monitor the flake movement during the pressing. A parameter called the moldability factor (MF) was used to quantify the molding difficulty of panels with different geometries [Haataja, Sandberg, and Liptak 1991]. By understanding the movement of the mat during pressing and adjusting the forming techniques accordingly, Michigan Technological University, with support from Weyerhaeuser Company, was able to produce deep full size corrugated panels. These panels ranged from $3 / 8$ " to $7 / 16$ " thick and 3" to 4" deep. Excellent strength and stiffness properties were reported on these deep drawn corrugated panels. However, the manufacturing process was not adopted by existing OSB mills due to one major problem: the complexity in the mat forming techniques which required a great degree of modification in the current mat forming process of OSB mills.

In addition to the research at Michigan Technological University, a project on deep drawn corrugated panels, called Waveboard $\AA^{*}$, was conducted at the Alberta Research Council (ARC) Forest Products Laboratory in Edmonton, Canada in the 1980s [Bach 1989]. Waveboard was produced on a set of platen assemblies that were mechanically converted from an initial stage of flat configuration to the final sine curve configuration. This pressing process eliminated transverse density variation that can

\footnotetext{
${ }^{*}$ Waveboard ${ }^{\circledR}$ is a registered name for corrugated waferboard developed by Alberta Research Council.
} 
result from fixed flat-top corrugated platens. In spite of that, Waveboard ${ }^{\circledR}$ did not go into commercial production because of the complications involved in fabricating, operating and maintaining the mechanical platens. Another disadvantage of sine wave cross section would be that attaching joists or flat panels would be difficult compared to a flat-top corrugated pattern.

\section{Research Objectives}

Past research has been focused mostly on the improvement of material properties in order to increase the performance of flat wood composite panels as decking materials. This research will focus on the use of a corrugated shape to gain strength rather than improving the panel material properties. Design, manufacturing and testing of corrugated panels will be the main focus for this research. A brief and preliminary study of the handling of corrugated panels during construction will be conducted to assess the adaptability of the current construction practices. There are four main objectives for this research:

1. Formulate finite element models and/or other mathematical models to predict and estimate the strength and stiffness for various corrugation profiles.

2. Develop a manufacturing process for corrugated panels that is feasible for large-scale commercial production. The goal is to produce corrugated panels with little or no change to the current OSB production lines, such as the flaking, drying, mat forming, pressing, and post-press handling processes.

3. Manufacture and test the performance of corrugated panels (trimmed size: 16”'16" and 4'x8') for comparison to flat panels. 
4. Construct and test the performance of floor system assemblies consisting of underlayments, corrugated panels as subfloors, and composite I-beams. Building of the full-scale floor system will provide an opportunity to study possible problems involving handling of corrugated panels during construction.

\section{Research Approach}

This project can be divided into six stages; (1) preliminary panel geometry studies, (2) mathematical and finite element (FE) modeling, (3) molding, testing and analysis of small specimens (16"x16" trimmed size), (4) molding, testing and analysis of full size panels (4'x8'), (5) composite action testing, and (6) construction of a mock-up floor system.

During the stage of preliminary panel geometry studies, the most promising shallow corrugated panel configuration was selected based on the molding difficulty of the corrugated profile, structural performance and compatibility with current construction practices. A mathematical model was used to predict the relative stiffness and relative strength gain of corrugated panels over flat panels of equivalent thickness. Molding difficulty was also taken into account when choosing corrugation profile, based on the research done at Michigan Technological University [Haataja, Sandberg and Liptak 1991].

The corrugated panel profile selected from preliminary geometry studies was further analyzed using two theoretical models: beam theory and a finite element model. Beam theory was easy to implement and it gave good predictions for the stiffness and strength behavior of corrugated panels. However, beam theory cannot completely describe the behavior of corrugated panels, primarily due to plate action in bending. One 
would assume classical plate theory is more suitable for modeling corrugated panels. Nevertheless, classical plate theory was not used because of the difficulties in solving the governing plate bending differential equation. The solution to a more comprehensive model lies in the use of computing power and the finite element method. Hence, finite element models were constructed to analyze the behavior of corrugated panels more accurately.

Molding trials of a corrugated pattern on an 18 "x18” press was the third phase. Small panels were produced at pilot scale with randomly formed mats and with typical OSB three-layer orientation mat to investigate the basic molding behavior. These specimens were examined visually at critical areas to ensure the design geometry was capable of producing defect-free shallow corrugated panels. The small panel specimens were used to evaluate strong axis bending, transverse bending (weak axis), shear and bearing capacities of the design section.

Full-scale 4-ft x 8-ft panel production on a large press followed as soon as the testing of small panels was completed. A set of aluminum dies and a mat loading device were fabricated for this process. The mat for these full-scale panels was formed randomly. These specimens were tested in bending both with and without an OSB top layer nailed-glued to the corrugated panels. Flexure tests were conducted on single-span and two-span conditions with both nominal 24" and 32” span (22.5” and 30.5” clear span).

Load sharing between the corrugated deck system (OSB top layer nailed-glued to corrugated panel) and the supporting joist was also studied. Four composite action specimens were built for this purpose. These test specimens consisted of a 24" wide deck 
system (OSB top layer nailed-glued to corrugated panel) nailed-glued to 10-ft long Ijoist. Testing was done in four-point bending at a 9'-8” clear span. A finite element model was constructed to analyze the test data.

Building of an 8'x12' mock up floor system was the final stage of this project. Evaluation of the construction procedures was the main focus in the process of assembling the mock up floor. The final floor system was used for subjective vibration testing. 


\section{Preliminary Panel Geometry Studies}

The first stage of this project involves the selection of suitable corrugation profiles based on these criteria: structural performance, manufacturability, and compatibility with current construction practices. A flat-top cross section was used in this study instead of a sine wave cross section for two reasons. First, the moment of inertia for a sine wave cross section is less compared to a flat-top cross section with the same wavelength (period) and overall depth (amplitude). Second, a flat-top cross section provides flat surfaces to simplify the attachment of flat panels as underlayment on top or to attach to joists at the bottom.

The general corrugation geometry chosen for this project is shown in Figure 2. In general, the upper deck width and the lower deck width can be different (unequal wave). However, an equal wavelength section was selected for geometry design studies because it has some advantages over the unequal wavelength section from the construction point of view. The equal wavelength sections reduce possible confusion in panel placement during construction, because the section is vertically symmetric and the mechanical properties are the same, no matter which side of the panel is placed as top.

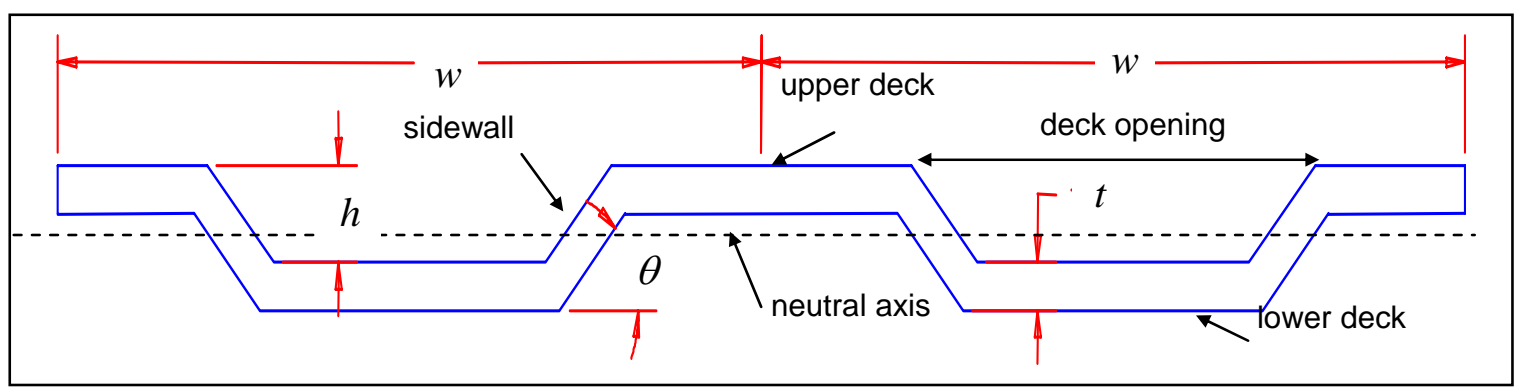

Figure 2: Geometric variables defining the corrugation profile. 
In geometry design studies, four geometric variables are needed to completely define an equal wavelength corrugation profile. These geometric variables are shown in Figure 2, where,

$$
\begin{aligned}
& w=\text { wavelength or period } \\
& h=\text { channel depth } \\
& t=\text { thickness } \\
& \theta=\text { sidewall angle or slope }
\end{aligned}
$$

Note that $h$ is not the overall or total depth (amplitude) of a panel. Instead, the total depth, $d$, is

$$
d=h+t
$$

These geometric variables are used in the calculation of the section properties, such as the moment of inertia and the section modulus, to estimate the relative structural performance of corrugated panels versus flat panels having the same thickness.

\section{Relative Stiffness and Relative Strength}

As discussed in the previous section, the stiffness and the strength of corrugated panels are expected to be higher compared to flat panels with the same thickness. Using simple beam theory, the stiffness and strength gains of corrugated panels over flat panels having the same thickness can be estimated using relative stiffness and relative strength, defined as:

$$
\begin{aligned}
& \text { Relative Stiffness }=\frac{E_{c} \times I_{c}}{E_{f} \times I_{f}} \\
& \text { Relative Strength }=\frac{R_{c} \times S_{c}}{R_{f} \times S_{f}}
\end{aligned}
$$

where, 
$E=$ modulus of elasticity

$R=$ modulus of rupture

$I=$ moment of inertia about the neutral axis of the cross section

$S=$ section modulus

Subscript, $c=$ corrugated panel

Subscript, $f=$ flat panel

The theoretical relative stiffness and relative strength of corrugated panels can be estimated using only the four geometric variables if the material properties, such as modulus of elasticity and modulus of rupture, are assumed to be the same for both corrugated and flat panels. As a result, the relative stiffness and relative strength become the ratio of $I_{c} / I_{f}$ and $S_{c} / S_{f}$, respectively.

The moment of inertia for the corrugated section about its neutral axis, $I_{c}$, can be written in terms of the four basic geometric variables.

$$
I_{c}=\left(\frac{w}{12}+\frac{h}{2 \sin (\theta)}-\frac{h}{2 \tan (\theta)}\right) t^{3}+\left(\frac{w h^{2}}{4}+\frac{h^{3}}{6 \sin (\theta)}-\frac{h^{3}}{2 \tan (\theta)}\right) t
$$

The moment of inertia calculated using equation (4) is for a complete wavelength of corrugation or over a width equal to $w$. The complete derivation of equation (4) can be found in Appendix A. On the other hand, the moment of inertia for the flat plate having the same thickness about its neutral axis, $I_{f}$, can be calculated using,

$$
I_{f}=\frac{w t^{3}}{12}
$$

Assuming both the corrugated and the flat panels have the same MOE, the relative stiffness can be computed by taking the ratio of $I_{c} / I_{f}$, using equations (4) and (5). 
Similarly, the relative strength can be computed by taking the ratio of $S_{c} / S_{f}$, if the corrugated panels and the flat panels are assumed to have the same MOR. The section modulus for the corrugated panels and the flat panels can be defined, in terms of the four basic geometric variables by using equations (4) and (5), respectively,

$$
\begin{gathered}
S_{c}=\frac{I_{c}}{(h+t) / 2} \\
S_{f}=\frac{I_{f}}{t / 2}
\end{gathered}
$$

Using equations (2) to (7), a series of sensitivity studies of relative bending stiffness and strength for all basic geometric variables ( $w, h, \theta$, and $t$ ) were carried out based on the assumption of unchanged material properties for both corrugated panels and flat panels. A baseline corrugation profile, with wavelength equal to 8”, channel depth equal to $3 / 4 ”$, sidewall angle equal to 45 degree, and panel thickness equal to $3 / 8$, was used in these sensitivity studies. The effect that each geometric variable has on the relative bending properties was investigated by varying the value of one variable and keeping the other three geometric variables constant. The results of sensitivity studies for all four geometric variables are plotted in Figure 3.

Channel depth has the most significant impact on the relative bending properties. Increasing the channel depth will dramatically improve the bending properties of corrugated panels, especially the bending stiffness. However, from a manufacturing standpoint, increasing the channel depth will substantially increase the difficulty of panel molding. Past research [Haataja, Sandberg and Liptak 1991] indicated that 3” deep corrugated panels are extremely difficult to mold and special forming techniques may be required. The moldability of the corrugated panels will be discussed in a later section. In 
addition to the channel depth, panel thickness also plays an important role in the relative bending properties.

As opposed to the channel depth, panel thickness has an inverse relation with the relative stiffness and strength. In other words, increasing the thickness will reduce the relative bending property gains of corrugated panels over flat panels having the same thickness. Both the relative stiffness and relative strength decrease asymptotically toward 1.0 as the panel thickness increases beyond the channel depth. This suggests that the thickness should be kept as thin as possible in order to maximize the stiffening effect of corrugations. Nevertheless, there are some limitations on the thinness of panels that can be used as structural decking materials. Panels less than $\frac{5}{16}$ " are not suitable for use as decking material because other problems, such as insufficient panel rigidity and panel punching shear strength through the thickness, may arise.

The effect of changing the wavelength is not significant. Changing the wavelength of the baseline corrugation profile from 4" to 12" slightly increases the relative stiffness and relative strength, from 11.1 to 12.4 and 3.7 to 4.2 , respectively. Increasing the wavelength also increases the deck opening (see Figure 2), which requires the underlayment to span a longer distance. This might impose bending or punching shear problems for the flat panels or underlayment placed on top of the corrugated panels. Thus, shorter wavelength is favorable as long as the selected wavelength does not greatly increase the difficulty in molding the section. Besides the bending performance, moldability is also another important factor to be considered in the determination of suitable corrugation profiles. The molding difficulty of different corrugated profiles will be discussed in the following section. 


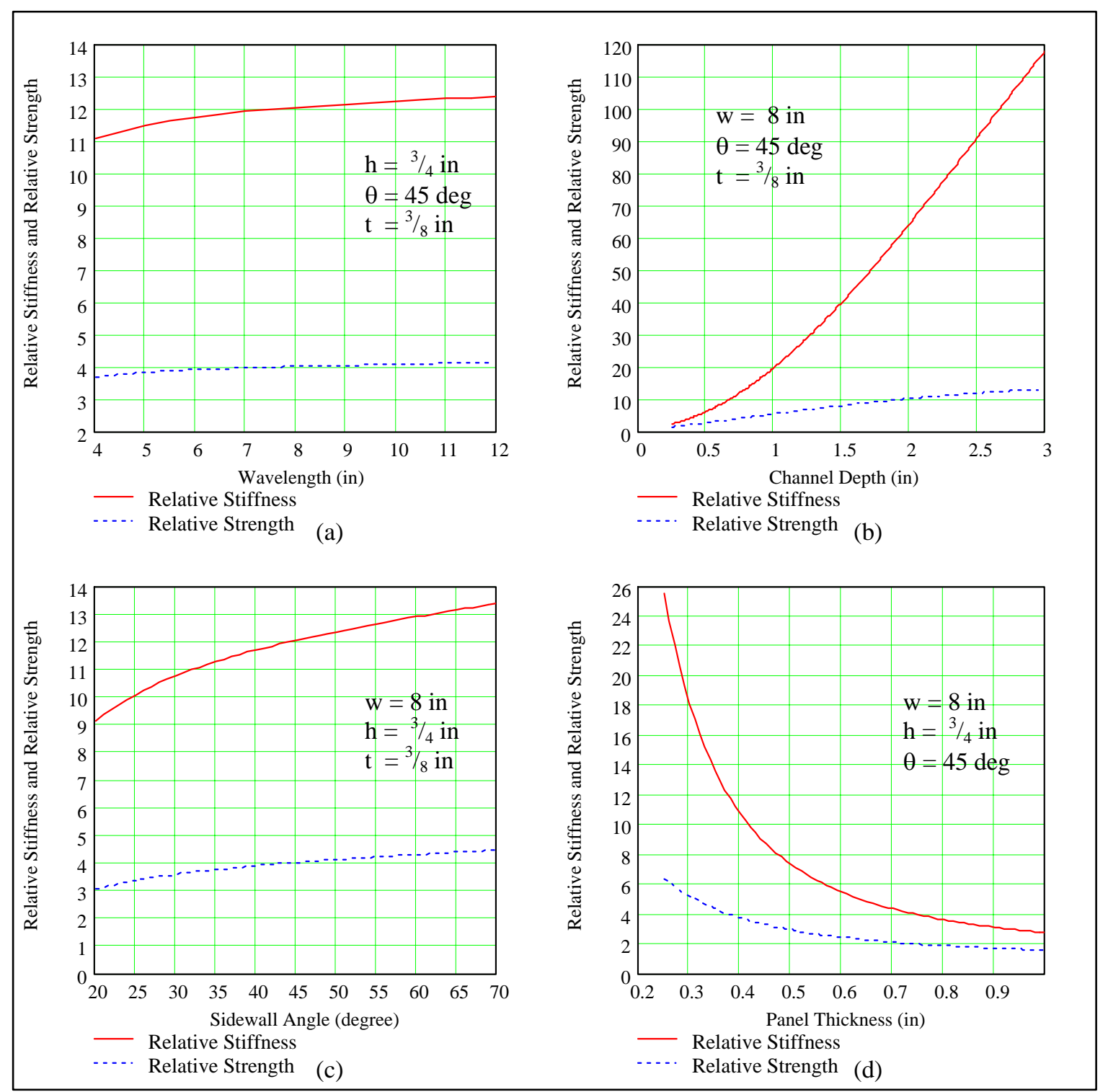

Figure 3: Relative bending stiffness and relative bending strength of corrugated panels over flat panels with varying (a) wavelength, (b) channel depth, (c) sidewall angle, and (d) panel thickness.

\section{Moldability}

Past research done at Michigan Technological University [Haataja, Sandberg and Liptak 1991] suggested the use of a qualitative index, moldability factor ( $M F$ ), to describe the molding behavior and molding difficulty for different corrugated sections. The $M F$ used in this research was modified from the original proposed factor to better 
quantify the relative molding difficulty of corrugated profiles considered in this research. The details of the MF calculations are listed in Appendix B. MF of 1 represents the molding of a flat panel and a $M F$ of 3 represents a relatively difficult to mold section. Sensitivity studies of $M F$ were conducted using the same baseline panel used in the sensitivity studies of relative bending performance. The results of $M F$ sensitivity studies for the four geometric variables are shown in Figure 4.

Channel depth and sidewall angle have the most impact on the moldability. Increasing the channel depth from $1 / 4$ " to 3 " and the sidewall angle from 20 degrees to 70 degrees raises $M F$ values from 1.16 to 1.84 and 1.12 to 1.88 , respectively. A corrugated panel with either a 3" channel depth or a 70 degree sidewall angle is a relatively difficult to mold section.

Figure 4 shows that $M F$ is inversely proportional to wavelength. Increasing the spacing of the channels can ease the molding difficulty since the mat interactions between adjacent channels will be reduced. Hence, longer wavelength has the advantage of producing an easier to mold section. Nevertheless, longer wavelength also creates a disadvantage because the underlayment will be required to span across a larger deck opening. The advantage and disadvantage of longer wavelength must be considered carefully in the process of choosing a corrugated section for molding trials.

Panel thickness has the least effect on the moldability of corrugated panels. Varying the thickness of the baseline panel from $1 / 4$ " to 1 " thick does not greatly change the moldability (1.366 to 1.374 ). This suggests that choosing a suitable panel thickness can be based almost entirely on the structural performance and compatibility with current construction practices. 


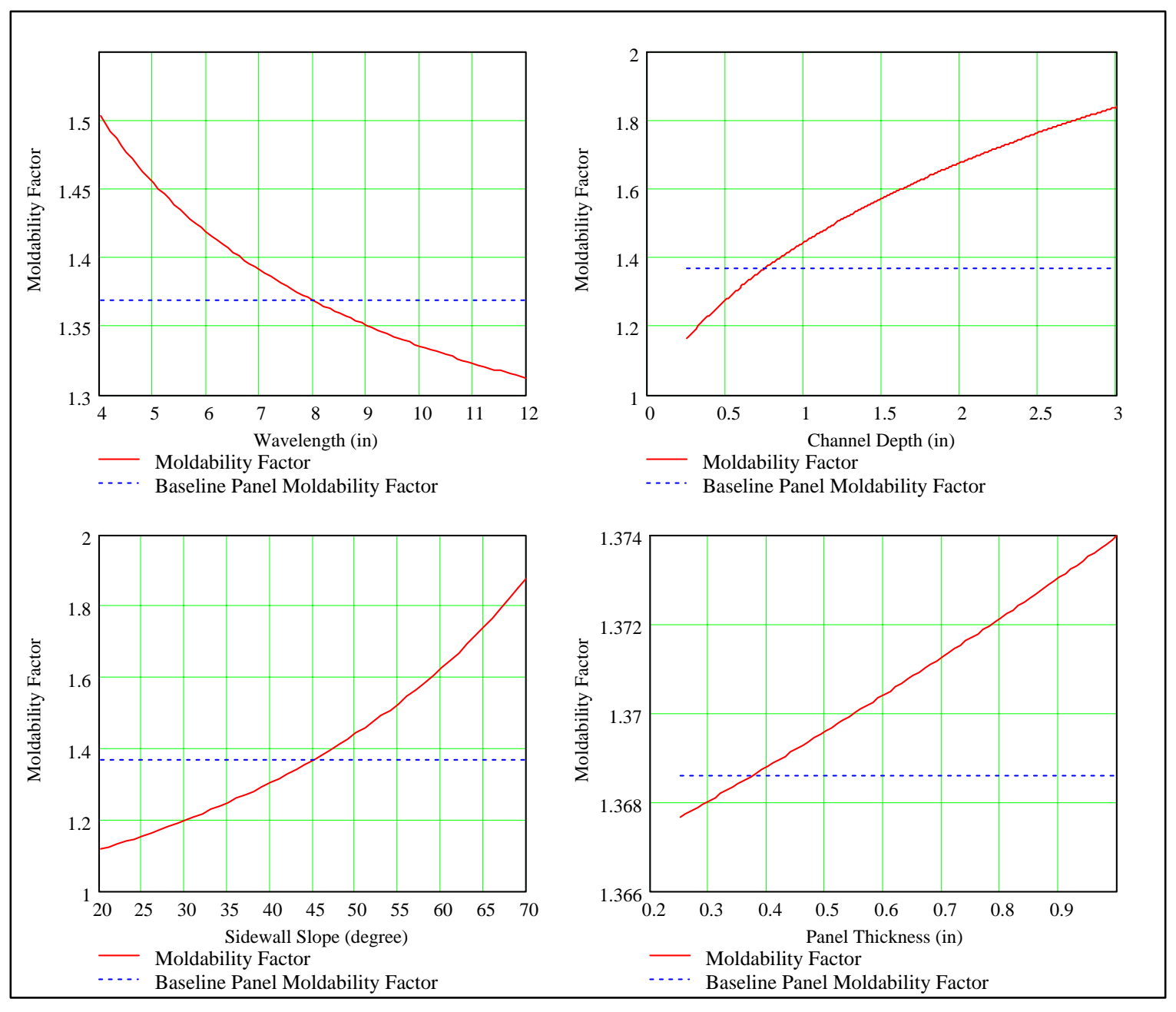

Figure 4: Moldability factor for corrugated panels with varying (a) wavelength, (b) channel depth, (c) sidewall angle, and (d) panel thickness.

\section{Corrugated Panel Profile for Molding Trials}

The determination of a suitable corrugated panel profile was based on three criteria: structural performance, moldability, and compatibility with current construction practices. The corrugation profile selected for molding trials has a wavelength equal to 8”, a channel depth equal to $3 / 4$ ”, a sidewall angle equal to 45 degrees, and a panel thickness equal to $3 / 8$ " (Figure 5). 


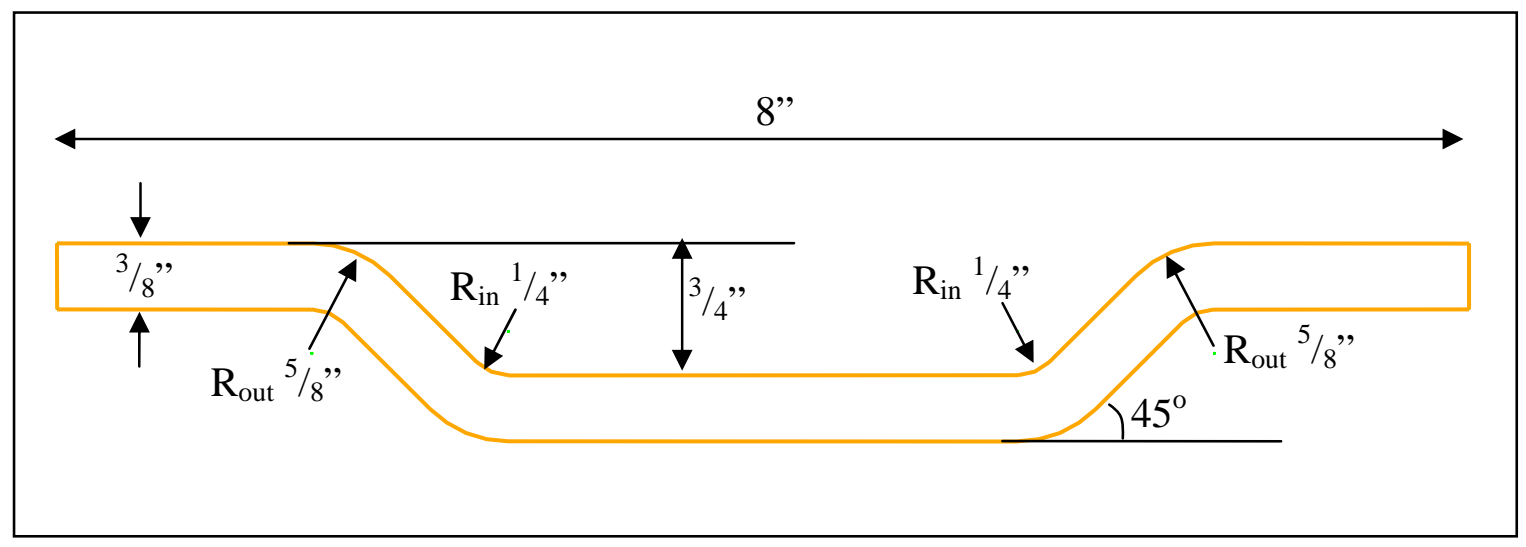

Figure 5: Corrugated profile for molding trials.

Corrugated sections were assumed to have sharp corners in the calculations of section properties in the previous section. However, the actual corrugated panels produced for this research were made with rounded corners at sidewalls. There are two main reasons for making a rounded corner profile. First, a rounded corner provides better "flow" properties for the mat and reduces the potential of mat separation during pressing. Second, a rounded corner profiles yield better consistency in thickness and density at the corners. For a sharp corner profile, the thickness at the sharp corner is actually greater than the target distance at the flat surfaces.

A thin corrugated panel has higher relative bending stiffness and strength compared to a flat panel of the same thickness. A corrugated panel of $3 / 8$ " thick was chosen because it yields better bending stiffness and strength gains than corrugated panels with greater thickness, such as $1 / 2$ " or $3 / 4$ ". The theoretical relative strong axis bending stiffness and strength of the selected corrugation profiles are 12.36 and 4.01 , respectively. The selected corrugated panel geometry is a relatively easy to mold shallow section (3/4" channel depth), with moldability factor of about 1.37 . One of the objectives of this research is to design a corrugation profile that can be used by current OSB mills 
with as little modification to the production line as possible. Hence, a relatively shallow corrugation profile was selected. There is no need to make any adjustment to the current OSB mat forming process because no special mat forming technique is required.

\section{Configuration of Composite Deck System}

A corrugated panel alone is not suitable for floor decking because of the ridges and grooves. A flat panel can be attached to the top of corrugated panel to form a composite deck system (Figure 6). The composite deck system consists of a corrugated panel as subfloor and a typical structural-use panel, such as oriented strandboard (OSB) or plywood, nailed-glued to the corrugated panel as underlayment. Typical non-rigid subfloor adhesive, complying with Engineered Wood Association (APA) AFG-01 standards, may be used for this purpose. The flat panel not only provides a flat surface, it also stiffens the composite deck system through composite action. The effect of composite action will be discussed in a later section.

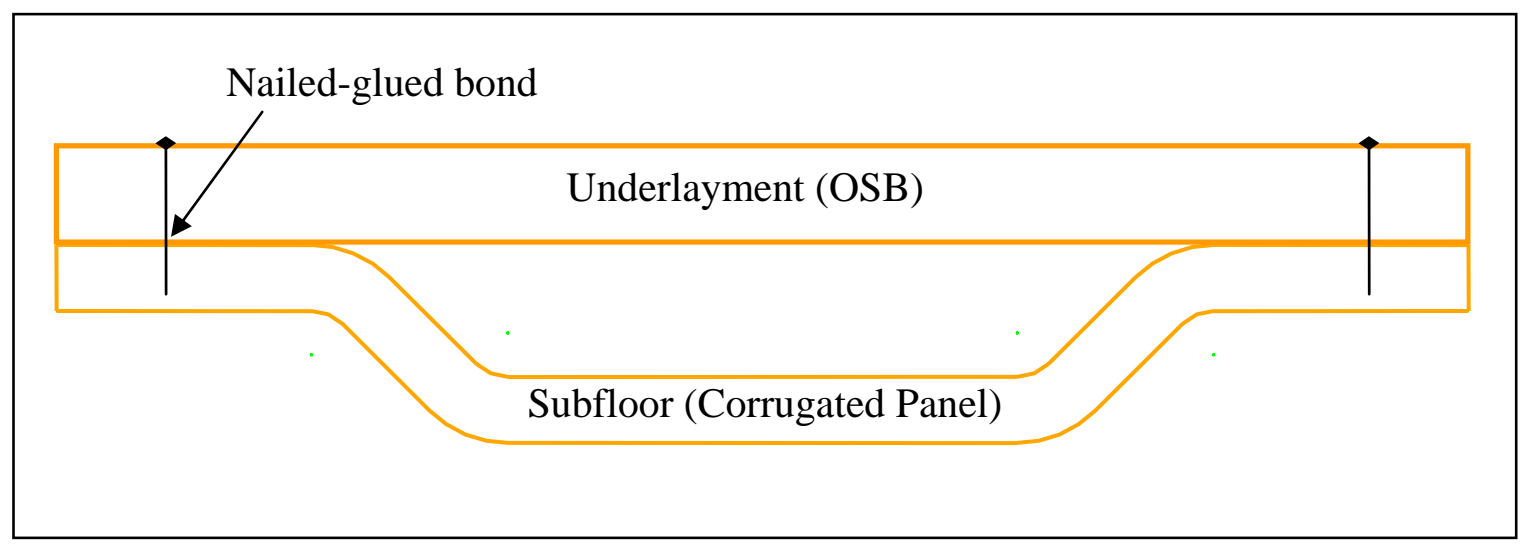

Figure 6: Composite deck system cross section view. 


\section{Mathematical Models}

Three different methods were used to analyze and model the mechanical properties of corrugated panels and composite deck system. Finite element (FE) analyses, classical plate theory, and basic structural engineering principles (based on beam theory), were the three approaches used to model the test data.

(1) Finite element (FE) modeling was used to verify the test results. The main advantage of using a FE analysis was that it could model almost any combination of loads and boundary conditions. However, there are some disadvantages of using a FE model. First, a FE model requires very intensive calculations and the computation time can be very long even using a fast computer. Second, FE only provides numerical solutions for the given panel geometry, loads and boundary conditions. Changes in panel geometry will require a complete new mesh and calculations. Empirical equations to describe the behaviors of a range of panel geometry or boundary conditions may be obtained by performing linear or non-linear regression on the results of a set of FE models.

(2) Classical plate theory was also used to analyze corrugated panels. In plate theory, the bending behaviors of a panel are governed by a classical plate bending differential equation. A solution for a rectangular orthotropic plate, simply supported at two opposite edges and free at the others, is discussed here. A uniformly distributed loads, 
uniform line loads, or concentrated loads can be applied to the plate model.

(3) Basic structural engineering principles, such as simple beam theory, were used as the basic model. The deflection of corrugated panels under certain loads and boundary conditions can be estimated, reasonably well, using beam theory. Modified beam models were also developed by calibrating the basic beam models to FE models. 


\section{Finite Element Model}

The analytic solutions for classical plate bending differential equation are not easily obtained and closed form solutions might not be available for some boundary conditions. Thus, a numerical solution to plate bending, the finite element (FE) method, was used to model corrugated panels. A FE program called I-DEAS ${ }^{{ }^{*}}$ developed by Structural Dynamics Research Corporation $\left(\mathrm{SDRC}^{\circledR}\right.$ ) was used to perform analysis of corrugated panels prior to any experimental work and also to verify the results of experimental testing.

\section{Specifications of Elements}

Corrugated panels and oriented strand boards (OSB) have plate-like geometry. Therefore, 2-dimentional (2D) FE elements are used to model the behavior of corrugated panels. In general, there are three common types of 2D elements; plane stress, plane strain and thin shell elements. Corrugated panels exhibit both in-plane (x-y plane, Figure 7) stress-strain behavior as well as out-of-plane (z-direction, Figure 7) bending when

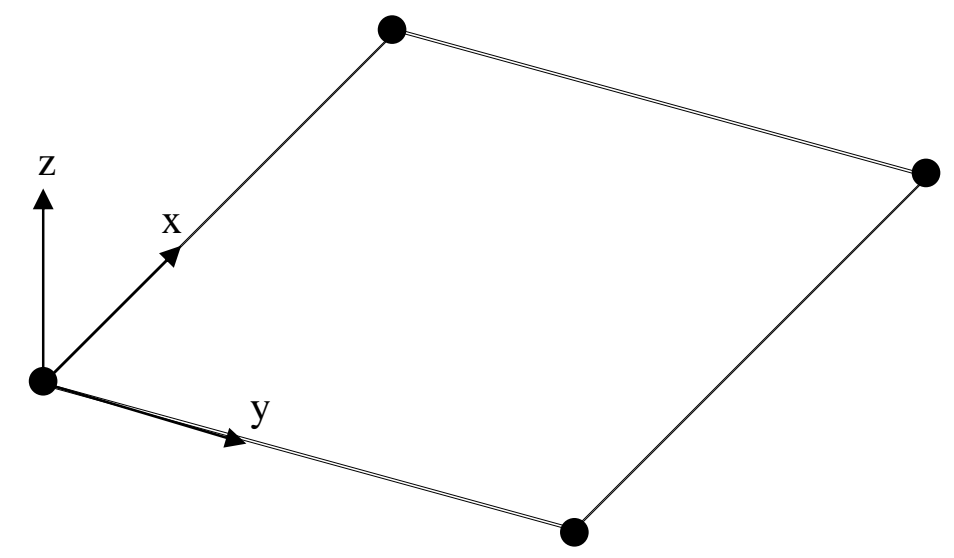

Figure 7: 4-node bilinear thin shell element.

\footnotetext{
${ }^{*}$ I-DEAS ${ }^{\circledR}$ and SDRC ${ }^{\circledR}$ are the registered trademarks of the Structural Dynamics Research Corporation.
} 
subject to loads. Thus, thin shell elements are more appropriate for the task of modeling both in-plane and out-of-plane behavior.

I-DEAS ${ }^{\circledR}$ provides three options for thin shell elements: 3-node, 4-node and 8node elements. Meshing was done with 4-node bilinear thin shells elements because of two main reasons. First, meshing rectangular plate structures with 4-node rectangular shape elements can simplify the process of applying load and boundary conditions to the model. Second, 8-node elements might produce better results than 4-node elements. However, the computational time and disk space required by the 8-node elements is more than double of the 4-node elements. Hence, 4-node elements are used for meshing corrugated panel and composite deck instead of 8-node elements. For a 4-node element, there are six degrees of freedom for each node for a 4-node bilinear element. There are three translational displacements in the $\mathrm{x}, \mathrm{y}, \mathrm{z}$ directions, $\Delta_{x}, \Delta_{y}, \Delta_{z}$, and three rotational displacements about all three x-, y-, and z-axes, $R_{x}, R_{y}, R_{z}$.

Corrugated panels produced with a random mat can be modeled with in-plane isotropic material. However, the moduli of elasticity for OSB are different in the strong axis and weak axis directions. Thus, an orthotropic material is used for the 4-node thin shell element to model both corrugated panels and OSB. Four basic parameters are needed to define an orthotropic 2D material. Two in-plane moduli of elasticity, $E_{x}$ and $E_{y}$, Poison's ratio, $v$, and an in-plane shear modulus, $G_{x y}$, are needed. The in-plane shear modulus is independent of both moduli of elasticity and the Poison's ratio for orthotropic materials. $E_{x}$ is equal to $E_{y}$ for random mat corrugated panels, because inplane isotropic behavior is assumed. 


\section{Boundary Conditions and Gap Elements}

Figure 8 shows a typical 4-node bilinear thin shell element mesh for a corrugated panel. The mesh is generated on the mid-surface of the skin thickness of the corrugated panel. The local coordinate systems for the elements are defined such that the $\mathrm{x}$-axis is parallel to the strong axis or the channels; the y-axis follows the corrugation across the width of the panel; z-axis is always perpendicular to the surface of the elements (refer to Figure 8).

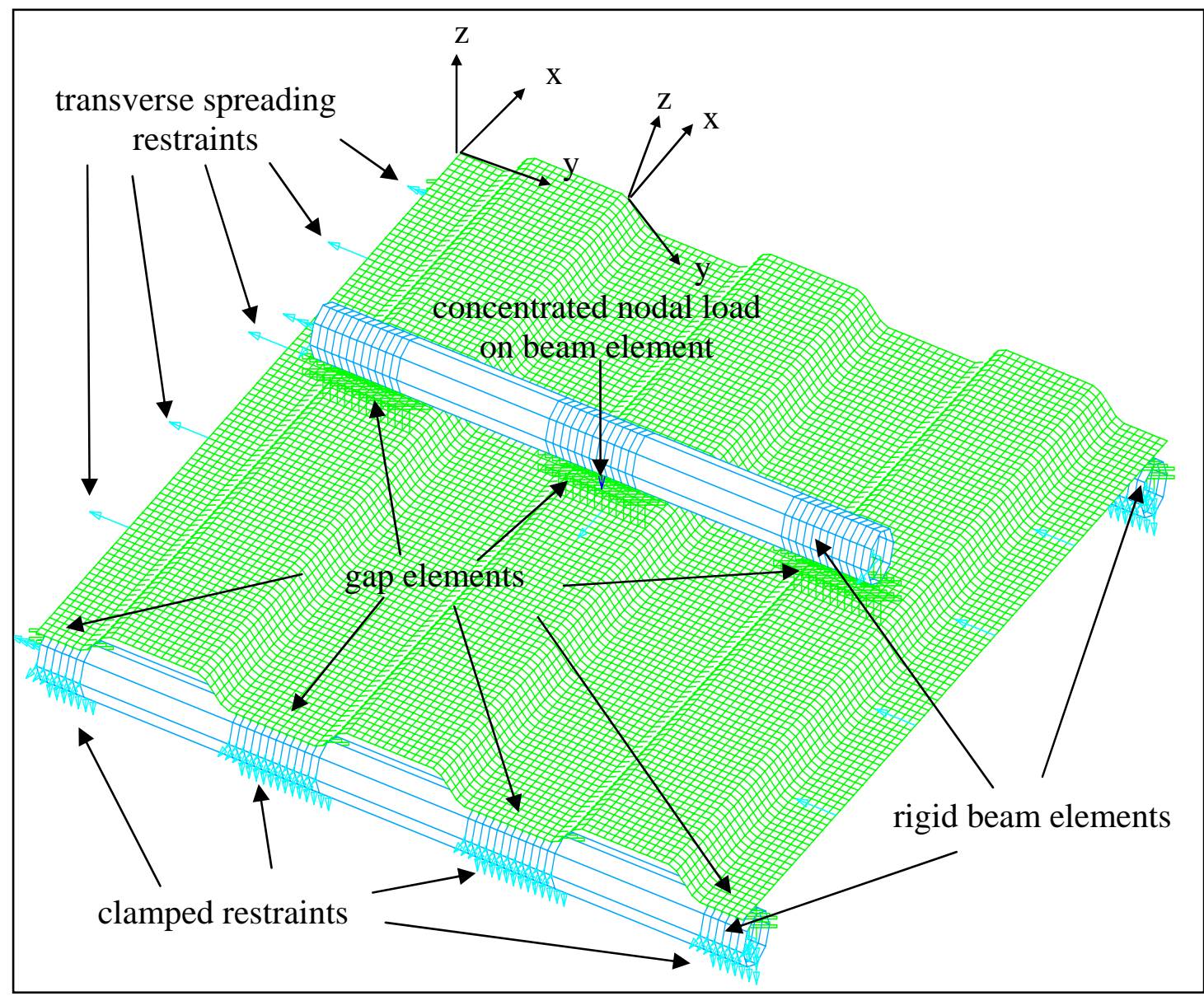

Figure 8: Typical 4-node thin shell elements mesh for corrugated panel. 
FE models are used to analyze both single-span and two-span conditions. The two supports and the loading bar are modeled with rigid beam elements. The simple support boundary conditions are modeled using gap elements. The two supporting bars are clamped in place while the loading bar is allowed to move in the vertical z-direction only. Gap elements are generated at the interface between the loading bar and the corrugated panel, as well as at the supports (Figure 8). Load is applied indirectly as a concentrated nodal force on the rigid beam element of the loading bar. The applied nodal force is then transferred to the corrugated panel as reaction forces through gap elements, at the supports and the loading line.

The distribution of the reaction forces generated by gap elements is able to closely mimic the actual support conditions. The deformed shape of a corrugated panel at the supports along with the reaction forces are shown in Figure 9. Uplift can be seen at both

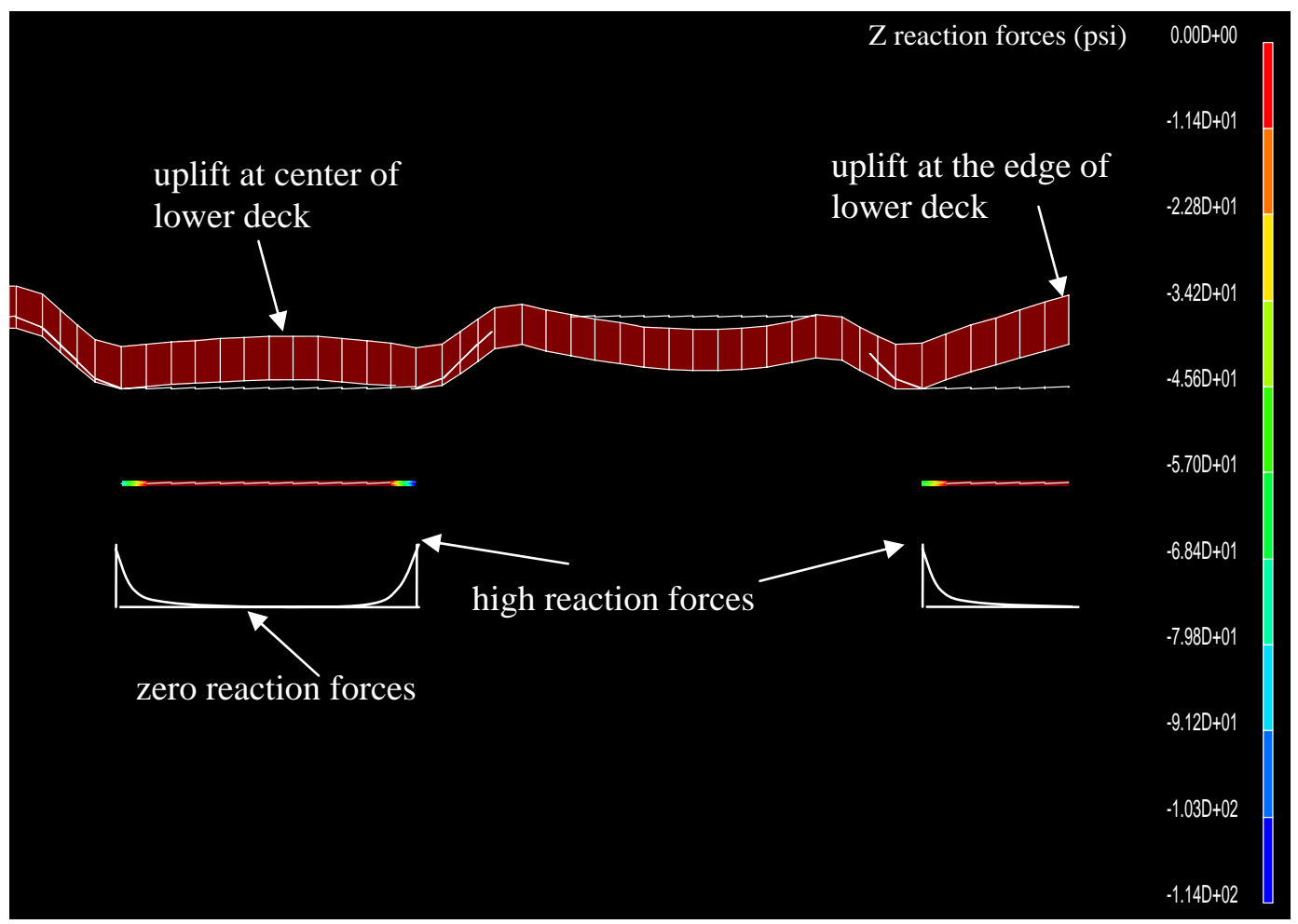

Figure 9: Reaction forces and deformed shape of corrugated panel at the supports of finite element model. 
the center of the lower decks as well as along the edges of the lower decks (Figure 9). The corrugated panel and the supports do not have 'contact' at the uplift regions, hence the reaction forces are zero at those regions. However, high reaction forces can be seen at the corners of the lower decks, near the sidewalls. Similar conditions can be seen at the interface of the loading bar.

\section{Non-Rigid Bond Model}

Figure 10 shows a typical mesh for composite deck consisting of OSB attached to corrugated panel using non-rigid construction adhesive. In a floor system, similar nonrigid bonds are formed between corrugated panels and the supporting joists. The ability to model the non-rigid bond using the FE method is essential to study composite action. Figure 11 shows a typical FE model of the partial composite joint between the corrugated panel and the OSB underlayment. Both the corrugated panel and the OSB are meshed

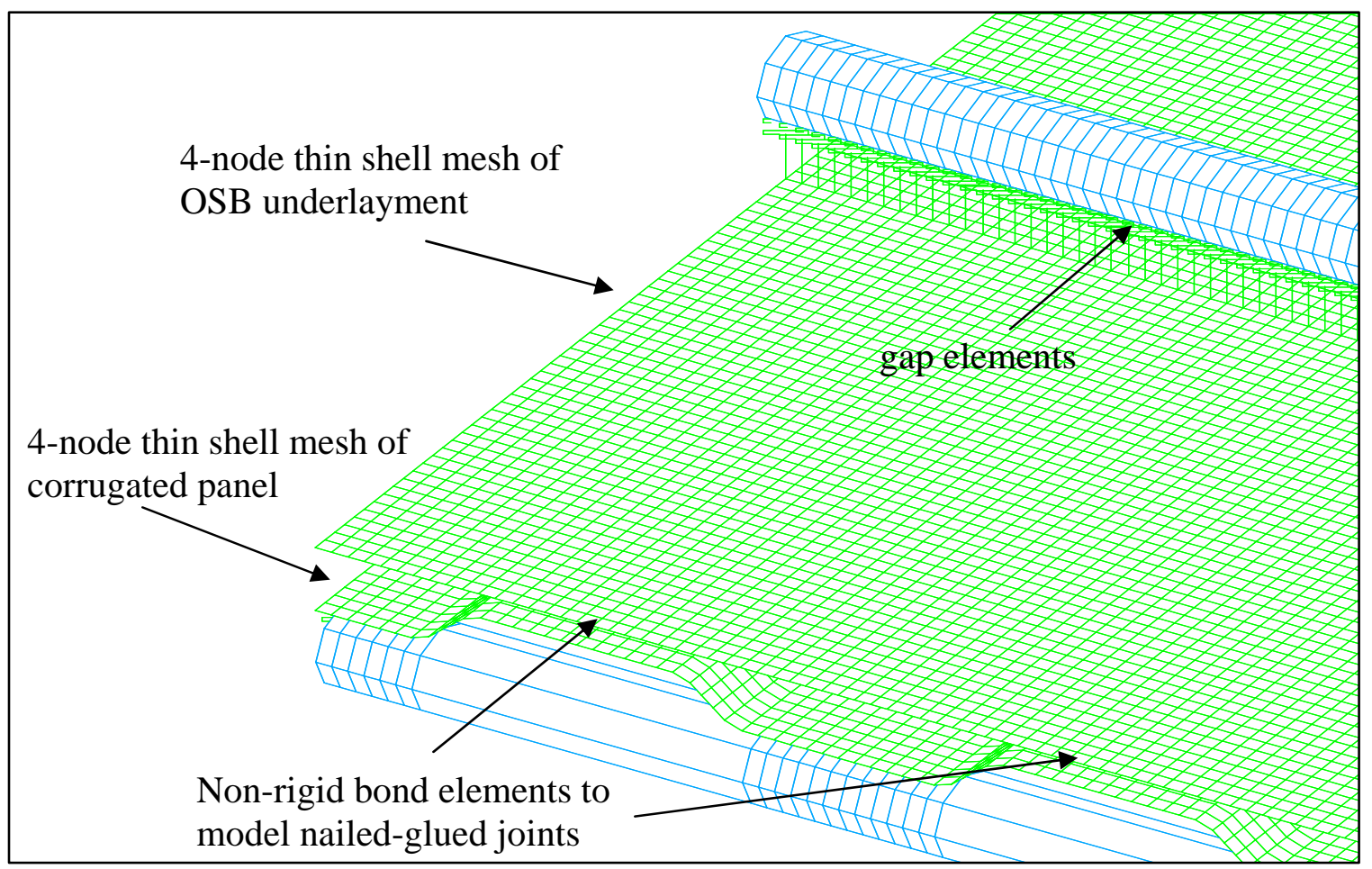

Figure 10: Typical mesh for composite deck FE model. 
with 4-node thin shell elements. In a composite deck system, interlayer slip occurs due to a non-rigid bond that provides only partial shear transfer from one surface to the other. To account for partial composite action, a series of non-rigid bond FE models are used.

A non-rigid bond FE model consists of an assembly of rigid bar elements and an

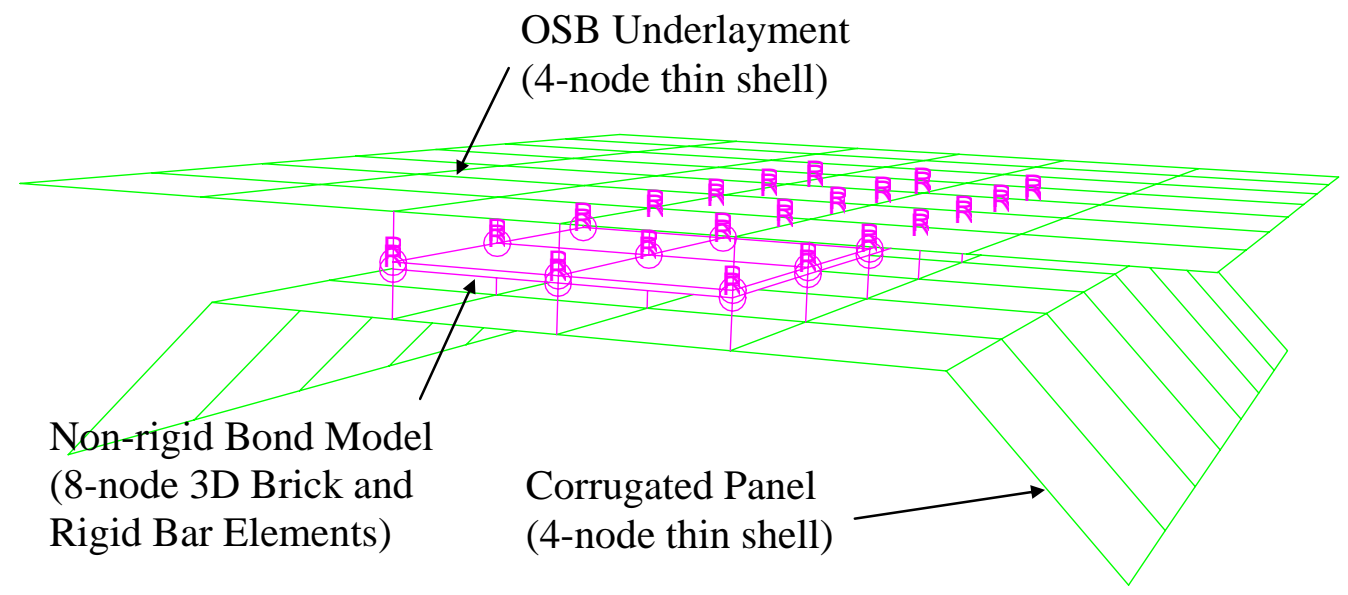

Figure 11: Finite element model of corrugated panel-OSB partial composite joint.

8-node, three dimensional (3D) brick element (see Figure 12). The 3D brick element represents the partial rigid nailed-glued bond (3d ringshank nails and AFG-01 adhesives). The height of the 3D brick element is assumed to be the thickness of the glue bond. AFG01 adhesive is assumed to behave as an incompressible isotropic material. I-DEAS ${ }^{\circledR}$ requires three input parameters for isotropic material; modulus of elasticity, $E$, shear modulus, $G$, and Poisson's ratio, $v$. However, the shear modulus for an isotropic material can be calculated if both the modulus of elasticity and Poisson's ratio are known.

$$
G=\frac{E}{2(1+v)}
$$

Therefore, there are only two independent variables for an isotropic material. $E$ and $v$ are the two independent input parameters for the 3D brick elements while the dependent parameter, $G$, is calculated using equation (8). The theoretical value of Poisson's ratio 
for an incompressible material is equal to 0.5 . However, numerical errors occurred when $v$ of 0.5 is used in the FE model. In order to prevent numerical errors and to maintain the near incompressible behavior of the adhesive at the same time, $v$ equal to 0.495 is used.

Rigid elements are used for connecting the thin shell elements (corrugated panel

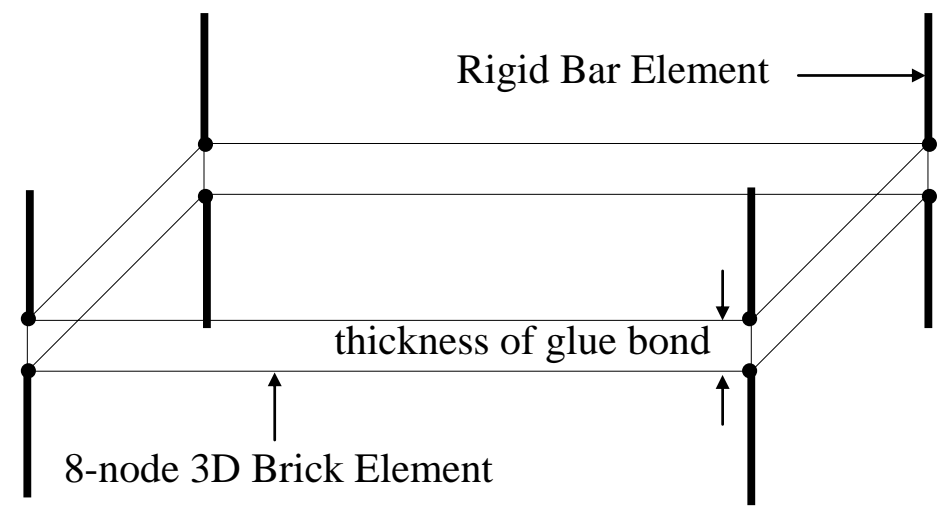

Figure 12: Non-rigid bond finite element model.

or OSB), which are meshed at the middle of the panel skin thickness, to the 3D brick elements (nailed-glued bond). There are two nodes in one rigid element. The rotations and displacements of both nodes are identical. Assignment of material properties is not required because the rigid element functions as a bridge to transfer the displacements and rotations from nodes of one element to the other. For a typical composite deck mesh as shown in Figure 11, the displacements and rotations of the top thin shells mesh (for OSB underlayment) are directly translated into the four nodes on the top of each 3D brick element. Similarly, the displacements and rotations of the bottom four nodes are influenced by the thin shell mesh of corrugated panel at the bottom layer. The differences of displacements between the top and bottom nodes of the 8-node brick element represent the interlayer slip between corrugated panel and OSB. 


\section{Orthotropic Plate Model}

Typical light-frame floor systems have joist spacing at about 24” to 48 ” on-center, resulting in a panel span-to-width ratio around 0.5 to 2 . Due to the span-to-width ratio near one and low thickness-to-width or span ratio, the bending behavior of corrugated panels might be modeled using classical plate theory.

For corrugated panels with random flake orientation, the in-plane material properties can be approximated as isotropic. However, the overall behavior of a corrugated panel acts like an orthotropic plate because the effective bending stiffness is different for the transverse (weak axis bending) and longitudinal (strong axis bending) directions. The bending of a corrugated panel can be modeled with an equivalent orthotropic plate (Figure 13). The governing equation for orthotropic plate bending is,

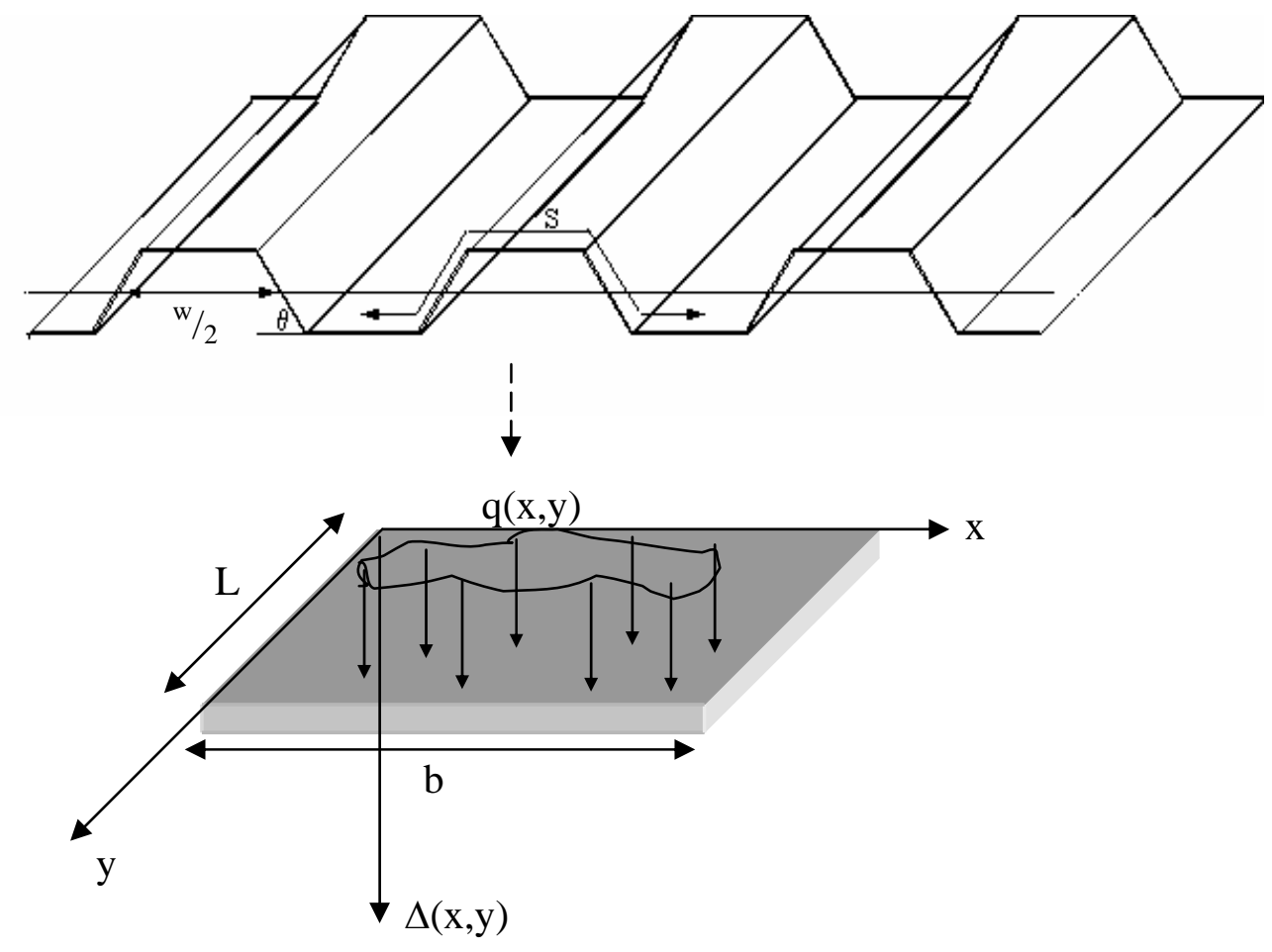

Figure 13: Equivalent orthotropic plate model of corrugated panel. 


$$
D_{x} \frac{\partial^{4} \Delta(x, y)}{\partial x^{4}}+2 H \frac{\partial^{4} \Delta(x, y)}{\partial x^{2} \partial y^{2}}+D_{y} \frac{\partial^{4} \Delta(x, y)}{\partial y^{4}}=q(x, y)
$$

where $q(x, y)$ can be any loading function and $\Delta(x, y)$ is the deflection normal to the plate or the solution for the differential equation. $D_{x}, D_{y}$, and $H$ are the flexural rigidities, which can, theoretically, be estimated from the following equations [Troitsky, 1976].

$$
\begin{gathered}
D_{x}=\frac{w / 2}{S} \frac{E t^{3}}{12\left(1-v^{2}\right)} \\
D_{y}=\frac{E I_{c}}{w} \\
H=D_{12}+2 D_{x y}
\end{gathered}
$$

where, $S$ is the arc length of one half of a wavelength, calculated as,

$$
S=w+2 h\left(\frac{1-\cos (\theta)}{\sin (\theta)}\right)
$$

and $D_{x y}$ is the torsional rigidity, approximated as,

$$
D_{x y}=\frac{S}{w / 2} \frac{G t^{3}}{12}
$$

$D_{12}$ is estimated as,

$$
D_{12}=v \frac{D_{x} D_{y}}{D_{x}+D_{y}}
$$

Bending moments, $\left(M_{x x}, M_{y y}\right.$, and $\left.M_{x y}\right)$, shear forces, $\left(V_{x}\right.$ and $\left.V_{y}\right)$, and reaction forces, ( $R_{x}$ and $R_{y}$ ), can expressed in terms of the deflection, $\Delta(x, y)$, or the solution to the plate bending equation (9).

$$
M_{x x}(x, y)=-D_{x} \frac{\partial^{2} \Delta(x, y)}{\partial x^{2}}-D_{12} \frac{\partial^{2} \Delta(x, y)}{\partial y^{2}}
$$




$$
\begin{gathered}
M_{y y}(x, y)=-D_{12} \frac{\partial^{2} \Delta(x, y)}{\partial x^{2}}-D_{y} \frac{\partial^{2} \Delta(x, y)}{\partial y^{2}} \\
M_{x y}(x, y)=-2 D_{x y} \frac{\partial^{2} \Delta(x, y)}{\partial x \partial y} \\
V_{x}(x, y)=-D_{x} \frac{\partial^{3} \Delta(x, y)}{\partial x^{3}}-H \frac{\partial^{3} \Delta(x, y)}{\partial x \partial y^{2}} \\
V_{y}(x, y)=-D_{y} \frac{\partial^{3} \Delta(x, y)}{\partial y^{3}}-H \frac{\partial^{3} \Delta(x, y)}{\partial x^{2} \partial y} \\
R_{x}(x, y)=-D_{x} \frac{\partial^{3} \Delta(x, y)}{\partial x^{3}}-\left(H+2 D_{x y}\right) \frac{\partial^{3} \Delta(x, y)}{\partial x \partial y^{2}} \\
R_{y}(x, y)=-D_{y} \frac{\partial^{3} \Delta(x, y)}{\partial y^{3}}-\left(H+2 D_{x y}\right) \frac{\partial^{3} \Delta(x, y)}{\partial x^{2} \partial y}
\end{gathered}
$$

\section{Trigonometric Series Expansion of Loads}

To account for some of the most commonly seen loading conditions for typical floor systems, single Fourier sine series can be used as an approximation, $\tilde{q}(x, y)$, for the loading function, $q(x, y)$,

$$
q(x, y) \approx \tilde{q}(x, y)=\sum_{n=1}^{M} q_{n}(x) \sin \left(\frac{n \pi}{L} y\right)
$$

where $M$ is the total number of terms used to approximate the actual loading function, $q(x, y) \cdot q_{n}(x)$ are the Fourier coefficients, which can be obtained by solving the following integral,

$$
q_{n}(x)=\frac{2}{L} \int_{0}^{L} q(x, y) \sin \left(\frac{n \pi}{L} y\right) d y
$$

The solutions to equation (24) for three different load distributions, uniformly distributed load, uniform line load and concentrated load, are discussed in the following sections. 


\section{Uniformly Distributed Load}

The exact representation of a uniformly distributed load (UDL) (Figure 14) is a constant given by

$$
q(x, y)=q_{o}
$$

where $q_{o}$ is the magnitude of the UDL, in terms of load per unit area (psi) . Substituting equation (25) into equation (24) leads to

$$
q_{n}(x)=\frac{2 q_{o}}{n \pi}(1-\cos (n \pi)) \quad \text { for } n=1,2,3, \ldots
$$

or

$$
q_{n}(x)=\frac{4 q_{o}}{n \pi} \quad \text { for } n=1,3,5, \ldots
$$

Figure 15 shows the nondimensionalized UDL approximations using various numbers of terms. UDL is nondimensionalized by letting $q_{o}$ and $L$ be equal to unitless numerical values of one. Eight $(n=1,3, . .15)$ or more terms yield a relatively good approximation of UDL.

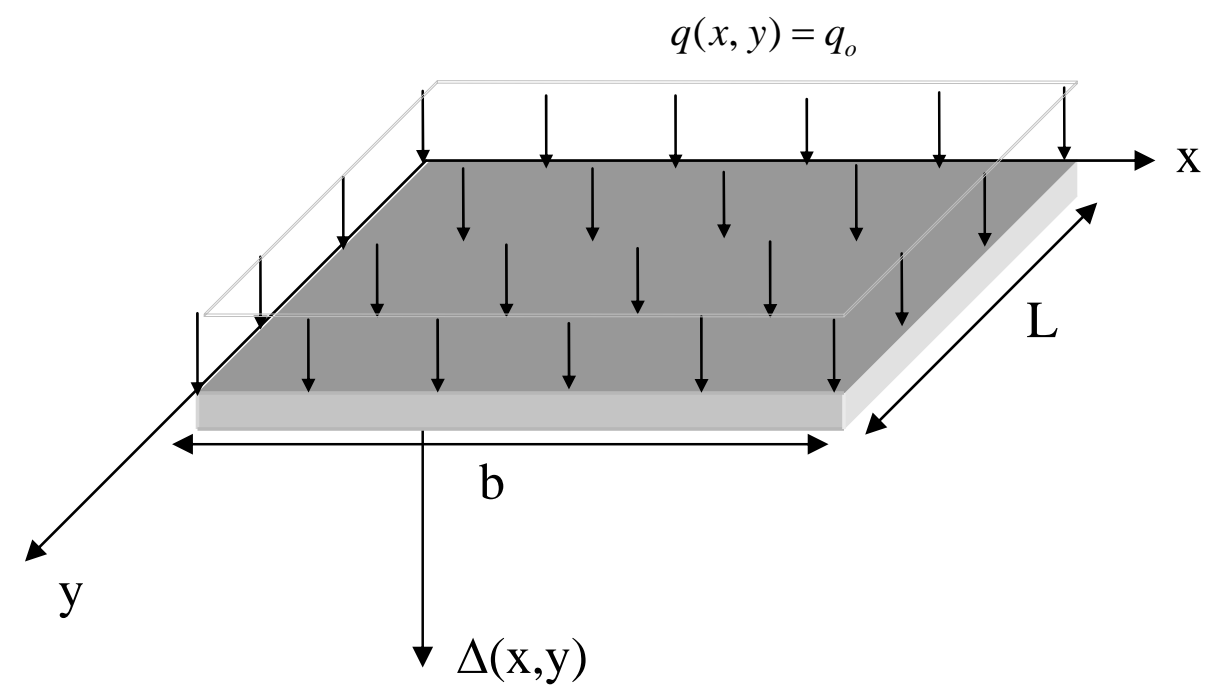

Figure 14: Uniformly distributed load on rectangular plate. 


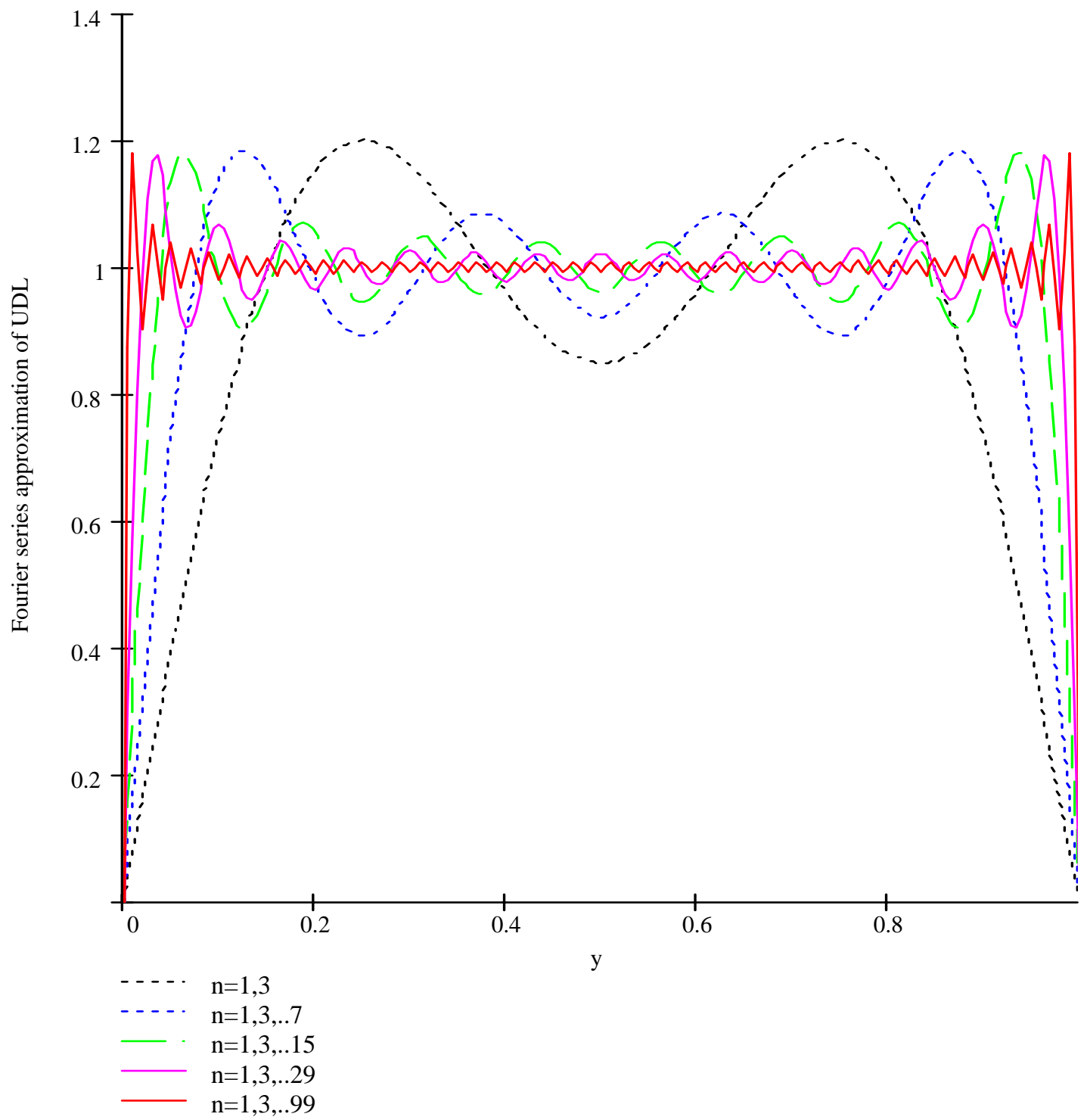

Figure 15: Fourier sine series approximation of uniformly distributed load. 


\section{Uniform Line Load}

Uniform line load (ULL) across the width, $b$, can be expressed using a unit impulse function as in the following equation

$$
q(x, y)=q_{L} \delta\left(y-y_{o}\right)
$$

where $q_{L}$ is the magnitude of ULL in terms of load per unit width $\left({ }^{\mathrm{lbs}} / \mathrm{in}\right) . y_{o}$ is the location of ULL measured from the x-axis (Figure 16). $\delta($.$) is the unit impulse function,$ also known as the Dirac delta function, and has the following characteristics

$$
\begin{array}{ll}
\delta\left(y-y_{o}\right)=1 & \text { for } y=y_{o} \\
\delta\left(y-y_{o}\right)=0 & \text { for } y \neq y_{o}
\end{array}
$$

Therefore, ULL only occurs at the location where $y$ equal to $y_{o}$ and is zero for all other values of $y$. Substituting equation (28) into equation (24) gives

$$
q_{n}(x)=\frac{2}{L} \int_{0}^{L} q_{L} \sin \left(\frac{n \pi}{L} y\right) \delta\left(y-y_{o}\right) d y
$$

Integrating the product of a Dirac delta function and a continuous function over the whole domain, i.e., from 0 to $\mathrm{L}$ for this case, is equivalent to evaluating the function at $y=y_{0}$. Hence, equation (31) can be expressed as

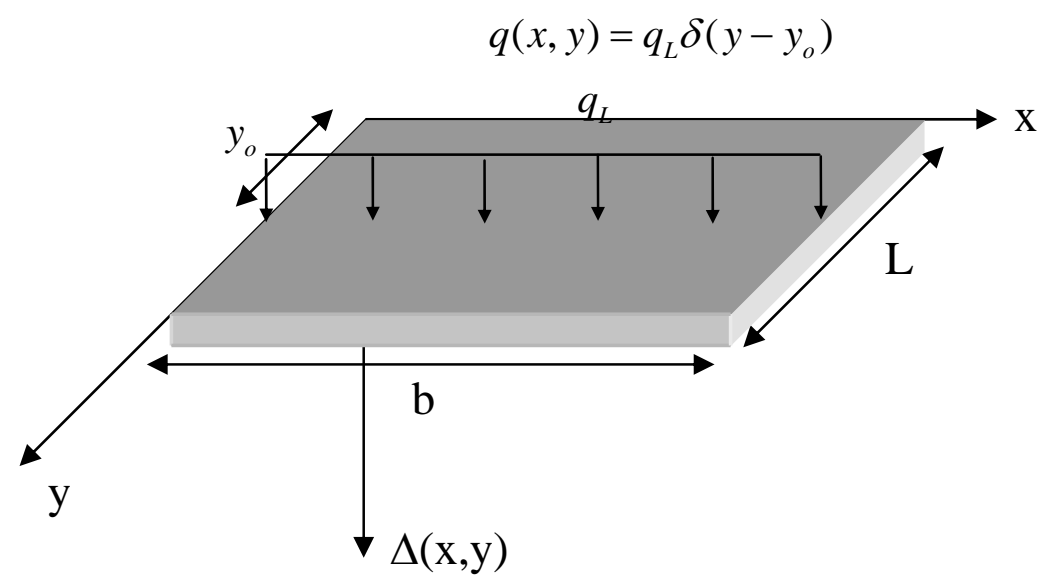

Figure 16: Uniform line load on rectangular plate. 


$$
q_{n}(x)=\frac{2 q_{L}}{L} \sin \left(\frac{n \pi}{L} y_{o}\right) \quad \text { for } n=1,2,3 \ldots
$$

The full representation of ULL can be obtained by substituting equation (32) into equation (23).

Fourier sine series approximations of ULL at mid-span, $\left(y_{o}=L / 2\right)$ are shown in Figure 17. The results are nondimensionalized as discussed in the previous section. The plot in Figure 17 indicates that to obtain idealized load pulses requires many terms of summation, i.e., about 100 or more. However, for the purpose of calculating the deflection of corrugated panels in this research only a few terms were required. Parameter studies on the number of load terms, $M$, show that only about 9 to 15 terms are required to obtain accuracy of deflection up to four significant figures.

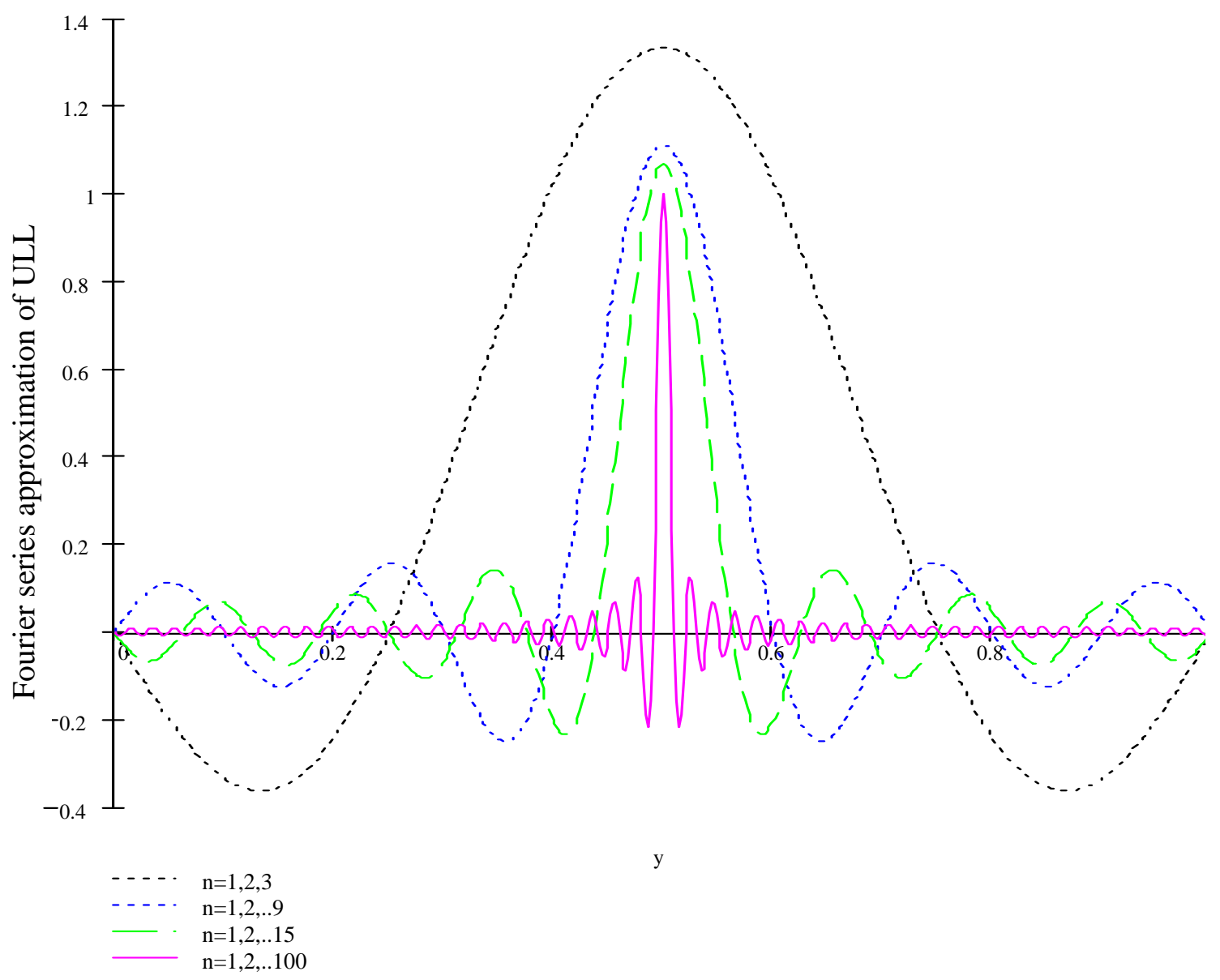

Figure 17: Fourier sine series approximation of uniform line load. 


\section{Concentrated Load}

A concentrated load (CL) is defined in a fashion similar to the uniform line load.

$$
q(x, y)=Q_{o} \delta\left(x-x_{o}\right) \delta\left(y-y_{o}\right)
$$

where $Q_{o}$ is the applied concentrated load (lbs). The location of the CL is defined by $x_{o}$ (in) and $y_{o}$ (in) (Figure 18), which are the distances from the y-axis and x-axis, respectively, to the CL. Fourier coefficients for CL are obtained by using the same approach as for obtaining ULL coefficients.

$$
q_{n}(x)=\frac{2 Q_{o}}{L} \delta\left(x-x_{o}\right) \sin \left(\frac{n \pi}{L} y_{o}\right) \quad \text { for } n=1,2,3 \ldots
$$

Replacing $q_{n}(x)$ in equation (23) with equation (34) gives the complete solution for a Fourier sine series approximation of CL. The approximated loads have characteristics similar to ULL, as shown in Figure 17.

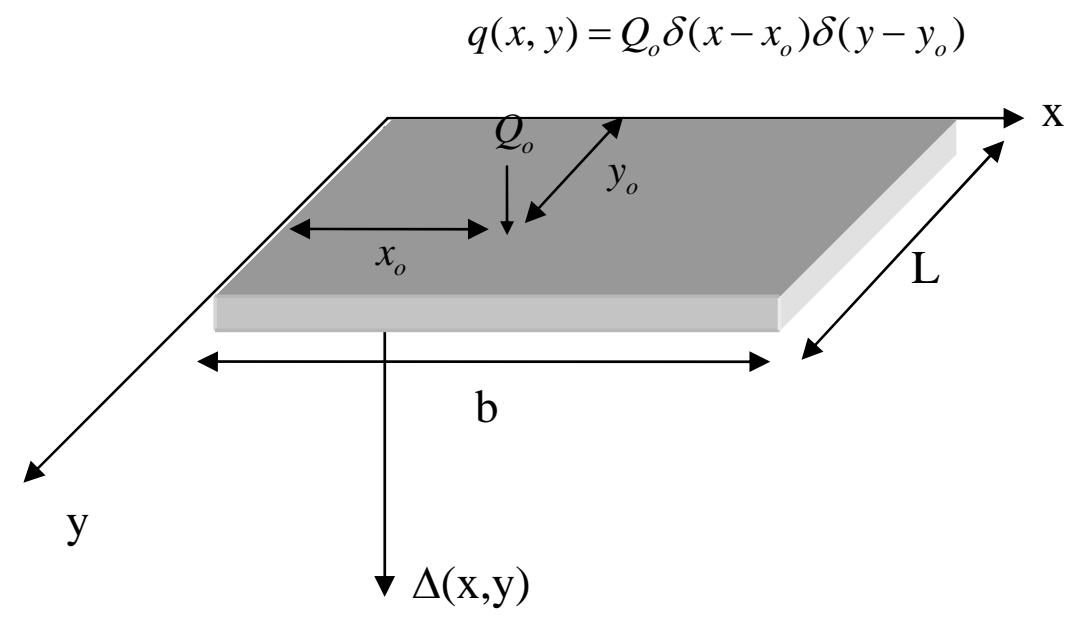

Figure 18: Concentrated point load on rectangular plate. 


\section{Free-Free and Simply Supported (FFSS) Plates}

Consider a single span corrugated panel supported by two joists. The boundary conditions along the two joists can be conservatively modeled as simple supports while the other two edges are free, FFSS, (Figure 19). Bending of FFSS plates can be solved using Levy's solution, expressed in terms of single Fourier sine series, similar to the approximation of loads.

$$
\Delta(x, y)=\sum_{n=1}^{\infty} \Delta_{n}(x) \sin \left(\frac{n \pi}{b} y\right)
$$

Equation (35) satisfies the boundary conditions at the simple supports ( $y=0$ and $y=L$ ) which require deflection and primary bending moment equal to zero.

$$
\begin{gathered}
\Delta(x, 0)=\Delta(x, L)=0 \\
M_{y y}(x, 0)=M_{y y}(x, L)=0
\end{gathered}
$$

The boundary conditions at the free edges $(x=0$ and $x=b)$ can be satisfied if a correct

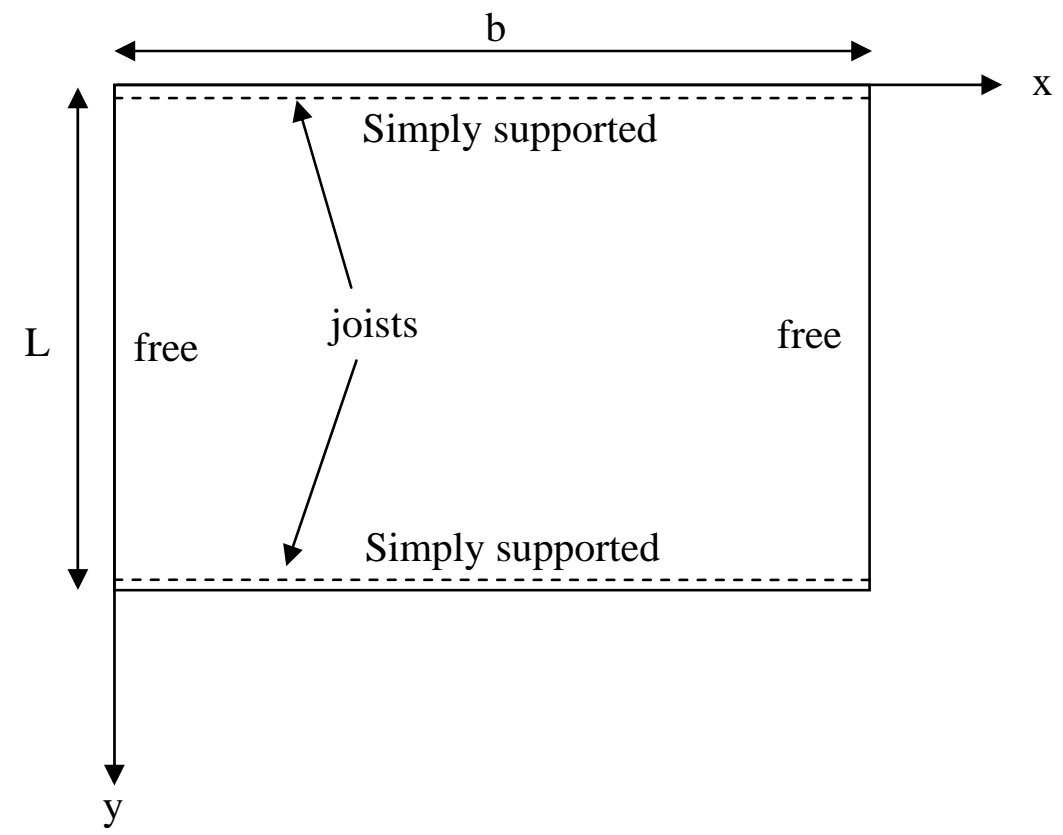

Figure 19: A rectangular plate with simple supports at two opposite edges and free on the other two edges (FFSS). 
function for $\Delta_{n}(x)$ is selected. Consider the governing orthotropic plate bending equation (9) again. Substitution of the Levy's solution, (equation (35)), and the approximation of loads, (equation (23)), into the orthotropic plate bending equation (9) yields

$$
\sum_{n=1}^{\infty}\left[D_{x} \frac{\partial^{4} \Delta_{n}(x)}{\partial x^{4}}-2 H\left(\frac{n \pi}{b}\right)^{2} \frac{\partial^{4} \Delta_{n}(x)}{\partial x^{2}}+D_{y}\left(\frac{n \pi}{b}\right)^{4} \Delta_{n}(x)-q_{n}(x)\right] \sin \left(\frac{n \pi}{b} y\right)=0
$$

Equation (38) can be further simplified into equation (39) because equation (38) must be zero for any $n$ and $y$ values.

$$
D_{x} \frac{\partial^{4} \Delta_{n}(x)}{\partial x^{4}}-2 H \beta_{n}{ }^{2} \frac{\partial^{4} \Delta_{n}(x)}{\partial x^{2}}+D_{y} \beta_{n}{ }^{4} \Delta_{n}(x)=q_{n}(x)
$$

where, $\beta_{n}$ is a new notation, defined as

$$
\beta_{n}=\frac{n \pi}{b}
$$

In general, there are two methods to obtain $\Delta_{n}(x)$; either by closed-form analytical solution or by an approximate method.

\section{Rayleigh-Ritz Method}

An approximate method using the Rayleigh-Ritz approach can be used to solve for $\Delta_{n}(x)$. The approximate solution for $\Delta_{n}(x)$ is acquired using a set of polynomials.

$$
\Delta_{n}(x) \approx \sum_{j=1}^{N} C_{j} \varphi_{j}(x)
$$

where $\varphi_{i}(x)$ are a set of polynomials that satisfies boundary conditions of free edges. $N$ is the number of polynomial functions to be used for approximation. $C_{i}$ are a set of coefficients to be determined using the weak form of equation (39). The weak form (equation (42)), for boundary conditions with free edges at $x=0$ and $x=b$, is derived using a variational approach or the principle of virtual displacements [Reddy 1999]. 


$$
\begin{aligned}
& \int_{0}^{b}\left(D_{x} \frac{\partial^{2} \Delta_{n}}{\partial x^{2}} \frac{\partial^{2} \delta \Delta_{n}}{\partial x^{2}}-2 H \beta_{n}{ }^{2} \frac{\partial \Delta_{n}}{\partial x} \frac{\partial \delta \Delta_{n}}{\partial x}+D_{y} \beta_{n}{ }^{4} \Delta_{n} \delta \Delta_{n}-q_{n} \delta \Delta_{n}\right) d x \\
& -\beta_{n}{ }^{2} D_{x y}\left[\Delta_{n} \frac{\partial \delta \Delta_{n}}{\partial x}+\frac{\partial \Delta_{n}}{\partial x} \delta \Delta_{n}\right]_{0}^{a}=0
\end{aligned}
$$

Replacing $\Delta_{n}$ and $\delta \Delta_{n}$ of the weak form with approximate functions (equation (41)), $C_{j} \varphi_{j}$ and $C_{i} \varphi_{i}$, respectively, results in the following system of equations

$$
\left[K_{i j}\right]\left\{C_{i}\right\}=\left\{F_{i}\right\}
$$

where,

$$
\begin{gathered}
K_{i j}=\int_{0}^{b}\left(D_{x} \frac{\partial^{2} \varphi_{j}}{\partial x^{2}} \frac{\partial^{2} \varphi_{i}}{\partial x^{2}}-2 H \beta_{n}{ }^{2} \frac{\partial \varphi_{j}}{\partial x} \frac{\partial \varphi_{i}}{\partial x}+D_{y} \beta_{n}{ }^{4} \varphi_{j} \varphi_{i}\right) d x-\beta_{n}{ }^{2} D_{x y}\left[\varphi_{j} \frac{\partial \varphi_{i}}{\partial x}+\frac{\partial \varphi_{j}}{\partial x} \varphi_{i}\right]_{0}^{a} \\
F_{i}=\int_{0}^{a} q_{n} \varphi_{i} d x
\end{gathered}
$$

where, $q_{n}$ can be obtained from either equations (26), (32) or (34), depending on the load

distributions. A set of coefficients, $C_{i}$, can be solved for each $n$ loading case. In order to solve for coefficients, $C_{i}$, a set of suitable polynomials, $\varphi_{j}(x)$, must be chosen for FFSS plates.

\section{Approximate Function for FFSS Plates}

Levy's solution, (equation (35)), satisfies the boundary conditions at simply supported edges. The remaining boundary conditions, namely the free edges for FFSS plates, must be satisfied by using the correct algebraic polynomials, $\varphi_{j}(x)$. The derivation of the weak form equation (42) is based on the natural boundary conditions of zero bending moments and reaction forces at free edges. Hence, the algebraic polynomials for the derived weak form are only required to have the basic characteristics 
of free edges, such as non-zero deflections and rotation. $\varphi_{j}(x)$ in the form of equation (46) can be used for these purpose.

$$
\varphi_{j}(x)=\left(\frac{x}{b}\right)^{j+1}+\left(1-\frac{x}{b}\right)^{j+1} \quad \text { for } \quad \mathrm{j}=1,2,3 \ldots
$$

where, $b$ is previously defined as the width of FFSS plates. The shapes of the first four algebraic polynomials $(N=4)$ are plotted in Figure 20. Deflections at free edges are non-zero since, $\varphi_{j}(x=0)$ and $\varphi_{j}(x=b)$ are both non-zero. The first derivative of $\varphi_{j}(x)$ is also non-zero at free edges, implying non-zero rotation at free edges.

The complete solution for FFSS plates is obtained by solving for a set of coefficients $C_{j}$ from equation (43) for each load case $n$ and then substituting equations (46) and (41) into equation (35).

$$
\Delta(x, y)=\sum_{n=1}^{M} \sum_{j=1}^{N} C_{j}\left[\left(\frac{x}{b}\right)^{j+1}+\left(1-\frac{x}{b}\right)^{j+1}\right] \sin \left(\frac{n \pi}{b} y\right)
$$

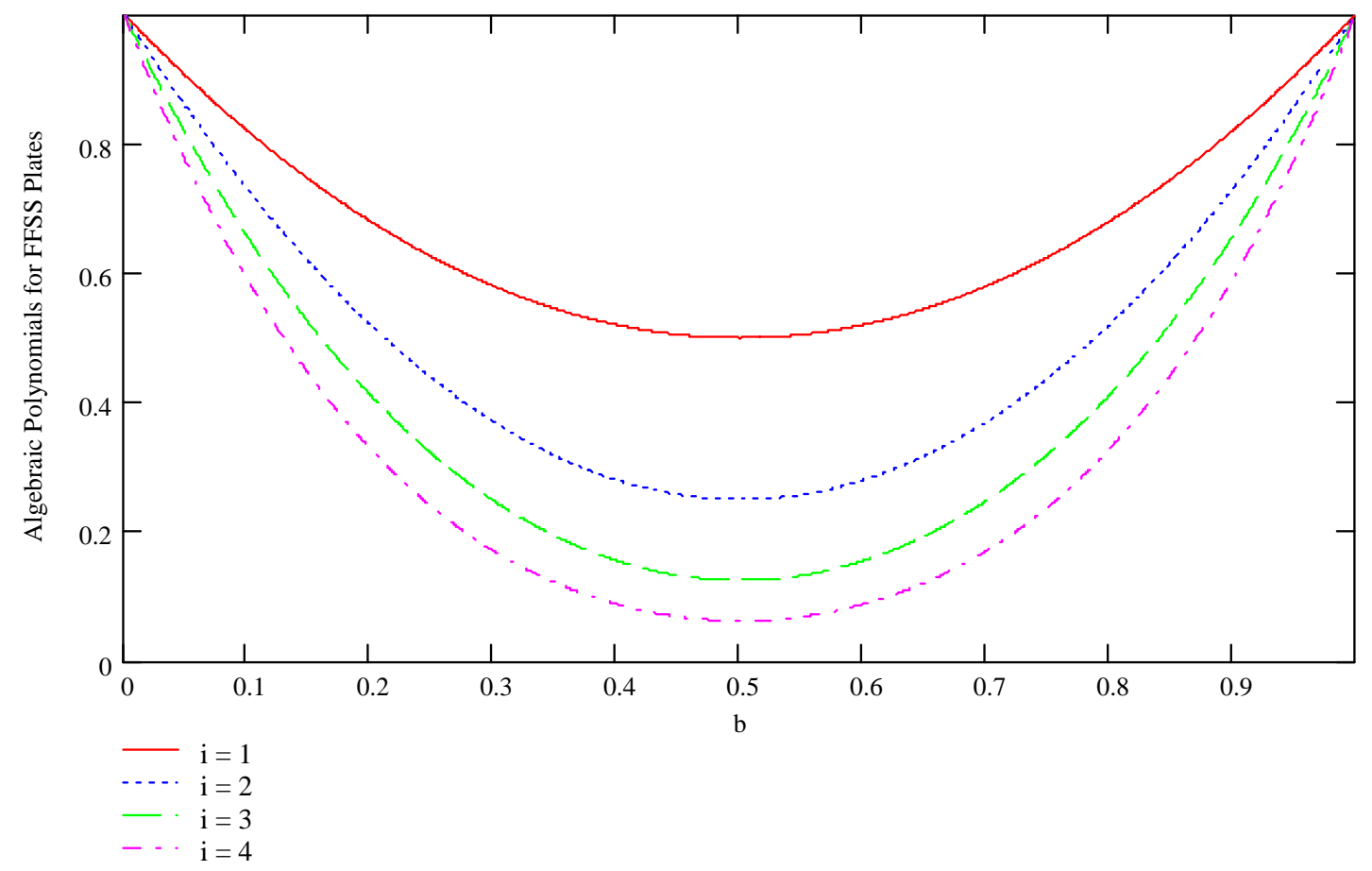

Figure 20: Rayleigh-Ritz approximate functions for FFSS plates. 


\section{Convergence studies of FFSS Plates}

The approximate solutions of FFSS plates, using the Rayleigh-Ritz method, were coded into MatLab ${ }^{\circledR}$ and MathCad ${ }^{\circledR}$ programs. The source codes for the MatLab ${ }^{\circledR}$ program are listed in Appendix D. Parameter studies on number of load terms, $M$, and number of algebraic polynomials, $N$, required to converge the solution were carried out using these two programs.

Table 1: Input properties of FFSS plate for convergence studies.

\begin{tabular}{|c|c|c|c|c|}
\hline $\begin{array}{l}\text { Geometric } \\
\text { Variables }\end{array}$ & Panel Size & $\begin{array}{l}\text { Applied } \\
\text { Line Load }\end{array}$ & $\begin{array}{l}\text { Material } \\
\text { Properties }\end{array}$ & $\begin{array}{l}{ }^{* *} \text { Flexural } \\
\text { Rigidities }\end{array}$ \\
\hline$h=3 / 4 ”$ & $\begin{array}{l}\text { Width } \\
b=48 ”\end{array}$ & $\begin{aligned} q_{L} & =\frac{80 \mathrm{lbs}}{b} \\
& =1.667^{\mathrm{lbs}} / \mathrm{in}\end{aligned}$ & $E=600,000$ psi & $D_{x}=2689^{l b s-i n^{2}} / i n$ \\
\hline$t=3 / 8 ”$ & $\begin{array}{l}\text { Span } \\
L=72 ”\end{array}$ & $\begin{aligned} * y_{o} & =b / 2 \\
& =36\end{aligned}$ & $\begin{aligned} \mathrm{G} & =\mathrm{E} / 6.5 \\
& =92,308 \mathrm{psi}\end{aligned}$ & $D_{y}=31756^{l b s-i n^{2}} / i n$ \\
\hline$w=8 ”$ & & & $v=0.3$ & $D_{12}=744^{l b s-i n^{2}} / i n$ \\
\hline$\theta=45$ deg. & & & & $H=437 l b s-i n^{2} / i n$ \\
\hline
\end{tabular}

* Uniform line load was applied at mid. Span, across the width.

${ }^{* *}$ Flexural rigidities were determined using equations (10) through (15).

Convergence studies were carried out on a 48” wide by 72” span FFSS plate, with geometry and material properties as listed in Table 1. A total 80 lbs of load was applied as a uniform line load across the mid-span, i.e., $y_{o}=b / 2$ (Figure 16). The number of polynomials, $N$-parameter Rayleigh-Ritz approximation, required for the solution to converge were determined by varying $N$ from 1 to 8 while keeping the number of load terms, $M$, at a large number, equal to 30. Figure 21 shows the results of $N$-parameter convergence studies of mid-span deflections. Both the deflections at the center of mid- 
span, $\Delta(b / 2, L / 2)$, and at the free edges of mid-span, $\Delta(b, L / 2)$ and $\Delta(0, L / 2)$, converged to a solution with accuracy up to four significant figures at $N$ equal to 3.

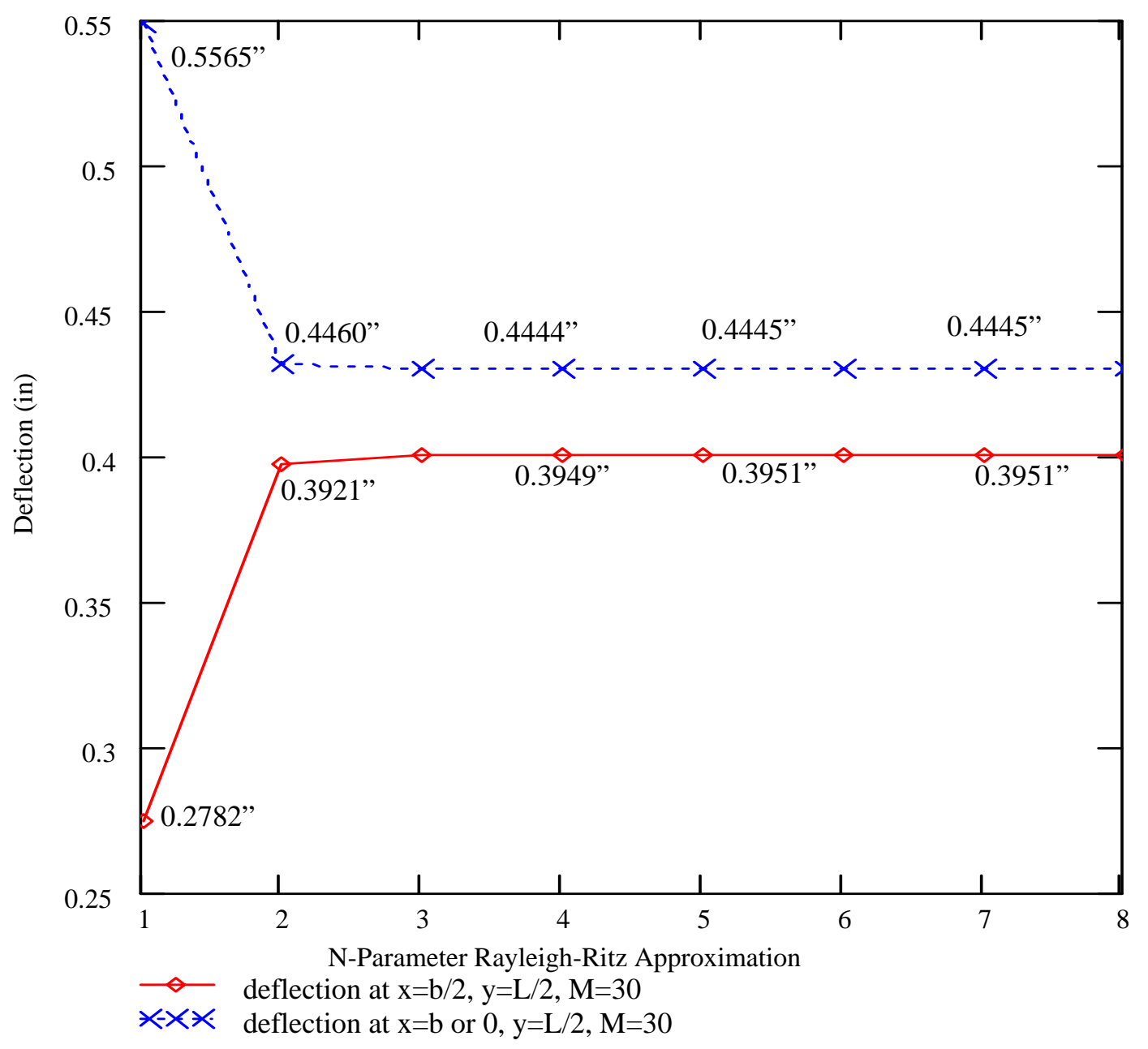

Figure 21: Convergence plot of N-parameter Rayleigh-Ritz approximation of FFSS plate subjected to uniform line load.

$N$ equal to 3 and higher produced good approximations for FFSS plates. Therefore, a convergence study on the number of load terms, $M$, was performed using a 3-parameter Rayleigh-Ritz approximation. $M$ was varied from 1 to 15 . The results show that 9 or more terms are adequate to achieve accuracy of four significant figures (Figure 22) for the deflections at mid-span. 


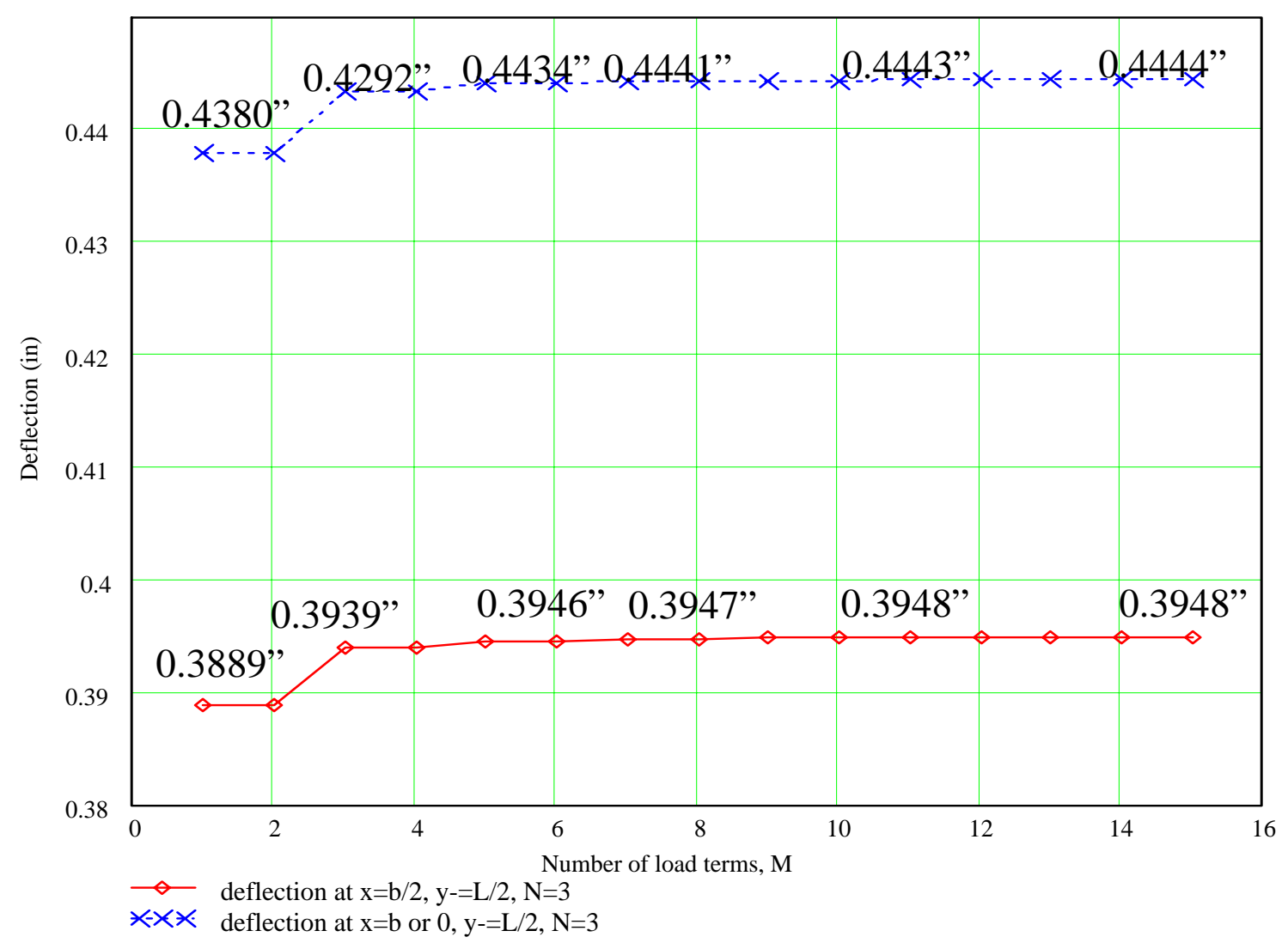

Figure 22: Convergence plot of M-load terms of FFSS plate subjected to uniform line load.

\section{Anticlastic Effect}

The results of convergence studies suggest that $N$ equal to 3 or higher and $M$ equal to 9 or higher should be used to obtain good deflection approximations. The deflected shape of a typical FFSS plate under uniform line load is shown in Figure 23. The 3D surface plot in Figure 23 was obtained by using input parameters listed in Table 1 along with $N$ equal to 3 and $M$ equal to 15 . The curvatures of primary bending, along the span, and the secondary bending, across the span, are in two opposite directions. The surface plot resembles a saddle-shape, which is also known as anticlastic bending. The 
plate model predicts deflection at the free edge to be about $5 \%$ to $10 \%$ higher than the deflection at the center. The difference is due to the flexural rigidity term, $D_{12}$, which describes the interaction between primary and secondary bending. The $D_{12}$ value obtained by using equation (15) is an estimation. Neglecting $D_{12}$ will be conservative because it removes the stiffening effect due to anticlastic bending. The FFSS plate model behaves like a beam model when $D_{12}$ is removed, leaving the deflection constant across the width.

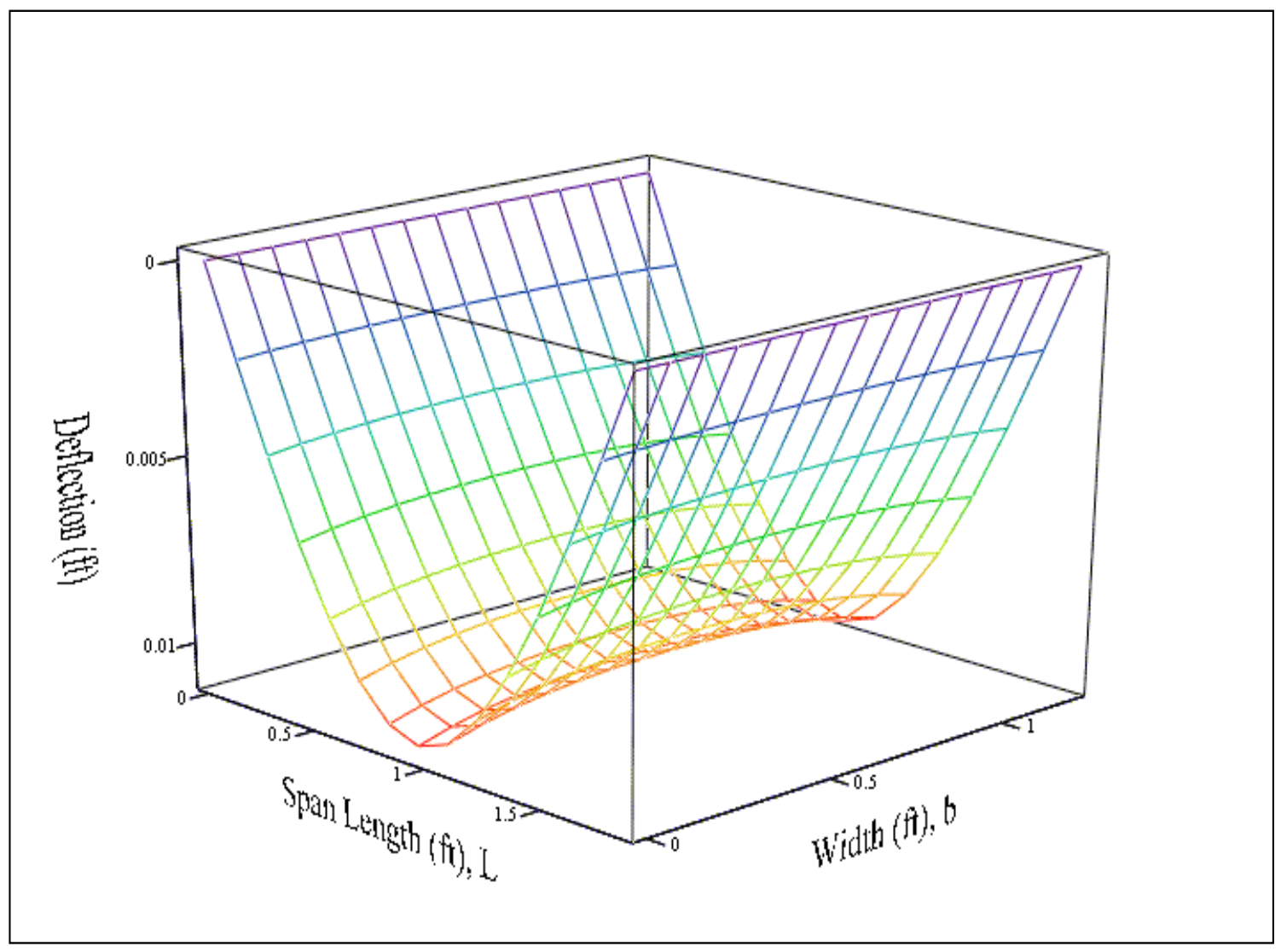

Figure 23: Anticlastic effect of FFSS plate model. 


\section{Beam Model}

In simple beam theory, the transverse bending of a corrugated panel is ignored. The longitudinal bending of a panel is modeled on a per unit width basis. Shear deformation is included in this model. Effective shear area, $A_{s}$, of the cross-section is determined using a parameter called the shear correction coefficient, $k_{s}$, which will be discussed in the following section. Two types of boundary conditions are considered here: single span and two-span conditions.

\section{Shear Correction Coefficient}

Shear deformation is caused by the shear stress through the thickness. Beam theory assumes constant shear stress distribution through the thickness of the panel. However, the actual shear stress distribution requires zero stress at the top and bottom surfaces. To account for the discrepancy, a correction factor called the shear correction coefficient, $k_{s}$, is defined to correct for the shear deformation of the beam model [Reddy 1999].

Consider a cross section equal to a complete wavelength. Shear stress distribution through the thickness based on first order theory, $\tau_{\text {first }}$, is

$$
\tau_{\text {first }}=\frac{V}{A_{c}}
$$

where, $V$ is the vertical external shear (lbs) and $A_{c}$ is the cross-sectional area of the corrugated panel for a complete wavelength $\left(\mathrm{in}^{2}\right) . A_{c}$ can be calculated using equation (49). 


$$
A_{c}=\left(\frac{2-2 \cos (\theta)}{\sin (\theta)} h+w\right) t
$$

All variables in equation (49) are previously defined. The complete derivation of equation (49) can be found in Appendix C. On the other hand, the actual shear stress distribution, $\tau_{\text {actual }}(z)$, through the thickness is defined by the following equation

$$
\tau_{\text {actual }}(z)=\frac{V Q(z)}{I_{c} t_{w}(z)}
$$

where, $Q(z)$ is the first moment about the neutral axis of the section either below or above the line where $\tau_{\text {actual }}(z)$ is to be determined. $t_{w}(z)$ is the horizontal thickness of the cross section where the horizontal shear stress is desired. $I_{c}$ is the moment of inertia of the corrugated panel about its neutral axis (equation (4)). $t_{w}(z)$ can be determined using equation (51) (see Figure 24).

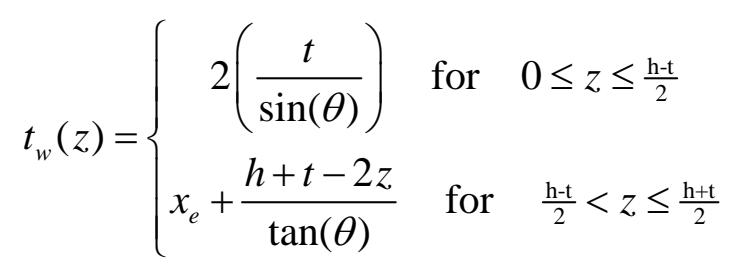

where, $x_{e}$ is the width of the top deck of corrugated panel (Figure 24).

$$
x_{e}=\frac{w}{2}-\frac{h}{\tan (\theta)}+t \tan \left(\frac{\theta}{2}\right)
$$

Notice that Figure 24 only shows the upper half of the corrugated section because both the corrugated section and the shear stress distribution are symmetric about its neutral axis. Similarly, the first static moment is also symmetric about the neutral axis.

$$
Q(z)=\int_{z}^{\frac{h+t}{2}} z t_{w}(z) d x
$$

Substituting equation (51) into equation (53) yields 


$$
Q(z)= \begin{cases}\int_{z}^{\frac{h-t}{2}} z\left(\frac{2 t}{\sin (\theta)}\right) d z+\int_{\frac{h-t}{2} z\left(x_{e}+\frac{h+t-2 z}{\tan (\theta)}\right) d z}^{\frac{h+t}{2}} & \text { for } 0 \leq \mathrm{z} \leq \frac{\mathrm{h}-\mathrm{t}}{2} \\ \int_{z}^{\frac{h+t}{2}} z\left(x_{e}+\frac{h+t-2 z}{\tan (\theta)}\right) d z & \text { for } \frac{\mathrm{h}-\mathrm{t}}{2}<\mathrm{z} \leq \frac{\mathrm{h}+\mathrm{t}}{2}\end{cases}
$$

The typical shape of the first static moment plot for the corrugated panel is shown in

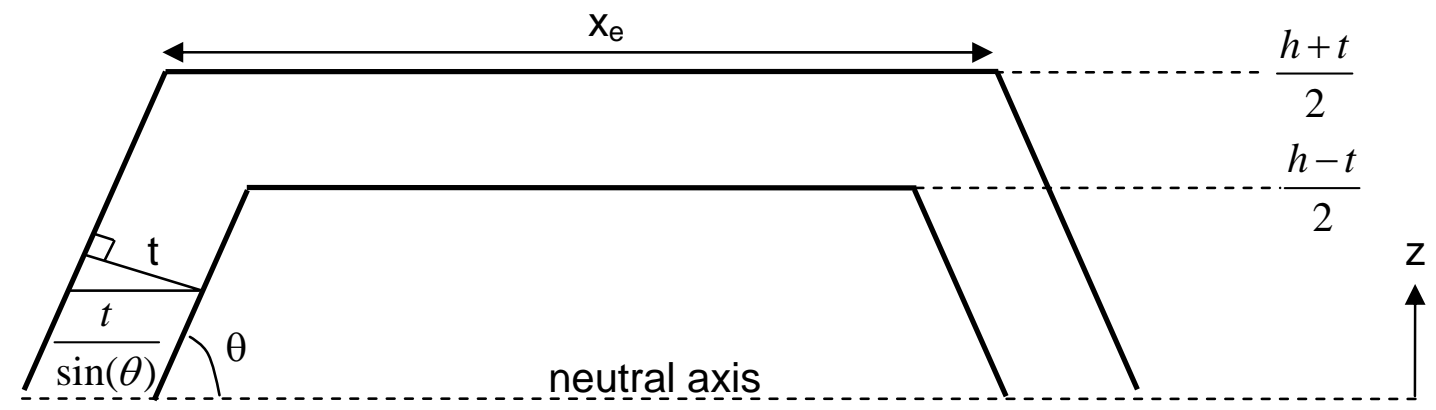

Figure 24: Cross section of corrugated panel above the neutral axis.

Figure 25.

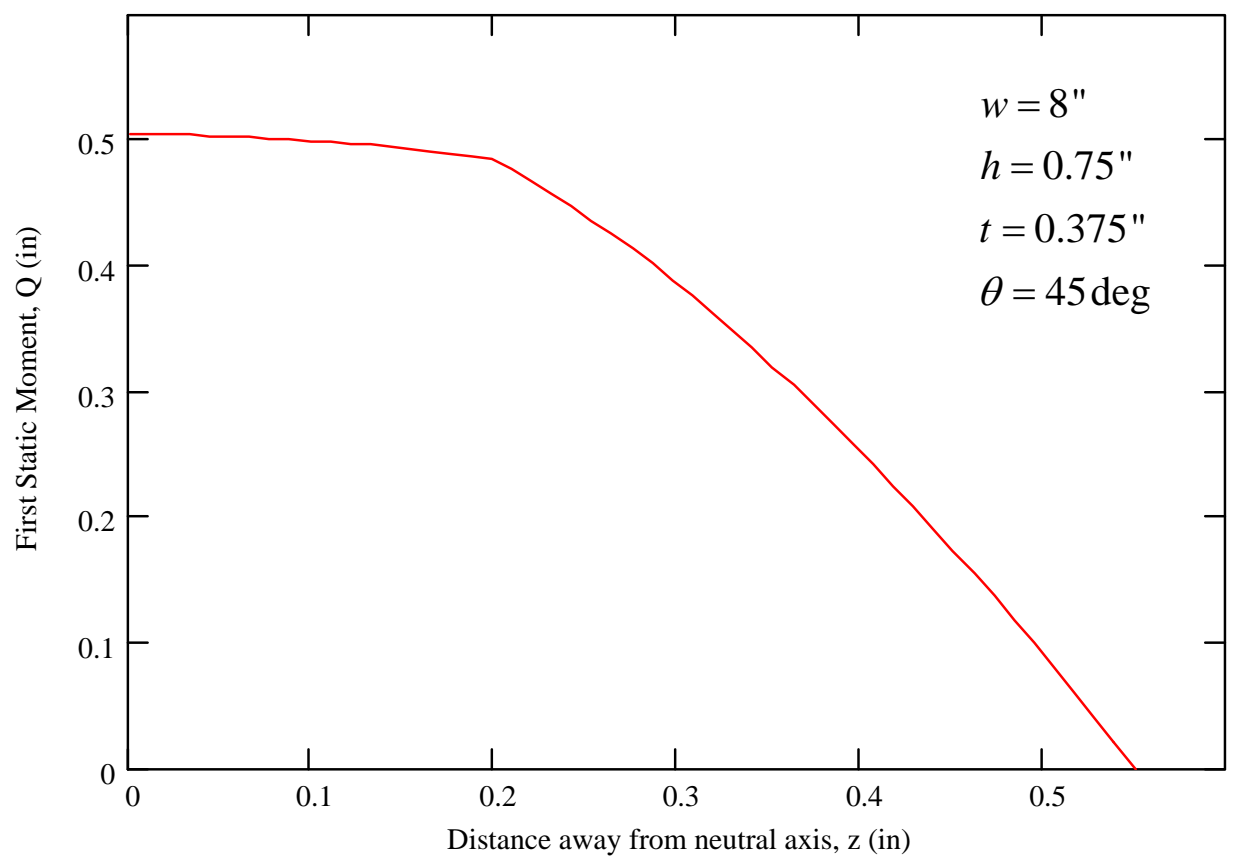

Figure 25: First static moment of corrugated panel. 
The actual shear stress distribution through the thickness can be obtained by substituting equations (54) and (51) into equation (50). The normalized (by letting $V=1 \mathrm{lb}$ ) actual shear stress and the first order shear stress plot are shown in Figure 26. The actual shear stress distribution in corrugated panels resembles the typical shear stress distribution of I-beam sections. The shallow corrugated panels behave like an I-beam with a short web and wide flanges.

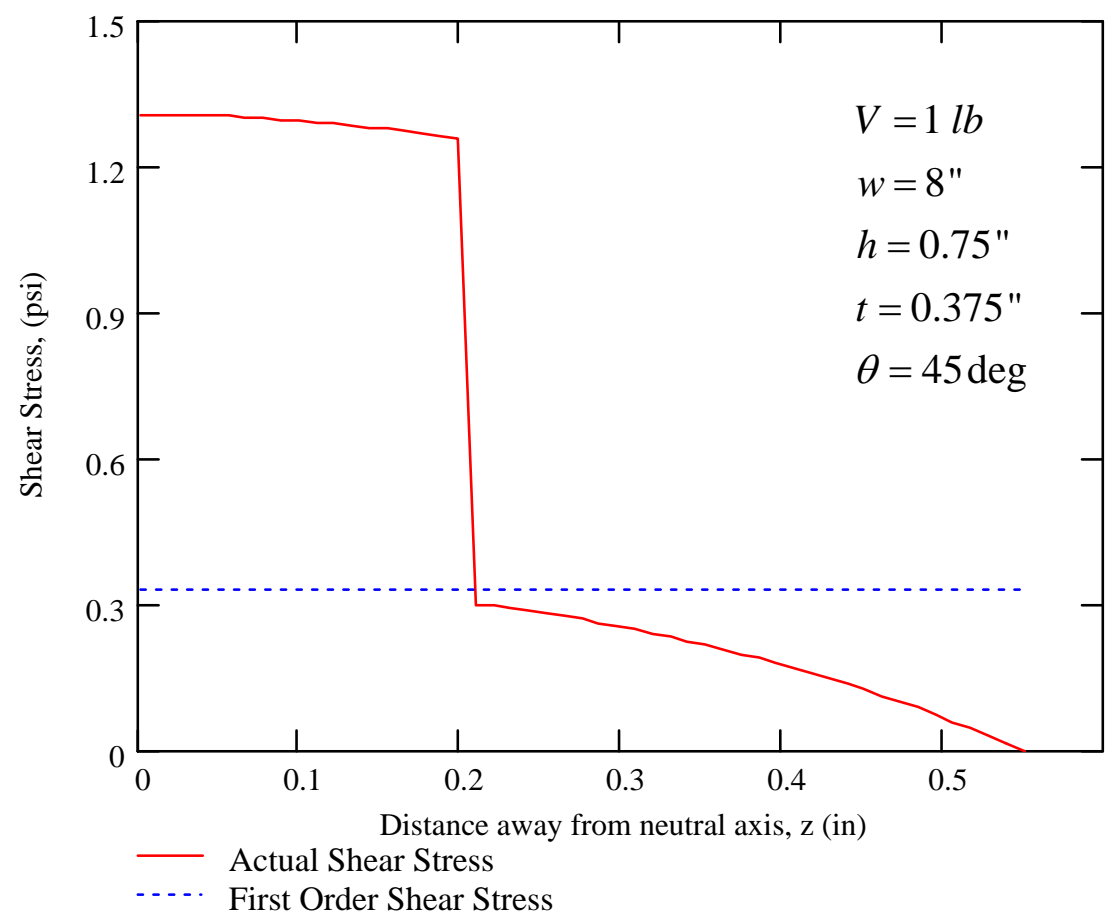

Figure 26: Shear stress distribution through the thickness of corrugated panel.

The shear deformation is proportional to the strain energy due to shear stress. The total strain energy due to actual shear stress, $U_{\text {actual }}$, and first order shear stress, $U_{\text {first }}$, can be determined using the following equations [Reddy 1999].

$$
U_{\text {actual }}=2\left[\frac{1}{2 G} \int_{0}^{\frac{h+t}{2}}\left(\tau_{\text {actual }}(z)\right)^{2} t_{w}(z) d z\right]
$$




$$
U_{\text {first }}=2\left[\frac{1}{2 G} \int_{0}^{\frac{h+t}{2}}\left(\tau_{\text {first }}(z)\right)^{2} t_{w}(z) d z\right]
$$

The shear correction coefficient, $k_{s}$, is defined as the ratio of the total shear strain energy from the actual shear stress distribution, $U_{\text {actual }}$, to the total shear strain energy calculated from first order theory, $U_{\text {first }}$.

$$
k_{s}=\frac{U_{\text {actual }}}{U_{\text {first }}}
$$

$k_{s}$ is a function of the geometry of the corrugated panels, i.e., a function of $w, h, t$ and $\theta$ only. The shear correction coefficient for corrugated panels with varying panel skin thickness is shown in Figure 27. As the thickness increases, $k_{\mathrm{s}}$ approaches 1.2, which is the shear correction factor for a rectangular cross section. However, there are some limitations for the $k_{s}$ calculations for corrugated panels. For example, equations (51),

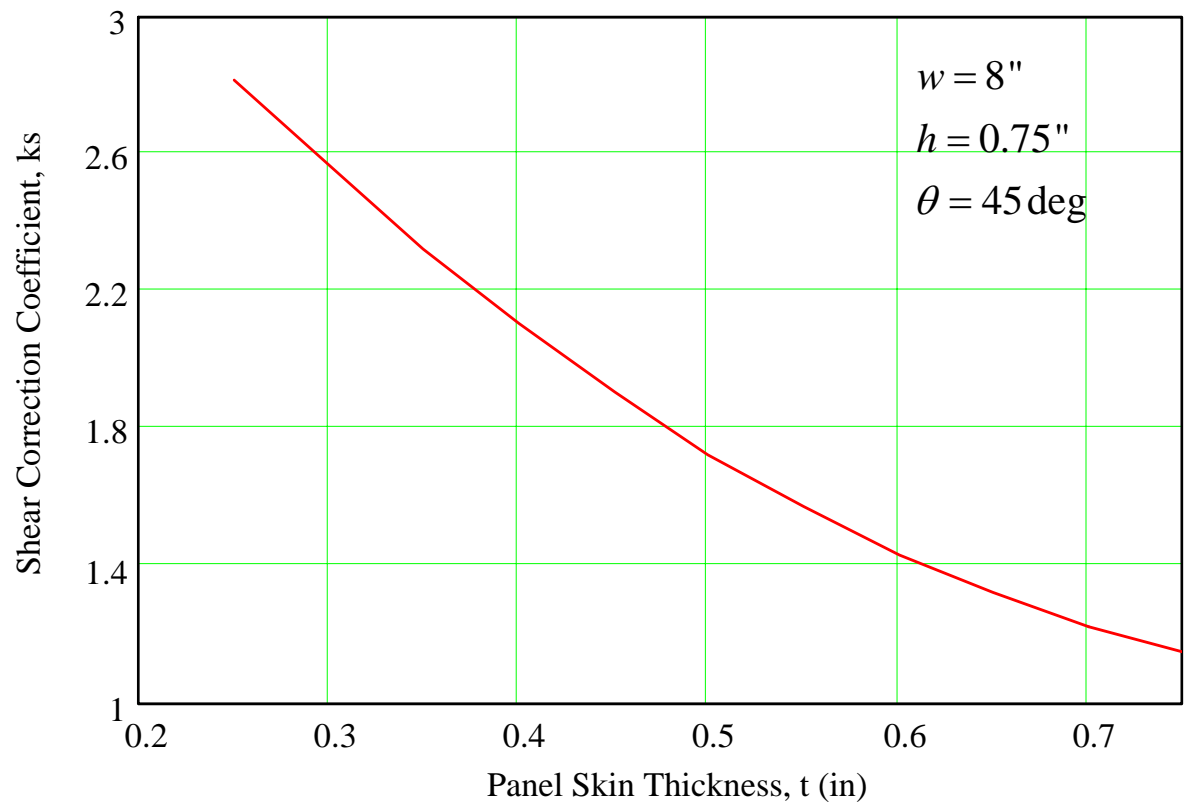

Figure 27: Shear correction coefficient of corrugated panels of varying panel skin thickness. 
(53), (54), (55), and (56) cannot be defined if the skin thickness, $t$, is greater than the

draw depth, $h . k_{s}$ is valid only if the mathematical definition of the corrugated panel geometry is the same as the physical panel geometry.

Effective shear area, $A_{s}$, which is used in the calculation of shear deformation of the beam model, is defined as the total area of the cross section divided by the shear correction coefficient.

$$
A_{s}=\frac{A}{k_{s}}=\frac{A_{c}}{k_{s}}\left(\frac{b}{w}\right)
$$

where, $A$ is the total area of the cross section $\left(\mathrm{in}^{2}\right)$ and $A_{c}$ is the area for a complete wavelength of a corrugated panel $\left(\mathrm{in}^{2}\right)$, (equation (49)). $b$ and $w$ are previously defined as width and wavelength, respectively.

\section{Single Span Model}

For a simple beam with concentrated load at mid-span (Figure 28), the total deflection at the point of load, $\Delta_{p}$, is given by equation (59)

$$
\Delta_{p}=\frac{P L^{3}}{48 E I}+\frac{P L}{4 G A_{s}}
$$

where, $P$ is the applied load (lbs) and $L$ is the span length (in). $E$ and $G$ are modulus

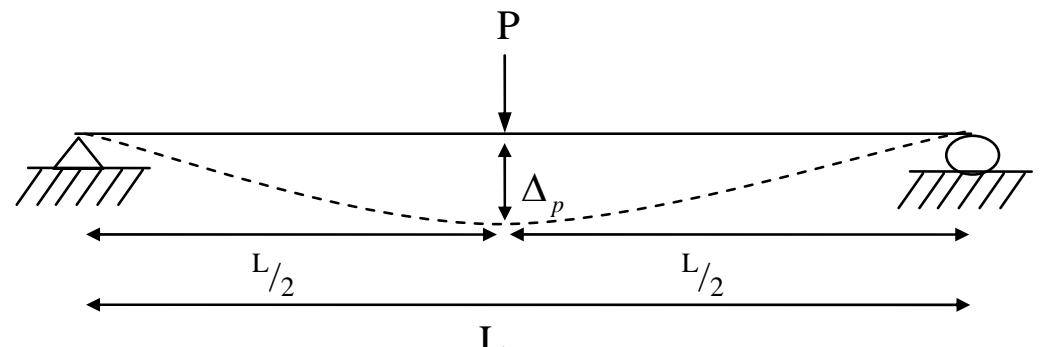

Figure 28: Simple beam with concentrated load at mid-span. 
of elasticity (psi) and shear modulus (psi), respectively. $A_{s}$ is the effective shear area, discussed in the previous section. I is the moment of inertia of the cross section, computed as

$$
I=I_{c} \frac{b}{w}
$$

where, $I_{c}$ is the moment of inertia for a complete wavelength, calculated using equation (4). $b$ is the width of the panel and $w$ is previously defined as the wavelength of the corrugated panel. The bending stiffness per unit width, $E I_{\text {beam } 1}$, can be calculated by rearranging equation (59).

$$
E I_{\text {beam } 1}=\left(\frac{P}{\Delta_{p}}\right)\left(\frac{L^{3}}{48}+\frac{L}{4} \frac{E}{G} \frac{I}{A_{s}}\right)\left(\frac{1}{b}\right)
$$

The $P / \Delta_{p}$ and $E / G$ ratios can determined experimentally. The bending strength or moment capacity, $F_{b} S_{\text {beam } 1}$, for the single span condition is determined as,

$$
F_{b} S_{\text {beam } 1}=\frac{M_{\max 1}}{b}=\frac{P_{\max } L}{4}\left(\frac{1}{b}\right)
$$

$F_{b} S_{\text {beam } 1}$ is equal to the maximum moment, $M_{\max 1}$, per unit width obtained by using beam theory. Maximum moment occurs at the point of load. $P_{\max }$ is the maximum applied load.

\section{Model Calibration}

The beam model is constructed based on some simplifying assumptions for the loading and boundary conditions that might affect the accuracy of the model. On the other hand, the FE model can better predict the actual stiffness response because it accounts for the actual geometry, boundary conditions and loading conditions. Beam 
models might produce different results from FE models for some cases, especially when shear deformation is important.

Model comparison was made between the FE and the beam model using a singlespan simply supported corrugated panel bending in the strong axis direction. The FE model was constructed as previously shown in Figure 8. The corrugated panel profile, material properties, and applied load are shown in Table 2. Four commonly used nominal spans (20”, 24”, 32” and 48”) and three shear moduli were used. Load was applied at mid-span and the deflection at the center of mid-span was compared. Deflection for the original beam model was obtained using equation (59). The original beam model greatly underestimated the deflection, especially for short span and low shear modulus models (Table 2).

Table 2: Deflection error of single-span original and corrected beam models from FE model.

\begin{tabular}{|c|c|c|c|c|c|c|}
\hline \multirow{2}{*}{$\begin{array}{l}\text { Actual Span* } \\
\text { (in) }\end{array}$} & \multicolumn{3}{|c|}{$\frac{\text { Original Beam Model (equation (59)): }}{\text { Shear Modulus (ksi) }}$} & \multicolumn{3}{|c|}{$\frac{\text { Calibrated Beam Model (equation (65)): }}{\text { Shear Modulus (ksi) }}$} \\
\hline & 25 & 92 & 300 & 25 & 92 & 300 \\
\hline 18.5 & $-43.74 \%$ & $-27.13 \%$ & $-16.42 \%$ & $3.85 \%$ & $-4.64 \%$ & $-4.83 \%$ \\
\hline 22.5 & $-37.72 \%$ & $-21.48 \%$ & $-12.81 \%$ & $1.33 \%$ & $-3.33 \%$ & $-2.94 \%$ \\
\hline 30.5 & $-28.06 \%$ & $-14.59 \%$ & $-8.93 \%$ & $-0.05 \%$ & $-1.40 \%$ & $-0.86 \%$ \\
\hline 46.5 & $-17.31 \%$ & $-9.09 \%$ & $-6.33 \%$ & $-0.11 \%$ & $0.05 \%$ & $0.38 \%$ \\
\hline $\begin{array}{l}\text { MOE = } 600 \mathrm{ksi}, \\
w=8 ", h=0.75 " \\
b=24 " \text { ( } 3 \text { waves } \\
\text { * Assumed supp }\end{array}$ & $\begin{array}{l}0.3 \\
=0.375 ", \theta=4 ! \\
P=\frac{1000 \mathrm{lbs},}{\mathrm{b}} \text { a } \\
\text { ed by nominal }\end{array}$ & $\begin{array}{l}\text { at mid-span } \\
\text { joists. }\end{array}$ & & & & \\
\hline
\end{tabular}

To correct for the discrepancies, two coefficients, $c_{b 1}$ and $c_{s 1}$, were used to modify the bending and shear deformations terms of the original beam bending equation. The coefficients were approximated from an overdetermined system of linear equations, by replacing $\Delta_{p}$ of equation (61) by the deflection obtained from the FE model, $\Delta_{F E}$. 


$$
\Delta_{F E} \approx c_{b 1} \frac{P L^{3}}{48 E I}+c_{s 1} \frac{P L}{4 G A_{s}}
$$

The overdetermined system of linear equations were written in matrix form

$$
\left\{\begin{array}{c}
\Delta_{F E_{1}} \\
\Delta_{F E_{2}} \\
\Delta_{F E_{3}} \\
\vdots \\
\Delta_{F E_{n}}
\end{array}\right\}=\left[\begin{array}{cc}
\frac{P L_{1}^{3}}{48 E I} & \frac{P L_{1}}{4 G_{1} A_{s}} \\
\frac{P L_{2}{ }^{3}}{48 E I} & \frac{P L_{2}}{4 G_{2} A_{s}} \\
\frac{P L_{3}^{3}}{48 E I} & \frac{P L_{3}}{4 G_{3} A_{s}} \\
\vdots & : \\
\frac{P L_{n}{ }^{3}}{48 E I} & \frac{P L_{n}}{4 G_{n} A_{s}}
\end{array}\right]\left\{\begin{array}{c}
c_{b 1} \\
C_{s 1}
\end{array}\right\}
$$

where $L$ and $G$ were the various spans and shear moduli used in Table 2. Each row of $\left\{\Delta_{F E}\right\}$ in equation (64) was a deflection obtained from the FE model. Twelve data points were used. A multiple linear regression [Wesolowsky, 1976] approach was used to solve for coefficients $c_{b 1}$ and $c_{s 1}$, and were determined to be 1.059 and 5.079, respectively. The deflection equation for the calibrated single-span beam model is

$$
\Delta_{p}=\frac{P L^{3}}{45.33 E I}+1.27 \frac{P L}{G A_{s}}
$$

The calibrated beam model has less than 5\% error compared to the FE model (Table 2 and Figure 29). The bending stiffness of the calibrated model becomes

$$
E I_{\text {beam } 1}=\left(\frac{P}{\Delta_{p}}\right)\left(\frac{L^{3}}{45.33}+1.27 L \frac{E}{G} \frac{I}{A_{s}}\right)\left(\frac{1}{b}\right)
$$

The solution for $c_{s 1}$ indicates that the original beam deflection equation underestimates the shear deformation by about 5 times. 


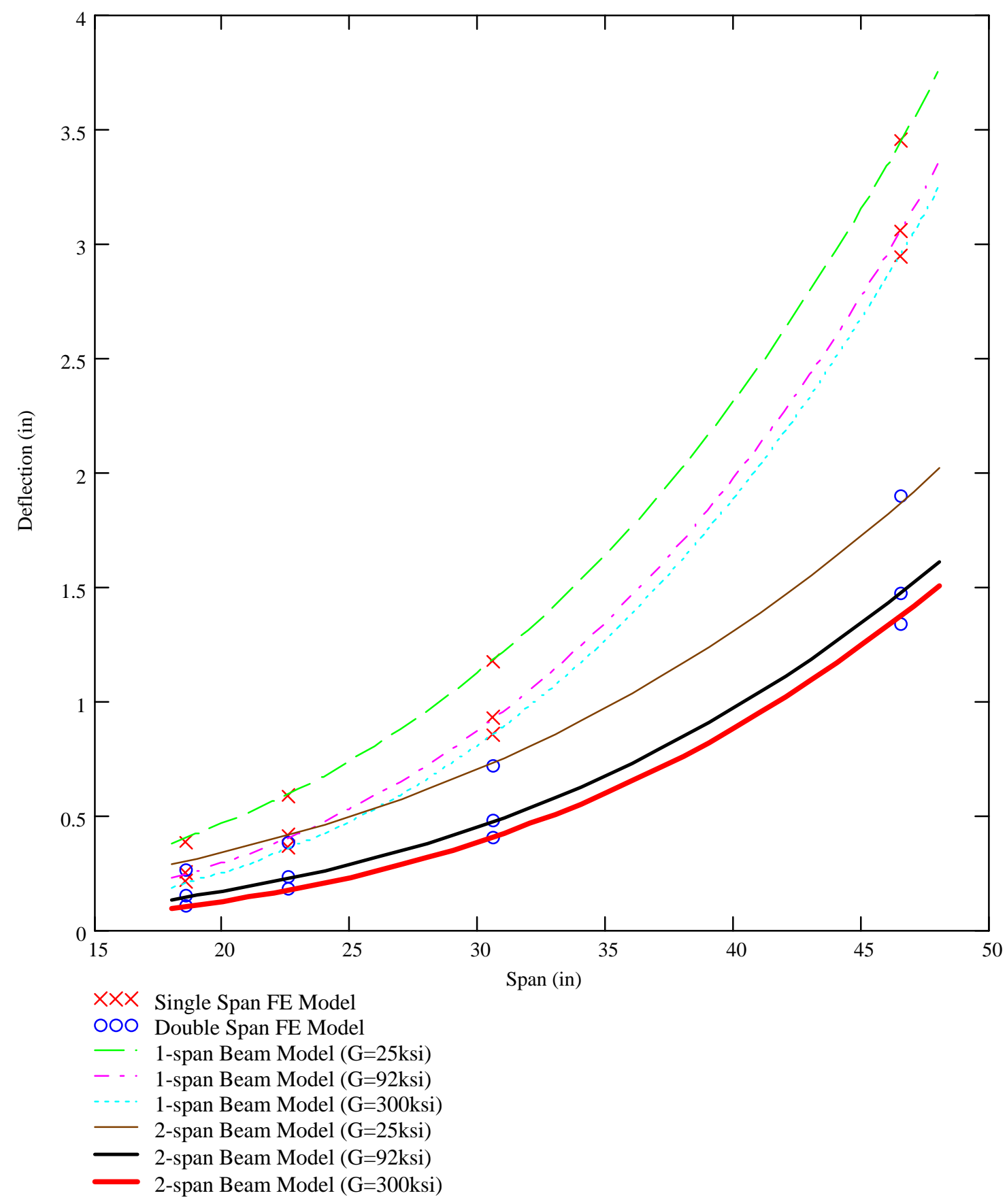

Figure 29: Deflections of calibrated single-span and two-span beam models. 


\section{Two-span Model}

For the two-span condition with equal concentrated load applied on both spans, the loading condition can be modeled as a single span with a simple support at one end and a fixed end support at the other (Figure 30). The deflection at the point of load can be computed as

$$
\Delta_{p}=\frac{7 P L^{3}}{768 E I}+\frac{73 P L}{256 G A_{s}}
$$

The bending stiffness per unit width, $E I_{\text {beam } 2}$, is calculated as,

$$
E I_{\text {beam } 2}=\left(\frac{P}{\Delta_{p}}\right)\left(\frac{7 L^{3}}{768}+\frac{73 L}{256} \frac{E}{G} \frac{I}{A_{s}}\right)\left(\frac{1}{b}\right)
$$

All variables in equations (67) and (68) are previously defined. Notice that $\Delta_{p}$ is the deflection measured at the load point. $\Delta_{p}$ is not the maximum deflection for the two-span condition.
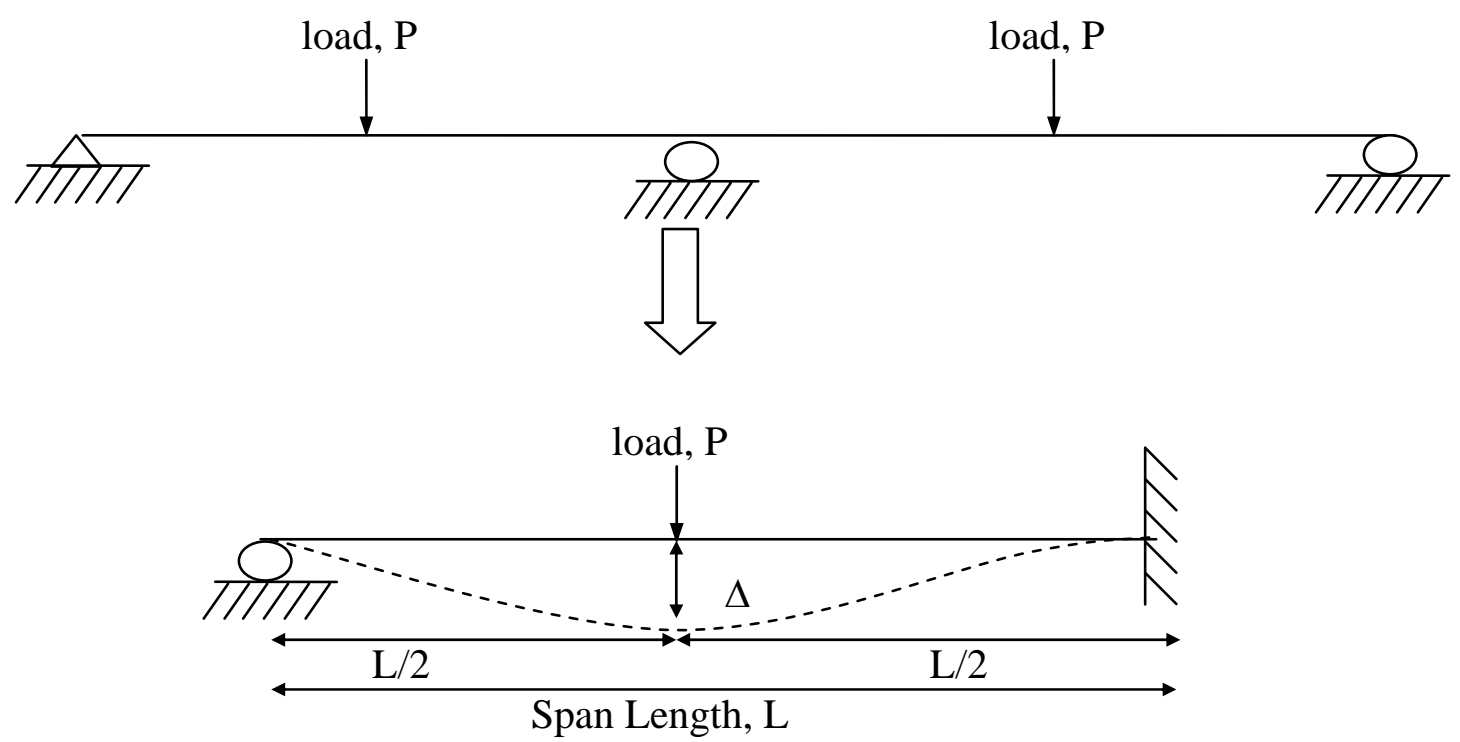

Figure 30: Beam fixed at one end, support at other and concentrated load at mid-span. 
The location at which maximum moment occurs determined the bending strength of the panel. The maximum moment for the two-span condition occurs at the middle support (or fixed end). However, the moment at point of load is close to the maximum moment at the middle support. The maximum moment at the middle support, $M_{\max 2}$, and the moment at point of load, $M_{p 2}$, are listed in the following equations.

$$
\begin{gathered}
M_{\max 2}=\frac{3 P_{\max } L}{16} \\
M_{p 2}=\frac{5 P_{\max } L}{32}
\end{gathered}
$$

The moment at the point of load is used to calculate the bending strength of the two-span model for two reasons. First, most of the test specimens failed at the point of load rather than at the middle support. Second, the bending strength calculated using the lower moment at the point of load is more conservative. Thus, the bending strength or moment capacity, $F_{b} S_{\text {beam } 2}$, per unit width of two-span condition is calculated as,

$$
F_{b} S_{\text {beam } 2}=\frac{M_{p 2}}{b}=\frac{5 P_{\max } L}{32}\left(\frac{1}{b}\right)
$$

Moment at the point of load can be calculated from equation (70) and all other variables are previously defined.

\section{Model Calibration}

The two-span beam model was compared to the FE model. Comparison was made using the same approach as used for the single-span beam model, by varying span length and shear modulus. The errors between two-span beam and FE models are shown in Table 3. A similar discrepancy to that observed in the original single-span beam model 
was encountered. The error was largest at the low shear modulus and short span combination.

Table 3: Deflection error of two-span original and corrected beam models from FE model.

\begin{tabular}{|c|c|c|c|c|c|c|}
\hline \multirow{3}{*}{$\begin{array}{l}\text { Actual Span* } \\
\text { (in) }\end{array}$} & \multirow{2}{*}{\multicolumn{3}{|c|}{$\frac{\text { Original Beam Model (equation (67)): }}{\text { Shear Modulus (ksi) }}$}} & \multirow{2}{*}{\multicolumn{3}{|c|}{$\frac{\text { Calibrated Beam Model (equation (73)): }}{\text { Shear Modulus (ksi) }}$}} \\
\hline & & & & & & \\
\hline & 25 & 92 & 300 & 25 & 92 & 300 \\
\hline 18.5 & $-52.94 \%$ & $-41.69 \%$ & $-27.89 \%$ & $13.34 \%$ & $-6.89 \%$ & $-8.22 \%$ \\
\hline 22.5 & $-49.67 \%$ & $-34.70 \%$ & $-21.39 \%$ & $6.33 \%$ & $-5.07 \%$ & $-4.11 \%$ \\
\hline 30.5 & $-41.63 \%$ & $-24.81 \%$ & $-14.30 \%$ & $1.56 \%$ & $-1.97 \%$ & $0.09 \%$ \\
\hline 46.5 & $-30.25 \%$ & $-16.23 \%$ & $-9.71 \%$ & $-1.60 \%$ & $-0.08 \%$ & $2.18 \%$ \\
\hline \multicolumn{7}{|c|}{$\mathrm{MOE}=600 \mathrm{ksi}, \mathrm{v}=0.3$} \\
\hline \multicolumn{7}{|c|}{$w=8 ", h=0.75^{\prime \prime}, t=0.375^{\prime \prime}, \theta=45$ deg. } \\
\hline \multicolumn{7}{|c|}{$\mathrm{b}=24$ " ( 3 waves), $P=\frac{1000 \mathrm{lbs},}{\mathrm{b}}$ applied at middle of each span } \\
\hline \multicolumn{7}{|c|}{ * Assumed supported by nominal 2" wide joists. } \\
\hline
\end{tabular}

Multiple linear regression was performed on the data to fit two coefficients, $c_{b 2}$ and $c_{s 2}$, to correct the bending and shear deformation terms of the two-span beam equation.

$$
\Delta_{F E} \approx c_{b 2} \frac{7 P L^{3}}{768 E I}+c_{s 2} \frac{73 P L}{256 G A_{s}}
$$

$c_{b 2}$ and $c_{s 2}$ were determined to be 1.104 and 4.464, respectively. Substitute $c_{b 2}$ and $c_{s 2}$ into equation (67) to obtain a calibrated two-span beam deflection equation.

$$
\Delta_{p}=\frac{P L^{3}}{99.39 E I}+1.27 \frac{P L}{G A_{s}}
$$

Notice that the shear deformation terms are identical for both calibrated single-span (equation (65)) and two-span (equation (73)) beam models. The calibrated bending stiffness equation for the two-span condition is

$$
E I_{\text {beam } 2}=\left(\frac{P}{\Delta_{p}}\right)\left(\frac{L^{3}}{99.39}+1.27 L \frac{E}{G} \frac{I}{A_{s}}\right)\left(\frac{1}{b}\right)
$$




\section{MOE and MOR of Corrugated Panels}

By knowing the load-to-deflection $\left(P / \Delta_{p}\right)$ ratio from experiments, bending stiffness per unit width of corrugated panel can be calculated from equations (66) and (74) for single-span and two-span conditions, respectively. Similarly, the bending strength per unit width can be computed from equations (62) and (71) by obtaining the maximum applied load, $P_{\max }$, from experimental tests.

The modulus of elasticity (MOE) of a corrugated panel can be calculated by dividing equations (66) or (74) by the moment of inertia of the corrugated panel per unit width $\left(I_{c} / w\right)$. MOE for single-span, $\left(E_{c 1}\right)$, and two-span, $\left(E_{c 2}\right)$, conditions are computed as:

$$
\begin{aligned}
& E_{c 1}=\frac{E I_{\text {beam } 1}}{I_{c} / w} \\
& E_{c 2}=\frac{E I_{\text {beam } 2}}{I_{c} / w}
\end{aligned}
$$

$w$ is previously defined as the wavelength of the corrugated panel. Similarly, the modulus of rupture (MOR) can be calculated by knowing the section modulus of the corrugated panel $\left(S_{c}\right)$.

$$
\begin{array}{r}
R_{c 1}=\frac{F_{b} S_{\text {beam } 1}}{S_{c} / w}=\frac{P_{\max } L}{S_{c} 4}\left(\frac{w}{b}\right) \\
R_{c 2}=\frac{F_{b} S_{\text {beam } 2}}{S_{c} / w}=\frac{5 P_{\max } L}{32}\left(\frac{w}{b}\right)
\end{array}
$$

$R_{c 1}$ and $R_{c 2}$ are MOR estimated for single-span and two-span conditions, respectively.

$S_{c}$ is defined by equation (6). 


\section{Composite Deck Beam Model}

Bending stiffness of a floor deck can be improved greatly by attaching oriented strand board (OSB) as underlayment to the corrugated panel. Increase of bending stiffness can be explained through the interaction between the underlayment and the corrugated subfloor, known as composite action. The composite deck beam model was developed by replacing the bending and shear stiffnesses of equations (65) and (73) with effective bending and shear stiffnesses for single-span and two-span conditions, respectively.

\section{Bending Stiffness of Partial Composite Deck}

The composite deck system consists of OSB underlayment nailed-glued to the corrugated subfloor. Full composite action is unlikely, especially with a flexible AFG-01 type adhesive. A method to calculate the effective bending stiffness of partial composite T- and I-beams was suggested by McCutcheon [McCutcheon, 1977 and 1986] based on composite beam research conducted in the early 1970s [Kuenzi and Wilkinson, 1971]. A different approach that leads to a similar result is used to derive the effective bending stiffness for the partial composite deck system.

The effective or reduced axial stiffness of the underlayment is modeled as a system of 'springs' in series relative to the movement of the corrugated panel shown in Figure 31(a).

$$
\frac{1}{\frac{E A_{u n}}{L_{u n}}}=\frac{1}{\frac{E A_{u n}}{L_{u n}}}+\frac{1}{c_{a d} \frac{G_{a d} A_{a d}}{t_{a d}}}
$$




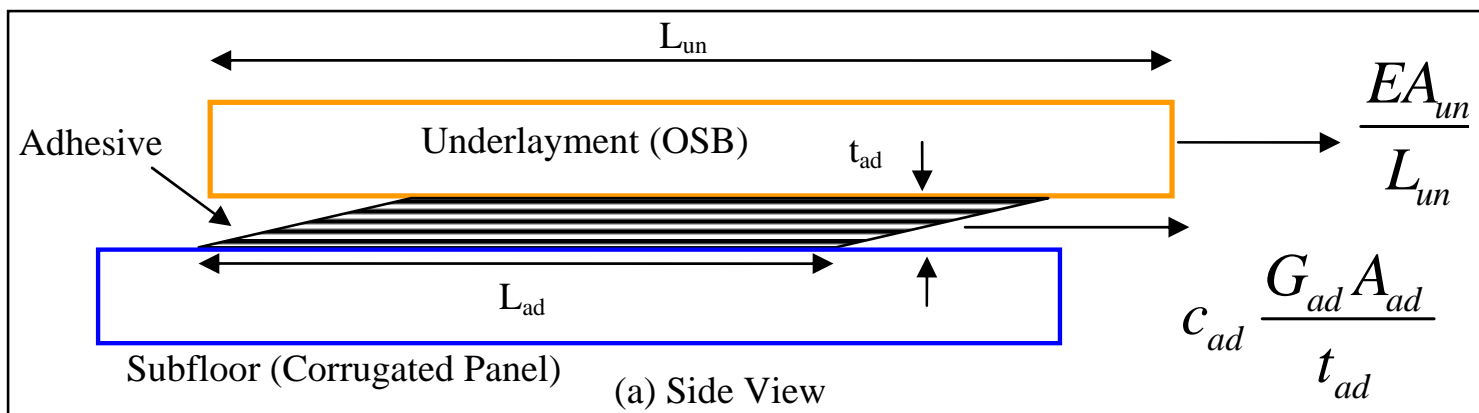

(a) Side View

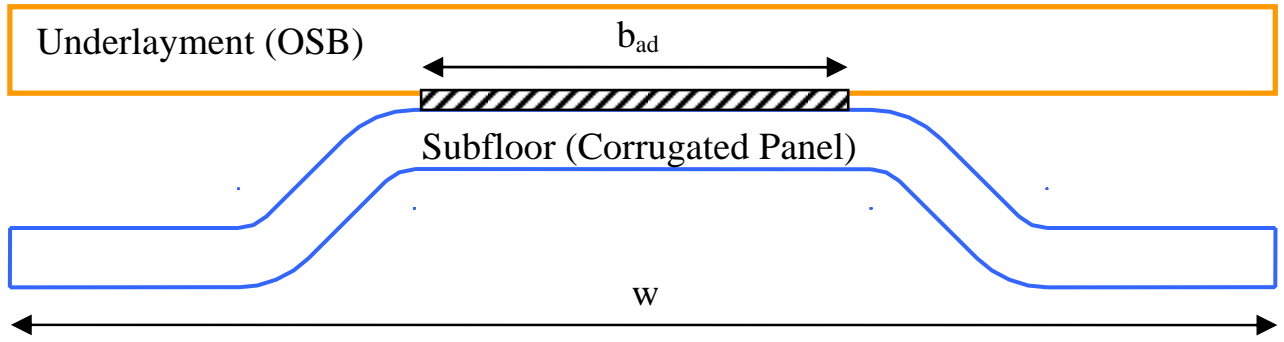

(b) Front View

Figure 31: Effective axial stiffness of the partial composite deck system for beam model.

$\overline{E A_{u n}}$ is the effective or reduced axial stiffness per unit width (lbs/ft) and $E A_{u n}$ is the axial stiffness per unit width (lbs/ft) of the underlayment. $G_{a d}$ is the shear modulus of the adhesive. $t_{a d}$ is the thickness of the adhesive, usually about $1 / 32$ " [McCutcheon, 1977]. $C_{a d}$ is a constant to account for the effectiveness of the glue joint. $C_{a d}$ will be obtained through curve fitting of the experimental and FE data. $A_{a d}$ is the area of the adhesive per unit width $\left(\mathrm{in}^{2} / \mathrm{ft}\right)$ computed as,

$$
A_{a d}=\frac{b_{a d} L_{a d}}{w}
$$

Where, $b_{a d}$ is the width of the adhesive on the top deck of the corrugated panel (Figure 31(b)) and $L_{a d}$ is the length of the adhesive. $w$ is previously defined as the wavelength 
of the corrugated panel. Substituting equation (80) into equation (79) and solving for the effective or reduced axial stiffness yields

$$
\overline{E A_{u n}}=\frac{E A_{u n}}{1+\frac{E A_{u n}}{c_{a d} \frac{G_{a d} b_{a d} L_{a d} L_{u n}}{t_{a d} w}}}
$$

The neutral axis of the partial composite deck system, $\bar{y}$, is located at

$$
\bar{y}=\frac{y_{c} E A_{c}+y_{u n} \overline{E A_{u n}}}{E A_{c}+\overline{E A_{u n}}}
$$

$\bar{y}$ is measured from the bottom of the corrugated panel. $E A_{c}$ is the axial stiffness of the corrugated panel per unit width (lbs/ft). $y_{c}$ and $y_{u n}$ are the locations for the center of gravity of the corrugated panel and underlayment, respectively (Figure 32).

$$
\begin{gathered}
y_{c}=\frac{h+t}{2} \\
y_{u n}=h+t+\frac{t_{u n}}{2}
\end{gathered}
$$

Knowing the neutral axis of the partial composite section, the parallel-axis theorem is applied to compute the effective bending stiffness.

$$
E I_{\text {eff }}=E I_{u}+E A_{c}\left(\bar{y}-y_{c}\right)^{2}+\overline{E A_{u n}}\left(\bar{y}-y_{u n}\right)^{2}
$$

$E I_{u}$ is the unattached bending stiffness of the partial composite section, taken as the sum of bending stiffnesses of the corrugated panel and OSB underlayment.

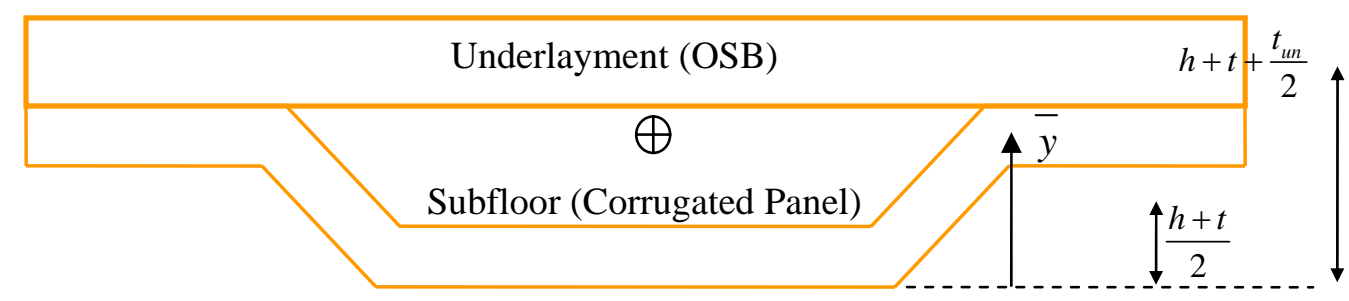

Figure 32: Neutral axis of the partial composite deck system. 


$$
E I_{u}=E I+E I_{u n}
$$

$E I$ is the bending stiffness of corrugated panel while $E I_{u n}$ is the bending stiffness of OSB underlayment. Equation (85) can be further simplified into

$$
E I_{\text {eff }}=E I_{u}+\frac{E A_{c} \overline{E A_{u n}}}{E A_{c}+\overline{E A_{u n}}}\left(y_{u n}-y_{c}\right)^{2}
$$

$E I_{u}$ represents the lower limit for the bending stiffness of the partial composite section, where there is no composite action between the corrugated panel and OSB underlayment. On the other hand, the upper limit for the bending stiffness is defined by the full composite stiffness, $E I_{\text {comp }}$, where a rigid bond is assumed. $E I_{\text {comp }}$ can be obtained by assuming full axial stiffness for the underlayment or letting $\overline{E A_{u n}}$ equal to $E A_{u n}$ in equation (87).

\section{Composite Factor}

The effective bending stiffness, $E I_{\text {eff }}$, of a composite deck falls between the full composite stiffness and the unattached bending stiffness. A composite factor, $C_{\text {eff }}$, is used to quantify the effectiveness of the bond between the corrugated panel and OSB. The factor is defined as:

$$
C_{\text {eff }}=\frac{E I_{\text {eff }}-E I_{u}}{E I_{\text {comp }}-E I_{u}}
$$

where, $E I_{\text {eff }}$ can be determined experimentally from bending tests on the composite deck system. For design purposes, the ability to predict or estimate $E I_{\text {eff }}$ is valuable. Rearranging equation (88), $E I_{\text {eff }}$ can be calculated if $C_{e f f}$ is known.

$$
E I_{\text {eff }}=C_{\text {eff }} E I_{\text {comp }}+\left(1-C_{\text {eff }}\right) E I_{u}
$$


$C_{\text {eff }}$ for a specific bond, such as a nailed-glued joint, can be determined through experimental testing. The effective stiffness of a composite deck can then be calculated for design purposes using an appropriate $C_{\text {eff }}$ for different applications (nail-only or nailed-glued) using equation (89).

\section{Shear Stiffness of Partial Composite Deck}

The effective shear stiffness, $G A_{\text {eff }}$, of a composite deck is estimated using the following equation.

$$
G A_{\text {eff }}=G A_{s}+C_{\text {eff }} C_{G} G A_{\text {un }}
$$

Where $C_{\text {eff }}$ is the composite factor discussed in previous section. $G A_{s}$ is the shear stiffness per unit width of the corrugated panel (lbs/ft). $c_{G}$ is a constant having a value in the range

of 0 to $1 . c_{G}$ accounts for the contribution of the underlayment shear stiffness. $c_{G}$ of $10 \%$ to $20 \%$ ( 0.1 to 0.2 ) appears to fit the FE and experimental data well. $G A_{u n}$ is the shear stiffness of the underlayment per unit width (lbs/ft), calculated as

$$
G A_{u n}=\frac{G_{u n} t_{u n}}{1.2}
$$

$G_{u n}$ is the shear modulus of the underlayment and 1.2 is the shear correction coefficient for a rectangular section. 


\section{Physical Properties}

Panel physical properties, such as dimensions and weight, were measured and recorded for each test specimen prior to testing. A thickness reading was taken at every sidewall and flat deck at both ends of the corrugated panels. Variation of thickness was found from panel to panel as well as within each panel itself. An averaging method was used to calculate an effective or representative thickness value for each corrugated panel. Density as tested, oven-dry density and moisture content are also reported herein for the test specimens.

\section{Thickness Variation}

Producing a corrugated panel with a consistent thickness throughout the panel is difficult to accomplish, especially with a manually operated press. The thickness of corrugated panels produced varied within the panel. There were two main factors that caused the variation of thickness. First, any error in machining of the dies would directly contribute to the differences of thickness within the panel. Second, the final closing gap of the dies during pressing caused the sidewalls to have thickness, in general, greater than both the lower and upper decks. This phenomenon occurred due to the nature of the die geometry. Figure 33 shows three final closing gaps for a pair of corrugated dies. The corrugated dies were designed and machined to produce a corrugated panel with $3 / 8$ " thickness throughout the panel (Figure 33(a)). If the closing gap of the dies was held narrower than the designed thickness (Figure 33(b)), the corrugated panel produced would have sidewall thickness greater than the lower and upper decks. On the other hand, 
if the closing gap was at a distance greater than the designed thickness (Figure 33(c)), the panel would have thicker decks and thinner sidewalls.

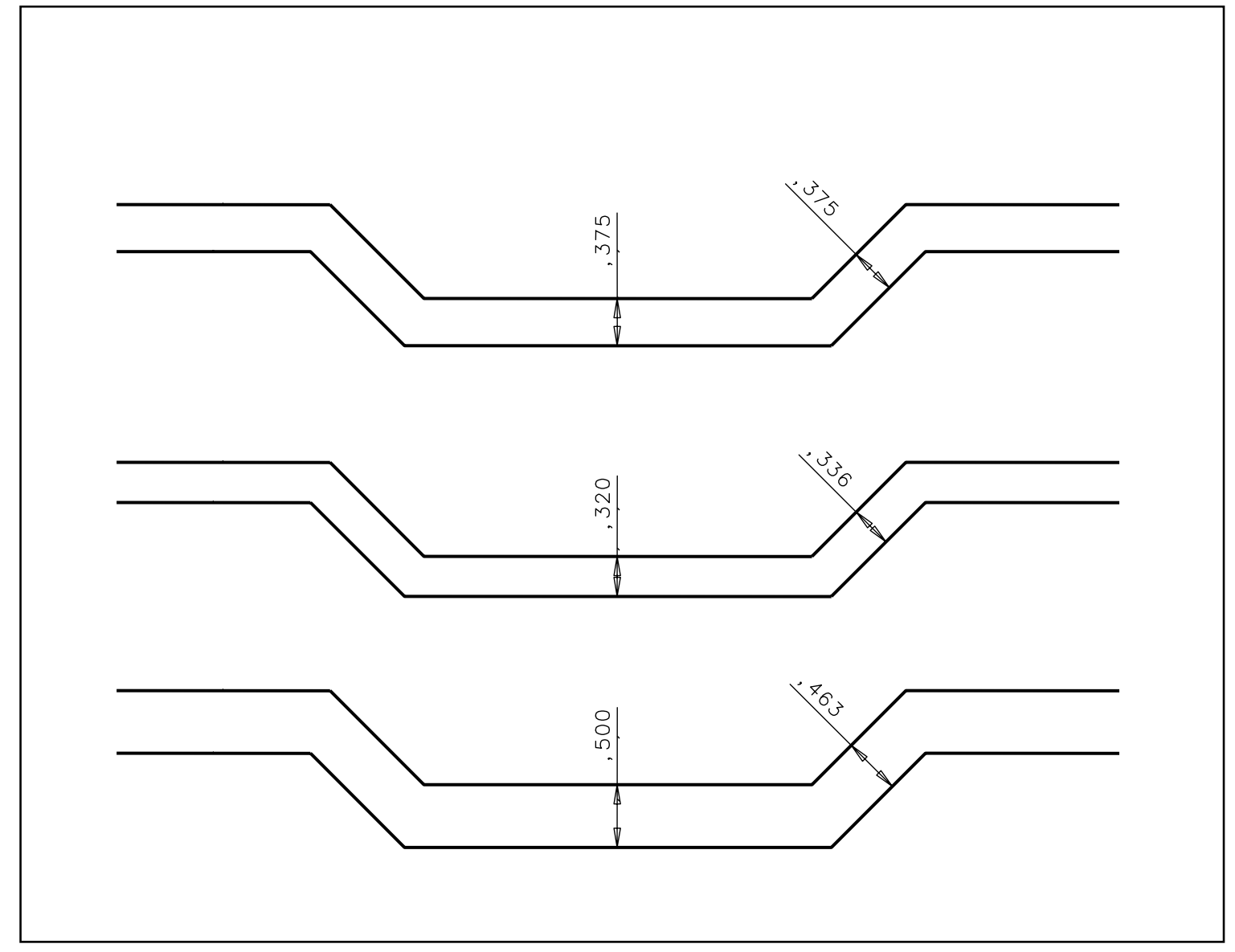

Figure 33: Thickness variation of corrugated panel due to die closing gap.

\section{Weighted Averaged Thickness}

Thickness variation within a panel could complicate the progress of analyzing the test results. To describe the thickness of the corrugated panel by one average or effective value, a weighted average thickness, $\tilde{t}_{\text {ave }}$, was used. The weighted average thickness is defined as the ratio of the sum of thicknesses multiplied by weighting factors over the sum of the weighting factors (equation (92)). The width of the mid surface, $s_{i}$, at sidewall and flat deck areas was used as a weighting factor for the weighted average thickness calculation (Figure 34). 


$$
\tilde{t}_{\text {ave }}=\frac{\sum s_{i} t_{i}}{\sum s_{i}}
$$

where,

$t_{i}=$ thickness at each section, (in)

$s_{i}=$ width of mid surface, (in)

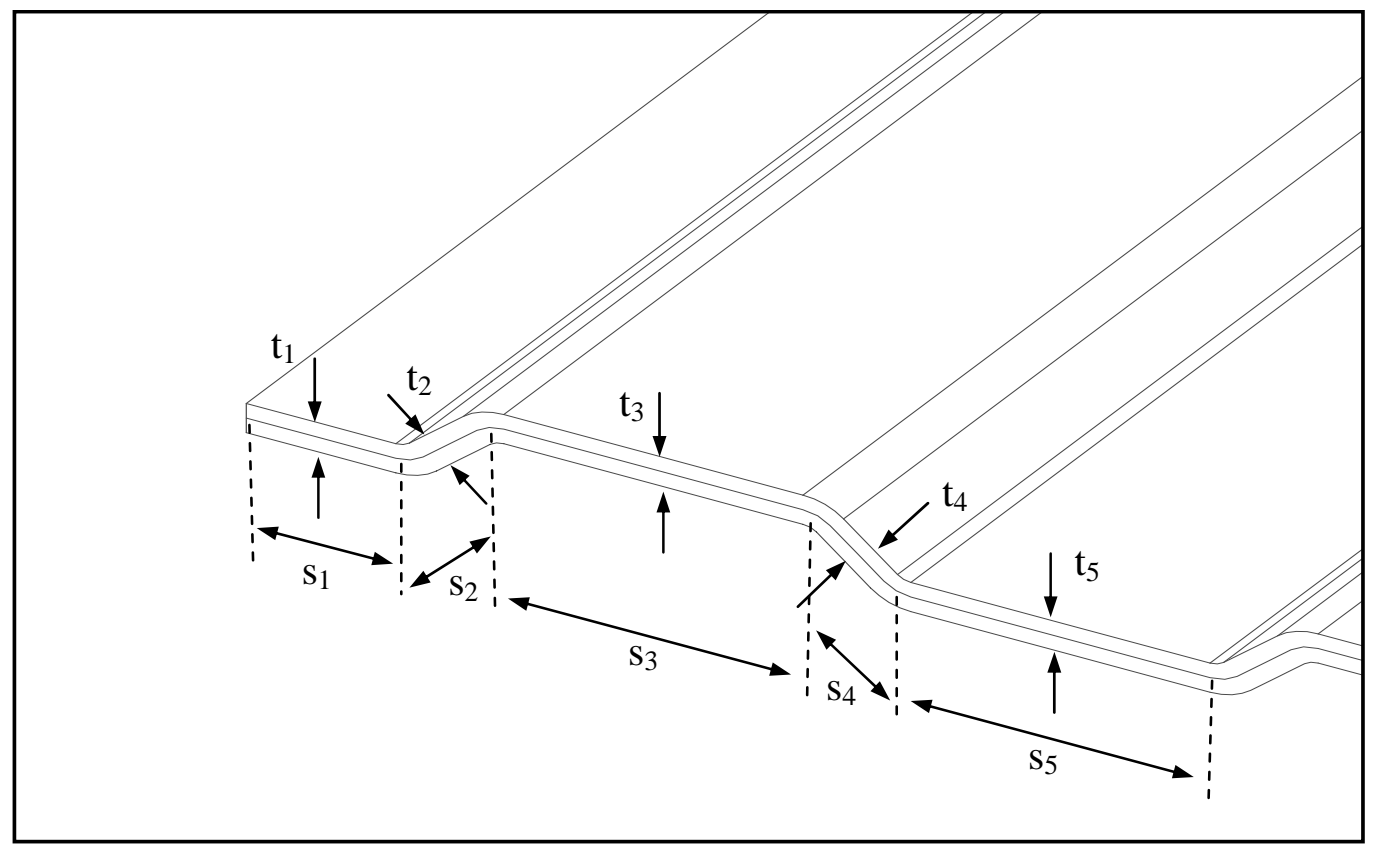

Figure 34: Weighted average thickness calculation.

The width of the mid surface was determined from the designed die geometry because the final shape of the panel was controlled by the geometry of the machined dies, except for the thickness, which was controlled by the pressure and final holding location of the dies during pressing. Appendix E shows the designed width of mid surface for the sidewall and flat deck regions. The weighted averaged thickness can be calculated by knowing the width of the mid surface and the thickness at each section.

\section{Density and Moisture Content}

There are two types of density of interest: the density of panel as tested and the oven-dry density. Density of panel as tested can be computed from the dimensions and 
weight of panel at the time of test. Density of corrugated panel as tested, $\rho_{\text {test }}$, can be calculated using equation (93), once the weighted averaged thickness is known.

$$
\rho_{\text {test }}=\frac{\tilde{w}}{n A_{c} \tilde{t}_{a v e} L}
$$

The denominator of equation (93) is the volume of the corrugated panel, $n$ is the number of complete waves or periods, $L$ is the length of the test specimen in inches, perpendicular to the direction of corrugations, $\varpi$ is the weight of the test specimen in pounds, recorded prior to each test, and $A_{c}$ is previously defined as the cross sectional area of one wavelength (see equation (49)) .

Oven-dry density, $\rho_{d r y}$, and moisture content, $M C$, are determined from 1”x1” samples cut from each test specimen. The initial weight and actual dimensions of the cut samples are recorded before putting them into an oven. Cut samples are allowed to dry at an oven temperature of $115^{\circ} \mathrm{C}$ for about two days, until the samples are completely dry. Moisture content is expressed as the percentage of weight change, initial weight minus oven-dry weight, over oven-dry weight. Dividing the oven-dry weight by the initial volume of the sample yields the oven-dry density. 


\section{Manufacture of 16"x16" Corrugated Panels}

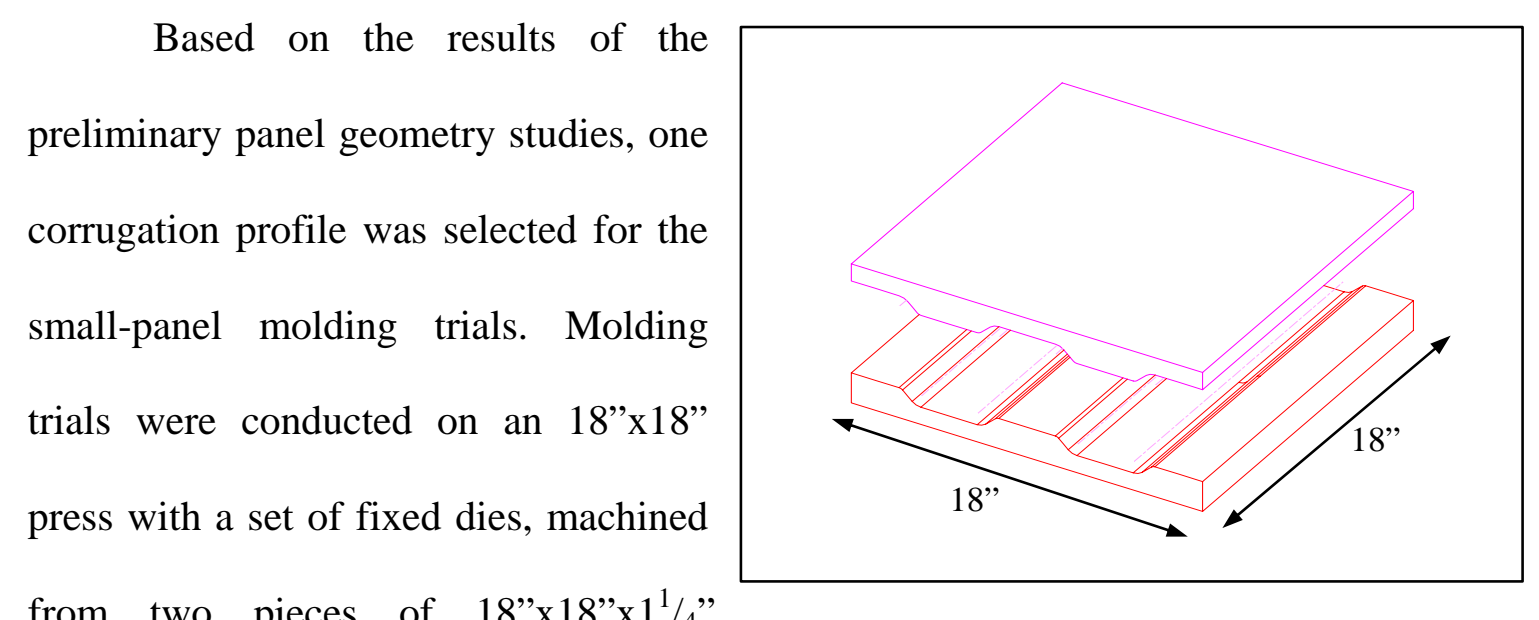

from two pieces of 18 ” $\times 18 ” \times 1 / 4$ ”

aluminum plate (see Figure 35).

Figure 35: 18"x18" corrugated dies for molding trials.

In the preliminary geometric design, the corrugated panels were assumed to have sharp corners. However, the 18”x18” dies were machined with rounded corners to provide better "flow" properties for the mat and to reduce the potential of mat separation during pressing. Also, dies with rounded corners produce panels with better consistency in thickness and density at the corners. The distance between two dies at the sharp corner is actually greater than the target distance at the flat surfaces. Hence, dies with sharp corners will tend to produce panels with loose or less dense corners.

\section{Manufacturing Process}

Test molding of the corrugated panels was performed on a small-scale. However, the manufacturing process closely mimicked typical processes and settings used by commercial plants. The process of producing 16”x16” (trimmed size) corrugated panels involved flaking, drying, blending, forming, and pressing. 
Green aspen logs were used to produce strands or flakes. First, aspen logs were debarked and cut into smaller bolts in order to feed them through a disk strander. Aspen bolts were then pushed against the rotating disk of the strander, using a hydraulic arm, to produce green aspen flakes. The size of the flakes were approximately $2 \frac{1 / 4}{4}$ ” long by $1 / 2$ ” wide by $0.025 ”$ thick.

Freshly produced aspen flakes have moisture content (MC) of about $100 \%$ by oven-dry weight. The moisture content must be reduced before the flakes could be further used to produce panels. Green aspen flakes were placed in a dryer where hot air was constantly circulating through the flakes. Aspen flakes remained in the dryer for about two days until the MC reached about 3\% by oven-dry weight. Dry flakes were then passed over sieves to remove fine particles. Then, they were sealed in airtight plastic drums.

Blending was performed in batches using a drum blender. Only adhesive and water were added to the flakes. No wax or water repellent was added because structural performance or mechanical properties are the interest of this research rather than water resisting capability of corrugated panels. The MC of each batch of flakes was determined prior to blending. For consistency, atomized water was sprayed to condition the flakes to 5\% MC by weight of the oven-dry weight. Methylene diphenyl diisocyanate (MDI) was selected as the binder. 5\% MDI by oven-dry flake weight was added to each blend. Each blend contained about 12 lbs of flakes, which was enough to produce four panels.

An 18”x18” forming box was used to hand-form mats for pressing. A thin sheet of metal was placed at the bottom of the forming box on top of an electronic scale. Flakes were dropped slowly into the box by hand to form a mat. Most test molding panels were 
pressed with a random mat. However, there were four panels produced using 3-layer aligned mats, typically used for OSB. To produce a 3-layer aligned mat, a screen made out of a series of parallel metal trips was placed at about 8" above the bottom of the forming box. Flakes were allowed to fall though the screen to obtain the alignment. The screen was rotated 90 degrees when alignment perpendicular the previous layer was required. The final loose mat formed was about 6” to 8” thick. When the amount of flakes (by weight) needed for one panel was reached, the forming box was removed before transferring the mat to the hot press.

The hot press was heated to $400^{\circ}$ Fahrenheit prior to pressing. Potassium oleate at $10 \%$ concentration was used as a release agent, to prevent flakes from bonding to the surfaces of the aluminum dies. The formed mat along with the sheet metal, functioning as a slip sheet, was placed on top of the lower die, after potassium oleate was coated on both top and bottom dies. A wooden block was held in place at one end of the mat while the slip sheet was slowly pulled out, leaving only the mat in the hot press. Once the slip sheet was removed, the dies were closed at high speed until the target thickness was reached. The thickness was controlled by placing press stops at each corner of the platen. The pressure was maintained at 750 psi gauge pressure (about 262 psi of mat pressure) for three minutes. Then, pressure was slowly reduced to open the dies, over a duration of 30 seconds. The press cycle is shown in Figure 36. The panel was removed from the dies and allowed to cool to room temperature. All panels were edge trimmed from 18”x18” to a final size of 16”x16” and stored in a conditioning room for three weeks prior to testing. 


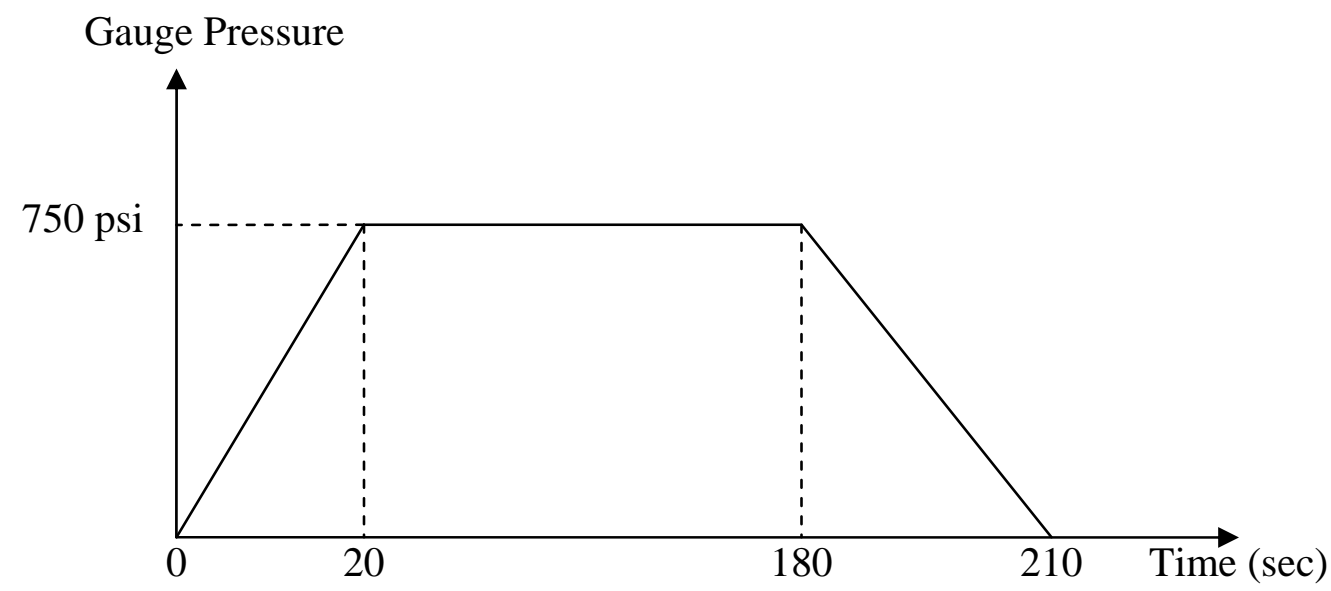

Figure 36: Press cycle for 16"x16" panels.

\section{Specifications of 16" $\times 16$ " Panels}

The molding trials were done with only one type of furnish to reduce variability of material properties from one panel to the other. Aspen flakes with 21/4” average length, 0.025” average thickness and 1/2" average width, were used throughout the panel production. Moisture content of flakes was conditioned to 5\% by weight of the oven-dry flakes before adding binder. MDI at 5\% by weight of the oven-dry flakes was used as the binder. The target oven-dry density of the panels was 40 pcf. Three types of panels were produced with different thicknesses and mat alignment. Panel type A was produced with a random mat and $3 / 8$ " panel thickness. Panel type B was produced using a 3-layer aligned mat with surface flakes parallel to the channels. Panel type $\mathrm{C}$ was made with a random mat and $1 / 2$ ” thickness. Specifications for the three types of panels produced are listed in Table 4. 
Table 4: Specifications for 16"x16" corrugated panels.

\begin{tabular}{|c|c|c|c|}
\hline Panel Type & A & $\mathrm{B}$ & $\mathrm{C}$ \\
\hline Wavelength & $8 ”$ & $8 ”$ & 8” \\
\hline Channel Depth & $3 / 4 "$ & $3 / 4 "$ & $3 / 4 "$ \\
\hline Sidewall Angle & $45^{\circ}$ & $45^{\circ}$ & $45^{\circ}$ \\
\hline Panel Thickness & $3 / 8 "$ & $3 / 8 "$ & $1 / 2$ \\
\hline Overall Depth & $1 \frac{1}{8} "$ & $1 \frac{1}{8} "$ & $1 / 4 ”$ \\
\hline Outer Radius & $5 / 8 ”$ & $5 / 8 "$ & $5 / 8 "$ \\
\hline Inner Radius & $1 / 4 "$ & $1 / 4 "$ & $1 / 4 "$ \\
\hline Flake Orientation & Random & $\begin{array}{l}\text { 3-layer OSB mat } \\
\text { with surface flakes } \\
\text { parallel to the } \\
\text { channels }\end{array}$ & Random \\
\hline
\end{tabular}




\section{Testing of 16"x16" Panels}

The structural performance of the 16”x16” corrugated panels was investigated using (1) a weak axis bending test, (2) a strong axis bending test, (3) a shear test, (4) a bearing or crush test, and (5) a edge point load test. The tests of the 16”x16” panels were focused primarily on type-A panels. Type-B and C panels were tested only for strong axis and weak axis bending. Table 5 shows the test plan for 16”x16” corrugated panels.

Table 5: Test layout for $16 " x 16 "$ corrugated panels.

\begin{tabular}{|c|c|c|c|}
\hline Panel Type & A & B & $\mathrm{C}$ \\
\hline Weak Axis Bending Test * & $4 \times 5$ & $1 \times 5$ & $1 \times 5$ \\
\hline Strong Axis Bending Test & 12 & 2 & 2 \\
\hline Shear Test $* *$ & 8 & N/A & N/A \\
\hline Bearing or Crush Test ** & 8 & N/A & N/A \\
\hline Edge Point Load Test *** & $8 \times 2$ & N/A & N/A \\
\hline Lateral Density Profile & 4 & N/A & N/A \\
\hline Panels Tested & 34 & 3 & 3 \\
\hline \multicolumn{4}{|c|}{$\begin{array}{l}\text { * Every } 16 \text { "x16” panel was cut into five 3"x16” strips across the corrugations for weak axis bending } \\
\text { testing. } \\
* * \text { Shear test and bearing/crush test were performed on the same specimen at different ends of the panel. } \\
* * * \text { Edge point load tests were performed twice on the same panel at two edges parallel to the } \\
\text { corrugation channels. }\end{array}$} \\
\hline
\end{tabular}

All tests were conducted using a Tinius Olsen testing machine and the displacement was measured with a Sensotec linear voltage displacement transducer (LVDT). An Optim data acquisition system was used to record the displacement and load simultaneously at a rate of 2 scans per second. 


\section{Weak Axis Bending Test}

\section{Test Procedures}

The weak axis static bending tests were conducted with the test assembly shown in Figure 37. According to ASTM D1037 [ASTM 1999] the width of the test specimens should be 3” for panels with nominal thickness greater than $1 / 4$ ” and the span should be at least 24 times the nominal thickness. Hence, each 16"x16" panel was cut into five 3" wide (perpendicular to the channel direction) by 16” long strips and tested on a 10" on-center span. The deflection was measured using an LVDT placed directly beneath the loading block. The loading rate of the test was $0.08 \mathrm{in} / \mathrm{min}$. Two 1 ” x 1 ” samples were cut from each test specimen to determine the moisture content and density.

\section{Test Results}

The moisture content and the density of the weak axis bending specimens were consistent with the measurements taken from strong axis bending specimens. The moisture contents were in the range of $5 \%$ to $6 \%$ (Table 6). The oven-dry densities were close to 40 pcf. The coefficients of variation of the moisture contents and densities were 
0.10 or lower. This indicates that the moisture content and density did not vary widely from one specimen to another.

Table 6: Moisture content and density of weak axis bending test specimens.

\begin{tabular}{cccc}
\hline & $\begin{array}{c}\text { Moisture Content } \\
(\%)\end{array}$ & $\begin{array}{c}\text { Wet Density } \\
\left(\mathrm{lbs} / \mathrm{ft}^{3}\right)\end{array}$ & $\begin{array}{c}\text { Oven Dry Density } \\
\left(\mathrm{lbs}_{\mathrm{ft}}{ }^{3}\right)\end{array}$ \\
\hline Type-A (19 specimens from 4 panels) & & 42.81 & \\
Mean & $5.64 \%$ & 3.02 & 2.53 \\
Sample Standard Deviation & $0.24 \%$ & 0.07 & 0.07 \\
Coefficient of Variation & 0.04 & & \\
\hline Type-B (5 specimens from 1 panel) & & 45.79 & 43.50 \\
Mean & $5.27 \%$ & 4.36 & 4.14 \\
Sample Standard Deviation & $0.06 \%$ & 0.10 & 0.10 \\
Coefficient of Variation & 0.01 & & 39.88 \\
\hline Type-C (5 specimens from 1 panel) & & & 1.64 \\
Mean & $5.55 \%$ & 42.09 & 0.04 \\
Sample Standard Deviation & $0.20 \%$ & 1.71 & \\
Coefficient of Variation & 0.04 & 0.04 & \\
\hline
\end{tabular}

All test specimens failed at either side of the upper corner of the sidewalls (Figure 37). The load-deflection curves for the test specimens are plotted in Figure 38. The loaddeflection curves of type-B panels are very similar to the type-A panels except panel 114-1 and 11-4-2 (Appendix F). Some visible weak spots or defects were observed for these two panels, prior to the testing. Type-C panels had a steeper slope for the load-deflection curve compared to type-A panels. Beam and FE models were used to analyze the test data. 


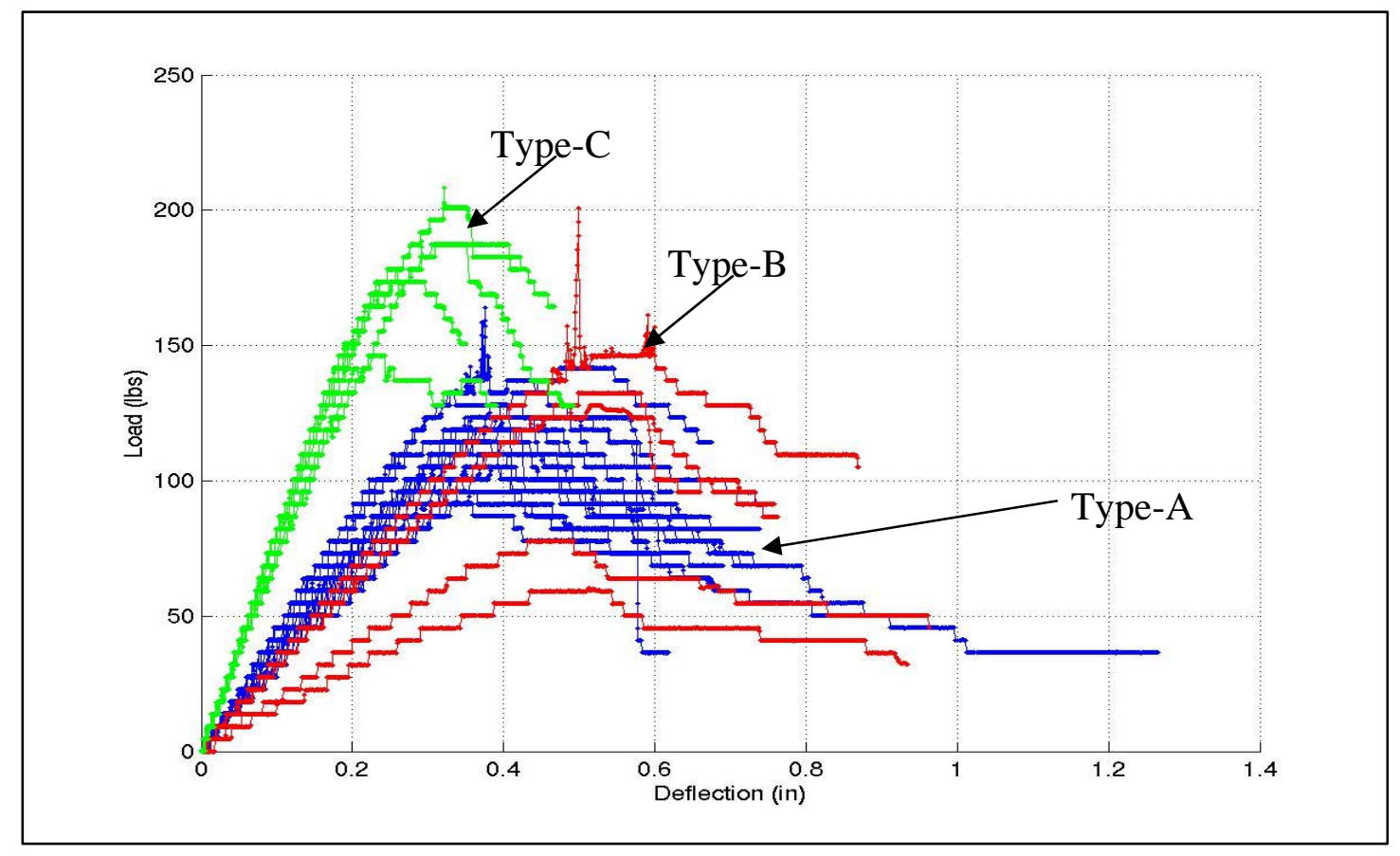

Figure 38: Load-deflection curves for weak axis bending specimens.

\section{Finite Element Model}

Figure 39 shows a typical mesh for the weak axis bending test FE model. The sizes of the elements were about 0.25 ” 0.25 ”. The mesh was generated using 4-node thin shell and gap elements, as discussed in the Finite Element Model chapter. A series of FE models were created for sensitivity studies of type-A panels, i.e., nominal 0.375 ” thick, random mat panels. The test specimens were assumed be in-plane isotropic, with modulus of elasticity (MOE) the same in both $\mathrm{x}$ and $\mathrm{y}$ directions, because of the random mat formation. However, the shear modulus, G, was assumed to be independent of both the MOE and Poisson's's ratio, $v$, i.e., equation (8) is not applied here. Sensitivity studies were performed on four parameters; MOE, G, Poisson's's ratio, and panel thickness. Other parameters, such as span length, panel width, etc were considered constants. 


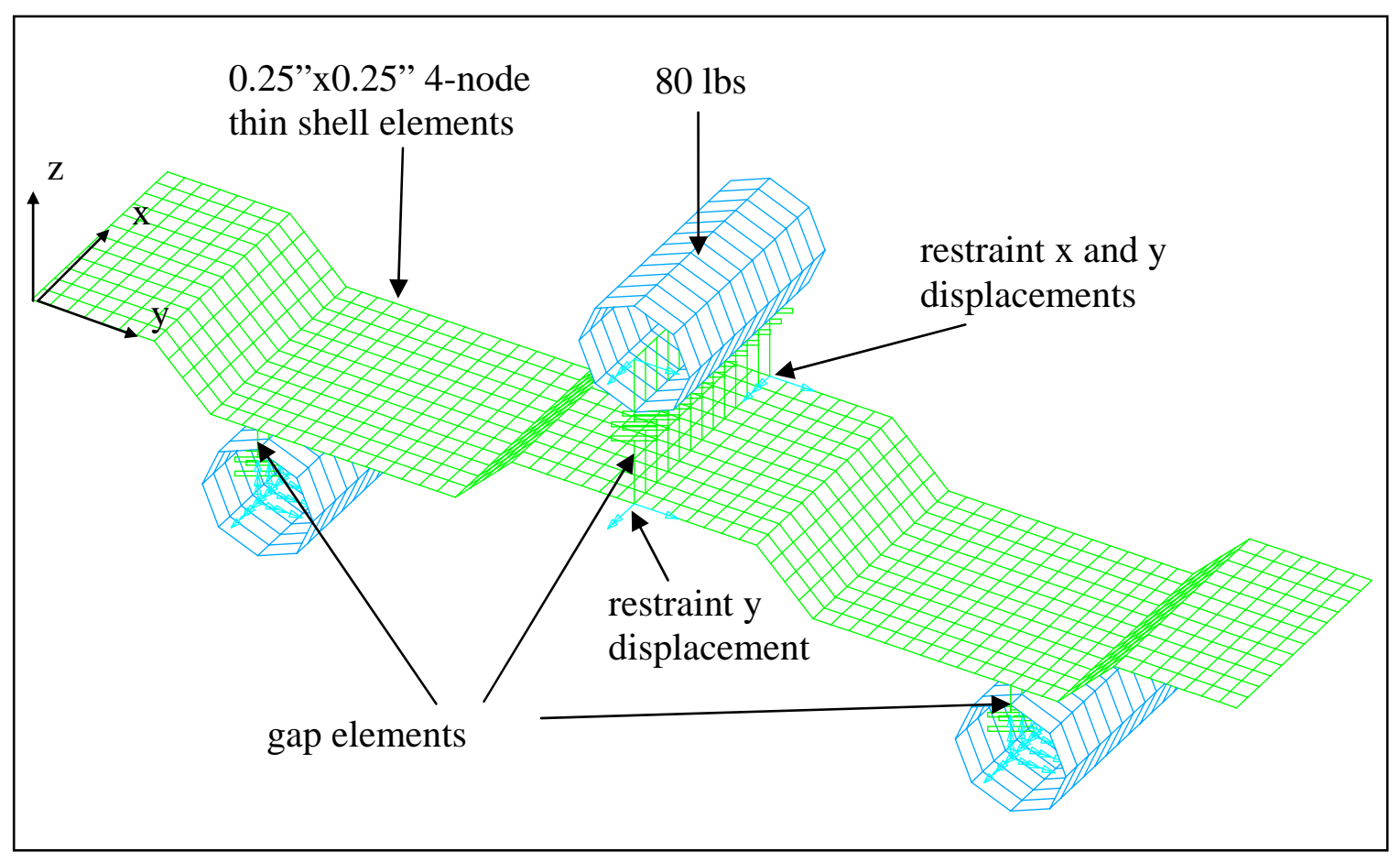

Figure 39: Finite element model for 3"x16" weak axis bending test.

\section{Effect of Poisson's's Ratio}

Four FE models were constructed with MOE equal to $600 \mathrm{ksi}$, shear modulus equal to 150 ksi and panel thickness of 0.375 ”. Poisson's's ratio was varied from 0.1 to 0.4. A load-to-deflection plot of the results is shown in Figure 40. Deflections were taken at the point of load and the applied load was 80 lbs. Poisson's's ratio is almost linearly proportional to the weak axis bending stiffness. The results indicate that Poisson's's ratio has little effect on the overall weak axis bending stiffness (Table 7).

Table 7: Sensitivity studies of Poisson's's ratio of 3"x16" weak axis bending specimens.

\begin{tabular}{cccc}
\hline $\begin{array}{c}\text { Poisson's's } \\
\text { Ratio }\end{array}$ & $\begin{array}{c}\text { Deflection } \\
\text { (in) }\end{array}$ & $\begin{array}{c}\text { Load/Deflection } \\
\text { (lbs/in) }\end{array}$ & Difference \\
\hline 0.1 & 0.2252 & 355 & - \\
0.2 & 0.2222 & 360 & $1.33 \%$ \\
0.3 & 0.2176 & 368 & $2.10 \%$ \\
0.4 & 0.2115 & 378 & $2.91 \%$ \\
\hline
\end{tabular}




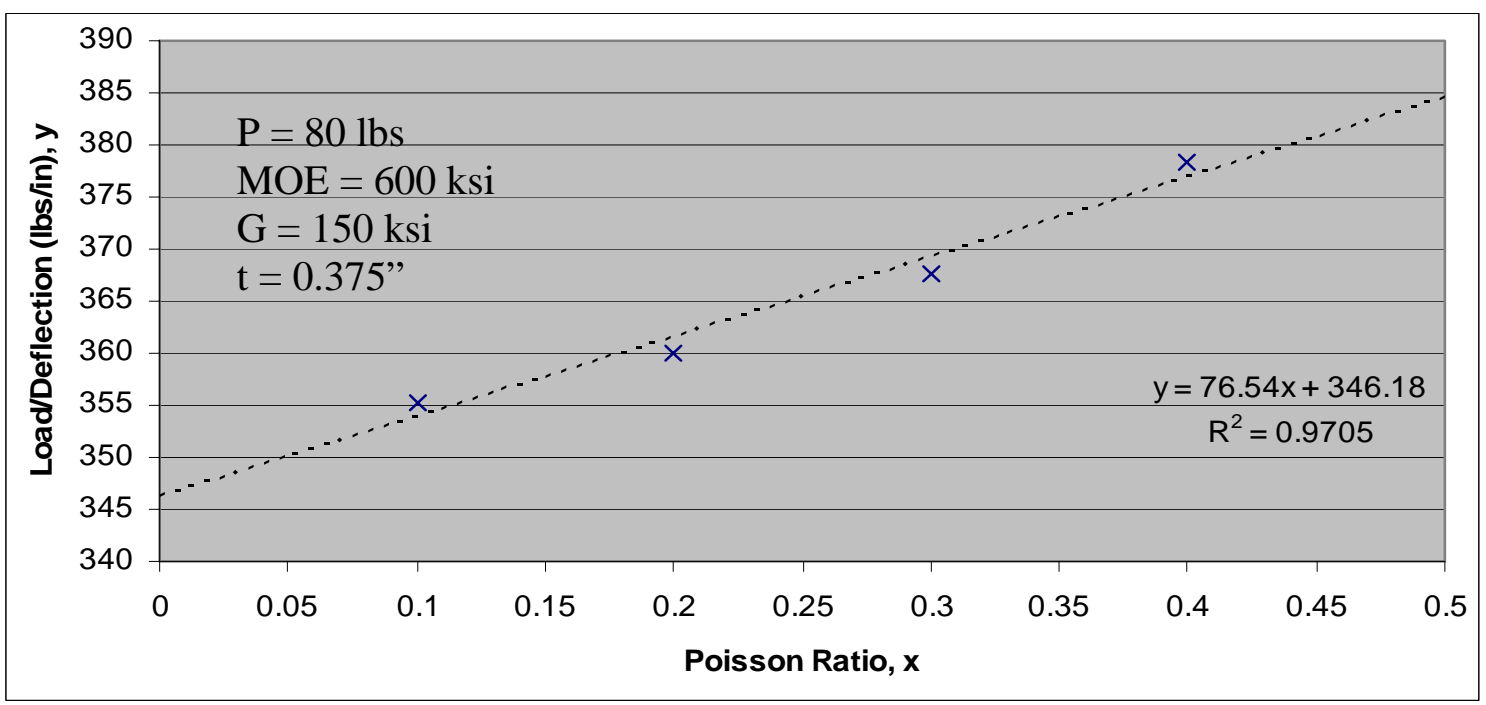

Figure 40: Poisson's ratio sensitivity studies of 3"x16" weak axis bending specimens.

\section{Effect of Thickness}

Sensitivity studies of thickness were performed by setting MOE and the shear modulus equal to $600 \mathrm{ksi}$ and $150 \mathrm{ksi}$, respectively, while generating FE models with three different thicknesses, 0.350 ”, 0.375 ” and $0.400 ”$. Poisson's ratio was concluded to have little effect on the weak axis bending, therefore a Poisson's ratio of 0.3 was used for all FE models of the weak axis bending test. The results are shown in Figure 37. The weak axis bending stiffness is linearly proportional to the thickness, for small variation of thickness. The tabulated results in Table 8 show that a small variation in of thickness, 0.025 ”, can cause more than $20 \%$ difference in the load-to-deflection ratio. Therefore, thickness cannot be ignored in the analysis.

Table 8: Sensitivity studies of thickness of 3"x16" weak axis bending specimens.

\begin{tabular}{cccc}
\hline $\begin{array}{c}\text { Thickness } \\
\text { (in) }\end{array}$ & $\begin{array}{c}\text { Deflection } \\
\text { (in) }\end{array}$ & $\begin{array}{c}\text { Load/Deflection } \\
\text { (lbs/in) }\end{array}$ & Difference \\
\hline 0.350 & 0.2670 & 300 & - \\
0.375 & 0.2176 & 368 & $22.70 \%$ \\
0.400 & 0.1797 & 445 & $21.07 \%$ \\
\hline
\end{tabular}




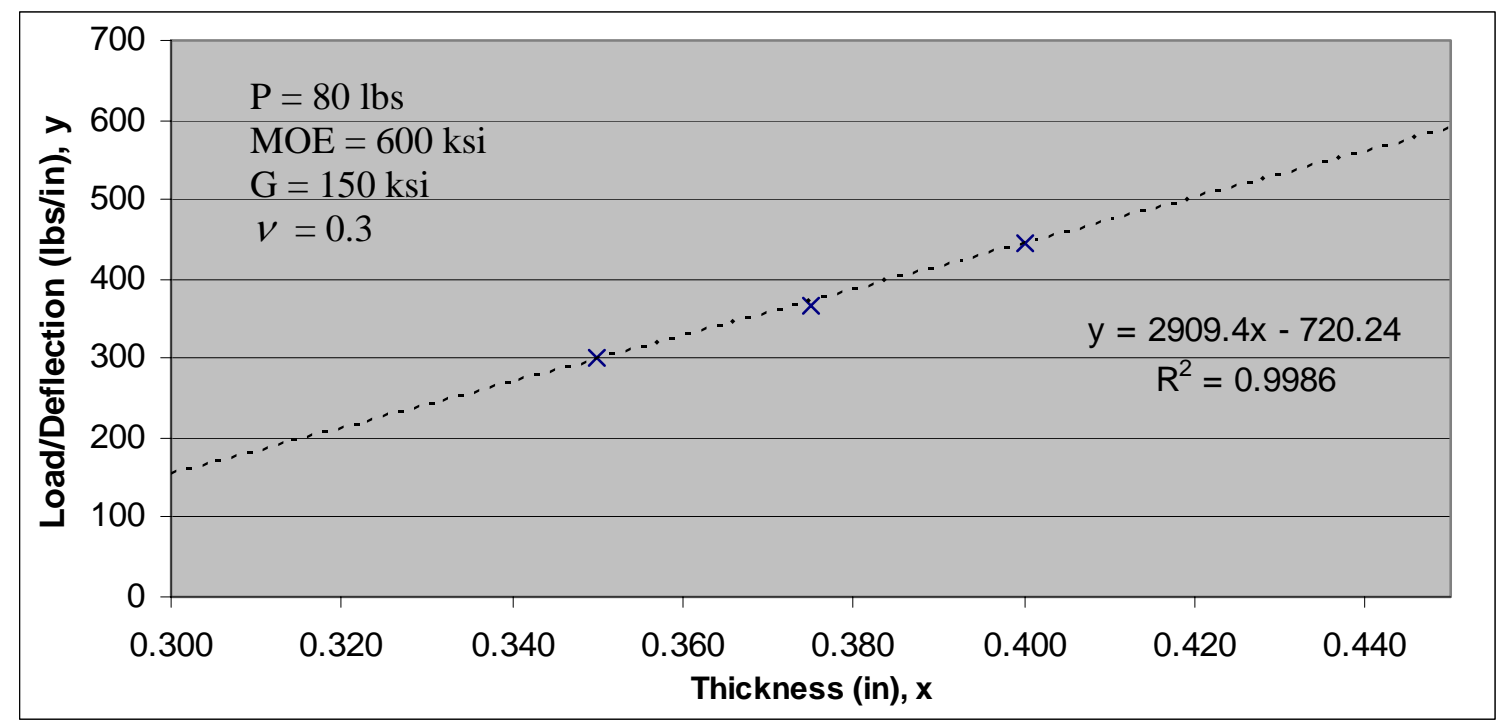

Figure 41: Panel skin thickness sensitivity studies of 3"x16" weak axis bending specimens.

\section{Effect of Shear Modulus}

Four FE models were used for sensitivity studies of shear modulus. Thickness, Poisson's ratio and MOE were kept constant at $0.375 ”, 0.3$ and $600 \mathrm{ksi}$, respectively. Shear modulus was varied within the appropriate range, from $25 \mathrm{ksi}$ to $300 \mathrm{ksi}$. The results listed in Table 9 show that weak axis bending stiffness is not sensitive to change in shear modulus. The difference is less than $5 \%$. The relationship between the weak axis bending stiffness and the shear modulus is non-linear (Figure 42).

Table 9: Sensitivity studies of shear modulus of 3"x16" weak axis bending specimens.

\begin{tabular}{cccc}
\hline $\begin{array}{c}\text { Shear Modulus } \\
(\mathrm{ksi})\end{array}$ & $\begin{array}{c}\text { Deflection } \\
\text { (in) }\end{array}$ & $\begin{array}{c}\text { Load/Deflection } \\
\text { (Ibs/in) }\end{array}$ & Difference \\
\hline 25 & 0.2446 & 327 & - \\
75 & 0.2366 & 338 & $3.41 \%$ \\
150 & 0.2339 & 342 & $1.16 \%$ \\
300 & 0.2321 & 345 & $0.78 \%$ \\
\hline
\end{tabular}




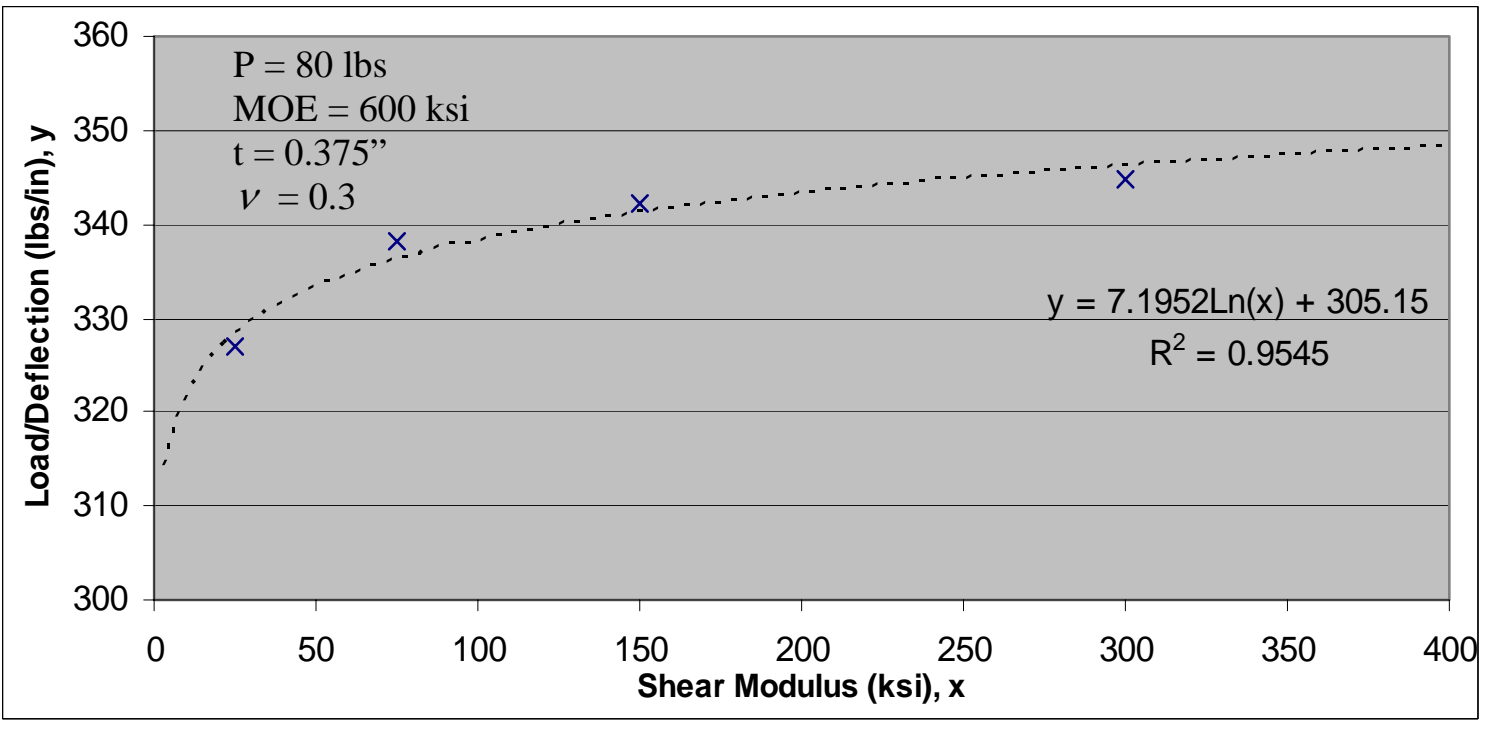

Figure 42: Shear modulus sensitivity studies of 3"x16" weak axis bending specimens.

\section{Effect of Modulus of Elasticity}

Sensitivity to MOE was also investigated. Three FE models with MOE equal to 400 ksi, 600 ksi and 800 ksi were used. Shear modulus, thickness and Poisson's ratio were kept at $150 \mathrm{ksi}, 0.375$ ” and 0.3 , respectively. As expected, MOE plays an important role in the weak axis bending stiffness (Table 10). The results also show that MOE is linearly proportional to the weak axis bending stiffness (Figure 43) for linear analysis.

Table 10: Sensitivity studies of MOE of 3"x16" weak axis bending specimens.

\begin{tabular}{cccc}
\hline $\begin{array}{c}\text { MOE } \\
(\mathrm{ksi})\end{array}$ & $\begin{array}{c}\text { Deflection } \\
\text { (in) }\end{array}$ & $\begin{array}{c}\text { Load/Deflection } \\
\text { (Ibs/in) }\end{array}$ & Difference \\
\hline 400 & 0.3248 & 246 & - \\
600 & 0.2176 & 368 & $49.26 \%$ \\
800 & 0.1639 & 488 & $32.76 \%$ \\
\hline
\end{tabular}




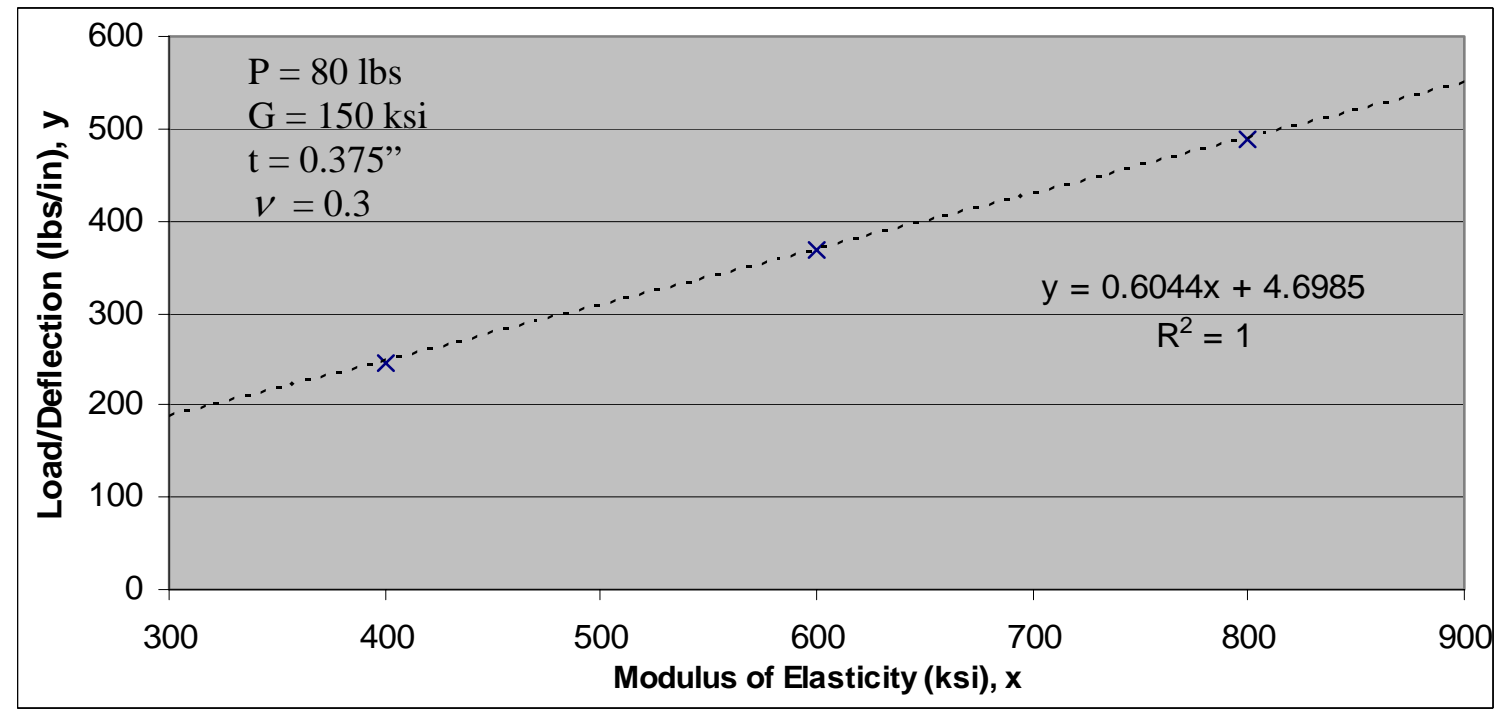

Figure 43: Modulus of elasticity sensitivity studies of 3 "x16" weak axis bending specimens.

\section{Determination of Weak Axis Bending Stiffness}

The results of sensitivity studies indicate that effect of Poisson's ratio and shear modulus are negligible to the weak axis bending stiffness, as long as reasonable values are used. Thus, there are only two variables, MOE and thickness, to be considered for the FE models. To estimate the weak axis bending stiffness, a series of FE models (see Table 11) with varying MOE (400 ksi, $600 \mathrm{ksi}$ and $800 \mathrm{ksi})$ and thicknesses (0.350, 0.375” and 0.400”) were used. Poisson's ratio and shear modulus were assumed constant at 0.3 and $150 \mathrm{ksi}$, respectively.

Table 11: FE models for weak axis bending of 3"x16" specimens with different MOE and thicknesses.

\begin{tabular}{|c|c|c|c|c|c|c|}
\hline \multirow{3}{*}{$\begin{array}{l}\mathrm{MOE} \\
(\mathrm{ksi})\end{array}$} & \multicolumn{3}{|c|}{ Thickness (in) } & \multicolumn{3}{|c|}{ Thickness (in) } \\
\hline & 0.350 & 0.375 & 0.400 & 0.350 & 0.375 & 0.400 \\
\hline & \multicolumn{3}{|c|}{$\begin{array}{l}\text { Deflection at } 80 \text { lbs load } \\
\text { (in) }\end{array}$} & \multicolumn{3}{|c|}{$\begin{array}{l}\text { Load/Deflection } \\
\text { (Ibs/in) }\end{array}$} \\
\hline 400 & 0.3987 & 0.3248 & 0.2682 & 201 & 246 & 298 \\
\hline 600 & 0.2670 & 0.2176 & 0.1797 & 300 & 368 & 445 \\
\hline 800 & 0.2011 & 0.1639 & 0.1354 & 398 & 488 & 591 \\
\hline
\end{tabular}


FE results and test data are plotted in Figure 44. Panel skin thickness is linearly proportional to the load-to-deflection ratio for a given MOE. A line was fitted through three data points at each MOE level and the equation of the line was determined. The three linear equations shown in Figure 44 were then used to interpolate MOE for each test specimen based on the actual or measured thickness. The average MOE of the test specimens was about $630 \mathrm{ksi}$ with a coefficient of variation of 0.12 . The weak axis bending stiffness was about 30,800 lbs-in²/ft (Table 12).

Table 12: MOE and weak axis bending stiffness of 3"x16” specimens estimated using FE models.

\begin{tabular}{ccc}
\hline $\begin{array}{c}\text { Type-A random mat panels } \\
\text { (19 specimens from 4 panels) }\end{array}$ & $\begin{array}{c}\text { Modulus of Elasticity } \\
(\mathrm{psi})\end{array}$ & $\begin{array}{c}\text { Bending Stiffness } \\
\left(\mathrm{Ibs}^{2}-\mathrm{in}^{2} / \mathrm{ft}\right)\end{array}$ \\
\hline Mean & 627,089 & 30,753 \\
Std.Dev. & 76,168 & 3,954 \\
COV & 0.12 & 0.13 \\
+2(Std.Dev.) & 779,425 & 38,660 \\
-2(Std.Dev.) & 474,753 & 22,846 \\
$5^{\text {th }}$ Percentile & 516,004 & 25,908 \\
\hline
\end{tabular}

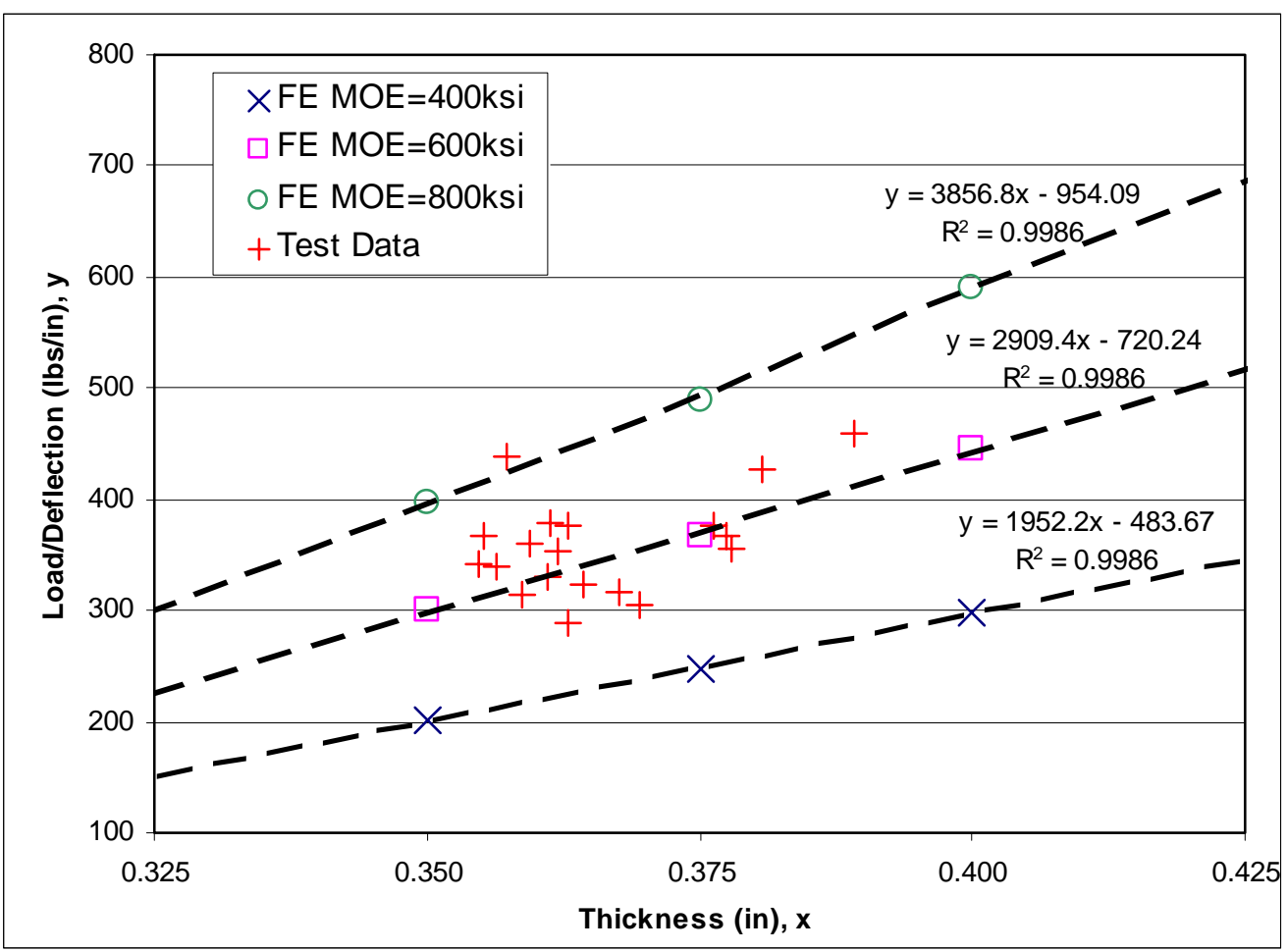

Figure 44: FE models and test data of 3"x16" weak axis bending test specimens. 


\section{Beam Model}
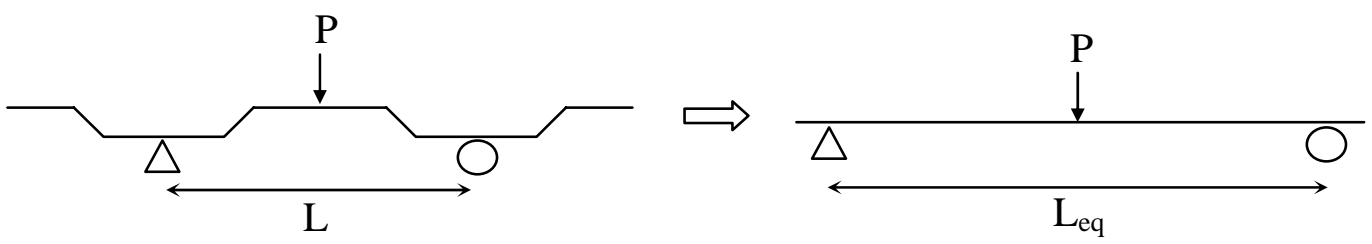

Figure 45: Equivalent length of simple beam with concentrated load at mid-span.

The span-to-thickness and the width-to-thickness ratios of the weak axis bending tests were based on ASTM D1307 [ASTM 1999] to minimize the effects of shear deformations. Therefore, shear deformation was not considered in this beam theory model of weak axis bending since it was assumed negligible. The weak axis bending test closely resembles a frame structure instead of a simple beam. However, the frame model can be simplified into a simple beam with an equivalent span length (Figure 45). The deflection at the point of load of the frame model, $\Delta_{\text {frame, }}$ was determined, and the equivalent length was calculated using the following equation.

$$
L_{e q}=\left(\frac{48 E I \Delta_{\text {frame }}}{P}\right)^{\frac{1}{3}}
$$

where, $P$ is the applied load and $E$ is the modulus of elasticity. $I$ is the moment of inertia equal to,

$$
I=\frac{b t^{3}}{12}
$$

where $b$ is the width of the test specimens which is equal to 3 ” and $t$ is the nominal thickness, which is $3 / 8$ ". A frame model with the actual corrugation profile was analyzed. For the 10 " span used in the tests, the equivalent span length was determined to be 10.23". The MOE for each test specimen, neglecting shear deformation, was computed with the following equation. 


$$
M O E=\left(\frac{P}{\Delta}\right)\left(\frac{L_{e q}^{3}}{48 I}\right)
$$

where, $P / \Delta$ is equal to the slope of the load-deflection curve. The $M O R$ was estimated with

$$
M O R=\frac{P_{\max } x t}{4 I}
$$

where, $P_{\max }$ is the maximum load and $x$ is the failure location, measured as distance from the support to the failure location (see Figure 37).

The nominal weak axis bending stiffness and strength for type-A, type-B, and type-C panels are summarized in Table 13. The details of the calculations for each test specimen can be found in Appendix F. The average weak axis bending stiffness of the type-B panels (with typical 3-layer OSB aligned mats) is lower by about $30 \%$ when compared to the panels with random mats. The high variability of the type-B panels is because the surface flakes were oriented parallel to the strong axis direction, which reduced the effective bending MOE in the weak axis direction. The variability in the test data was also higher for the type-B panels compared to type-A panels. The high variability in the test data of type-B panels can be explained by the higher number of defects observed at the sidewalls or the corners because of the surface flake alignment. The higher average weak axis bending stiffness of the nominal $1 / 2$ ” thick panels (type-C) compared to the type-A panels was expected. The average stiffness ratio of the type-C to type-A panels (2.14) matched the prediction using the ratio of the moment of inertia (2.37) well. Similarly, the section modulus ratio of the type-C to type-A panels (1.78) was reasonably close to the average bending strength ratio (1.53). 
Table 13: MOE, bending stiffness and strength of weak axis bending tests, estimated using beam models.

\begin{tabular}{|c|c|c|c|c|}
\hline & $\begin{array}{l}\text { Modulus of } \\
\text { Elasticity } \\
\text { MOE } \\
\left(\mathrm{lbs} / \mathrm{in}^{2}\right)\end{array}$ & $\begin{array}{c}\text { Modulus of } \\
\text { Rupture } \\
\text { MOR } \\
\left(\mathrm{lbs} / \mathrm{in}^{2}\right)\end{array}$ & $\begin{array}{c}\text { Weak Axis } \\
\text { Bending } \\
\text { Stiffness } \\
E_{\mathrm{C}_{\mathrm{C}}} \\
\text { (lbs-in } / \mathrm{ft})\end{array}$ & $\begin{array}{c}\text { Weak Axis } \\
\text { Bending } \\
\text { Strength } \\
\mathrm{F}_{\mathrm{b}} \mathrm{S}_{\mathrm{c}} \\
\text { (in-lbs/ft) }\end{array}$ \\
\hline \multicolumn{5}{|c|}{ Type-A (19 specimens from 4 panels) random mat } \\
\hline Mean & 653,813 & 2,985 & 32,067 & 798 \\
\hline Std. Dev. & 77,415 & 468 & 4,055 & 113 \\
\hline $\mathrm{COV}$ & 0.12 & 0.16 & 0.13 & 0.14 \\
\hline+2 (Std.Dev.) & 808,643 & 3,921 & 40,178 & 1,025 \\
\hline$-2($ Std.Dev.) & 498,982 & 2,049 & 23,956 & 571 \\
\hline $5^{\text {th }}$ Percentile & 540,630 & 2,442 & 27,144 & 645 \\
\hline \multicolumn{5}{|c|}{ Type-B (5 specimens from 1 panel) aligned mat } \\
\hline Mean & 493,689 & 2,908 & 22,311 & 740 \\
\hline Std. Dev. & 124,965 & 870 & 7,188 & 258 \\
\hline $\mathrm{COV}$ & 0.25 & 0.30 & 0.32 & 0.35 \\
\hline+2 (Std.Dev.) & 743,619 & 4,648 & 36,687 & 1,255 \\
\hline$-2($ Std.Dev.) & 243,760 & 1,168 & 7,936 & 224 \\
\hline $5^{\text {th }}$ Percentile & 337,067 & 1,843 & 13,524 & 432 \\
\hline \multicolumn{5}{|c|}{ Type-C (5 specimens from 1 panel) nominal $1 / 2$ ” thick, random mat } \\
\hline Mean & 576,437 & 2,524 & 68,632 & 1221 \\
\hline Std. Dev. & 36,432 & 345 & 3,076 & 155 \\
\hline $\mathrm{COV}$ & 0.06 & 0.14 & 0.04 & 0.13 \\
\hline +2(Std.Dev.) & 649,302 & 3,214 & 74,785 & 1,530 \\
\hline-2 (Std.Dev.) & 503,572 & 1,834 & 62,480 & 912 \\
\hline $5^{\text {th }}$ Percentile & 527,127 & 2,087 & 64,429 & 1,025 \\
\hline
\end{tabular}

\section{Strong Axis Bending Test}

\section{Test Procedures}

The strong axis static bending test of the 16”x16” specimens was carried out with the test assembly shown in Figure 46. American Society of Testing Material (ASTM) provides standard test methods for flat wood-base panels in ASTM D1037 [ASTM 1999]. The test assembly shown in Figure 46 is not intended to follow or meet all the criteria in ASTM D1037 because it is written specifically for flat panels. However, ASTM D1037 was used as a guideline in the strong axis static bending test. 
According to ASTM D1037,

the radius of the supports and the loading block should at least $1 \frac{1}{2}$ times the thickness of the panel to avoid crushing of the specimen.

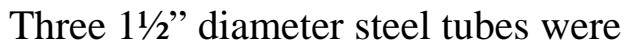
used as the supports and the loading block for panels with $3 / 8$ " and $1 / 2$ ” thickness. The supports were placed

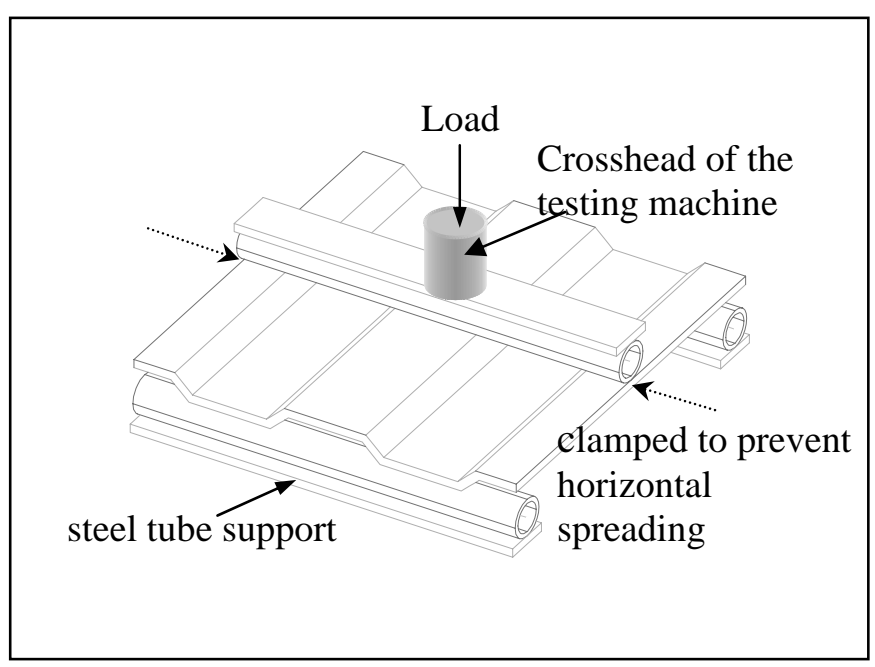

Figure 46: Strong axis bending test assembly for 16"x16" corrugated panels.

at 3/4" from each end of the panel resulting in an overall span length of $141 / 2$ ” from center to center of supports. The loading block was located at the mid-span of the panel and load was applied by slowly moving the crosshead of the testing machine at the mid length of the loading block (Figure 46). The displacement was measured at the center of the panel by placing a LVDT at the bottom of the specimen. Load was applied at a uniform rate of $0.1 \mathrm{in} / \mathrm{min}$ throughout the test and the total loading time (time to failure) was kept in the range of 5 to 10 minutes. Two 1 ” x 1 ” samples were cut from each test specimen to determine the density as tested, the oven-dry density, and the moisture content.

\section{Test Results}

12 type-A panels ( ${ }^{3} / 8$ " thick, random mat), 2 type-B panels $\left({ }^{3} / 8\right.$ " thick, surface flakes aligned parallel to the corrugations), and 2 type-C panels ( $1 / 2$ ” thick, random mat), were tested (refer Table 5). The moisture content and density of the tested panels are listed in Table 14. The average oven-dry densities were close to the target density of 40 pcf except type-B panels (aligned mat) with an average oven-dry density of 43.27 pcf. 
The moisture contents of the specimens ranged from $5.0 \%$ to $5.6 \%$ with coefficient of variation $(\mathrm{COV})$ of less than 0.1 .

Table 14: Moisture content and density of strong axis bending test specimens.

\begin{tabular}{cccc}
\hline & $\begin{array}{c}\text { Moisture Content } \\
(\%)\end{array}$ & $\begin{array}{c}\text { Wet Density } \\
\left(\mathrm{lbs} / \mathrm{ft}^{3}\right)\end{array}$ & $\begin{array}{c}\text { Oven Dry Density } \\
\left(\mathrm{lbs} / \mathrm{ft}^{3}\right)\end{array}$ \\
\hline Type-A (12 panels) & & & \\
Mean & $5.61 \%$ & 42.02 & 39.79 \\
Sample Standard Deviation & $0.31 \%$ & 3.09 & 2.86 \\
Coefficient of Variation & 0.06 & 0.07 & 0.07 \\
\hline Type-B (2 panels) & & & \\
Panel \# 11-1 & $5.30 \%$ & 42.66 & 40.52 \\
Panel \# 11-3 & $5.04 \%$ & 48.35 & 46.03 \\
Mean & $5.17 \%$ & 45.50 & 43.27 \\
\hline Type-C (2 panels) & & & \\
Panel \# 12-2 & $5.41 \%$ & 41.80 & 39.66 \\
Panel \# 12-4 & $5.66 \%$ & 43.32 & 41.01 \\
Mean & $5.53 \%$ & 42.56 & 40.33 \\
\hline
\end{tabular}

The load-displacement curves for these panels are plotted in Figure 48. The slope of the load-displacement curve is proportional to the strong axis bending stiffness and the maximum load is proportional to the strong axis bending strength. The load-deflection curves of type-B panels do not show any noticeable difference compared to the type-A panels. This suggests that flake alignment has negligible effect on both the strong axis bending stiffness and strength of the corrugated panels. On the other hand, the increases of the strong axis bending stiffness and strength of type-C panels ( $1 \frac{1}{2}$ ” thick) compared to type-A panels are significant. A line was fitted to the linear portion of the load-deflection curve of every test specimen (Figure 47). The slope of the linear regression line was used to estimate bending stiffness, $E I_{c}$, and modulus of elasticity, $M O E$, using both beam 
theory and a finite element model. Bending strength, $F_{b} S_{c}$, and modulus of rupture, $M O R$, are estimated using maximum load based on beam theory.

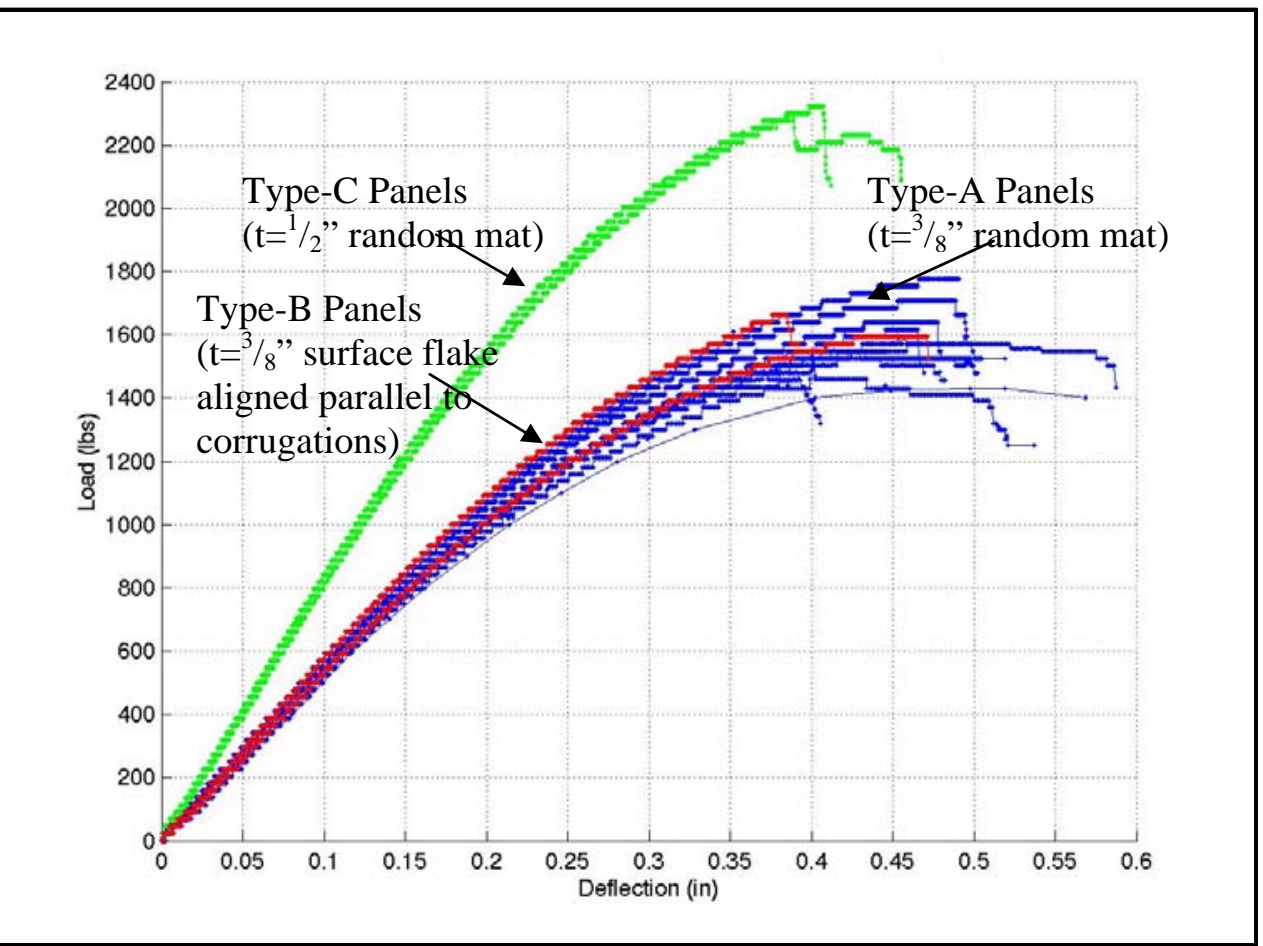

Figure 48: Load-displacement curves for strong axis bending specimens.

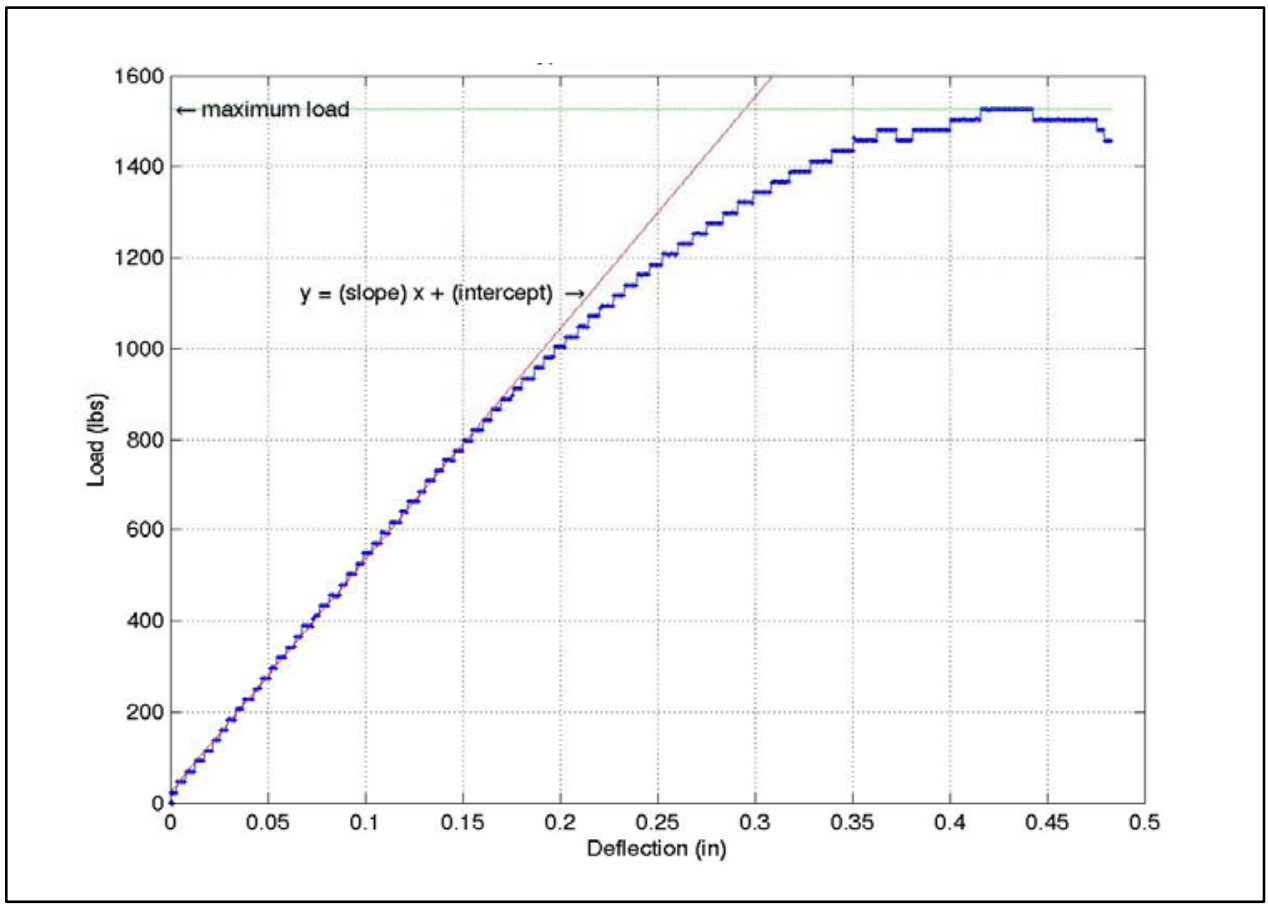

Figure 47: Linear regression for typical load-deflection curve. 


\section{Finite Element Model}

FE models were generated to simulate the strong axis bending test assembly, as shown in Figure 49. The mesh was generated using 0.25 ” 0.25 ” thin shell elements. 500 lbs of force was applied and the deflection at the center of mid-span was used to determine the load-to-deflection ratio. The same material properties used in the weak axis bending FE models were used. Sensitivity studies of modulus of elasticity, shear modulus, Poisson’s ratio and panel thickness were performed.

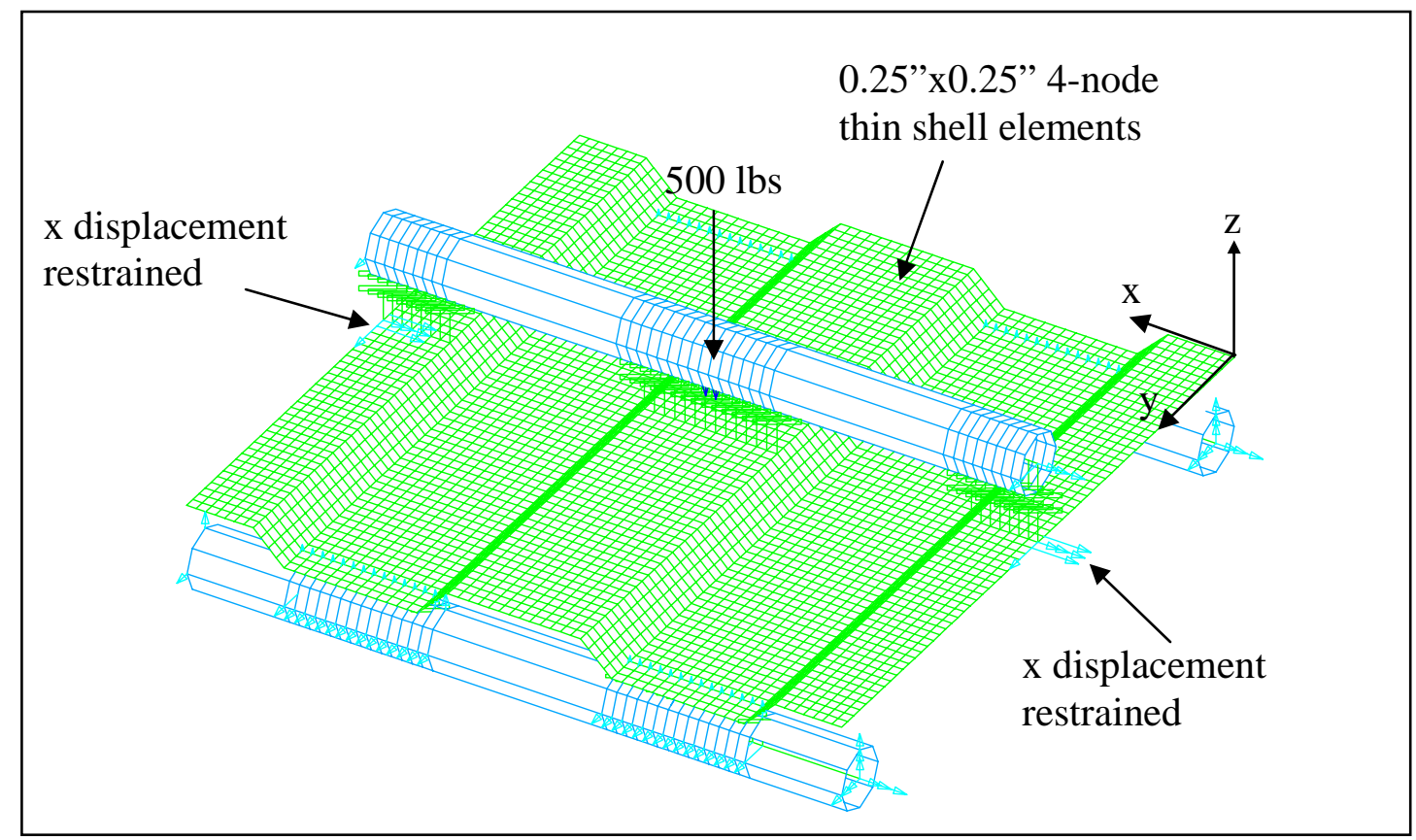

Figure 49: Finite element model for 16”x16” strong axis bending test.

\section{Effect of Poisson's Ratio}

Sensitivity studies of Poisson's ratio for strong axis bending FE models were conducted similar to those for the weak axis bending FE models. Four FE models with Poisson's ratio varied from 0.1 to 0.4 were used. MOE, shear modulus and thickness were kept at $500 \mathrm{ksi}, 150 \mathrm{ksi}$ and $0.375 ”$, respectively. Load-to-deflection ratio is not 
sensitive to the change in Poisson's ratio, with less than $2 \%$ difference (Table 15).

Poisson’s ratio is linearly proportional to the load-to-deflection ratio (Figure 50).

Table 15: Sensitivity studies of Poisson's ratio of 16"x16" strong axis bending specimens.

\begin{tabular}{cccc}
\hline $\begin{array}{c}\text { Poisson's } \\
\text { Ratio }\end{array}$ & $\begin{array}{c}\text { Deflection } \\
\text { (in) }\end{array}$ & $\begin{array}{c}\text { Load/Deflection } \\
\text { (lbs/in) }\end{array}$ & Difference \\
\hline 0.1 & 0.1023 & 4888 & - \\
0.2 & 0.1011 & 4947 & $1.20 \%$ \\
0.3 & 0.0997 & 5016 & $1.40 \%$ \\
0.4 & 0.0980 & 5100 & $1.67 \%$ \\
\hline
\end{tabular}

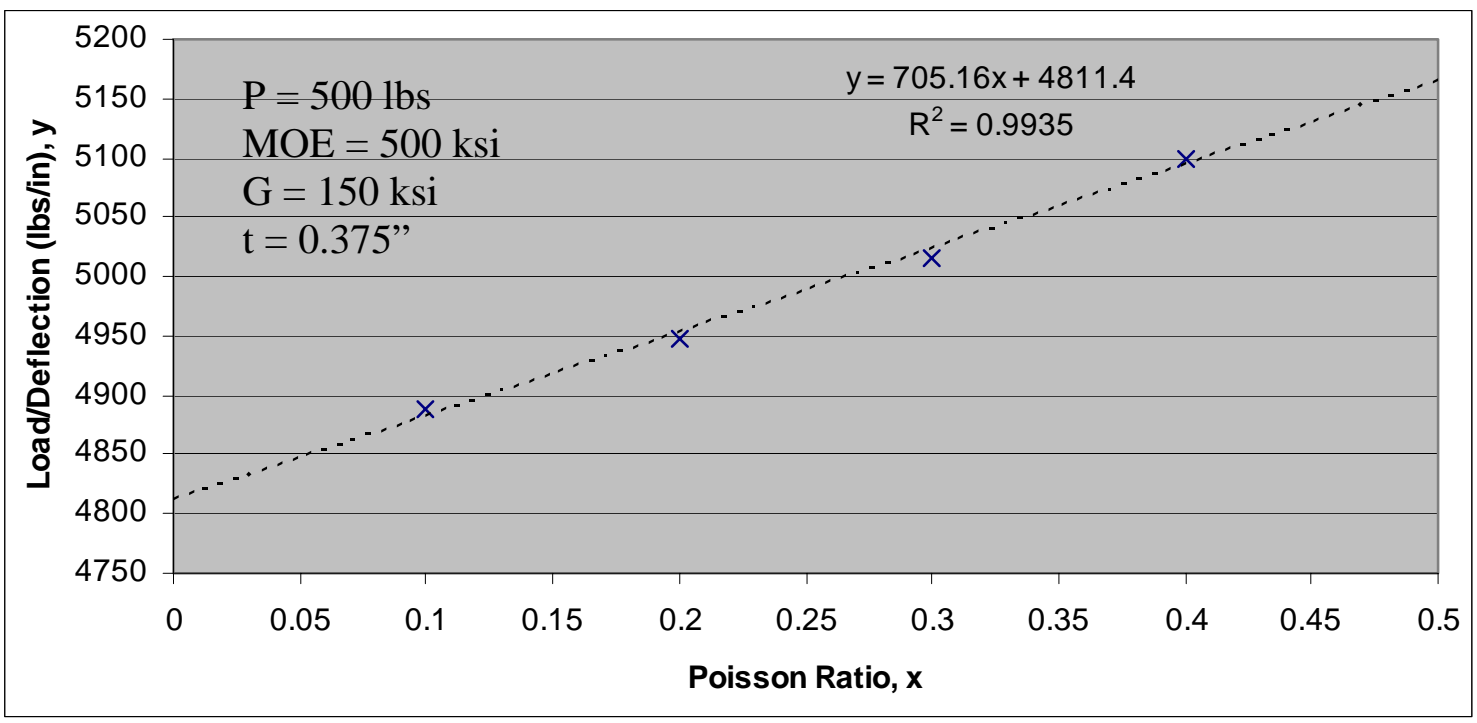

Figure 50: Poisson's ratio sensitivity studies of 16 "x16" strong axis bending specimens.

\section{Effect of Thickness}

The effect of thickness variation on the strong axis bending stiffness was investigated by varying the thickness of FE models from 0.350 ” to 0.400 ”. Other parameters were maintained constant; MOE equal to $500 \mathrm{ksi}$, Poisson's ratio equal to 0.3 and shear modulus equal to $150 \mathrm{ksi}$. The results show that load-to-deflection ratio changed by over $8 \%$ for every 0.025 ” difference in thickness (Table 16). This suggests that the effect of thickness variation should be taken into consideration in the analysis. 
The panel skin thickness also exhibits a linear relationship with the load-to-deflection ratio for small variation in thickness (Figure 51).

Table 16: Sensitivity studies of thickness of $16 " x 16 "$ strong axis bending specimens.

\begin{tabular}{cccc}
\hline $\begin{array}{c}\text { Thickness } \\
\text { (in) }\end{array}$ & $\begin{array}{c}\text { Deflection } \\
\text { (in) }\end{array}$ & $\begin{array}{c}\text { Load/Deflection } \\
\text { (lbs/in) }\end{array}$ & Difference \\
\hline 0.350 & 0.1085 & 4610 & - \\
0.375 & 0.0997 & 5016 & $8.81 \%$ \\
0.400 & 0.0920 & 5435 & $8.36 \%$ \\
\hline
\end{tabular}

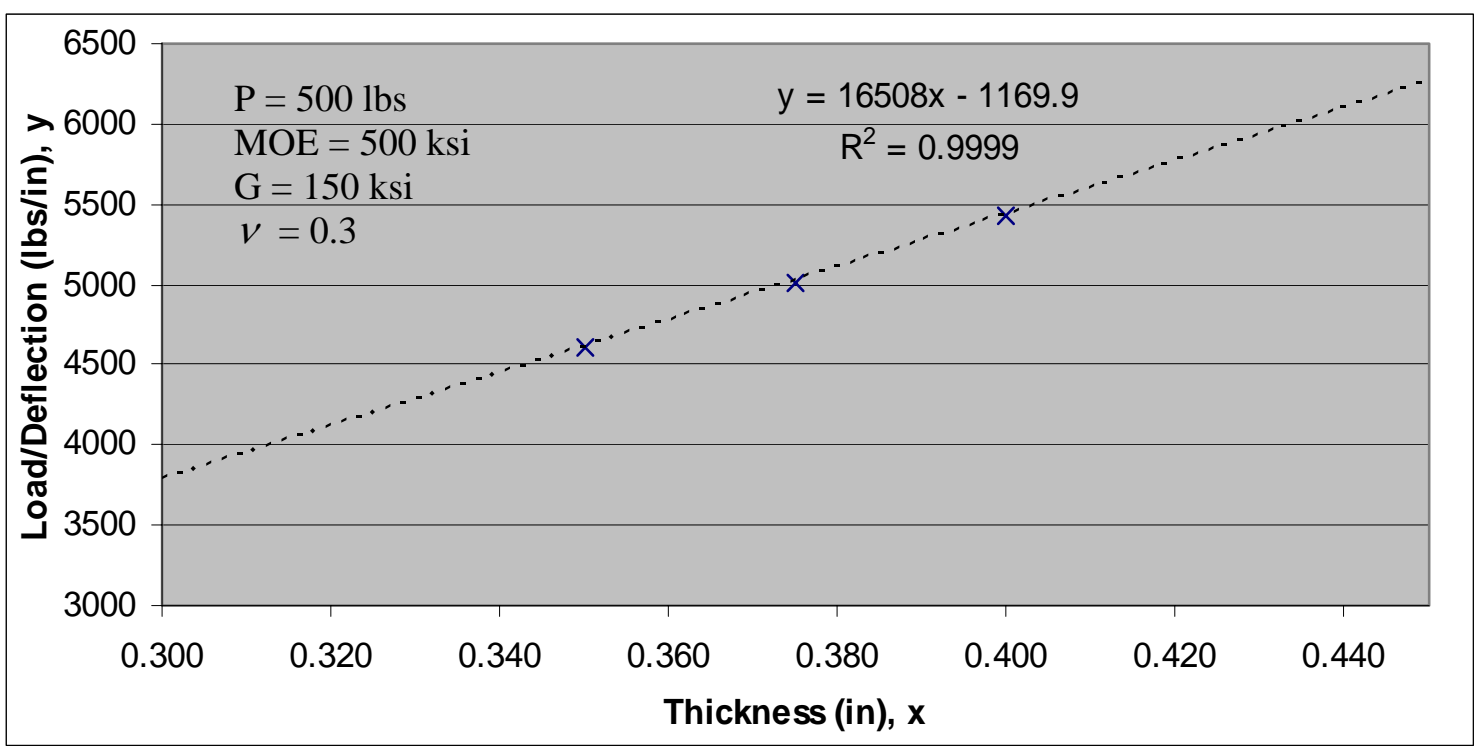

Figure 51: Panel skin thickness sensitivity studies of 16"x16" strong axis bending specimens.

\section{Effect of Modulus of Elasticity}

Sensitivity studies of MOE on strong axis bending were conducted using three FE models with MOE equal to 400 ksi, 500 ksi and 600 ksi. Poisson’s ratio, thickness and shear modulus were $0.3,0.375 ”$ and $150 \mathrm{ksi}$, respectively, for all three models. The loadto-deflection ratio is very sensitive to the change in MOE. The load-to-deflection ratio decreases for about 15\% 20\% for every 100 ksi reduction in MOE (Table 17). The fitted 
line shown in Figure 52 indicates that MOE is linearly proportional to the load-todeflection ratio.

Table 17: Sensitivity studies of MOE of 16"x16" strong axis bending specimens.

\begin{tabular}{cccc}
\hline $\begin{array}{c}\text { MOE } \\
(\mathrm{ksi})\end{array}$ & $\begin{array}{c}\text { Deflection } \\
\text { (in) }\end{array}$ & $\begin{array}{c}\text { Load/Deflection } \\
(\mathrm{lbs} / \mathrm{in})\end{array}$ & Difference \\
\hline 400 & 0.1194 & 4188 & - \\
500 & 0.0997 & 5016 & $19.78 \%$ \\
600 & 0.0864 & 5786 & $15.34 \%$ \\
\hline
\end{tabular}

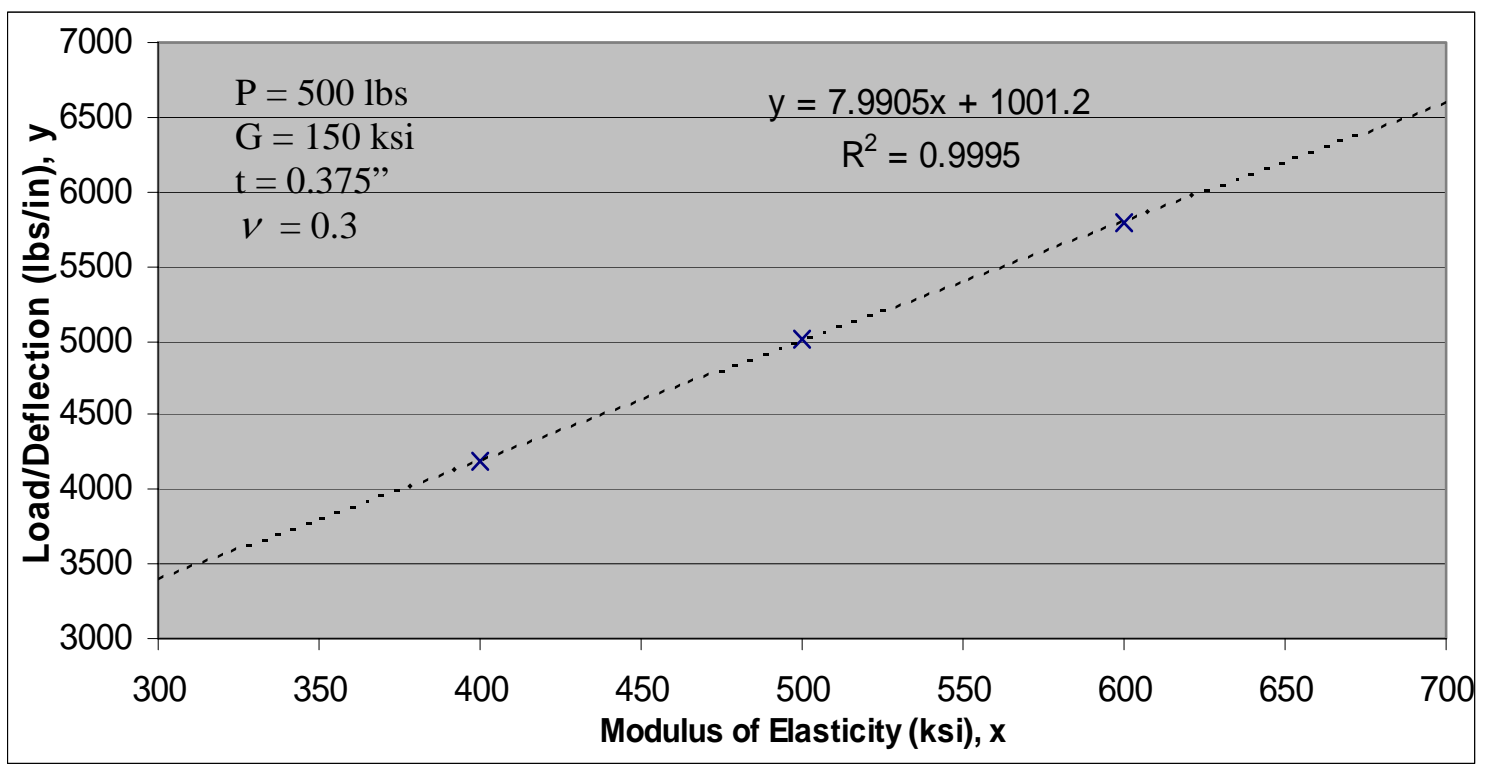

Figure 52: Modulus of elasticity sensitivity studies of 16 "x16" strong axis bending specimens.

\section{Effect of Shear Modulus}

The influence of shear modulus on strong axis bending was assessed using four FE models with four different shear moduli as shown in Table 18. MOE, Poisson's ratio and thickness were $500 \mathrm{ksi}, 0.3$ and 0.375 ”, respectively. The relationship between strong axis load-to-deflection ratio and shear modulus is non-linear (Figure 53), similar to the weak axis bending (see Figure 42). Unlike the effect of shear modulus on the weak axis bending, shear modulus has important effect on the strong axis load-to-deflection ratio. 
The load-to-deflection ratio can differ by as much as $50 \%$, especially in the low shear modulus region (Figure 53).

Table 18: Sensitivity studies of shear modulus of 16 "x16" strong axis bending specimens.

\begin{tabular}{cccc}
\hline $\begin{array}{c}\text { Shear Modulus } \\
(\mathrm{ksi})\end{array}$ & $\begin{array}{c}\text { Deflection } \\
\text { (in) }\end{array}$ & $\begin{array}{c}\text { Load/Deflection } \\
\text { (lbs/in) }\end{array}$ & Difference \\
\hline 25 & 0.1779 & 2810 & - \\
75 & 0.1181 & 4234 & $50.67 \%$ \\
150 & 0.0997 & 5016 & $18.46 \%$ \\
300 & 0.0895 & 5588 & $11.39 \%$ \\
\hline
\end{tabular}

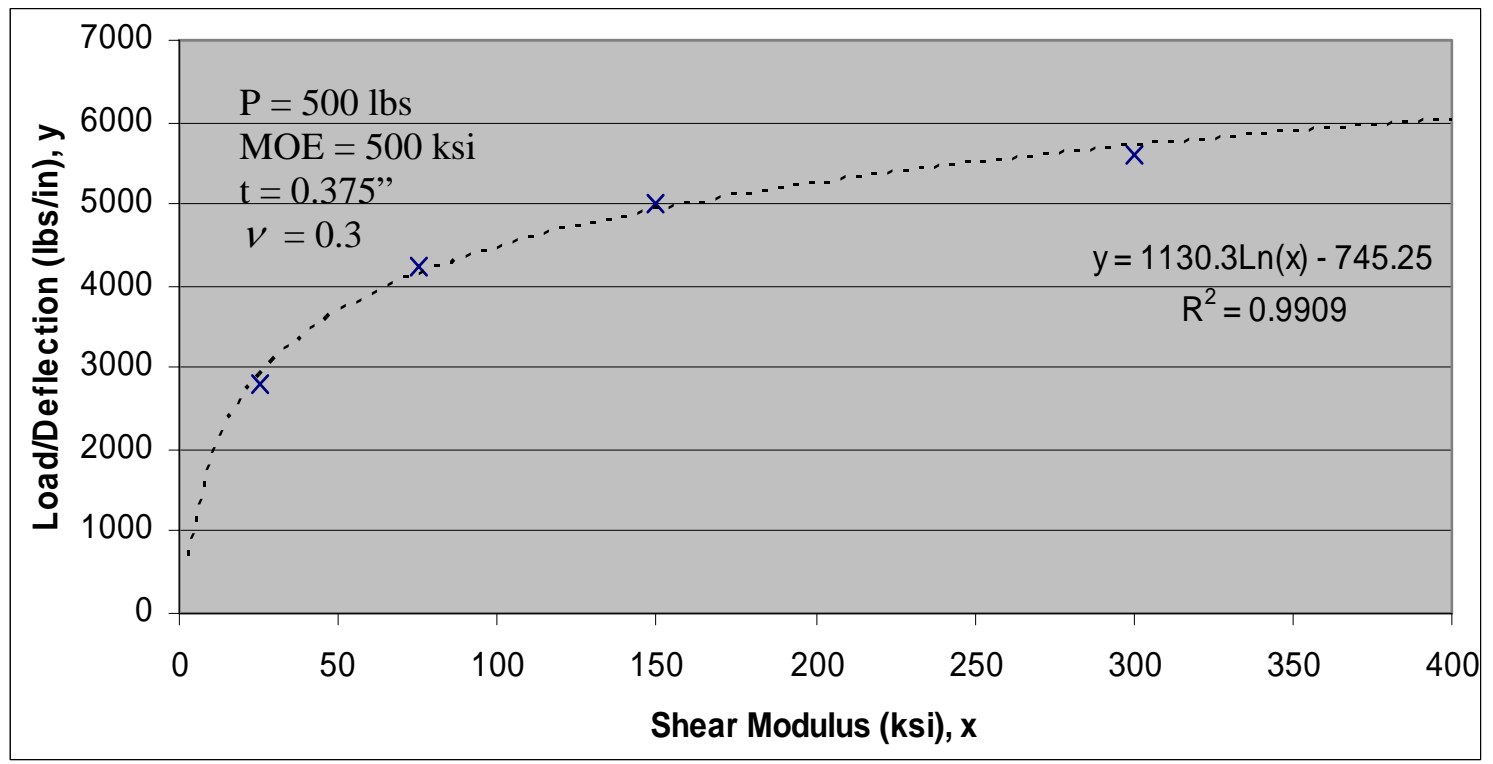

Figure 53: Shear modulus sensitivity studies of 16"x16" strong axis bending specimens.

\section{Estimation of Shear Modulus}

Parametric studies of strong axis bending show that modulus of elasticity, shear modulus and thickness are important variables. In the follow up analyses, shear modulus and modulus of elasticity are assumed to have direct correlation. The $E / G$ ratio was determined using average MOE from the weak axis bending test $(627,089$ psi; refer to Table 12) and average panel thickness (0.376”; refer to Appendix F) of strong axis 
bending specimens. The corrugated panels were produced from random mat therefore inplane isotropic behavior was assumed. Five FE models with various shear moduli were constructed to fit a curve through data points, as shown in Figure 54. A logarithmic curve fitted the data well, with a goodness-of-fit value of 0.995. By using the average load-todeflection ratio of strong axis bending test specimens $\left(5,255^{\mathrm{lbs}} /\right.$ in ; refer to Appendix F) and the equation for the fitted curve, an average shear modulus of 96,793 psi was determined. The $\mathrm{E} / \mathrm{G}$ ratio calculated from average MOE and shear modulus was 6.5.

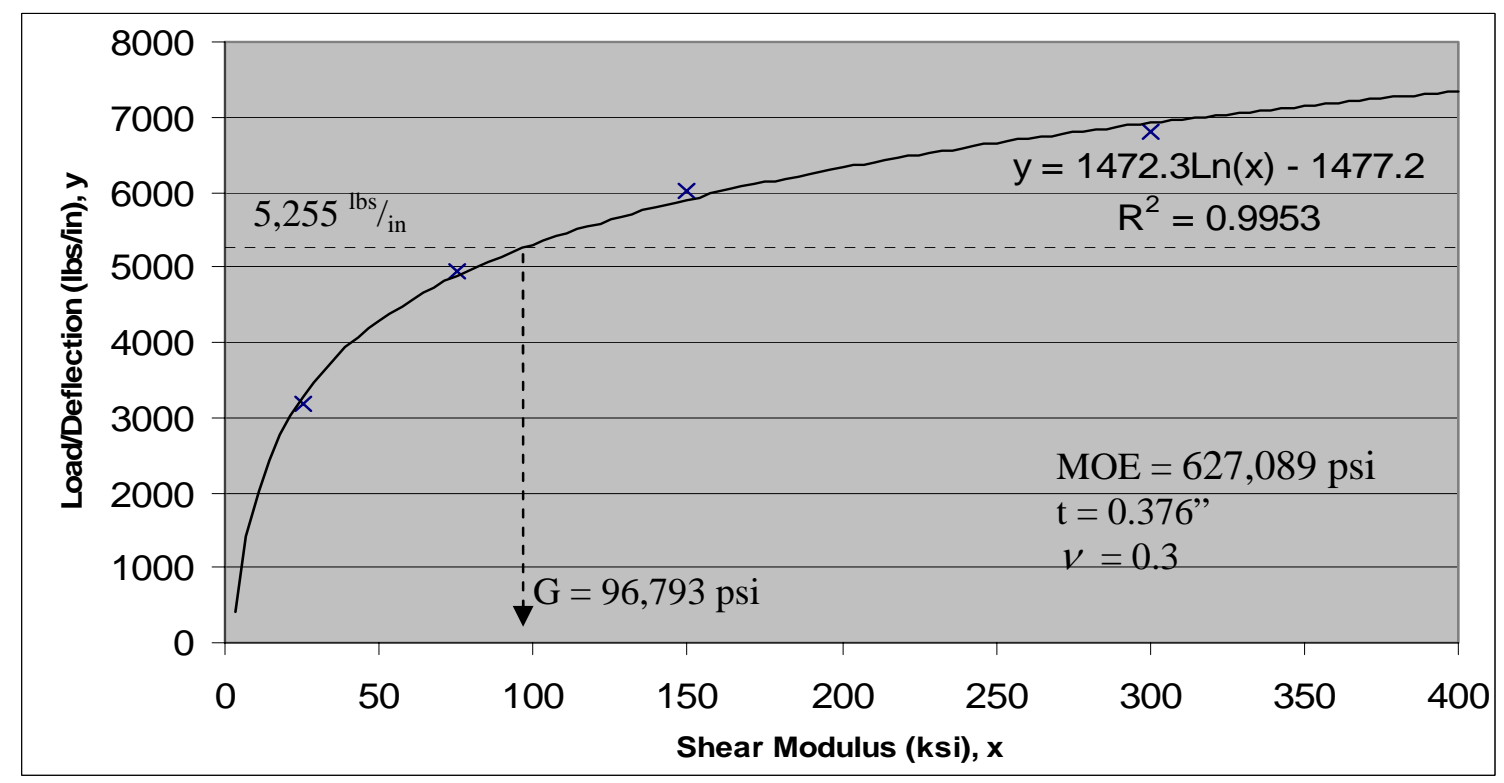

Figure 54: Determination of modulus of elasticity to shear modulus ratio.

\section{Determination of Strong Axis Bending Stiffness}

The same procedures used to obtain weak axis bending stiffness were used to determine the strong axis bending stiffness of individual specimens. A total of nine FE models were used. Three sets of FE models were meshed with thickness equal to 0.350 ”, 0.375” and 0.400 ”. Three different values of MOE, $400 \mathrm{ksi}, 600 \mathrm{ksi}$ and $800 \mathrm{ksi}$, were 
used for each thickness level. The shear modulus associated with each MOE was obtained using the previously determined $\mathrm{E} / \mathrm{G}$ ratio of 6.5 .

Table 19: FE models for strong axis bending of 16"x16" specimens with different MOE and thicknesses.

\begin{tabular}{|c|c|c|c|c|c|c|c|}
\hline \multirow{3}{*}{$\begin{array}{l}\text { MOE } \\
(\mathrm{ksi})\end{array}$} & \multirow{3}{*}{$\begin{array}{c}G \\
(\mathrm{ksi})\end{array}$} & \multicolumn{3}{|c|}{ Thickness (in) } & \multicolumn{3}{|c|}{ Thickness (in) } \\
\hline & & 0.350 & 0.375 & 0.400 & 0.350 & 0.375 & 0.400 \\
\hline & & \multicolumn{3}{|c|}{$\begin{array}{c}\text { Deflection at } 500 \text { lbs load } \\
\text { (in) }\end{array}$} & \multicolumn{3}{|c|}{$\begin{array}{l}\text { Load/Deflection } \\
\text { (Ibs/in) }\end{array}$} \\
\hline 400 & 61.538 & 0.1596 & 0.1463 & 0.1347 & 3133 & 3418 & 3713 \\
\hline 600 & 92.308 & 0.1067 & 0.0978 & 0.0901 & 4687 & 5112 & 5552 \\
\hline 800 & 123.077 & 0.0802 & 0.0736 & 0.0677 & 6233 & 6793 & 7381 \\
\hline
\end{tabular}

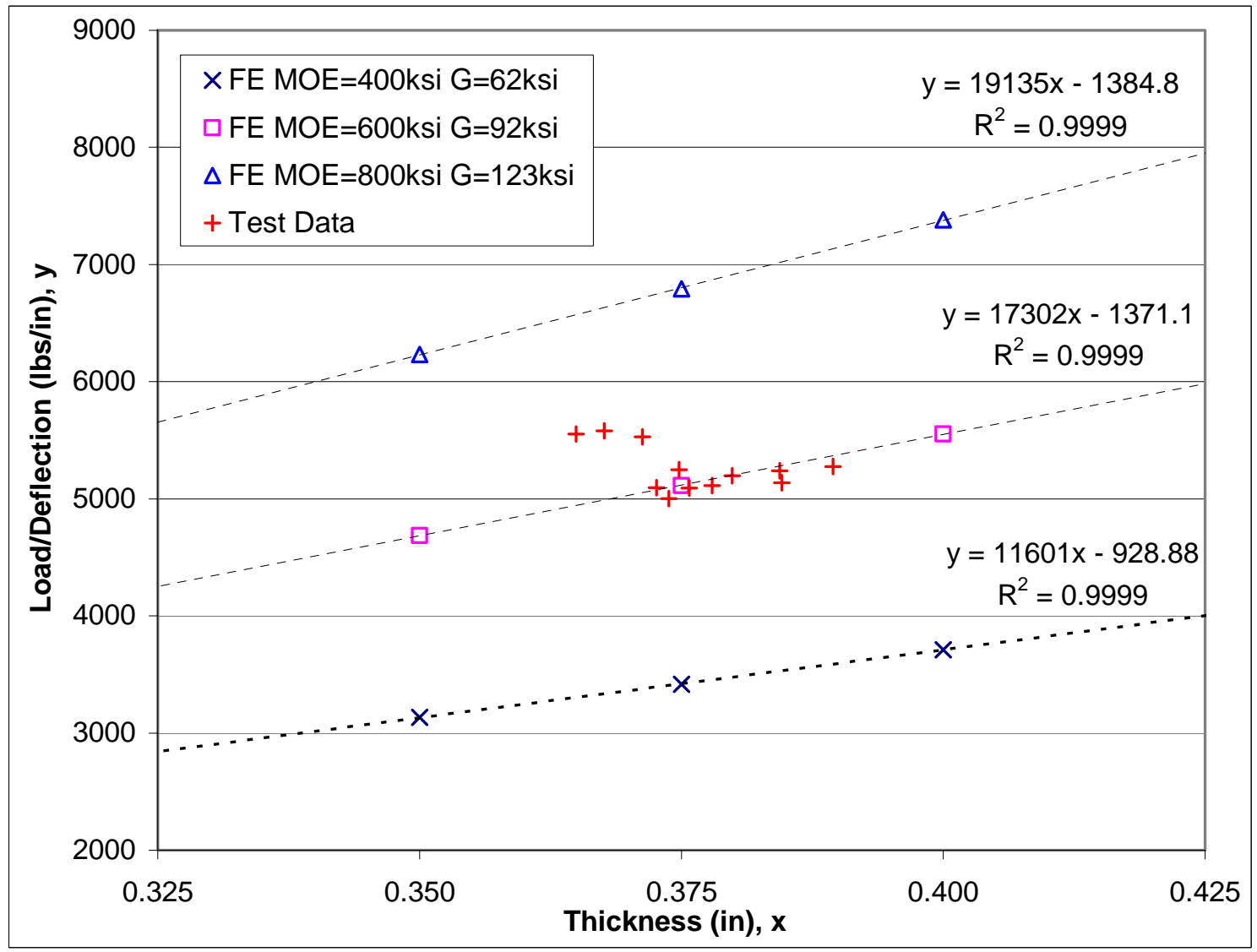

Figure 55: FE models and test data of 16"x16" strong axis bending test specimens. 
Table 20: MOE and strong axis bending stiffness of 16"x16" specimens estimated using FE models.

\begin{tabular}{ccc}
\hline $\begin{array}{c}\text { Type-A random mat } \\
\text { (12 panels) }\end{array}$ & $\begin{array}{c}\text { Modulus of Elasticity } \\
(\mathrm{psi})\end{array}$ & $\begin{array}{c}\text { Bending Stiffness } \\
\left(\mathrm{lbs}^{2}-\mathrm{in}^{2} / \mathrm{ft}\right)\end{array}$ \\
\hline Mean & 641,636 & 434,470 \\
Std.Dev. & 78,812 & 45,165 \\
COV & 0.12 & 0.10 \\
+2(Std.Dev.) & 799,259 & 524,800 \\
-2(Std.Dev.) & 484,012 & 344,140 \\
$5^{\text {th }}$ Percentile & 586,267 & 399,937 \\
\hline
\end{tabular}

The results of FE models and test data are plotted in Figure 55. Average MOE interpolated from the three equations in Figure 55 was about $640 \mathrm{ksi}$. The difference is about $2 \%$ compared to the average MOE of 630 ksi estimated for weak axis bending. Average strong axis bending stiffness was about 430,000 lbs-in ${ }^{2} / \mathrm{ft}$.

\section{Beam Model}

Bending stiffness and bending strength for the strong axis bending specimens were calculated using calibrated equations (65) and (66), respectively. The span length, $L$, is equal to 14.5 ” and the width of the panel, $b$, is equal to 16 ”. Load was applied at mid-span. An $E / G$ ratio of 6.5 was used. $P / \Delta_{p}$ is the slope of the load versus displacement curve (see Figure 47), obtained from the test. Moment of inertia, $I_{c}$, and section modulus, $S_{c}$, must be determined in order to compute modulus of elasticity (MOE) and modulus of rupture (MOR). $I_{c}$ and $S_{c}$ were calculated using equations (4) and (6), respectively. Weighted average thickness (see equation (93)) of each test panel was used to compute $I_{c}$ and $S_{c}$. By knowing $I_{c}$ and $S_{c}$, MOE and MOR were calculated using equations (75) and (76), for the single-span condition. The results of the strong axis bending tests are summarized in Table 21. The estimated $M O E, M O R, E I_{c}$, and $F_{b} S_{c}$ for all strong axis bending test specimens are listed in Appendix F. 
The smallest span used in the calibration of the beam model (equations (65) and (66)) was 18.5”, which was larger than the test span of 14.5 ”. Therefore, the mean bending stiffness estimated by using the beam model was about 400,000 lbs-in ${ }^{2} / \mathrm{ft}$, which is about $8 \%$ lower than that obtained from FE model, 434,470 lbs-in ${ }^{2} / \mathrm{ft}$. The difference in the $5^{\text {th }}$ percentile value is about the same, with $399,937 \mathrm{lbs}-\mathrm{in}^{2} / \mathrm{ft}$ and $385,955 \mathrm{lbs}-\mathrm{in}^{2} / \mathrm{ft}$ for FE and beam models, respectively. The modified beam model provides an easy means to determine deflection and bending stiffness of corrugated panels with little difference from the FE results. The bending stiffness of aligned mat panels was not greatly different from the random mat panels. The nominal 1/2” thick panels were about 1.5 times stiffer than the average nominal $3 / 8$ " panels.

Table 21: Bending stiffness and bending strength of strong axis bending test estimated using beam theory.

\begin{tabular}{|c|c|c|c|c|c|}
\hline & $\begin{array}{l}\text { Modulus of } \\
\text { Elasticity } \\
\text { MOE } \\
\left(\text { lbs/in }{ }^{2}\right)\end{array}$ & $\begin{array}{l}\text { Modulus of } \\
\text { Rupture } \\
\text { MOR } \\
\left(\text { lbs/in }^{2}\right)\end{array}$ & $\begin{array}{c}\text { Bending } \\
\text { Stiffness } \\
\mathrm{El}_{\mathrm{c}} \\
\text { (lbs-in } / \mathrm{ft} \text { ) }\end{array}$ & $\begin{array}{c}\text { Shear } \\
\text { Stiffness } \\
\mathrm{GA}_{\mathrm{s}} \\
(\mathrm{lbs} / \mathrm{ft})\end{array}$ & $\begin{array}{c}\text { Bending } \\
\text { Strength } \\
\mathrm{F}_{\mathrm{b}} \mathrm{S}_{\mathrm{c}} \\
\text { (in-lbs/ft) }\end{array}$ \\
\hline \multicolumn{6}{|c|}{ Type-A (12 panels) ${ }^{*}$ random mat } \\
\hline Mean & 629,498 & 3,754 & 401,293 & 213,757 & 4,250 \\
\hline Std.Dev. & 35,436 & 291 & 15,733 & 7,330 & 291 \\
\hline COV & 0.06 & 0.08 & 0.04 & 0.03 & 0.07 \\
\hline+2 (Std.Dev.) & 700,369 & 4,335 & 432,759 & 228,416 & 4,833 \\
\hline$-2($ Std.Dev.) & 558,627 & 3,173 & 369,826 & 199,098 & 3,668 \\
\hline $5^{\text {th }}$ Percentile & 599,484 & 3,442 & 385,955 & 204,916 & 3,903 \\
\hline \multicolumn{6}{|c|}{ Type-B (2 panels) ${ }^{*}$ aligned mat } \\
\hline Panel \# 11-1 & 650,528 & 3,901 & 404,439 & 212,986 & 4,337 \\
\hline Panel \# 11-3 & 700,443 & 4,063 & 436,746 & 230,300 & 4,527 \\
\hline Mean & 675,486 & 3,982 & 420,593 & 221,643 & 4,432 \\
\hline \multicolumn{6}{|c|}{ Type-C (2 panels) ${ }^{* *}$ nominal 1/2” thick } \\
\hline Panel \# 12-2 & 671,358 & 4,320 & 602,683 & 377,046 & 6,240 \\
\hline Panel \# 12-4 & 662,701 & 4,367 & 593,149 & 370,559 & 6,294 \\
\hline Mean & 667,030 & 4,344 & 597,916 & 373,803 & 6,267 \\
\hline
\end{tabular}

${ }^{*} w=8 ", h=0.75 "$, target $t=0.375 ", \theta=45$ deg.

$\star * w=8 ", h=0.75 "$, target $t=0.5 ", \theta=45$ deg. Random mat 


\section{Shear Test}

\section{Test Procedures}

Shear tests were carried out on eight 16 ”x16” corrugated panels. The test assemblies for the shear and strong axis bending tests were the same in every way except the shear test loading block was located at a distance of

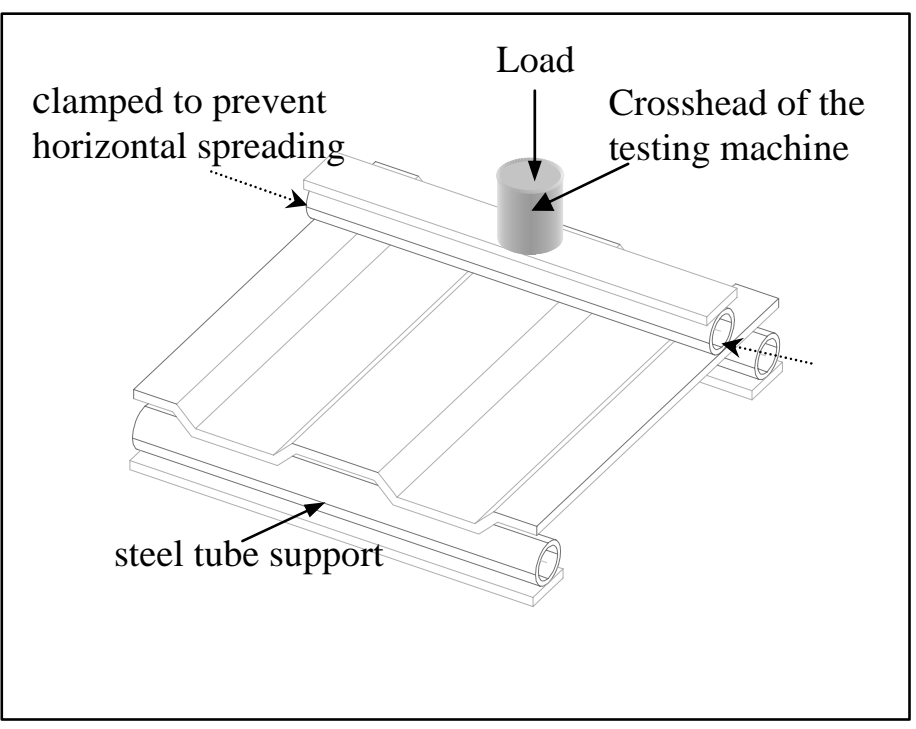

Figure 56: Shear test assembly for 16 "x16" corrugated panels.

3” from the end of the support instead of at mid-span (Figure 56). To maintain consistency with the strong axis bending test, the free edges of each corrugated panel under the loading block were clamped in the same way as the strong axis bending test. Measurement of displacement directly beneath the crosshead of the testing machine was not possible. As a result, the movement of the crosshead was measured using an LVDT and recorded through the data acquisition system. The movement of the crosshead was maintained at about $0.06 \mathrm{in} / \mathrm{min}$. The ultimate or maximum loads were manually recorded from the dial gauge of the testing machine. After completion of shear tests, specimens were sealed in plastic bags for later end bearing or crush tests since one end of every panel was undamaged. Two 1”x1” samples were cut from every specimen once both shear and bearing tests were completed to determine the moisture contents and densities. 


\section{Test Results}

The average moisture content, wet density and oven-dry density of the shear and end bearing specimens are listed in Table 22. The average moisture content for the tested panels was $5.22 \%$ with little variation, COV of 0.03 . The target density of 40 pcf was closely approximated for shear and end bearing specimens. The average oven dry-density was 40.84 pcf with a COV of 0.08 .

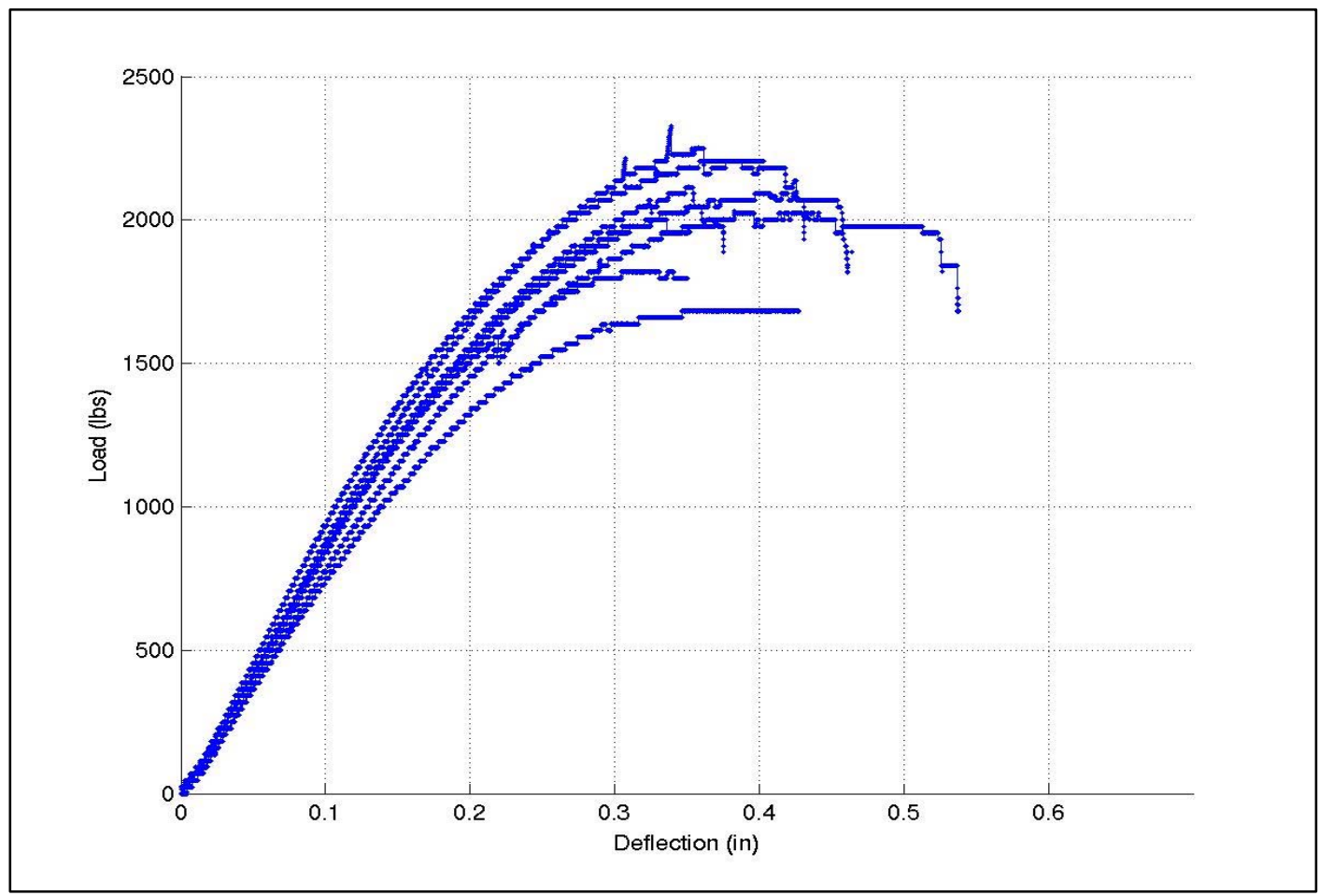

Figure 57: Load-displacement curves for shear test specimens.

Table 22: Average moisture content and densities for the shear and end bearing tests specimens.

\begin{tabular}{cccc}
\hline $\begin{array}{c}\text { Type-A random mat } \\
(8 \text { panels })\end{array}$ & $\begin{array}{c}\text { Moisture Content } \\
(\%)\end{array}$ & $\begin{array}{c}\text { Wet Density } \\
\left(\mathrm{lbs} / \mathrm{ft}^{3}\right)\end{array}$ & $\begin{array}{c}\text { Oven Dry Density } \\
\left(\mathrm{lbs}^{3} \mathrm{ft}^{3}\right)\end{array}$ \\
\hline Mean & $5.22 \%$ & 42.96 & 40.84 \\
Sample Standard Deviation & $0.14 \%$ & 3.61 & 3.45 \\
Coefficient of Variation & 0.03 & 0.08 & 0.08 \\
\hline
\end{tabular}


The load-displacement curves for shear tests are plotted in Figure 57. The failure conditions of the shear test specimens were similar to the failure conditions observed in strong axis bending tests. All tested specimens failed at the load point where the maximum moment occurred. Hence, bending induced failure is believed to be the cause of failure in the shear test specimens. The shear test setup used was not able to assess the theoretical shear strength of the corrugated panel directly. However, an indirect estimation of the shear strength was performed using combined data from both the shear and strong axis bending tests.

The maximum shear and moment (per unit width) for a simply supported beam under a point load can be calculated using the following equations.

$$
\begin{gathered}
V_{\max }=\frac{P\left(L-x_{p}\right)}{L} \frac{1}{\mathrm{~b}} \text { for } x_{p} \leq L / 2 \\
M_{\max }=\frac{P x_{p}\left(L-x_{p}\right)}{L} \frac{1}{b}
\end{gathered}
$$

where $P$ is the maximum applied load (lbs) and $L$ is the span length (in). The distance from the left support to the point load is defined as $x_{p}$ (in) (Figure 58) and the width of the beam (or panel) is defined as $b$ (in). The maximum shear and moment for the shear $\left(x_{p}=3 "\right)$ and the strong axis bending $\left(x_{p}=7.25 "\right)$ tests were calculated using maximum loads recorded. The $L$ and $b$ were 14.5 ” and 16”, respectively.

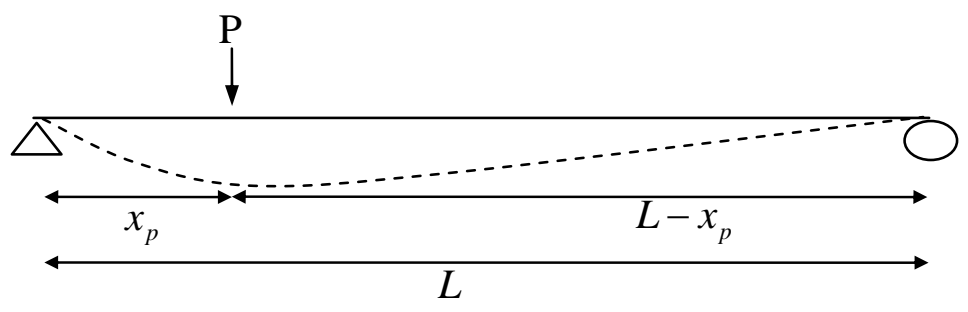

Figure 58: Simple beam with concentrated load at any point. 
Table 23: Maximum shear and moment for the shear and strong axis bending tests.

\begin{tabular}{|c|c|c|c|c|c|c|}
\hline \multirow{2}{*}{$\begin{array}{l}\text { Type-A } \\
\text { random mat } \\
\text { (8 panels) }\end{array}$} & \multicolumn{3}{|c|}{$\begin{array}{l}\text { Shear Test } \\
\qquad x_{p}=3 "\end{array}$} & \multicolumn{3}{|c|}{$\begin{array}{l}\text { Strong Axis Bending Test } \\
\qquad x_{p}=7.25 "\end{array}$} \\
\hline & $\begin{array}{l}\text { Maximum } \\
\text { Load } \\
\text { (lbs) }\end{array}$ & $\begin{array}{l}\text { Maximum } \\
\text { Shear } \\
\text { (lbs/ft) }\end{array}$ & $\begin{array}{l}\text { Maximum } \\
\text { Moment } \\
\text { (lbs-in/ft) }\end{array}$ & $\begin{array}{l}\text { Maximum } \\
\text { Load } \\
\text { (lbs) }\end{array}$ & $\begin{array}{l}\text { Maximum } \\
\text { Shear } \\
\text { (lbs/ft) }\end{array}$ & $\begin{array}{l}\text { Maximum } \\
\text { Moment } \\
\text { (lbs-in/ft) }\end{array}$ \\
\hline Mean & 2032 & 1209 & 3627 & 1563 & 586 & 4250 \\
\hline Std.Dev. & 205 & 122 & 366 & 107 & 40 & 291 \\
\hline COV & 0.10 & 0.10 & 0.10 & 0.07 & 0.07 & 0.07 \\
\hline$+2($ Std.Dev.) & 2442 & 1453 & 4359 & 1778 & 667 & 4833 \\
\hline-2 (Std.Dev.) & 1622 & 965 & 2895 & 1349 & 506 & 3668 \\
\hline $5^{\text {th }} \%$ & 1729 & 1028 & 3085 & 1436 & 538 & 3903 \\
\hline
\end{tabular}

The maximum moment as a function of the load point, $x_{p}$, is symmetric about the mid-span with the maximum value occuring at mid-span and zero moment at the two supports. Based on these assumptions, two empirical maximum moment equations, $\tilde{M}$ and $\tilde{M}_{05}$, (Figure 59(a))were obtained by fitting the test data at the mean and the $5^{\text {th }}$ percentile values (Table 24 columns (b) and (e)).

$$
\begin{aligned}
& \tilde{M}\left(x_{p}\right)=-1.3434 x_{p}{ }^{4}+38.96 x_{p}{ }^{3}-433.94 x_{p}{ }^{2}+2196.4 x_{p} \\
& \tilde{M}_{05}\left(x_{p}\right)=-0.8402 x_{p}{ }^{4}+24.366 x_{p}{ }^{3}-295.07 x_{p}{ }^{2}+1717 x_{p}
\end{aligned}
$$

Equations (100) and (101) have built-in units associated with all the constant terms. The estimated moments have units in terms of lbs-in/ft with $x_{p}$ in inches. Substituting equations (100) and (101) into equation (99) to replace the $M_{\max }$ and solving for the maximum load yields

$$
\begin{gathered}
\tilde{P}\left(x_{p}\right)=\frac{L b}{x_{p}\left(L-x_{p}\right)} \tilde{M}\left(x_{p}\right) \\
\tilde{P}_{05}\left(x_{p}\right)=\frac{L b}{x_{p}\left(L-x_{p}\right)} \tilde{M}_{05}\left(x_{p}\right)
\end{gathered}
$$


$\tilde{P}$ and $\tilde{P}_{05}$ are the estimations for the maximum loads in pounds for the mean and the $5^{\text {th }}$ percentile values, respectively (Figure 59(b)). Similarly, substituting equations (102) and (103) into equation (98) yields the predictions for the maximum shears

$$
\begin{array}{cc}
\tilde{V}=\frac{\tilde{P}\left(x_{p}\right)\left(L-x_{p}\right)}{L} \frac{1}{\mathrm{~b}} & \text { for } x_{p} \leq L / 2 \\
\tilde{V}_{05}=\frac{\tilde{P}_{05}\left(x_{p}\right)\left(L-x_{p}\right)}{L} \frac{1}{\mathrm{~b}} & \text { for } x_{p} \leq L / 2
\end{array}
$$

The maximum shear equations are symmetric about the mid-span and have units of lbs/ft. The shear strength of the 16 " 16 " corrugated panel was obtained by evaluating the limit of the maximum shear equations as the point load approaching the support ( $x_{p} \rightarrow 0$ or $\left.x_{p} \rightarrow L\right)$. The predicted shear strengths were about $2200 \mathrm{lbs} / \mathrm{ft}$ and $1700 \mathrm{lbs} / \mathrm{ft}$ for the mean and $5^{\text {th }}$ percentile, respectively (Figure 59(c), and Table 24 columns (d) and (g)).

\begin{tabular}{|c|c|c|c|c|c|c|}
\hline \multirow{2}{*}{$\begin{array}{c}(\mathrm{a}) \\
\text { Distance } \\
\text { from } \\
\text { Support } \\
x_{p} \\
\text { (in) }\end{array}$} & \multicolumn{3}{|c|}{ Mean } & \multicolumn{3}{|c|}{$5^{\text {th }}$ Percentile } \\
\hline & $\begin{array}{c}(\mathrm{b}) \\
\text { Maximum } \\
\text { Moment } \\
\text { (lbs-in/ft) }\end{array}$ & $\begin{array}{c}\text { (c) } \\
\text { Maximum } \\
\text { Load } \\
\text { (lbs) }\end{array}$ & $\begin{array}{c}(\mathrm{d}) \\
\text { Maximum } \\
\text { Shear } \\
(\mathrm{lbs} / \mathrm{ft})\end{array}$ & $\begin{array}{c}(\mathrm{e}) \\
\text { Maximum } \\
\text { Moment } \\
\text { (lbs-in/ft) }\end{array}$ & $\begin{array}{c}(f) \\
\text { Maximum } \\
\text { Load } \\
\text { (lbs) }\end{array}$ & $\begin{array}{c}(\mathrm{g}) \\
\text { Maximum } \\
\text { Shear } \\
(\mathrm{lbs} / \mathrm{ft})\end{array}$ \\
\hline 0 & 0 & $2929 *$ & $2196^{*}$ & 0 & $2289^{*}$ & $1717^{*}$ \\
\hline 3" & 3627 & 2032 & 1209 & 3085 & 1729 & 1028 \\
\hline $7.25 "$ & 4250 & 1563 & 586 & 3903 & 1436 & 538 \\
\hline $11.5 "$ & 3627 & 2032 & 1209 & 3085 & 1729 & 1028 \\
\hline $14.5 "$ & 0 & $2929 *$ & $2196^{*}$ & 0 & $2289 *$ & $1717^{*}$ \\
\hline $\begin{array}{l}\text { ^Predicted va } \\
\text { or L. }\end{array}$ & 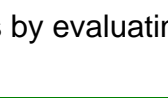 & limit of $m$ & um shear & อуimum I & xpressions & ${ }_{p}$ equal to $C$ \\
\hline
\end{tabular}

Table 24: Estimation of shear strength for 16"x16" corrugated panel. 


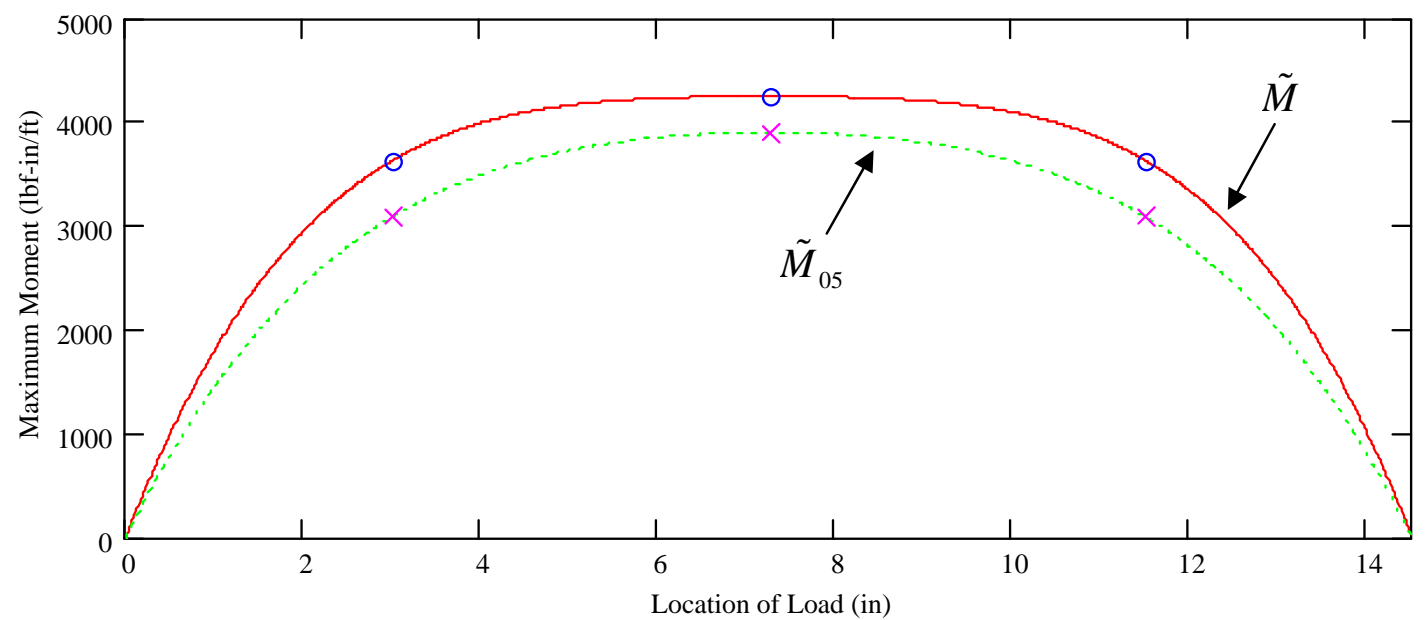

(a)

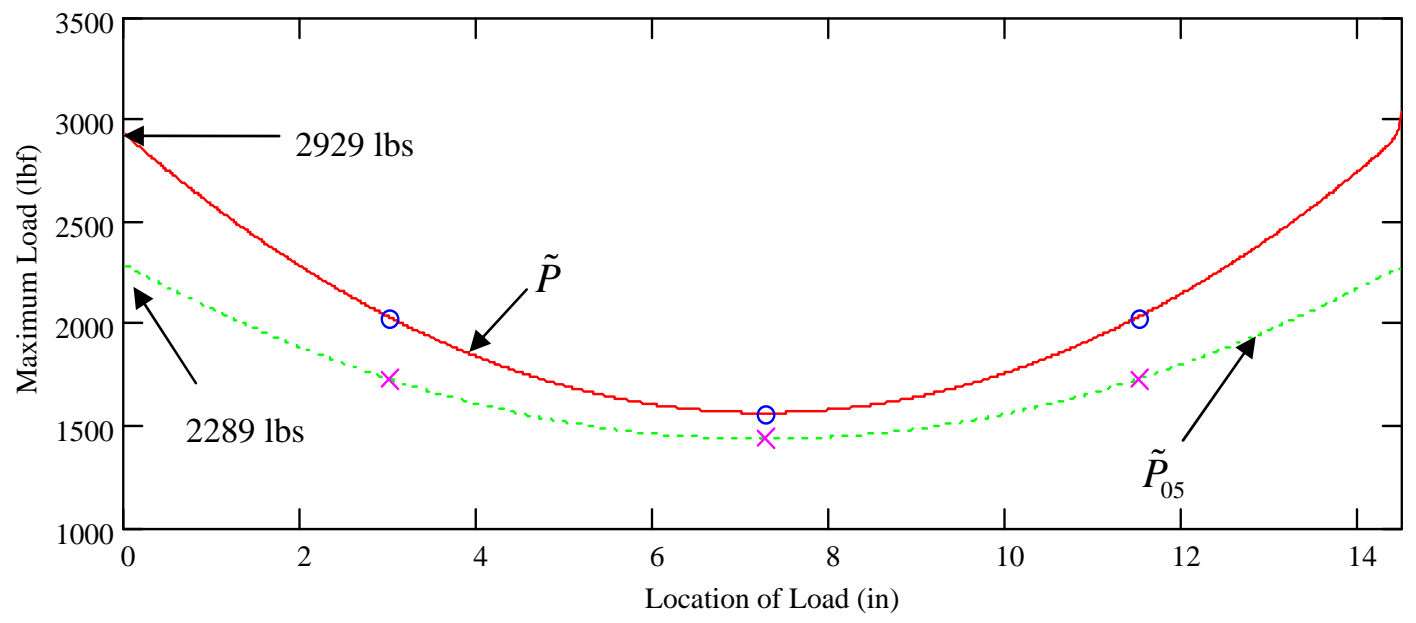

(b)

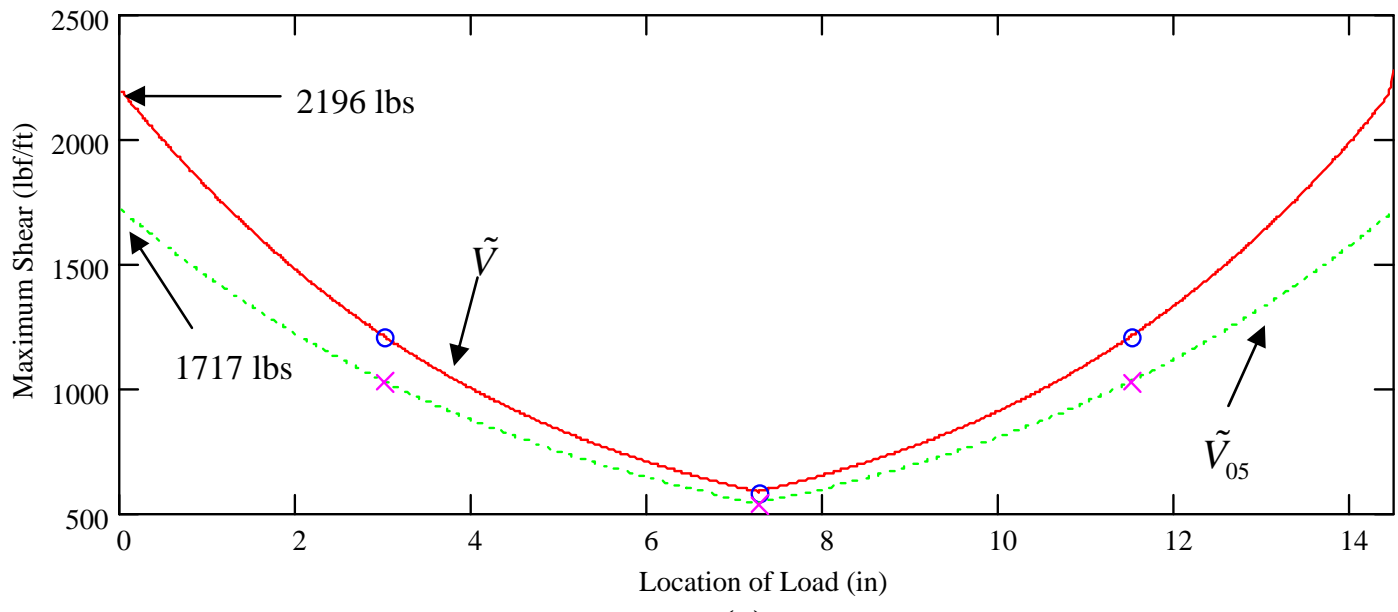

(c)

O०O Test Data (Mean)

-... Estimation (5th \%)

$\times \times \times \quad$ Test Data (5th \%)

Figure 59: Estimation of the shear strength for 16"x16" corrugated panel using empirical equations; (a) maximum moment, (b) maximum load, and (c) maximum shear. 


\section{Bearing or Crush Test}

\section{Test Procedures}

The bearing or crush test was setup to investigate the effects of compression line loads caused by bearing walls. The worst case scenario, a stack of two bearing walls, above and below, was modeled by locating

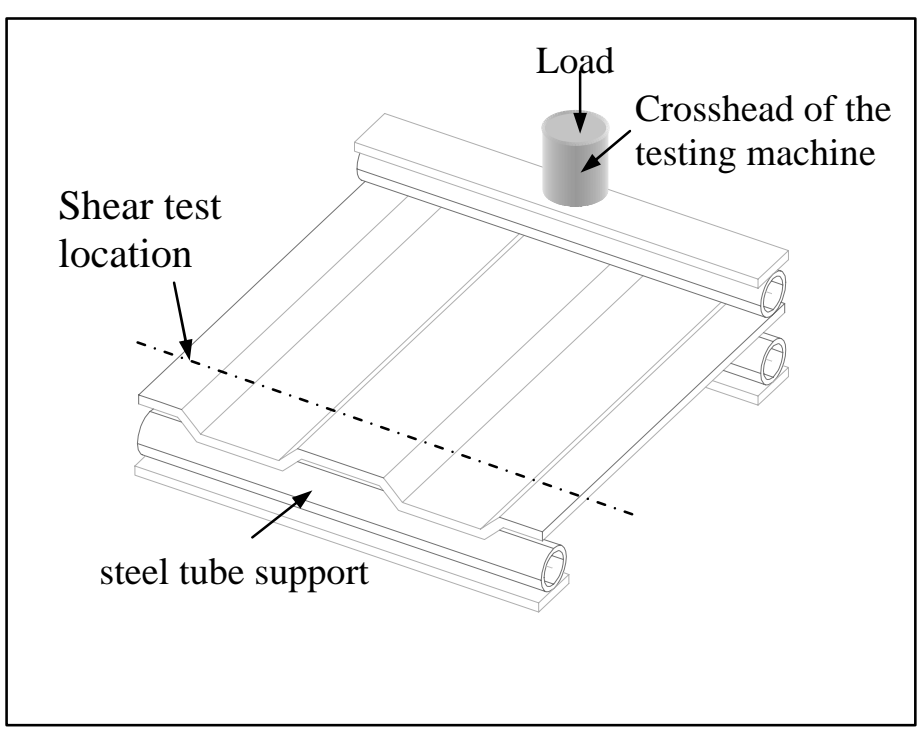

Figure 60: Bearing or crush test assembly for 16"x16" panels.

the loading block directly on top of a support at the end of a panel (Figure 60). The same panels used in the shear tests were tested for crushing since the far end from the shear test location was considered undamaged. The movement of the crosshead was kept at a constant rate of about $0.035 \mathrm{in} / \mathrm{min}$. The crosshead movement was used as a measurement of the deformation of the panel. The deflections and loads were recorded using a data acquisition system. Maximum deflection and load were not recorded since no distinct failure point could be identified. The test was stopped after a deflection of at least 0.2 ” was reached. 


\section{Test Results}

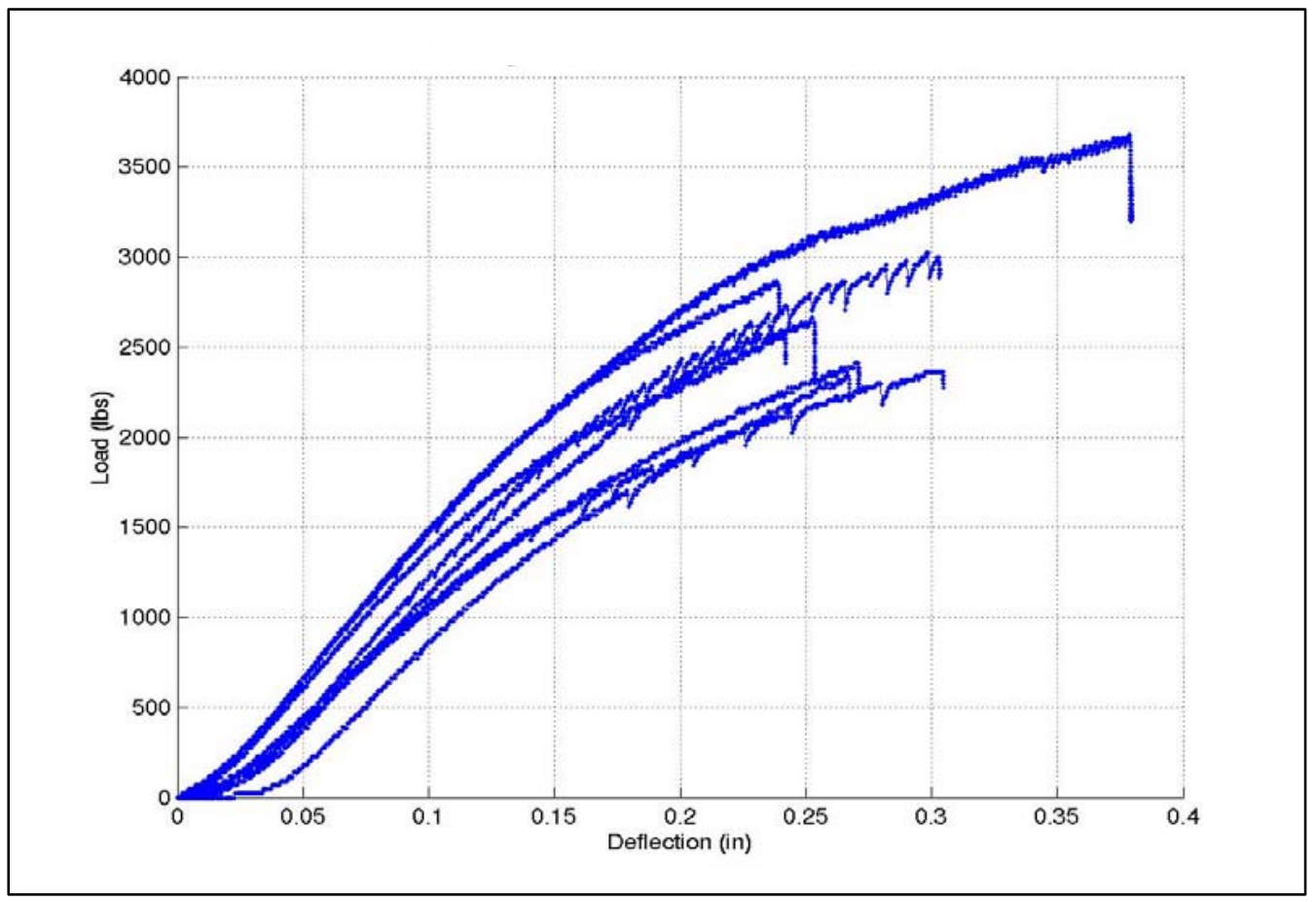

Figure 61: Load-deflection curves for crush test panels.

The moisture contents and the densities for the tested panels were the same as the shear test panels (Table 22). The load-deflection curves are plotted in Figure 61. The initial gradual gradient region of the load-deflection curve was caused by the establishment of contact between the loading blocks and the corrugated panel. Lines were fitted to load-deflection curves to estimate the slopes for all curves. The results of the fitted lines can be found in Appendix F. The average slope for the panel was $11259 \mathrm{lbs} /$ in per foot of panel width. Assuming a deformation limit of 0.02 ”, the tested corrugated panel had a compression strength of about $225 \mathrm{lbf} / \mathrm{ft}$. The crush test specimens were tested on simple supports. The corrugated panel was susceptible to a flattening effect (spreading across the corrugations) under this test setup. In an actual floor system, the bottom decks of the corrugated panel will be attached (nailed or nailed-glued) to the joists with finite width of real supports (nominal 2" 4"), which will increase the compression strength. 
Uniform load capacities based on the 0.02 " limit for the four commonly used joist spacings of 24" on-center or larger are listed in Table 25. Based on the conservative assumption, the corrugated panel can withstand more than typical residential loads of 40 psf. As an alternative, nominal 1" lumber (actual 3/4" thickness) can be placed at the channels of the corrugated panel as blocking materials to increase the compression strength.

Table 25: Uniform load capacities (psf) of the 16”x16" corrugated panel at 0.02 " of deformation under compression.

\begin{tabular}{ccccc}
\hline $\begin{array}{c}\text { Type-A } \\
\text { random mat } \\
\text { (8 panels) }\end{array}$ & 24 & 32 & 40 & 48 \\
\cline { 2 - 4 } Mean & 112.6 & 84.4 & 67.6 & 56.3 \\
Std.Dev. & 12.23 & 9.17 & 7.34 & 6.11 \\
COV & 0.11 & 0.11 & 0.11 & 0.11 \\
+2(Std.Dev.) & 137.0 & 102.8 & 82.2 & 68.5 \\
-2(Std.Dev.) & 88.1 & 66.1 & 52.9 & 44.1 \\
$5^{\text {th }}$ Percentile & 96.1 & 72.1 & 57.7 & 48.1 \\
\hline
\end{tabular}

\section{Edge Point Load Test}

Edge tests were setup to investigate the ability of a corrugated panel to withstand concentrated loads applied at the free edges. The edge load carrying capacity is particularly important for safety during the construction phase, when construction workers might be standing and working at the edge of a bare corrugated panel.

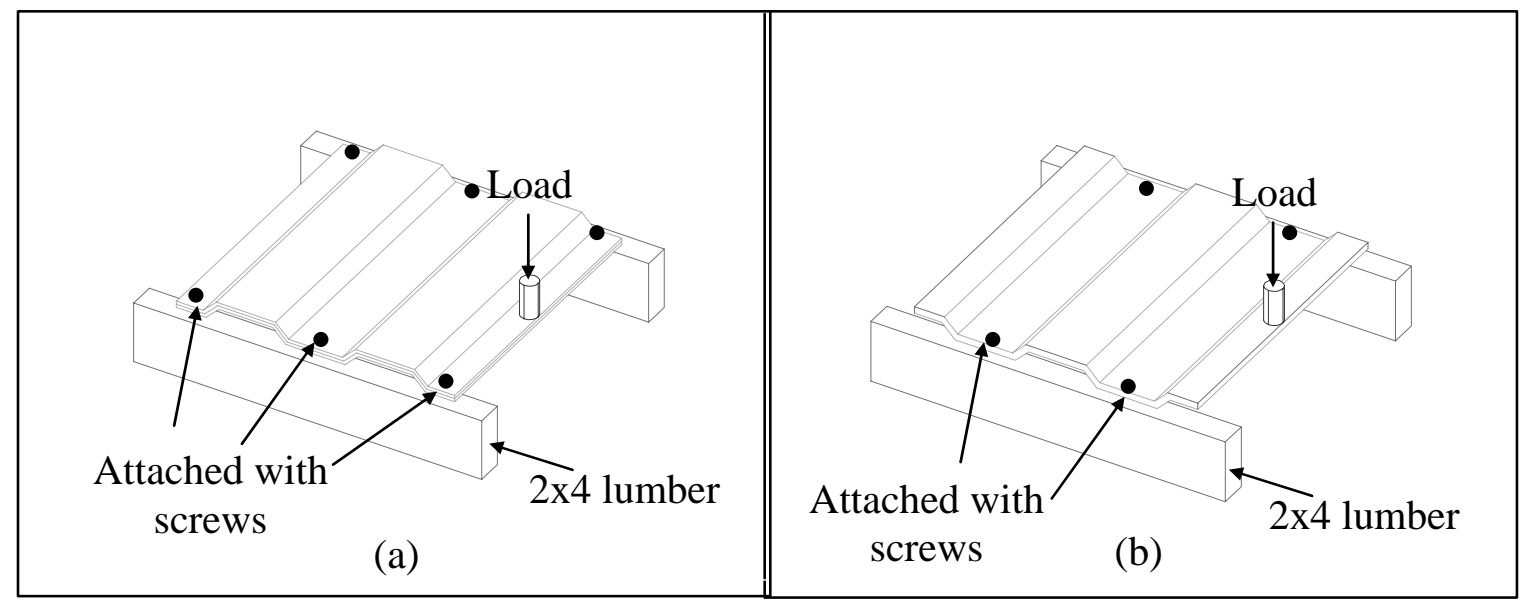

Figure 62: Edge point load test assemblies for 16"x16" panels with (a) lower decks as free edges (b) upper decks as free edges. 


\section{Test Procedures}

Two edge test assemblies were used to examine the load carrying capacity of two different cases, with lower decks as free edges (case A) and with upper decks as free edges (case B) (Figure 62). Nominal 2x4 lumber was used as supports and corrugated panels were placed with the channels perpendicular to the $2 \times 4$ lumber. The clear span of the panel was 14.5 ”. Corrugated panels were fastened to the $2 \times 4$ lumber at the lower decks with No. 8, 1" wood screws. For the test assembly with lower decks as free edges, the panel was fastened with 6 screws. For the test assembly with upper decks as free edges, the panel was fastened with 4 screws. Load was applied to a 1" diameter steel rod placed at the edge of the mid-span. The movement of the crosshead (about $0.08 \mathrm{in} / \mathrm{min}$ ) was recorded as the displacement of the edge. The test was stopped once the maximum load was achieved. Two 1"x1" samples were cut from each test specimen to determine the moisture content, the density as tested, and the oven-dry density.

\section{Test Results}

The average moisture content for the edge test specimens was consistent with the rest of the test specimens. The tested panels had moisture contents in the range of $5.5 \%$ to $6 \%$. The average oven dry density was close to the target density of 40 pcf.

Table 26: Average moisture content and densities for edge test specimens.

\begin{tabular}{ccccccc}
\hline & \multicolumn{3}{c}{$\begin{array}{c}\text { Lower Decks as Free Edges } \\
(\text { Case A) }\end{array}$} & \multicolumn{3}{c}{$\begin{array}{c}\text { Upper Decks as Free Edges } \\
(\text { Case B) }\end{array}$} \\
\hline $\begin{array}{c}\text { Type-A } \\
\text { random mat } \\
\text { (4 panels) }\end{array}$ & $\begin{array}{c}\text { Moisture } \\
\text { Content } \\
(\%)\end{array}$ & $\begin{array}{c}\text { Wet } \\
\text { Density } \\
\left(\mathrm{lbs} / \mathrm{ft}^{3}\right)\end{array}$ & $\begin{array}{c}\text { Oven } \\
\text { Dry } \\
\text { Density } \\
\left(\mathrm{lbs} / \mathrm{ft}^{3}\right)\end{array}$ & $\begin{array}{c}\text { Moisture } \\
\text { Content } \\
(\%)\end{array}$ & $\begin{array}{c}\text { Wet } \\
\text { Density } \\
\left(\mathrm{lbs} / \mathrm{ft}^{3}\right)\end{array}$ & $\begin{array}{c}\text { Oven } \\
\text { Dry } \\
\text { Density } \\
\left(\mathrm{lbs} / \mathrm{ft}^{3}\right)\end{array}$ \\
\hline Mean & $5.81 \%$ & 40.80 & 38.56 & $5.61 \%$ & 43.70 & 41.38 \\
Sample Standard Deviation & $0.46 \%$ & 4.31 & 4.16 & $0.19 \%$ & 1.78 & 1.71 \\
Coefficient of Variation & 0.08 & 0.11 & 0.11 & 0.03 & 0.04 & 0.04 \\
\hline
\end{tabular}




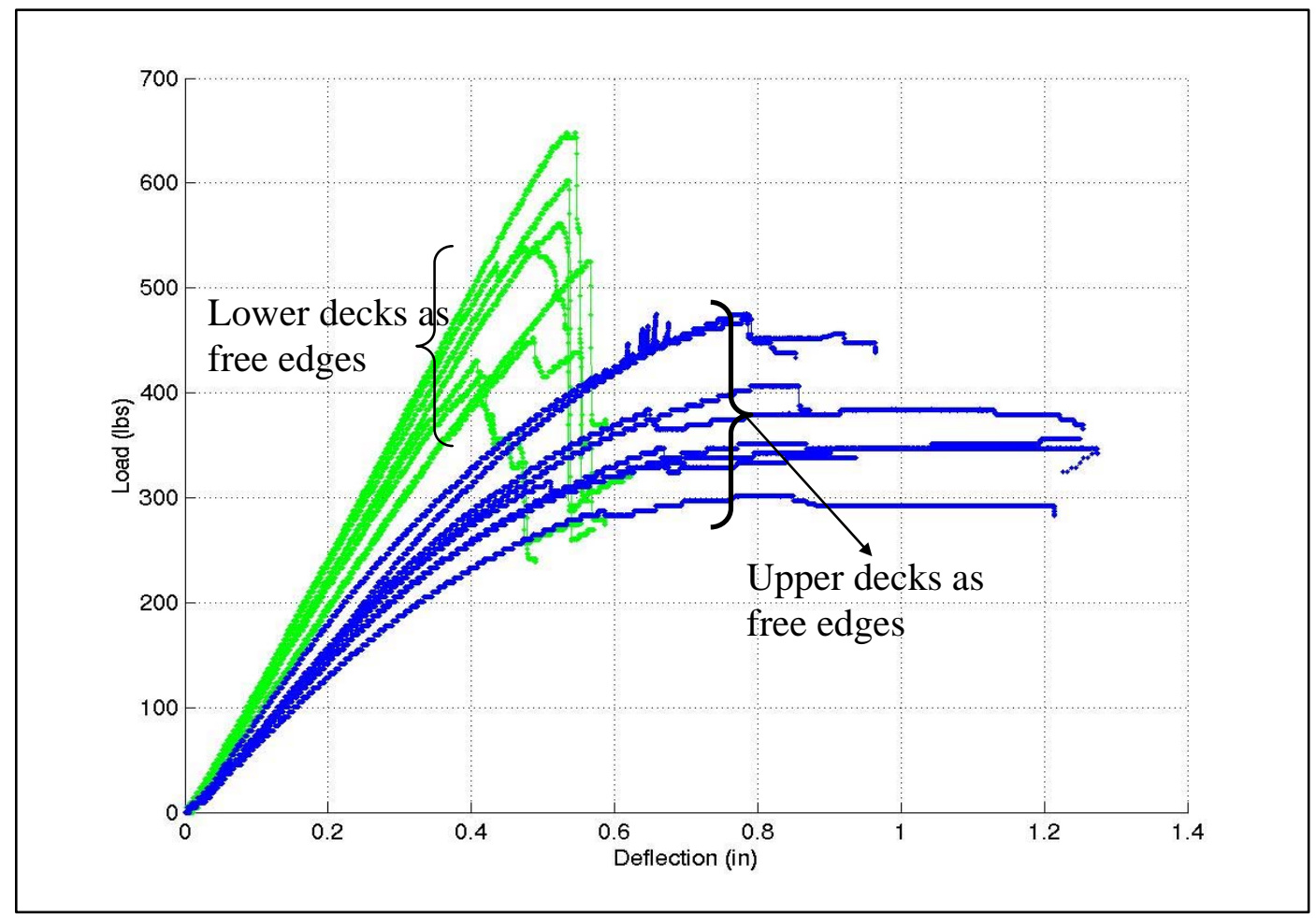

Figure 63: Load-deflection curves for edge test panels.

The load-deflection curves for the two cases of edge tests are plotted in Figure 63.

The panels with lower decks placed as free edges demonstrated both higher stiffness and maximum load than the panels with upper decks placed as free edges. The average stiffness of case A compared to case B was higher by $54 \%$ and the average maximum load was higher by about 35\%.

Table 27: Average stiffness and average maximum load for edge test specimens.

\begin{tabular}{ccccc}
\hline $\begin{array}{c}\text { Type-A } \\
\text { random mat } \\
\text { (8 tests on 4 panels) }\end{array}$ & \multicolumn{2}{c}{$\begin{array}{c}\text { Lower Decks as Free Edges } \\
\text { (Case A) }\end{array}$} & \multicolumn{2}{c}{$\begin{array}{c}\text { Upper Decks as Free Edges } \\
\text { (Case B) }\end{array}$} \\
\cline { 2 - 5 } & $\begin{array}{c}\text { Stiffness } \\
\text { (lbs/in) }\end{array}$ & $\begin{array}{c}\text { Maximum Load } \\
\text { (lbs) }\end{array}$ & $\begin{array}{c}\text { Stiffness } \\
\text { (lbs/in) }\end{array}$ & $\begin{array}{c}\text { Maximum Load } \\
\text { (lbs) }\end{array}$ \\
\hline Mean & 1,135 & 520 & 736 & 385 \\
$\begin{array}{c}\text { Sample Standard } \\
\text { Deviation }\end{array}$ & 106 & 84 & 79 & 61 \\
Coefficient of Variation & 0.09 & 0.16 & 0.11 & 0.16 \\
\hline
\end{tabular}




\section{Lateral Density Profile}

The 16"x16" corrugated panels were produced from flat mats that elongate to assume the shape of the corrugated dies. Hence, density variation across the corrugations may occur. Four corrugated panels were cut into 17 strips parallel to the corrugations to determine the lateral density profiles. All strips were cut into 1" horizontal projected widths except the first and the last strips which were 1/2” wide. Each strip was weighed and the volume was determined from the measured dimensions.

The lateral density profiles (under standard room conditions) for the four corrugated panels are shown in Figure 64. All four panels show a general trend of slight decrease of density at the sidewalls. However, the sidewall densities were not greatly lower than the upper deck and channel bottom densities. The densities at the middle portion of the panels (strip no. 4 to 14) were fairly uniform. There might be some biases in the mat caused by hand forming. This problem will not be a factor in commercial plants or OSB mills because a more uniform machine forming is used.

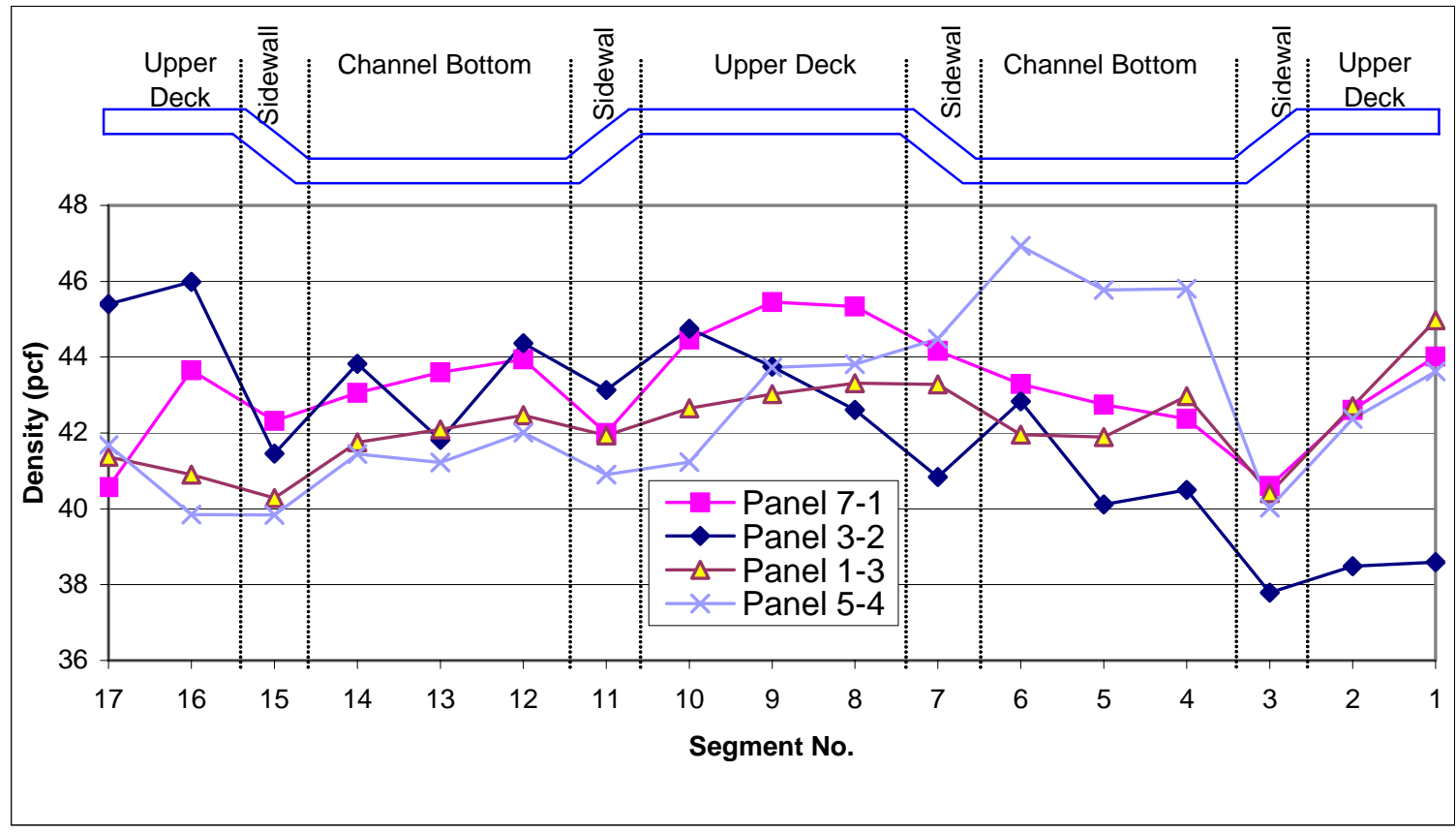

Figure 64: Lateral density profiles of corrugated panels. 


\section{Comparison of Corrugated Panel and APA Rated Sturd-I-Floor}

The bending stiffness and bending strength per foot width of corrugated panel in both the strong axis and weak axis are summarized in Table 28. The nominal bending stiffness in both directions was conservatively estimated from the calibrated beam model. The design bending stiffness and strength for APA Rated Sturd-I-Floor for 24”o.c., 32”o.c. and 48”o.c. span rating are shown in Table 29 for comparison to the bending performance of the corrugated panel. By comparing Table 28 to Table 29 , the bare $3 / 8$ " corrugated panel meets the bending performance of APA Rated Sturd-I-Floor at a 24”o.c. span rating. The overall corrugated decking system with suitable underlayment nailed and glued to the corrugated panel will have the potential to meet a 32”o.c. span rating.

Table 28: Bending stiffness and strength of corrugated panel estimated from small specimen testing.

\begin{tabular}{|c|c|c|c|c|}
\hline & \multicolumn{2}{|c|}{ Strong Axis } & \multicolumn{2}{|c|}{ Weak Axis } \\
\hline & Nominal & Nominal & Nominal & Nominal \\
\hline & Stiffness & Strength & Stiffness & Strength \\
\hline & $\underset{(\mathrm{lbs}-\mathrm{in} / \mathrm{ift})}{\mathrm{El}_{\mathrm{C}}}$ & $\begin{array}{c}\mathrm{F}_{\mathrm{b}} \mathrm{S}_{\mathrm{c}} \\
\text { (in-lbs/ft) }\end{array}$ & $\underset{\left(\mathrm{lbs}-\mathrm{in}_{\mathrm{C}}^{2} / \mathrm{ft}\right)}{\mathrm{El}}$ & $\begin{array}{c}\mathrm{F}_{\mathrm{b}} \mathrm{S}_{\mathrm{c}} \\
\text { (in-lbs/ft) }\end{array}$ \\
\hline Mean & 401,293 & 4,250 & 32,067 & 798 \\
\hline Std.Dev. & 15,733 & 291 & 4,055 & 113 \\
\hline cov & 0.04 & 0.07 & 0.13 & 0.14 \\
\hline +2(Std.Dev.) & 432,759 & 4,833 & 40,178 & 1,025 \\
\hline -2(Std.Dev.) & 369,826 & 3,668 & 23,956 & 571 \\
\hline $5^{\text {th }}$ Percentile & 385,955 & 3,903 & 27,144 & 645 \\
\hline
\end{tabular}

Table 29: Panel design bending stiffness and strength for APA Rated Sturd-I-Floor.

\begin{tabular}{ccccc}
\hline & \multicolumn{2}{c}{ Strong Axis } & \multicolumn{2}{c}{ Weak Axis } \\
\hline \multirow{2}{*}{ Span Rating } & Stiffness & Strength & Stiffness & Strength \\
& $\mathrm{El}_{\mathrm{c}}$ & $\mathrm{F}_{\mathrm{b}} \mathrm{S}_{\mathrm{c}}$ & $\mathrm{El}_{\mathrm{c}}$ & $\mathrm{F}_{\mathrm{b}} \mathrm{S}_{\mathrm{c}}$ \\
& $\left(\mathrm{lbs}-\mathrm{in}^{2} / \mathrm{ft}\right)$ & $(\mathrm{in}-\mathrm{lbs} / \mathrm{ft})$ & $\left(\mathrm{lbs}-\mathrm{in}^{2} / \mathrm{ft}\right)$ & $(\mathrm{in}-\mathrm{lbs} / \mathrm{ft})$ \\
24 oc & 300,000 & 640 & 26,000 & 215 \\
32 oc & 650,000 & 870 & 75,000 & 380 \\
48 oc & $1,150,000$ & 1600 & 160,000 & 680 \\
\hline
\end{tabular}




\section{Manufacture of $4 \mathrm{ft} \times \mathbf{8 f t}$ Corrugated Panels}

Shallow $4 \mathrm{ft} \times 8 \mathrm{ft}$ corrugated panels were manufactured following the typical process by which oriented strand board (OSB) or flakeboard is produced in large industrial plants. The manufacturing process involved flaking, drying, blending, forming, mat loading, pressing and finishing.

\section{Manufacturing Process}

Flaking - Wood flakes used to produce the 4'x8' shallow corrugated panel were purchased from GFP Strandwood Corporation. The flakes were stranded from aspen logs into an approximate length of 6”, a width of 2" and a thickness of 0.03 ”.

Drying - The moisture content (MC) of the flakes were reduced from green to about $2 \%$ to $3 \%$ by oven-dry weight in a conveyor dryer.

Blending - Moisture and resin were added to the flakes in $48 \mathrm{lb}$ batches due to the limitation of the blender. First, the flakes were equilibrated to 5\% MC by spraying atomized water in a drum blender for about 5 minutes. At 5\% MC, the flakes were further blended with 5\% Methylene diphenyl diisocyanate (MDI) by oven-dry weight for about 10 minutes. Wax or water repellent and additives, such as wood preservatives, were not added into the blend. 
Forming - Blended flakes were

fed into the hopper of a mat former. The flakes were moved through a conveyor belt and were allowed to fall randomly at one end of the former. A forming box with inner dimensions of 54”x102”, placed on top of the mat loader, was used to collect the flakes. A motorized carrier moved the forming box and the mat loader forward (Figure 65(a)) and backward (Figure 65(b)) to collect flakes in several passes. The number of passes required to form the final targeted mat weight were predetermined by adjusting the travel speed of the carrier and weighting the amount of flakes collected in one pass. The travel speed of the carrier was adjusted such that seven passes were needed to obtain the targeted weight for the mat.

Mat loading - A mat loader was built specifically for loading the mat into the hydraulic press. After the mat was formed, the forming box was removed from the top of the mat loader. Liquid potassium oleate at $10 \%$ concentration was sprayed on the surfaces of both the upper and the lower dies, before loading the mat into the press, to prevent bonding of wood to the aluminum dies. The dies were fabricated to have the same width 
as the carrier with an idea of designing the mat loader to be able to move from the carrier to the lower die easily. With the wheels of the mat loader riding on the edges of the carrier as guides, the mat loader was able to move to the top of the lower die by slowly pushing the end of the mat loader into the press (Figure 66(b)). Once the mat loader was place directly on top of the lower die, the belt end of the mat loader near the carrier was locked and the mat loader was retracted to the carrier to allow the mat to fall on the lower die (Figure 66(c)). This kind of mat loading method causes little to no distortion to the mat.

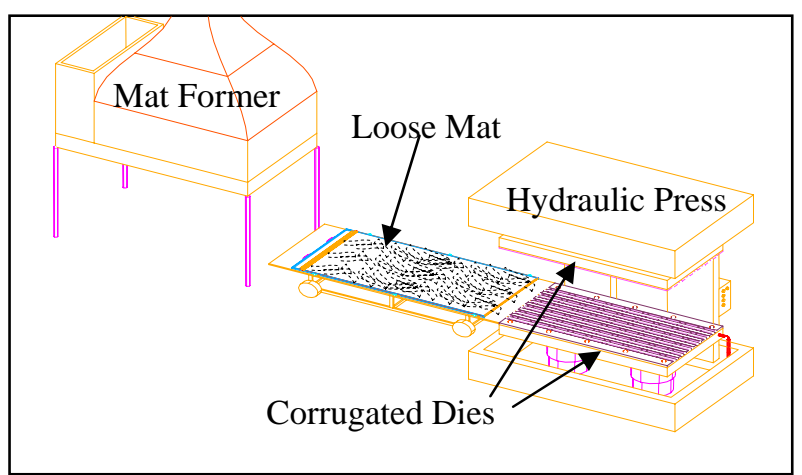

(a)

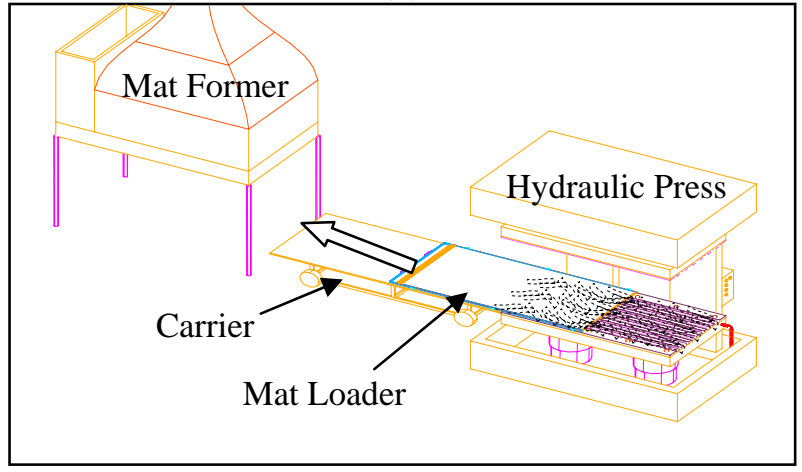

(c)

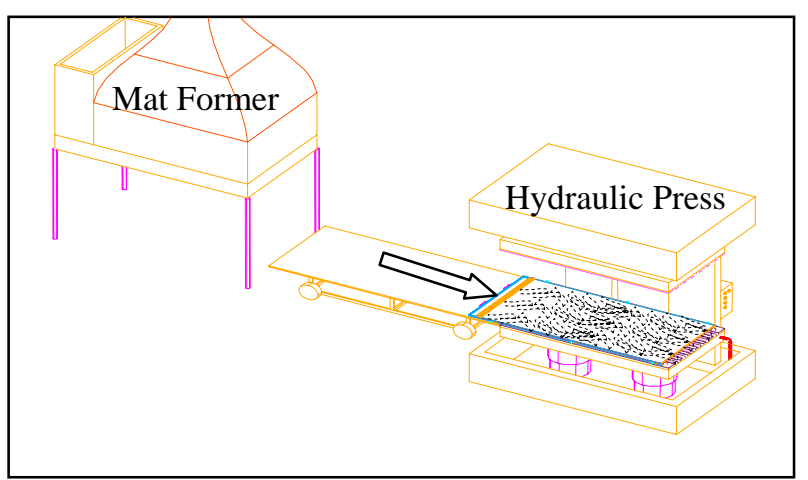

(b)

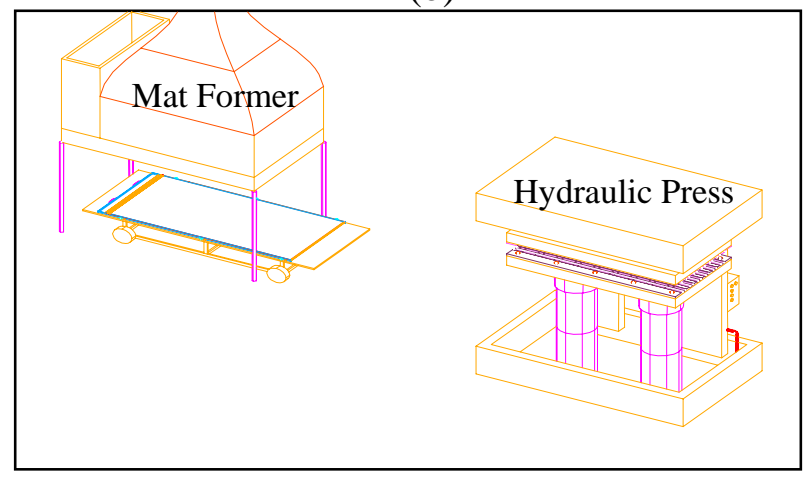

(d)

Figure 66: Mat loading process.

Pressing - The temperature of the press platens was maintained at $375{ }^{\circ} \mathrm{F}$. The opening of the press was closed at high speed once the mat was set into place on top of the lower die until the lower die hit the stops. Once there was zero day-light, the gauge 
pressure was maintained at $750 \mathrm{psi}$ for 3 mins. The pressure was then slowly reduced over a period of 30 seconds to avoid any damage to the panel due to the steam release.

Finishing - The corrugated panels were allowed to cool to room temperature before trimming. All panels were trimmed from initial dimensions of 54"x102” to final dimensions of 48"x96". 


\section{Full-Scale Panel Testing}

Bending properties of corrugated panels in the strength direction, where the corrugations are perpendicular to the span, were the main focus in this study. Flexure tests were performed on full size (4'x8') corrugated panels to determine the nominal panel bending stiffness. Selected corrugated panels were cut into smaller specimens (24”x24”, 24”x48”, 24”x32” and 24”x64”) and further load-to-failure tests were conducted to obtain both bending stiffness and bending strength. The bending properties of a composite deck system, with OSB nailed-glued to the corrugated panel, were also included in this study. Both the corrugated panels and the composite deck specimens were tested as simply supported single-spans and as two-span continuous spans with line load applied at the mid-span.

\section{Strength Axis Flexure Test of 4'x8' Corrugated Panels}

\section{Test Procedures}

Each corrugated panel was equilibrated to room conditions for three weeks before testing. Panel weight and thickness measurements were taken prior to each test. Thicknesses at each sidewall and flat deck were measured at both longitudinal ends of the panels. Density and weighted average thickness of each panel were calculated from the panel weight and thickness data.

A non-destructive flexure test was performed on each of the 53 corrugated panels produced. The test setup consisted of a simply supported span at 72 ” on-center and a single line load at mid-span (Figure 67). Two dial gauges were placed 4" from the 
longitudinal edges of the panel to measure the deflection of the bottom decks at midspan. A static weight of $80 \mathrm{lbs}$ was applied. The deflection readings at both left and right dial gauges were recorded immediately after load was applied at mid-span. The average deflection of the two measurements was then calculated.

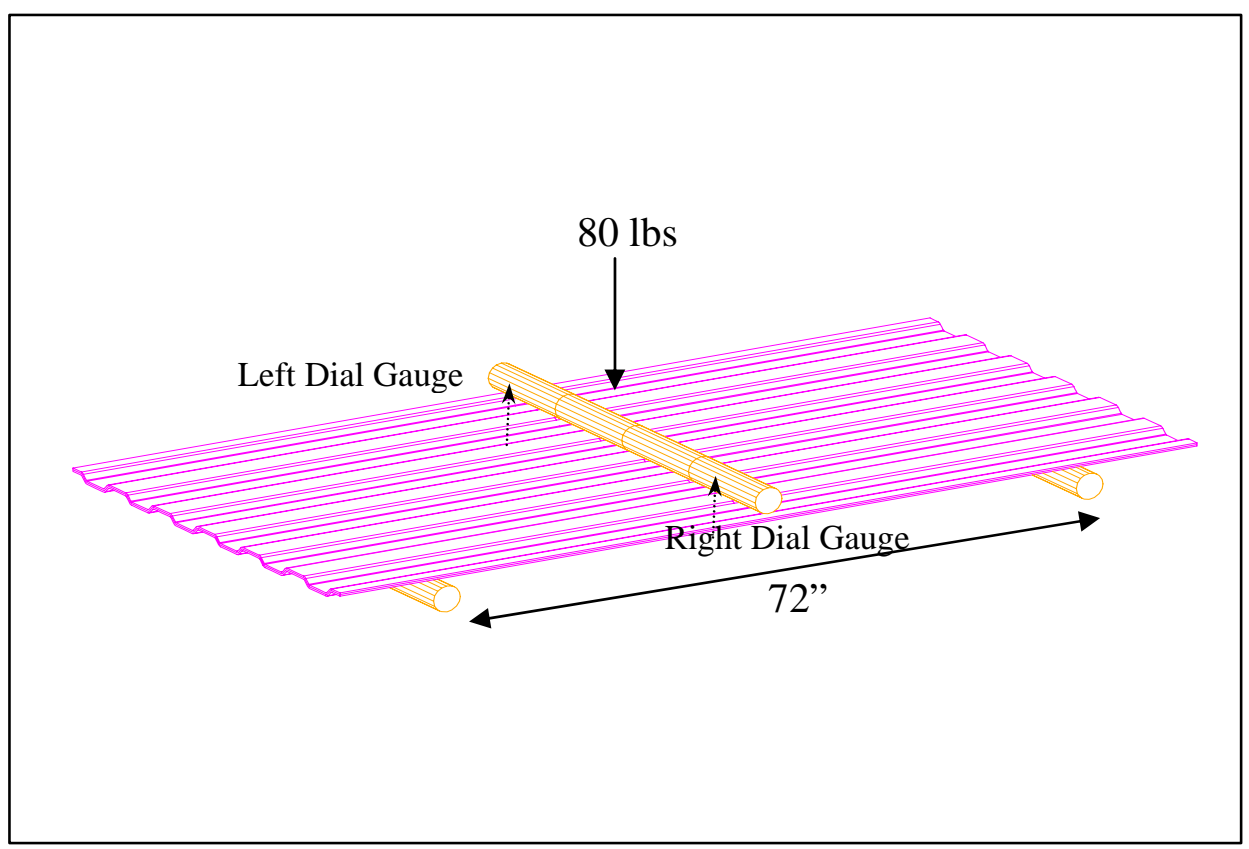

Figure 67: 4'x8' corrugated panel flexure test setup.

\section{Test Results}

The beam model and the plate model were used to analyze the test data. Bending stiffness was determined for each panel by using the load-to-deflection ratio and the weighted average thickness obtained from the test. The $\mathrm{E} / \mathrm{G}$ ratio of 6.5 , previously determined from 16"x16" panels, was used in these two models. The FFSS (simple support at two edges and free at the other two) plate model with uniform line load across the mid-span was used to calculate the plate bending stiffness in the strong axis direction. Uniform line load was approximated using a Fourier sine series with $n$ equal to 15 . The Rayleigh-Ritz method with 3-parameter algebraic function, $(N=3)$, was used to 
approximate the solution for deflection. Figure 67 shows load-to-deflection ratio versus thickness of all test specimens. Estimations using beam and plate models at three different modulus of elasticity (400ksi, 600ksi and 800ksi) are also plotted in Figure 67.

The difference between plate and calibrated beam model predictions was significant. The calibrated beam model was able to predict the stiffness respond better than the plate model because it was calibrated to the FE model. Furthermore, the plate

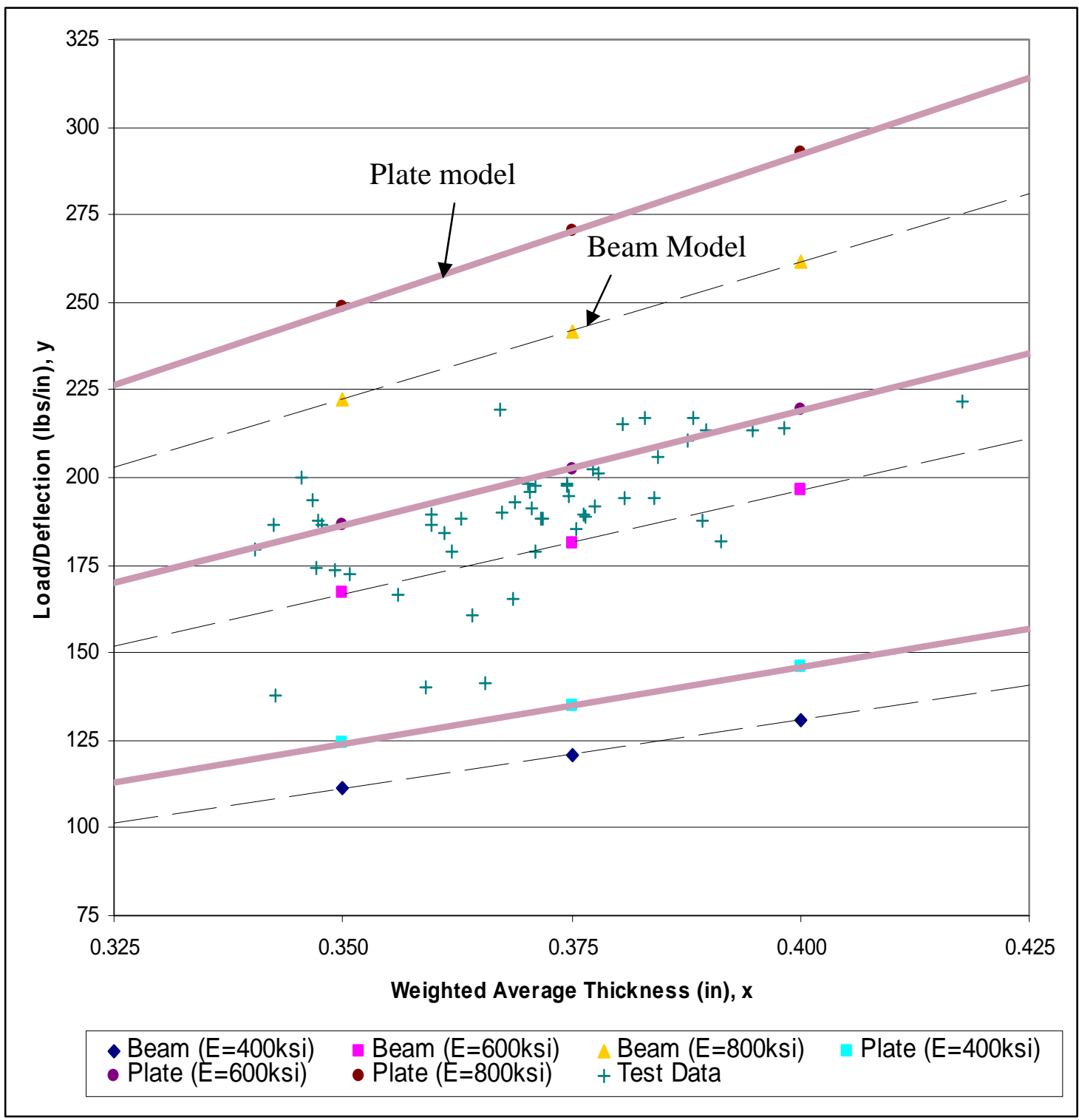

Figure 68: Load-to-deflection ratio versus thickness of beam model, plate model and test data of 4'x8' panels flexure test. 
model was constructed based on pure bending plate theory and through thickness shear deformation was ignored. The beam model was used to determine the strong axis bending stiffness of the 4'x8' corrugated panels. From the modified beam model the bending stiffness per unit width of the panel was obtained by using equation (66) and the previously determined $E / G$ ratio of 6.5 . The shear stiffness was then back calculated from equation (65) once the bending stiffness was known. Figure 69 shows the bending stiffness computed using the beam model and the corresponding panel density. Density was determined using the method previously discussed. Panel number 27, 28 and 49 were defective, with low density and low bending stiffness. These three panels were excluded from any further analysis.

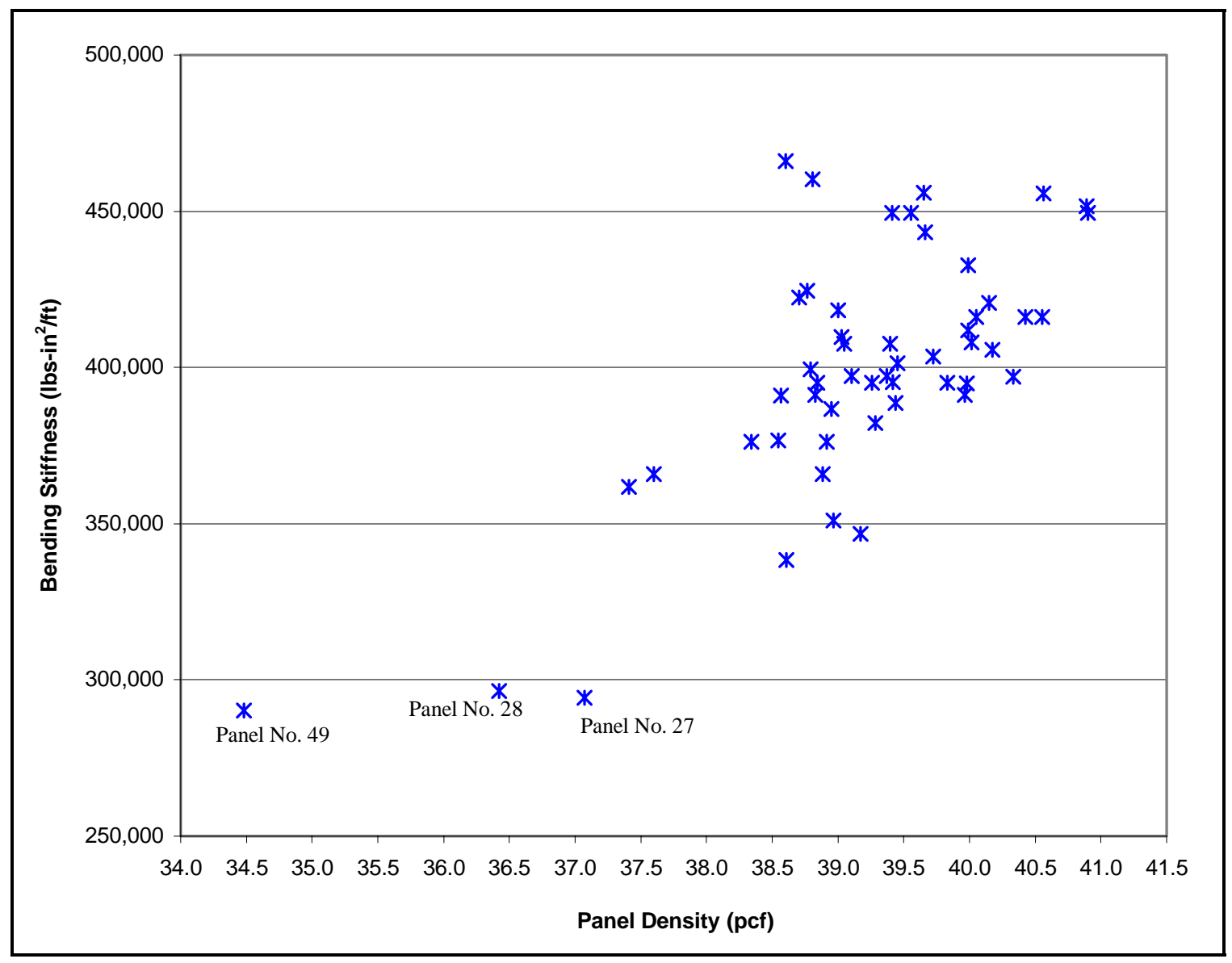

Figure 69: Bending stiffness versus panel density plot for 4'x8' corrugated panels. 
Table 30: Flexure test results of 4'x8' corrugated panel.

\begin{tabular}{ccccc}
\hline 51 Panels & $\begin{array}{c}\text { Weighted } \\
\text { Average } \\
\text { Thickness } \\
\text { (in) }\end{array}$ & $\begin{array}{c}\text { Panel } \\
\text { Density } \\
(\mathrm{pcf})\end{array}$ & $\begin{array}{c}\text { Bending } \\
\text { Stiffness } \\
\mathrm{EI}_{\mathrm{c}} \\
\left(\mathrm{lb}-\mathrm{in}^{2} / \mathrm{ft}\right)\end{array}$ & $\begin{array}{c}\text { Shear } \\
\text { Stiffness } \\
\mathrm{GA}_{\mathrm{s}} \\
(\mathrm{lbs} / \mathrm{ft})\end{array}$ \\
\hline Mean & 0.370 & 39.17 & 398,862 & 210,837 \\
Std.Dev. & 0.016 & 1.11 & 39,510 & 24,127 \\
\hline COV & 0.04 & 0.03 & 0.10 & 0.11 \\
\hline+2 (Std.Dev.) & 0.402 & 41.40 & 477,882 & 259,091 \\
\hline -2(Std.Dev.) & 0.337 & 36.94 & 319,842 & 162,584 \\
\hline $5^{\text {th }}$ Percentile & 0.344 & 37.26 & 319,505 & 167,290 \\
\hline
\end{tabular}

A summary of the flexure test results is presented in Table 30. The average panel density and thickness were slightly lower, 39.17 pcf and 0.370”, than the targeted values of 40 pcf and 0.375 in, respectively. The average bending stiffness in the strength axis was about $400,000 \mathrm{lbs}-\mathrm{in}^{2} / \mathrm{ft}$. The $5^{\text {th }}$ percentile of the test data was about $320,00 \mathrm{lbs}-\mathrm{in}^{2} / \mathrm{ft}$ which meets and exceeds the strength axis bending stiffness requirement of 300,000 lb$\mathrm{in}^{2} / \mathrm{ft}$ for APA Rated Sturd-I-Floor with 24” o.c. span rating. Typical thickness of 24” o.c. APA Rated Sturd-I-Floor panel is either $23 / 32$ " or $3 / 4$ ”, which is about double the thickness of $3 / 8$ " corrugated panels.

\section{Strength Axis Static Bending of 2' Wide Corrugated Panel}

Full size panels were further cut into 24”x24” and 24”x32” for single span strong axis static bending tests. Test specimens were cut according to the board diagram shows in Appendix I. The specimens were not placed in a conditioning room with controlled temperature and humidity. Instead, the test specimens were exposed to room conditions for a week prior to testing. Panel weight and panel skin thickness at various locations were recorded before each test was carried out. Density and weighted average thickness of each panel were calculated using the method described in the previous section. 
At the time the strong axis static bending testing was conducted, there was no known test standard written for corrugated wood composite panels used as structural decking. However, American Society of Testing Material (ASTM) test standard D1037 was used as a guideline in setting up the test assembly for the 2' wide strong axis static bending test.

\section{Corrugated Panel Single Span Test}

The use of single spans in floor layout should be avoided because it produces more severe deflection than two-span or three-span conditions, under the same applied load per span. There were two main reasons for testing bare corrugated panels with single span setup. First, the single span test was used to determine the bending stiffness and bending strength of the corrugated panel. Second, this test was used to simulate the worst loading condition during the construction phase, even though single span installation is not recommended.

\section{Test Procedures}

The test assembly shown in Figure 70 was used in the single span strong axis static bending test. To avoid crushing of the specimen, ASTM D1307 was used as guideline to determine the radius needed for supports and loading block. Based on ASTM D1307, the radius of the supports and the loading block should at least $1 \frac{1}{2}$ times the thickness of the panel. The supports and loading block were made from three 11/2" diameter, 0.181 ” thick steel tubes welded to $1 / 4$ ” thick steel plates. Single span tests were carried out on two types of specimens, 24” and 32” long panels. The supports were place at $3 / 4$ ” from the end of the panel resulting in span length of $22 \frac{1}{2}$ ” and $30 \frac{1}{2}$ ” from center to 


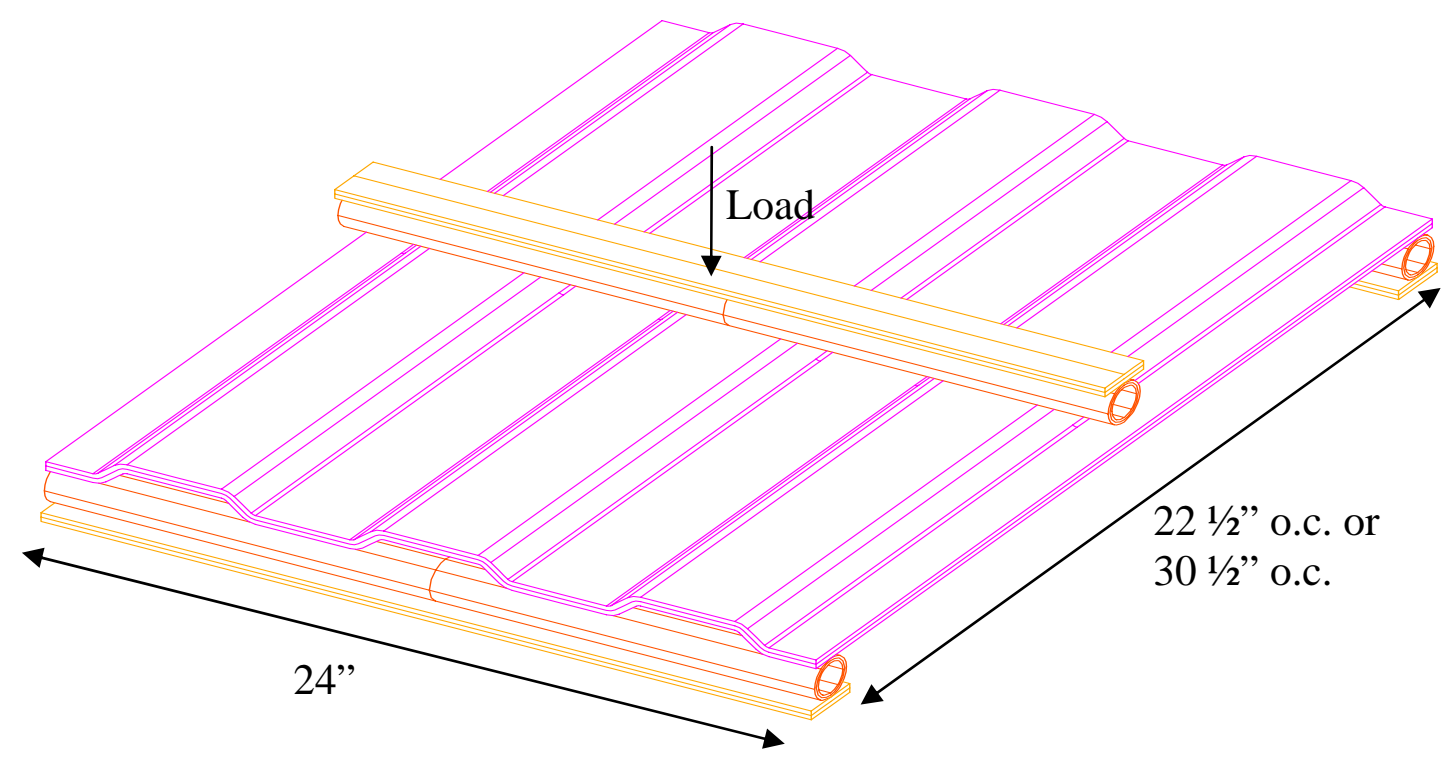

Figure 70: Bare panel single-span bending test assembly.

center of the supports for 24”x24” and 24”x32” specimens, respectively. Load was applied at mid-span through the loading block with loading rate of $0.06 \mathrm{in} / \mathrm{min}$ and 0.08 in/min for the nominal 24" and 32” spans, respectively. Six specimens each were tested on 221/2” and 301/2” specimens to simulate nominal 24” and 32” span conditions.

Deflection was measured directly underneath the load point using a Sensotec linear voltage displacement transducer (LVDT). Load was applied indirectly through the displacement of the crosshead of a Tinius Olsen testing machine at $0.06 \mathrm{in} / \mathrm{min}$ and 0.08 in/min for the nominal 24” and 32” tests, respectively. Displacement and load readings were recorded using an Optim data acquisition system at a rate of 2 readings per second.

\section{Test Results}

Finite element models were generated to simulate the nominal 24” and 32” spans bending test. The mesh was generated with 0.25 ” 0.25 ” thin shell elements. The simple 
support conditions were modeled using gap elements. $1000 \mathrm{lbs}$ of load was applied to each FE model. Nine FE models (Figure 71) were used for each span test to determine the bending stiffness. The test data and FE model results are shown in Figure 72(a) and Figure 72(b) for 24” and 32” span tests, respectively. Bending stiffness for each specimen was interpolated from the three fitted curves for each test. The calibrated beam model was also used to determine the bending stiffness and bending strength of the test specimens. The predictions of the calibrated beam model are shown in Figure 72 . Bending stiffness and strength using the beam model were calculated using equations (65) and (66), respectively.

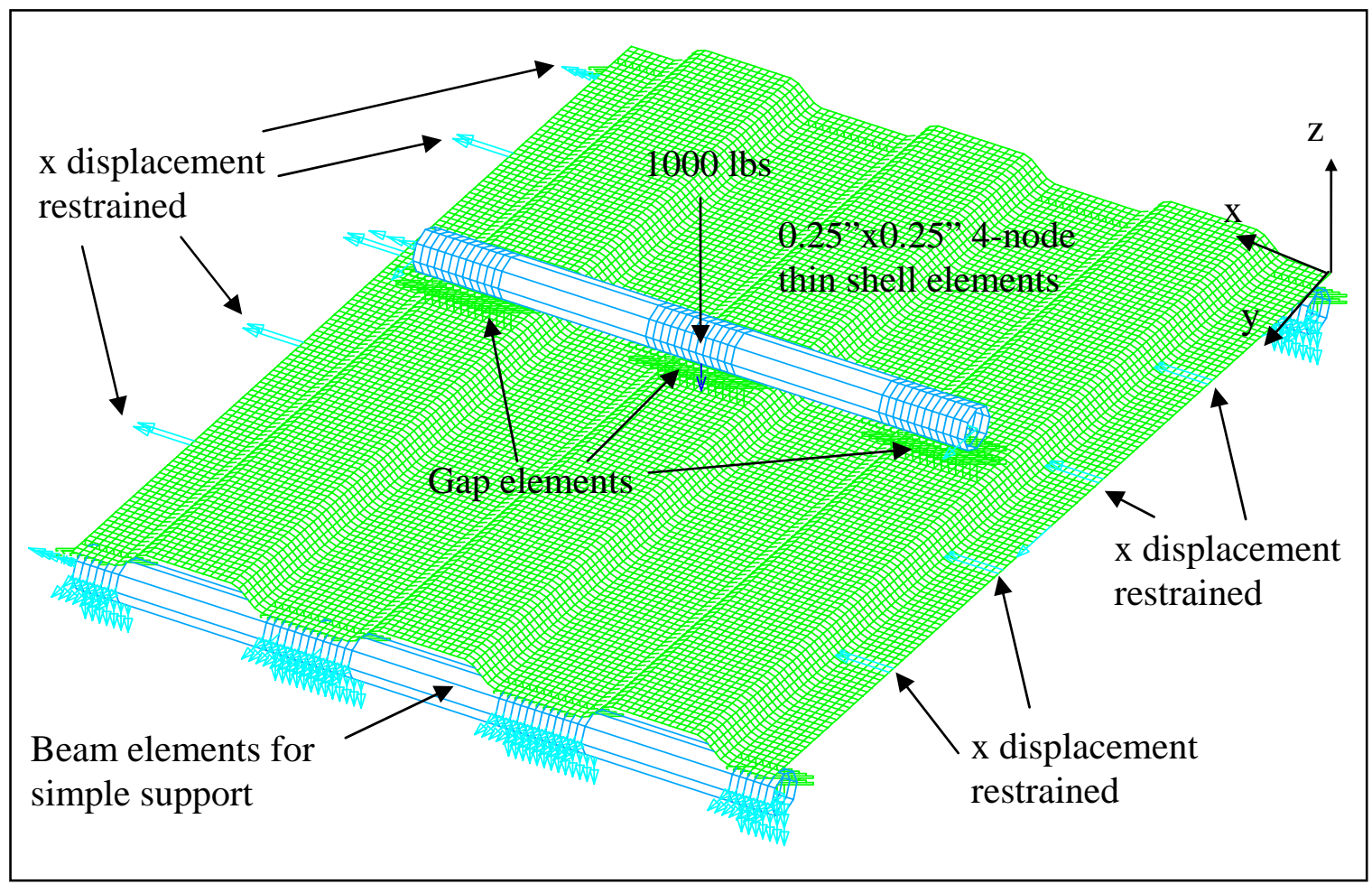

Figure 71: Typical finite element model for 2' wide single-span bending test.

The results of the bare panel single-span test are listed in Table 31. The bending stiffness estimated from both models closely agreed. The $5^{\text {th }}$ percentile values of the 
bending stiffness were both over $400,000 \mathrm{lb}-\mathrm{in}^{2} / \mathrm{ft}$. Both mean and $5^{\text {th }}$ percentile bending stiffnesses were about the same as the results obtained from 16"x16” panels (refer to Table 28).

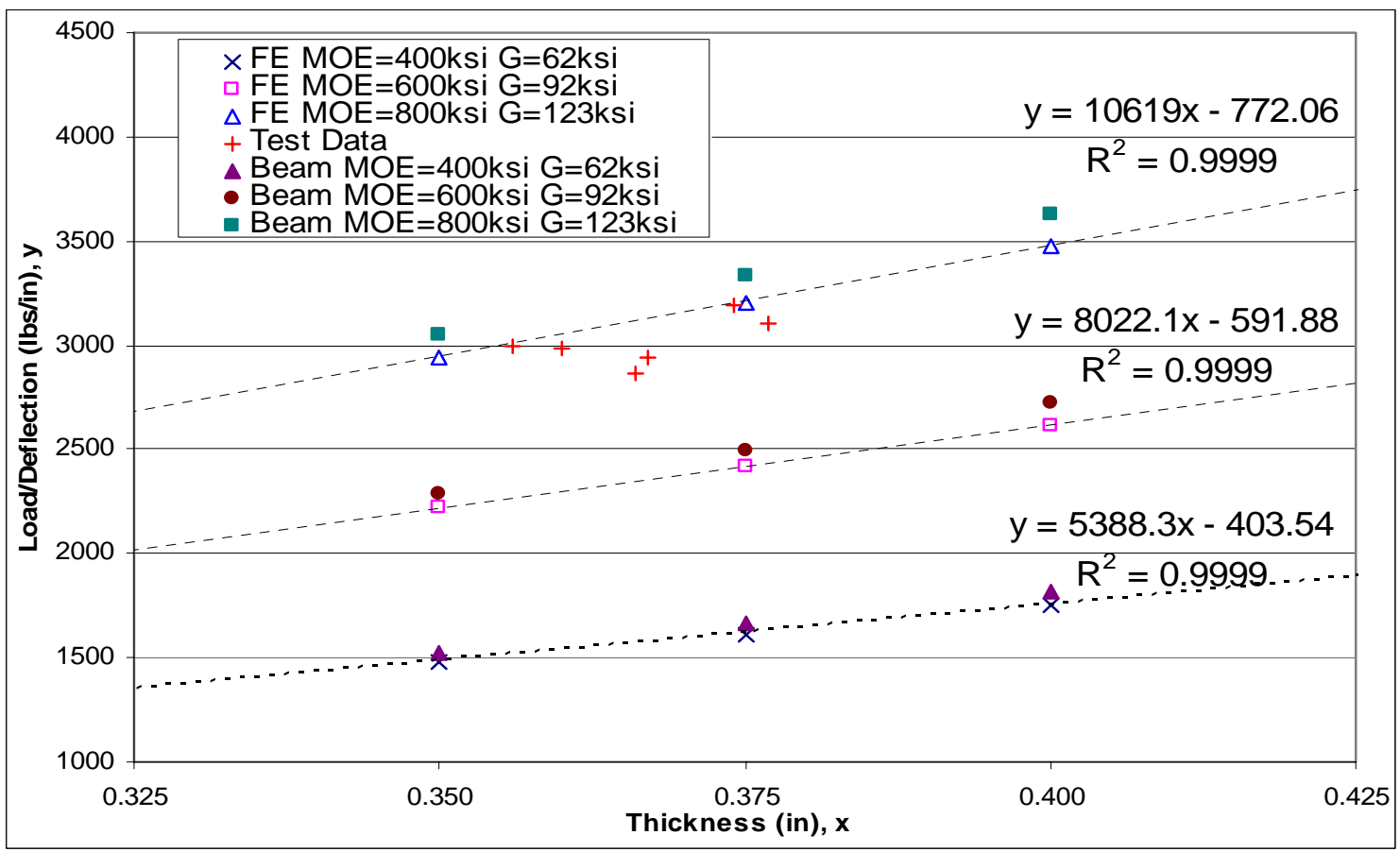

(a)

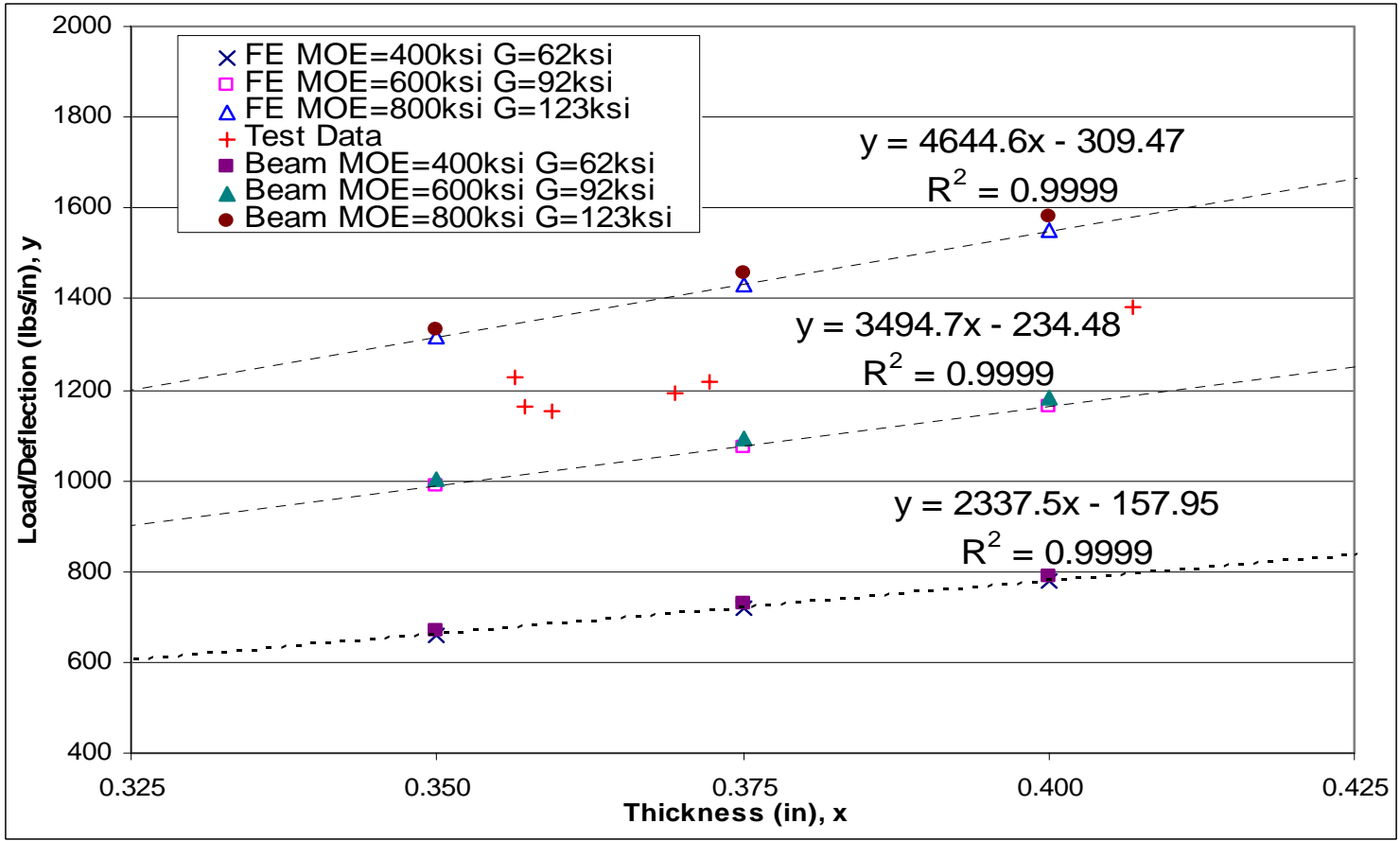

(b)

Figure 72: Test results of bare corrugated panel single-span test for nominal (a) 24" and (b) 32" nominal spans. 
Table 31: Bare corrugated panel single span bending test results.

\begin{tabular}{|c|c|c|c|c|c|c|}
\hline & & & FE Model & & Beam Model & \\
\hline 6 Panels & $\begin{array}{l}\text { Weighted } \\
\text { Average } \\
\text { Thickness } \\
\text { (in) }\end{array}$ & $\begin{array}{l}\text { Panel } \\
\text { Density } \\
\text { (pcf) }\end{array}$ & $\begin{array}{l}\text { Bending } \\
\text { Stiffness } \\
\mathrm{EI}_{\mathrm{c}} \\
\left(\mathrm{lb}-\mathrm{in}^{2} / \mathrm{ft}\right)\end{array}$ & $\begin{array}{l}\text { Bending } \\
\text { Stiffness } \\
\mathrm{EI}_{\mathrm{c}} \\
\left(\mathrm{lb}-\mathrm{in}^{2} / \mathrm{ft}\right)\end{array}$ & $\begin{array}{c}\text { Shear } \\
\text { Stiffness } \\
\text { GA }_{\mathrm{s}} \\
\text { (lbs/ft) }\end{array}$ & $\begin{array}{c}\text { Bending } \\
\text { Strength } \\
\mathrm{F}_{\mathrm{b}} \mathrm{S}_{\mathrm{c}} \\
\text { (in-lbs/ft) }\end{array}$ \\
\hline \multicolumn{3}{|c|}{ 24" Nominal Span (Actual 22 1/2") } & & & & \\
\hline Mean & 0.367 & 40.10 & 477,398 & 460,599 & 242,014 & 4,341 \\
\hline Std. & 0.008 & 1.57 & 18,762 & 17,679 & 11,157 & 508 \\
\hline COV & 0.02 & 0.04 & 0.04 & 0.04 & 0.05 & 0.12 \\
\hline +2(Std.Dev.) & 0.383 & 43.24 & 514,922 & 495,957 & 264,328 & 5,356 \\
\hline$-2($ Std.Dev.) & 0.351 & 36.97 & 439,874 & 425,242 & 219,700 & 3,325 \\
\hline 5th Percentile & 0.357 & 38.62 & 456,616 & 440,825 & 231,428 & 3,755 \\
\hline \multicolumn{3}{|c|}{ 32" Nominal Span (Actual 30 1/2") } & & & & \\
\hline Mean & 0.370 & 38.78 & 461,065 & 427,234 & 225,933 & 3,561 \\
\hline Std. & 0.019 & 1.24 & 31,710 & 28,104 & 21,335 & 362 \\
\hline cov & 0.05 & 0.03 & 0.07 & 0.07 & 0.09 & 0.10 \\
\hline+2 (Std.Dev.) & 0.409 & 41.26 & 524,484 & 483,441 & 268,603 & 4,285 \\
\hline -2(Std.Dev.) & 0.332 & 36.31 & 397,645 & 371,026 & 183,263 & 2,837 \\
\hline 5th Percentile & 0.357 & 37.46 & 435,606 & 404,344 & 209,902 & 3,169 \\
\hline
\end{tabular}




\section{Corrugated Panel Two-Span Continuous Test}

Continuous spans are more commonly seen in the panel layout of a floor system. Two-span continuous bending tests were performed to simulate nominal 24” and 32” conditions. Six specimens were tested for each span

\section{Test Procedures}

Two-span continuous tests were performed on two types of specimens, 24”x48” and 24”x64” panels. Test assembly was similar to single span test, as shown in Figure 73. One steel tube support was placed at the middle of the panel and two supports were placed at $1 \frac{1 / 2}{2}$ from the end of the panel. The actual spans of the test specimens were 22

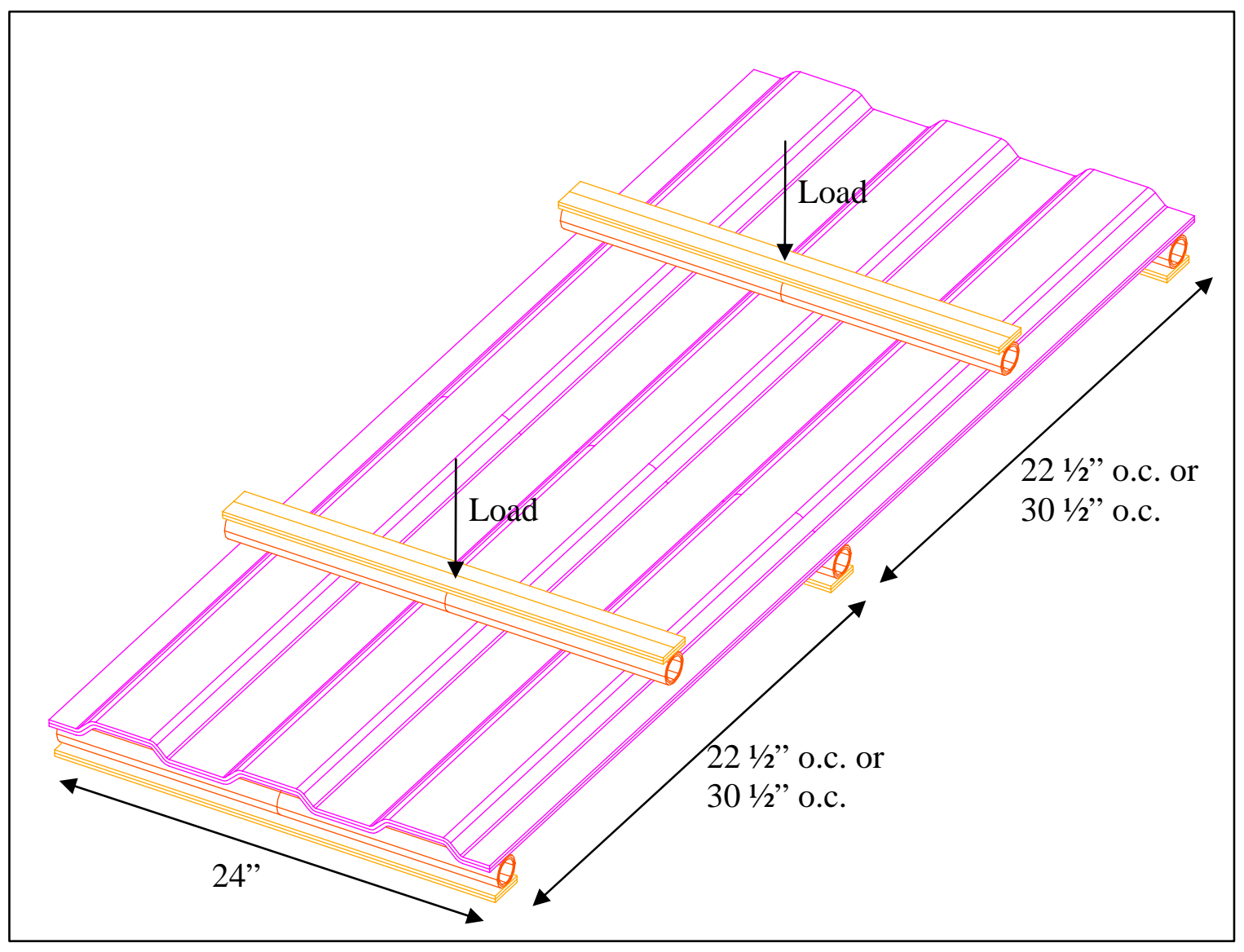

Figure 73: Test assembly for two-span continuous strong axis static bending test. 
$1 / 2$ ” and 30 1/2" on-center for 48 ” and 64" long specimens, respectively. Line load was applied at the middle of each span with loading rate of $0.06 \mathrm{in} / \mathrm{min}$ and $0.08 \mathrm{in} / \mathrm{min}$ for the nominal 24" and 32" spans, respectively. Deflection was measured directly underneath the load, at the center of the panel.

\section{Test Results}

The FE and calibrated beam models were used to determine the bending stiffness of the tested specimens. The FE model was generated with 0.25 ” 0.25 ” elements. A typical two-span FE model is shown in Figure 74. A E/G of 6.5 and Poisson's ratio of 0.3 were used in the model. Similar to the single-span model, MOE and thickness were varied. The results for nominal 24" and 32" span FE model are shown in Figure 75. Bending stiffness of the test specimens were interpolated from the three fitted curves of the FE model. The bending stiffness predicted by the beam model was slightly lower than

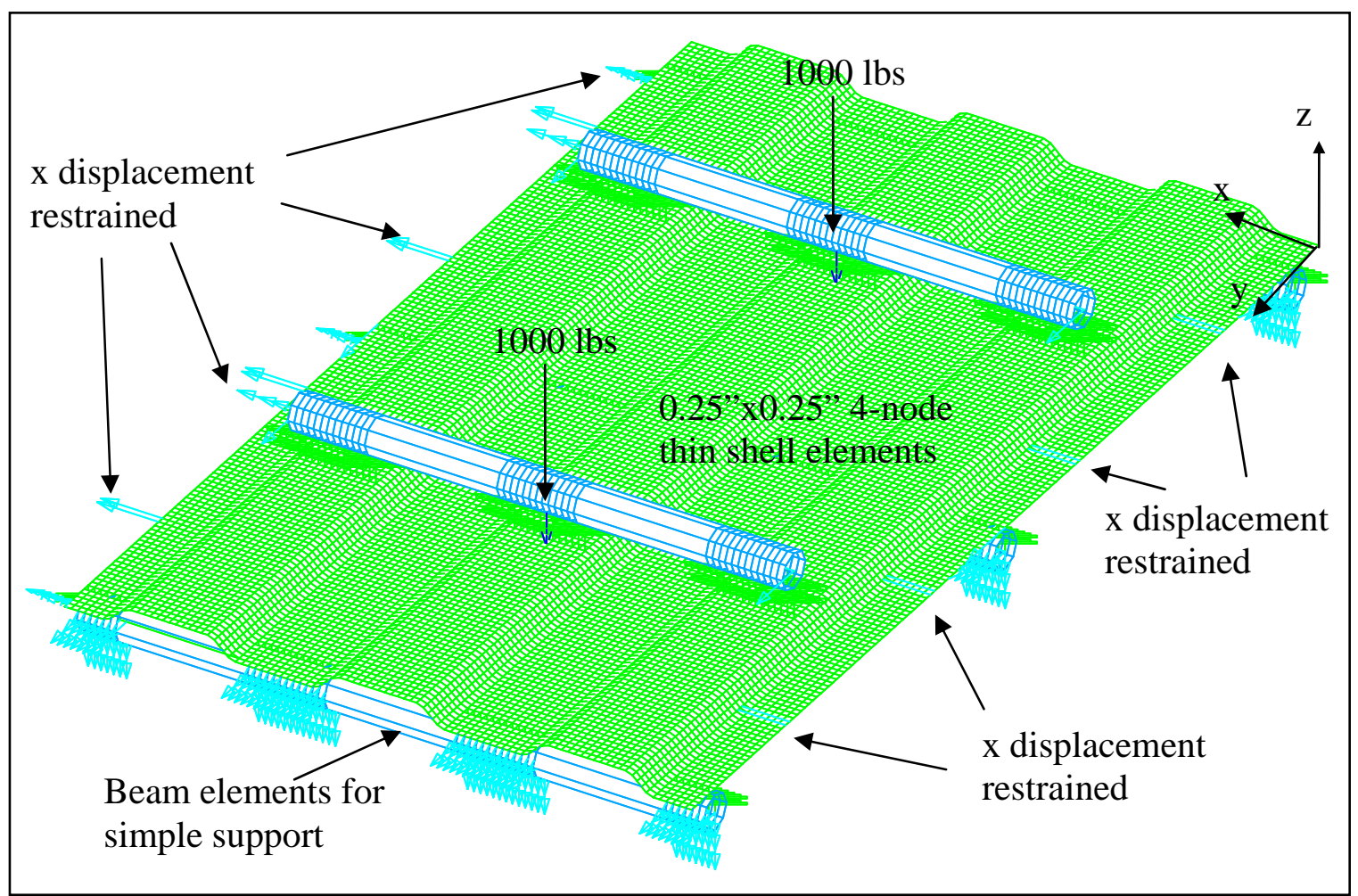

Figure 74: Typical finite element model for 2' wide two-span continuous bending test. 
the FE model estimation. The average of $5^{\text {th }}$ percentile values for 24 ” and 32 ” spans of both models were about $400,000 \mathrm{lb}-\mathrm{in}^{2} / \mathrm{ft}$. The $5^{\text {th }}$ percentile bending strength was around 3,000 in-lbs/ft.

Table 32: Bare corrugated panel two-span continuous bending test results.

\begin{tabular}{|c|c|c|c|c|c|c|}
\hline \multirow[b]{2}{*}{6 Panels } & \multirow[b]{2}{*}{$\begin{array}{l}\text { Weighted } \\
\text { Average } \\
\text { Thickness } \\
\text { (in) }\end{array}$} & \multirow[b]{2}{*}{$\begin{array}{l}\text { Panel } \\
\text { Density } \\
\text { (pcf) }\end{array}$} & \multicolumn{2}{|l|}{ FE Model } & \multicolumn{2}{|c|}{ 3eam Model } \\
\hline & & & $\begin{array}{l}\text { Bending } \\
\text { Stiffness } \\
\mathrm{EI}_{\mathrm{c}} \\
\left(\mathrm{lb}-\mathrm{in}^{2} / \mathrm{ft} \text { ) }\right.\end{array}$ & $\begin{array}{c}\text { Bending } \\
\text { Stiffness } \\
\mathrm{EI}_{\mathrm{c}} \\
\left(\mathrm{lb}-\mathrm{in}^{2} / \mathrm{ft} \text { ) }\right.\end{array}$ & $\begin{array}{c}\text { Shear } \\
\text { Stiffness } \\
\mathrm{GA}_{\mathrm{s}} \\
\left(\mathrm{lb}-\mathrm{in}^{2} / \mathrm{ft}\right)\end{array}$ & $\begin{array}{c}\text { Bending } \\
\text { Strength } \\
\mathrm{F}_{\mathrm{b}} \mathrm{S}_{\mathrm{c}} \\
\text { (in-lbs/ft) }\end{array}$ \\
\hline \multicolumn{3}{|c|}{ 24" Nominal Span (Actual 22 1/2") } & \multirow[b]{2}{*}{467,297} & \multirow[b]{2}{*}{417,060} & \multirow[b]{2}{*}{220,134} & \multirow[b]{2}{*}{3,658} \\
\hline Mean & 0.370 & 39.97 & & & & \\
\hline Std. & 0.008 & 1.49 & 32,733 & 30,944 & 17,922 & 367 \\
\hline COV & 0.02 & 0.04 & 0.07 & 0.07 & 0.08 & 0.10 \\
\hline +2(Std.Dev.) & 0.386 & 42.95 & 532,762 & 478,948 & 255,978 & 4,392 \\
\hline$-2($ Std.Dev.) & 0.354 & 37.00 & 401,832 & 355,172 & 184,289 & 2,925 \\
\hline 5th Percentile & 0.361 & 38.37 & 426,906 & 380,443 & 199,366 & 3,152 \\
\hline \multicolumn{3}{|c|}{ 32" Nominal Span (Actual 30 1/2") } & \multirow[b]{2}{*}{459,703} & \multirow[b]{2}{*}{428,108} & \multirow[b]{2}{*}{227,418} & \multirow[b]{2}{*}{3,266} \\
\hline Mean & 0.373 & 38.70 & & & & \\
\hline Std. & 0.019 & 0.90 & 32,773 & 38,065 & 26,792 & 296 \\
\hline COV & 0.05 & 0.02 & 0.07 & 0.09 & 0.12 & 0.09 \\
\hline$+2($ Std.Dev.) & 0.412 & 40.51 & 525,249 & 504,238 & 281,002 & 3,858 \\
\hline$-2($ Std.Dev.) & 0.334 & 36.89 & 394,157 & 351,979 & 173,834 & 2,675 \\
\hline 5th Percentile & 0.360 & 37.67 & 423,684 & 390,934 & 206,319 & 2,958 \\
\hline
\end{tabular}




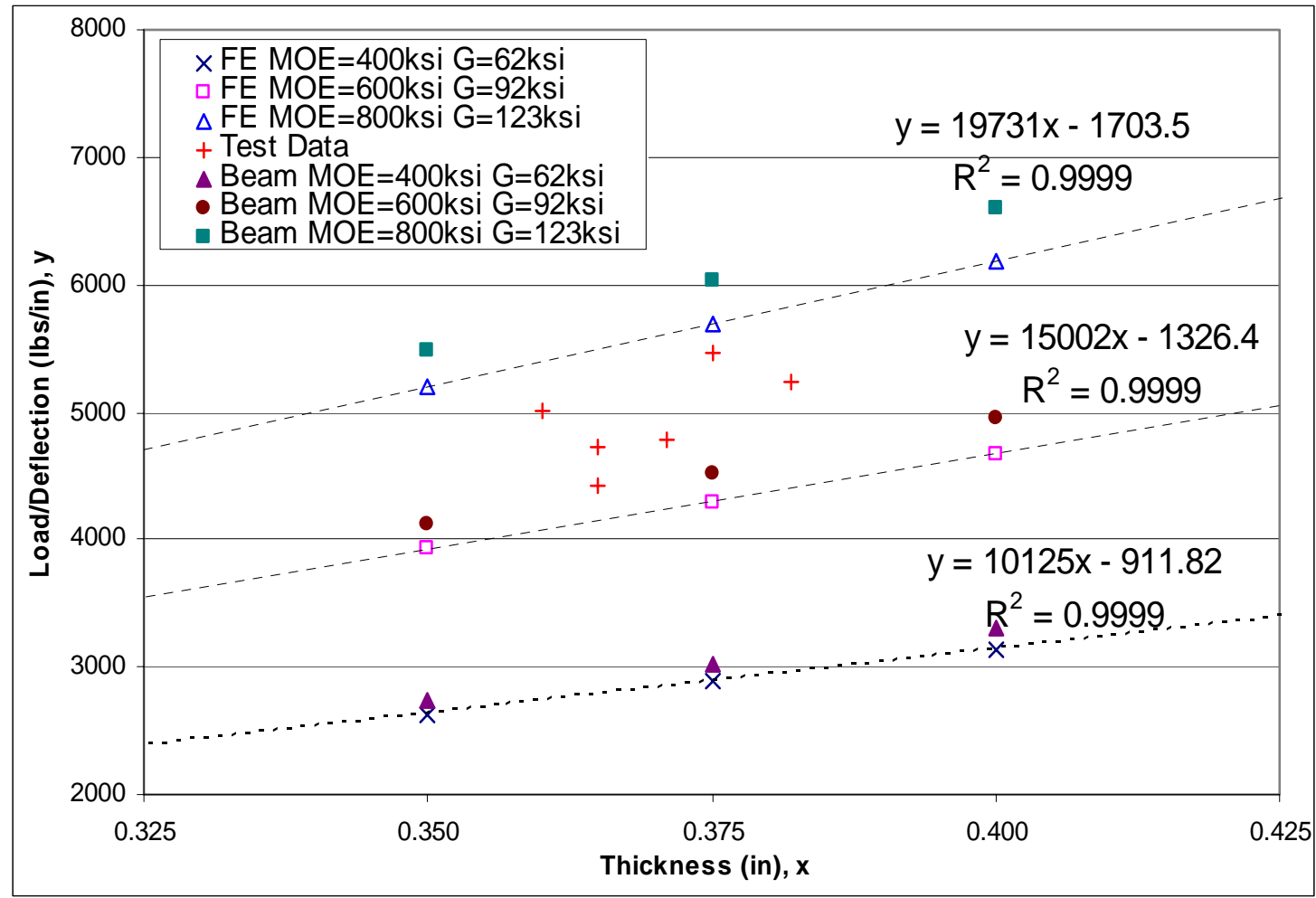

(a)

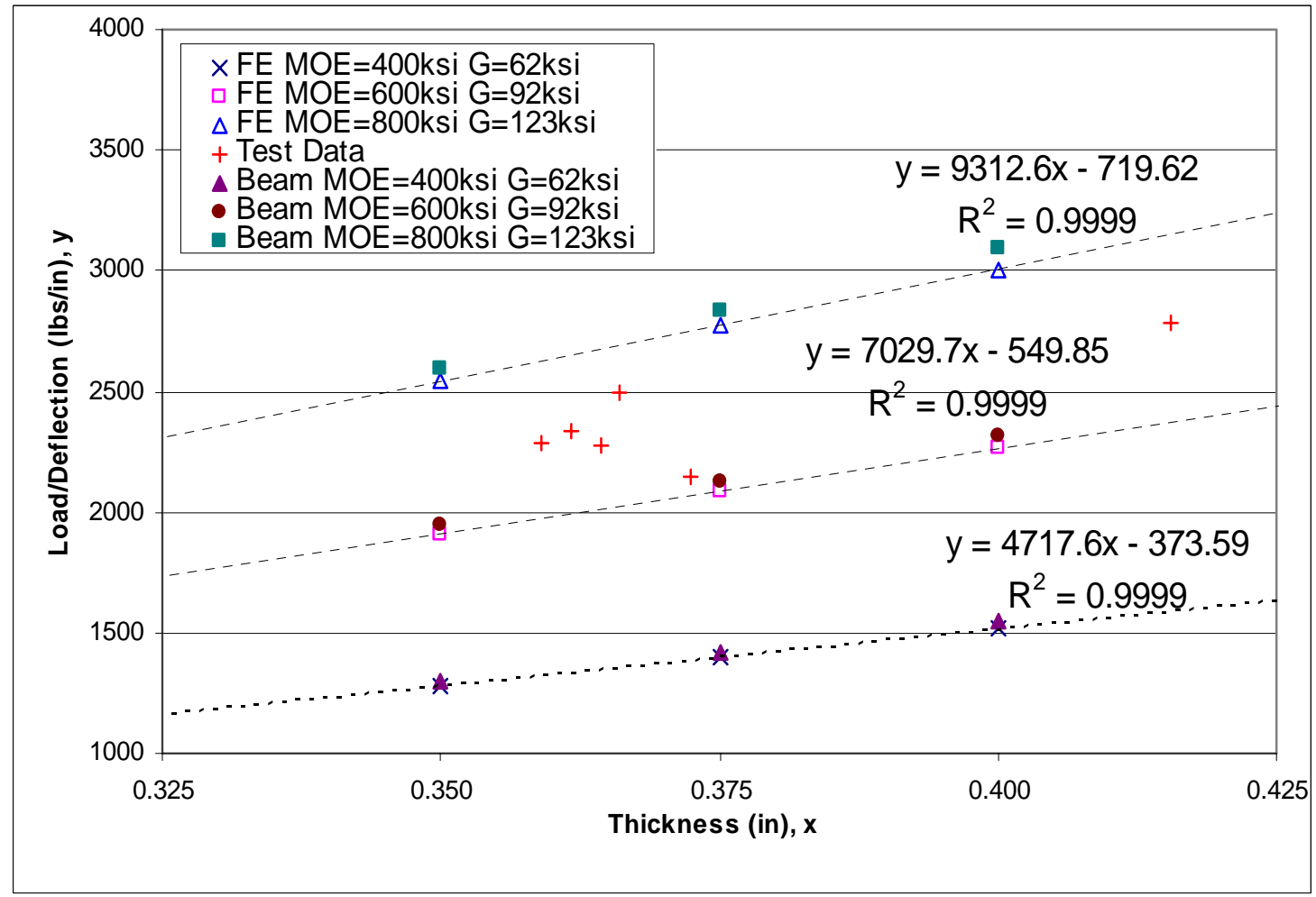

(b)

Figure 75: Test results of bare corrugated panel double-span test for nominal (a) 24" and (b) 32" nominal spans. 


\section{Strength Axis Static Bending of 2' Wide Partial Composite Deck}

\section{Single Span Partial Composite Deck Test}

Single span bending tests were performed on the composite deck system to determine the bending stiffness and bending strength of the full system. The composite deck single span test also represents the worst case scenario during service conditions because it produces more severe deflection than a multiple span layout under the same load.

\section{Specifications of Single-Span Composite Deck Test Specimens}

Six single-span composite deck test specimens were prepared for 24” and for 32” span bending tests. Test specimens were 24"x24” and 24"x32” for 24" and 32” spans,

respectively. ${ }^{15} / 32$ " thick oriented strandboard (OSB), that meets APA rated 32/16 sheathing specifications, was used as underlayment. Composite deck test specimens were prepared using a nailed-glued system. APA AFG-01 subfloor adhesive and 3d ringshank nails were used to attach the OSB underlayment to the corrugated panels.

To provide better bonding surfaces, top decks of the corrugated panels were lightly touch sanded to remove the release agent (Potassium Oleate) used during production of the panels. A continuous 1/4" bead adhesive was then applied at each top deck of the corrugated panel (Figure 76). Immediately after the adhesive was applied, OSB underlayment was set down on top of the corrugated panel with strength axis, surface flake orientation, aligned in the direction of the channels. Finally, a single line of nails spaced at about 6" on-center were placed along each top deck. Composite deck test 
specimens were left at room conditions for at least two days to allow the nailed-glued bond to develop its strength (Figure 77).

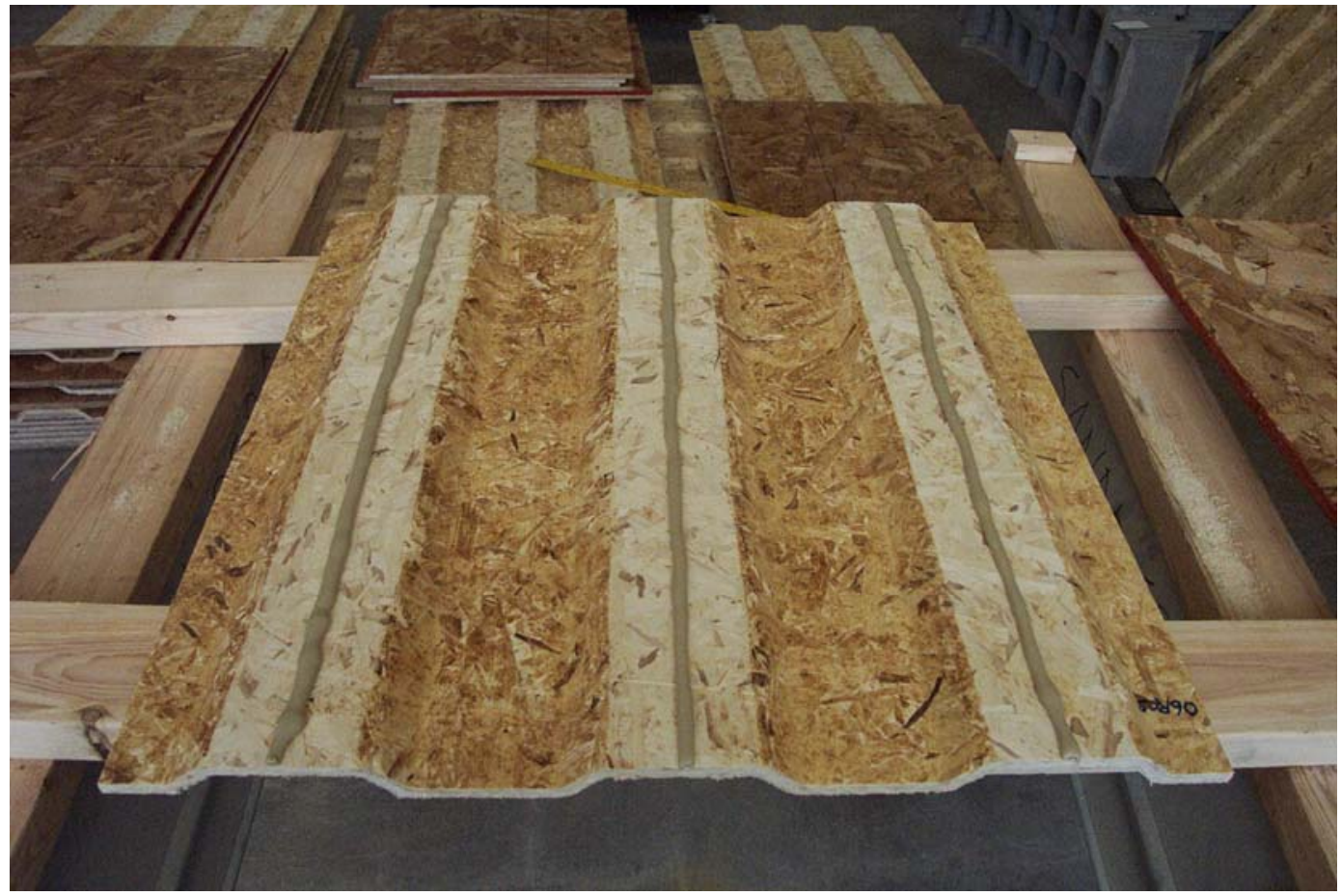

Figure 76: ${ }^{1} / 4 "$ bead adhesive on corrugated panel.

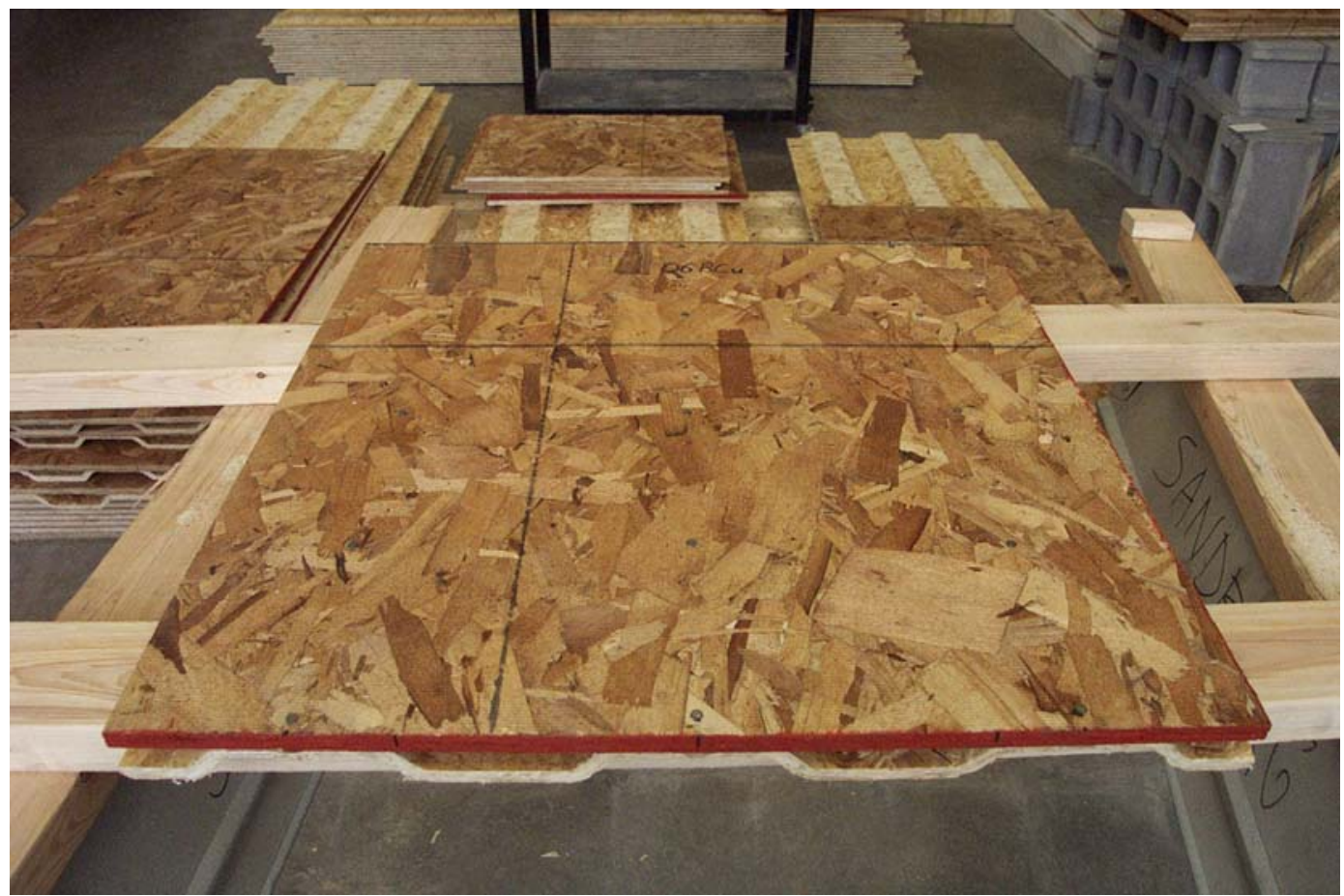

Figure 77: Single-span composite deck test specimen. 


\section{Test Procedures}

Non-destructive flexure tests were performed on the corrugated panel and OSB pieces, individually, prior to attaching them together. Corrugated panels were stressed to about $1 / 3$ of their maximum load carrying capacity as determined from single-span bending tests. The maximum bending strength of OSB was obtained from APA published design values [APA, 2004]. Ramp loads were applied on corrugated panels to maximum values of $500 \mathrm{lbs}$ and $300 \mathrm{lbs}$ at 22 1/2” and 30 1/2” on-center, respectively. As for the OSB, maximum ramp loads of $200 \mathrm{lbs}$ and $150 \mathrm{lbs}$ were used.

The corrugated panel and OSB underlayment were attached together using the procedures described in the previous section to form a composite deck system. Composite deck specimens were tested using a similar test assembly as for the bare panel single-span bending test. Figure 78 shows the test assembly used for composite deck single-span bending test. Loading rates were adjusted for both spans $(0.05 \mathrm{in} / \mathrm{min}$ for the

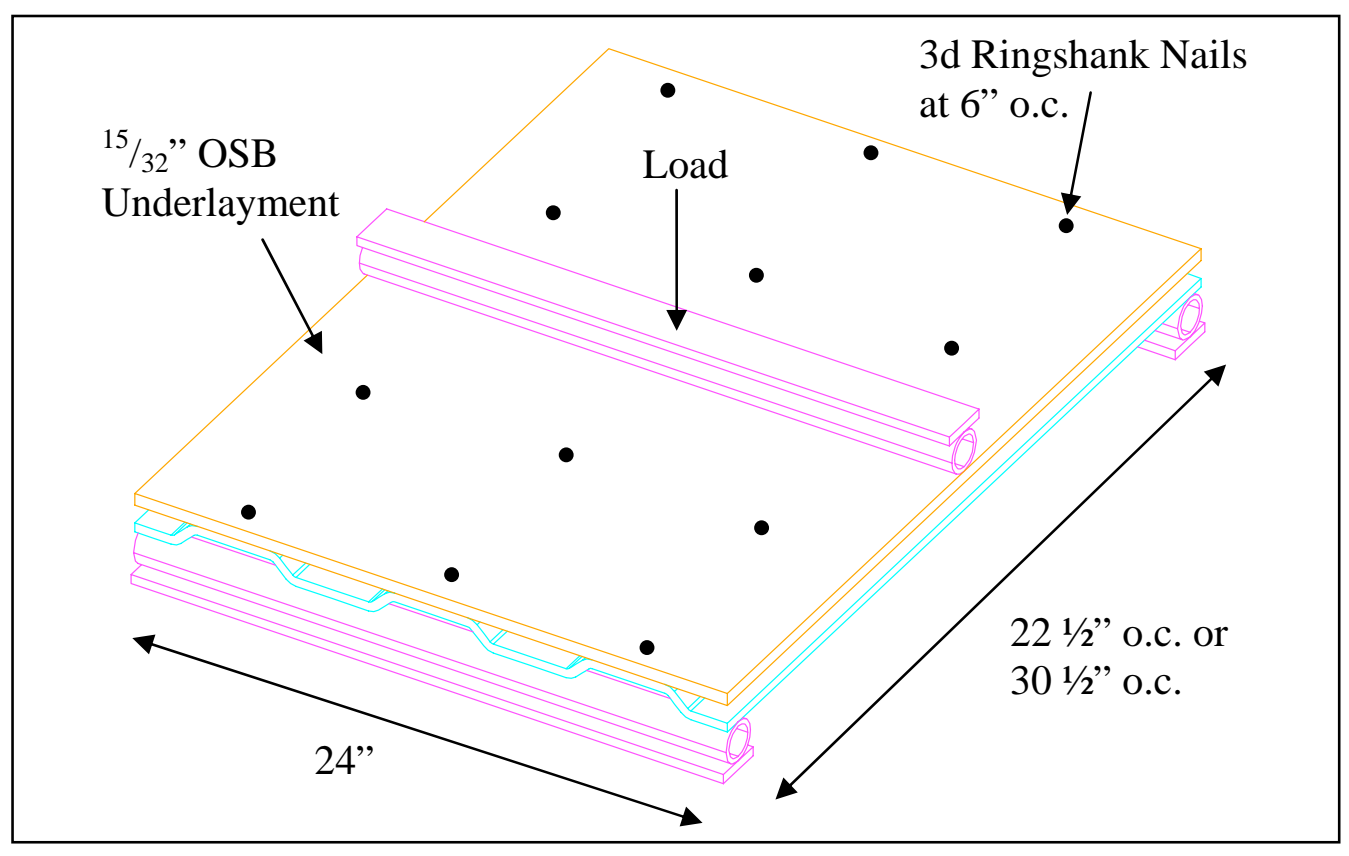

Figure 78: Composite deck single-span bending test assembly 
24" span and $0.08 \mathrm{in} / \mathrm{min}$ for the 32" span) such that load-to-failure time occurred in between 5 to 10 mins. Load and deflection at the bottom surface of mid-span were recorded at a rate of 2 measurements per second until failure.

\section{Test Results}

Finite element models with non-rigid bond elements were used to analyze the test results. A typical FE model for a single-span partial composite deck is shown in Figure 79. Both OSB underlayment and corrugated panel were meshed with 0.25 ”x0.25” thin shell elements. The measured average thicknesses (Table 33) of the test specimens were

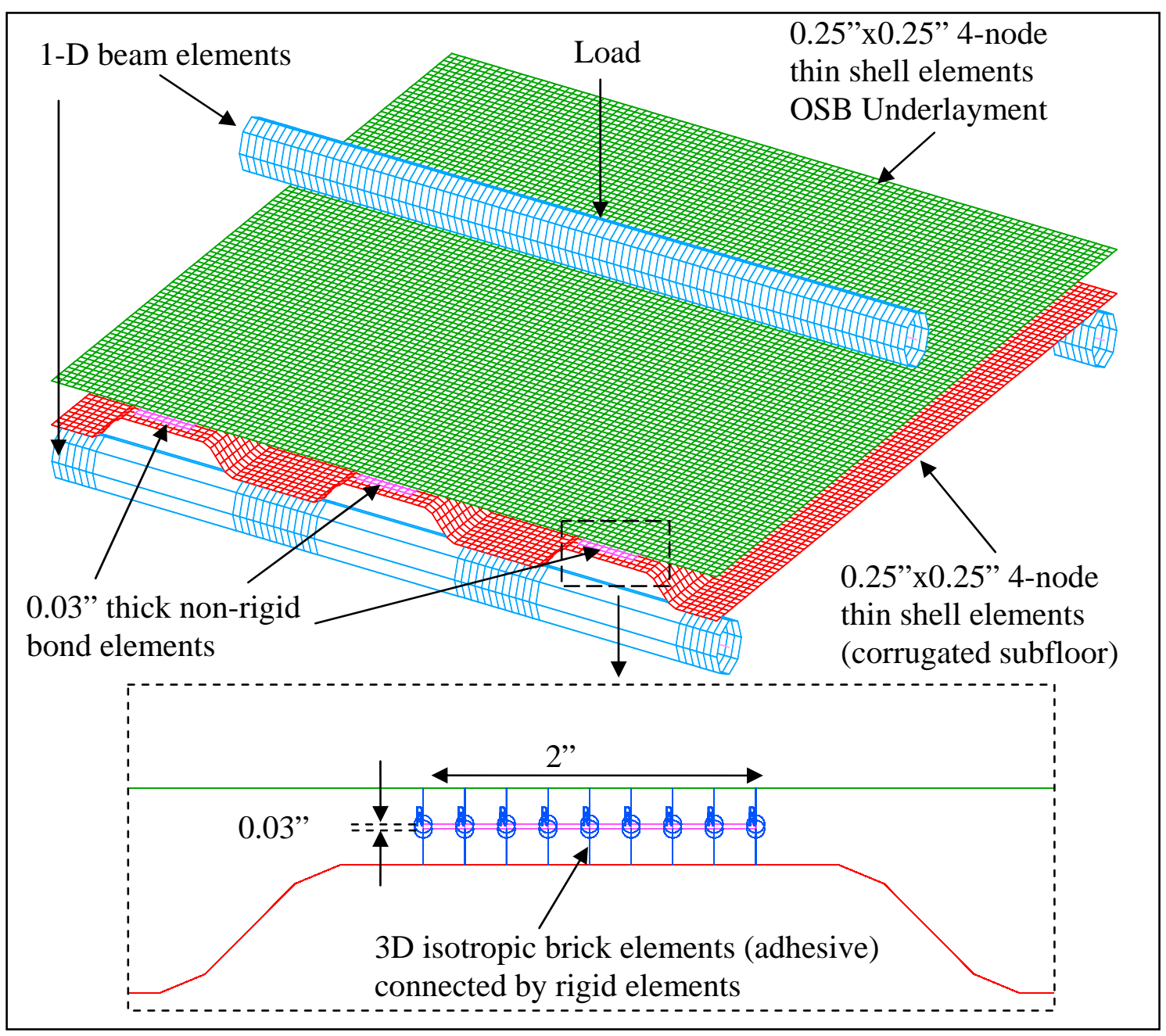

Figure 79: Typical finite element model for 2' wide single-span partial composite bending test. 
used as the element thicknesses for the 4-node thin shell elements. In-plane isotropic material properties were assumed for both corrugated panel and OSB. Average MOE of the corrugated panel was obtained from the non-destructive flexure test performed prior to the assembly of the composite deck system (using equations (66) and (75)). The axial MOE of a typical 3-layer OSB can be approximated using the average MOE obtained from strength axis (surface flake parallel to the primary stress) and weak axis (surface flake perpendicular to the primary stress) bending. Strength axis bending MOE of the OSB was determined from the non-destructive flexure test. A weak axis flexure test was not performed for the OSB. The MOE for the weak axis direction was calculated from the published bending stiffness of APA rated 32/16 sheathing [APA, 2004]. The average axial MOE of the OSB underlayment was used in the FE model. The contribution of the axial stiffness, $E A_{u n}$, (multiplied by the square of the distance away from the neutral axis) to the overall effective composite bending stiffness, $E I_{\text {eff }}$, was expected to be more significant than the bending stiffness of the OSB about its neutral axis, $E I_{u n}$ (see equation (85)). The adhesive joint was modeled with a group of 8-node isotropic brick elements located in between the OSB and the corrugated panel. Rigid elements were used to connect the brick elements to the top (OSB) and bottom (corrugated panel) layers of thin shell elements. The adhesive was assumed to behave like an incompressible isotropic material. A Poisson's ratio of 0.495 was used to approximate the incompressible behavior. The thickness of the adhesive was assumed to be 0.03 ”. McCutcheon suggested a glueline thickness of $1 / 32$ " for typical nailed-glued floor joist [McCutcheon, 1977]. The width of the glueline was about 2", based on observation of the built partial composite decks. Elastic modulus of the adhesive, $E_{a d}$, was varied from 1 psi to $1 \times 10^{7}$ psi (zero 
composite to full composite). Shear modulus of the adhesive, $G_{a d}$, was determined using the governing equation (8) for isotropic material. The load-to-deflection curves for the 22.5” and 30.5” span partial composite deck models at various adhesive shear stiffnesses are shown in Figure 80(a) and Figure 80(b), respectively.

Table 33: Input parameters of the FE model for single-span partial composite deck bending test.

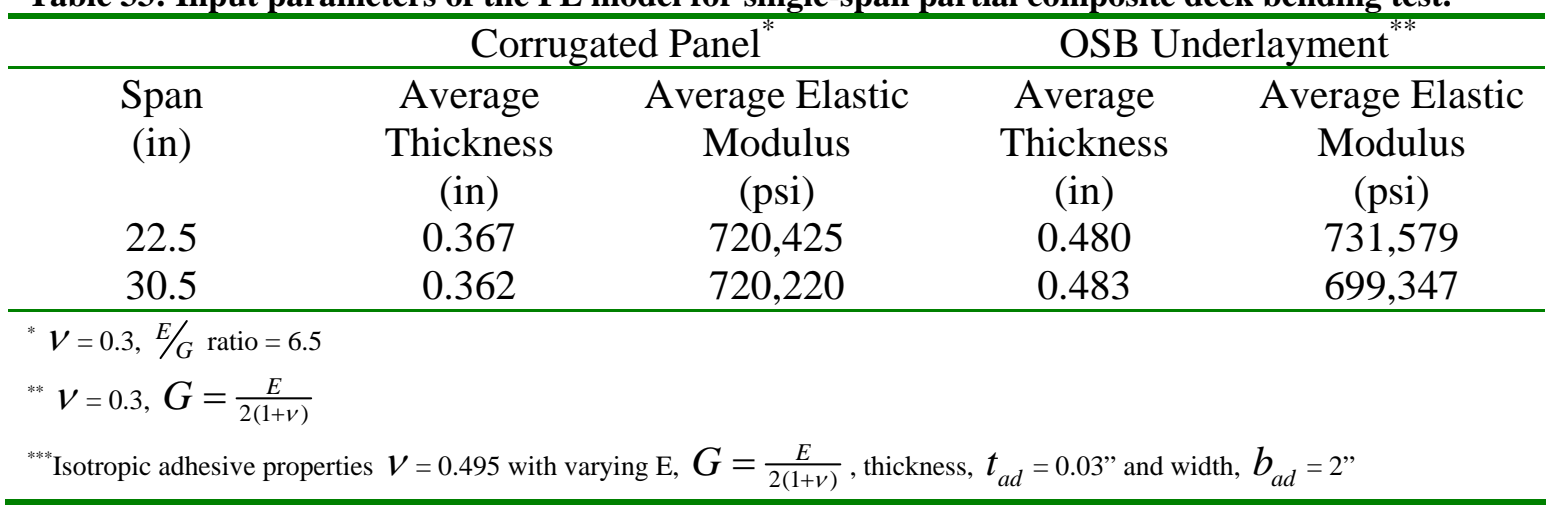

The partial composite beam model, previously discussed in the Beam Model chapter, was also used to model the test results. The bending stiffness of the individual components were determined from non-destructive flexure tests. The axial stiffnesses for the OSB and corrugated panel were calculated using the MOE listed in Table 33. The length of the glueline, $L_{a d}$, and underlayment, $L_{u n}$, used in the computation of the effective or reduced axial stiffness, $\overline{E A_{u n}}$, (equation (81)) of the underlayment, were equal to the span length. The results of the beam and FE models show good agreement when the two constants defined for the partial composite beam model, $c_{a d}$ and $c_{G}$, equal $1 / 8$ and $10 \%$, respectively, for the 24 " span (see Figure 80(a)). Similarly, $c_{a d}$ and $c_{G}$, were equal to $1 / 8$ and $20 \%$, respectively, for the 32" span model (see Figure $80(\mathrm{~b})$ ). The beam model estimated the shear stiffness of the adhesive at about 300 psi to 600 psi (visual inspection of Figure 80(a) and (b)) based on the average load-to-deflection ratios 
of the partial composite test. Figure 80 shows the stiffness (load/deflection) of the composite deck versus the shear modulus of the adhesive in log scale. Therefore the estimation of the adhesive shear modulus using Figure 80 may vary greatly with slight variation in the load/deflection measurement of the test specimens.

The stiffness of the adhesive joint can be expressed in terms of shear/slip per unit length, $S$,

$$
S=\frac{G_{a d} b_{a d}}{t_{a d}}
$$

S was about 20,000 psi to 40,000 psi per glueline for the tested partial composite deck specimen assuming thickness, $t_{a d}$, and width, $b_{a d}$, of the adhesive joint were equal to 0.03 ” and 2", respectively. Shear/slip of a typical adhesive joint for 1.5 ” dimension lumber is in the range of 25,000 psi to 100,000 psi [McCutcheon, 1977]. The beam model matches the results of the FE model well, except when the shear modulus of the adhesive approaches the rigid bond condition where the FE model is stiffer than the beam model. The stiffening effect of the FE model is due to the artificial induced bending stiffness of the 8-node brick elements when the adhesive shear stiffness (and the elastic modulus) is relatively large compared to the MOE of the OSB and corrugated panel. At high adhesive MOE, the relatively thin glueline (0.03") starts behaving like a stiff thin metal plate which increases the overall bending stiffness of the system.

Effective bending stiffness and shear stiffness of each partial composite deck specimen were determined by varying the shear modulus of the adhesive until the loadto-deflection ratio matched he measured data. The results of the tested partial composite deck specimens are summarized in Table 34 . The $5^{\text {th }}$ percentile effective bending stiffness obtained from both 24" and 32" span test was about equivalent to the strength 
axis bending stiffness $\left(1,150,000 \mathrm{lbs}^{2} \mathrm{in}^{2} / \mathrm{ft}\right)$ of a solid $1 \frac{1}{8} \mathrm{~g}^{\prime}$ thick APA rated 48 o.c. Sturd-I-Floor system [APA, 2004]. The average composite factor indicated that the nailed-glued (with AFG-01 adhesive) partial composite deck system developed about $60 \%$ of the full composite stiffness. The $5^{\text {th }}$ percentile strong axis bending strength or moment capacity was over 5,000 in-lbs/ft, which was noticeably higher than the 1,900 inlbs/ft for a typical APA rated 48 o.c. Sturd-I-Floor [APA, 2004]. 


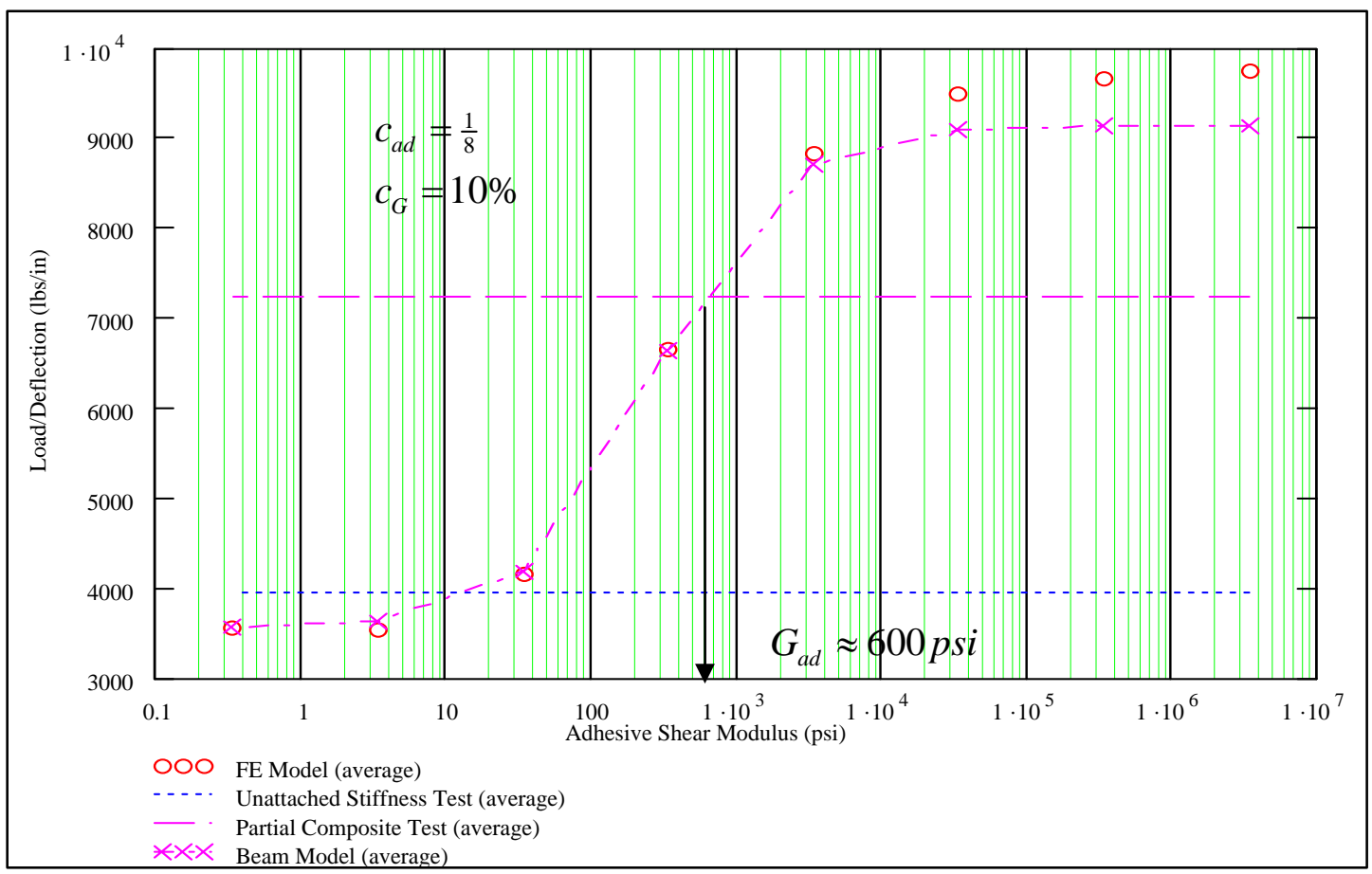

(a)

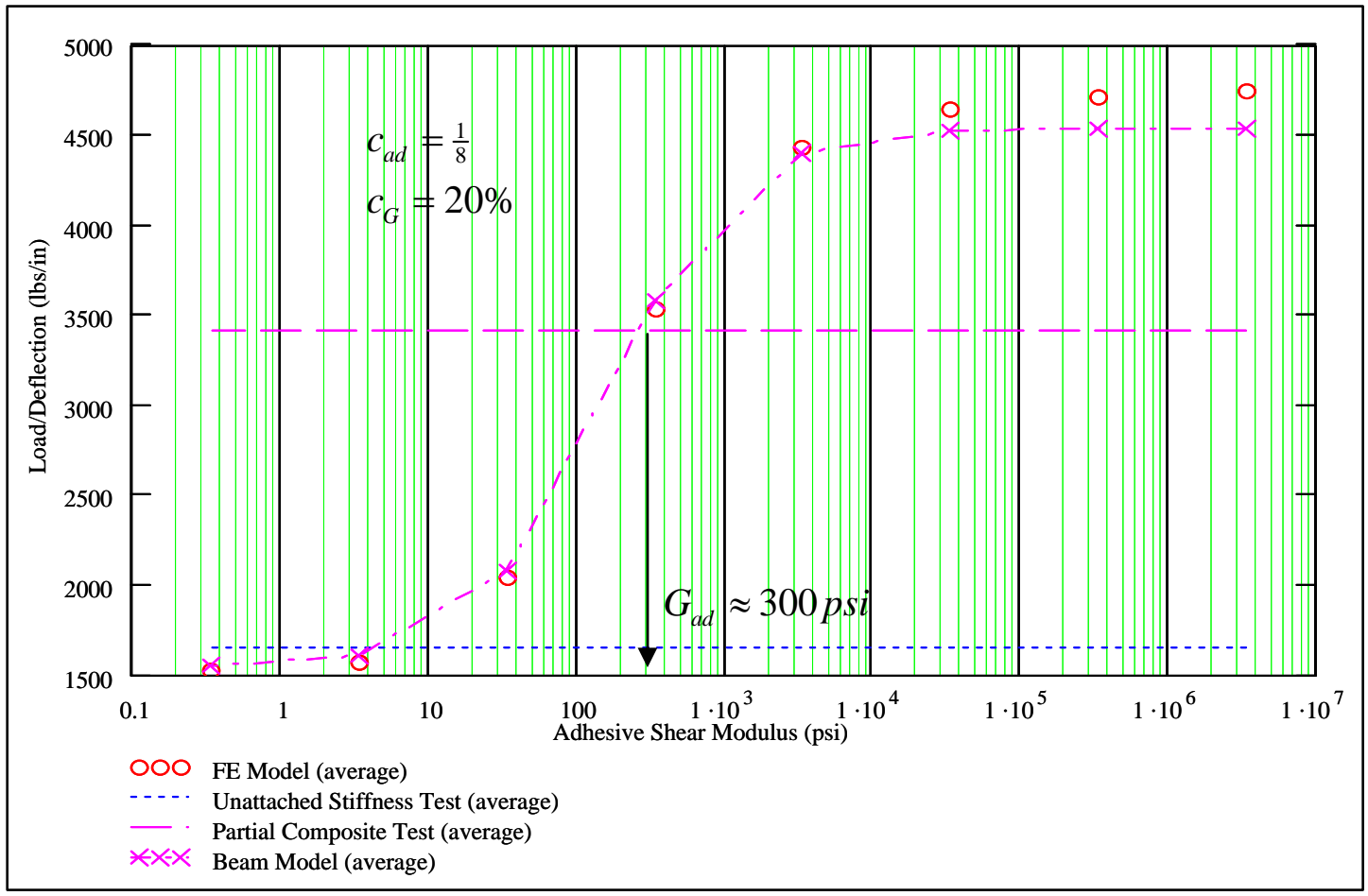

(b)

Figure 80: Load-to-deflection versus adhesive shear modulus plots of the (a) 24" and (b) 32" single-span FE and beam models. 
Table 34: Partial composite deck single-span bending test results.

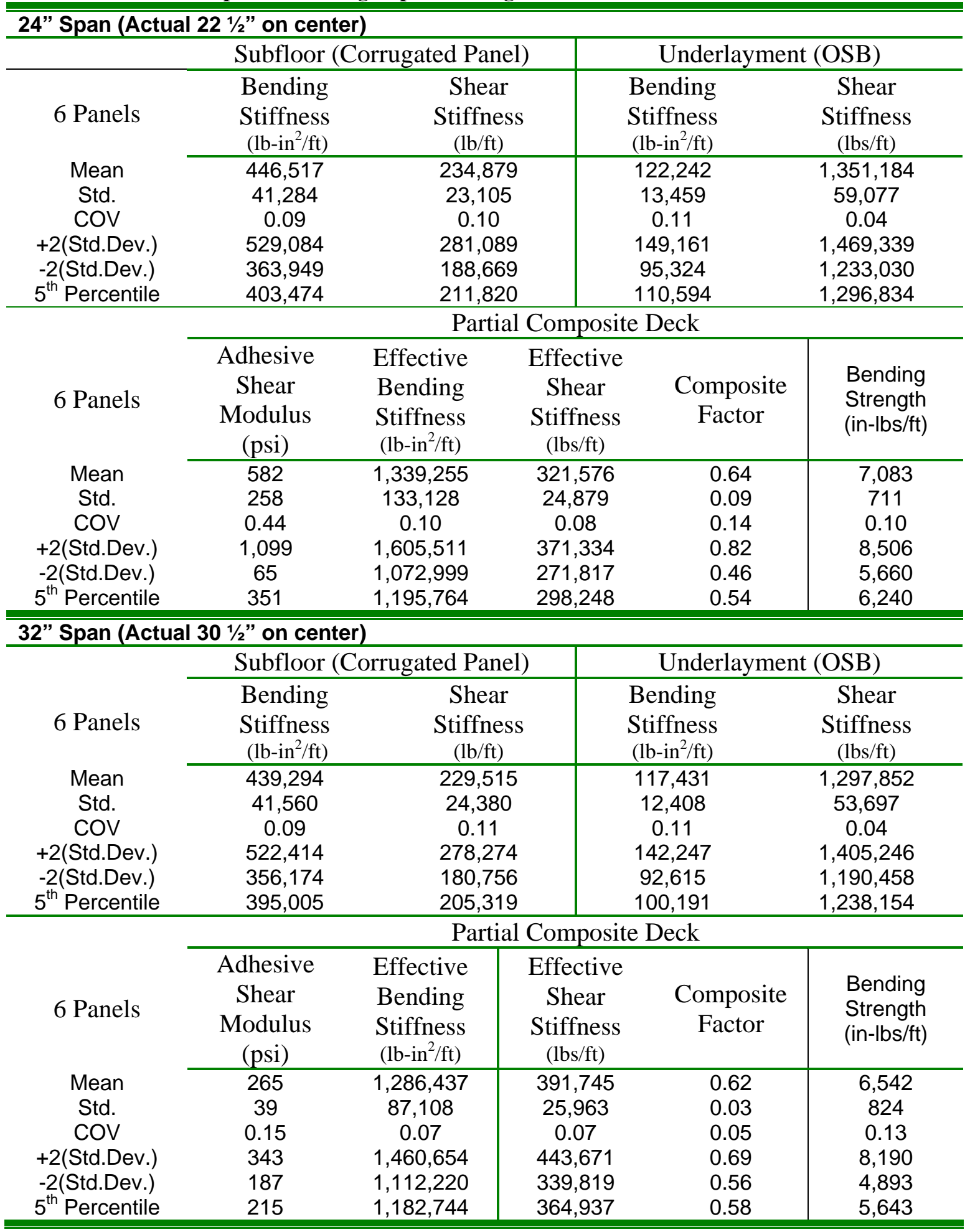




\section{Composite Deck Two-Span Continuous Bending Test}

The use of single-span in floor layout should be avoided if possible. Multiplespan is more commonly used in floor layout than single-span. Partial composite decks were constructed and tested under two-span continuous bending at nominal 24" and 32" spans.

\section{Specifications of Two-Span Continuous Deck Test Specimens}

Six 24"x48" and 24"x64" partial composite deck specimens were constructed for nominal 24" and 32" span bending tests, respectively. The 24" span partial composite deck consisted of a 24"x48" corrugated subfloor and two pieces of 15/32" thick APA rated 32/16 OSB sheathing (24”x18” and 24”x30”) as underlayment. Similarly, the 32” span deck was composed of a 24"x64" corrugated panel and two pieces of OSB underlayment at 24"x24" and 24"x40". The partial composite decks were nailed-glued

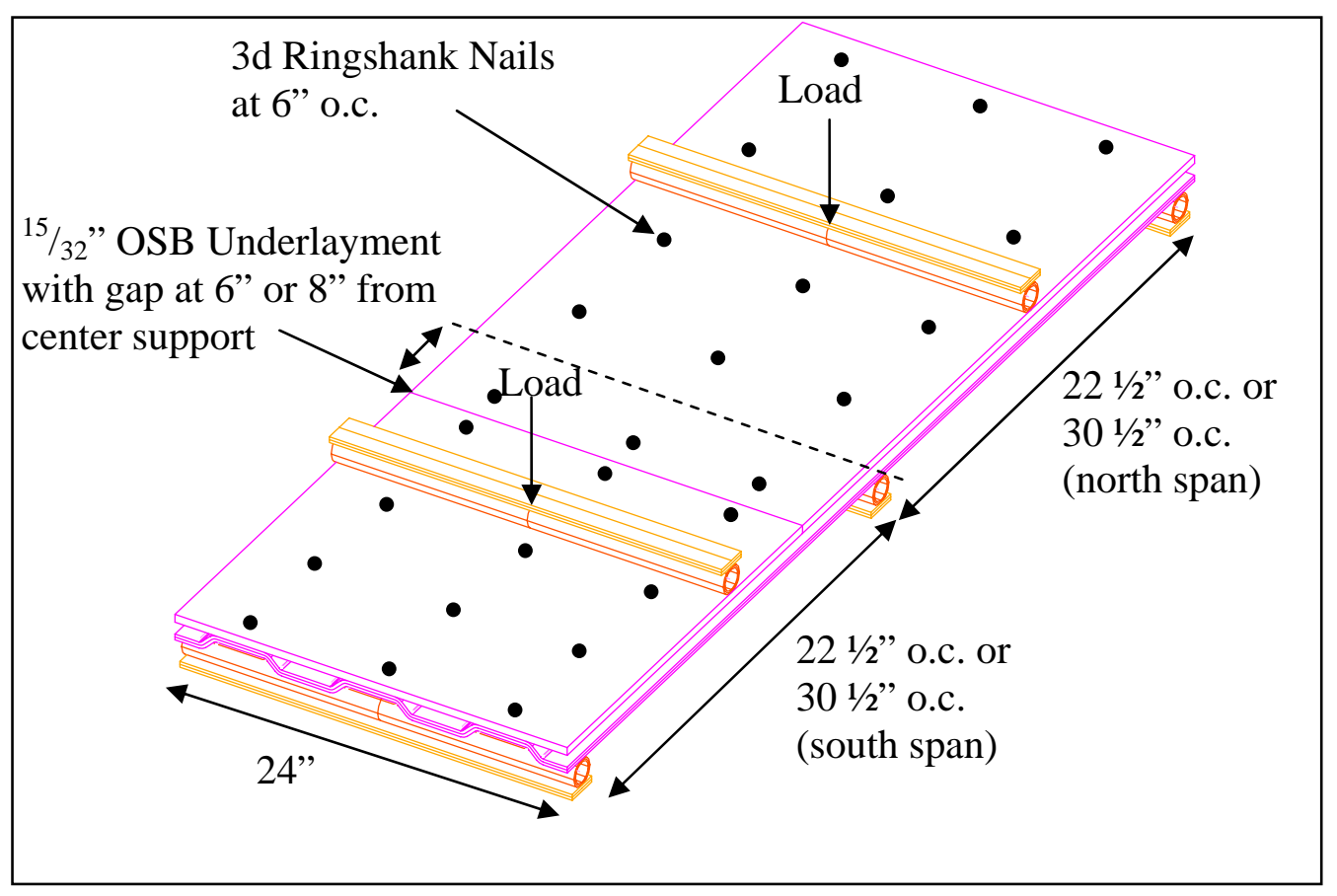

Figure 81: Composite deck two-span bending test assembly 
together using AFG-01 subfloor adhesive and 3d ringshank nails at about 6” on-center. The strength axis of the OSBs was placed parallel to the strength axis of the corrugated panel with a gap of about 1/32”. The gap between the two OSBs was controlled using 1/32” shims.

\section{Test Procedures}

Bending stiffness of each OSB panel was determined from a single-span nondestructive flexure test by stressing the panel to about $1 / 3$ of the maximum allowable stress. The average bending stiffness of the two OSB pieces used as underlayment for each partial composite deck was calculated. A single-span flexure test was also performed at two locations (north and south spans, Figure 81) of the corrugated panel, and the average bending stiffness was recorded.

The partial composite deck specimens were tested using the test assembly shown in Figure 81. An interior support was placed across the middle of the composite deck, and two exterior supports were placed at a distance of 1.5 ” from each end. A gap existed in the underlayment at 6” and 8” from the center support for the nominal 24” and 32” spans tests, respectively. Loads were applied through the loading blocks located across the middle of each span. The loading rates were $0.05 \mathrm{in} / \mathrm{min}$ and $0.08 \mathrm{in} / \mathrm{min}$ for the nominal 24" and 32" spans, respectively, and deflections were measured directly below the corrugated panel at the loading point at 2 measurements per second. The test specimens were loaded to ultimate capacity and the maximum loads were recorded.

\section{Test Results}

Two sets of finite element models were created to predict the bending behavior of the two-span partial composite decks. The same element types (4-node thin shell, 3-D 
brick elements for adhesive, etc.) used for the single-span partial composite deck models were used to mesh the two-span models. However, the average size of the thin shell elements was increased to about 0.5 ” 0.5 ” to reduce the computational time and the disk space required for the FE models. Equal loads were applied to both spans. The occurrence of a gap in the underlayment was included in the FE models by using two sets of thin shell meshes separated by a $1 / 32$ " gap to model the two pieces of OSBs (Figure 82). Average materials properties, such as thickness and MOE, were used (Table 36). The shear modulus of the adhesive was varied to model the partial composite behavior of the two-span continuous deck. Load-to-deflection ratios were determined for eight different adhesive shear stiffnesses. Deflections were determined from the nodes of the corrugated panel directly underneath the loading points. The load-to-deflection curves of the FE models are shown in Figure 83 (a) and (b) for 24” and 32” spans, respectively.

The partial composite beam model was also used to analyze the test data. The two-span partial composite beam model matched the FE results well when the two constants, $c_{a d}$ and $c_{G}$, were equal to $1 / 15$ and $10 \%$, respectively (see Figure 83(a) and (b)). Based on the average load-to-deflection ratio obtained from the tests, the average adhesive shear modulus was about $200 \mathrm{psi}$ and the average composite factor was 0.31 for the tested 24" span specimens (Table 36). This composite factor was relatively low compared to the other tests (24” and 32” single-span tests, and 32” two-span test). The average composite factor for the 32" two-span specimens was about 0.58 , which was consistent with the results of the single-span tests (about $60 \%$ composite action). This suggested that there might be some consistency errors in the 24" two-span partial composite test or errors during the preparation of the test specimens. However, the cause 
of the discrepancy was not identified. The $5^{\text {th }}$ percentile bending strength of the test specimens was more than $2 \frac{1}{2}$ times stronger (about 5,100 in-lbs/ft) than the minimum requirement of APA rated 48 o.c. Sturd-I-Floor of 1,900 in-lbs/ft [APA, 2004]

Table 35: Input parameters of the FE model for two-span partial composite deck bending test.

\begin{tabular}{|c|c|c|c|c|}
\hline & \multicolumn{2}{|c|}{ Corrugated Panel $^{*}$} & \multicolumn{2}{|c|}{ OSB Underlayment $^{* *}$} \\
\hline \multirow{2}{*}{$\begin{array}{l}\text { Span } \\
\text { (in) }\end{array}$} & Average & Average Elastic & Average & Average Elastic \\
\hline & $\begin{array}{l}\text { Thickness } \\
\text { (in) }\end{array}$ & $\begin{array}{l}\text { Modulus } \\
\text { (psi) }\end{array}$ & $\begin{array}{l}\text { Thickness } \\
\text { (in) }\end{array}$ & $\begin{array}{l}\text { Modulus } \\
\text { (psi) }\end{array}$ \\
\hline 22.5 & 0.373 & 672,112 & 0.478 & 698,704 \\
\hline 30.5 & 0.364 & 722,891 & 0.482 & 723,589 \\
\hline \multicolumn{5}{|c|}{${ }^{*} V=0.3, E / G$ ratio $=6.5$} \\
\hline \multicolumn{5}{|c|}{$\nu=0.3, G=\frac{E}{2(1+v)}$} \\
\hline \multicolumn{5}{|c|}{ Isotropic adhesive properties $v=0.495$ with varying E, $G=\frac{E}{2(1+v)}$, thickness, $t_{a d}=0.03$ " and width, $b_{a d}=2$ " } \\
\hline
\end{tabular}

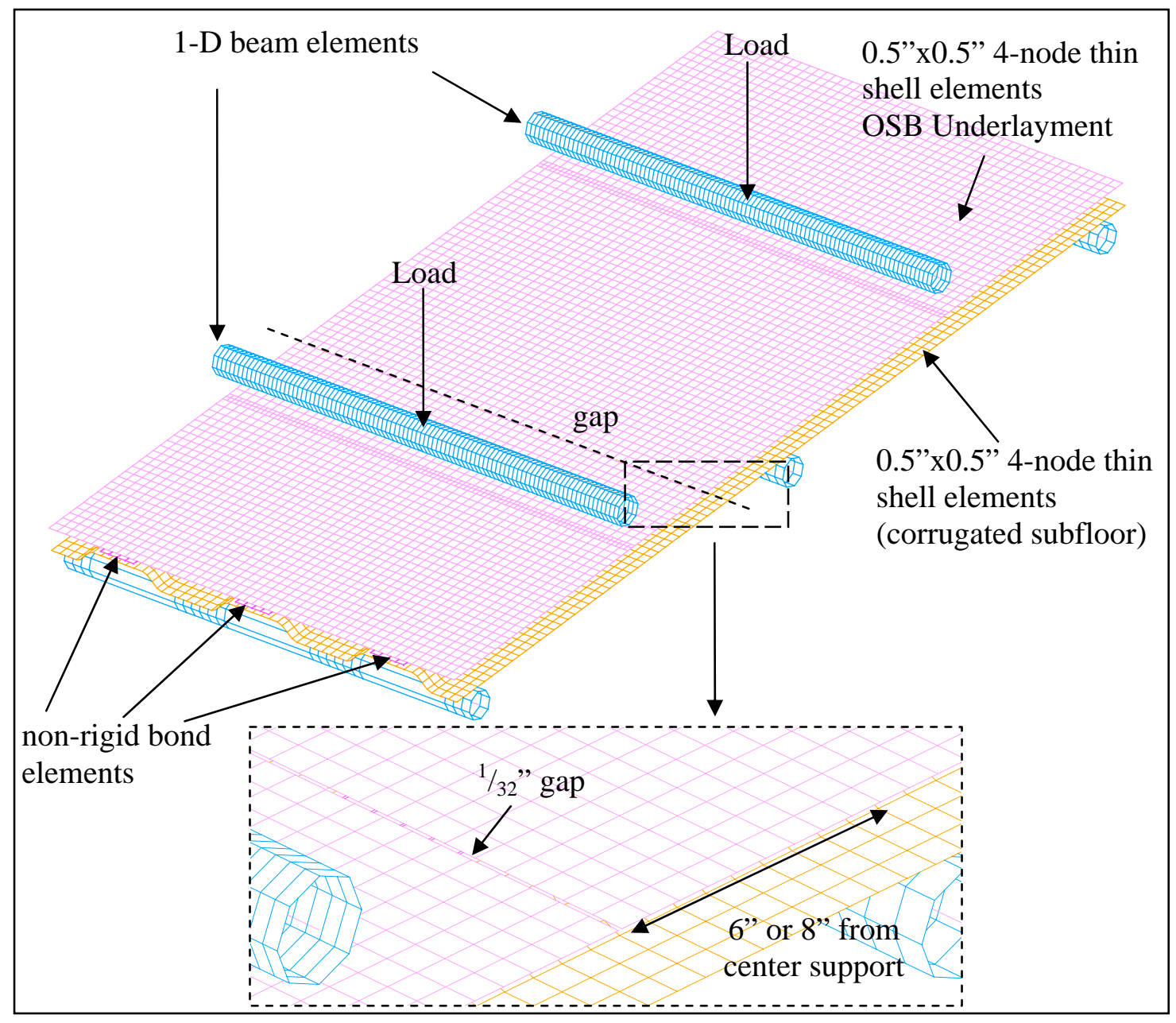

Figure 82: Typical finite element model for 2' wide two-span partial composite bending test. 


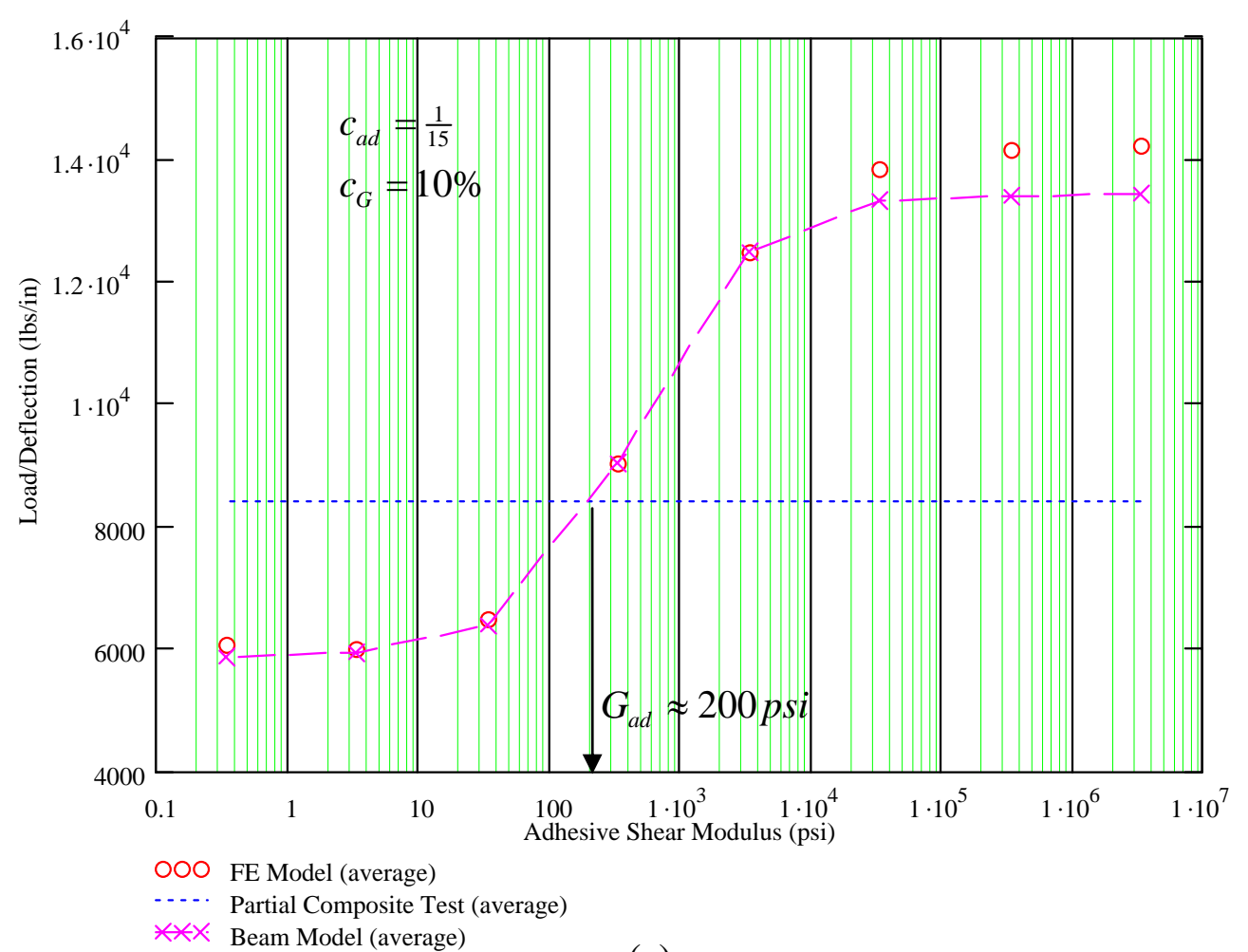

(a)

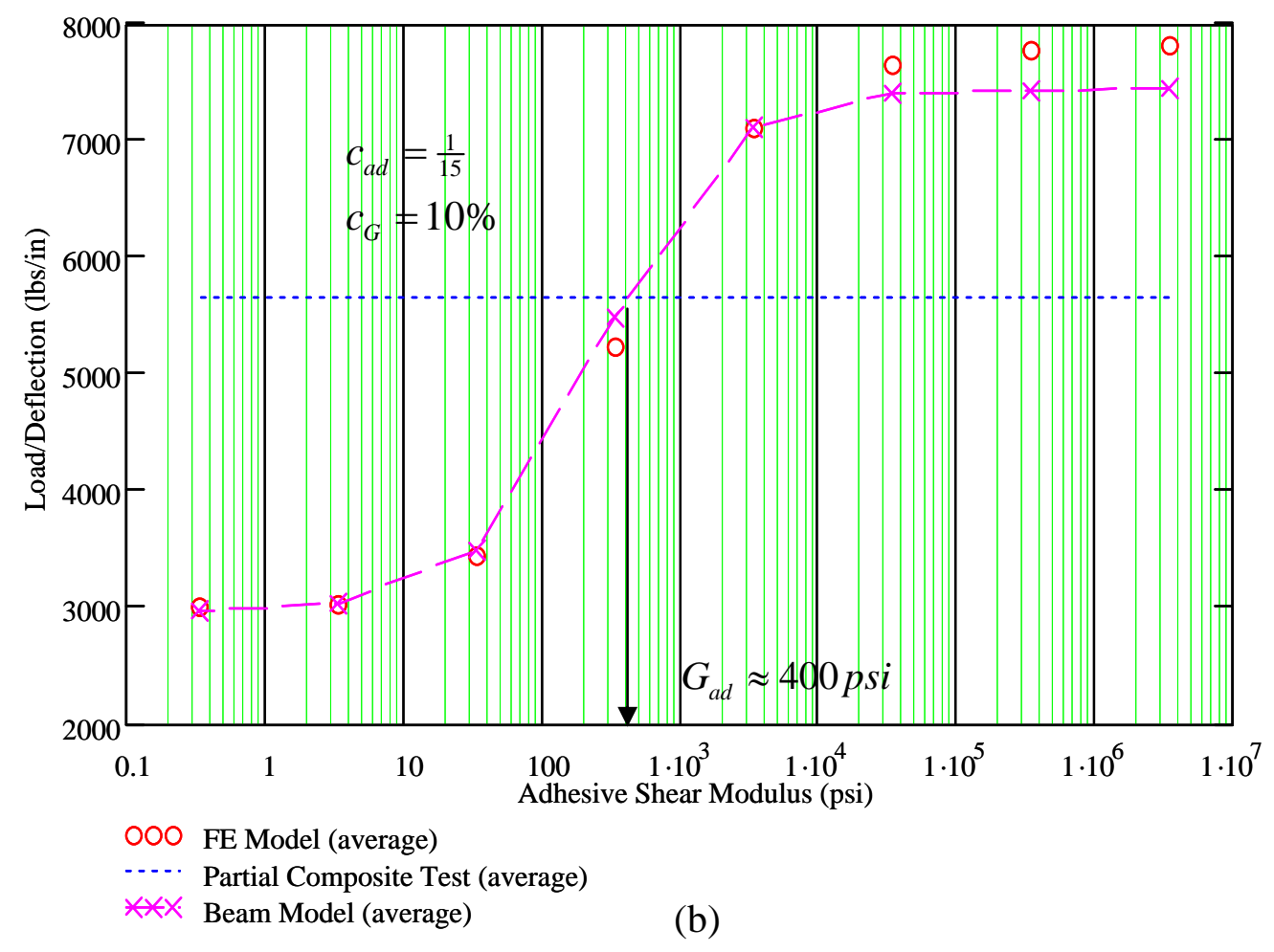

Figure 83: Load-to-deflection versus adhesive shear modulus plots of the (a) 24" and (b) 32" double-span FE and beam models. 
Table 36: Partial composite deck double-span bending test results.

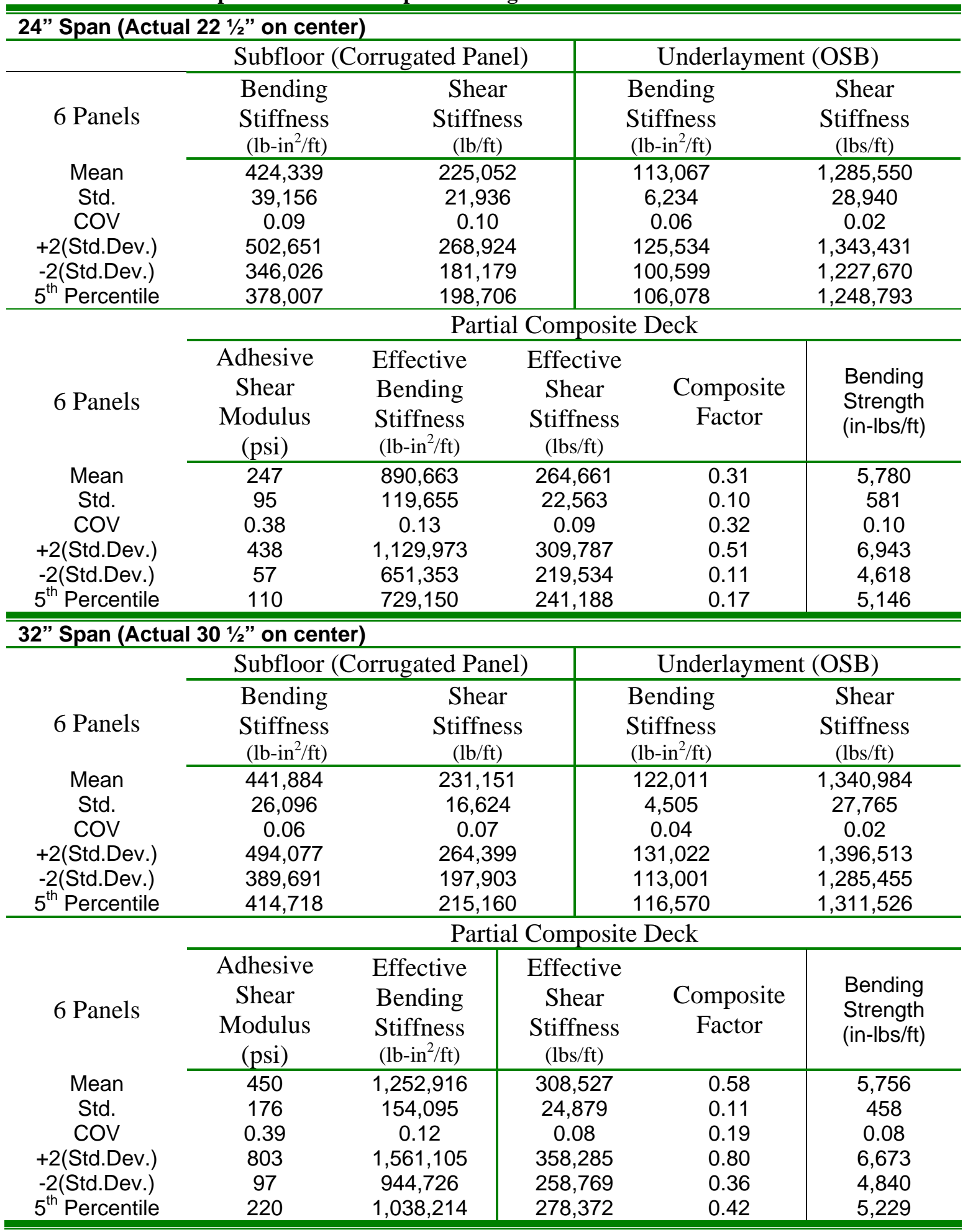




\section{Composite T-Beam}

Composite nailed-glued floors with conventional OSB sheathings as decking materials are common in light-frame residential construction. Floor systems with 3 or more joists spaced at 24 " on center or less, and connected by $15 / 32$ " or thicker structuraluse panels, are considered repetitive-member wood systems. These types of floor assemblies gain significant benefit from the system behavior. The increase in performance for repetitive-member floor systems, over a single member stiffness and resistance, is recognized by the LRFD design specification through the use of a composite action factor $\left(C_{E}\right)$ and a load-sharing factor $\left(C_{r}\right)$ [AF\&PA, 1996a]. The composite action system effect of the corrugated wood floor system was investigated through experimental testing of composite T-beams, which consisted of a corrugated wood composite deck nailed-glued to an I-joist.

\section{Specifications of T-beam}

The composite T-beams were first assembled as double T-beams as shown in Figure 84 and then cut into two T-beam test specimens. A composite T-beam consisted of a 9 1/2” deep, 10 foot long I-joist connected to a 24” wide corrugated composite deck with 15/32" thick APA rated 32/16 OSB sheathing as underlayment. Both corrugated panels and OSBs were oriented with the strength axis across the joists. Corrugated panels were nailed-glued to the I-joist using AFG-01 construction adhesive and 6d box nails. Adhesive was applied continuously on the top flange of the I-joist and two $6 \mathrm{~d}$ nails were placed at each bottom deck of the corrugated panel resulting in a 4 inch effective nail 
spacing along the joist. A continuous $1 / 4$ " bead of adhesive was applied at each top deck of the corrugated panel, along with 3d ringshank nails spaced at 6 inches on center, to attach the OSB. Gaps of about $1 / 16$ " and $1 / 32$ " were provided in the corrugated subfloor and OSB underlayment, respectively. A total of four composite T-beams were assembled for testing.

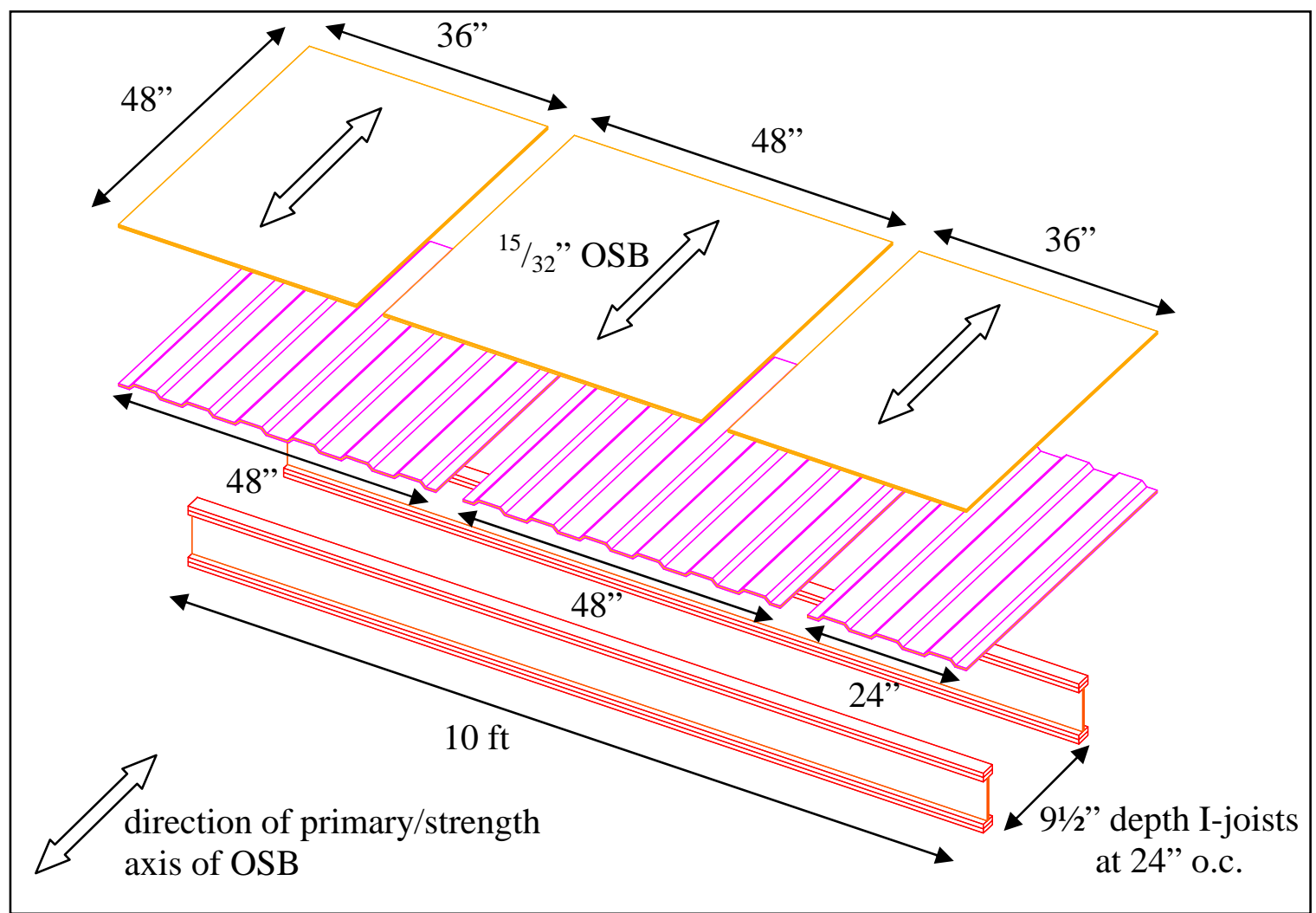

Figure 84: Assembly of double-T-beam.

\section{Experimental Procedures and Results}

The bending stiffness of each I-joist was determined through a non-destructive flexure test prior to the construction of the T-beam. The I-joist was simply supported at 2 inches away from each end of the beam (116” span) and loaded with two symmetrically placed loads at a distance 30.5” apart. This was the same test arrangement as for the Tbeams, as shown in Figure 85. Displacement , $\Delta$, was recorded at the mid-span of the 
bottom flange of the I-joist. A total load of $800 \mathrm{lbs}$ was applied ( $\mathrm{P}=400 \mathrm{lbs}$ ) and the load-to-deflection ratio, $\frac{P}{\Delta}$, was determined for each joist. Four nailed-glued composite T-beams were constructed from the tested I-joists. The static bending test of the T-beam was carried out using the same test assembly. All composite T-beams were loaded to ultimate capacity. Bending stiffness and strength of each T-beam were determined. The test results are shown in Table 37.

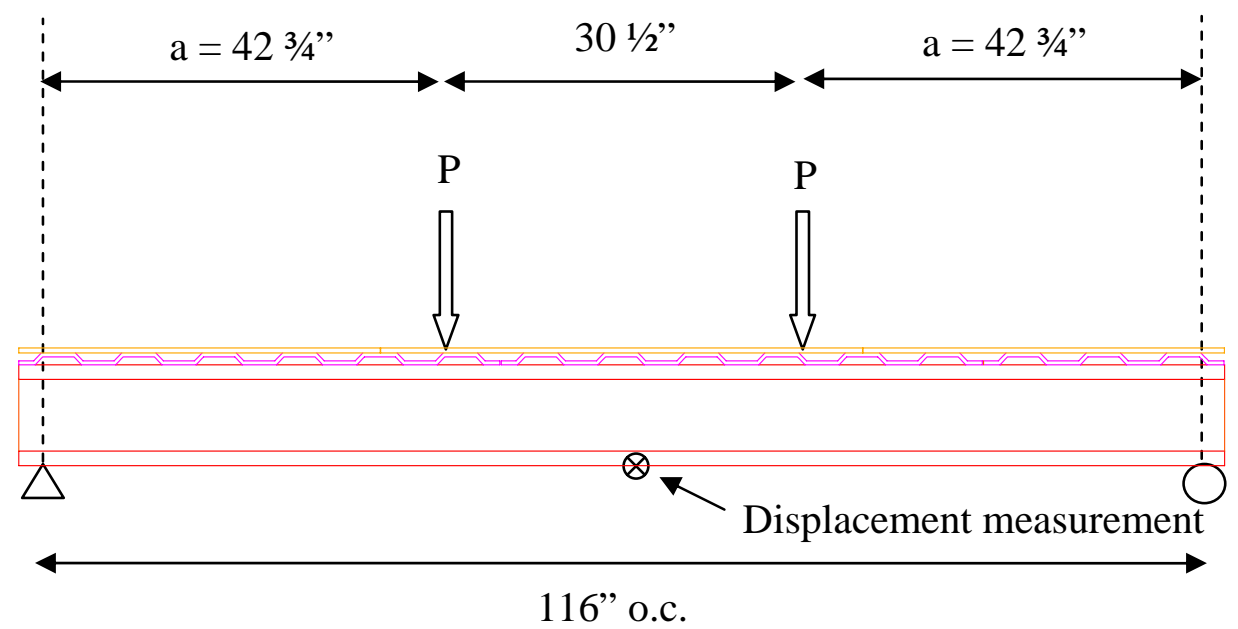

Figure 85: Composite T-beam test with two equal loads symmetrically placed.

Table 37: Test results of composite T-beams.

\begin{tabular}{ccccc}
\hline $\begin{array}{c}\text { Beam } \\
\text { No. }\end{array}$ & $\begin{array}{c}\text { I-Joist } \\
\text { Stiffness } \\
\text { (lbs/in) }\end{array}$ & $\begin{array}{c}\text { Composite } \\
\text { T-beam } \\
\text { Stiffness } \\
\text { (lbs/in) }\end{array}$ & $\begin{array}{c}\text { **Ultimate Load } \\
\text { of T-beam } \\
(\text { lbs) }\end{array}$ & $\begin{array}{c}\text { T-beam/I-Joist } \\
* \text { Stiffness }\end{array}$ \\
\hline 1 & 2,266 & 3,823 & 3,590 & 1.69 \\
2 & 2,101 & 4,105 & 4,000 & 1.95 \\
3 & 2,186 & 3,781 & 3,390 & 1.73 \\
4 & 2,048 & 3,480 & 3,300 & 1.70 \\
\hline Mean & 2,150 & 3,797 & 3,570 & 0.13 \\
Std. & 96 & 256 & 311 & 0.07 \\
COV & 0.04 & 0.07 & 0.09 & \\
\hline *Stiffness or the load/deflection was based on a single point load, P. \\
**Ultimate load was based on single point load P. Total applied load equal to 2P.
\end{tabular}




\section{Theoretical Analysis}

\section{Stiffness of I-joist}

The total mid-span deflection, including shear deflection, of a simply supported Ijoist under two equal point loads symmetrically placed can be approximated by the following equation,

$$
\Delta=\frac{P a}{24 E I_{j}}\left(3 L^{2}-4 a^{2}\right)+\frac{P a}{G_{w} t_{w} d_{j}}
$$

where,

$$
\begin{aligned}
& \Delta=\text { mid-span deflection (in) } \\
& L=\text { span length (in) } \\
& a=\text { distance from simple support to the nearest point load, see Figure 85, (in) } \\
& P=\text { applied point load (lbs) } \\
& E I_{j}=\text { bending stiffness of I-joist (lbs-in }{ }^{2} \text { ) } \\
& G_{w}=\text { shear modulus of the web (psi) } \\
& t_{w}=\text { web thickness (in) } \\
& d_{j}=\text { total depth of I-joist (in) }
\end{aligned}
$$

Equation (107) assumes shear deflection of the I-joist due to shear deformation in the web area only. $G_{w}$ is implicitly given by the published design properties of the I-joist as 150,000 psi (see Appendix K). Bending stiffness of the I-joist can be determined using the parallel axis theorem.

$$
E I_{j}=E I_{w}+2\left[E I_{f}+E A_{f}\left(\frac{h_{w}+t_{f}}{2}\right)^{2}\right]
$$


$E I_{w}$ and $E I_{f}$ are the bending stiffnesses of the web and flange, respectively, and $E A_{f}$ is the axial stiffness of the flange.

$$
\begin{gathered}
E I_{w}=E_{w} \frac{t_{w} h_{w}{ }^{3}}{12} \\
E I_{f}=E_{f} \frac{b_{f} t_{f}{ }^{3}}{12} \\
E A_{f}=E_{f}\left(b_{f} t_{f}\right)
\end{gathered}
$$

Similarly, the axial stiffness of the web is equal to

$$
E A_{w}=E_{w}\left(h_{w} t_{w}\right)
$$

$E_{w}$ and $E_{f}$ are the elastic moduli of the web and flange, respectively. The top and bottom flanges of the tested I-joists consisted of $2 \frac{5}{16}$ " wide by $1 \frac{3}{3} / 8$ " thick laminated veneer lumber (LVL), and the web was a $3 / 8$ " thick OSB (Figure 86). $E_{w}$ was estimated to be 650,000 psi, based on the design axial stiffness of APA 24/0 rated OSB sheathing, in the $4 \mathrm{ft}$ direction [APA, 2004]. The MOE of the LVL flange (1,385,000 psi) and the average bending stiffness of the I-joist $\left(153 \times 10^{6} \mathrm{psi}\right)$ were determined by matching the stiffness response of the analytical model to the test result average load/deflection ratio of 2150 lbs/in.

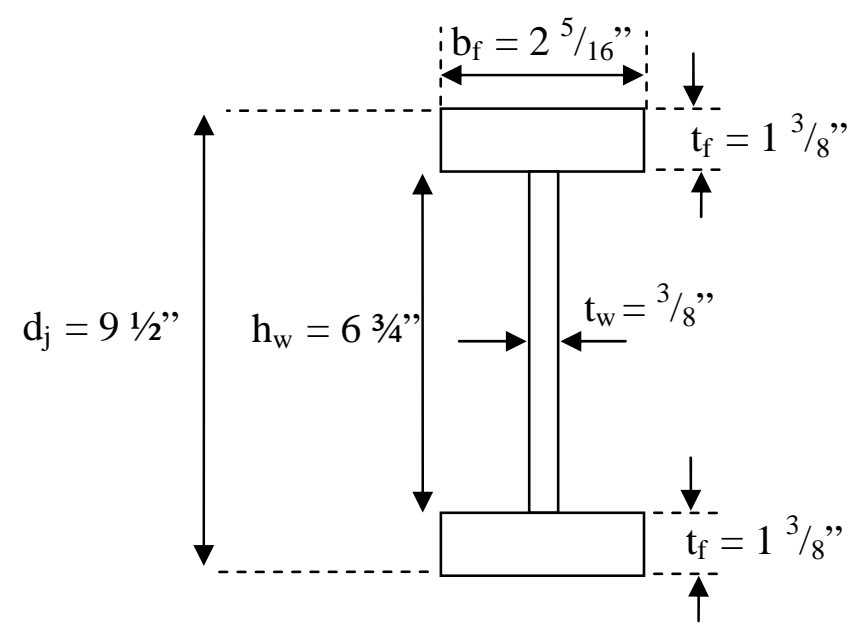

Figure 86: Cross sectional view of prefabricated wood I-joist. 


\section{Stiffness of Partial Composite T-beam}

A theoretical model of the partial composite T-beam was developed based on the reduced or effective axial stiffness method. There are two layers of nailed-glued joints in a partial composite T-beam; between underlayment and corrugated subfloor, and between subfloor and I-joist. The effective bending stiffness of the partial composite T-beam can be computed by using the parallel axis theorem on the reduced axial stiffness of the corrugated composted deck.

The effective axial stiffness of the composite deck is obtained by first determining

the reduced axial stiffness of the OSB underlayment, $\overline{E A}_{O S B}$, relative to the corrugated subfloor.

$$
\overline{E A}_{O S B}=\frac{E A_{O S B}}{1+\frac{E A_{O S B}}{c_{a d} \frac{G_{a d} L_{a d} L}{t_{a d}}\left(b_{d}\right)}}
$$

The axial stiffness of the OSB, $E A_{\text {OSB }}$, was $7,200,000 \mathrm{lbs} ;{ }^{15} / 32$ " thick, APA rated 32/26 OSB was assumed $(3,600,000 \mathrm{lbs} / \mathrm{ft}$ of deck $)$ [APA, 2004]. $G_{a d}$ is the shear modulus of the adhesive joint and $c_{a d}$ is a constant that can be determined from FE analysis. Width of the nailed-glued joint was equal to the 24 " deck width, $b_{d}$, and joint thickness, $t_{a d}$, of 0.03 " was assumed. McCutheon estimated the thickness of typical joint around $1 / 32$ ” [McCutheon, 1977]. Total length of the adhesive joint, $L_{a d}$, can be determined using the following equation

$$
L_{a d}=\frac{L}{w} \tilde{L}_{a d}
$$


where $\tilde{L}_{a d}$ is the length of the adhesive joint per wavelength (Figure 87 ) and $w$ is previously defined as the wavelength of the corrugated panel. $\tilde{L}_{a d}$ was about 2” resulting in a total joint length of 29”, between the underlayment and the corrugated panel, for the 116 ” span T-beam. The reduced axial stiffness of the composite deck, $\overline{E A}_{\text {deck }}$, relative to the I-joist, is estimated as

$$
\overline{E A}_{\text {deck }}=\frac{\overline{E A}_{O S B}+E A_{c}}{1+\frac{\overline{E A}_{O S B}+E A_{c}}{c_{a d} \frac{G_{a d} L_{a d} L}{t_{a d}}\left(b_{f}\right)}}
$$

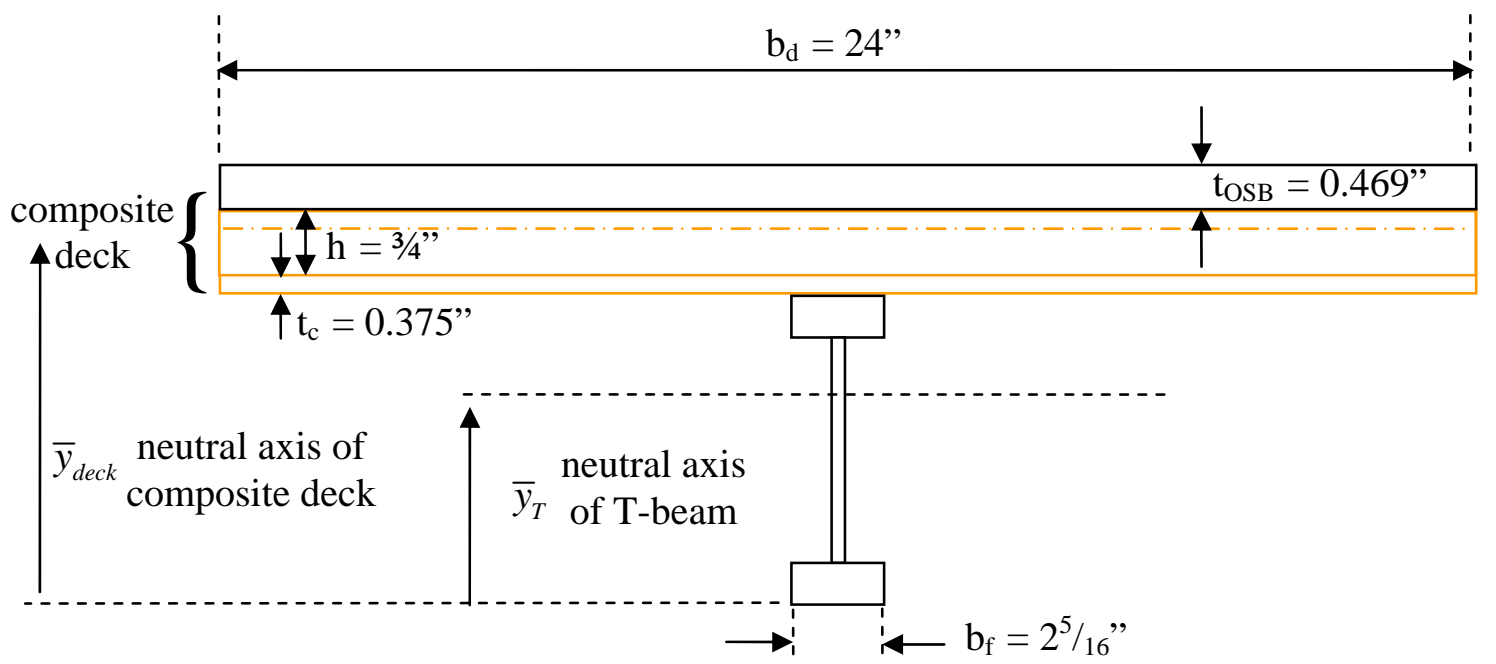

(a)

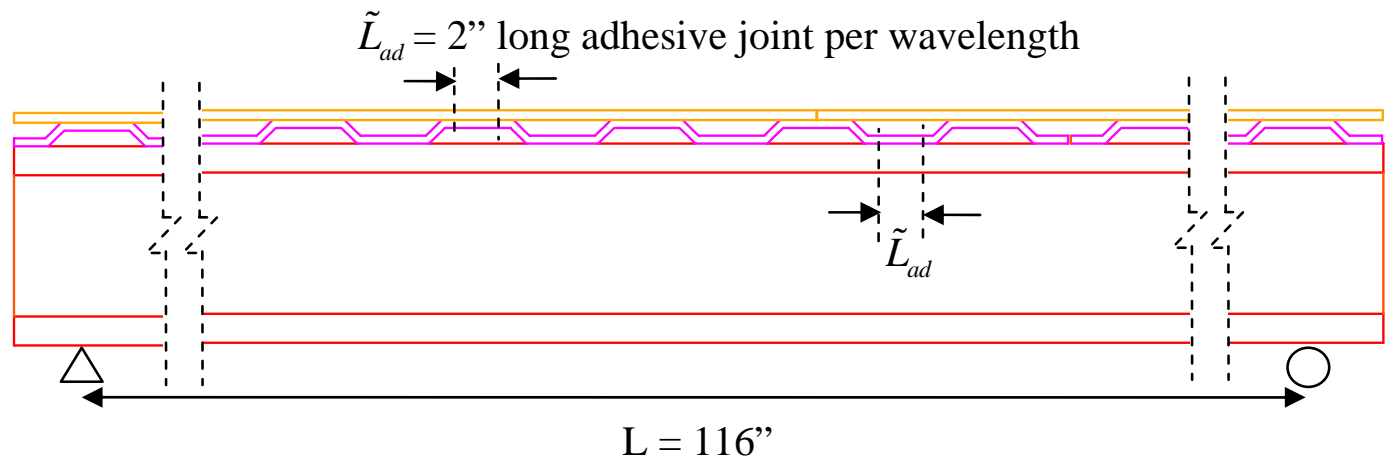

(b)

Figure 87: Cross sectional view of composite T-beam: (a) end view and (b) side view. 
$E A_{c}$ was 6,300,000 lbs for 24 " wide deck, assuming $3 / 8$ " thickness and 700,000 psi MOE (based on typical MOE of the tested corrugated panels). The width of the joint between corrugated panel and I-joist was equal to the flange width, $b_{f}$. The total length and thickness of the joint were taken as 29 " and 0.03 ”, respectively (same as the joint between underlayment and corrugated subfloor). The neutral axes of the composite deck, $\bar{y}_{\text {deck }}$, and composite T-beam, $\bar{y}_{T}$, (see Figure 87) can be determined from the following equations

$$
\begin{gathered}
\bar{y}_{\text {deck }}=\frac{\overline{E A}_{\text {OSB }}\left(y_{\text {OSB }}\right)+E A_{c}\left(y_{c}\right)}{\overline{E A}_{\text {OSB }}+E A_{c}} \\
\bar{y}_{T}=\frac{\overline{E A}_{\text {deck }}\left(\bar{y}_{\text {deck }}\right)+E A_{j}\left(y_{j}\right)}{\overline{E A}_{\text {deck }}+E A_{j}}
\end{gathered}
$$

where $y_{j}, y_{c}$, and $y_{O S B}$ are locations of the centroid for I-joist, corrugated panel, and OSB, computed from the base of the I-joist, respectively. $E A_{j}$ is the axial stiffness of the I-joist

$$
E A_{j}=E A_{w}+2 E A_{f}
$$

$E A_{w}$ and $E A_{f}$ are previously defined as the axial stiffnesses for web and flange of the I-joist. The effective bending stiffness of the partial composite T-beam, $E I_{\text {effT }}$, defined using the parallel axis theorem is

$$
E I_{\text {eff } T}=E I_{u}+E A_{j}\left(y_{j}-\bar{y}_{T}\right)^{2}+\overline{E A}_{\text {deck }}\left(\bar{y}_{\text {deck }}-\bar{y}_{T}\right)^{2}
$$

Substituting equation (117) into equation (119) yields

$$
E I_{\text {effT }}=E I_{u}+\frac{E A_{j} \overline{E A}_{\text {deck }}}{E A_{j}+\overline{E A}_{\text {deck }}}\left(\bar{y}_{\text {deck }}-y_{j}\right)^{2}
$$


$E I_{u}$ is the bending stiffness of the T-beam if the components are completely unattached.

$E I_{u}$ is calculated as the sum of the stiffness of the I-joist, corrugated panel and OSB.

However, the sum of the unattached bending stiffness from the corrugated panel and OSB underlayment is negligible. For the tested T-beam, the sum of the unconnected deck stiffness is less than $1 \%$ of the I-joist stiffness. Hence, for most practical cases, $E I_{u}$ can be taken as I-joist stiffness, $E I_{j}$, alone.

The total deflection of the T-beam at mid-span can be determined using equation (107), by replacing the I-joist stiffness, $E I_{j}$, with the effective bending stiffness of the Tbeam, $E I_{\text {effT }}$. Shear deformation due to the composite deck is neglected hence the shear deflection term in equation (107) remains the same.

\section{Finite Element Analysis}

A finite element T-beam model was generated to analyze the composite action between the composite deck and I-joist. The material properties for the T-beam components are listed in Table 38. The FE I-joist mesh consisted of 4-node thin shell elements for the LVL flanges and 4-node membrane elements for the OSB web, meshed at mid surfaces. The web of the I-joist can be modeled with 2D membrane elements because there is no out-of-plane bending in the web. Thin shell elements of the top and bottom flanges are connected to the web membrane elements with rigid bar elements (see Figure 88). Simple supports and symmetrically placed equal loads were applied to the FE I-joist model to determine the load/deflection ratio. The load-to-deflection ratio of the FE model was $2,244 \mathrm{lbs} / \mathrm{in}$, based on a single load, $P$, and the mid-span deflection of the bottom flange. The FE I-joist was about $4 \%$ stiffer than the average test data $(2,150 \mathrm{lbs} / \mathrm{in})$. 
The partial composite T-beam mesh was built by adding the composite deck to the FE I-joist. Both corrugated subflooor and OSB underlayment meshes were generated using 4-node thin shell elements. Gaps in the composite deck were taken into account in the FE model. The previously discussed non-rigid FE joint model (with 3D brick and rigid bar elements) was used to connect the underlayment to the corrugated panel and also the corrugated panel to the I-joist. The thickness of the adhesive joint was taken as 0.03” and near incompressible isotropic material properties (Poisson’s ratio equal 0.495) were assumed for the 3D brick elements. Loads were applied to the underlayment through contact or gap elements (Figure 88). The shear modulus of the adhesive or 3D brick elements was varied to model different stiffness in the nailed-glued joint.

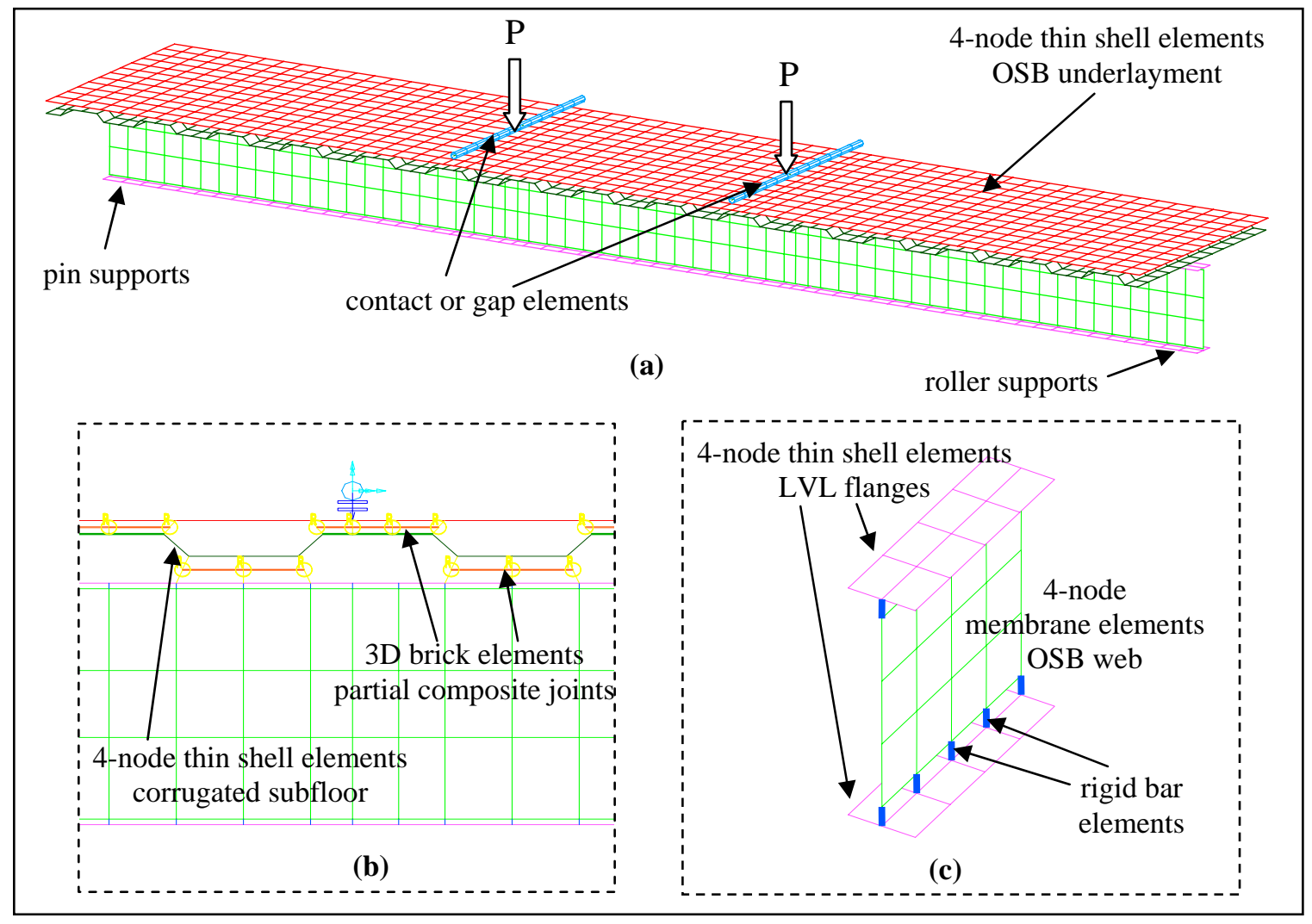

Figure 88: Finite element model of partial composite T-beam; (a) isometric view, (b) side view, and (c) I-joist model. 
Table 38: Material properties of the partial composite T-beam finite element mesh.

\begin{tabular}{|c|c|c|c|c|c|c|}
\hline \multirow[b]{2}{*}{${ }^{(a)}$ I-joist } & \multicolumn{3}{|c|}{ Flange } & \multicolumn{3}{|c|}{ Web } \\
\hline & $\begin{array}{c}\text { Elastic } \\
\text { Modulus } \\
\mathrm{E}_{\mathrm{f}} \\
(\mathrm{psi})\end{array}$ & $\begin{array}{c}\text { Shear } \\
\text { Modulus } \\
\mathrm{G}_{\mathrm{f}} \\
\text { (psi) }\end{array}$ & $\begin{array}{c}\text { Thickness } \\
\mathrm{t}_{\mathrm{f}} \\
\text { (in) }\end{array}$ & $\begin{array}{c}\text { Elastic } \\
\text { Modulus } \\
\mathrm{E}_{\mathrm{w}} \\
(\mathrm{psi})\end{array}$ & $\begin{array}{c}\text { Shear } \\
\text { Modulus } \\
\mathrm{G}_{\mathrm{w}} \\
\text { (psi) }\end{array}$ & $\begin{array}{c}\text { Thickness } \\
\mathrm{t}_{\mathrm{w}} \\
\text { (in) }\end{array}$ \\
\hline \multirow[b]{2}{*}{$\begin{array}{c}\text { Composite } \\
\text { Deck }\end{array}$} & \multicolumn{3}{|c|}{${ }^{(b)}$ Corrugated Subfloor } & \multicolumn{3}{|c|}{${ }^{\text {(c) OSB Underlayment }}$} \\
\hline & $\begin{array}{c}\text { Elastic } \\
\text { Modulus } \\
\mathrm{E}_{\mathrm{c}} \\
(\mathrm{psi}) \\
700,000\end{array}$ & $\begin{array}{c}\text { Shear } \\
\text { Modulus } \\
\mathrm{G}_{\mathrm{c}} \\
(\mathrm{psi}) \\
107,700\end{array}$ & $\begin{array}{c}\text { Thickness } \\
\mathrm{t}_{\mathrm{c}} \\
\text { (in) }\end{array}$ & $\begin{array}{c}\text { Elastic } \\
\text { Modulus } \\
\mathrm{E}_{\mathrm{w}} \\
(\mathrm{psi}) \\
640,000\end{array}$ & $\begin{array}{c}\text { Shear } \\
\text { Modulus } \\
\mathrm{G}_{\mathrm{w}} \\
(\mathrm{psi}) \\
246,150\end{array}$ & $\begin{array}{c}\text { Thickness } \\
\text { tosB } \\
\text { (in) }\end{array}$ \\
\hline \multicolumn{7}{|c|}{ 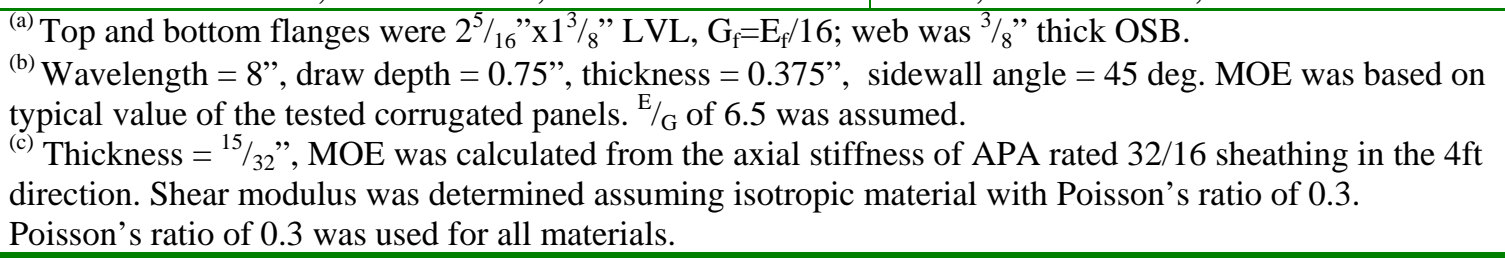 } \\
\hline
\end{tabular}

\section{Comparison of FE and Beam Models}

The effect of composite action was investigated using both FE and beam models by varying the joint stiffness. Average properties of the T-beam components, previously discussed, were used in these two models. The interlayer slip resistance of the nailedglued joint was modeled by changing the adhesive shear modulus, $G_{a d}$. Effective bending stiffness of the beam model was calculated with constant $c_{a d}$ equal to $1 / 15$.

The components of the T-beam were considered unconnected when a low shear modulus was assigned for the adhesive joint. Thus, the stiffness of the T-beam approached the stiffness of the I-joist (2150 $\mathrm{lbs} /$ in for average value of the tested I-joists) because of no composite action between the corrugated deck and the joist (see Table 39 and Figure 89). Full composite action was achieved when the shear modulus was about 
3000 psi and higher. The agreement between the two models was very good. The load/deflection ratio difference was about $5 \%$ or less at any point.

Table 39: Comparison of partial composite T-beam FE and beam models.

\begin{tabular}{ccccc}
\hline $\begin{array}{c}\text { Elastic Modulus } \\
\text { (ksi) }\end{array}$ & $\begin{array}{c}\text { Shear Modulus } \\
(\mathrm{ksi})\end{array}$ & $\begin{array}{c}\text { FE Model } \\
\text { Load/defl } \\
\text { (lbs/in) }\end{array}$ & $\begin{array}{c}\text { Beam Model } \\
\text { Load/defl } \\
\text { (lbs/in) }\end{array}$ & Ratio \\
\hline 10,000 & $3,344.482$ & 3976 & 4004 & 1.01 \\
1,000 & 334.448 & 3863 & 4003 & 1.04 \\
100 & 33.445 & 3803 & 3988 & 1.05 \\
10 & 3.344 & 3636 & 3857 & 1.06 \\
1 & 0.334 & 3050 & 3141 & 1.03 \\
0.1 & 0.033 & 2491 & 2336 & 0.94 \\
0.01 & 0.003 & 2294 & 2170 & 0.95 \\
0.001 & 0.0003 & 2244 & 2153 & 0.96 \\
\hline
\end{tabular}

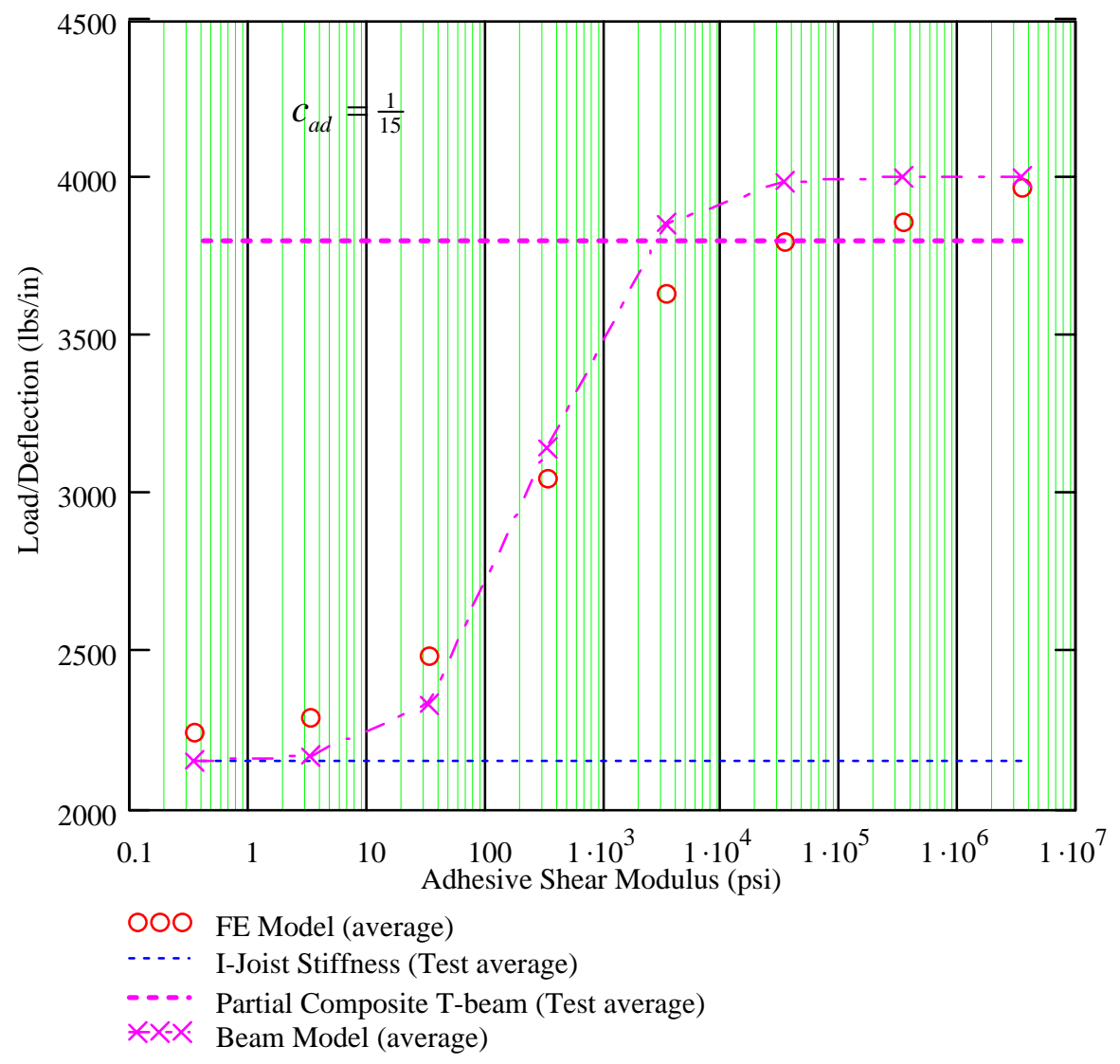

Figure 89: Load-to-deflection versus adhesive shear modulus of the partial composite T-beam. 


\section{System Behavior}

The bending stiffness improved significantly when the corrugated deck system was attached to the I-joist. The tested T-beam was about twice as stiff as the I-joist alone (see Table 40). The LRFD design specification allows the use of a composite action factor $\left(C_{E}\right)$ equal to 1.10 [AF\&PA, 1996a] for nailed-glued floors with solid sawn lumber as joists and sheathing with gaps. The effective bending stiffness ratios listed in Table 40 are comparable to the LRFD design factor $C_{E}$. Current design practice has been based on the mean value for serviceability or deflection calculations. The mean bending stiffness ratio is about 2.03, for the tested corrugated T-beam assembly. The test results are based on a small sample size (4 samples) and short-term deflection without considering any long-term deflection or creep. Furthermore, higher variability can be expected for field nailed-glued joints. $C_{E}$ can be conservatively estimated as 1.60 using the value at two standard deviations below the mean.

The Wood I-Joist Manufacturers Association (WIJMA) uses a difference approach (see footnote of Table 40 or equation (88)) in the determination of effective bending stiffness of a composite T-beam. WIJMA suggests the use of a composite factor equal to 0.45 for a typical nailed-glued I-joist assembly with APA rated Sturd-I-Floor panel as decking material [WIJMA, 2002]. According to the test results, the nailed-glued corrugated floor system achieved about $80 \%$ of the full composite stiffness with a typical subfloor adhesive. However, examination of the test data at two standard deviations below the mean yields composite factor equal to 0.48 , which is close to the composite factor suggested by WIJMA. 
The allowable moment for the I-joist according to the manufacturer is 2,680 ft-lbs [TJI ,2002]. To compare the test results to the I-joist, the allowable moment for the composite T-beam, $M_{a}$, is estimated, based on the $5^{\text {th }}$ percentile value $(11,800 \mathrm{ft}-\mathrm{lbs}$, Table 40) of the ultimate moment, $M_{5 t h}$.

$$
M_{a}=\frac{M_{5 t h}}{L F / \phi_{b} \lambda}
$$

For residential construction with dead load and live load applied to the structure, the resistance factor for flexure $\left(\phi_{b}\right)$ and time effect factor $(\lambda)$ are 0.85 and 0.8 , respectively [AF\&PA, 1996a]. The load factor, $L F$, can be conservatively taken as 1.6 by assuming very high live load to dead load ratio. Therefore, the factor of safety, ${ }^{L F} / \phi_{b} \lambda$, is about 2.35 and the allowable moment for the T-beam is about $5000 \mathrm{ft}$-lbs (see Appendix L). The allowable moment of the T-beam is about $85 \%$ higher than that of the I-joist. The LRFD design specification permits up to $15 \%$ increase in moment resistance over single member strength, the load-sharing factor $\left(C_{E}\right)$ equal to 1.15 [AF\&PA, 1996a] for repetitive-member floor systems. The test result is not directly comparable to the loadsharing factor. However, the test shows that T-beam action benefits strength gain through the attached corrugated deck system. Possibly, a higher load-sharing factor might be used for floor assembly with a corrugated deck system for more efficient design. Further testing should be conducted on full-scale floor systems (with 3 or more joists) to verify the load-sharing effect. The corrugated deck system is expected to perform better in loadsharing than a typical flat panel, since the stiffness of the deck is higher above the joists. 
Table 40: System effect of nailed-glued T-beam assembly with corrugated composite deck system.

\begin{tabular}{|c|c|c|c|c|c|c|}
\hline \multirow{2}{*}{$\begin{array}{l}\text { Beam } \\
\text { No. }\end{array}$} & \multicolumn{3}{|c|}{$\begin{array}{l}\text { (a) Bending Stiffness } \\
\left(\mathrm{x} 10^{6} \mathrm{lbs}^{2} \mathrm{in}^{2}\right)\end{array}$} & \multirow{2}{*}{$\begin{array}{l}\text { (b) T-Beam } \\
\text { Ultimate } \\
\text { Moment } \\
\text { Capacity } \\
\text { (ft-lbs) }\end{array}$} & \multirow{2}{*}{$\begin{array}{c}\text { Effective } \\
\text { Bending Stiffness } \\
{ }^{(\mathrm{c})} \text { Ratio }\end{array}$} & \multirow{2}{*}{$\begin{array}{l}\text { (d) Composite } \\
\text { Factor }\end{array}$} \\
\hline & I-Joist & T-Beam & $\begin{array}{c}\text { Full } \\
\text { Comp. }\end{array}$ & & & \\
\hline 1 & 163 & 320 & 366 & 12,789 & 1.96 & 0.77 \\
\hline 2 & 149 & 347 & 343 & 14,250 & 2.33 & 1.02 \\
\hline 3 & 156 & 306 & 354 & 12,077 & 1.96 & 0.76 \\
\hline 4 & 144 & 266 & 334 & 11,756 & 1.85 & 0.64 \\
\hline Mean & 153 & 310 & 349 & 12,718 & 2.03 & 0.80 \\
\hline Std. & 8 & 33 & 13 & 1,109 & 0.21 & 0.16 \\
\hline COV & 0.05 & 0.11 & 0.04 & 0.09 & 0.10 & 0.20 \\
\hline$+2(s t d)$ & 170 & 377 & 376 & 14,936 & 2.45 & 1.11 \\
\hline$-2(\mathrm{std})$ & 136 & 243 & 322 & 10,501 & 1.60 & 0.48 \\
\hline $5^{\text {th }} \%$ & 145 & 272 & 336 & 11,804 & 1.86 & 0.66 \\
\hline \multicolumn{7}{|c|}{$\begin{array}{l}\text { (a) Bending stiffness is based on load/deflection ratio of test data (see Table 37), including the effect of shear deformation. } \\
\text { (b) Ultimate moment capacity is based on the ultimate load applied (see Table 37) on the tested partial composite T-beam specimens. } \\
\text { (c) Ratio is based on the effective bending stiffness of T-beam over the I-joist bending stiffness. } \\
\text { (d) Composite factor is calculated as } \frac{E I_{e f f}-E I_{j}}{E I_{\text {comp }}-E I_{j}} \text {, see equation (88). }\end{array}$} \\
\hline
\end{tabular}




\section{Mock-Up Floor}

Test results show that the corrugated deck system has benefits over traditional flat panels because of its increased stiffness and strength. However, there might be potential pitfalls in the system, during the construction phase especially, because of the three dimensional shapes involved. In the final phase of this project, a mock-up corrugated floor system was built for the evaluation of construction procedures.

A 8' x 12' mock-up floor was constructed with four I-joists at 32” spacing, as shown in Figure 90. The four 9 1/2” deep I-joists were tied together at the joists ends only with two 11/4" x 9 1/2/2 rim boards. Three standard size corrugated panels were placed with corrugations (strong axis) across the I-joists. APA rated 32/16 OSB sheathing was used as underlayment, with the strength axis or surface flakes oriented parallel to the corrugations of the corrugated subfloor. End joints in underlayment panels were staggered. 

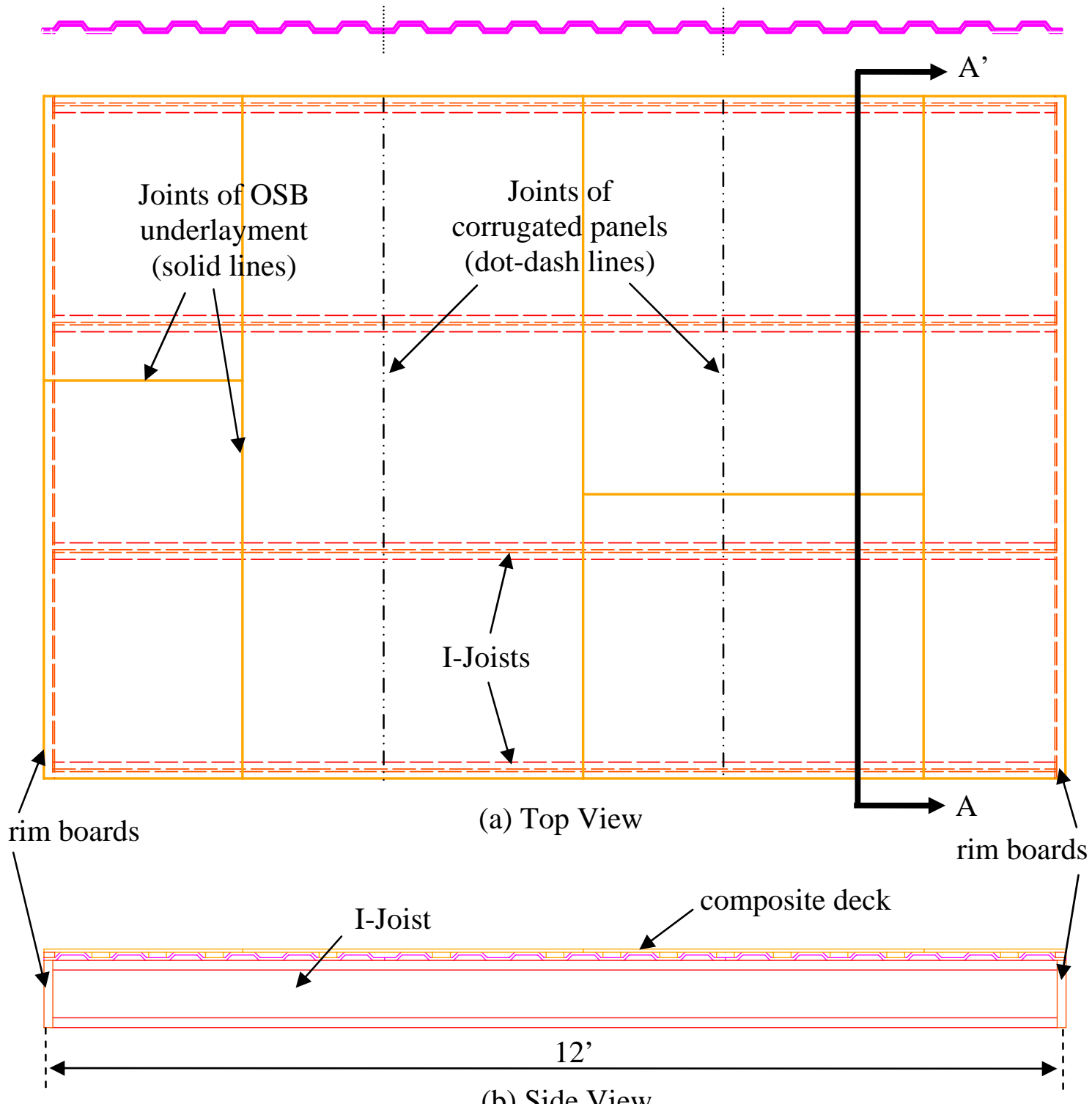

(b) Side View

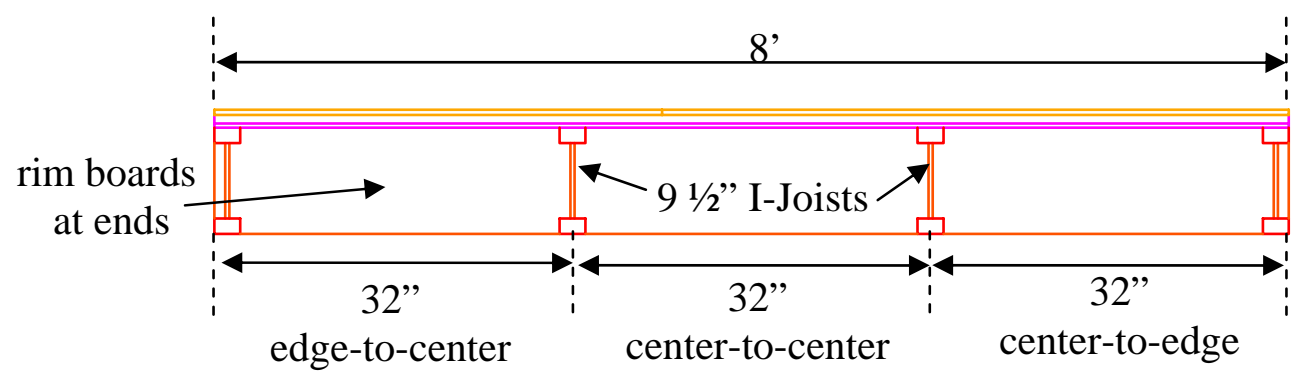

(c) Front View (Section A-A')

Figure 90: Schematic of the composite corrugated floor system; (a) top view, (b) side view, and (c) front view. 


\section{Construction Procedures}

Four 91/2” depth I-joists were spaced at 32” on-center for the interior spacing and measured 32" from the center of the interior joist to the edge of the exterior joist (see Figure 90(c)). The edge to edge dimension of the floor was $8 \mathrm{ft}$. The I-joists were cut to 11 '-9.5” in length and connected together at the joist ends with two 11/4" x 91/2” laminated strand lumber (LSL) rim boards resulting in a $12 \mathrm{ft}$ long floor, measured from edge to edge (Figure 91). The top flanges of the I-joists were lightly cleaned to remove dirt particles and a continuous line of AFG-01 adhesive (about 1/4” diameter) was applied (Figure 92). Adhesive was spread only enough to lay one corrugated panel at a time to prevent premature setting of the adhesive.

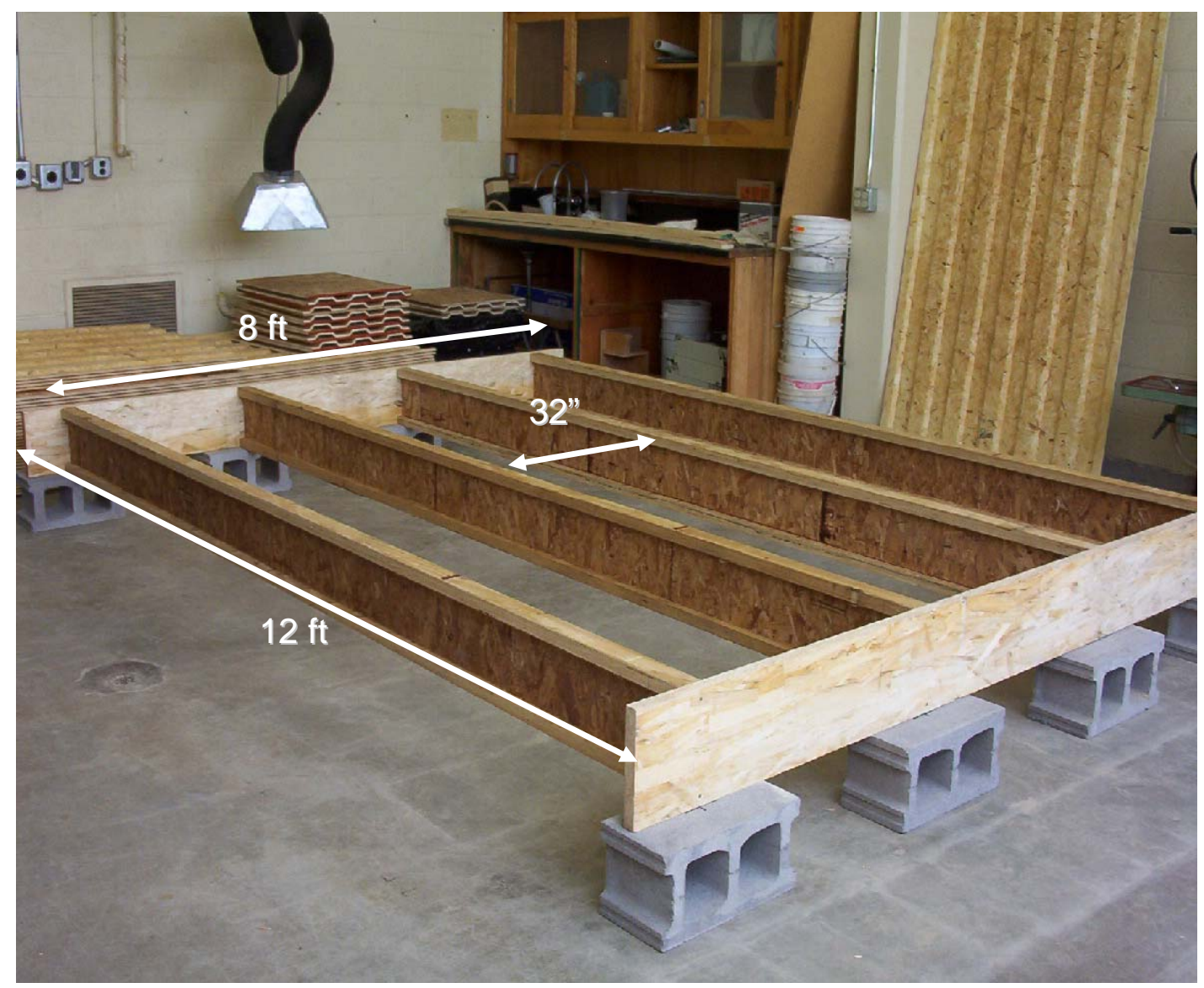

Figure 91: Mock-up floor construction; four I-joists at 32" spacing. 


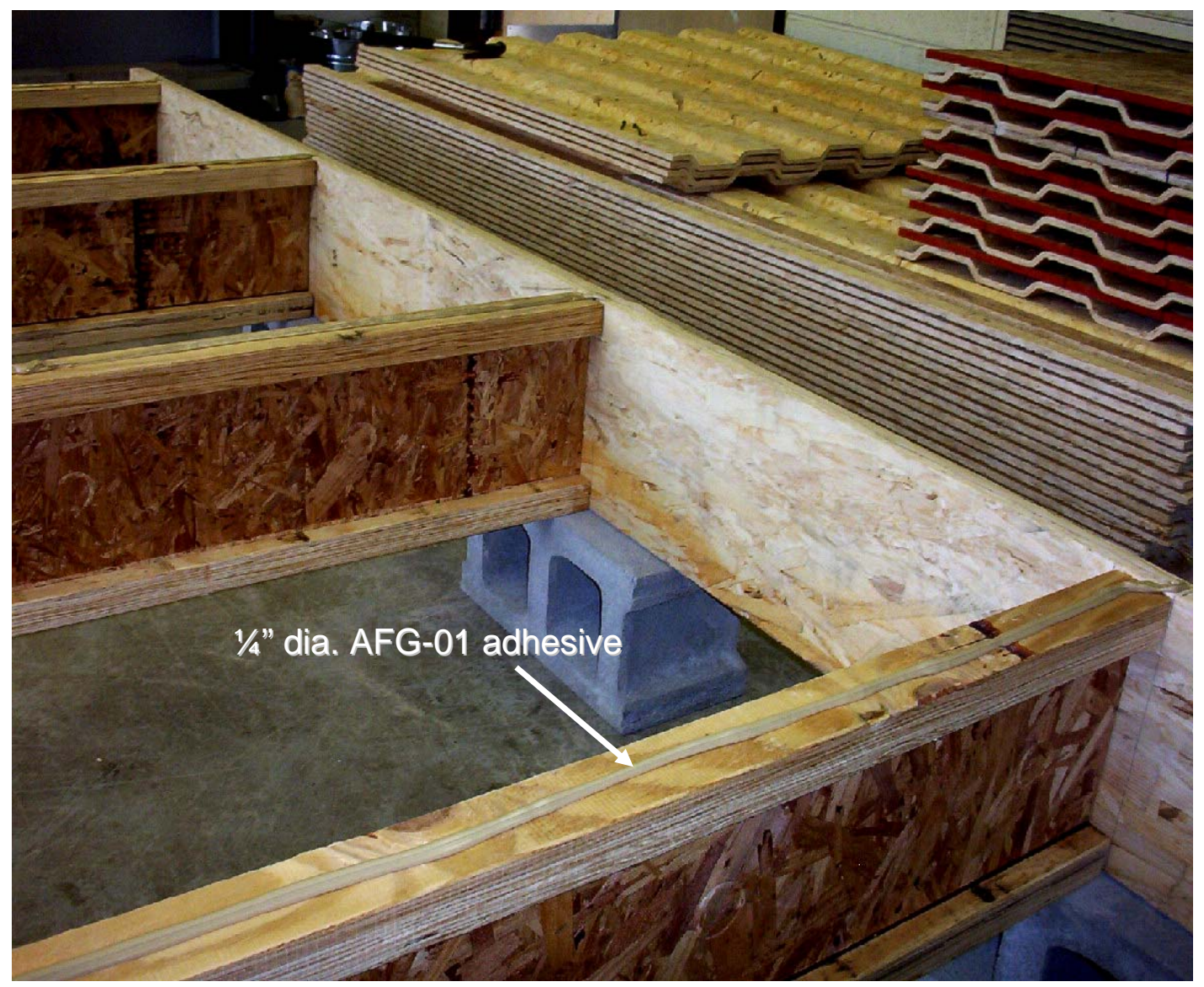

Figure 92: Mock-up floor construction; 1/4" diameter AFG-01 adhesive on I-joist.

The subfloor consisted of three corrugated panels with the corrugations laid across the I-joists. The corrugated panels were placed such that the gaps or joints parallel to the corrugations were located at lower decks. Shims were used to maintain the gaps in the corrugated panels to about $1 / 16$ ". The corrugated panels were fastened to the I-joists using $6 \mathrm{~d}$ box nails at about 4" effective spacing around the floor edges (with two nails at each lower deck of the exterior joists, see Figure 93). The nail spacing for the interior joists was equal to the wavelength of the corrugated panel which was 8" (with one nail at each lower deck). 


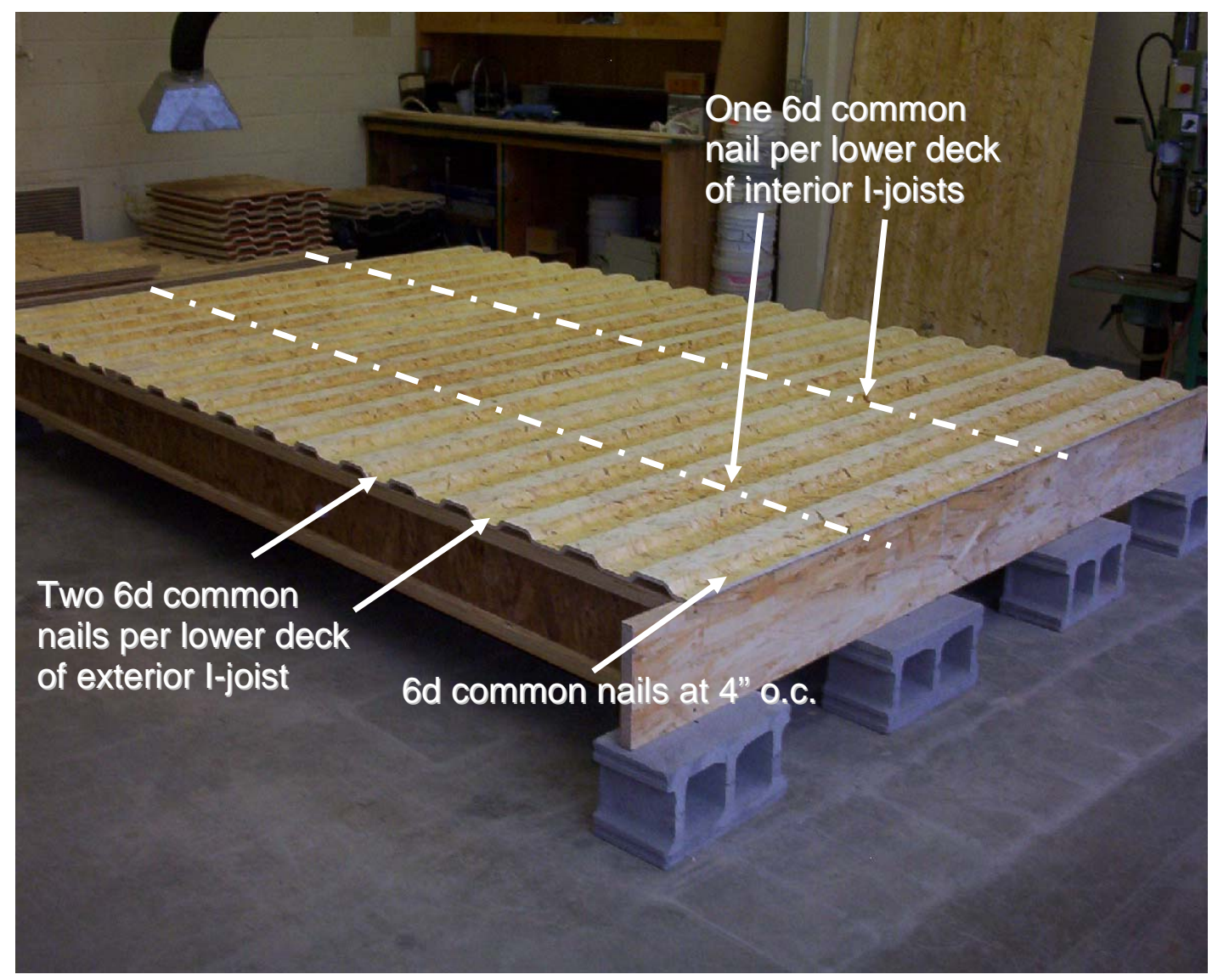

Figure 93: Mock-up floor construction; nails schedule of corrugated subfloor.

Blocking materials were provided along the exterior I-joists to demonstrate an option of providing additional bearing strength for carrying concentrated loads, such as wall load, if necessary. The depth of the corrugated panel is $3 / 4$ ", thus nominal 1 " lumber (actual 3/4" thick) can be conveniently used as blocking material. Blocking was held in place at every other channel by some adhesive and one 3d ringshank nail. Continuous blocking was also provided along the two edges of the floor that were parallel to the corrugations using nominal 1"x2” lumber.

Adhesive that conformed to the APA AFG-01 specification was applied (about $1 / 4$ " diameter) on the top decks of the corrugated panels (Figure 94). A separate layer of underlayment, APA rated 32/16 OSB sheathing, was then installed with the joints located on the top decks and offset from the joints of the corrugated subfloor. Intermediate 
blockings were also installed at the end joints of the underlayment to demonstrate an alternative to the tongue-and-groove (T\&G) joint if needed, as shown in Figure 94. The end joints in each succeeding row of underlayment were staggered. 3d ringshank nails were used to attach the underlayment to the subfloor with 6" spacing along each top deck. Snapping chalk lines or marking of the nail schedule was not needed because the ridges of the corrugated panels provided easy reference lines for nailing of the underlayment (Figure 95). Nailing of each underlayment was done before the adhesive set. The final corrugated composite floor system is shown in Figure 96.

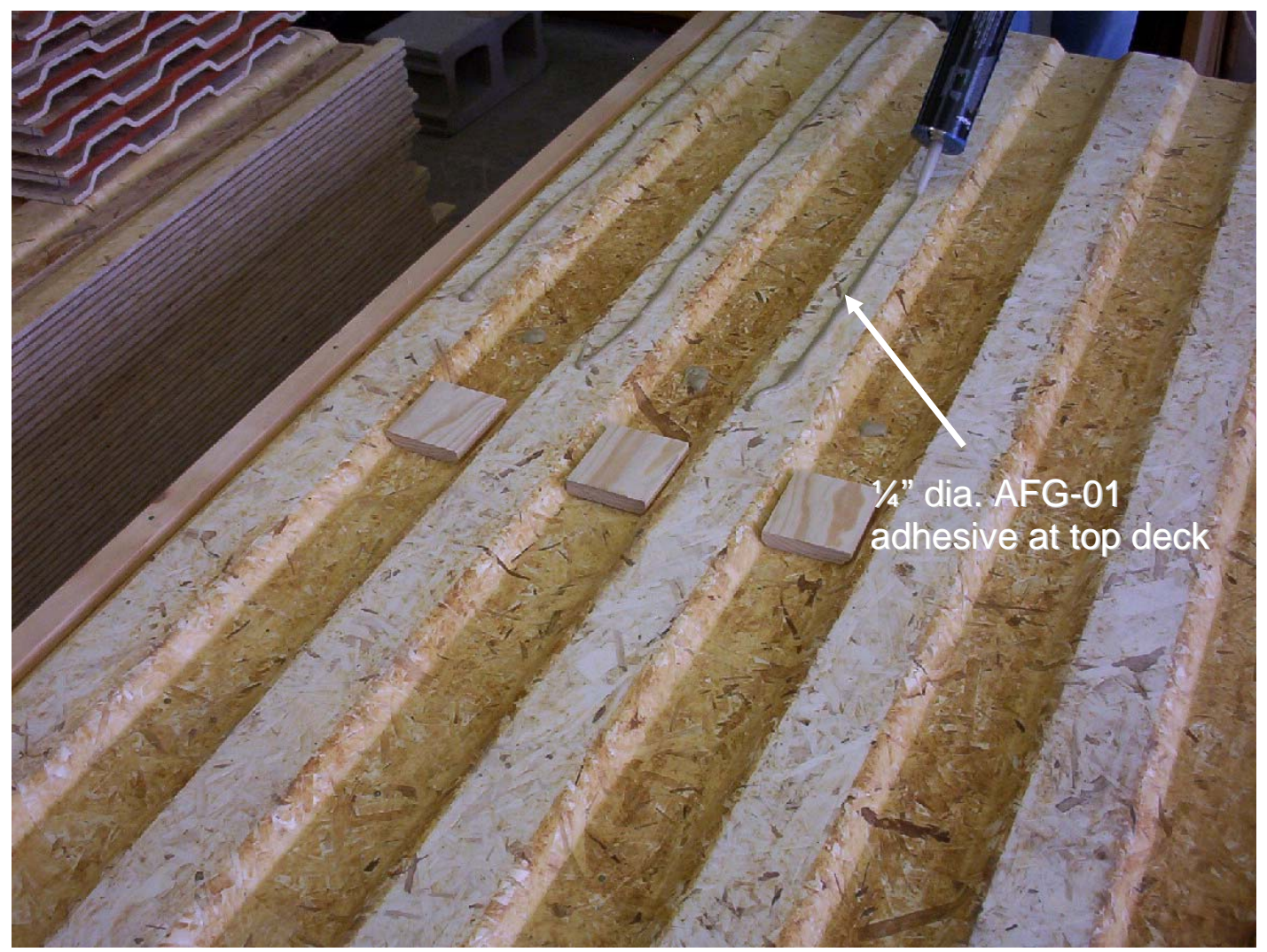

Figure 94: Mock-up floor construction; application of adhesive on corrugated subfloor. 


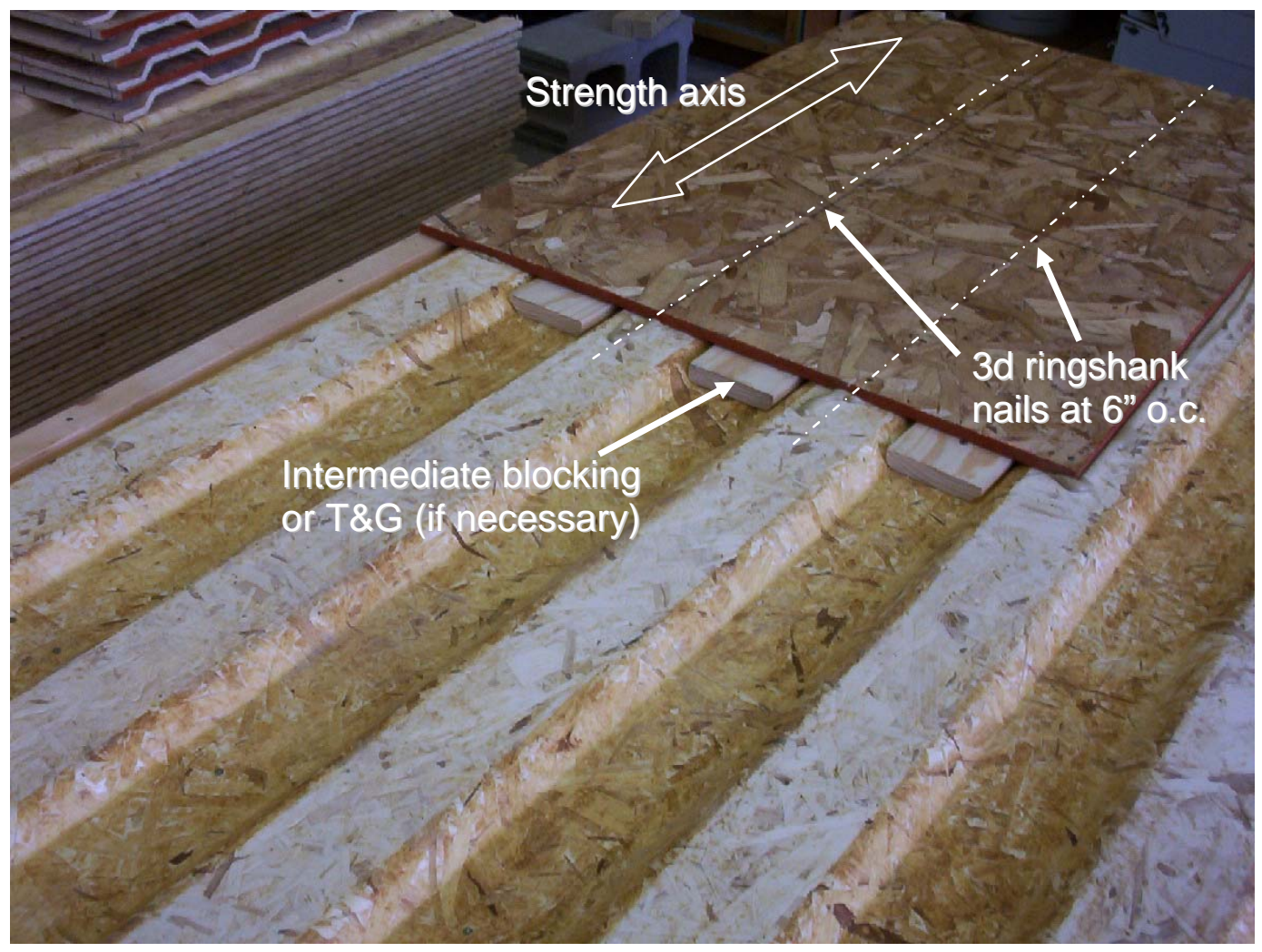

Figure 95: Mock-up floor construction; installation of underlayment.

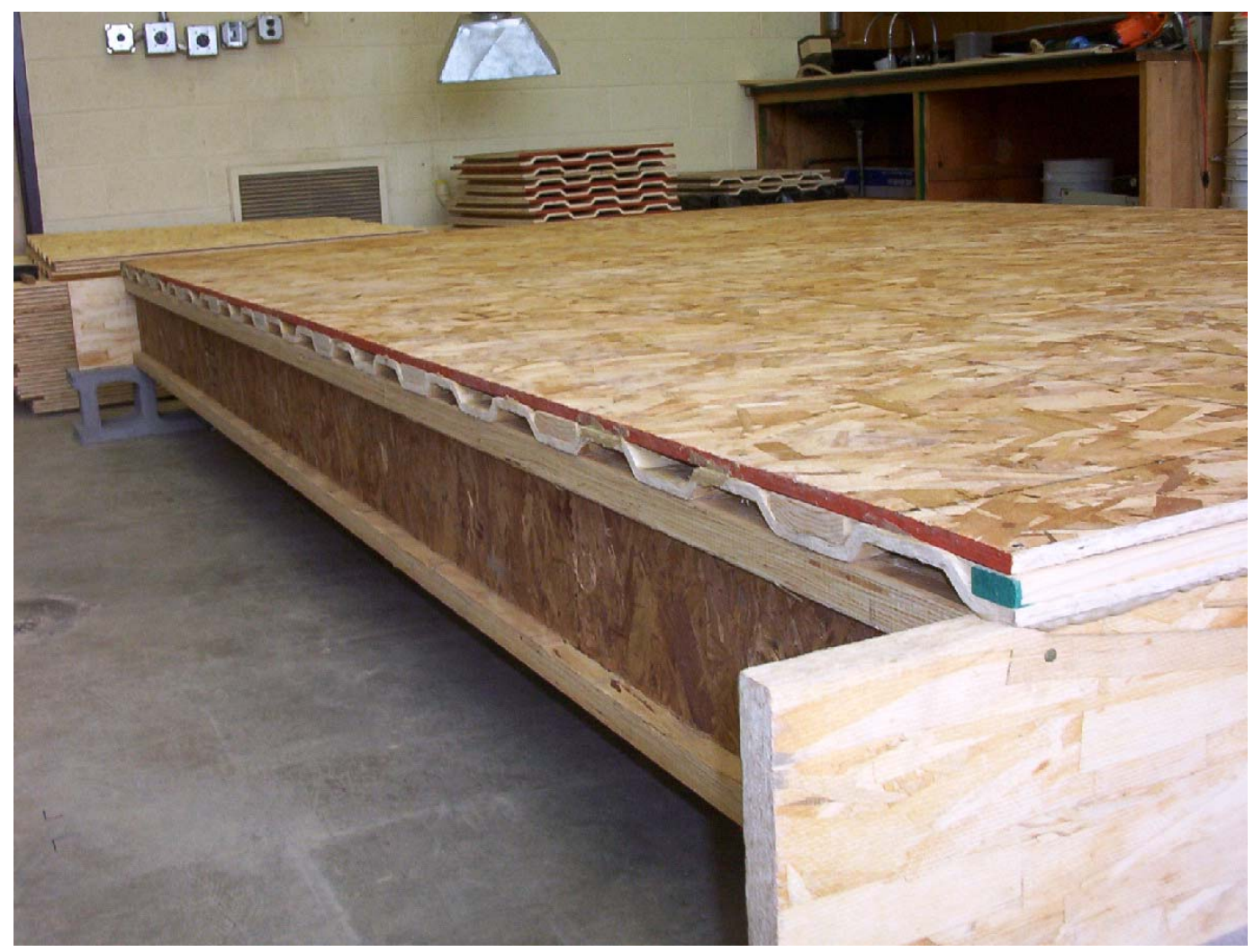

Figure 96: Corrugated composite floor system. 


\section{Comparison to Traditional Floor Systems}

The two most commonly used flooring systems in residential construction today are a two-layer subfloor-underlayment system and a single layer Sturd-I-Floor system. The traditional two-layer system consists of rated sheathing as subflooring and a separate layer of underlayment installed over the subfloor. In recent years, the Sturd-I-Floor system has gained popularity over the two-layer system due to the reduction of costs that the Sturd-I-Floor system provides by replacing the subfloor and underlayment with a single layer of thick plywood or OSB. In order for the corrugated floor system to be used in residential construction, it must be able to compete with these traditional floor systems both in terms of construction costs and also structural performance.

\section{Construction Costs}

A basic feasibility study considering the use of a corrugated floor system was performed by Mathieu in 1992 to compare the construction costs of the traditional floor systems [Mathieu, 1992]. The construction costs may have changed greatly over the past ten years; however, the results of the cost analysis still provide some insight into the potential for using corrugated subfloor as a structural component. For floors with comparable performance, the cost estimate for the two-layer corrugated floor system shows lower construction costs than the traditional two-layer system. Mathieu estimated slightly lower constructions costs for Sturd-I-Floor compared to a corrugated floor system. The study was based on deeper corrugated panels that involved complex mat forming technique thus increasing the production cost. The corrugated panels produced for this project utilize the same basic production process as typical OSB without the complexity of forming the mat. The use of random mats in the production even further 
simplified the process by eliminating the need to align the flakes in multiple layers. The production cost of a shallow random mat corrugated panel is expected to be the same as (if not cheaper than) a typical OSB panel because of two main reasons; utilizing less raw material and requiring no flake alignment. The two-layer corrugated floor system might be able to gain competitiveness over the cheaper labor costs provided by the single layer Sturd-I-Floor through cheaper materials and better performance. A more in depth cost analysis should be performed before a conclusion can be drawn.

\section{Flexural Performances}

Based on the flexural test results, baseline flexural capacities and load-span tables that conform to the LRFD design philosophy were developed for the corrugated panel and the composite deck. The section properties of the corrugated panel are summarized in Table 41. The MOE and MOR were estimated from the $5^{\text {th }}$ percentile values of the test. The area, moment of inertia and section modulus were calculated using equations (49), (4), and (6), respectively, and then dividing through by the wavelength to obtain section properties per width.

Table 41: Section properties of corrugated panel.

\begin{tabular}{ccccc}
\hline $\begin{array}{c}\text { Wavelength } \\
\text { (in) }\end{array}$ & $\begin{array}{c}\text { Angle } \\
\text { (deg) }\end{array}$ & $\begin{array}{c}\text { Draw Depth } \\
\text { (in) }\end{array}$ & $\begin{array}{c}\text { Thickness } \\
\text { (in) }\end{array}$ & $\begin{array}{c}\text { Approximate } \\
\text { Weight } \\
\text { (psf) }\end{array}$ \\
8 & 45 & $3 / 4$ & $3 / 8$ & 1.25 \\
\hline \hline $\begin{array}{c}\text { Area } \\
\left(\mathrm{in}^{2} / \mathrm{ft}\right)\end{array}$ & $\begin{array}{c}\text { Moment of } \\
\text { Inertia } \\
\left(\text { in }^{4} / \mathrm{ft}\right)\end{array}$ & $\begin{array}{c}\text { Section } \\
\text { Modulus } \\
\left(\text { in }^{3} / \mathrm{ft}\right)\end{array}$ & $\begin{array}{c}\text { MOE } \\
(\mathrm{psi})\end{array}$ & $\begin{array}{c}\text { MOR } \\
(\mathrm{psi})\end{array}$ \\
4.849 & 0.635 & 1.129 & 620,000 & 2,700 \\
\hline
\end{tabular}


The baseline flexural capacities of the corrugated panel and the composite deck system (with 15/32" thick APA rated 32/16 sheathing as underlayment) were conservatively estimated from the $5^{\text {th }}$ percentile values of the test. The tabulated factored moment capacities were based on a LRFD bending resistance factor, $\phi_{b}$, of 0.85 and time effect factor, $\lambda$, of 0.8 for typical residential construction. Flexural capacities of composite deck in the weak axis (secondary) are not available. Weak axis bending of the composite deck was not tested since the deck was intended to be used as a "one-way slab” system with primary bending parallel to the corrugations. The primary bending stiffness of the corrugated panel is about the same as a typical APA rated 48/24 sheathing which is about twice as thick ( $(3 / 4)$ as the corrugated panel $(3 / 8$ "). The two-layer composite deck system is comparable to a $1 \frac{1}{8} 8$ " thick, 48 oc Sturd-I-Floor system with primary EI of 1150 kip-in ${ }^{2} / f t$. However, the factored moment capacities of both the corrugated panel and the composite deck system are noticeably higher than that of the 48/24 sheathing (1.460 kip-in/ft) and 48 oc Sturd-I-Floor (2.765 kip-in/ft).

Table 42: Baseline flexural capacities of corrugated panel and composite deck system.

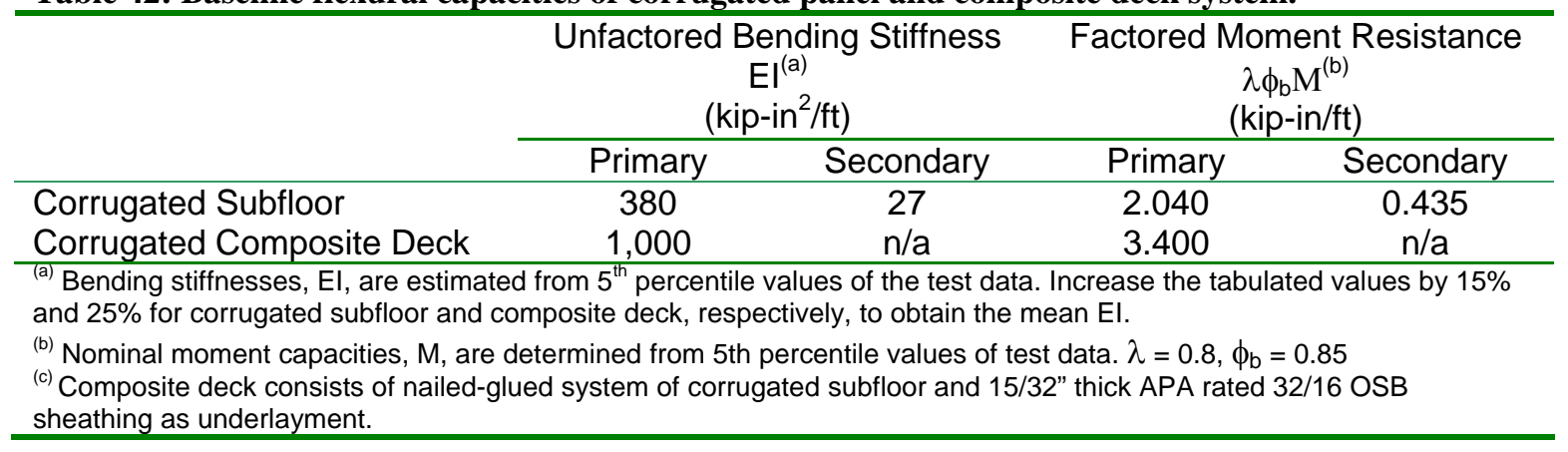

Load-span tables were generated for both the corrugated panel and composite deck system to provide an overview of the floor performances. The tabulated unfactored uniform load capacities were determined conforming to the assumptions used in the 
LRFD Structural-Use Panels design supplement [AF\&PA, 1996b]. The uniform load capacities were based on deflection (stiffness) and moment strength limit states. Baseline shear strength of the corrugated panel was not established, thus the shear limit state was not included in the tables. However, test results indicate that shear strength is not likely to be the governing factor (compared to deflection and moment) for the ultimate load capacity. The composite deck system is suitable for joist spacings up to 48 ” on-center under normal residential loads (about 40 psf) with a L/480 deflection limitation.

Table 43: Unfactored uniform load capacities (psf) of corrugated panel.

\begin{tabular}{c|ccccccc|cccc}
\hline & \multicolumn{5}{c|}{$\begin{array}{c}\text { Primary Axis } \\
\text { Across Supports }\end{array}$} & \multicolumn{4}{c}{$\begin{array}{c}\text { Secondary Axis } \\
\text { Across Supports }\end{array}$} \\
\cline { 2 - 14 } & \multicolumn{4}{c|}{ Center-to-Center Span (in) } & & & \multicolumn{3}{c}{ Center-to-Center Span (in) } \\
\hline Limit State & 12 & 16 & 19.2 & 24 & 32 & 40 & 48 & 12 & 16 & 19.2 & 24 \\
\hline (a)L/480 & 1,111 & 430 & 239 & 117 & 47 & 27 & 15 & 79 & 31 & 17 & 8 \\
(a)L/360 & 1,481 & 573 & 318 & 156 & 63 & 36 & 20 & 105 & 41 & 23 & 11 \\
(a) L/240 & 2,221 & 860 & 477 & 234 & 95 & 54 & 30 & 158 & 61 & 34 & 17 \\
(a)L/180 & 2,962 & 1,147 & 636 & 313 & 127 & 72 & 40 & 210 & 81 & 45 & 22 \\
(b)Moment & 1,065 & 600 & 418 & 268 & 152 & 98 & 69 & 229 & 130 & 91 & 59 \\
\hline
\end{tabular}

(a)For support spacing less than or equal to 32", 3 spans and nominal 2" joists are assumed. Deflection limit states are calculated using clear span plus $0.25 "$.

For support spacing greater than 32", 2 spans and nominal 2" joists are assumed. Deflection limit states are calculated using clear span plus $0.625 "$.

(b) Moment limit state is based on the LRFD specification with time effect factor, $\lambda$, equal to 0.8 and resistance factor for bending, $\phi_{\mathrm{b}}$, equal to 0.85 . A $1.2 \mathrm{D}+1.6 \mathrm{~L}$ load combination and $10 \mathrm{psf}$ of dead load are assumed.

Table 44: Unfactored uniform load capacity (psf) of corrugated composite deck (with 15/32" rated 32/16 OSB sheathing as underlayment)

\begin{tabular}{c|ccccccc}
\hline & \multicolumn{7}{|c}{ Primary Axis Across Supports } \\
\cline { 2 - 7 } & 12 & 16 & 19.2 & 24 & 32 & 40 & 48 \\
\hline Limit State & 128 Center-to-Center Span (in) \\
\hline (a) $L / 480$ & 2,923 & 1,132 & 628 & 308 & 125 & 71 & 40 \\
(a) $L / 360$ & 3,897 & 1,509 & 837 & 411 & 167 & 95 & 53 \\
(a) $L / 240$ & 5,846 & 2,263 & 1,256 & 617 & 250 & 142 & 79 \\
(a) $L / 180$ & 7,795 & 3,018 & 1,674 & 822 & 333 & 189 & 105 \\
(b)Moment & 1,773 & 999 & 694 & 445 & 252 & 162 & 113 \\
\hline
\end{tabular}

(a)For support spacing less than or equal to 32", 3 spans and nominal 2" joists are assumed. Deflection limit states are calculated using clear span plus $0.25 "$.

For support spacing greater than 32", 2 spans and nominal 2" joists are assumed. Deflection limit states are calculated using clear span plus $0.625 "$.

(b) Moment limit state is based on the LRFD specification with time effect factor, $\lambda$, equal to 0.8 and resistance factor for bending, $\phi_{\mathrm{b}}$, equal to 0.85 . A $1.2 \mathrm{D}+1.6 \mathrm{~L}$ load combination and $10 \mathrm{psf}$ of dead load are assumed. 


\section{Conclusions and Recommendations}

\section{Conclusions}

This research investigated the potential of using shallow corrugated wood composite panels as structural decking material for light frame construction. The corrugation profile selected for this research has a wavelength equal to 8”, a channel depth equal to $3 / 4$ ”, a sidewall angle equal to 45 degrees, and a panel skin thickness equal to $3 / 8$ ". Molding trials of the 16 "x16” and the 4'x8' corrugated panels indicated that largescale production of the shallow corrugated panel is feasible. The production of the corrugated panel follows typical manufacturing processes used by current OSB plants. Modification to the current mat forming process of existing OSB plants is not required. The flexural test data showed that the corrugated panels produced using a random mat and a typical 3-layer OSB flake alignment had similar strong axis bending stiffness and strength.

The flexural performance of the $\frac{3}{8}$ " thick shallow corrugated panel is comparable to a typical APA rated 48/24 sheathing or a 24 oc Sturd-I-Floor. The tested nailed-glued (using AFG-01 adhesive) corrugated composite deck system with a $15 / 32$ ” thick APA rated $32 / 16$ sheathing as underlayment achieved about 50\% to $60 \%$ composite action. This composite deck system is suitable for use in floor systems with joist spacing at 32”, 40” and 48” on-center. The composite deck system can carry about 40 psf of unfactored uniform load with a deflection limit of $\mathrm{L} / 480$.

The bending stiffness of the composite T-beam, with a 24” wide corrugated composite deck system, was about twice as stiff as the $9 \frac{1}{2} 2^{\prime}$ I-joist. The nailed-glued 
corrugated composite T-beam specimens achieved about $80 \%$ composite action on average. The composite T-beams also provided significant gain in moment resistance (about 85\% higher than the I-joist) through the T-beam action between the I-joist and the corrugated deck system.

The corrugated composite floor system has advantages over the traditional twolayer subfloor-underlayment system with better flexural performance (stronger and stiffer floor) under similar or lower material and labor costs. Without an in depth cost analysis, whether the corrugated floor system can offset the cheaper labor costs of the single-layer Sturd-I-Floor through the material savings is not clear. However, with the diminishing of the large diameter roundwood, the potential of the corrugated composite deck system to offer an effective and economical alternative in the near future is high.

\section{Recommendations for Future Work}

The flexural stiffnesses of the corrugated panel and composite deck system were obtained through short-term testing only. The long-term load or creep effects on the corrugated panel are not known. In addition to the long-term behavior of the corrugated panel, the creep in the nailed-glued joints could have impact on the overall system behavior of the composite deck and the T-beam. Sustained load tests should be performed to study the long-term behavior of the corrugated composite deck system.

The use of the corrugated composite deck system may change the diaphragm shear strength of the floor system. The effect that the wave shape has on the diaphragm strength is not clear. Mathematical models along with experimental testing should be used to investigate the diaphragm strength of the corrugated panel compared on the traditional floor systems. 
The potential of using the shallow corrugated panel as a subfloor base for lightweight concrete floor systems is great. The high stiffness corrugated panel can minimize the deflection during pouring of lightweight concrete. In addition, the foldedplate structure of the corrugated panel provides an excellent form for the final ribbed slab system which will greatly increase the overall floor stiffness. The corrugated panel also offers a possible efficient way to install in-floor heating systems. Hot water tubes can be easily laid down in the 3/4" depth channels.

Aside from the floor application, corrugated panels may be a possible substitution for the current light-frame stud wall systems. The use of the corrugated panel to replace wall studs may greatly reduce the construction costs of the light-frame wood wall systems. The buckling strength of the corrugated panel with various corrugation profiles should be studied in order to assess the usage of corrugated panels in the wall system. 


\section{Notation}

$A_{a d}=$ area of the adhesive joint $\left(\mathrm{in}^{2}\right)$

$A_{c}=$ area of the corrugated panel (in ${ }^{2}$ per wavelength)

$A_{s}=$ shear area $\left(\right.$ in $\left.^{2}\right)$

$a=$ distance from the support to the nearest point load (in)

$b=$ panel width (in)

$b_{a d}=$ width of the adhesive (in)

$b_{f}=$ I-joist flange width (in)

$C_{E}=$ composite action factor

$C_{\text {eff }}=$ composite factor

$C_{i}=$ coefficients for polynomial functions

$C_{r}=$ load sharing factor

$c_{a d}=$ constant for composite model

$c_{b 1}, c_{s 1}=$ single-span beam model calibration coefficients

$c_{b 2}, c_{s 2}=$ two-span beam model calibration coefficients

$D_{x}=$ flexural rigidity of the plate in the weak axis direction (lbs-in 2 /in)

$D_{y}=$ flexural rigidity of the plate in the strong axis direction (lbs-in $2 /$ in)

$D_{x y}=$ torsional rigidity of the plate (lbs-in $2 /$ in)

$D_{12}=$ flexural rigidity term of the plate (lbs-in $\left.{ }^{2} / \mathrm{in}\right)$

$d=$ total depth or amplitude of the corrugated panel, $h+t$, (in) 
$d_{j}=$ depth of I-joist (in)

$E=$ modulus of elasticity (psi)

$E_{c}=$ modulus of elasticity of the corrugated panel (psi)

$E_{f}=$ modulus of elasticity of the flange of I-joist (psi)

$E_{w}=$ modulus of elasticity of the web of I-joist (psi)

$E_{c 1}=$ modulus of elasticity of the corrugated panel estimated from the single-span condition (psi)

$E_{c 2}=$ modulus of elasticity of the corrugated panel estimated from the two-span condition (psi)

$E_{f}=$ modulus of elasticity of the flat panel (psi)

$\overline{E A}=$ total transformed or effective axial stiffness of the composite deck section (lbs/ft)

$E A_{c}=$ axial stiffness of the corrugated panel (lbs per wavelength)

$E A_{\text {deck }}=$ axial stiffness of the composite deck for T-beam (lbs)

$\overline{E A}_{d e c k}=$ effective axial stiffness of the composite deck for T-beam (lbs)

$E A_{f}=$ axial stiffness of the flange of the I-joist (lbs/in)

$E A_{j}=$ axial stiffness of the I-joist (lbs)

$\overline{E A_{O S B}}=$ effective axial stiffness of the OSB underlayment for T-beam (lbs/in)

$E A_{O S B}=$ axial stiffness of the OSB underlayment for T-beam (lbs/in)

$E A_{u n}=$ axial stiffness of the underlayment (lbs/in)

$\overline{E A}_{u n}=$ transformed or effective axial stiffness of the underlayment (lbs/in)

$E A_{w}=$ axial stiffness of the web of the I-joist (lbs/in) 
$E I_{\text {beam } 1}=$ bending stiffness per unit width of the single span condition $\left(\mathrm{in}^{2}-\mathrm{lb} / \mathrm{ft}\right)$

$E I_{\text {beam } 2}=$ bending stiffness per unit width of the two-span condition $\left(\mathrm{in}^{2}-\mathrm{lb} / \mathrm{ft}\right)$

$E I_{\text {comp }}=$ bending stiffness of the full composite deck(lbs-in $\left.{ }^{2} / \mathrm{ft}\right)$

$E I_{\text {eff }}=$ effective bending stiffness (lbs-in $\left.{ }^{2} / \mathrm{ft}\right)$

$E I_{\text {eff }}=$ effective bending stiffness for T-beam (lbs-in ${ }^{2}$ )

$E I_{f}=$ bending stiffness of the I-joist flange (lbs-in ${ }^{2}$ )

$E I_{j}=$ bending stiffness of the I-joist (lbs-in²)

$E I_{u}=$ unattached bending stiffness (lbs-in ${ }^{2} / \mathrm{ft}$ )

$E I_{w}=$ bending stiffness of the I-joist web (lbs-in $\left.{ }^{2}\right)$

$F=$ force vector for the plate model

$F_{b} S_{\text {beam1 }}=$ bending strength or moment capacity per unit width of single span condition ( $^{\text {in- }}$ $\mathrm{lbs} / \mathrm{ft}$ )

$F_{b} S_{\text {beam } 2}=$ bending strength or moment capacity per unit width of two-span condition ( ${ }^{\text {in- }}$ $\mathrm{lbs} / \mathrm{ft}$ )

$G=$ shear modulus (psi)

$G_{a d}=$ shear modulus of adhesive (psi)

$G_{u n}=$ shear modulus of the underlayment (psi)

$G_{w}=$ shear modulus of the I-joist web (psi)

$G A_{\text {eff }}=$ effective shear stiffness (lbs/ft)

$G A_{t n}=$ shear stiffness of the underlayment (in)

$H=$ flexural rigidity term of the plate (lbs-in $\left.{ }^{2} / \mathrm{in}\right)$ 
$h=$ channel depth of the corrugated panel (in)

$h_{w}=$ height of the I-joist web (in)

$I=$ moment of inertia $\left(\right.$ in $\left.^{4}\right)$

$I_{c}=$ moment of inertia of the corrugated panel (in ${ }^{4}$ per wavelength)

$I_{f}=$ moment of inertia of the flat panel (in ${ }^{4}$ per wavelength)

$K=$ stiffness matrix of the plate model

$k_{s}=$ shear correction coefficient

$L=$ span length (in)

$\tilde{L}=$ length of adhesive joint (in per wave length)

$L_{a d}=$ length of the adhesive joint (in)

$L_{e q}=$ equivalent span length (in)

$L_{u n}=$ length of the underlayment (in)

$L F=$ load factor

$M=$ number of terms for the approximate loading function

$M_{a}=$ allowable moment (in-lbs)

$M_{p 2}=$ moment at point of load for two-span condition (in-lbs)

$M_{x x}, M_{y y}, M_{x y}=$ bending moments of the plate (lbs-in/in)

$M_{\max 1}=$ maximum applied moment of the single span condition (in-lbs)

$M_{\max 2}=$ maximum applied moment of the two-span condition (in-lbs)

$M_{5 t h}=5^{\text {th }}$ percentile value of ultimate moment capacity of T-beam (in-lbs)

$\tilde{M}=$ empirical maximum moment equation 
$\tilde{M}_{05}=$ empirical maximum moment equation of the $5^{\text {th }}$ percentile value

$M O R_{c}=$ modulus of rupture of corrugated panel (in $\left.{ }^{4}\right)$

$M O R_{f}=$ modulus of rupture of flat panel $\left(\mathrm{in}^{4}\right)$

$N=$ number of polynomial functions

$P=$ applied load (lbs)

$\tilde{P}=$ empirical equation for the maximum load (lbs)

$\tilde{P}_{05}=$ empirical equation for the maximum load of the $5^{\text {th }}$ percentile (lbs)

$P_{\max }=$ maximum applied load (lbs)

$Q()=$. first moment $\left(\mathrm{in}^{3}\right)$

$Q_{o}=$ concentrated load (lbs)

$q=$ loading function

$\tilde{q}=$ single Fourier sine series approximation of the loading function

$q_{L}=$ uniform line load (psi)

$q_{n}=$ Fourier coefficients

$q_{o}=$ uniformly distributed load (psi)

$R_{c}=$ modulus of rupture of the corrugated panel (psi)

$R_{f}=$ modulus of rupture of the flat panel (psi)

$R_{\text {in }}=$ inner radius of chamfer at the corner of sidewall (in)

$R_{\text {out }}=$ outer radius of chamfer at the corner of sidewall (in)

$R_{x}, R_{y}=$ reaction forces of the plate (lbs/in)

$S=$ arc length of one half of the wavelength (in); shear/slip ratio (lbs/in) 
$S_{c}=$ section modulus of the corrugated panel (in ${ }^{3}$ per wavelength)

$S_{f}=$ section modulus of the flat panel (in ${ }^{3}$ per wavelength)

$s_{i}=$ length of mid surface (in)

$t=$ thickness of the corrugated panel (in)

$t_{a d}=$ thickness of adhesive (in)

$t_{f}=$ thickness of the flat panel (in); flange thickness of the I-joist (in)

$t_{u n}=$ thickness of the underlayment (in)

$t_{w}=$ horizontal thickness or width of the corrugated panel (in); web thickness of the Ijoist (in)

$\tilde{t}_{\text {ave }}=$ weighted average thickness of corrugated panel (in)

$U_{\text {first }}=$ first order shear strain energy

$U_{\text {actual }}=$ actual shear strain energy

$V_{\max }=$ maximum shear (lbs)

$V_{x}, V_{y}=$ shear forces of the plate (lbs/in)

$\tilde{V}=$ empirical maximum shear equation (lbs)

$\tilde{V}_{05}=$ empirical maximum shear equation of the $5^{\text {th }}$ percentile value (lbs)

$w$ = wavelength of the corrugated panel (in)

$x_{e}=$ top deck width of the corrugated panel (in)

$x_{0}=\mathrm{x}$ location of the concentrated load for the plate model (in)

$x_{p}=$ distance from the support to the point load (in)

$y_{c}=$ center of gravity of the corrugated panel (in) 
$y_{j}=$ center of gravity of the I-joist (in)

$y_{\text {OSB }}=$ center of gravity of the OSB underlayment (in)

$y_{o}=\mathrm{y}$ location of the uniform line load or the concentrated load for the plate model (in)

$y_{u n}=$ center of gravity of the underlayment (in)

$\bar{y}=$ neutral axis of the composite deck system (in)

$\bar{y}_{\text {deck }}=$ neutral axis of the composite deck measure from the base of the I-joist (in)

$\bar{y}_{T}=$ neutral axis of the composite T-beam (in)

$\beta_{n}=\frac{n \pi}{b}$

$\Delta=$ deflection (in)

$\Delta_{F E}=$ deflection of the finite element model (in)

$\Delta_{p}=$ deflection at point of load (in)

$\Delta_{n}=$ approximate deflection function for the plate model (in)

$\Delta_{\text {frame }}=$ deflection of the frame model (in)

$\delta()=$. unit impulse function $(0$ or 1$)$

$\phi_{b}=$ resistance factor for bending

$\varphi_{i}=$ algebraic polynomials for the plate model

$\lambda=$ time effect factor

$v=$ Poisson's ratio (unitless)

$\theta=$ sidewall angle or slope (degree)

$\rho_{\text {test }}=$ density of test specimen (pcf)

$\tau_{\text {actual }}=$ actual shear stress distribution 
$\tau_{\text {first }}=$ first order shear stress

$\varpi=$ weight of panel (lbs) 


\section{References}

AF\&PA (1996a). Load and Resistance Factor Design (LRFD), Manual for Engineered Wood Construction, American Forest and Paper Association, Washington, DC.

AF\&PA (1996b) “Supplement-Structural-Use Panels”, Manual for Engineered Wood Construction, American Forest and Paper Association, Washington, DC.

APA (2004) “Panel Design Specification”, The Engineered Wood Association.

ASTM. (1999). “Standard Test Methods for Evaluating Properties of Wood-base Fiber and Particle Panel Materials”, D1037, Vol. 4, No. 10, p142-171.

Baas, T.J., (1989). Deep Draw Molding of Wood Flake Composites: Geometric Effects, M.S. Thesis, Department of Civil and Environmental Engineering, Michigan Tech. Unv., Houghton, MI.

Bach, L. (1989). "Manufacture of Corrugated Waferboard”, Forest Products Journal, Vol. 39, No. 10, p58-62.

Haataja, B.A., Sandberg, L.B. and Liptak, R.E. Jr. (1991). “Observation and Control of Mat Behavior in Molding with Wood Flakes”, Forest Products Journal, Vol. 41, No. 7/8, p21-26. 
Howard, J.L. (2001). “U.S. Forest Products Annual Market Review and prospects, 19992002”, Forest Products Laboratory Research Note, FPL-RN-0282. Madison, WI.

Kuenzi, E.W. and Wilkinson, T.L. (1971). Composite Beams - Effect of Adhesive or Fastener Rigidity ,Research Paper FPL 152, Forest Products Laboratory, U.S. Dept. of Agriculture, Forest Service, Madison, WI.

Liptak, Jr., R.E. (1989). Mat Deformation in Molded Wood Composites, M.S. Thesis, Department of Civil and Environmental Engineering, Michigan Tech. Unv., Houghton, MI.

Mathieu, C.A. (1992) Molded Strandboard Corrugated Paneling As a Structural Component in Residential Floor Systems, M.S. Report, Civil Engineering Department, Michigan Technological University, MI.

McCutcheon, W.J. (1977). Method for Predicting the Stiffness of Wood-Joist Floor Systems with Partial Composite Action, Research Paper FPL 289, Forest Products Laboratory, U.S. Dept. of Agriculture, Forest Service, Madison, WI.

McCutcheon, W.J. (1986). "Stiffness of Framing Members with Partial Composite Action”, Journal of Structural Engineering, ASCE, Vol. 112, No. 7, 1623-1637. 
Price, E.W. and Kessler, C.E. (1974). Analysis of Southern Hardwoods As Furnish For A Wood Flake-Resin Composite Structural Material, T.A.\&M. Report No. 389, Unv. of Illinois. p72-85.

Reddy, J.N. (1999). Theory and Analysis of Elastic Plates, Taylor and Francis, Philadelphia, PA.

TJI (2002). “Specifier’s Guide TJI/Pro 100TS \& 130 Joists - Featuring the Silent Floor System for Residential Application”, TrusJoist, Boise, ID.

Troitsky, M.S. (1976). Stiffened Plates Bending, Stability and Vibrations, Elsevier Scientific Plublishing Company, Amsterdam, The Netherlands. p62-113.

Vandenbergh, W.W., (1988). Molding Behavior of Wood Flake Composites: Forming and Alignment Effects, M.S. Thesis, Department of Civil and Environmental Engineering, Michigan Tech. Unv., Houghton, MI.

Wesolowsky, G.O. (1976). Multiple Regression and Analysis of Variance, John Wiley \& Sons, NY.

WIJMA (2002). “Establishing Prefabricated Wood I-Joist Composite EI” Wood I-Joist Manufacturers Association, URL: www.i-joist.org . 


\section{Appendix A. Moment of Inertia of Corrugated Panel}

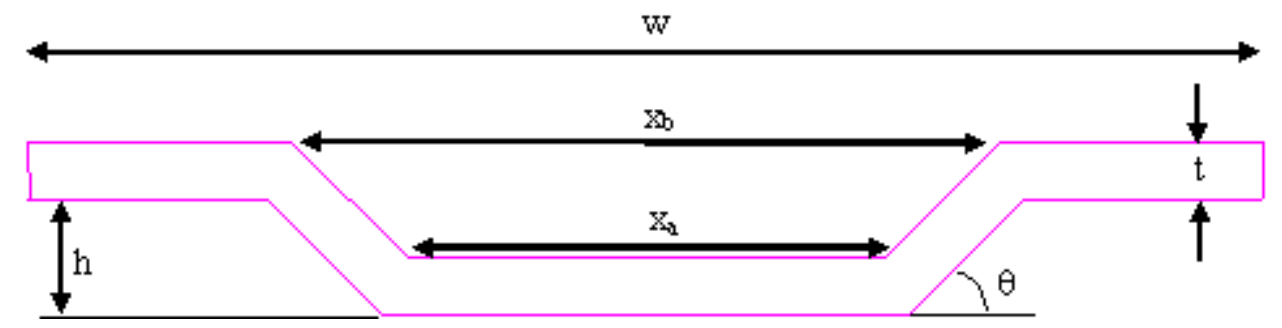

Moment of Inertia of 'Solid' Section about its centroid

$\mathrm{I}_{\text {solid }}=\frac{\mathrm{W} \cdot(\mathrm{h}+\mathrm{t})^{3}}{12}$

Centroid of the 'solid' section or corrugated section $\mathrm{C}_{\mathrm{C}}=\frac{\mathrm{h}+\mathrm{t}}{2}$

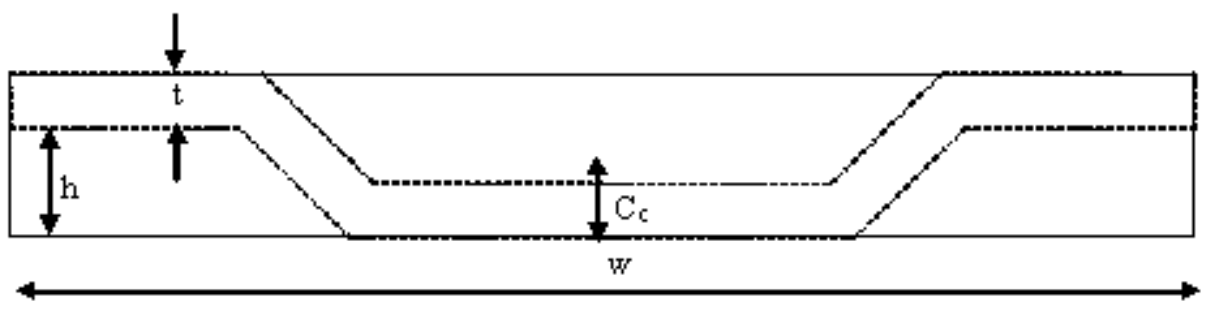

Moment of Inertia of one "hollow" trapezoid section about its centroid

$I_{\text {trapezoid }}=\frac{h^{3} \cdot\left(x_{a}{ }^{2}+4 \cdot x_{a} \cdot x_{b}+x_{b}{ }^{2}\right)}{36 \cdot\left(x_{a}+x_{b}\right)}$

Area of the one "hollow" trapezoid section

$\mathrm{A}_{\text {trapezoid }}=\frac{\mathrm{h}}{2} \cdot\left(\mathrm{x}_{\mathrm{a}}+\mathrm{x}_{\mathrm{b}}\right)$

Centroid of the "hollow" trapezoid measured from the base of the section $\mathrm{C}_{\text {trapezoid }}=\frac{\mathrm{h}}{3} \cdot\left(\frac{2 \cdot \mathrm{x}_{\mathrm{a}}+\mathrm{x}_{\mathrm{b}}}{\mathrm{x}_{\mathrm{a}}+\mathrm{x}_{\mathrm{b}}}\right)$

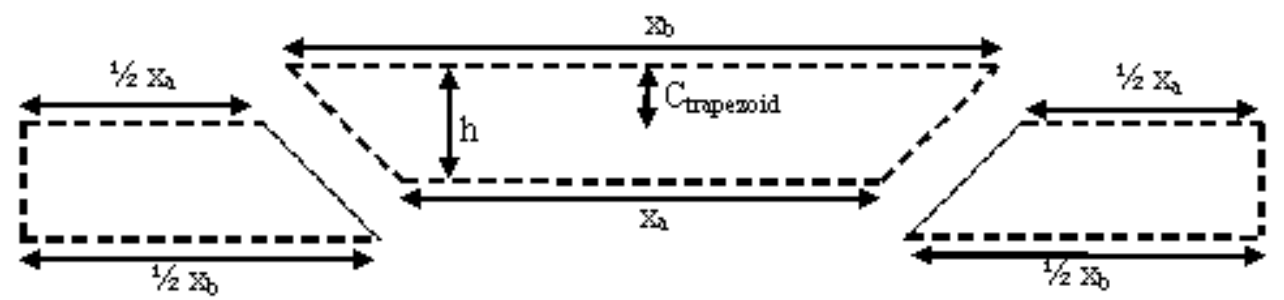


Moment of Inertia for the corrugated section about its centroid can be found by using parallel-axis theorem

$$
\begin{aligned}
& \mathrm{I}_{\mathrm{C}}=\mathrm{I}_{\text {solid }}-2\left[\mathrm{I}_{\text {trapezoid }}+\mathrm{A}_{\text {trapezopid }} \cdot\left(\mathrm{C}_{\mathrm{C}}-\mathrm{C}_{\text {trapezoid }}\right)^{2}\right] \\
& I_{C}=\frac{w \cdot(h+t)^{3}}{12}-2 \cdot\left[\frac{h^{3} \cdot\left(x_{a}{ }^{2}+4 \cdot x_{a} \cdot x_{b}+x_{b}{ }^{2}\right)}{36 \cdot\left(x_{a}+x_{b}\right)}+\left[\frac{h}{2} \cdot\left(x_{a}+x_{b}\right)\right] \cdot\left[\frac{h+t}{2}-\frac{h}{3} \cdot\left(\frac{2 \cdot x_{a}+x_{b}}{x_{a}+x_{b}}\right)\right]^{2}\right] \\
& I_{C}=\frac{w \cdot h^{3}}{12}+\frac{w \cdot h^{2} \cdot t}{4}+\frac{w \cdot h \cdot t^{2}}{4}+\frac{w \cdot t^{3}}{12}-2 \cdot\left(\frac{x_{a} \cdot h^{3}}{24}-\frac{x_{a} \cdot h^{2} \cdot t}{12}+\frac{x_{a} \cdot h \cdot t^{2}}{8}+\frac{x_{b} \cdot h^{3}}{24}+\frac{x_{b} \cdot h^{2} \cdot t}{12}+\frac{x_{b} \cdot h \cdot t^{2}}{8}\right) \\
& I_{C}=\frac{w \cdot h^{3}}{12}+\frac{w \cdot h^{2} \cdot t}{4}+\frac{w \cdot h \cdot t^{2}}{4}+\frac{w \cdot t^{3}}{12}-\left(\frac{h^{3}}{12}-\frac{h^{2} \cdot t}{6}+\frac{h \cdot t^{2}}{4}\right) \cdot x_{a}-\left(\frac{h^{3}}{12}+\frac{h^{2} \cdot t}{6}+\frac{h \cdot t^{2}}{4}\right) \cdot x_{b}
\end{aligned}
$$

substitute ' $\mathrm{x}_{\mathrm{a}}$ ' and ' $\mathrm{x}_{\mathrm{b}}$ ' into the above equation

$$
\begin{aligned}
& \mathrm{x}_{\mathrm{a}}=\frac{\mathrm{w}}{2}-\left(\frac{\mathrm{h}}{\tan (\theta)}\right)-\mathrm{t} \cdot \tan \left(\frac{\theta}{2}\right) \\
& \mathrm{x}_{\mathrm{b}}=\left[\frac{\mathrm{w}}{2}-\left(\frac{\mathrm{h}}{\tan (\theta)}\right)\right]-\mathrm{t} \cdot \tan \left(\frac{\theta}{2}\right)+2 \cdot \mathrm{h} \cdot \tan \left(\frac{\pi}{2}-\theta\right)=\frac{\mathrm{w}}{2}+\frac{\mathrm{h}}{\tan (\theta)}-\mathrm{t} \cdot \tan \left(\frac{\theta}{2}\right)
\end{aligned}
$$

\section{collect "t" terms}

$$
I_{C}=\left(\frac{w}{12}+\frac{h}{2 \cdot \sin (\theta)}-\frac{h}{2 \cdot \tan (\theta)}\right) \cdot t^{3}+\left(\frac{w \cdot h^{2}}{4}+\frac{h^{3}}{6 \cdot \sin (\theta)}-\frac{h^{3}}{2 \cdot \tan (\theta)}\right) \cdot t
$$

\section{collect "h" terms}

$$
I_{C}=\left(\frac{t}{6 \cdot \sin (\theta)}-\frac{t}{2 \cdot \tan (\theta)}\right) \cdot h^{3}+\left(\frac{w \cdot t}{4}\right) \cdot h^{2}+\left(\frac{t^{3}}{2 \cdot \sin (\theta)}-\frac{t^{3}}{2 \cdot \tan (\theta)}\right) \cdot h+\frac{w \cdot t^{3}}{12}
$$

\section{collect "w" terms}

$$
I_{C}=\left(\frac{t \cdot h^{2}}{4}+\frac{t^{3}}{12}\right) \cdot \mathrm{w}+\left(\frac{1}{6 \cdot \sin (\theta)}-\frac{1}{2 \cdot \tan (\theta)}\right) \cdot t \cdot h^{3}+\left(\frac{1}{2 \cdot \sin (\theta)}-\frac{1}{2 \cdot \tan (\theta)}\right) \cdot \mathrm{t}^{3} \cdot \mathrm{h}
$$




\section{Appendix B. Moldability Factor}

Concentration Elongation (CE) Indicator:

$C E=\frac{L_{e d}}{W_{e d}}$

$=\frac{h / \sin (\theta)+b_{i}+d_{i}}{h / \tan (\theta)}$

note: $\mathrm{CE}$ is being modified from the original equation.

Proximity Factor (P):

$P=\frac{L_{p}}{P_{w}}$

$=\frac{2\left(b_{i}+h / \sin (\theta)\right)+(w / 2-h / \tan (\theta))-t \tan (\theta / 2)}{2\left(b_{i}+h / \tan (\theta)\right)+(w / 2-h / \tan (\theta))-t \tan (\theta / 2)}$

Channel depth to width ratio (DW):

$D W=\frac{h}{(w / 2-h / \tan (\theta))-\mathrm{t} \tan (\theta / 2)}$

Moldability Factor (MF):

$M F=[0.7 C E+0.3(1+D W)] P \quad$ note: $M F$ is being modified from the original equation.

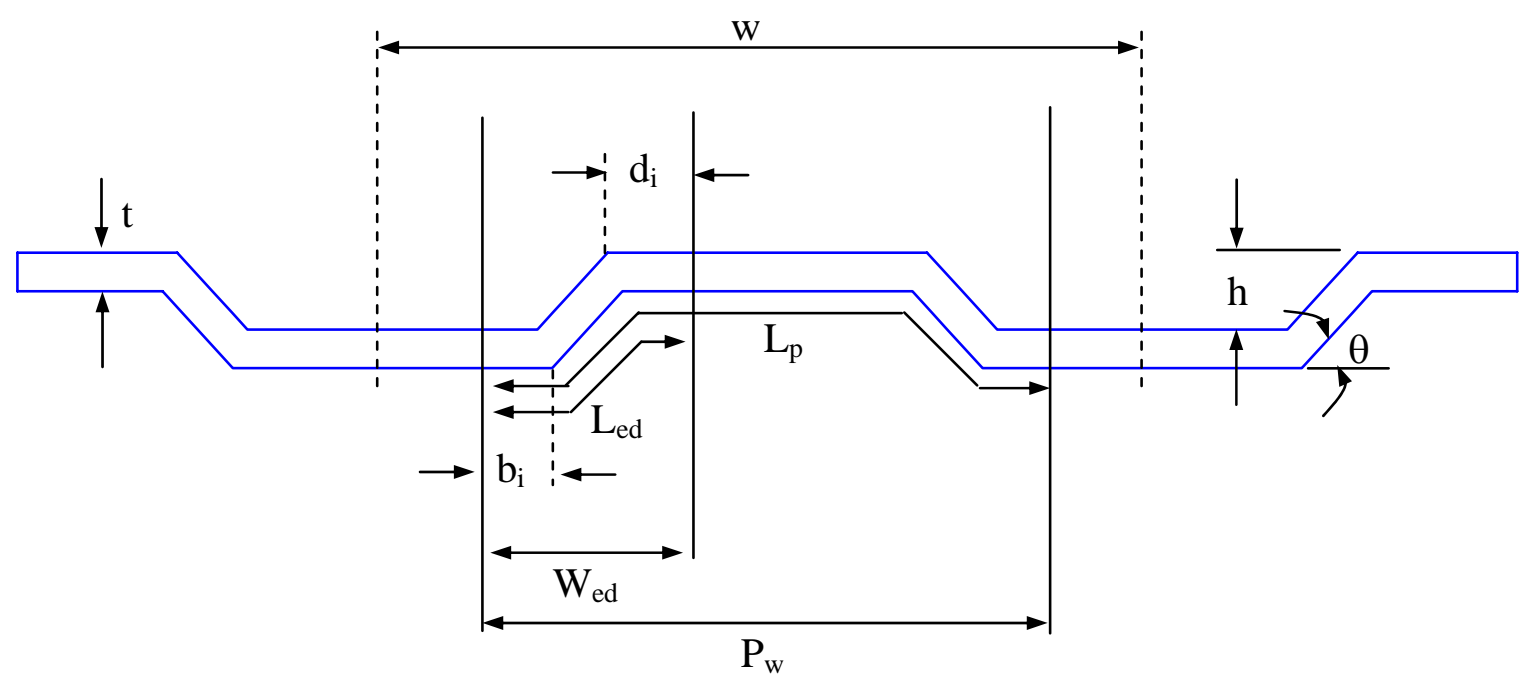




\section{Appendix C. Cross-sectional Area of Corrugated Panel}

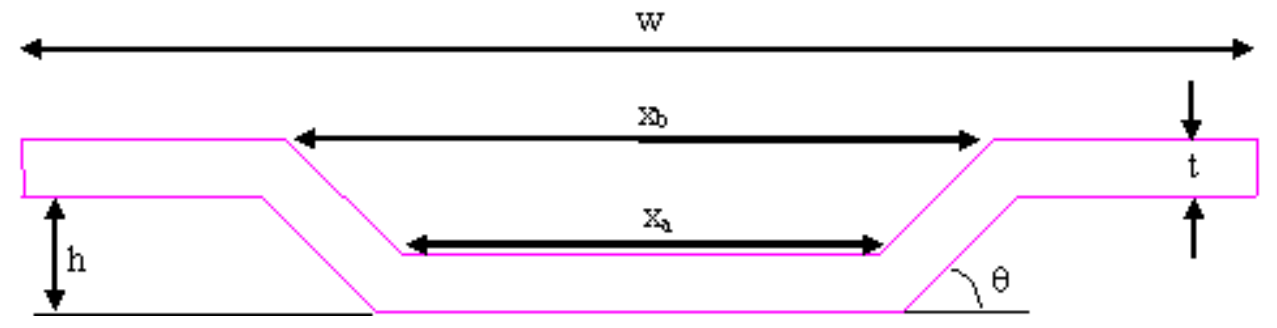

Area of Solid Section

$\mathrm{A}_{\text {solid }}=\mathrm{w} \cdot(\mathrm{h}+\mathrm{t})$

Area of the "hollow" trapezoid section

$\mathrm{A}_{\text {trapezoid }}=\frac{\mathrm{h}}{2} \cdot(\mathrm{a}+\mathrm{b})$

Net Area

$$
\begin{aligned}
& A_{C}=w \cdot(h+t)-2 \cdot\left[\frac{h}{2} \cdot\left(x_{a}+x_{b}\right)\right] \\
& A_{C}=w \cdot(h+t)-h \cdot\left(x_{a}+x_{b}\right)
\end{aligned}
$$

substitute ' $\mathrm{X}_{\mathrm{a}}$ ' and ' $\mathrm{X}_{\mathrm{b}}$ ' into the above equation

$$
\begin{aligned}
& \mathrm{x}_{\mathrm{a}}=\left[\frac{\mathrm{w}}{2}-\left(\frac{\mathrm{h}}{\tan (\theta)}\right)\right]-\mathrm{t} \cdot \tan \left(\frac{\theta}{2}\right) \\
& \mathrm{x}_{\mathrm{b}}=\left[\frac{\mathrm{w}}{2}-\left(\frac{\mathrm{h}}{\tan (\theta)}\right)\right]-\mathrm{t} \cdot \tan \left(\frac{\theta}{2}\right)+2 \cdot \mathrm{h} \cdot \tan \left(\frac{\pi}{2}-\theta\right)
\end{aligned}
$$

Area of corrugated panel per wavelength:

$$
\begin{aligned}
& A_{C}=w \cdot(h+t)-h \cdot\left[\left[\frac{\mathrm{w}}{2}-\left(\frac{\mathrm{h}}{\tan (\theta)}\right)\right]-\mathrm{t} \cdot \tan \left(\frac{\theta}{2}\right)+\left[\left[\frac{\mathrm{w}}{2}-\left(\frac{\mathrm{h}}{\tan (\theta)}\right)\right]-\mathrm{t} \cdot \tan \left(\frac{\theta}{2}\right)+2 \cdot \mathrm{h} \cdot \tan \left(\frac{\pi}{2}-\theta\right)\right]\right] \\
& A_{C}=\left(\frac{2-2 \cdot \cos (\theta)}{\sin (\theta)} \cdot \mathrm{h}+\mathrm{w}\right) \cdot \mathrm{t}
\end{aligned}
$$




\section{Appendix D. FFSS Plate Under Line Load for Matlab Program}

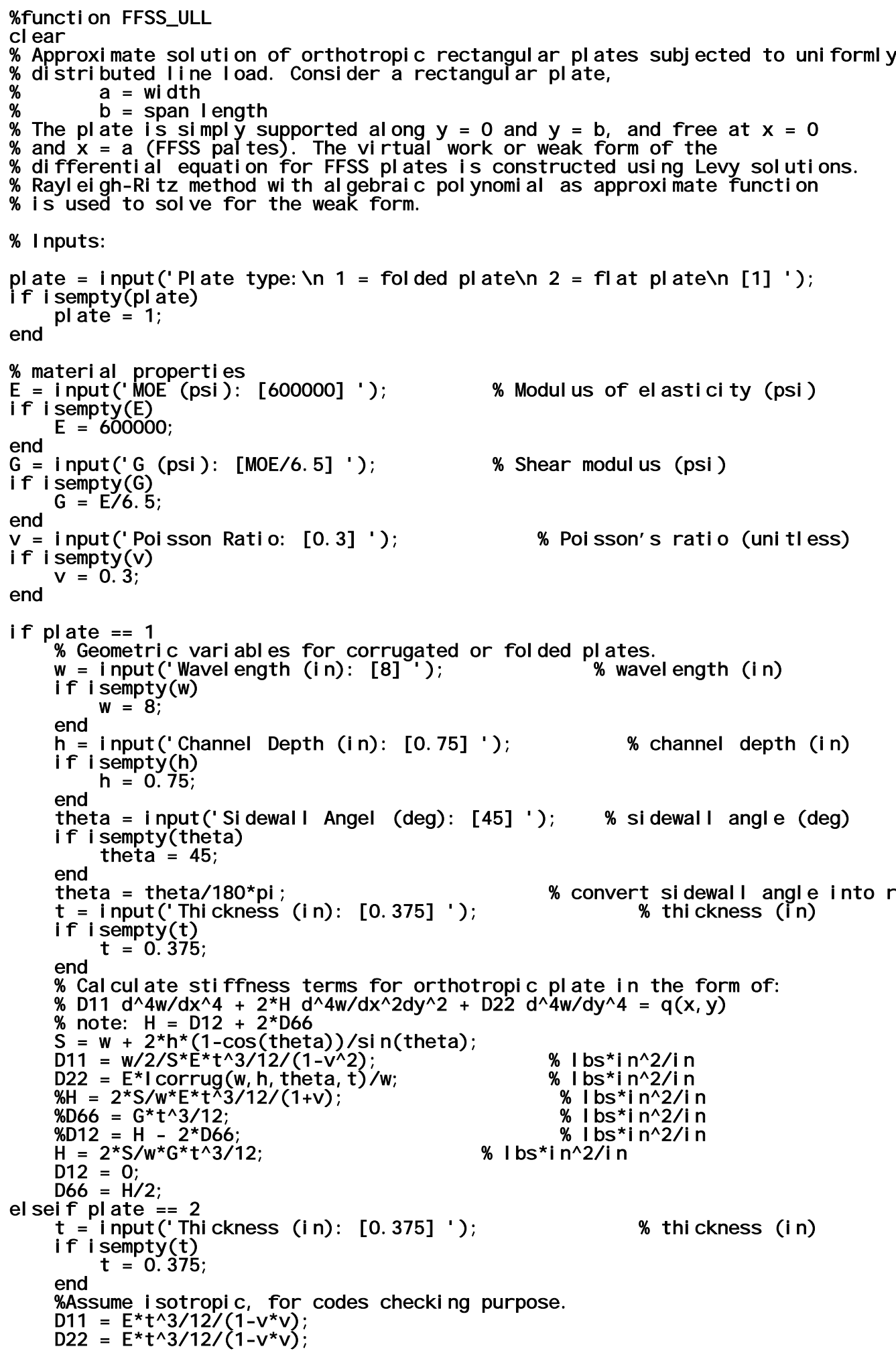




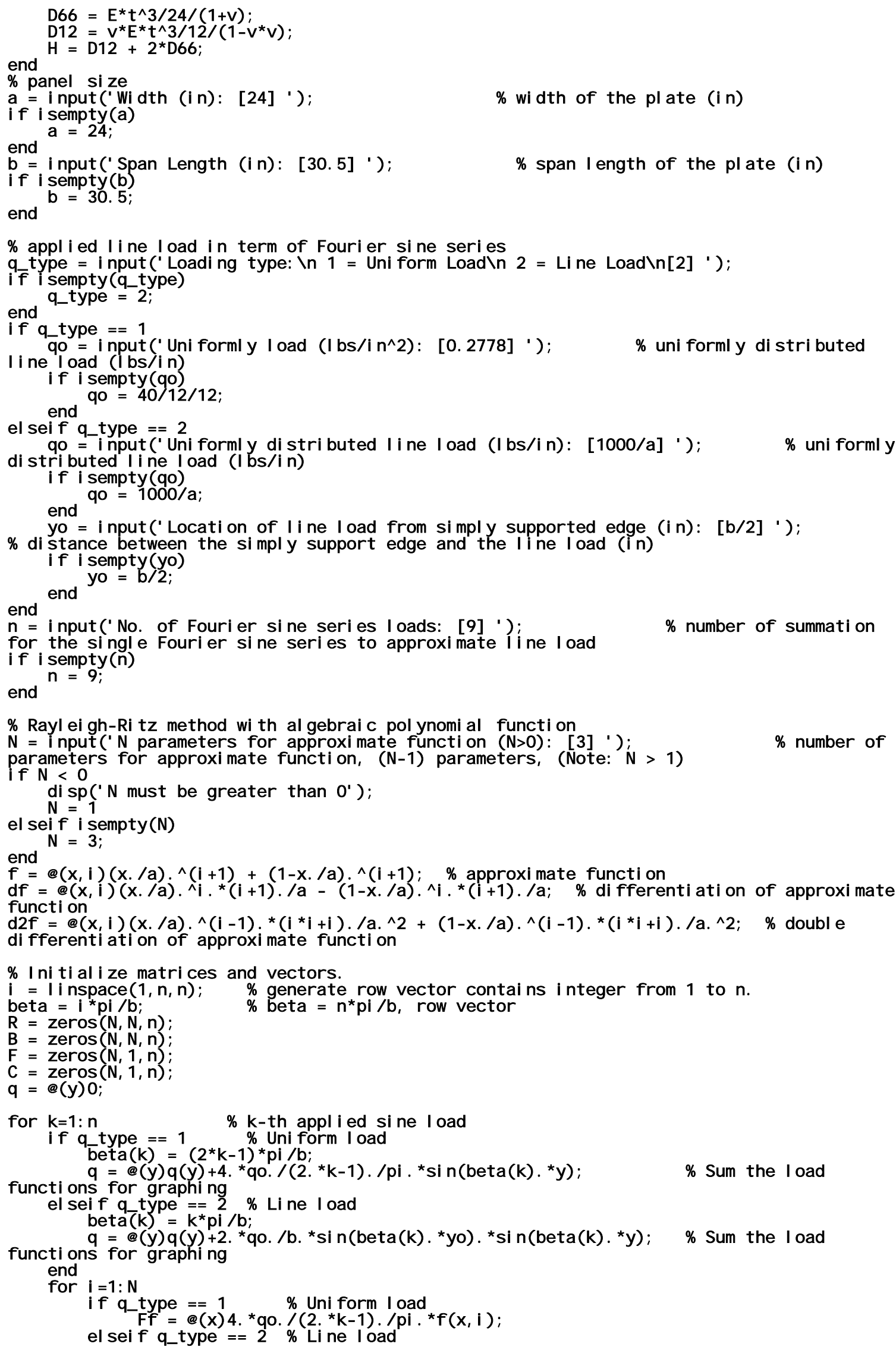




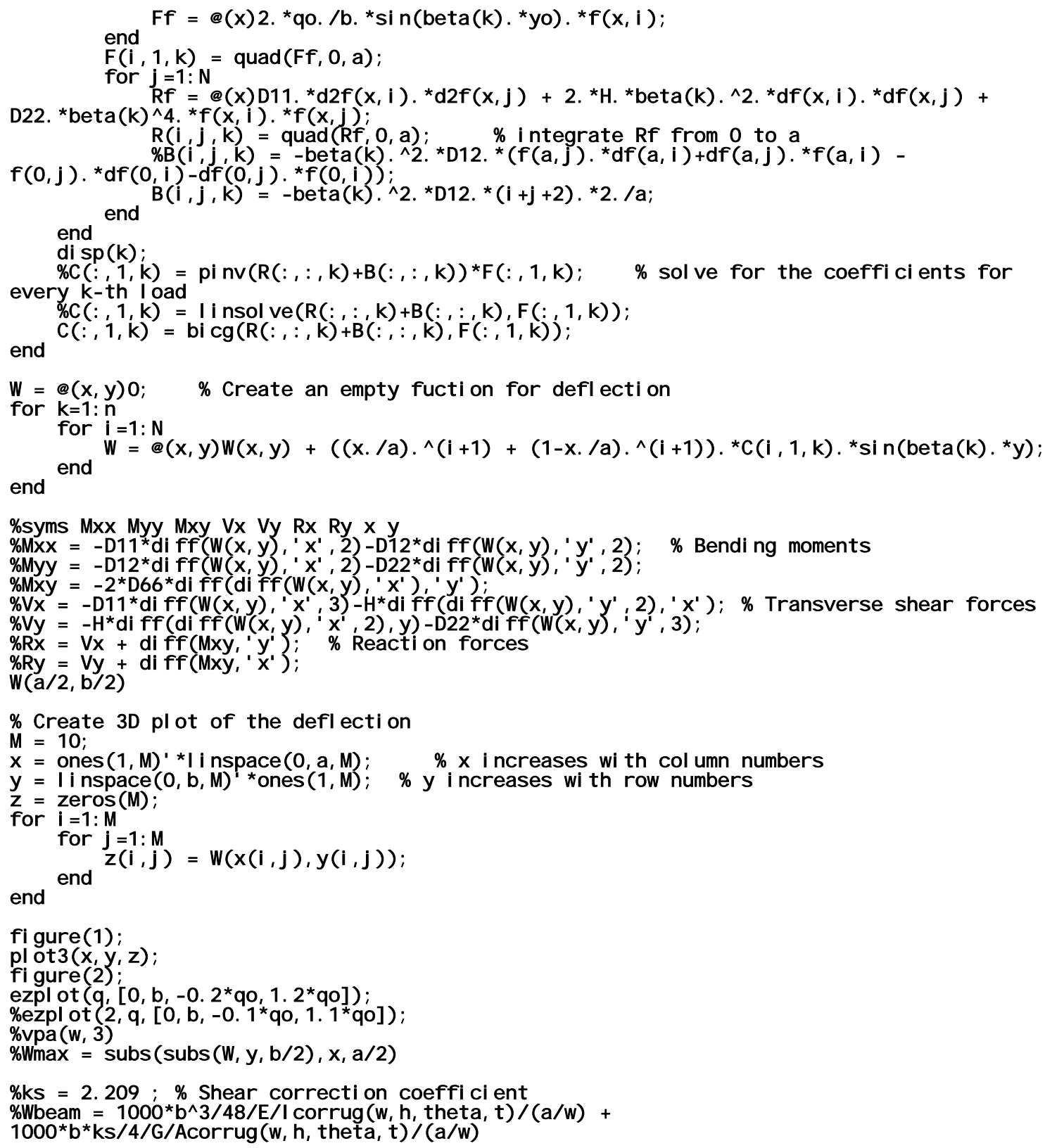




\section{Appendix E. Dimensions of Mid Surfaces}

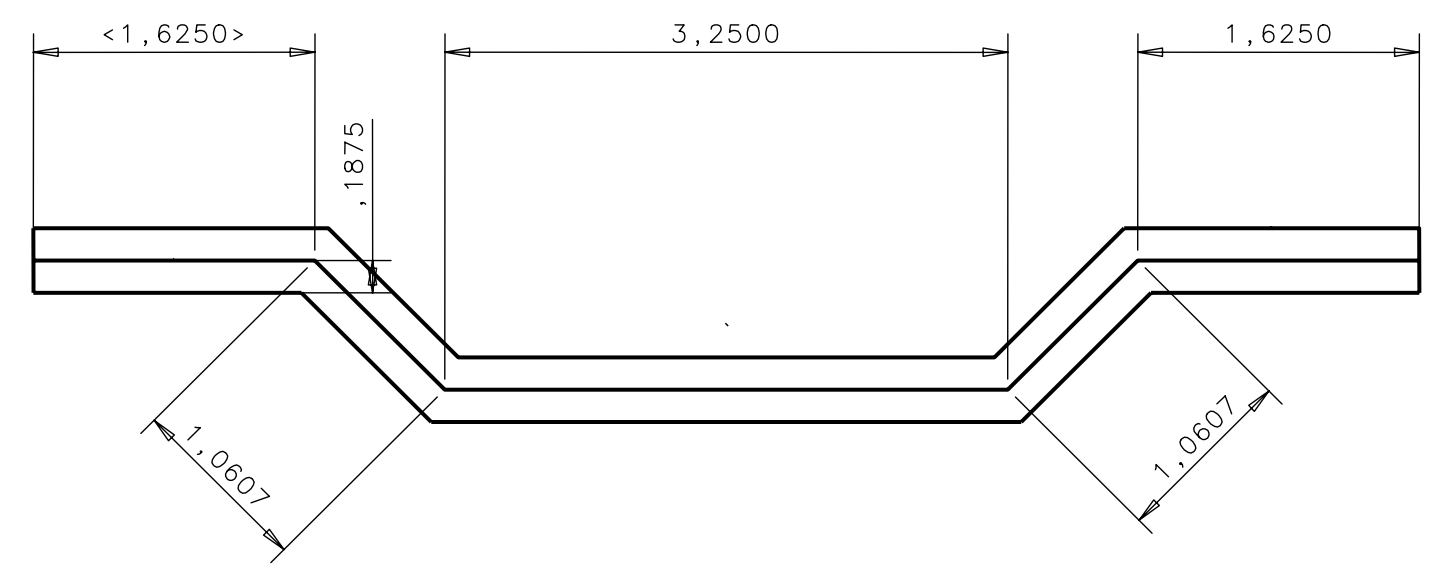

Note: Units are in inches. 


\section{Appendix F. Test Data for 16"x16" Panels}

\begin{tabular}{|c|c|c|c|c|c|c|c|c|c|c|c|}
\hline \multirow{2}{*}{\multicolumn{3}{|c|}{$\begin{array}{l}\text { Actual Span: } \\
\text { Equivalent Span: } \\
\text { Failure location (from support) } \\
\text { Panel Type-A }\end{array}$}} & \multicolumn{2}{|c|}{$\begin{array}{r}10 \text { in } \\
10.232 \text { in } \\
3.375 \text { in }\end{array}$} & & & & & & & \\
\hline & & & & & & & & & & & \\
\hline Panel \# & \begin{tabular}{|c|} 
Weighted \\
Average \\
Thickness \\
(in)
\end{tabular} & $\begin{array}{c}\text { Moisture } \\
\text { Content } \\
(\%)\end{array}$ & $\begin{array}{c}\text { Wet } \\
\text { Density } \\
\text { (lbs/ft3) }\end{array}$ & $\begin{array}{l}\text { Oven Dry } \\
\text { Density } \\
\text { (lbs/ft3) }\end{array}$ & $\begin{array}{l}\text { Load/Defl. } \\
\text { (lbs/in) }\end{array}$ & $\begin{array}{c}\text { Maximum } \\
\text { Load } \\
\text { (lbs) }\end{array}$ & $\begin{array}{l}\text { Moment of } \\
\text { Inertia } \\
\left(\mathrm{in}^{4} / \mathrm{ft}\right)\end{array}$ & $\begin{array}{l}\text { Bending } \\
\text { Stiffness } \\
\text { (lbs-in }{ }^{2} / \mathrm{ft} \text { ) }\end{array}$ & $\begin{array}{c}\text { Maximum } \\
\text { Moment } \\
\text { (in-lbs/ft) }\end{array}$ & $\begin{array}{c}\text { MOE } \\
(p s i)\end{array}$ & $\begin{array}{l}\text { MOR } \\
\text { (psi) }\end{array}$ \\
\hline $4-2-1$ & 0.377 & $5.92 \%$ & 37.87 & 35.76 & 368 & 105 & 0.0538 & 32,860 & 711 & 611,074 & 2,494 \\
\hline $4-2-2$ & 0.376 & $5.72 \%$ & 38.21 & 36.14 & 377 & 128 & 0.0533 & 33,684 & 866 & 632,442 & 3,058 \\
\hline $4-2-3$ & 0.378 & $5.74 \%$ & 41.62 & 39.36 & 356 & 115 & 0.0540 & 31,812 & 774 & 589,130 & 2,708 \\
\hline $4-2-4$ & 0.381 & $5.66 \%$ & 40.75 & 38.57 & 427 & 119 & 0.0552 & 38,142 & 803 & 691,110 & 2,771 \\
\hline $4-2-5$ & 0.389 & $5.78 \%$ & 39.88 & 37.70 & 460 & 133 & 0.0590 & 41,066 & 895 & 696,534 & 2,954 \\
\hline $8-3-1$ & 0.368 & $5.90 \%$ & 40.10 & 37.86 & 316 & 92 & 0.0497 & 28,222 & 619 & 567,650 & 2,291 \\
\hline $8-3-2$ & 0.363 & $5.81 \%$ & 44.79 & 42.34 & 288 & 96 & 0.0478 & 25,715 & 648 & 537,549 & 2,459 \\
\hline $8-3-3$ & 0.361 & $5.42 \%$ & 41.77 & 39.62 & 379 & 101 & 0.0471 & 33,870 & 679 & 718,787 & 2,603 \\
\hline $8-3-4$ & 0.361 & $5.60 \%$ & 46.13 & 43.68 & 330 & 114 & 0.0470 & 29,426 & 772 & 625,496 & 2,962 \\
\hline $8-3-5$ & 0.364 & $5.98 \%$ & 44.89 & 42.35 & 323 & 123 & 0.0484 & 28,833 & 833 & 596,063 & 3,139 \\
\hline $9-1-3$ & 0.370 & $5.67 \%$ & 41.24 & 39.03 & 306 & 110 & 0.0505 & 27,303 & 742 & 540,972 & 2,716 \\
\hline $9-1-2$ & 0.363 & $5.39 \%$ & 45.11 & 42.81 & 377 & 142 & 0.0478 & 33,686 & 957 & 705,060 & 3,636 \\
\hline $9-1-3$ & 0.357 & $5.09 \%$ & 49.23 & 46.85 & 440 & 164 & 0.0456 & 39,245 & 1,107 & 859,781 & 4,334 \\
\hline $9-1-4$ & 0.355 & $5.27 \%$ & 44.83 & 42.58 & 342 & 124 & 0.0446 & 30,547 & 834 & 684,644 & 3,315 \\
\hline $9-1-5$ & 0.355 & $5.44 \%$ & 44.49 & 42.20 & 368 & 124 & 0.0448 & 32,867 & 834 & 733,610 & 3,306 \\
\hline $10-2-2$ & 0.362 & $5.46 \%$ & 41.22 & 39.08 & 352 & 119 & 0.0474 & 31,439 & 804 & 662,782 & 3,069 \\
\hline $10-2-3$ & 0.360 & $5.72 \%$ & 42.41 & 40.12 & 360 & 124 & 0.0465 & 32,122 & 835 & 691,166 & 3,228 \\
\hline $10-2-4$ & 0.359 & $5.65 \%$ & 47.02 & 44.49 & 315 & 110 & 0.0461 & 28,076 & 742 & 608,510 & 2,883 \\
\hline $10-2-5$ & 0.356 & $5.90 \%$ & 41.91 & 39.57 & 340 & 105 & 0.0453 & 30,356 & 711 & 670,083 & 2,796 \\
\hline Mean & 0.366 & $5.64 \%$ & 42.81 & 40.53 & 359 & 118 & 0.0492 & 32,067 & 798 & 653,813 & 2,985 \\
\hline Std. & 0.010 & $0.24 \%$ & 3.02 & 2.92 & 45 & 17 & 0.004 & 4,055 & 113 & 77,415 & 468 \\
\hline COV & 0.03 & 0.04 & 0.07 & 0.07 & 0.13 & 0.14 & 0.08 & 0.13 & 0.14 & 0.12 & 0.16 \\
\hline+2 (std) & 0.386 & $6.12 \%$ & 48.86 & 46.36 & 450 & 152 & 0.057 & 40,178 & 1,025 & 808,643 & 3,921 \\
\hline$-2(s t d)$ & 0.346 & $5.16 \%$ & 36.77 & 34.70 & 268 & 85 & 0.041 & 23,956 & 571 & 498,982 & 2,049 \\
\hline 5th \% & 0.355 & $5.25 \%$ & 38.18 & 36.10 & 304 & 96 & 0.045 & 27,144 & 645 & 540,630 & 2,442 \\
\hline
\end{tabular}

Note: Panel 10-2-1 was unsuccessful and the results were not used.

Panel Type-B

\begin{tabular}{|c|c|c|c|c|c|c|c|c|c|c|c|}
\hline Panel \# & $\begin{array}{c}\text { Weighted } \\
\text { Average } \\
\text { Thickness } \\
\text { (in) }\end{array}$ & $\begin{array}{c}\text { Moisture } \\
\text { Content } \\
(\%)\end{array}$ & $\begin{array}{c}\text { Wet } \\
\text { Density } \\
\text { (lbs/ft3) }\end{array}$ & $\begin{array}{c}\text { Oven Dry } \\
\text { Density } \\
\text { (lbs/ft3) }\end{array}$ & $\begin{array}{c}\text { Load/Defl. } \\
\text { (lbs/in) }\end{array}$ & $\begin{array}{c}\text { Maximum } \\
\text { Load } \\
\text { (bs) }\end{array}$ & $\begin{array}{c}\text { Moment of } \\
\text { Inertia } \\
\text { (in /ft) }\end{array}$ & $\begin{array}{c}\text { Bending } \\
\text { Stiffness } \\
\text { (lbs-in } / f t)\end{array}$ & $\begin{array}{c}\text { Maximum } \\
\text { Moment } \\
\text { (in-lbs/ft) }\end{array}$ & $\begin{array}{c}\text { MOE } \\
(\mathrm{psi})\end{array}$ & $\begin{array}{c}\text { MOR } \\
(\mathrm{psi})\end{array}$ \\
\hline $11-4-1$ & 0.341 & $5.30 \%$ & 39.00 & 37.03 & 143 & 61 & 0.0397 & 12,741 & 409 & 321,028 & 1,757 \\
\hline $11-4-2$ & 0.346 & $5.29 \%$ & 44.31 & 42.09 & 187 & 78 & 0.0415 & 16,655 & 525 & 401,227 & 2,190 \\
\hline $11-4-3$ & 0.352 & $5.19 \%$ & 46.76 & 44.45 & 296 & 128 & 0.0438 & 26,394 & 864 & 602,987 & 3,479 \\
\hline $11-4-4$ & 0.359 & $5.35 \%$ & 49.45 & 46.95 & 296 & 133 & 0.0464 & 26,415 & 895 & 568,714 & 3,463 \\
\hline $11-4-5$ & 0.371 & $5.25 \%$ & 49.43 & 46.96 & 329 & 149 & 0.0511 & 29,352 & 1,006 & 574,491 & 3,652 \\
\hline Mean & 0.354 & $5.27 \%$ & 45.79 & 43.50 & 250 & 110 & 0.0445 & 22,311 & 740 & 493,689 & 2,908 \\
\hline Std. & 0.012 & $0.06 \%$ & 4.36 & 4.14 & 81 & 38 & 0.004 & 7,188 & 258 & 124,965 & 870 \\
\hline COV & 0.03 & 0.01 & 0.10 & 0.10 & 0.32 & 0.35 & 0.10 & 0.32 & 0.35 & 0.25 & 0.30 \\
\hline+2 (std) & 0.378 & $5.39 \%$ & 54.50 & 51.78 & 411 & 186 & 0.053 & 36,687 & 1,255 & 743,619 & 4,648 \\
\hline-2 (std) & 0.331 & $5.16 \%$ & 37.08 & 35.21 & 89 & 33 & 0.036 & 7,936 & 224 & 243,760 & 1,168 \\
\hline 5th \% & 0.342 & $5.20 \%$ & 40.06 & 38.04 & 151 & 64 & 0.040 & 13,524 & 432 & 337,067 & 1,843 \\
\hline
\end{tabular}

Panel Type-C

\begin{tabular}{|c|c|c|c|c|c|c|c|c|c|c|c|}
\hline Panel \# & $\begin{array}{c}\text { Weighted } \\
\text { Average } \\
\text { Thickness } \\
\text { (in) }\end{array}$ & $\begin{array}{c}\text { Moisture } \\
\text { Content } \\
(\%)\end{array}$ & $\begin{array}{c}\text { Wet } \\
\text { Density } \\
\text { (lbs/ft3) }\end{array}$ & $\begin{array}{c}\text { Oven Dry } \\
\text { Density } \\
\text { (lbs/ft3) }\end{array}$ & $\begin{array}{c}\text { Load/Defl. } \\
\text { (lbs/in) }\end{array}$ & $\begin{array}{c}\text { Maximum } \\
\text { Load } \\
\text { (lbs) }\end{array}$ & $\begin{array}{l}\text { Moment of } \\
\text { Inertia } \\
\left(\text { in }^{4} / \mathrm{ft}\right)\end{array}$ & $\begin{array}{l}\text { Bending } \\
\text { Stiffness } \\
\text { (lbs-in } 2 / f t)\end{array}$ & $\begin{array}{c}\text { Maximum } \\
\text { Moment } \\
\text { (in-lbs/ft) }\end{array}$ & $\begin{array}{l}\text { MOE } \\
(\mathrm{psi})\end{array}$ & $\begin{array}{c}\text { MOR } \\
\text { (psi) }\end{array}$ \\
\hline $12-1-1$ & \begin{tabular}{|l|}
0.497 \\
\end{tabular} & $5.65 \%$ & 40.39 & 38.23 & 712 & 146 & 0.1230 & 63,602 & 988 & 517,254 & 1,997 \\
\hline $12-1-2$ & 0.492 & $5.57 \%$ & 40.80 & 38.65 & 790 & 187 & 0.1193 & 70,505 & 1,265 & 590,892 & 2,610 \\
\hline $12-1-3$ & 0.490 & $5.31 \%$ & 41.78 & 39.67 & 790 & 174 & 0.1174 & 70,555 & 1,173 & 601,081 & 2,447 \\
\hline $12-1-4$ & 0.489 & $5.41 \%$ & 44.63 & 42.34 & 793 & 208 & 0.1167 & 70,764 & 1,406 & 606,337 & 2,943 \\
\hline $12-1-5$ & 0.493 & $5.82 \%$ & 42.87 & 40.51 & 759 & 189 & 0.1195 & 67,735 & 1,273 & 566,620 & 2,623 \\
\hline Mean & 0.492 & $5.55 \%$ & 42.09 & 39.88 & 769 & 181 & 0.1192 & 68,632 & 1,221 & 576,437 & 2,524 \\
\hline Std. & 0.003 & $0.20 \%$ & 1.71 & 1.64 & 34 & 23 & 0.002 & 3,076 & 155 & 36,432 & 345 \\
\hline cov & 0.01 & 0.04 & 0.04 & 0.04 & 0.04 & 0.13 & 0.02 & 0.04 & 0.13 & 0.06 & 0.14 \\
\hline+2 (std) & 0.499 & $5.95 \%$ & 45.52 & 43.16 & 838 & 227 & 0.124 & 74,785 & 1,530 & 649,302 & 3,214 \\
\hline-2 (std) & 0.485 & $5.15 \%$ & 38.67 & 36.60 & 700 & 135 & 0.114 & 62,480 & 912 & 503,572 & 1,834 \\
\hline 5th \% & 0.489 & $5.33 \%$ & 40.47 & 38.31 & 722 & 152 & 0.117 & 64,429 & 1,025 & 527,127 & 2,087 \\
\hline
\end{tabular}




\section{Strong Axis Bending}

Load Point (from support) $\quad 7.25$

\begin{tabular}{|c|c|c|c|c|c|c|c|c|c|c|c|c|c|c|c|c|}
\hline Panel \# & $\begin{array}{l}\text { Weighted } \\
\text { Average } \\
\text { Thickness } \\
\text { (in) }\end{array}$ & $\begin{array}{c}\text { Moisture } \\
\text { Content } \\
(\%)\end{array}$ & $\begin{array}{c}\text { Wet } \\
\text { Density } \\
\text { (lbs/ft3) }\end{array}$ & $\begin{array}{c}\text { Oven Dry } \\
\text { Density } \\
\text { (lbs/ft3) }\end{array}$ & $\begin{array}{c}\text { Load/Defl. } \\
\text { (Ibs/in) }\end{array}$ & $\begin{array}{c}\text { Maximum } \\
\text { Load } \\
\text { (Ibs) }\end{array}$ & $\begin{array}{c}\text { Moment } \\
\text { of Inertia } \\
\left(\mathrm{in}^{4} / \mathrm{ft}\right)\end{array}$ & $\begin{array}{c}\text { Area } \\
\left(\mathrm{in}^{2} / \mathrm{ft}\right)\end{array}$ & $\begin{array}{c}\text { Shear } \\
\text { Correction } \\
\text { Coefficient }\end{array}$ & $\begin{array}{c}\text { Bending } \\
\text { Stiffness } \\
\text { (lbs-in } / \mathrm{ft} \text { ) }\end{array}$ & $\begin{array}{l}\text { Shear } \\
\text { Stiffness } \\
\text { (lbs/ft) }\end{array}$ & $\begin{array}{c}\text { Maximum } \\
\text { Moment } \\
\text { (in-lbs/ft) }\end{array}$ & \begin{tabular}{|c|} 
Maximum \\
Shear \\
(lbs/ft)
\end{tabular} & $\begin{array}{c}\mathrm{MOE} \\
(\mathrm{psi})\end{array}$ & $\begin{array}{c}\text { MOR } \\
(\mathrm{psi})\end{array}$ & $\begin{array}{c}\mathrm{G} \\
\text { (psi) }\end{array}$ \\
\hline $1-1$ & 0.373 & $6.08 \%$ & 42.68 & 40.24 & 5096 & 1,510 & 0.631 & 4.82 & 2.22 & 389,755 & 206,623 & 4,105 & 566 & 618,559 & 3,656 & 95,022 \\
\hline $1-4$ & 0.376 & $6.04 \%$ & 43.39 & 40.92 & 5092 & 1,440 & 0.637 & 4.86 & 2.21 & 388,876 & 207,052 & 3,915 & 540 & \begin{tabular}{|l|l|}
610,782 \\
\end{tabular} & 3,461 & 93,897 \\
\hline $2-2$ & 0.380 & $5.91 \%$ & 41.86 & 39.52 & 5199 & 1,440 & 0.645 & 4.91 & 2.19 & 396,273 & 212,210 & 3,915 & 540 & \begin{tabular}{|l|}
614,267 \\
\end{tabular} & 3,429 & 94,468 \\
\hline $2-4$ & 0.374 & $5.96 \%$ & 47.45 & 44.79 & 5001 & 1,430 & 0.633 & 4.84 & 2.21 & 382,301 & 202,964 & 3,888 & 536 & \begin{tabular}{|l}
604,328 \\
\end{tabular} & 3,453 & 92,905 \\
\hline $3-4$ & 0.385 & $5.52 \%$ & 38.90 & 36.86 & 5137 & 1,560 & 0.656 & 4.98 & 2.17 & 390,598 & 210,680 & 4,241 & 585 & \begin{tabular}{|l}
596,602 \\
\end{tabular} & 3,675 & 91,651 \\
\hline $4-3$ & 0.384 & $5.39 \%$ & 38.38 & 36.42 & 5240 & 1,575 & 0.654 & 4.97 & 2.17 & 398,623 & 214,700 & 4,282 & 591 & \begin{tabular}{|l}
609,008 \\
\end{tabular} & 3,711 & 93,830 \\
\hline $5-1$ & 0.389 & $5.37 \%$ & 39.52 & 37.51 & 5275 & 1,615 & 0.664 & 5.03 & 2.15 & 400,319 & 217,165 & 4,391 & 606 & \begin{tabular}{|l}
601,842 \\
\end{tabular} & 3,762 & 92,758 \\
\hline $6-2$ & 0.378 & $5.13 \%$ & 37.55 & 35.72 & 5114 & 1,535 & 0.641 & 4.89 & 2.20 & 390,174 & 208,343 & 4,173 & 576 & \begin{tabular}{|l}
608,685 \\
\end{tabular} & 3,671 & 93,609 \\
\hline $7-3$ & 0.368 & $5.47 \%$ & 49.57 & 47.00 & 5579 & 1,705 & 0.621 & 4.76 & 2.24 & 427,750 & 225,132 & 4,635 & 639 & \begin{tabular}{|l}
689,955 \\
\end{tabular} & 4,177 & 105,988 \\
\hline $8-4$ & 0.375 & $5.51 \%$ & 42.09 & 39.89 & 5250 & 1,535 & 0.635 & 4.85 & 2.21 & 401,139 & 213,273 & 4,173 & 576 & \begin{tabular}{|l}
632,069 \\
\end{tabular} & 3,698 & 97,169 \\
\hline $9-3$ & 0.365 & $5.33 \%$ & 42.49 & 40.34 & 5552 & 1,775 & 0.615 & 4.72 & 2.25 & 426,314 & 223,404 & 4,826 & 666 & \begin{tabular}{|c|}
693,627 \\
\end{tabular} & 4,376 & 106,672 \\
\hline $10-3$ & 0.371 & $5.59 \%$ & 40.42 & 38.28 & 5528 & 1,640 & 0.627 & 4.80 & 2.23 & 423,212 & 223,712 & 4,459 & 615 & \begin{tabular}{|l|l}
674,252 \\
\end{tabular} & 3,983 & \begin{tabular}{|l|}
103,847 \\
\end{tabular} \\
\hline Mean & 0.376 & $5.61 \%$ & 42.02 & 39.79 & 5,255 & 1,563 & 0.638 & 4.87 & 2.20 & 401,278 & 213,772 & 4,250 & 586 & 629,498 & 3,754 & 96,818 \\
\hline Std. & 0.007 & $0.31 \%$ & 3.09 & 2.86 & 196 & 107 & 0.015 & 0.09 & 0.03 & 15,742 & 7,310 & 291 & 40 & 35,436 & 291 & 5,442 \\
\hline COV & 0.02 & 0.06 & 0.07 & 0.07 & 0.04 & 0.07 & $\begin{array}{l}0.02 \\
\end{array}$ & 0.02 & 0.01 & 0.04 & 0.03 & 0.07 & 0.07 & 0.06 & 0.08 & 0.06 \\
\hline+2 (std) & 0.391 & $6.23 \%$ & 48.20 & 45.52 & 5,647 & 1,778 & 0.667 & 5.05 & 2.27 & 432,761 & 228,392 & 4,833 & 667 & 700,369 & 4,335 & \begin{tabular}{|l|}
107,701 \\
\end{tabular} \\
\hline $\begin{array}{l}-2(\mathrm{std}) \\
\end{array}$ & 0.362 & $4.99 \%$ & 35.85 & 34.06 & 4,864 & 1,349 & 0.609 & 4.69 & 2.14 & 369,795 & 199,151 & 3,668 & 506 & 558,627 & 3,173 & 85,935 \\
\hline 5th \% & 0.366 & $5.24 \%$ & 38.01 & 36.10 & 5,051 & 1,436 & 0.618 & 4.74 & 2.16 & 385,917 & 204,976 & 3,903 & 538 & \begin{tabular}{|l|l}
599,484 \\
\end{tabular} & 3,442 & 92,260 \\
\hline
\end{tabular}

\begin{tabular}{|c|c|c|c|c|c|c|c|c|c|c|c|c|c|c|c|c|}
\hline Panel \# & $\begin{array}{l}\text { Weighted } \\
\text { Average } \\
\text { Thickness } \\
\text { (in) }\end{array}$ & $\begin{array}{c}\text { Moisture } \\
\text { Content } \\
(\%)\end{array}$ & $\begin{array}{c}\text { Wet } \\
\text { Density } \\
\text { (Ibs/ft3) }\end{array}$ & $\begin{array}{c}\text { Oven Dry } \\
\text { Density } \\
\text { (Ibs/ft3) }\end{array}$ & $\begin{array}{c}\text { Load/Defl. } \\
\text { (Ibs/in) }\end{array}$ & $\begin{array}{l}\text { Maximum } \\
\text { Load } \\
\text { (Ibs) }\end{array}$ & $\begin{array}{c}\text { Moment } \\
\text { of Inertia } \\
\text { (in } / \mathrm{ft} \text { ) }\end{array}$ & $\begin{array}{l}\text { Area } \\
\left(\mathrm{in}^{2} / \mathrm{ft}\right)\end{array}$ & $\begin{array}{c}\text { Shear } \\
\text { Correction } \\
\text { Coefficient }\end{array}$ & $\begin{array}{c}\text { Bending } \\
\text { Stiffness } \\
\left.\text { (lbs-in }{ }^{2} / \mathrm{ft}\right)\end{array}$ & $\begin{array}{l}\text { Shear } \\
\text { Stiffness } \\
\text { (lbs/ft) }\end{array}$ & $\begin{array}{l}\text { Maximum } \\
\text { Moment } \\
\text { (in-lbs/ft) }\end{array}$ & $\begin{array}{c}\text { Maximum } \\
\text { Shear } \\
(\mathrm{lbs} / \mathrm{ft})\end{array}$ & $\begin{array}{c}\mathrm{MOE} \\
(\mathrm{psi})\end{array}$ & $\begin{array}{l}\text { MOR } \\
(\mathrm{psi})\end{array}$ & $\begin{array}{c}\mathrm{G} \\
(\mathrm{psi})\end{array}$ \\
\hline 11-1 & 0.368 & $5.30 \%$ & 42.66 & 40.52 & 5276 & 1,595 & 0.622 & 4.76 & 2.24 & 404,439 & 212,986 & 4,336 & 598 & 650,528 & 3,900 & 100,081 \\
\hline 11-3 & 0.369 & $5.04 \%$ & 48.35 & 46.03 & 5700 & 1,665 & 0.624 & 4.78 & 2.23 & 436,746 & 230,300 & 4,527 & 624 & 700,443 & 4,063 & 107,760 \\
\hline Mean & 0.369 & $5.17 \%$ & 45.50 & 43.27 & 5,488 & 1,630 & 0.623 & 4.77 & 2.24 & 420,593 & 221,643 & 4,432 & 611 & 675,486 & 3,982 & 103,921 \\
\hline
\end{tabular}

\begin{tabular}{|c|c|c|c|c|c|c|c|c|c|c|c|c|c|c|c|c|}
\hline $\begin{array}{c}\text { Panel } \\
\#\end{array}$ & \begin{tabular}{|c} 
Weighted \\
Average \\
Thickness \\
(in)
\end{tabular} & $\begin{array}{c}\text { Moisture } \\
\text { Content } \\
(\%)\end{array}$ & $\begin{array}{c}\text { Wet } \\
\text { Density } \\
\text { (Ibs/ft3) }\end{array}$ & $\begin{array}{c}\text { Oven Dry } \\
\text { Density } \\
\text { (Ibs/ft3) }\end{array}$ & $\begin{array}{c}\text { Load/Defl. } \\
\text { (lbs/in) }\end{array}$ & $\begin{array}{l}\text { Maximum } \\
\text { Load } \\
\text { (lbs) }\end{array}$ & $\begin{array}{c}\text { Moment } \\
\text { of Inertia } \\
\left.\text { (in }{ }^{4} / \mathrm{ft}\right)\end{array}$ & $\begin{array}{l}\text { Area } \\
\left(\text { in }^{2} / \mathrm{ft}\right)\end{array}$ & $\begin{array}{c}\text { Shear } \\
\text { Correction } \\
\text { Coefficient }\end{array}$ & $\begin{array}{c}\text { Bending } \\
\text { Stiffness } \\
\text { (lbs-in } / \mathrm{ft} \text { ) }\end{array}$ & $\begin{array}{c}\text { Shear } \\
\text { Stiffness } \\
\text { (lbs/ft) }\end{array}$ & $\begin{array}{c}\text { Maximum } \\
\text { Moment } \\
\text { (in-lbs/ft) }\end{array}$ & \begin{tabular}{|c|} 
Maximum \\
Shear \\
(lbs/ft)
\end{tabular} & $\begin{array}{l}\text { MOE } \\
\text { (psi) }\end{array}$ & $\begin{array}{l}\text { MOR } \\
\text { (psi) }\end{array}$ & $\begin{array}{c}\mathrm{G} \\
\text { (psi) }\end{array}$ \\
\hline $12-2$ & 0.493 & $5.41 \%$ & 41.80 & 39.66 & 8312 & 2,295 & 0.898 & 6.38 & 1.75 & 602,683 & 377,046 & 6,240 & 861 & 671,358 & 4,320 & 103,286 \\
\hline $12-4$ & 0.492 & $5.66 \%$ & 43.32 & 41.01 & 8177 & 2,315 & 0.895 & 6.36 & 1.75 & 593,149 & 370,559 & 6,294 & 868 & 662,701 & 4,367 & 101,954 \\
\hline Mean & 0.493 & $5.53 \%$ & 42.56 & 40.33 & 8,245 & 2,305 & 0.896 & 6.37 & 1.75 & 597,916 & 373,803 & 6,267 & 865 & 667,030 & 4,344 & 102,620 \\
\hline
\end{tabular}

\section{Shear}

Actual Span:

Load Point (from support)

Panel Type-A

\begin{tabular}{|c|c|c|c|c|c|c|c|c|}
\hline Panel \# & $\begin{array}{c}\text { Weighted } \\
\text { Average } \\
\text { Thickness } \\
\text { (in) }\end{array}$ & $\begin{array}{c}\text { Moisture } \\
\text { Content } \\
\text { (\%) }\end{array}$ & $\begin{array}{c}\text { Wet } \\
\text { Density } \\
\text { (lbs/ft3) }\end{array}$ & $\begin{array}{c}\text { Oven Dry } \\
\text { Density } \\
\text { (lbs/ft3) }\end{array}$ & $\begin{array}{c}\text { Load/Defl. } \\
\text { (lbs/in) }\end{array}$ & $\begin{array}{c}\text { Maximum } \\
\text { Load } \\
\text { (lbs) }\end{array}$ & $\begin{array}{c}\text { Maximum } \\
\text { Moment } \\
\text { (in-lbs/ft) }\end{array}$ & $\begin{array}{c}\text { Maximum } \\
\text { Shear } \\
\text { (lbs/ft) }\end{array}$ \\
\hline $3-3$ & 0.387 & $5.50 \%$ & 38.16 & 36.18 & 7458 & 1680 & 2,998 & 999 \\
\hline $4-4$ & 0.388 & $5.28 \%$ & 37.74 & 35.85 & 8749 & 1820 & 3,247 & 1,082 \\
\hline $5-2$ & 0.380 & $5.12 \%$ & 41.84 & 39.80 & 8778 & 2010 & 3,587 & 1,196 \\
\hline $6-3$ & 0.370 & $5.04 \%$ & 43.56 & 41.47 & 9144 & 2325 & 4,149 & 1,383 \\
\hline $7-2$ & 0.372 & $5.18 \%$ & 46.18 & 43.90 & 8258 & 2025 & 3,614 & 1,205 \\
\hline $8-1$ & 0.371 & $5.33 \%$ & 44.05 & 41.82 & 8998 & 2085 & 3,721 & 1,240 \\
\hline $9-2$ & 0.369 & $5.15 \%$ & 44.10 & 41.94 & 8745 & 2110 & 3,765 & 1,255 \\
\hline $10-4$ & 0.368 & $5.17 \%$ & 48.09 & 45.73 & 9793 & 2205 & 3,935 & 1,312 \\
\hline Mean & 0.376 & $5.22 \%$ & 42.96 & 40.84 & 8740 & 2032 & 3,627 & 1,209 \\
\hline Std. & 0.008 & $0.14 \%$ & 3.61 & 3.45 & 678 & 205 & 366 & 122 \\
\hline COV & 0.02 & 0.03 & 0.08 & 0.08 & 0.08 & 0.10 & 0.10 & 0.10 \\
\hline+2 (std) & 0.392 & $5.51 \%$ & 50.18 & 47.74 & 10,096 & 2,442 & 4,359 & 1,453 \\
\hline-2 (std) & 0.359 & $4.93 \%$ & 35.75 & 33.93 & 7,385 & 1,622 & 2,895 & 965 \\
\hline 5 th \% & 0.368 & $5.07 \%$ & 37.89 & 35.96 & 7,738 & 1,729 & 3,085 & 1,028 \\
\hline
\end{tabular}

\section{Crush/Bearing}

\begin{tabular}{|c|c|c|c|c|c|}
\cline { 3 - 6 } \multicolumn{2}{c|}{} & \multicolumn{4}{|c|}{$\begin{array}{c}\text { Uniform Load (psf) at 0.02" deformation } \\
\text { Center-to-Center Spacing (in) }\end{array}$} \\
\hline $\begin{array}{c}\text { Load/Defl. } \\
\text { (Ibs/in) }\end{array}$ & $\begin{array}{c}\text { Stiffness } \\
\text { (Ibs/in/ft) }\end{array}$ & 24 & 32 & 40 & 48 \\
\hline 16,224 & 12,168 & 121.7 & 91.3 & 73.0 & 60.8 \\
\hline 13,880 & 10,410 & 104.1 & 78.1 & 62.5 & 52.1 \\
\hline 16,637 & 12,478 & 124.8 & 93.6 & 74.9 & 62.4 \\
\hline 15,168 & 11,376 & 113.8 & 85.3 & 68.3 & 56.9 \\
\hline 16,708 & 12,531 & 125.3 & 94.0 & 75.2 & 62.7 \\
\hline 15,841 & 11,881 & 118.8 & 89.1 & 71.3 & 59.4 \\
\hline 12,814 & 9,611 & 96.1 & 72.1 & 57.7 & 48.1 \\
\hline 12,821 & 9,616 & 96.2 & 72.1 & 57.7 & 48.1 \\
\hline 15012 & 11259 & 112.6 & 84.4 & 67.6 & 56.3 \\
\hline 1,631 & 1,223 & 12.2 & 9.2 & 7.3 & 6.1 \\
\hline 0.11 & 0.11 & 0.11 & 0.11 & 0.11 & 0.11 \\
\hline 18,273 & 13,705 & 137.0 & 102.8 & 82.2 & 68.5 \\
\hline 11,751 & 8,813 & 88.1 & 66.1 & 52.9 & 44.1 \\
\hline 12,816 & 9,612 & 96.1 & 72.1 & 57.7 & 48.1 \\
\hline
\end{tabular}




\section{Edge Point Load}

Panel Type-A

Lower decks as free edges

\begin{tabular}{|c|c|c|c|c|c|c|}
\hline Panel \# & $\begin{array}{l}\text { Weighted } \\
\text { Average } \\
\text { Thickness } \\
\text { (in) }\end{array}$ & $\begin{array}{c}\text { Moisture } \\
\text { Content } \\
(\%)\end{array}$ & $\begin{array}{c}\text { Wet } \\
\text { Density } \\
\left(\mathrm{lbs} / \mathrm{ft}^{3}\right)\end{array}$ & $\begin{array}{c}\text { Oven Dry } \\
\text { Density } \\
\left(\mathrm{lbs} / \mathrm{ft}^{3}\right)\end{array}$ & $\begin{array}{c}\text { Load/Defl } \\
\text { (lbs/in) }\end{array}$ & $\begin{array}{c}\text { Maximum } \\
\text { Load } \\
\text { (Ibs) }\end{array}$ \\
\hline $1-2-E$ & \multirow{2}{*}{0.374} & \multirow{2}{*}{$6.40 \%$} & \multirow{2}{*}{40.88} & \multirow{2}{*}{38.42} & 976 & 522 \\
\hline $1-2-W$ & & & & & 1163 & 560 \\
\hline $2-1-E$ & \multirow{2}{*}{0.376} & \multirow{2}{*}{$5.94 \%$} & \multirow{2}{*}{36.10} & \multirow{2}{*}{34.08} & 1027 & 449 \\
\hline $2-1-W$ & & & & & 1077 & 413 \\
\hline $5-3-E$ & \multirow{2}{*}{0.374} & \multirow{2}{*}{$5.48 \%$} & \multirow{2}{*}{44.71} & \multirow{2}{*}{42.39} & 1128 & 428 \\
\hline $5-3-W$ & & & & & 1295 & 646 \\
\hline 6-4-E & \multirow{2}{*}{0.376} & \multirow{2}{*}{$5.42 \%$} & \multirow{2}{*}{41.48} & \multirow{2}{*}{39.35} & 1173 & 601 \\
\hline $6-4-W$ & & & & & 1240 & 537 \\
\hline Mean & 0.375 & $5.81 \%$ & 40.80 & 38.56 & 1135 & 520 \\
\hline Std. & 0.001 & $0.46 \%$ & 4.31 & 4.16 & 106 & 84 \\
\hline COV & 0.003 & 0.08 & 0.11 & 0.11 & 0.09 & 0.16 \\
\hline$+2(\mathrm{std})$ & 0.377 & $6.73 \%$ & 49.42 & 46.88 & 1,348 & 687 \\
\hline$-2(\mathrm{std})$ & 0.372 & $4.89 \%$ & 32.17 & 30.25 & 922 & 352 \\
\hline 5th \% & 0.374 & $5.43 \%$ & 36.82 & 34.73 & 994 & 418 \\
\hline
\end{tabular}

Upper decks as free edges

\begin{tabular}{|c|c|c|c|c|c|c|}
\hline Panel \# & \begin{tabular}{|c|} 
Weighted \\
Average \\
Thickness \\
(in)
\end{tabular} & $\begin{array}{c}\text { Moisture } \\
\text { Content } \\
(\%)\end{array}$ & $\begin{array}{c}\text { Wet } \\
\text { Density } \\
\left(\mathrm{lbs} / \mathrm{ft}^{3}\right)\end{array}$ & $\begin{array}{c}\text { Oven Dry } \\
\text { Density } \\
\text { (lbs/ft }{ }^{3} \text { ) }\end{array}$ & $\begin{array}{c}\text { Load/Defl. } \\
\text { (lbs/in) }\end{array}$ & $\begin{array}{l}\text { Maximum } \\
\text { Load } \\
\text { (lbs) }\end{array}$ \\
\hline $4-1-E$ & \multirow{2}{*}{0.3905} & \multirow{2}{*}{$5.42 \%$} & \multirow{2}{*}{41.48} & \multirow{2}{*}{39.35} & 717 & 349 \\
\hline $4-1-W$ & & & & & 749 & 405 \\
\hline $8-2-E$ & \multirow{2}{*}{0.3711} & \multirow{2}{*}{$5.82 \%$} & \multirow{2}{*}{41.82} & \multirow{2}{*}{39.52} & 732 & 354 \\
\hline $8-2-W$ & & & & & 740 & 382 \\
\hline $9-4-E$ & \multirow{2}{*}{0.3671} & \multirow{2}{*}{$5.48 \%$} & \multirow{2}{*}{44.71} & \multirow{2}{*}{42.39} & 841 & 466 \\
\hline 9-4-W & & & & & 674 & 346 \\
\hline $10-1-E$ & \multirow{2}{*}{0.3677} & \multirow{2}{*}{$5.72 \%$} & \multirow{2}{*}{46.77} & \multirow{2}{*}{44.24} & 835 & 475 \\
\hline 10-1-W & & & & & 599 & 301 \\
\hline Mean & 0.374 & $5.61 \%$ & 43.70 & 41.38 & 736 & 385 \\
\hline Std. & 0.011 & $0.19 \%$ & 1.78 & 1.71 & 79 & 61 \\
\hline COV & 0.030 & 0.03 & 0.04 & 0.04 & 0.11 & 0.16 \\
\hline$+2(\mathrm{std})$ & 0.396 & $6.00 \%$ & 47.25 & 44.79 & 894 & 506 \\
\hline$-2(\mathrm{std})$ & 0.352 & $5.22 \%$ & 40.14 & 37.96 & 577 & 263 \\
\hline 5th \% & 0.367 & $5.43 \%$ & 41.53 & 39.38 & 625 & 317 \\
\hline
\end{tabular}




\section{Appendix G. Test Data for 4'x8' Panels}

\begin{tabular}{|c|c|c|c|c|c|c|c|c|c|c|c|c|c|c|c|c|c|c|c|}
\hline \multirow{2}{*}{$\begin{array}{c}\text { Panel } \\
\text { No. }\end{array}$} & \multirow{2}{*}{$\begin{array}{c}\text { Weight } \\
\text { (lbs) }\end{array}$} & \multirow{2}{*}{$\begin{array}{l}\text { Weighted } \\
\text { Average } \\
\text { Thickness } \\
\text { (in) }\end{array}$} & \multirow{2}{*}{$\begin{array}{c}\text { Shear } \\
\text { Correction } \\
\text { Factor }\end{array}$} & \multirow{2}{*}{$\begin{array}{c}\text { Area } \\
\left(\mathrm{in}^{2} / \mathrm{ft}\right)\end{array}$} & \multirow{2}{*}{$\begin{array}{l}\text { Shear } \\
\text { Area } \\
\text { (in } / 2 \mathrm{ft})\end{array}$} & \multirow{2}{*}{$\begin{array}{c}\text { Moment } \\
\text { of Inertia } \\
\text { (in } / \mathrm{ft})\end{array}$} & \multirow{2}{*}{$\begin{array}{c}\text { Density } \\
\text { (pcf) }\end{array}$} & Left Di & $\begin{array}{l}\text { Gage } \\
\text { (in) }\end{array}$ & eading & Right D & $\begin{array}{l}\text { al Gage } \\
\text { (in) }\end{array}$ & Reading & Average & & $\begin{array}{l}\text { Bending } \\
\text { Stiffness }\end{array}$ & $\begin{array}{c}\text { Shear } \\
\text { Stiffness }\end{array}$ & & $G$ \\
\hline & & & & & & & & Initial & Final & Net & Initial & Final & Net & & & $\left(\mathrm{lb}-\mathrm{in}^{2} / \mathrm{ft}\right)$ & & & \\
\hline 1 & 41.0 & $\mathrm{n} / \mathrm{a}$ & $\mathrm{n} / \mathrm{a}$ & $\mathrm{n} / \mathrm{a}$ & $\mathrm{n} / \mathrm{a}$ & $\mathrm{n} / \mathrm{a}$ & $\mathrm{n} / \mathrm{a}$ & 0.270 & 0.658 & 0.388 & 0.361 & 0.720 & \begin{tabular}{|l|}
0.359 \\
\end{tabular} & 0.374 & 214 & $\mathrm{n} / \mathrm{a}$ & $\mathrm{n} / \mathrm{a}$ & $\mathrm{n} / \mathrm{a}$ & $\mathrm{n} / \mathrm{a}$ \\
\hline$\frac{1}{2}$ & 39.5 & 0.376 & 2.205 & 4.862 & 2.205 & 0.6363 & 39.44 & $\begin{array}{l}0.27 \\
0.344\end{array}$ & 0.814 & 0.470 & 0.471 & 0.865 & \begin{tabular}{|l|}
0.394 \\
\end{tabular} & $\begin{array}{l}0.0732 \\
\end{array}$ & 185 & 388,737 & \begin{tabular}{|l}
206,977 \\
\end{tabular} & 610,112 & 93,863 \\
\hline 3 & 42.5 & 0.390 & 2.144 & 5.044 & 2.352 & 0.6654 & 40.90 & 0.392 & 0.789 & 0.397 & 0.450 & 0.802 & \begin{tabular}{|l|}
0.352 \\
\end{tabular} & 0.375 & 214 & 449,491 & \begin{tabular}{|l|l}
244,190 \\
\end{tabular} & 674,873 & 103,827 \\
\hline 4 & 38.5 & 0.371 & 2.227 & 4.798 & 2.154 & 0.6269 & 38.92 & 0.403 & 0.890 & 0.487 & $\begin{array}{l}0.4325 \\
0.425\end{array}$ & 0.032 & \begin{tabular}{|l|}
0.407 \\
\end{tabular} & 0.447 & 179 & 376,185 & \begin{tabular}{|l}
198,853 \\
\end{tabular} & $\begin{array}{l}599,999 \\
\end{array}$ & $\frac{10,021}{92,308}$ \\
\hline 5 & 41.5 & $\begin{array}{l}0.381 \\
0.381\end{array}$ & 2.183 & 4.927 & 2.257 & 0.6466 & 40.89 & $\begin{array}{l}0.415 \\
\end{array}$ & 0.692 & 0.477 & 0.409 & $\begin{array}{l}0.0375 \\
0.775\end{array}$ & \begin{tabular}{|l|}
0.466 \\
\end{tabular} & $\begin{array}{l}0.4717 \\
\end{array}$ & 215 & $\begin{array}{l}451,709 \\
\end{array}$ & \begin{tabular}{|l}
242,245 \\
\end{tabular} & $\begin{array}{l}697,719 \\
\end{array}$ & $\frac{10,}{107,341}$ \\
\hline 6 & 42.0 & 0.388 & 2.153 & 5.018 & 2.331 & 0.6624 & 40.56 & 0.341 & 0.739 & 0.398 & 0.392 & 0.732 & \begin{tabular}{|l|}
0.340 \\
\end{tabular} & 0.369 & 217 & 455,818 & \begin{tabular}{|l|l|}
246,919 \\
\end{tabular} & 688,675 & 105,950 \\
\hline 7 & 39.5 & 0.372 & 2.223 & 4.811 & 2.164 & 0.6288 & 39.83 & 0.399 & 0.878 & 0.479 & 0.383 & 0.755 & \begin{tabular}{|l|}
0.372 \\
\end{tabular} & 0.426 & 188 & 395,087 & \begin{tabular}{|l}
209,147 \\
\end{tabular} & 628,114 & 96,633 \\
\hline 8 & 40.0 & 0.384 & 2.170 & $\begin{array}{l}4.011 \\
.966\end{array}$ & $\begin{array}{l}2.288 \\
\end{array}$ & 0.6539 & 39.05 & $\begin{array}{l}0.329 \\
\end{array}$ & 0.735 & 0.406 & 0.445 & $\begin{array}{l}0.1362 \\
0.862\end{array}$ & \begin{tabular}{|l|}
0.417 \\
\end{tabular} & $\begin{array}{l}0.412 \\
\end{array}$ & 194 & $\frac{407,553}{407,53}$ & \begin{tabular}{|l|}
219,509 \\
\end{tabular} & $\frac{023,14}{623,559}$ & $\begin{array}{l}0,05,932 \\
\end{array}$ \\
\hline 9 & 39.5 & 0.370 & 2.232 & 4.785 & 2.144 & 0.6257 & 39.99 & 0.308 & 0.728 & 0.420 & 0.365 & 0.762 & \begin{tabular}{|l|}
0.397 \\
\end{tabular} & 0.409 & 196 & 411,924 & \begin{tabular}{|l|}
217,431 \\
\end{tabular} & 659,134 & 101,405 \\
\hline 10 & 37.0 & 0.362 & 2.267 & 4.681 & 2.065 & 0.6085 & 38.34 & 0.366 & 0.841 & 0.475 & 0.401 & 0.821 & \begin{tabular}{|l|}
0.420 \\
\end{tabular} & 0.448 & 179 & 376,286 & \begin{tabular}{|l}
196,332 \\
\end{tabular} & 618,057 & 95,086 \\
\hline 11 & 41.0 & $\begin{array}{l}0.308 \\
0.388\end{array}$ & 2.153 & 5.018 & 2.0031 & $\begin{array}{l}0.6612 \\
0.6612\end{array}$ & 39.66 & 0.306 & $\begin{array}{l}0.718 \\
\end{array}$ & 0.412 & 0.475 & $\begin{array}{l}0.722 \\
\end{array}$ & \begin{tabular}{|l|}
0.447 \\
\end{tabular} & $\begin{array}{l}0.480 \\
0.380\end{array}$ & 211 & $\frac{4}{443,215}$ & \begin{tabular}{|l|}
240,091 \\
\end{tabular} & $\begin{array}{l}0109,033 \\
669,63\end{array}$ & 103,020 \\
\hline 12 & 40.5 & 0.383 & 2.175 & 4.953 & 2.278 & 0.6515 & 39.65 & 0.304 & 0.680 & 0.376 & 0.408 & 0.769 & 0.361 & 0.369 & 217 & 455,884 & 245,188 & 699,716 & 107,649 \\
\hline 13 & 39.0 & 0.371 & 2.227 & 4.798 & 2.154 & 0.6263 & 39.45 & 0.325 & 0.745 & 0.420 & 0.450 & 0.868 & \begin{tabular}{|l|}
0.418 \\
\end{tabular} & 0.419 & 191 & 401,404 & 212,184 & 640,223 & 98,496 \\
\hline 14 & 43.0 & 0.418 & 2.028 & 5.406 & 2.666 & 0.7250 & 38.60 & 0.377 & 0.743 & 0.366 & 0.448 & 0.803 & \begin{tabular}{|l|}
0.355 \\
\end{tabular} & 0.361 & 222 & 465,930 & \begin{tabular}{|l}
263,381 \\
\end{tabular} & 642,206 & 98,801 \\
\hline$\frac{14}{15}$ & $\begin{array}{l}42.0 \\
42.0\end{array}$ & $\begin{array}{l}.416 \\
0.398\end{array}$ & $\begin{array}{l}2.020 \\
2.110\end{array}$ & 5.147 & $\begin{array}{l}2.000 \\
2.439\end{array}$ & $\begin{array}{l}0.1250 \\
0.6832\end{array}$ & $\begin{array}{l}39.00 \\
39.55\end{array}$ & $\begin{array}{l}.511 \\
0.337\end{array}$ & 0.724 & $\begin{array}{l}0.000 \\
0.387\end{array}$ & $\begin{array}{l}0.440 \\
0.400\end{array}$ & $\begin{array}{l}.005 \\
0.761\end{array}$ & \begin{tabular}{|l|}
0.365 \\
0.361
\end{tabular} & $\begin{array}{l}.001 \\
0.374\end{array}$ & $\frac{221}{214}$ & 449,388 & \begin{tabular}{|l}
20,001 \\
246,941 \\
\end{tabular} & $\begin{array}{l}658,200 \\
658,162\end{array}$ & $\begin{aligned} 0,001 \\
101,256\end{aligned}$ \\
\hline$\frac{1}{16}$ & 41.5 & 0.395 & 2.123 & 5.108 & $\begin{array}{l}.4506 \\
\end{array}$ & $\begin{array}{l}0.6762 \\
0.672\end{array}$ & 39.41 & $\begin{array}{l}0.341 \\
\end{array}$ & 0.734 & 0.393 & 0.499 & 0.755 & \begin{tabular}{|l|}
0.356 \\
\end{tabular} & 0.375 & 214 & 449,427 & \begin{tabular}{|l|}
245,907 \\
\end{tabular} & $\frac{03,102}{664,353}$ & $\frac{10,2}{102,208}$ \\
\hline 17 & 39.0 & 0.378 & 2.196 & 4.888 & 2.226 & 0.6409 & 38.71 & 0.342 & 0.755 & 0.413 & 0.400 & 0.783 & \begin{tabular}{|l|}
0.383 \\
\end{tabular} & 0.398 & 201 & 422,332 & \begin{tabular}{|l}
225,514 \\
\end{tabular} & 658,609 & 101,325 \\
\hline$\frac{17}{18}$ & 39.0 & $\begin{array}{l}0.370 \\
0.377\end{array}$ & $\begin{array}{l}2.1501 \\
2.201\end{array}$ & $\begin{array}{l}4.000 \\
4.875\end{array}$ & $\frac{2.220}{2.215}$ & $\begin{array}{l}0.640398 \\
0.639\end{array}$ & $\begin{array}{l}38.11 \\
38.76\end{array}$ & $\begin{array}{l}0.342 \\
0.392\end{array}$ & 0.806 & $\begin{array}{l}0.415 \\
0.414\end{array}$ & $\begin{array}{l}0.4004 \\
0.384\end{array}$ & $\begin{array}{l}.105 \\
0.761\end{array}$ & \begin{tabular}{|l|}
0.377 \\
0.377
\end{tabular} & $\begin{array}{l}0.390 \\
0.396\end{array}$ & $\frac{201}{202}$ & $\frac{42,352}{424,446}$ & \begin{tabular}{|l|}
22,014 \\
226,316 \\
\end{tabular} & $\frac{030,005}{664,026}$ & $\frac{101,320}{102,158}$ \\
\hline 19 & 38.0 & 0.367 & 2.245 & 4.746 & 2.114 & 0.6193 & 38.81 & 0.320 & 0.684 & $\begin{array}{l}0.414 \\
0.364\end{array}$ & 0.004 & 0.760 & \begin{tabular}{|l|}
0.365 \\
\end{tabular} & 0.365 & 219 & 460,303 & \begin{tabular}{|l|}
241,915 \\
\end{tabular} & 743,769 & $\frac{10,140}{114,426}$ \\
\hline 20 & 38.5 & 0.370 & 2.232 & 4.785 & 2.144 & 0.6253 & 39.00 & 0.398 & 0.821 & 0.423 & 0.428 & 0.811 & \begin{tabular}{|l|}
0.383 \\
\end{tabular} & 0.403 & 199 & 418,229 & \begin{tabular}{|l}
220,759 \\
\end{tabular} & 669,223 & 102,957 \\
\hline 21 & $\begin{array}{l}38.5 \\
38.0\end{array}$ & $\begin{array}{l}0.370 \\
0.367\end{array}$ & $\frac{2.252}{2.245}$ & $\begin{array}{l}.103 \\
4.746\end{array}$ & $\begin{array}{l}2.144 \\
2.114\end{array}$ & 0 & $\begin{array}{l}38.00 \\
38.79\end{array}$ & $\begin{array}{l}.396 \\
0.418\end{array}$ & 0.021 & $\begin{array}{l}.4 \angle 35 \\
0.442\end{array}$ & $\begin{array}{l}0.4205 \\
0.405\end{array}$ & $\begin{array}{l}0.011 \\
0.805\end{array}$ & \begin{tabular}{|l|}
0.300 \\
0.400
\end{tabular} & \begin{tabular}{|l}
0.4031 \\
0.421
\end{tabular} & 190 & $\begin{array}{l}410,2<5 \\
399,350\end{array}$ & \begin{tabular}{|l|}
209,881 \\
\end{tabular} & $\frac{00,250}{645,279}$ & $\frac{10, \text { ind }}{99,274}$ \\
\hline 22 & 40.5 & 0.377 & 2.201 & 4.875 & 2.215 & 0.6383 & 40.33 & 0.479 & 0.928 & 0.449 & 0.423 & 0.821 & \begin{tabular}{|l|}
0.398 \\
\end{tabular} & 0.424 & 189 & 397,130 & \begin{tabular}{|l|}
211,751 \\
\end{tabular} & 621,291 & 95,583 \\
\hline 23 & 37.0 & 0.360 & 2.276 & 4.656 & 2.045 & 0.6043 & 38.57 & $\begin{array}{l}0.427 \\
0.427\end{array}$ & 0.860 & $\begin{array}{l}0.4433 \\
\end{array}$ & $\begin{array}{l}0.4235 \\
0.435\end{array}$ & 0.060 & \begin{tabular}{|l|}
0.425 \\
\end{tabular} & $\begin{array}{l}0.429 \\
0.429\end{array}$ & 186 & $\begin{array}{l}391,025 \\
\end{array}$ & \begin{tabular}{|l}
203,431 \\
\end{tabular} & 646,518 & $\begin{array}{l}0,090 \\
99,464\end{array}$ \\
\hline$\frac{50}{24}$ & 38.0 & $\begin{array}{l}0.3603 \\
0.363\end{array}$ & $\begin{array}{l}2.2610 \\
2.263\end{array}$ & $\begin{array}{l}4.0504 \\
4.694\end{array}$ & $\begin{array}{l}2.045 \\
2.075\end{array}$ & 0.6108 & $\begin{array}{l}39.51 \\
39.26\end{array}$ & $\begin{array}{l}0.421 \\
0.403\end{array}$ & 0.060 & $\begin{array}{l}0.435 \\
0.462\end{array}$ & $\begin{array}{l}0.435 \\
0.435\end{array}$ & $\begin{array}{l}0.000 \\
0.824\end{array}$ & \begin{tabular}{|l|}
0.483 \\
0.389
\end{tabular} & $\begin{array}{l}.4 \angle 26 \\
0.42\end{array}$ & $\begin{array}{l}100 \\
188\end{array}$ & $\begin{array}{l}39,025 \\
39,194\end{array}$ & \begin{tabular}{|l|}
20,401 \\
20,496 \\
\end{tabular} & $\frac{040,010}{646,981}$ & $\begin{array}{l}99,404 \\
99,536\end{array}$ \\
\hline 25 & 37.0 & 0.356 & 2.294 & 4.604 & 2.007 & 0.5970 & 38.97 & 0.370 & 0.807 & 0.437 & 0.563 & 1.086 & \begin{tabular}{|l|}
0.523 \\
\end{tabular} & 0.480 & 167 & 351,124 & \begin{tabular}{|l}
181,615 \\
\end{tabular} & 588,306 & 90,509 \\
\hline 26 & 37.5 & 0.364 & 2.258 & 4.707 & 2.084 & 0.6133 & 38.61 & 0.440 & 0.868 & 0.428 & 0.557 & 1.123 & \begin{tabular}{|l|}
0.566 \\
\end{tabular} & $\begin{array}{l}0.497 \\
\end{array}$ & 161 & 338,427 & \begin{tabular}{|l|l}
177,091 \\
\end{tabular} & 552,230 & $\begin{array}{l}8,959 \\
84,95\end{array}$ \\
\hline 27 & 35.5 & 0.359 & 2.281 & 4.643 & 2.036 & 0.6030 & $\begin{array}{l}37.07 \\
\end{array}$ & $\begin{array}{l}0.4406 \\
\end{array}$ & 1.095 & 0.4599 & 0.406 & 0.949 & \begin{tabular}{|l|}
0.543 \\
\end{tabular} & $\begin{array}{l}.4571 \\
\end{array}$ & 140 & $\begin{array}{l}304,429 \\
29,32\end{array}$ & \begin{tabular}{|l|}
152,903 \\
\end{tabular} & 488,255 & 75,116 \\
\hline 28 & 35.5 & 0.365 & 2.254 & 4.720 & 2.094 & 0.6158 & 36.42 & 0.469 & 1.068 & 0.599 & 0.533 & 1.068 & \begin{tabular}{|l|}
0.535 \\
\end{tabular} & 0.567 & 141 & 296,377 & \begin{tabular}{|l|}
155,312 \\
\end{tabular} & 482,034 & 74,159 \\
\hline$\frac{20}{29}$ & $\begin{array}{l}30.5 \\
39.5\end{array}$ & $\begin{array}{l}.503 \\
0.369\end{array}$ & $\begin{array}{l}2.254 \\
2.236\end{array}$ & $\begin{array}{l}4.1720 \\
.772\end{array}$ & $\begin{array}{l}.094 \\
2.134\end{array}$ & $\begin{array}{l}0.0150 \\
0.6224\end{array}$ & $\frac{0.4 L}{40.17}$ & $\begin{array}{l}0.405 \\
0.415\end{array}$ & 0.841 & $\begin{array}{l}.0956 \\
.426\end{array}$ & $\begin{array}{l}0.353 \\
0.461\end{array}$ & $\begin{array}{l}1.006 \\
0.865\end{array}$ & \begin{tabular}{|l|}
0.404 \\
0.404
\end{tabular} & $\begin{array}{l}.501 \\
0.415\end{array}$ & $\begin{array}{l}141 \\
193\end{array}$ & $\begin{array}{l}2505,361 \\
4\end{array}$ & \begin{tabular}{|l|}
13,012 \\
213,800
\end{tabular} & $\frac{40,054,175}{651,17}$ & $\begin{array}{l}14,150 \\
100,181\end{array}$ \\
\hline 30 & 40.0 & 0.371 & 2.227 & 4.798 & 2.154 & 0.6271 & 40.42 & 0.436 & 0.850 & 0.414 & 0.519 & 0.914 & \begin{tabular}{|l|}
0.395 \\
\end{tabular} & 0.405 & 198 & 416,115 & \begin{tabular}{|l|}
219,961 \\
\end{tabular} & 663,686 & 102,106 \\
\hline$\frac{30}{31}$ & $\frac{40.0}{40.5}$ & $\begin{array}{l}0.311 \\
0.375\end{array}$ & $\frac{2.221}{2.210}$ & $\begin{array}{l}.190 \\
4.850\end{array}$ & $\begin{array}{l}.1545 \\
2.195\end{array}$ & $\begin{array}{l}0.0271 \\
0.6341\end{array}$ & $\begin{array}{l}40.4 L \\
40.55\end{array}$ & $\begin{array}{l}.4396 \\
0.394\end{array}$ & $\begin{array}{l}0.000 \\
0.817\end{array}$ & $\begin{array}{l}.414 \\
0.423\end{array}$ & $\begin{array}{l}0.519 \\
0.466\end{array}$ & $\begin{array}{l}0.914 \\
0.850\end{array}$ & \begin{tabular}{|l|}
0.3954 \\
0.384
\end{tabular} & $\begin{array}{l}0.405 \\
0.404\end{array}$ & $\frac{196}{198}$ & $\begin{array}{l}41,11005 \\
416,06\end{array}$ & $\begin{array}{l}21,91,91 \\
221,29\end{array}$ & $\frac{000,000}{655,103}$ & $\frac{10,100}{100,785}$ \\
\hline$\frac{31}{32}$ & 40.0 & $\begin{array}{l}0.378 \\
0.378\end{array}$ & $\frac{2.210}{2.196}$ & $\begin{array}{l}.050 \\
4.888\end{array}$ & $\frac{2.195}{2.226}$ & $\frac{0.6341}{0.6404}$ & $\begin{array}{l}49.55 \\
39.73\end{array}$ & 0.0300 & 0.011 & $\begin{array}{l}0.4 \angle 5 \\
0.405\end{array}$ & $\begin{array}{l}0.400 \\
0.480\end{array}$ & $\begin{array}{l}0.0309 \\
0.909\end{array}$ & \begin{tabular}{|l|}
0.304 \\
0.429
\end{tabular} & $\begin{array}{l}0.4047 \\
0.417\end{array}$ & $\begin{array}{l}196 \\
192\end{array}$ & $\begin{array}{l}411,03,422 \\
\end{array}$ & \begin{tabular}{|l}
215,40 \\
216,4
\end{tabular} & $\frac{03,193}{629,119}$ & $\frac{10,105}{96,788}$ \\
\hline 33 & 41.5 & 0.389 & 2.149 & 5.031 & 2.341 & 0.6645 & 39.98 & 0.401 & 0.854 & 0.453 & 0.502 & 0.902 & \begin{tabular}{|l|}
0.400 \\
\end{tabular} & 0.427 & 188 & $\begin{array}{l}94,891 \\
\end{array}$ & \begin{tabular}{|l|}
214,221 \\
\end{tabular} & 594,755 & 91,501 \\
\hline$\frac{53}{34}$ & $\begin{array}{l}4.5 \\
40.0\end{array}$ & $\begin{array}{l}0.389 \\
0.381\end{array}$ & $\begin{array}{l}.149 \\
2.183\end{array}$ & $\begin{array}{l}.051 \\
4.927\end{array}$ & $\begin{array}{l}.541 \\
2.257\end{array}$ & $\begin{array}{l}0.0045 \\
0.6469\end{array}$ & $\begin{array}{l}39.96 \\
39.40\end{array}$ & $\begin{array}{l}.401 \\
0.405\end{array}$ & $\begin{array}{l}0.034 \\
0.825\end{array}$ & $\begin{array}{l}.453 \\
0.420\end{array}$ & $\begin{array}{l}0.502 \\
0.470\end{array}$ & $\begin{array}{l}.902 \\
0.873\end{array}$ & \begin{tabular}{|l|}
0.400 \\
0.403
\end{tabular} & $\begin{array}{l}.4 \angle 12 \\
0.412\end{array}$ & $\begin{array}{l}100 \\
194\end{array}$ & $\begin{array}{l}394,091 \\
407,588\end{array}$ & \begin{tabular}{|l|}
$21,22,5$ \\
218,50
\end{tabular} & $\frac{394,150}{629,570}$ & $\begin{array}{l}1,1,001 \\
96,857\end{array}$ \\
\hline 35 & 39.0 & 0.375 & 2.210 & 4.850 & 2.195 & 0.6346 & 39.03 & 0.398 & 0.784 & 0.486 & 0.470 & 0.960 & \begin{tabular}{|l|}
0.4355 \\
\end{tabular} & 0.4111 & 195 & 409,761 & \begin{tabular}{|l|}
217,857 \\
\end{tabular} & 645,177 & $\begin{array}{l}0,09,258 \\
9,58\end{array}$ \\
\hline 36 & 38.5 & 0.369 & 2.236 & 4.772 & 2.134 & 0.6221 & 39.17 & 0.406 & 0.857 & 0.451 & $\begin{array}{l}0.479 \\
\end{array}$ & 0.995 & \begin{tabular}{|l|}
0.516 \\
\end{tabular} & 0.484 & 165 & 346,783 & \begin{tabular}{|l}
182,782 \\
\end{tabular} & 556,704 & 85,647 \\
\hline$\frac{30}{37}$ & $\begin{array}{l}30.5 \\
39.5\end{array}$ & $\begin{array}{l}.309 \\
0.376\end{array}$ & $\begin{array}{l}2.230 \\
2.205\end{array}$ & $\begin{array}{l}4.172 \\
4.862\end{array}$ & $\begin{array}{l}.1344 \\
2.205\end{array}$ & $\begin{array}{l}0.0221 \\
0.6376\end{array}$ & $\begin{array}{l}39.17 \\
39.37\end{array}$ & $\begin{array}{l}0.400 \\
0.327\end{array}$ & $\begin{array}{l}0.051 \\
0.744\end{array}$ & $\begin{array}{l}0.451 \\
0.417\end{array}$ & $\begin{array}{l}0.419 \\
0.492\end{array}$ & $\begin{array}{l}.9950 \\
.920\end{array}$ & \begin{tabular}{|l|}
0.510 \\
0.428 \\
\end{tabular} & $\begin{array}{l}0.404 \\
0.423\end{array}$ & $\begin{array}{l}105 \\
189\end{array}$ & $\begin{array}{l}344,103 \\
397,142\end{array}$ & \begin{tabular}{|l}
$10,11,453$ \\
21,43 \\
\end{tabular} & $\frac{50,104}{623,303}$ & $\begin{array}{l}5,04,893 \\
95,83\end{array}$ \\
\hline 38 & 38.5 & 0.372 & 2.223 & 4.811 & 2.164 & 0.6284 & 38.84 & 0.398 & 0.830 & $\begin{array}{l}0.411 \\
0.432\end{array}$ & $\begin{array}{l}0.431 \\
0.431\end{array}$ & 0.849 & \begin{tabular}{|l|}
0.420 \\
\end{tabular} & 0.425 & 188 & 395,087 & \begin{tabular}{|l|}
209,147 \\
20,1
\end{tabular} & $\frac{028,00}{628,114}$ & $\begin{array}{l}96,633 \\
6,63\end{array}$ \\
\hline 39 & 41.0 & 0.384 & 2.170 & 4.966 & 2.288 & 0.6546 & 39.99 & 0.377 & 0.769 & 0.392 & 0.451 & 0.836 & \begin{tabular}{|l|}
0.385 \\
\end{tabular} & 0.389 & 206 & 432,762 & \begin{tabular}{|l}
233,087 \\
\end{tabular} & 662,129 & 101,866 \\
\hline 40 & 40.0 & $\begin{array}{l}0.304 \\
0.375\end{array}$ & $\frac{2.170}{2.210}$ & $\begin{array}{l}4.900 \\
.850\end{array}$ & $\begin{array}{l}2.200 \\
2.195\end{array}$ & $\begin{array}{l}0.0340 \\
0.6341\end{array}$ & 40.05 & $\begin{array}{l}0.311 \\
0.359\end{array}$ & 0.757 & $\begin{array}{l}.0398 \\
0.398\end{array}$ & $\begin{array}{l}0.401 \\
0.490\end{array}$ & $\begin{array}{l}0.030 \\
0.902\end{array}$ & \begin{tabular}{|l|}
0.312 \\
0.412
\end{tabular} & $\begin{array}{l}0.305 \\
0.405\end{array}$ & 198 & $\begin{array}{l}43,102 \\
416,065\end{array}$ & \begin{tabular}{|l|l}
$20,1,209$ \\
22,2
\end{tabular} & $\frac{00,125}{655,103}$ & $\frac{101,000}{100,785}$ \\
\hline 41 & 41.0 & 0.391 & 2.140 & 5.056 & 2.363 & 0.6689 & 39.29 & 0.396 & 0.778 & 0.382 & 0.584 & 1.082 & \begin{tabular}{|l|}
0.498 \\
\end{tabular} & 0.440 & 182 & 382,266 & \begin{tabular}{|l}
207,967 \\
\end{tabular} & 572,151 & 88,023 \\
\hline 42 & 37.5 & 0.360 & 2.276 & 4.656 & 2.045 & 0.6041 & 39.10 & 0.416 & 0.834 & 0.418 & 0.415 & 0.842 & \begin{tabular}{|l|}
0.427 \\
\end{tabular} & 0.423 & 189 & 397,332 & \begin{tabular}{|l}
206,712 \\
\end{tabular} & 656,946 & $\begin{array}{l}101,069 \\
\end{array}$ \\
\hline 43 & 37.5 & & 2.272 & 4.068 & 2.055 & 0.6068 & 38.95 & 0.410 & 1.009 & $\begin{array}{l}0.4109 \\
0.499\end{array}$ & $\begin{array}{l}0.4152 \\
0.45\end{array}$ & $\begin{array}{l}0.0423 \\
0.823\end{array}$ & \begin{tabular}{|l|}
0.471 \\
\end{tabular} & $\begin{array}{l}0.435 \\
\end{array}$ & 184 & $\begin{array}{l}386,809 \\
\end{array}$ & \begin{tabular}{|l|}
201,530 \\
\end{tabular} & $\frac{03,040}{637,438}$ & 98,067 \\
\hline 44 & 35.0 & 0.351 & 2.317 & 4.539 & 1.959 & 0.5866 & 37.41 & 0.604 & 1.072 & 0.468 & 0.532 & 0.992 & \begin{tabular}{|l|}
0.460 \\
\end{tabular} & 0.464 & 172 & $\begin{array}{l}361,692 \\
\end{array}$ & $\begin{array}{l}185,726 \\
\end{array}$ & $\begin{array}{r}616,248 \\
\end{array}$ & 94,807 \\
\hline $\begin{array}{l}445 \\
45\end{array}$ & $\frac{30.0}{36.5}$ & $\frac{0.351}{0.347}$ & $\frac{2.517}{2.335}$ & \begin{tabular}{|l|}
4.5397 \\
\end{tabular} & $\begin{array}{l}1.9591 \\
1.921\end{array}$ & $\begin{array}{l}0.5000 \\
0.5795\end{array}$ & $\frac{5.41}{39.42}$ & $\begin{array}{l}.004 \\
0.464\end{array}$ & $\begin{array}{l}1.0172 \\
0.908\end{array}$ & $\begin{array}{l}.406 \\
0.444\end{array}$ & $\begin{array}{l}0.532 \\
0.461\end{array}$ & $\frac{0.992}{0.870}$ & \begin{tabular}{|l|}
0.400 \\
0.409 \\
\end{tabular} & $\begin{array}{l}0.404 \\
0.427\end{array}$ & $\frac{172}{188}$ & $\frac{301,092}{395,387}$ & \begin{tabular}{|l|}
$10,1,80$ \\
2
\end{tabular} & $\frac{01,2,240}{682,828}$ & $\frac{94,001}{105,050}$ \\
\hline 46 & 35.0 & & & 4.497 & 1.857 & 0.5663 & 38.55 & $\begin{array}{l}0.4045 \\
0.415\end{array}$ & 0.865 & 0.450 & $\begin{array}{l}0.468 \\
0.468\end{array}$ & 0.010 & \begin{tabular}{|l|}
0.442 \\
0.442
\end{tabular} & $\begin{array}{l}0.421 \\
0.446\end{array}$ & 179 & $\begin{array}{l}376,541 \\
\end{array}$ & \begin{tabular}{|l}
190,277 \\
\end{tabular} & $\begin{array}{l}06,06,036 \\
66,0\end{array}$ & 102,467 \\
\hline $\begin{array}{l}40 \\
47\end{array}$ & 35.0 & $\begin{array}{l}0.340 \\
0.349\end{array}$ & $\begin{array}{l}.368 \\
2.326\end{array}$ & $\begin{array}{l}4.3971 \\
4.513\end{array}$ & $\frac{1.851}{1.940}$ & $\begin{array}{l}0.58633 \\
0.5831\end{array}$ & $\begin{array}{l}37.55 \\
37.60\end{array}$ & \begin{tabular}{|l}
0.415 \\
0.479
\end{tabular} & 0.865 & $\begin{array}{l}0.450 \\
0.474\end{array}$ & $\begin{array}{l}0.468 \\
0.462\end{array}$ & $\begin{array}{l}0.910 \\
0.909\end{array}$ & \begin{tabular}{|l|}
0.4427 \\
0.447
\end{tabular} & $\begin{array}{l}.446 \\
0.461\end{array}$ & $\frac{179}{174}$ & $\frac{317,541}{365,921}$ & \begin{tabular}{|l|}
19,277 \\
187,351
\end{tabular} & $\frac{060,030}{627,673}$ & $\frac{10<, 401}{96,565}$ \\
\hline$\frac{41}{48}$ & 30.0 & $\begin{array}{l}0.045 \\
0.347\end{array}$ & $\frac{1.520}{2.335}$ & $\begin{array}{l}4.015 \\
.487\end{array}$ & $\frac{1.540}{1.921}$ & 0.03794 & 38.00 & $\begin{array}{l}.415 \\
0.424\end{array}$ & 0.835 & $\begin{array}{l}0.414 \\
0.411\end{array}$ & $\begin{array}{l}0.402 \\
0.547\end{array}$ & $\begin{array}{l}.9056 \\
1.056\end{array}$ & \begin{tabular}{|l|}
0.4509 \\
0.509
\end{tabular} & $\begin{array}{l}.401 \\
0.460\end{array}$ & $\frac{174}{174}$ & $\begin{array}{l}30,921 \\
65,943\end{array}$ & \begin{tabular}{|l}
186,818 \\
\end{tabular} & $\frac{021,015}{631,979}$ & $\begin{array}{l}0,000 \\
97,228\end{array}$ \\
\hline 49 & 31.5 & & 2.354 & 4.436 & $\begin{array}{l}1.084 \\
.884\end{array}$ & 0.5703 & $\begin{array}{l}34.06 \\
\end{array}$ & 0.4606 & 1.286 & 0.411 & 0.034 & 1.115 & \begin{tabular}{|l|}
0.481 \\
\end{tabular} & $\begin{array}{l}0.4081 \\
\end{array}$ & 138 & 290,267 & \begin{tabular}{|l}
147,323 \\
\end{tabular} & $\begin{array}{l}008,169 \\
\end{array}$ & 78,180 \\
\hline 50 & $\frac{31.5}{36.0}$ & $\begin{array}{l}.343 \\
0.348\end{array}$ & $\begin{array}{l}.354 \\
2.331\end{array}$ & $\begin{array}{l}.430 \\
4.500\end{array}$ & $\begin{array}{l}1.8841 \\
1.931\end{array}$ & $\begin{array}{l}0.50353 \\
0.5804\end{array}$ & $\begin{array}{l}38.48 \\
38.83\end{array}$ & $\begin{array}{l}0.006 \\
0.431\end{array}$ & $\begin{array}{l}1.286 \\
0.862\end{array}$ & $\begin{array}{l}.080 \\
0.431\end{array}$ & $\begin{array}{l}0.034 \\
0.478\end{array}$ & $\begin{array}{l}.115 \\
0.906\end{array}$ & \begin{tabular}{|l|}
0.481 \\
0.428 \\
\end{tabular} & $\begin{array}{l}.581 \\
0.430\end{array}$ & $\frac{138}{186}$ & $\begin{array}{l}299,201 \\
391,169\end{array}$ & \begin{tabular}{|l|}
$14,39,387$ \\
\end{tabular} & $\frac{50,169}{673,256}$ & $\frac{10,180}{103,578}$ \\
\hline 51 & 36.5 & 0.342 & 2.359 & 4.423 & 1.875 & 0.5702 & 39.96 & 0.379 & 0.770 & 0.701 & 0.451 & 0.919 & \begin{tabular}{|l|}
0.468 \\
\end{tabular} & 0.430 & 186 & 391,242 & \begin{tabular}{|l|}
198,283 \\
\end{tabular} & 687,297 & 105,738 \\
\hline 52 & 37.0 & 0.346 & 2.340 & 4.475 & 1.912 & 0.5763 & 40.15 & 0.396 & 0.818 & 0.422 & 0.471 & 0.848 & \begin{tabular}{|l|}
0.377 \\
\end{tabular} & 0.400 & 200 & 420,638 & \begin{tabular}{|l}
214,427 \\
\end{tabular} & 728,908 & 112,140 \\
\hline$\frac{32}{53}$ & $\begin{array}{l}37.0 \\
37.0\end{array}$ & $\begin{array}{l}0.040 \\
0.347\end{array}$ & $\frac{2.040}{2.335}$ & $\begin{array}{l}4.410 \\
4.487\end{array}$ & $\frac{1.912}{1.921}$ & 0.5785 & $\frac{40.15}{40.01}$ & $\begin{array}{l}0.3903 \\
0.393\end{array}$ & $\begin{array}{l}0.010 \\
0.792\end{array}$ & $\begin{array}{l}.4 \angle L \\
0.399\end{array}$ & $\begin{array}{l}0.471 \\
0.499\end{array}$ & $\begin{array}{l}0.046 \\
0.926\end{array}$ & \begin{tabular}{|l|}
0.427 \\
0.427
\end{tabular} & $\begin{array}{l}.400 \\
0.413\end{array}$ & 194 & $\begin{array}{l}4208,050 \\
40,006\end{array}$ & \begin{tabular}{|l|}
$208,4,291$ \\
\end{tabular} & $\frac{120,900}{704,620}$ & $\frac{11,140}{108,403}$ \\
\hline Min. & 31.5 & & & & 1.857 & & & 0.304 & 0.680 & 0.364 & & 0.722 & 0.340 & 0.361 & 138 & 290,267 & & & 74,159 \\
\hline Max. & 43.0 & 0.418 & $\begin{array}{l}2.020 \\
2.368\end{array}$ & 5.406 & $\begin{array}{l}2.031 \\
2.666\end{array}$ & 0.7250 & $\begin{array}{l}40.90 \\
40.90\end{array}$ & 0.606 & 1.286 & 0.680 & 0.634 & 1.123 & 0.566 & 0.581 & 222 & 465,930 & 263,381 & $\begin{array}{l}40,034 \\
743,769\end{array}$ & 114,426 \\
\hline Mean & 38.65 & 0.370 & 2.233 & 4.784 & 2.148 & 0.6251 & 39.17 & 0.0099 & 0.834 & 0.435 & 0.458 & 0.875 & 0.017 & 0.426 & 190 & 398,862 & 210,837 & 637,857 & 98,132 \\
\hline Std. & 2.32 & 0.016 & 0.072 & 0.210 & 0.164 & 0.0329 & 1.11 & 0.064 & 0.112 & 0.058 & 0.058 & 0.101 & 0.054 & 0.048 & 19 & 39,510 & 24,127 & 52,292 & 8,045 \\
\hline $\mathrm{cOV}$ & 0.06 & 0.04 & 0.03 & 0.04 & 0.08 & 0.05 & $\begin{array}{l}0.03 \\
0.03\end{array}$ & 0.16 & 0.13 & 0.13 & 0.13 & 0.12 & 0.13 & 0.11 & 0.10 & 0.10 & $\begin{array}{c}24,121 \\
0.11\end{array}$ & 0.08 & $\begin{array}{c}0,040 \\
0.08\end{array}$ \\
\hline+2 (Std) & 40.3 & 0.402 & 2.376 & 0.203 & 2.476 & 0.691 & "2.1.40 & 0.528 & 1.059 & 0.551 & 0.573 & 1.078 & 0.525 & 0.522 & 227 & $4 \quad 477,882$ & 259,091 & $\overline{742,440}$ & 114,222 \\
\hline$-2(\mathrm{Std})$ & $\begin{array}{l}34.0 \\
34.0\end{array}$ & $\begin{array}{l}0.402 \\
0.337\end{array}$ & 2.090 & $\begin{array}{l}4.203 \\
4.365\end{array}$ & $\begin{array}{l}2.410 \\
1.819\end{array}$ & 0.559 & $\begin{array}{l}4.40 \\
36.94\end{array}$ & 0.270 & $\begin{array}{l}0.609 \\
0.09\end{array}$ & 0.319 & 0.343 & 0.673 & $\begin{array}{l}0.320 \\
0.309\end{array}$ & 0.331 & $\begin{array}{l}221 \\
152\end{array}$ & 319,842 & $\begin{array}{l}25,02,584 \\
162\end{array}$ & 533,273 & 82,042 \\
\hline 5th \% & 35.0 & 0.344 & 2.133 & 4.457 & 1.900 & 0.574 & 37.26 & 0.312 & 0.706 & 0.377 & 0.384 & 0.755 & 0.354 & 0.369 & 152 & 319,505 & 167,290 & 532,403 & 81,908 \\
\hline
\end{tabular}




\section{Appendix H. Lateral Density Profile Data}

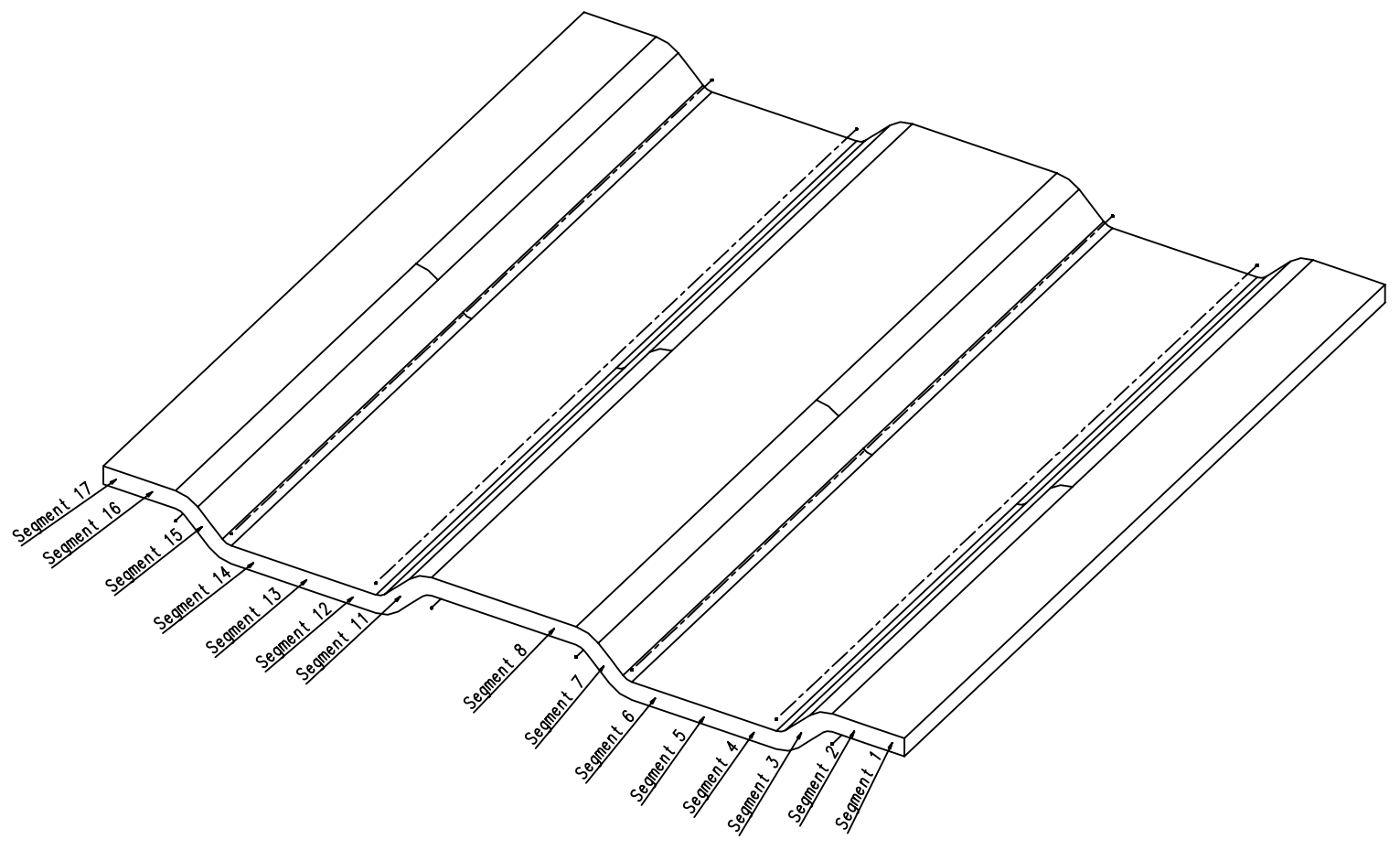

$\begin{array}{lc}\text { Panel: } & 3-2 \\ \text { Date: } & \text { November 10, } 2002\end{array}$

Width (in):

\begin{tabular}{|c|c|c|c|c|c|c|c|c|c|c|c|c|c|c|c|c|c|c|}
\hline \multirow{2}{*}{$\begin{array}{l}\text { Distance } \\
\text { From North } \\
\text { End (in) } \\
\end{array}$} & \multicolumn{17}{|c|}{ Segment No. } & \multirow{2}{*}{$\begin{array}{l}\text { Total } \\
\text { Width } \\
\text { (in) }\end{array}$} \\
\hline & $3-2-1$ & $3-2-2$ & $3-2-3$ & $3-2-4$ & $3-2-5$ & $3-2-6$ & $3-2-7$ & $3-2-8$ & $3-2-9$ & 3-2-10 & 3-2-11 & $\mid 3-2-12$ & 3-2-13 & 3-2-14 & $3-2-15$ & 3-2-16 & 3-2-17 & \\
\hline $\begin{array}{l}0 \\
0\end{array}$ & 0.5385 & 0.9780 & 0.9290 & \begin{tabular}{|l|l|}
0.9610 \\
\end{tabular} & 0.9550 & 0.9635 & 0.9530 & 0.9670 & 0.9730 & 0.9490 & 0.9605 & 0.9640 & \begin{tabular}{|l|l|}
0.9400 \\
\end{tabular} & 0.9955 & \begin{tabular}{|l|l|} 
\\
\end{tabular} & \begin{tabular}{|l|l|}
0.9660 \\
\end{tabular} & 0.4565 & 15.4230 \\
\hline 4 & 0.5340 & 0.9845 & 0.9165 & \begin{tabular}{|l|}
0.9625 \\
\end{tabular} & 0.9570 & 0.9685 & 0.9630 & 0.9665 & 0.9710 & 0.9470 & 0.9665 & 0.9395 & \begin{tabular}{|l|}
0.9555 \\
\end{tabular} & 1.0045 & \begin{tabular}{|l|}
0.9805 \\
\end{tabular} & \begin{tabular}{|l|}
0.9720 \\
\end{tabular} & 0.4455 & 15.4345 \\
\hline 8 & 0.5330 & 0.9835 & 0.9245 & \begin{tabular}{|l|}
0.9620 \\
\end{tabular} & 0.9580 & 0.9700 & \begin{tabular}{|l|l|}
0.9570 \\
\end{tabular} & 0.9640 & 0.9700 & 0.9510 & \begin{tabular}{|l|}
0.9695 \\
\end{tabular} & 0.9615 & 0.9310 & 0.9945 & 0.9705 & \begin{tabular}{|l|l|}
0.9750 \\
\end{tabular} & 0.4330 & 15.4080 \\
\hline 12 & 0.5260 & 0.9920 & 0.9125 & 0.9600 & 0.9575 & 0.9670 & 0.9610 & 0.9660 & 0.9680 & 0.9485 & \begin{tabular}{|l|}
0.9910 \\
\end{tabular} & \begin{tabular}{|l|l|}
0.9645 \\
\end{tabular} & & 0.9935 & \begin{tabular}{|l|}
0.9805 \\
\end{tabular} & 0.9800 & & 15.4315 \\
\hline 16 & 0.5270 & 0.9780 & 0.9135 & \begin{tabular}{|l|}
0.9575 \\
\end{tabular} & 0.9570 & 0.9630 & 0.9575 & 0.9655 & 0.9680 & 0.9460 & 0.9630 & 0.9280 & 0.9550 & 1.0000 & 0.9815 & \begin{tabular}{|l|}
0.9910 \\
\end{tabular} & \begin{tabular}{|l|l|}
0.3975 \\
\end{tabular} & 15.3490 \\
\hline
\end{tabular}

\begin{tabular}{|c|c|c|c|c|c|c|c|c|c|c|c|c|c|c|c|c|c|c|}
\hline \multirow{2}{*}{$\begin{array}{l}\text { Distance } \\
\text { From North } \\
\text { End (in) } \\
\end{array}$} & \multicolumn{17}{|c|}{ Segment No. } & \multirow{2}{*}{\begin{tabular}{|c|} 
Ave. \\
Thickness \\
(in)
\end{tabular}} \\
\hline & $3-2-1$ & $3-2-2$ & $3-2-3$ & $3-2-4$ & $3-2-5$ & $3-2-6$ & 3-2-7 & $3-2-8$ & $3-2-9$ & $3-2-10$ & 3-2-11 & 3-2-12 & 3-2-13 & 3-2-14 & 3-2-15 & 3-2-16 & 3-2-17 & \\
\hline 0 & 0.3880 & 0.3920 & 0.3795 & 0.3900 & 0.3860 & 0.3855 & \begin{tabular}{|l|l|}
0.3890 \\
\end{tabular} & 0.3900 & 0.3835 & 0.3810 & \begin{tabular}{|l|}
0.3735 \\
\end{tabular} & 0.3820 & 0.3845 & \begin{tabular}{|l|l|}
0.3885 \\
\end{tabular} & 0.3930 & \begin{tabular}{|l|l|}
0.3945 \\
\end{tabular} & \begin{tabular}{|l|}
0.3985 \\
\end{tabular} & \begin{tabular}{|l|}
0.3870 \\
\end{tabular} \\
\hline 4 & 0.3800 & 0.3860 & 0.3710 & 0.3750 & 0.3745 & 0.3730 & 0.3740 & 0.3740 & 0.3770 & 0.3740 & 0.3685 & 0.3760 & 0.3755 & \begin{tabular}{|l|l|}
0.3755 \\
\end{tabular} & 0.3765 & \begin{tabular}{|l|}
0.3815 \\
\end{tabular} & 0.3870 & 0.3764 \\
\hline 8 & \begin{tabular}{|l|}
0.3720 \\
\end{tabular} & 0.3745 & 0.3740 & 0.3690 & 0.3695 & 0.3690 & $\mid 0.3660$ & 0.3710 & 0.3790 & 0.3710 & \begin{tabular}{|l|}
0.3735 \\
\end{tabular} & 0.370 & 0.3720 & \begin{tabular}{|c|}
0.3710 \\
\end{tabular} & 0.3715 & 0.3796 & 0.3780 & 0.3724 \\
\hline 12 & 0.372 & 0.3775 & 0.3725 & \begin{tabular}{|l|l|}
0.3740 \\
\end{tabular} & 0.370 & 0.3675 & 0.36 & 0.3660 & 0.3660 & 0.3675 & & & & 0.3695 & & & 0.3775 & 0.3703 \\
\hline 16 & 0.3810 & 0.3890 & \begin{tabular}{|l|l|}
0.3795 \\
\end{tabular} & 0.3745 & 0.3725 & 0.3750 & 0.3625 & 0.3645 & 0.3665 & 0.3690 & \begin{tabular}{|l|}
0.3695 \\
\end{tabular} & 0.3670 & 0.3650 & \begin{tabular}{|l|}
0.3645 \\
\end{tabular} & \begin{tabular}{|l|}
0.3660 \\
\end{tabular} & \begin{tabular}{|l|}
0.3810 \\
\end{tabular} & \begin{tabular}{|l|l|}
0.3780 \\
\end{tabular} & 0.3721 \\
\hline
\end{tabular}

Estimated Volume $\left(\mathrm{in}^{3}\right.$ ):
\begin{tabular}{|c|c|c|c|c|c|c|c|c|c|c|c|c|c|c|c|c|c|c|}
\hline $\begin{array}{c}\text { Distance } \\
\text { From North } \\
\text { End (in) }\end{array}$ & $3-2-1$ & $3-2-2$ & $3-2-3$ & $3-2-4$ & $3-2-5$ & $3-2-6$ & $3-2-7$ & $3-2-8$ & $3-2-9$ & $3-2-10$ & $3-2-11$ & $3-2-12$ & $3-2-13$ & $3-2-14$ & $3-2-15$ & $3-2-16$ & $3-2-17$ & $\begin{array}{c}\text { Horizontal } \\
\text { Sum }\end{array}$ \\
\hline $0-4$ & 0.8237 & 1.5268 & 1.7927 & 1.4715 & 1.4541 & 1.4654 & 1.8771 & 1.4772 & 1.4784 & 1.4315 & 1.8339 & 1.4430 & 1.4404 & 1.5279 & 1.9228 & 1.5038 & 0.7086 & 25.1787 \\
\hline $4-8$ & 0.8024 & 1.4967 & 1.7760 & 1.4318 & 1.4248 & 1.4384 & 1.8237 & 1.4382 & 1.4674 & 1.4140 & 1.8407 & 1.4180 & 1.4102 & 1.4923 & 1.8670 & 1.4807 & 0.6722 & 24.6945 \\
\hline $8-12$ & 0.7884 & 1.4856 & 1.7765 & 1.4280 & 1.4165 & 1.4266 & 1.7914 & 1.4224 & 1.4438 & 1.4028 & 1.8577 & 1.4185 & 1.3829 & 1.4721 & 1.8432 & 1.4819 & 0.6573 & 24.4957 \\
\hline $12-16$ & 0.7934 & 1.5098 & 1.7811 & 1.4352 & 1.4215 & 1.4330 & 1.783 & 1.4110 & 1.4181 & 1.3953 & 1.8429 & 1.3881 & 1.3874 & 1.4632 & 1.8376 & 1.4980 & 0.6304 & 24.4294 \\
\hline Vertical Sum & 3.2080 & 6.0189 & 7.1263 & 5.7666 & 5.7168 & 5.7633 & 7.2754 & 5.7488 & 5.8078 & 5.6436 & 7.3751 & 5.6676 & 5.6210 & 5.9555 & 7.4706 & 5.9644 & 2.6685 & 98.7982 \\
\hline
\end{tabular}

Estimated Density (pcf):

\begin{tabular}{|c|c|c|c|c|c|c|c|c|c|c|c|c|c|c|c|c|c|c|}
\hline & \multicolumn{17}{|c|}{ Segment No. } & \multirow[b]{2}{*}{ Total } \\
\hline & $3-2-1$ & $3-2-2$ & $3-2-3$ & $3-2-4$ & $3-2-5$ & $3-2-6$ & $3-2-7$ & $3-2-8$ & $3-2-9$ & 3-2-10 & 3-2-11 & 3-2-12 & 3-2-13 & 3-2-14 & 3-2-15 & $3-2-16$ & $\mid 3-2-17$ & \\
\hline & 32.5 & $\begin{array}{ll}60.8 \\
\end{array}$ & 70.7 & 61.3 & \begin{tabular}{|l|}
60.2 \\
\end{tabular} & $\begin{array}{ll}64.8 \\
\end{array}$ & 78.0 & & $\begin{array}{ll}66.7 \\
\end{array}$ & $\begin{array}{ll}66.3 \\
\end{array}$ & \begin{tabular}{l|l|}
83.5 \\
\end{tabular} & \begin{tabular}{|l|}
66.0 \\
\end{tabular} & \begin{tabular}{|l|}
61.7 \\
\end{tabular} & 68.5 & & 72.0 & & \\
\hline & 0.0717 & 0.1340 & 0.1559 & 0.1351 & 0.1327 & 0.1429 & 0.1720 & 0.1418 & 0.1470 & 0.1462 & 0.1841 & 0.1455 & 0.1360 & 0.1510 & 0.1792 & \begin{tabular}{|l|}
0.1587 \\
\end{tabular} & & \\
\hline Density (pcf) & 38.59 & \begin{tabular}{|l|l|}
38.48 \\
\end{tabular} & 37.80 & 40.50 & 40.12 & 42.83 & 40.84 & & & & & 44.36 & & & 41.46 & \begin{tabular}{|l|}
45.99 \\
\end{tabular} & 45.40 & 42.05 \\
\hline
\end{tabular}

Note: Gray regions are sidewalls. 


\begin{tabular}{|c|c|c|c|c|c|c|c|c|c|c|c|c|c|c|c|c|c|c|}
\hline \multirow{2}{*}{$\begin{array}{l}\text { Panel: } \\
\text { Date: } \\
\text { Width (in): }\end{array}$} & \multicolumn{18}{|c|}{$\begin{array}{l}1-3 \\
\text { November } 11,2002\end{array}$} \\
\hline & & & & & & & & & & & & & & & & & & \\
\hline \multirow{2}{*}{$\begin{array}{l}\text { Distance } \\
\text { From North } \\
\text { End (in) }\end{array}$} & \multicolumn{17}{|c|}{ Segment No. } & \multirow{2}{*}{$\begin{array}{l}\text { Total } \\
\text { Width } \\
\text { (in) }\end{array}$} \\
\hline & $1-3-1$ & $1-3-2$ & $1-3-3$ & $1-3-4$ & $1-3-5$ & $1-3-6$ & $1-3-7$ & $1-3-8$ & 1-3-9 & 1-3-10 & $1-3-11$ & $\mid 1-3-12$ & 1-3-13 & $1-3-14$ & 1-3-15 & 1-3-16 & 1-3-17 & \\
\hline 0 & 0.5380 & 0.9820 & 0.9105 & \begin{tabular}{|l|}
0.9595 \\
\end{tabular} & \begin{tabular}{|l|}
0.9585 \\
\end{tabular} & 0.9675 & 0.9610 & 0.9660 & 0.9720 & 0.9570 & 0.9610 & 0.9625 & 0.9670 & \begin{tabular}{|l|}
0.9970 \\
\end{tabular} & 0.9665 & 0.9560 & \begin{tabular}{|l|}
0.4440 \\
\end{tabular} & 15.4260 \\
\hline 4 & \begin{tabular}{|l|}
0.5520 \\
\end{tabular} & 0.9795 & \begin{tabular}{|l|}
0.9195 \\
\end{tabular} & 0.9590 & \begin{tabular}{|l|}
0.9670 \\
\end{tabular} & \begin{tabular}{|l|}
0.9680 \\
\end{tabular} & \begin{tabular}{|l|}
0.9675 \\
\end{tabular} & \begin{tabular}{|l|}
0.9665 \\
\end{tabular} & \begin{tabular}{|l|}
0.9725 \\
\end{tabular} & 0.9470 & 0.9765 & \begin{tabular}{|l|}
0.9510 \\
\end{tabular} & 0.9615 & 0.9940 & 0.9745 & 0.9675 & \begin{tabular}{|l|}
0.4645 \\
\end{tabular} & 15.4880 \\
\hline 8 & 0.5540 & 0.9790 & 0.9170 & 0.9590 & 0.9595 & \begin{tabular}{|l|}
0.9705 \\
\end{tabular} & 0.9505 & \begin{tabular}{|l|}
0.9660 \\
\end{tabular} & 0.9745 & 0.9500 & 0.9835 & 0.9600 & 0.9350 & 0.9935 & 0.9690 & 0.9830 & 0.4525 & 15.4565 \\
\hline 12 & 0.5480 & 0.9770 & 0.9200 & 0.9660 & \begin{tabular}{|l|}
0.9570 \\
\end{tabular} & 0.9720 & 0.9565 & \begin{tabular}{|l|}
0.9660 \\
\end{tabular} & 0.9715 & 0.9505 & 0.9790 & \begin{tabular}{|l|}
0.9625 \\
\end{tabular} & 0.9200 & 0.9985 & 0.9825 & 0.9930 & \begin{tabular}{|l|}
0.4540 \\
\end{tabular} & 15.4740 \\
\hline 16 & 0.5450 & 0.9850 & \begin{tabular}{|l|}
0.9060 \\
\end{tabular} & \begin{tabular}{|l|}
0.9650 \\
\end{tabular} & \begin{tabular}{|l|}
0.9540 \\
\end{tabular} & \begin{tabular}{|l|}
0.9725 \\
\end{tabular} & \begin{tabular}{|l|}
0.9470 \\
\end{tabular} & \begin{tabular}{|l|}
0.9625 \\
\end{tabular} & \begin{tabular}{|l|}
0.9685 \\
\end{tabular} & 0.9495 & \begin{tabular}{|l|l|}
0.9845 \\
\end{tabular} & \begin{tabular}{|l|}
0.9225 \\
\end{tabular} & \begin{tabular}{|l|l|}
0.9485 \\
\end{tabular} & \begin{tabular}{|l|}
0.9970 \\
\end{tabular} & \begin{tabular}{|l|l|}
0.9615 \\
\end{tabular} & 1.0080 & \begin{tabular}{|l|}
0.4645 \\
\end{tabular} & 15.4415 \\
\hline
\end{tabular}

\begin{tabular}{|c|c|c|c|c|c|c|c|c|c|c|c|c|c|c|c|c|c|c|}
\hline \multirow{2}{*}{$\begin{array}{c}\text { Distance } \\
\text { From North } \\
\text { End (in) }\end{array}$} & \multicolumn{17}{|c|}{ Segment No. } & \multirow{2}{*}{\begin{tabular}{|c} 
Ave. \\
Thickness \\
(in)
\end{tabular}} \\
\hline & $1-3-1$ & $1-3-2$ & $1-3-3$ & $1-3-4$ & $1-3-5$ & $1-3-6$ & $1-3-7$ & $1-3-8$ & $1-3-9$ & $1-3-10$ & $1-3-11$ & $\mid 1-3-12$ & $1-3-13$ & 1-3-14 & $1-3-15$ & $\mid 1-3-16$ & 1-3-17 & \\
\hline 0 & 0.3890 & \begin{tabular}{|l|}
0.3675 \\
\end{tabular} & 0.3795 & \begin{tabular}{|l|}
0.3820 \\
\end{tabular} & 0.3810 & 0.3780 & \begin{tabular}{|l|}
0.3730 \\
\end{tabular} & \begin{tabular}{|l|}
0.3780 \\
\end{tabular} & \begin{tabular}{|l|}
0.3740 \\
\end{tabular} & 0.3775 & \begin{tabular}{|l|}
0.3695 \\
\end{tabular} & \begin{tabular}{|l|}
0.3740 \\
\end{tabular} & \begin{tabular}{|l|}
0.3780 \\
\end{tabular} & 0.3800 & 0.3790 & \begin{tabular}{|l|}
0.3850 \\
\end{tabular} & \begin{tabular}{|l|}
0.3895 \\
\end{tabular} & 0.3785 \\
\hline 4 & 0.3755 & \begin{tabular}{|l|}
0.3650 \\
\end{tabular} & 0.3685 & \begin{tabular}{|l|}
0.3685 \\
\end{tabular} & 0.3705 & 0.3665 & \begin{tabular}{|l|}
0.3640 \\
\end{tabular} & \begin{tabular}{|l|}
0.3745 \\
\end{tabular} & \begin{tabular}{|l|}
0.3705 \\
\end{tabular} & \begin{tabular}{|l|}
0.3805 \\
\end{tabular} & \begin{tabular}{|l|}
0.3685 \\
\end{tabular} & \begin{tabular}{|l|}
0.3705 \\
\end{tabular} & \begin{tabular}{|l|}
0.3715 \\
\end{tabular} & \begin{tabular}{|l|}
0.3735 \\
\end{tabular} & 0.3705 & \begin{tabular}{|l|}
0.3780 \\
\end{tabular} & 0.3785 & 0.3715 \\
\hline 8 & 0.3690 & 0.3645 & 0.3635 & \begin{tabular}{|l|}
0.3625 \\
\end{tabular} & 0.3615 & 0.3605 & 0.3600 & \begin{tabular}{|l|}
0.3665 \\
\end{tabular} & 0.3660 & \begin{tabular}{|l|}
0.3745 \\
\end{tabular} & 0.3660 & \begin{tabular}{|l|}
0.3640 \\
\end{tabular} & 0.3660 & \begin{tabular}{|l|}
0.3655 \\
\end{tabular} & 0.3600 & \begin{tabular}{|l|}
0.3710 \\
\end{tabular} & 0.3710 & 0.3654 \\
\hline 12 & 0.3650 & \begin{tabular}{|l|}
0.3720 \\
\end{tabular} & 0.3635 & \begin{tabular}{|l|}
0.3625 \\
\end{tabular} & 0.3575 & 0.3585 & \begin{tabular}{|l|}
0.3505 \\
\end{tabular} & \begin{tabular}{|l|}
0.3565 \\
\end{tabular} & \begin{tabular}{|l|}
0.3560 \\
\end{tabular} & \begin{tabular}{|l|}
0.3650 \\
\end{tabular} & \begin{tabular}{|l|}
0.3615 \\
\end{tabular} & \begin{tabular}{|l|}
0.3610 \\
\end{tabular} & \begin{tabular}{|l|}
0.3615 \\
\end{tabular} & \begin{tabular}{|l|}
0.3610 \\
\end{tabular} & 0.3580 & \begin{tabular}{|l|}
0.3705 \\
\end{tabular} & 0.3740 & 0.3620 \\
\hline 16 & 0.3710 & \begin{tabular}{|l|}
0.3890 \\
\end{tabular} & 0.3705 & \begin{tabular}{|l|}
0.3630 \\
\end{tabular} & 0.3625 & 0.3615 & \begin{tabular}{|l|}
0.3490 \\
\end{tabular} & \begin{tabular}{|l|}
0.3600 \\
\end{tabular} & \begin{tabular}{|l|}
0.3555 \\
\end{tabular} & \begin{tabular}{|l|}
0.3580 \\
\end{tabular} & \begin{tabular}{|l|}
0.3630 \\
\end{tabular} & \begin{tabular}{|l|}
0.3590 \\
\end{tabular} & \begin{tabular}{|l|}
0.3585 \\
\end{tabular} & \begin{tabular}{|l|}
0.3615 \\
\end{tabular} & 0.3570 & \begin{tabular}{|l|}
0.3705 \\
\end{tabular} & 0.3705 & 0.3635 \\
\hline
\end{tabular}

Estimated Volume $\left(\mathrm{in}^{3}\right)$ :

\begin{tabular}{|c|c|c|c|c|c|c|c|c|c|c|c|c|c|c|c|c|c|c|}
\hline \multirow{2}{*}{$\begin{array}{c}\text { Distance } \\
\text { From North } \\
\text { End (in) }\end{array}$} & \multicolumn{17}{|c|}{ Segment No. } & \multirow{2}{*}{$\begin{array}{l}\text { Horizontal } \\
\text { Sum }\end{array}$} \\
\hline & $1-3-1$ & $1-3-2$ & $1-3-3$ & $1-3-4$ & $1-3-5$ & $1-3-6$ & $1-3-7$ & $1-3-8$ & $1-3-9$ & $1-3-10$ & $1-3-11$ & 1-3-12 & $1-3-13$ & $1-3-14$ & $1-3-15$ & 1-3-16 & $1-3-17$ & \\
\hline $0-4$ & 0.8331 & 1.4368 & 1.7746 & 1.4398 & 1.4469 & 1.4410 & 1.8226 & 1.4542 & 1.4477 & 1.4432 & 1.8318 & 1.4246 & \begin{tabular}{|l|l|}
1.4454 \\
\end{tabular} & 1.5002 & 1.8630 & 1.4676 & 0.6975 & 24.7702 \\
\hline $4-8$ & 0.8234 & 1.4287 & 1.7416 & 1.4021 & 1.4103 & 1.4093 & 1.7829 & 1.4320 & 1.4340 & 1.4322 & 1.8399 & 1.4036 & \begin{tabular}{|l|}
1.3988 \\
\end{tabular} & 1.4688 & 1.8178 & 1.4608 & 0.6874 & 24.3734 \\
\hline $8-12$ & 0.8089 & 1.4406 & 1.7301 & 1.3956 & 1.3780 & 1.3967 & 1.7416 & 1.3968 & 1.4050 & 1.4054 & 1.8242 & 1.3938 & \begin{tabular}{|l|}
1.3496 \\
\end{tabular} & 1.4472 & 1.7924 & 1.4652 & 0.6753 & 24.0464 \\
\hline $12-16$ & 0.8044 & 1.4932 & 1.7384 & 1.4009 & 1.3759 & 1.4000 & 1.7122 & 1.3818 & 1.3803 & 1.3737 & 1.8174 & 1.3573 & 1.3452 & 1.4417 & 1.7795 & 1.4827 & 0.6838 & 23.9686 \\
\hline Vertical Sum & 3.2698 & 5.7993 & 6.9847 & 5.6385 & 5.6111 & 5.6469 & 7.0592 & 5.6648 & 5.6670 & 5.6545 & 7.3134 & 5.5793 & 5.5391 & 5.8579 & 7.2526 & 5.8763 & 2.7440 & 97.1585 \\
\hline
\end{tabular}

Estimated Density (pcf):

\begin{tabular}{|c|c|c|c|c|c|c|c|c|c|c|c|c|c|c|c|c|c|c|}
\hline & \multicolumn{17}{|c|}{ Segment No. } & \multirow{2}{*}{ Total } \\
\hline & $1-3-1$ & $1-3-2$ & $1-3-3$ & $1-3-4$ & $1-3-5$ & $1-3-6$ & $1-3-7$ & $1-3-8$ & $1-3-9$ & $1-3-10$ & 1-3-11 & 1-3-12 & $1-3-13$ & 1-3-14 & 1-3-15 & 1-3-16 & 1-3-17 & \\
\hline Weight $(\mathrm{g})$ & 38.6 & 65.0 & 74.1 & 63.6 & 61.7 & 62.2 & 80.2 & 64.4 & 64.0 & 63.3 & 80.5 & 62.2 & 61.2 & 64.2 & 76.7 & 63.1 & 29.8 & 1074.8 \\
\hline Weight (lb) & 0.0851 & 0.1433 & 0.1634 & 0.1402 & 0.1360 & 0.1371 & 0.1768 & 0.1420 & 0.1411 & 0.1396 & \begin{tabular}{|l|}
0.1775 \\
\end{tabular} & 0.1371 & 0.1349 & 0.1415 & 0.1691 & 0.1391 & 0.0657 & 2.370 \\
\hline Density (pcf & 44.97 & 42.70 & 40.42 & 42.97 & 41.89 & 41.96 & 43.28 & 43.31 & 43.02 & 42.65 & 41.93 & 42.47 & 42.09 & 41.75 & 40.29 & 40.91 & 41.37 & 42.14 \\
\hline
\end{tabular}

Note: Gray regions are sidewalls.

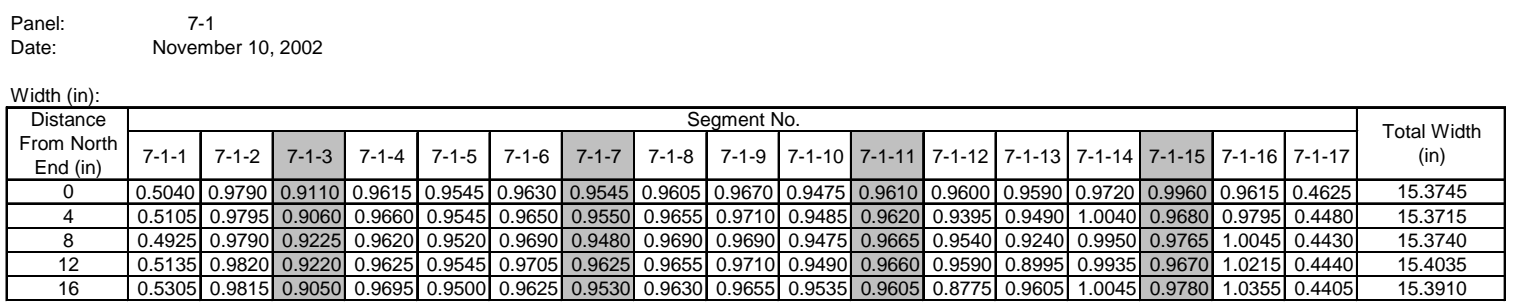

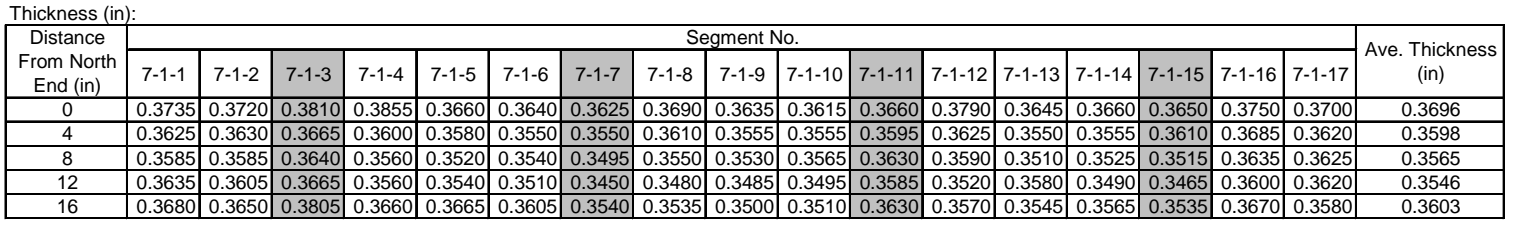

Estimated Volume $\left(\mathrm{in}^{3}\right)$ :

\begin{tabular}{|c|c|c|c|c|c|c|c|c|c|c|c|c|c|c|c|c|c|c|}
\hline \multirow{2}{*}{$\begin{array}{l}\text { Distance } \\
\text { From North } \\
\text { End (in) }\end{array}$} & \multicolumn{17}{|c|}{ Segment No. } & \multirow[b]{2}{*}{ Horizontal Sum } \\
\hline & 7-1-1 & $7-1-2$ & $7-1-3$ & $7-1-4$ & $7-1-5$ & $7-1-6$ & $7-1-7$ & 7-1-8 & $7-1-9$ & $7-1-10$ & $7-1-11$ & 7-1-12 & 7-1-13 & 7-1-14 & 7-1-15 & 7-1-16 & 7-1-17 & \\
\hline $0-4$ & 0.7466 & 1.4395 & 1.7636 & 1.4368 & 1.3821 & 1.3862 & 1.7606 & 1.4059 & 1.3934 & 1.3594 & 1.7902 & 1.4088 & 1.3729 & 1.4253 & \begin{tabular}{|l|}
1.8217 \\
\end{tabular} & 1.4430 & 0.6666 & 24.0027 \\
\hline $4-8$ & 0.7232 & 1.4131 & 1.7320 & 1.3805 & 1.3536 & 1.3712 & 1.7241 & 1.3851 & 1.3745 & 1.3500 & 1.7868 & 1.3661 & 1.3224 & 1.4153 & 1.7735 & 1.4522 & 0.6455 & 23.5691 \\
\hline $8-12$ & 0.7264 & 1.4100 & 1.7440 & 1.3702 & 1.3460 & 1.3673 & 1.7048 & 1.3600 & 1.3609 & 1.3389 & 1.7873 & 1.3601 & 1.2927 & 1.3949 & 1.7369 & 1.4658 & 0.6426 & 23.4089 \\
\hline $12-16$ & 0.7638 & 1.4245 & 1.7698 & 1.3950 & 1.3721 & 1.3753 & 1.7194 & 1.3528 & 1.3526 & 1.3327 & 1.7828 & 1.3017 & 1.3250 & 1.4097 & 1.7429 & 1.4955 & 0.6369 & 23.5525 \\
\hline Vertical Sum & 2.9600 & 5.6870 & 7.0094 & 5.5825 & 5.4539 & 5.5000 & 6.9088 & 5.5038 & 5.4814 & 5.3810 & 7.1471 & 5.4367 & 5.3131 & 5.6453 & 7.0750 & 5.8565 & 2.5916 & 94.5332 \\
\hline
\end{tabular}

Estimated Density (pcf):

\begin{tabular}{|c|c|c|c|c|c|c|c|c|c|c|c|c|c|c|c|c|c|c|}
\hline & \multicolumn{17}{|c|}{ Segment No. } & \multirow[b]{2}{*}{ Total } \\
\hline & 7-1-1 & $7-1-2$ & $7-1-3$ & $7-1-4$ & $7-1-5$ & $7-1-6$ & $7-1-7$ & $7-1-8$ & $7-1-9$ & $7-1-10$ & 7-1-11 & 7-1-12 & $7-1-13$ & 7-1-14 & 7-1-15 & 7-1-16 & 7-1-17 & \\
\hline Weight (g) & 34.2 & 63.6 & \begin{tabular}{|l|l|}
74.7 \\
\end{tabular} & 62.1 & 61.2 & 62.5 & 80.1 & 65.5 & 65.4 & 62.8 & \begin{tabular}{|l|}
78.8 \\
\end{tabular} & \begin{tabular}{|l|}
62.7 \\
\end{tabular} & 60.8 & 63.8 & 78.6 & \begin{tabular}{|l|}
67.1 \\
\end{tabular} & 27.6 & 1071.5 \\
\hline Weight (Ib) & \begin{tabular}{|l|}
0.0754 \\
\end{tabular} & 0.1402 & 0.1647 & 0.1369 & 0.1349 & 0.1378 & 0.1766 & 0.1444 & 0.1442 & 0.1385 & 0.1737 & 0.1382 & 0.134 & 0.1407 & 0.1733 & 0.1479 & 0.0608 & 2.362 \\
\hline Density (pcf) & 44.02 & 42.60 & 40.60 & 42.38 & 42.75 & 43.29 & 44.17 & 45.34 & 45.45 & 44.46 & 42.00 & 43.93 & 43.59 & 43.05 & 42.32 & 43.65 & 40.57 & 43.18 \\
\hline
\end{tabular}

Note: Gray regions are sidewalls. 


\begin{tabular}{|c|c|c|c|c|c|c|c|c|c|c|c|c|c|c|c|c|c|c|}
\hline \multirow{2}{*}{$\begin{array}{l}\text { Panel: } \\
\text { Date: } \\
\text { Width (in): }\end{array}$} & \multicolumn{3}{|c|}{$\begin{array}{l}\quad 5-4 \\
\text { November 11, } 2002\end{array}$} & & & & & & & & & & & & & & & \\
\hline & \multirow{2}{*}{\multicolumn{17}{|c|}{ Segment No. }} & \\
\hline Distance & & & & & & & & & & & & & & & & & & \multirow{2}{*}{$\begin{array}{l}\text { Total } \\
\text { Width } \\
\text { (in) }\end{array}$} \\
\hline $\begin{array}{l}\text { From North } \\
\text { End (in) }\end{array}$ & $5-4-1$ & $5-4-2$ & $5-4-3$ & $5-4-4$ & $5-4-5$ & $5-4-6$ & $5-4-7$ & $5-4-8$ & $5-4-9$ & $5-4-10$ & $5-4-11$ & $5-4-12$ & $5-4-13$ & $5-4-14$ & $5-4-15$ & $5-4-16$ & 5-4-17 & \\
\hline 0 & 0.4830 & \begin{tabular}{|l|}
0.9805 \\
\end{tabular} & 0.9125 & \begin{tabular}{|l|}
0.9525 \\
\end{tabular} & 0.9565 & \begin{tabular}{|l|}
0.9660 \\
\end{tabular} & 0.9550 & 0.9600 & 0.9670 & 0.9435 & 0.9665 & 0.9625 & 0.9545 & \begin{tabular}{|l|}
0.9970 \\
\end{tabular} & 0.9745 & $\mid 0.9510$ & 0.4530 & 15.3355 \\
\hline 4 & 0.4925 & \begin{tabular}{|l|}
0.9830 \\
\end{tabular} & 0.9040 & \begin{tabular}{|l|}
0.9625 \\
\end{tabular} & \begin{tabular}{|l|}
0.9600 \\
\end{tabular} & \begin{tabular}{|l|}
0.9730 \\
\end{tabular} & \begin{tabular}{|l|}
0.9515 \\
\end{tabular} & $\begin{array}{l}0.9650 \\
\end{array}$ & 0.9730 & \begin{tabular}{|l|}
0.9490 \\
\end{tabular} & \begin{tabular}{|l|}
0.9730 \\
\end{tabular} & \begin{tabular}{|l|}
0.9550 \\
\end{tabular} & \begin{tabular}{|l|}
0.9660 \\
\end{tabular} & \begin{tabular}{|l|}
0.9920 \\
\end{tabular} & 0.9735 & \begin{tabular}{|l|}
0.9580 \\
\end{tabular} & \begin{tabular}{|l|}
0.4535 \\
\end{tabular} & 15.3845 \\
\hline 8 & 0.5220 & \begin{tabular}{|l|}
0.9850 \\
\end{tabular} & 0.9120 & \begin{tabular}{|l|}
0.9595 \\
\end{tabular} & 0.9580 & \begin{tabular}{l|l|}
0.9685 \\
\end{tabular} & 0.9650 & 0.9640 & 0.9715 & 0.9470 & 0.9810 & 0.9635 & 0.9560 & \begin{tabular}{|l|}
0.9870 \\
\end{tabular} & 0.9770 & \begin{tabular}{|l|}
0.9620 \\
\end{tabular} & \begin{tabular}{|l|}
0.4465 \\
\end{tabular} & 15.4255 \\
\hline 12 & 0.5135 & \begin{tabular}{|l|}
0.9830 \\
\end{tabular} & 0.9040 & \begin{tabular}{|l|}
0.9580 \\
\end{tabular} & \begin{tabular}{|l|}
0.9590 \\
\end{tabular} & \begin{tabular}{|l|}
0.9705 \\
\end{tabular} & \begin{tabular}{|l|}
0.9585 \\
\end{tabular} & \begin{tabular}{|l|}
0.9635 \\
\end{tabular} & 0.9760 & \begin{tabular}{|l|}
0.9465 \\
\end{tabular} & \begin{tabular}{|l|}
0.9770 \\
\end{tabular} & \begin{tabular}{|l|}
0.9690 \\
\end{tabular} & 0.9615 & \begin{tabular}{|l|}
0.9890 \\
\end{tabular} & 0.9600 & \begin{tabular}{|l|}
0.9645 \\
\end{tabular} & \begin{tabular}{|l|}
0.4415 \\
\end{tabular} & 15.3950 \\
\hline 16 & 0.5400 & 0.9785 & 0.9035 & \begin{tabular}{|l|}
0.9745 \\
\end{tabular} & \begin{tabular}{|l|}
0.9600 \\
\end{tabular} & \begin{tabular}{|l|}
0.9685 \\
\end{tabular} & \begin{tabular}{|l|}
0.9495 \\
\end{tabular} & 0.9630 & 0.9685 & 0.9470 & \begin{tabular}{|l|}
0.9730 \\
\end{tabular} & \begin{tabular}{|l|}
0.9640 \\
\end{tabular} & 0.9615 & \begin{tabular}{|l|}
1.0015 \\
\end{tabular} & 0.9640 & \begin{tabular}{|l|}
0.9645 \\
\end{tabular} & \begin{tabular}{|l|}
0.4600 \\
\end{tabular} & 15.4415 \\
\hline
\end{tabular}

\begin{tabular}{|c|c|c|c|c|c|c|c|c|c|c|c|c|c|c|c|c|c|c|}
\hline \multirow{2}{*}{$\begin{array}{c}\text { Distance } \\
\text { From North } \\
\text { End (in) }\end{array}$} & \multicolumn{17}{|c|}{ Segment No. } & \multirow{2}{*}{\begin{tabular}{|c} 
Ave. \\
Thickness \\
(in)
\end{tabular}} \\
\hline & $5-4-1$ & $5-4-2$ & $5-4-3$ & $5-4-4$ & $5-4-5$ & $5-4-6$ & $5-4-7$ & $5-4-8$ & $5-4-9$ & $5-4-10$ & $5-4-11$ & $5-4-12$ & $5-4-13$ & $5-4-14$ & $5-4-15$ & $5-4-16$ & 5-4-17 & \\
\hline 0 & 0.3875 & \begin{tabular}{|l|}
0.3780 \\
\end{tabular} & 0.3895 & 0.3800 & \begin{tabular}{|l|}
0.3755 \\
\end{tabular} & 0.3725 & 0.3625 & 0.3690 & \begin{tabular}{|l|}
0.3705 \\
\end{tabular} & 0.3710 & \begin{tabular}{|l|}
0.3765 \\
\end{tabular} & 0.3705 & 0.3705 & 0.3710 & 0.3605 & \begin{tabular}{|l|}
0.3725 \\
\end{tabular} & 0.3740 & \begin{tabular}{|l|}
0.3736 \\
\end{tabular} \\
\hline 4 & 0.3820 & \begin{tabular}{|l|}
0.3785 \\
\end{tabular} & 0.3785 & 0.3760 & \begin{tabular}{|l|}
0.3730 \\
\end{tabular} & \begin{tabular}{|l|}
0.3715 \\
\end{tabular} & 0.3525 & 0.3685 & \begin{tabular}{|l|}
0.3705 \\
\end{tabular} & \begin{tabular}{|l|}
0.3745 \\
\end{tabular} & \begin{tabular}{|l|}
0.3740 \\
\end{tabular} & 0.3805 & 0.3685 & \begin{tabular}{|l|}
0.3730 \\
\end{tabular} & 0.3560 & 0.3860 & 0.3760 & 0.3729 \\
\hline 8 & 0.3740 & \begin{tabular}{|l|}
0.3765 \\
\end{tabular} & 0.3805 & \begin{tabular}{|l|}
0.3675 \\
\end{tabular} & \begin{tabular}{|l|}
0.3650 \\
\end{tabular} & \begin{tabular}{|l|}
0.3710 \\
\end{tabular} & 0.3535 & 0.3635 & \begin{tabular}{|l|}
0.3735 \\
\end{tabular} & 0.3705 & \begin{tabular}{|l|}
0.3715 \\
\end{tabular} & 0.3730 & 0.3690 & \begin{tabular}{|l|}
0.3645 \\
\end{tabular} & \begin{tabular}{|l|}
0.3535 \\
\end{tabular} & \begin{tabular}{|l|}
0.3775 \\
\end{tabular} & \begin{tabular}{|l|}
0.3740 \\
\end{tabular} & 0.3693 \\
\hline 12 & 0.3785 & \begin{tabular}{|l|}
0.3785 \\
\end{tabular} & 0.3795 & 0.3710 & 0.3655 & 0.3710 & 0.3460 & 0.3610 & 0.3620 & 0.3700 & 0.3700 & 0.3620 & 0.3630 & 0.3655 & \begin{tabular}{|l|}
0.3485 \\
\end{tabular} & \begin{tabular}{|l|}
0.3735 \\
\end{tabular} & \begin{tabular}{|l|}
0.3730 \\
\end{tabular} & 0.3670 \\
\hline 16 & 0.3845 & \begin{tabular}{|l|}
0.3835 \\
\end{tabular} & 0.3955 & \begin{tabular}{|l|}
0.3770 \\
\end{tabular} & 0.3775 & \begin{tabular}{|l|}
0.3760 \\
\end{tabular} & 0.3525 & 0.3690 & \begin{tabular}{|l|}
0.3710 \\
\end{tabular} & 0.3700 & 0.3790 & 0.3660 & 0.3680 & 0.3700 & \begin{tabular}{|l|}
0.3520 \\
\end{tabular} & \begin{tabular}{|l|}
0.3795 \\
\end{tabular} & \begin{tabular}{|l|}
0.3790 \\
\end{tabular} & 0.3735 \\
\hline
\end{tabular}

Estimated Volume $\left(\mathrm{in}^{3}\right)$ :

\begin{tabular}{|c|c|c|c|c|c|c|c|c|c|c|c|c|c|c|c|c|c|c|}
\hline \multirow{2}{*}{$\begin{array}{l}\text { Distance } \\
\text { From North } \\
\text { End (in) }\end{array}$} & \multicolumn{17}{|c|}{ Segment No. } & \multirow{2}{*}{$\begin{array}{c}\text { Horizontal } \\
\text { Sum }\end{array}$} \\
\hline & $5-4-1$ & $5-4-2$ & $5-4-3$ & $5-4-4$ & $5-4-5$ & $5-4-6$ & $5-4-7$ & $5-4-8$ & $5-4-9$ & $5-4-10$ & 5-4-11 & 5-4-12 & $5-4-13$ & $5-4-14$ & 5-4-15 & $5-4-16$ & 5-4-17 & \\
\hline $0-4$ & 0.7506 & 1.4854 & 1.8116 & 1.4477 & 1.4345 & 1.4426 & 1.7523 & 1.4197 & 1.4375 & 1.4109 & 1.8644 & 1.4400 & 1.4192 & \begin{tabular}{|c|}
1.4798 \\
\end{tabular} & 1.7861 & \begin{tabular}{|l|}
1.4481 \\
\end{tabular} & 0.6799 & 24.5103 \\
\hline $4-8$ & 0.7667 & 1.4858 & 1.7899 & 1.4290 & 1.4155 & 1.4416 & \begin{tabular}{|l|}
1.7374 \\
\end{tabular} & 1.4120 & \begin{tabular}{|l|}
1.4467 \\
\end{tabular} & 1.4125 & 1.8629 & 1.4455 & 1.4175 & 1.4596 & 1.7705 & \begin{tabular}{|l|}
1.4659 \\
\end{tabular} & 0.6750 & 24.4341 \\
\hline $8-12$ & 0.7792 & 1.4858 & 1.7922 & \begin{tabular}{|l|}
1.4161 \\
\end{tabular} & 1.4004 & \begin{tabular}{|l|}
1.4387 \\
\end{tabular} & 1.7264 & 1.3965 & \begin{tabular}{|l|}
1.4323 \\
\end{tabular} & 1.4021 & 1.8560 & 1.4203 & 1.4036 & 1.4425 & 1.7422 & \begin{tabular}{|l|}
1.4468 \\
\end{tabular} & 0.6633 & 24.2445 \\
\hline $12-16$ & 0.8040 & 1.4946 & 1.8208 & \begin{tabular}{|l|}
1.4456 \\
\end{tabular} & 1.4258 & 1.4484 & 1.7128 & 1.4063 & \begin{tabular}{|l|}
1.4253 \\
\end{tabular} & 1.4012 & 1.8686 & \begin{tabular}{|l|}
1.4072 \\
\end{tabular} & \begin{tabular}{|l|}
1.4057 \\
\end{tabular} & 1.4641 & 1.7292 & 1.4525 & 0.6780 & 24.3903 \\
\hline Vertical Sum & 3.1005 & 5.9517 & 7.2145 & 5.7384 & 5.6762 & 5.7713 & 6.9290 & 5.6345 & 5.7418 & \begin{tabular}{|l|}
5.6267 \\
\end{tabular} & 7.4519 & 5.7130 & 5.6460 & 5.8459 & 7.0280 & 5.8133 & 2.6963 & 97.5792 \\
\hline
\end{tabular}

\begin{tabular}{|c|c|c|c|c|c|c|c|c|c|c|c|c|c|c|c|c|c|c|}
\hline & \multicolumn{17}{|c|}{ Segment No. } & \multirow{2}{*}{ Total } \\
\hline & $5-4-1$ & $5-4-2$ & $5-4-3$ & $5-4-4$ & $5-4-5$ & $5-4-6$ & $5-4-7$ & $5-4-8$ & $5-4-9$ & $5-4-10$ & 5-4-11 & 5-4-12 & $5-4-13$ & 5-4-14 & 5-4-15 & $5-4-16$ & 5-4-17 & \\
\hline Weight (g) & 35.5 & 66.2 & 75.8 & 69.0 & 68.2 & 71.1 & 80.9 & 64.8 & 65.9 & 60.9 & 80.0 & 63.0 & 61.1 & 63.6 & 73.5 & 60.8 & 29.5 & 1089.8 \\
\hline Weight (lb) & 0.0783 & 0.1459 & 0.1671 & 0.1521 & \begin{tabular}{|l|}
0.1504 \\
\end{tabular} & 0.1567 & 0.1784 & 0.1429 & \begin{tabular}{|l|}
0.1453 \\
\end{tabular} & 0.1343 & \begin{tabular}{|l|}
0.1764 \\
\end{tabular} & 0.1389 & 0.1347 & 0.1402 & 0.1620 & \begin{tabular}{|l|}
0.1340 \\
\end{tabular} & 0.0650 & 2.403 \\
\hline Density (pcf) & 43.62 & 42.37 & 40.03 & 45.81 & \begin{tabular}{|l|}
45.77 \\
\end{tabular} & 46.93 & 44.48 & 43.81 & \begin{tabular}{|l|}
43.72 \\
\end{tabular} & 41.23 & 40.90 & 42.01 & 41.23 & 41.45 & 39.84 & \begin{tabular}{|l|}
39.84 \\
\end{tabular} & \begin{tabular}{|l|}
41.68 \\
\end{tabular} & 42.55 \\
\hline
\end{tabular}

Note: Gray regions are sidewalls. 


\section{Appendix I. 4'x8' Corrugated Panels Board Diagram}

Summary of Cutting Plan:

\begin{tabular}{|c|c|c|c|c|c|c|c|c|}
\hline Panel No. & Test & $48 " \times 96 "$ & $48 " \times 32 "$ & $48 " x 48$ & $24 " x 64 "$ & $24 " \times 32 "$ & $24 " x 48 "$ & $24 " \times 24 "$ \\
\hline 5 & bare panel bending & & & & & & 3 & 2 \\
\hline 6 & composite bending & & & & & & 2 & 4 \\
\hline 8 & bare panel bending & & & & 2 & 2 & & \\
\hline 11 & composite bending & & & & & & 3 & 2 \\
\hline 12 & bare panel bending & & & & & & 2 & 4 \\
\hline 14 & bare panel bending & & & & 2 & 2 & & \\
\hline 17 & composite bending & & & & 2 & 2 & & \\
\hline 18 & bare panel bending & & & & 2 & 2 & & \\
\hline 19 & composite bending & & & & 2 & 2 & & \\
\hline 30 & T-beam \& bare panel bending & & & 1 & & & 2 & \\
\hline 35 & composite bending & & & & 2 & 2 & & \\
\hline 28 & test setup trials & & & & 2 & 2 & & \\
\hline 49 & test setup trials & & & & & & 3 & 2 \\
\hline 34 & T-beam & & & 2 & & & & \\
\hline 29 & T-beam & & & 2 & & & & \\
\hline 39 & T-beam & & & 2 & & & & \\
\hline 40 & T-beam & & & 2 & & & & \\
\hline 15 & mock-up floor & 1 & & & & & & \\
\hline 16 & mock-up floor & 1 & & & & & & \\
\hline 31 & mock-up floor & 1 & & & & & & \\
\hline 4 & Diaphragm & 1 & & & & & & \\
\hline 10 & Diaphragm & 1 & & & & & & \\
\hline
\end{tabular}
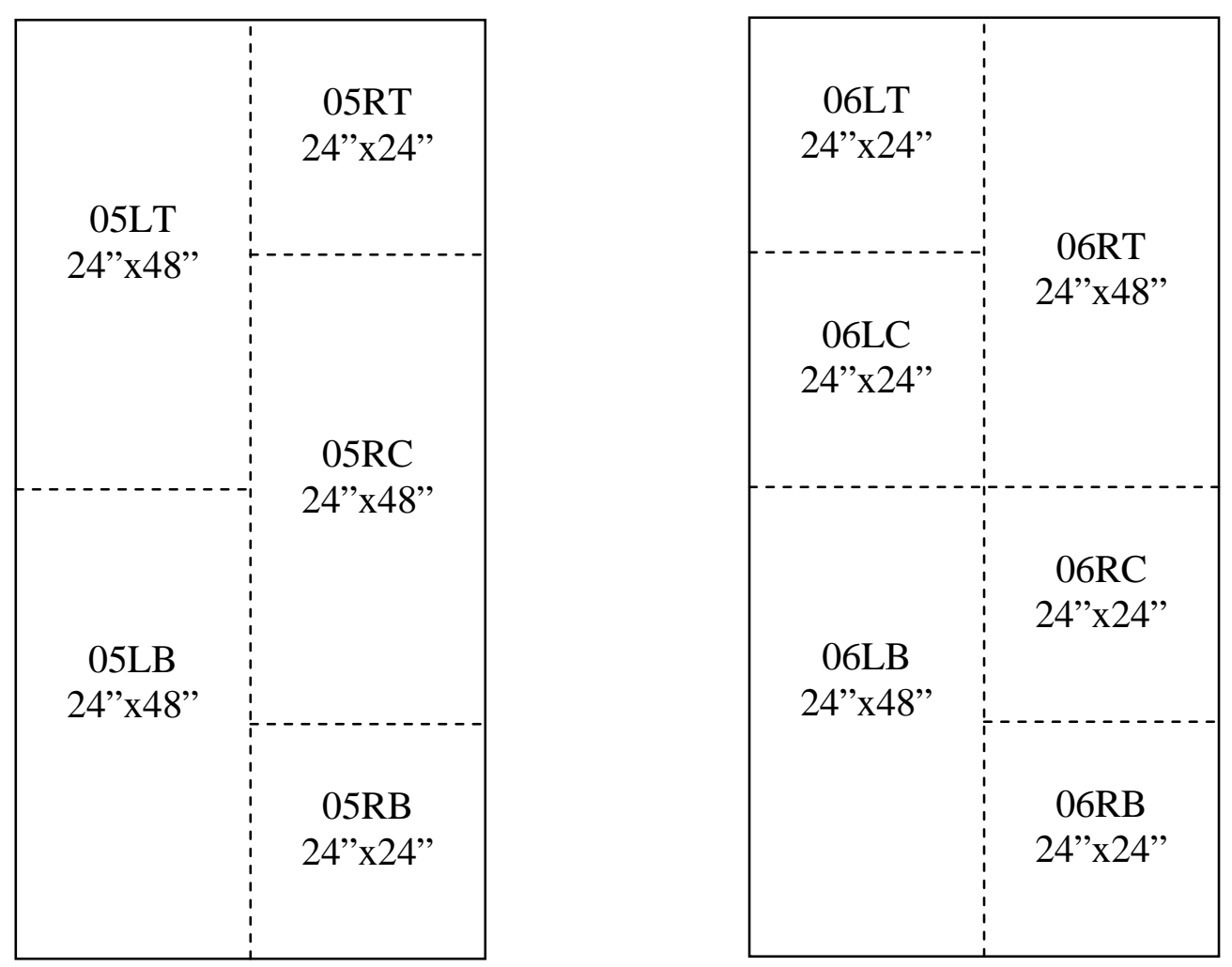

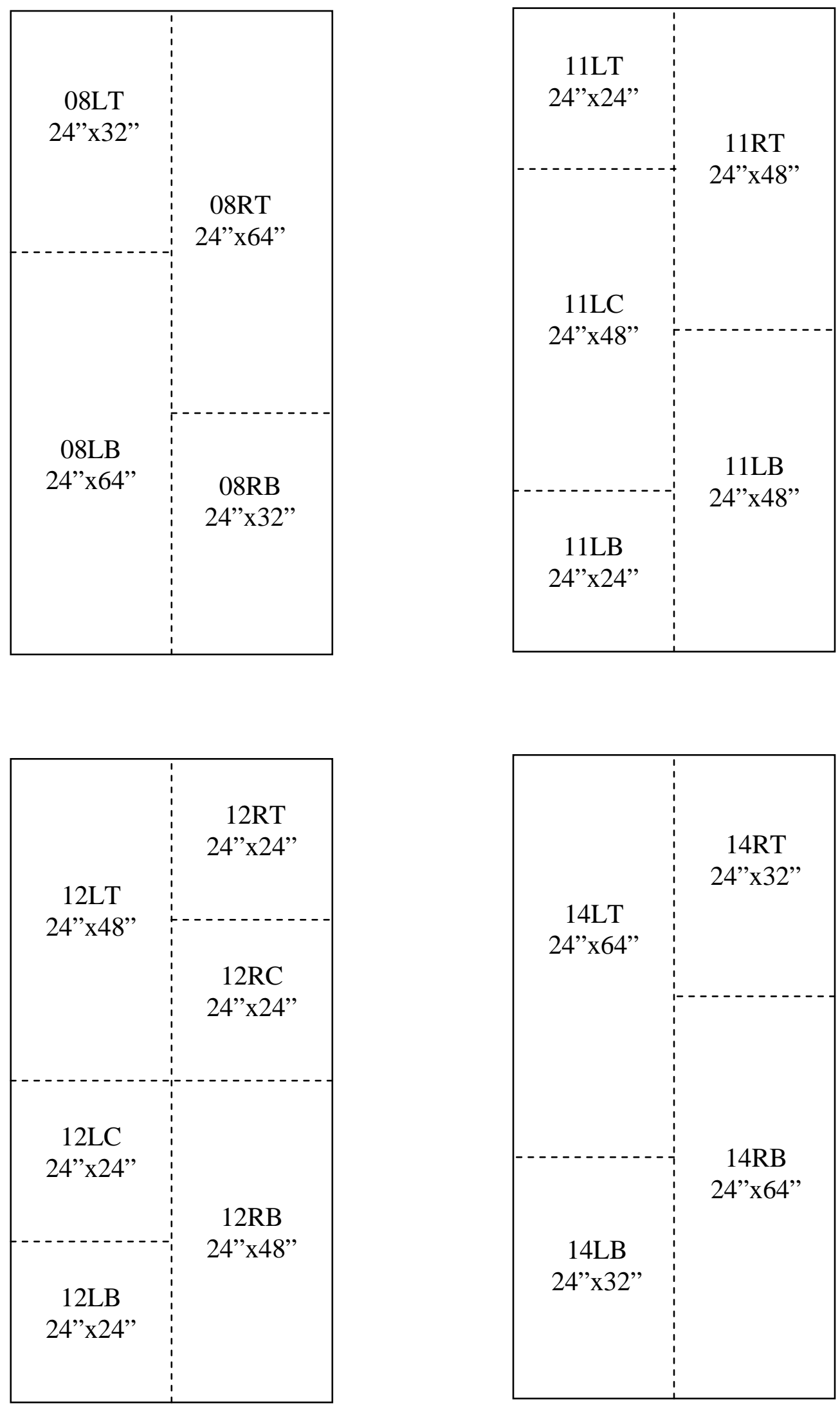

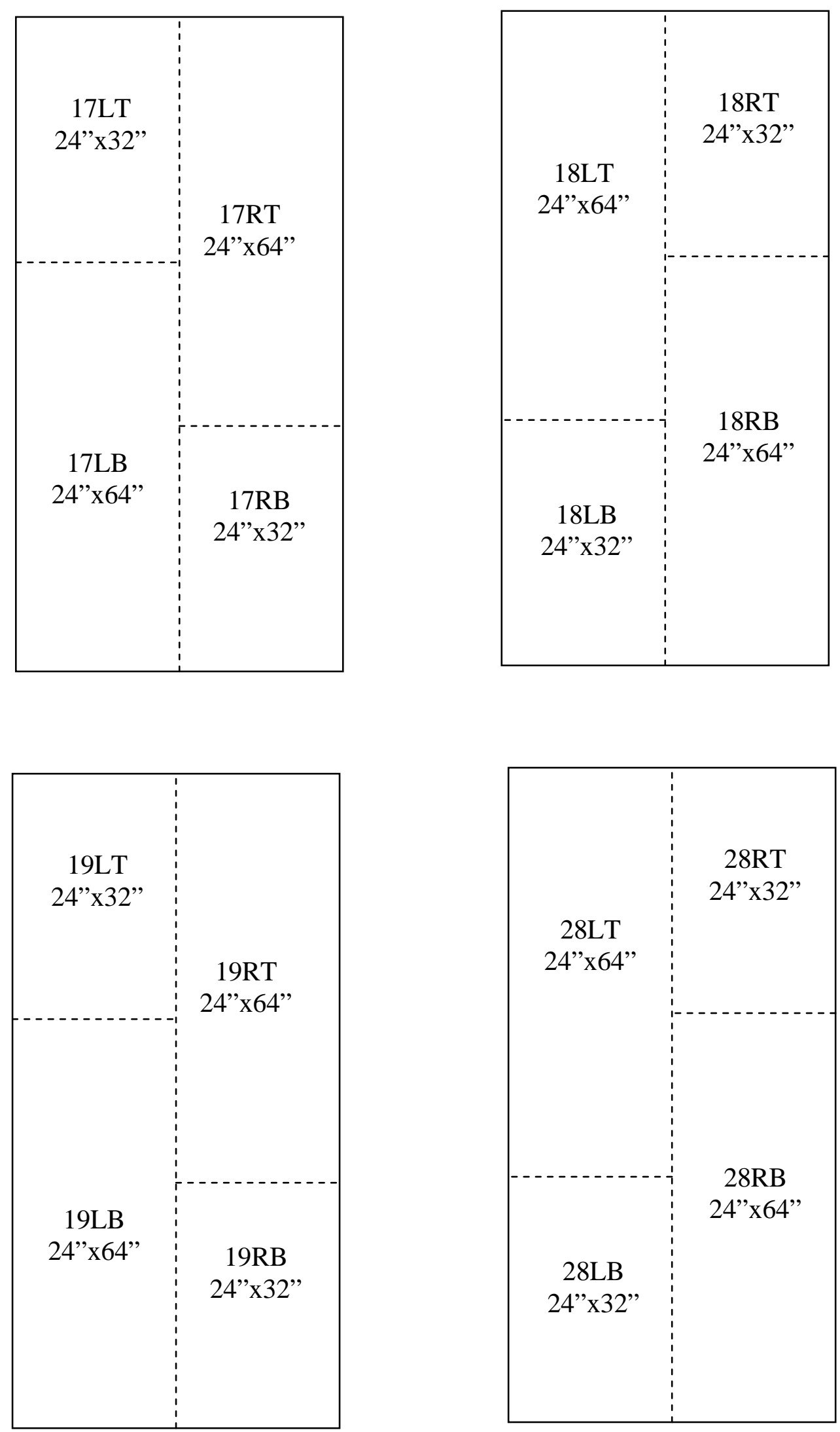

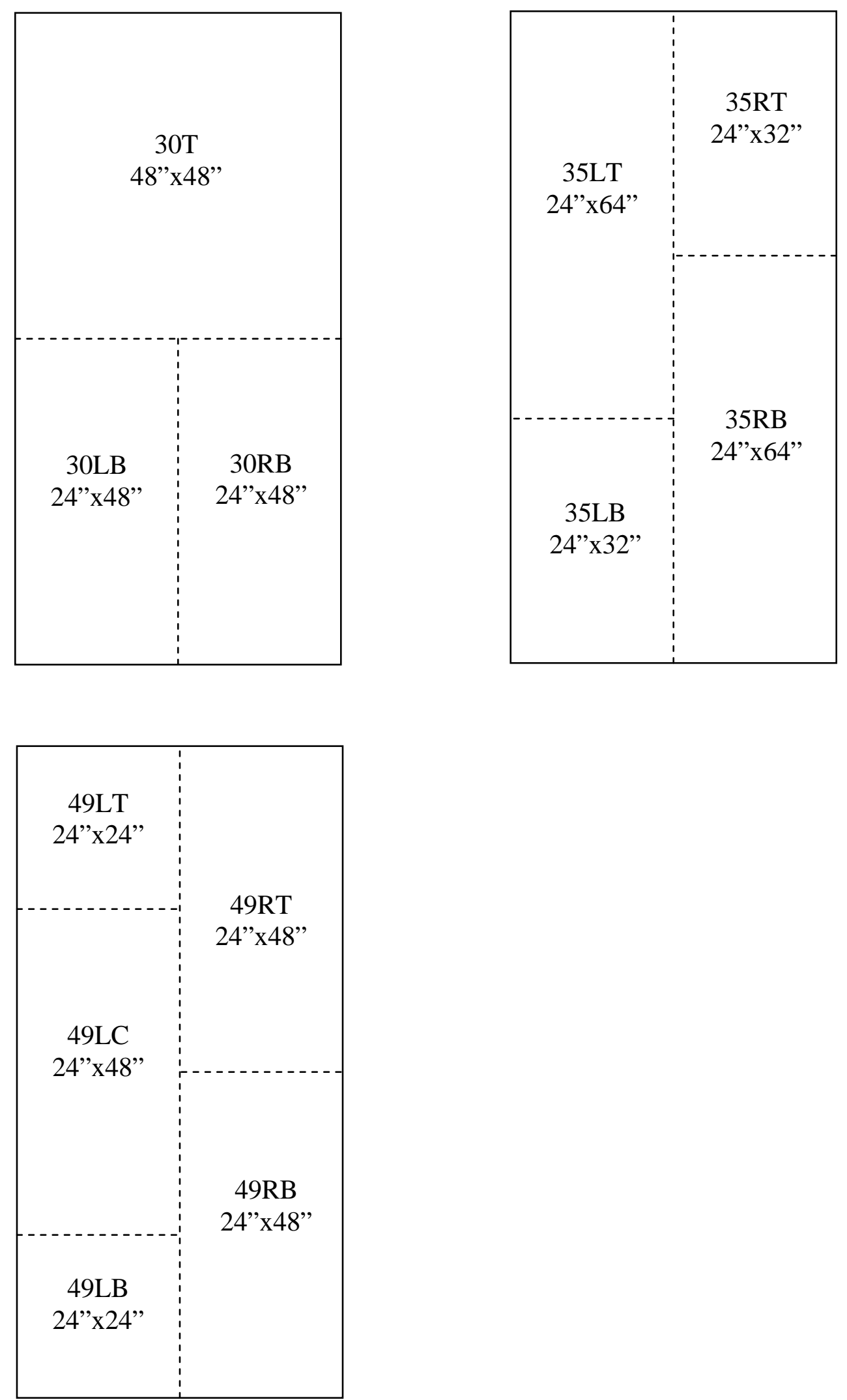


\section{Appendix J. Test Data for 2' Wide Corrugated Panels and Composite Decks}

\begin{tabular}{|c|c|c|c|c|c|c|c|c|c|c|c|c|c|}
\hline $\begin{array}{l}\text { Panel } \\
\text { No. }\end{array}$ & \begin{tabular}{|c|} 
Weighted \\
Average \\
Thickness \\
(in)
\end{tabular} & $\begin{array}{l}\text { Density } \\
\text { (pcf) }\end{array}$ & $\begin{array}{l}\text { Load/Defl } \\
\text { (lbs/in) }\end{array}$ & $\begin{array}{l}\text { Maximum } \\
\text { Load } \\
\text { (lbs) }\end{array}$ & $\begin{array}{c}\text { Moment of } \\
\text { Inertia } \\
\left(\mathrm{in}^{4} / \mathrm{ft}\right)\end{array}$ & $\begin{array}{c}\text { Area } \\
\left(\text { in }^{2} / f t\right)\end{array}$ & $\begin{array}{c}\text { Shear } \\
\text { Correction } \\
\text { Coefficient } \\
\mathrm{k}_{\mathrm{s}}\end{array}$ & $\begin{array}{l}\text { Bending } \\
\text { Stiffness } \\
(\text { (lbf-in'/ft) }\end{array}$ & $\begin{array}{l}\text { Shear } \\
\text { Stiffness } \\
\text { (lbf/ft) }\end{array}$ & $\begin{array}{l}\text { Bending } \\
\text { Strength } \\
\text { (in-lbs/ft) }\end{array}$ & $\begin{array}{l}\mathrm{MOE} \\
(\mathrm{psi})\end{array}$ & $\begin{array}{c}\mathrm{G} \\
\text { (psi) }\end{array}$ & $\begin{array}{c}\text { MOR } \\
\text { (psi) }\end{array}$ \\
\hline $12 \mathrm{RC}$ & 0.356 & 40.07 & 2,992 & 1550 & 0.5968 & 4.604 & 2.294 & 458,582 & 237,196 & 4,359 & 768,351 & 118,208 & 4,039 \\
\hline 12RT & 0.367 & 38.71 & 2,939 & 1500 & 0.6189 & 4.746 & 2.245 & 449,127 & 236,042 & 4,219 & 725,710 & 111,648 & 3,807 \\
\hline $12 \mathrm{LC}$ & 0.360 & 39.67 & 2,982 & 1525 & 0.6048 & 4.656 & 2.276 & 456,502 & 237,496 & 4,289 & 754,778 & 116,120 & 3,936 \\
\hline $12 \mathrm{LB}$ & 0.377 & 38.59 & 3,108 & 1560 & 0.6392 & 4.875 & 2.201 & 4773,704 & 252,581 & 4,388 & 741,088 & 114,014 & 3,868 \\
\hline 05RT & 0.374 & 42.84 & 3,197 & 1845 & 0.6331 & 4.837 & 2.214 & 487,624 & 258,880 & 5,189 & 770,246 & 118,499 & 4,606 \\
\hline $05 R B$ & 0.366 & 40.73 & 2,866 & 1280 & 0.6169 & 4.733 & 2.249 & 438,057 & 229,890 & 3,600 & 710,137 & 109,252 & 3,256 \\
\hline Mean & & 40.10 & 3,014 & 1543 & 0.6183 & 4.742 & 2.247 & 460,599 & 242,014 & 4,341 & 745,052 & 114,624 & 3,919 \\
\hline Std. & 0.008 & 1.57 & 119 & 180 & 0.0161 & 0.103 & 0.036 & 17,679 & 11,157 & 508 & 24,004 & 3,693 & 434 \\
\hline COV & 0.02 & & 0.04 & 0.12 & & 0.02 & & & & & 0.03 & 0.03 & 0.11 \\
\hline$+2(\mathrm{Std})$ & & & 3,253 & 1,904 & & 4.948 & & & 264,328 & 5,3 & 793,060 & 122,009 & 4,787 \\
\hline$-2(\mathrm{Std})$ & 0.351 & 36.97 & 2,775 & 1,182 & 0.586 & 4.535 & 2.175 & 425,242 & 219,700 & 3,325 & 697,043 & 107,238 & 3,051 \\
\hline 5 th \% & 0.357 & 38.62 & 2,884 & $\frac{1,102}{1,335}$ & 0.599 & 4.617 & 2.204 & 4440,825 & $\frac{21,100}{231,428}$ & 3,755 & $\begin{array}{l}03,040 \\
714,030\end{array}$ & $\frac{109,250}{1051}$ & $\frac{3,011}{3,394}$ \\
\hline
\end{tabular}

\section{Nominal 32" Single-Span Test}

\begin{tabular}{|c|c|c|c|c|c|c|c|c|c|c|c|c|c|}
\hline $\begin{array}{l}\text { Panel } \\
\text { No. }\end{array}$ & $\begin{array}{l}\text { Weighted } \\
\text { Average } \\
\text { Thickness } \\
\text { (in) }\end{array}$ & $\begin{array}{l}\text { Density } \\
\text { (pcf) }\end{array}$ & $\begin{array}{c}\text { Load/Defl } \\
\text { (lbs/in) }\end{array}$ & $\begin{array}{l}\text { Maximum } \\
\text { Load } \\
\text { (lbs) }\end{array}$ & $\begin{array}{c}\text { Moment } \\
\text { of Inertia } \\
\left(\mathrm{in}^{4} / \mathrm{ft}\right)\end{array}$ & $\begin{array}{c}\text { Area } \\
\left(\mathrm{in}^{2} / \mathrm{ft}\right)\end{array}$ & $\begin{array}{c}\text { Shear } \\
\text { Correction } \\
\text { Coefficient } \\
\mathrm{k}_{\mathrm{s}}\end{array}$ & $\begin{array}{l}\text { Bending } \\
\text { Stiffness } \\
\text { (Ibf-in'/ft) }\end{array}$ & $\begin{array}{l}\text { Shear } \\
\text { Stiffness } \\
\text { (lbf/ft) }\end{array}$ & $\begin{array}{l}\text { Bending } \\
\text { Strength } \\
\text { (in-lbs/ft) }\end{array}$ & $\begin{array}{l}\mathrm{MOE} \\
(\mathrm{psi})\end{array}$ & $\begin{array}{c}\mathrm{G} \\
\text { (psi) }\end{array}$ & $\begin{array}{l}\text { MOR } \\
(\mathrm{psi})\end{array}$ \\
\hline $18 \mathrm{RT}$ & 0.356 & 39.83 & 1226 & 847 & 0.5968 & 4.604 & \begin{tabular}{|l|}
2.294 \\
\end{tabular} & 429,551 & 222,180 & 3,229 & 719,711 & 110,725 & 2,993 \\
\hline $18 \mathrm{LB}$ & 0.370 & 37.34 & 1192 & 977 & 0.6249 & 4.785 & 2.232 & 416,742 & 219,974 & 3,725 & 666,844 & 102,591 & 3,337 \\
\hline $\begin{array}{l}08 \mathrm{LT} \\
\end{array}$ & 0.357 & 39.27 & 1165 & 910 & 0.5988 & 4.617 & 2.290 & 408,116 & 211,400 & 3,469 & 681,523 & 104,850 & 3,208 \\
\hline $08 \mathrm{RB}$ & 0.372 & 40.43 & 1216 & 959 & 0.6290 & 4.811 & 2.223 & 425,005 & 224,985 & 3,656 & 675,677 & 103,950 & 3,262 \\
\hline 14RT & 0.407 & 38.02 & 1383 & 1085 & 0.7019 & 5.263 & 2.073 & 480,900 & 267,657 & 4,137 & 685,171 & 105,411 & 3,409 \\
\hline $14 \mathrm{LB}$ & 0.359 & 37.81 & 1151 & 826 & 0.6028 & 4.643 & 2.281 & 403,087 & 209,402 & 3,149 & 668,670 & 102,872 & 2,898 \\
\hline Mean & 0.370 & 38.78 & 1,222 & 934 & 0.6257 & 4.787 & 2.232 & 427,234 & 225,933 & 3,561 & 682,933 & 105,067 & 3,184 \\
\hline Std. & 0.019 & 1.24 & 84 & 95 & 0.0398 & 0.249 & 0.084 & 28,104 & 21,335 & 362 & 19,363 & 2,979 & 199 \\
\hline COV & 0.05 & 0.03 & 0.07 & 0.10 & 0.06 & 0.05 & 0.04 & 0.07 & 0.09 & 0.10 & 0.03 & 0.03 & 0.06 \\
\hline$+2(\mathrm{Std})$ & 0.409 & 41.26 & 1,390 & 1,124 & 0.705 & 5.286 & 2.399 & 483,441 & 268,603 & 4,285 & 721,658 & 111,025 & 3,583 \\
\hline $2(\mathrm{Std})$ & 0.332 & 36.31 & 1,055 & 744 & 0.546 & 4.288 & 2.065 & 371,026 & 183,263 & 2,837 & 644,207 & 99,108 & 2,786 \\
\hline 5th \% & 0.357 & 37.46 & 1,155 & 831 & 0.597 & 4.607 & 2.110 & 404,344 & 209,902 & 3,169 & 667,301 & 102,661 & 2,922 \\
\hline
\end{tabular}

\section{Nominal 24" Two-Span Test}

\begin{tabular}{|c|c|c|c|c|c|c|c|c|c|c|c|c|c|c|c|}
\hline $\begin{array}{c}\text { Panel } \\
\text { No. }\end{array}$ & $\begin{array}{c}\text { Weighted } \\
\text { Average } \\
\text { Thickness } \\
\text { (in) }\end{array}$ & $\begin{array}{c}\text { Density } \\
\text { (pcf) }\end{array}$ & $\begin{array}{c}\text { North } \\
\text { Span } \\
\text { Load/Defl } \\
\text { (lbs/in) }\end{array}$ & $\begin{array}{c}\text { South } \\
\text { Span } \\
\text { Load/Defl } \\
\text { (lbs/in) }\end{array}$ & $\begin{array}{c}\text { Average } \\
\text { Load/Defl } \\
\text { (lbs/in) }\end{array}$ & \begin{tabular}{|ll}
\multicolumn{2}{|c}{ Maximum } \\
Load \\
$2 P \quad$ (lbs)
\end{tabular} & $\begin{array}{c}\text { Moment } \\
\text { of Inertia } \\
\left.\text { (in }{ }^{4} / \mathrm{ft}\right)\end{array}$ & $\begin{array}{c}\text { Area } \\
\left(\mathrm{in}^{2} / \mathrm{ft}\right)\end{array}$ & $\begin{array}{c}\text { Shear } \\
\text { Correction } \\
\text { Coefficient } \\
k_{\mathrm{s}}\end{array}$ & $\begin{array}{l}\text { Bending } \\
\text { Stiffness } \\
\text { (lbf-in } / \mathrm{ft} \text { ) }\end{array}$ & $\begin{array}{l}\text { Shear } \\
\text { Stiffness } \\
\text { (lbf/ft) }\end{array}$ & $\begin{array}{l}\text { Bending } \\
\text { Strength } \\
\text { (in-lbs/ft) }\end{array}$ & $\begin{array}{c}\text { MOE } \\
\text { (psi) }\end{array}$ & $\begin{array}{c}\mathrm{G} \\
(\mathrm{psi})\end{array}$ & $\begin{array}{c}\text { MOR } \\
\text { (psi) }\end{array}$ \\
\hline $12 \mathrm{RB}$ & 0.375 & 40.35 & 5,614 & 5,322 & 5,468 & 4480 & 0.6351 & 4.850 & 2.210 & 460,598 & 244,886 & 3,938 & 725,221 & 111,572 & 3,487 \\
\hline $12 \mathrm{LT}$ & 0.371 & 38.36 & 4,883 & 4,682 & 4,782 & 3505 & 0.6270 & 4.798 & 2.227 & 403,559 & 213,324 & 3,081 & 643,660 & 99,025 & 2,754 \\
\hline 11RT & 0.382 & 40.25 & 5,419 & 5,046 & 5,233 & 4370 & 0.6495 & 4.940 & 2.179 & 439,389 & 235,977 & 3,841 & 676,539 & 104,083 & 3,347 \\
\hline $05 R C$ & 0.360 & 42.77 & 5,313 & 4,702 & 5,008 & 4590 & 0.6048 & 4.656 & 2.276 & 424,810 & 221,008 & 4,034 & 702,379 & 108,058 & 3,702 \\
\hline $05 \mathrm{LT}$ & 0.365 & 39.73 & 4,992 & 4,464 & 4,728 & 4200 & 0.6148 & 4.720 & 2.254 & 400,119 & 209,677 & 3,691 & 650,761 & 100,117 & 3,347 \\
\hline $05 \mathrm{LB}$ & 0.365 & 38.37 & 4,428 & 4,408 & 4,418 & 3830 & 0.6148 & 4.720 & 2.254 & 373,884 & 195,929 & 3,366 & 608,092 & 93,553 & 3,052 \\
\hline Mean & 0.370 & 39.97 & 5,108 & 4,771 & 4,939 & 4163 & 0.6243 & 4.781 & 2.233 & 417,060 & 220,134 & 3,658 & 667,775 & 102,735 & 3,282 \\
\hline Std. & 0.008 & 1.63 & 429 & 351 & 377 & 417 & 0.0162 & 0.103 & 0.035 & 30,944 & 17,922 & 367 & 42,444 & 6,529 & 334 \\
\hline COV & 0.02 & 0.04 & 0.08 & 0.07 & 0.08 & 0.10 & 0.03 & $\begin{array}{l}0.02 \\
\end{array}$ & $\begin{array}{l}0.02 \\
\end{array}$ & 0.07 & 0.08 & 0.10 & 0.06 & 0.06 & 0.10 \\
\hline$+2(\mathrm{Std})$ & 0.386 & 43.23 & 5,967 & 5,473 & 5,694 & 4,997 & 0.657 & 4.987 & 2.304 & 478,948 & 255,978 & 4,392 & 752,663 & 115,794 & 3,950 \\
\hline$-2(\mathrm{Std})$ & 0.354 & 36.72 & 4,250 & 4,068 & 4,185 & 3,328 & 0.592 & 4.574 & 2.163 & 355,172 & 184,289 & 2,925 & 582,888 & 89,676 & 2,613 \\
\hline 5 th \% & 0.361 & 38.37 & 4,542 & 4,422 & 4,496 & 3,586 & 0.607 & 4.672 & 2.187 & 380,443 & 199,366 & 3,152 & 616,984 & 94,921 & 2,828 \\
\hline
\end{tabular}




\section{Nominal 32” Two-Span Test}

\begin{tabular}{|c|c|c|c|c|c|c|c|c|c|c|c|c|c|c|c|}
\hline $\begin{array}{l}\text { Panel } \\
\text { No. }\end{array}$ & $\begin{array}{c}\text { Weighted } \\
\text { Average } \\
\text { Thickness } \\
\text { (in) }\end{array}$ & $\begin{array}{c}\text { Density } \\
\text { (pcf) }\end{array}$ & $\begin{array}{c}\text { North } \\
\text { Span } \\
\text { Load/Defl } \\
\text { (lbs/in) }\end{array}$ & $\begin{array}{c}\text { South } \\
\text { Span } \\
\text { Load/Defl } \\
\text { (lbs/in) }\end{array}$ & $\begin{array}{c}\text { Average } \\
\text { Load/Defl } \\
\text { (lbs/in) }\end{array}$ & \begin{tabular}{|ll}
\multicolumn{2}{|c}{ Maximum } \\
Load \\
$2 P$ & $(\mathrm{lbs})$
\end{tabular} & $\begin{array}{c}\text { Moment } \\
\text { of Inertia } \\
\left(\mathrm{in}^{4} / \mathrm{ft}\right)\end{array}$ & $\begin{array}{c}\text { Area } \\
\left(\text { (in }^{2} / \mathrm{ft}\right)\end{array}$ & $\begin{array}{c}\text { Shear } \\
\text { Correction } \\
\text { Coefficient } \\
\mathrm{k}_{\mathrm{s}}\end{array}$ & $\begin{array}{l}\text { Bending } \\
\text { Stiffness } \\
\left(\text { (bf-in }^{2} / \mathrm{ft}\right)\end{array}$ & $\begin{array}{l}\text { Shear } \\
\text { Stiffness } \\
\text { (lbf/ft) }\end{array}$ & $\begin{array}{l}\text { Bending } \\
\text { Strength } \\
\text { (in-lbs/ft) }\end{array}$ & $\begin{array}{l}\mathrm{MOE} \\
(\mathrm{psi})\end{array}$ & $\begin{array}{c}\mathrm{G} \\
(\mathrm{psi})\end{array}$ & $\begin{array}{l}\text { MOR } \\
(\mathrm{psi})\end{array}$ \\
\hline $18 \mathrm{RL}$ & 0.366 & 40.23 & 2,488 & 2,498 & 2,493 & 2965 & 0.6169 & 4.733 & 2.249 & 447,986 & 235,101 & 3,533 & 726,234 & 111,728 & 3,196 \\
\hline $18 \mathrm{LT}$ & 0.362 & 37.63 & 2,395 & 2,283 & 2,339 & 2640 & 0.6088 & 4.681 & 2.267 & 420,841 & 219,579 & 3,145 & 691,240 & 106,345 & 2,872 \\
\hline $14 \mathrm{RL}$ & 0.415 & 39.40 & 2,824 & 2,748 & 2,786 & 3105 & 0.7190 & 5.367 & 2.040 & 493,755 & 277,934 & 3,699 & 686,696 & 105,645 & 2,998 \\
\hline $14 \mathrm{LT}$ & 0.359 & 38.41 & 2,274 & 2,302 & 2,288 & 2460 & 0.6028 & 4.643 & 2.281 & 412,064 & 214,066 & 2,931 & 683,563 & 105,164 & 2,696 \\
\hline 08RT & 0.364 & 38.73 & 2,289 & 2,262 & 2,275 & 2730 & 0.6128 & 4.707 & 2.258 & 409,136 & 214,091 & 3,253 & 667,610 & 102,709 & 2,958 \\
\hline $08 \mathrm{LL}$ & 0.372 & 37.79 & 2,209 & 2,082 & 2,145 & 2550 & 0.6290 & 4.811 & 2.223 & 384,867 & 203,737 & 3,038 & 611,865 & 94,133 & 2,711 \\
\hline Mean & 373 & 38.70 & 2,413 & 2,362 & 2,388 & 2742 & 0.6316 & 4.824 & 2.220 & 428,108 & 227,418 & 3,266 & 677,868 & 104,287 & 2,905 \\
\hline Std. & 0.021 & 0.99 & 224 & 231 & 225 & 248 & 0.0437 & 0.272 & 0.090 & 38,065 & 26,792 & 296 & 37,657 & 5,793 & 189 \\
\hline $\mathrm{cov}$ & 0.06 & 0.03 & 0.09 & 0.10 & 0.09 & 0.09 & 0.07 & 0.06 & 0.04 & 0.09 & 0.12 & 0.09 & 0.06 & 0.06 & 0.07 \\
\hline$+2(\mathrm{Std})$ & 0.416 & 40.68 & 2,861 & 2,824 & 2,838 & 3,238 & 0.719 & 5.368 & 2.400 & 504,238 & 281,002 & 3,858 & 753,181 & 115,874 & 3,283 \\
\hline$-2(\mathrm{Std})$ & & 36.72 & 1,965 & 1,901 & 1,937 & 2,245 & 0.544 & 4.280 & 2.039 & 351,979 & 173,834 & 2,675 & 602,555 & 92,701 & 2,527 \\
\hline 5th \% & 0.360 & 37.67 & 2,225 & 2,127 & 2,178 & 2,483 & 0.604 & 4.652 & 2.086 & 390,934 & 206,319 & 2,958 & 625,801 & 96,277 & 2,700 \\
\hline
\end{tabular}

Nominal 24" Single-Span Composite Test

\begin{tabular}{|c|c|c|c|c|c|c|c|}
\hline $\begin{array}{l}\text { Panel } \\
\text { No. }\end{array}$ & $\begin{array}{c}\text { Load/Defl } \\
\text { (lbs/in) }\end{array}$ & $\begin{array}{c}\text { Weighted } \\
\text { Average } \\
\text { Thickness } \\
\mathrm{T}_{\text {sub }} \\
\text { (in) } \\
\end{array}$ & $\begin{array}{c}\text { Density } \\
\begin{array}{c}\square_{\text {sub }} \\
\text { (pcf) }\end{array}\end{array}$ & $\begin{array}{c}\text { Bending } \\
\text { Stiffness } \\
\mathrm{El}_{\text {sub }} \\
(\mathrm{lbs} / \mathrm{ft})\end{array}$ & $\begin{array}{c}\text { Shear } \\
\text { Stiffness } \\
\text { GA }_{\text {sub }} \\
\text { (lbs-in } / \mathrm{ft} \text { ) }\end{array}$ & $\begin{array}{c}\text { Axial } \\
\text { Stiffness } \\
\text { EA }_{\text {sub }} \\
\text { (lbs/ft) }\end{array}$ & $\begin{array}{l}\text { Moment of } \\
\text { Inertia } \\
\mathrm{I}_{\text {sub }} \\
\left(\mathrm{in}^{4} / \mathrm{ft}\right)\end{array}$ \\
\hline 06LTs & 2,619 & 0.366 & 38.38 & 400,323 & 210,088 & $3,071,625$ & 0.6169 \\
\hline 06LCs & 2,917 & 0.356 & 39.67 & 447,073 & 231,243 & $3,448,551$ & 0.5968 \\
\hline 06RBs & 3,298 & 0.380 & 40.50 & 502,275 & 268,975 & $3,824,668$ & 0.6454 \\
\hline 06RCs & 3,198 & 0.366 & 42.44 & 488,869 & 256,556 & $3,751,029$ & 0.6169 \\
\hline 11LBs & 2,702 & 0.367 & 37.44 & 412,928 & 217,017 & $3,166,643$ & 0.6189 \\
\hline 11LTs & 2,800 & 0.369 & 37.96 & 427,631 & 225,396 & $3,275,876$ & 0.6229 \\
\hline Mean & 2,922 & 0.367 & 39.40 & $\overline{4446,517}$ & $\overline{234,879}$ & $3,423,065$ & 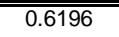 \\
\hline Std. & 273 & 0.008 & 1.87 & 41,284 & 23,105 & 309,975 & 0.0156 \\
\hline COV & 0.09 & 0.02 & 0.05 & 0.09 & 0.10 & 0.09 & 0.03 \\
\hline$+2(\mathrm{Std})$ & 3,468 & 0.383 & 43.13 & 529,084 & 281,089 & $4,043,015$ & 0.651 \\
\hline$-2(S t d)$ & 2,376 & 0.352 & 35.66 & 363,949 & 188,669 & $2,803,116$ & 0.589 \\
\hline 5th \% & 2,640 & 0.359 & 37.57 & 403,474 & 211,820 & $3,095,380$ & 0.602 \\
\hline \multicolumn{8}{|c|}{ Underlayment (OSB) } \\
\hline $\begin{array}{l}\text { Panel } \\
\text { No. }\end{array}$ & $\begin{array}{c}\text { Load/Defl } \\
\text { (Ibs/in) }\end{array}$ & $\begin{array}{c}\text { Weighted } \\
\text { Average } \\
\text { Thickness } \\
t_{\text {und }} \\
\text { (in) }\end{array}$ & $\begin{array}{l}\text { Density } \\
\text { घund } \\
\text { (pcf) }\end{array}$ & $\begin{array}{l}\text { Bending } \\
\text { Stiffness } \\
\text { El }_{\text {und }} \\
\text { (lbs-in } / \mathrm{ft} \text { ) }\end{array}$ & $\begin{array}{l}\text { Shear } \\
\text { Stiffness } \\
\text { GA }_{\text {und }} \\
\text { (lbs/ft) }\end{array}$ & $\begin{array}{c}\text { Axial } \\
\text { Stiffness } \\
\text { EA }_{\text {und }} \\
\text { (lbs/ft) }\end{array}$ & $\begin{array}{c}\text { Modulus of } \\
\text { Elasticity } \\
\text { E }_{\text {und }} \\
(p s i)\end{array}$ \\
\hline $06 \mathrm{LTu}$ & 1,226 & 0.500 & 41.12 & 145,496 & $1,426,889$ & $4,451,893$ & 742,353 \\
\hline $06 \mathrm{LCu}$ & 963 & 0.474 & 39.75 & 114,273 & $1,320,477$ & $4,119,889$ & 724,312 \\
\hline 06RBu & 1,006 & 0.485 & 38.67 & 119,360 & $1,302,847$ & $4,064,883$ & 698,704 \\
\hline 06RCu & 965 & 0.471 & 40.96 & 114,499 & $1,339,305$ & $4,178,633$ & 739,319 \\
\hline $11 \mathrm{LBu}$ & 922 & 0.471 & 39.76 & 109,368 & $1,294,829$ & $4,039,867$ & 714,768 \\
\hline $11 \mathrm{LTu}$ & 1,099 & 0.480 & 39.33 & 130,458 & $1,422,759$ & $4,439,008$ & 770,862 \\
\hline Mean & 1,030 & 0.480 & 39.93 & 12122,242 & $\overline{11,351,184}$ & "4,215,696 & $7 \overline{731,720}$ \\
\hline Std. & 113 & 0.011 & 0.95 & 13,459 & 59,077 & 184,321 & 25,041 \\
\hline COV & 0.11 & 0.02 & 0.02 & 0.11 & 0.04 & 0.04 & 0.03 \\
\hline$+2(\mathrm{Std})$ & 1,257 & 0.502 & 41.82 & 149,161 & $1,469,339$ & $4,584,337$ & 781,802 \\
\hline$-2(S t d)$ & 803 & 0.458 & 38.04 & 95,324 & $1,233,030$ & $3,847,054$ & 681,638 \\
\hline 5th \% & 932 & 0.471 & 38.84 & 110,594 & $1,296,834$ & $4,046,121$ & 702,720 \\
\hline
\end{tabular}

\begin{tabular}{|c|c|c|c|c|c|c|c|c|c|c|}
\hline \multicolumn{4}{|c|}{ Composite Deck (Nail-glued System) } & \multicolumn{7}{|c|}{ Partial Composite Action } \\
\hline $\begin{array}{c}\text { Panel } \\
\text { No. }\end{array}$ & $\begin{array}{l}\text { Load/Defl } \\
\text { (Ibs/in) }\end{array}$ & $\begin{array}{l}\text { Maximum } \\
\text { Load } \\
\text { (lbs) }\end{array}$ & $\begin{array}{c}\text { Nominal } \\
\text { Strength } \\
\mathrm{F}_{\mathrm{b}} \mathrm{S}_{\mathrm{c}} \\
\text { (in-lbs/ft) }\end{array}$ & $\begin{array}{l}\text { Adhesive } \\
\text { Shear } \\
\text { Modulus } \\
\mathrm{G}_{\mathrm{ad}} \\
(\mathrm{psi})\end{array}$ & \begin{tabular}{|c|} 
Effective \\
Axial \\
Stiffness of \\
Underlayment \\
EA $_{\text {und_eff }}$ \\
(lbs/ft)
\end{tabular} & $\begin{array}{l}\text { Effective } \\
\text { Bending } \\
\text { Stiffness } \\
\quad \mathrm{El}_{\text {eff }} \\
\left.\text { (lbs-in }{ }^{2} / \mathrm{ft}\right)\end{array}$ & $\begin{array}{c}\text { Effective } \\
\text { Shear } \\
\text { Stiffness } \\
\text { GA }_{\text {eff }} \\
\text { (lbs/ft) }\end{array}$ & $\begin{array}{l}\text { Unattached } \\
\text { Stiffness } \\
\text { El }_{\text {no_comp }} \\
\left.\text { (lbs-in }^{2} / \mathrm{ft}\right)\end{array}$ & $\begin{array}{c}\text { Full } \\
\text { Composite } \\
\text { Stiffness } \\
\text { El }_{\text {full_comp }} \\
\left(\text { lbs-in }^{2} / \mathrm{ft}\right)\end{array}$ & $\begin{array}{c}\text { Composite } \\
\text { Factor }\end{array}$ \\
\hline $06 \mathrm{LT}$ & 6,820 & 2,320 & 6,525 & 456 & $1,750,136$ & $1,273,694$ & 297,613 & 545,818 & $1,732,447$ & 0.61 \\
\hline 06LC & 6,463 & 2,435 & 6,848 & 324 & $1,368,307$ & $1,172,726$ & 300,152 & 561,347 & $1,732,921$ & 0.52 \\
\hline 06RB & 8,090 & 2,860 & 8,044 & 674 & $2,081,901$ & $1,500,665$ & 358,105 & 621,635 & $1,906,551$ & 0.68 \\
\hline 06RC & 7,277 & 2,720 & 7,650 & 433 & $1,655,938$ & $1,326,695$ & 334,394 & 603,368 & $1,847,951$ & 0.58 \\
\hline 11LB & 6,827 & 2,185 & 6,145 & 553 & $1,875,520$ & $1,264,879$ & 302,933 & 522,296 & $1,641,430$ & 0.66 \\
\hline $11 \mathrm{LT}$ & 7,911 & 2,590 & 7,284 & 1,051 & $2,662,255$ & $1,496,870$ & 336,256 & 558,089 & $1,762,906$ & 0.78 \\
\hline Mean & 7,231 & 2,518 & 7,083 & 582 & $1,899,010$ & $1,339,255$ & 321,576 & 568,759 & $1,770,701$ & 0.64 \\
\hline Std. & 652 & 253 & 711 & 258 & 442,592 & 133,128 & 24,879 & 37,007 & 93,899 & 0.09 \\
\hline COV & 0.09 & 0.10 & 0.10 & 0.44 & 0.23 & 0.10 & 0.08 & 0.07 & 0.05 & 0.14 \\
\hline$+2(\mathrm{Std})$ & 8,535 & 3,024 & 8,506 & 1,099 & $2,784,193$ & $1,605,511$ & 371,334 & 642,773 & $1,958,499$ & 0.82 \\
\hline$-2(S t d)$ & 5,928 & 2,012 & 5,660 & 65 & $1,013,826$ & $1,072,999$ & 271,817 & 494,745 & $1,582,903$ & 0.46 \\
\hline 5th $\%$ & 6,553 & 2,219 & 6,240 & 351 & $1,440,215$ & $1,195,764$ & 298,248 & 528,177 & $1,664,184$ & 0.54 \\
\hline
\end{tabular}


Nominal 32" Single-Span Composite Deck Test

\begin{tabular}{|c|c|c|c|c|c|c|c|c|c|c|c|}
\hline Panel No. & $\begin{array}{c}\text { Load/Defl } \\
\text { (Ibs/in) }\end{array}$ & \begin{tabular}{|l|} 
Weighted \\
Average \\
Thickness \\
$\mathrm{T}_{\text {sub }}$ (in) \\
\end{tabular} & $\begin{array}{c}\text { Density } \\
\begin{array}{c}\square \text { sub } \\
\text { (pcf) }\end{array}\end{array}$ & $\begin{array}{c}\text { Nominal } \\
\text { Stiffness } \\
\text { El }_{\text {sub }} \\
\left(\mathrm{lbs}-\mathrm{in}^{2} / \mathrm{ft}\right) \\
\end{array}$ & $\begin{array}{c}\text { Shear } \\
\text { Stiffness } \\
\text { GA }_{\text {sub }} \\
\left(\mathrm{lbs}-\mathrm{in}^{2} / \mathrm{ft}\right)\end{array}$ & $\begin{array}{c}\text { Axial Stiffness } \\
\text { EA }_{\text {sub }} \\
(\mathrm{lbs} / \mathrm{ft})\end{array}$ & $\begin{array}{c}\text { Moment } \\
\text { of Inertia } \\
\mathrm{I}_{\text {sub }} \\
\left(\mathrm{in}^{4} / \mathrm{ft}\right) \\
\end{array}$ & \begin{tabular}{|c|}
$\begin{array}{c}\text { Modulus of } \\
\text { Elasticity } \\
\mathrm{E}_{\text {sub }} \\
(\mathrm{psi})\end{array}$ \\
\end{tabular} & $\begin{array}{c}\text { Shear } \\
\text { Modulus } \\
\mathrm{G}_{\text {sub }} \\
\text { (psi) }\end{array}$ & $\begin{array}{c}\text { Area } \\
\mathrm{A}_{\text {sub }} \\
\left(\mathrm{in}^{2} / \mathrm{ft}\right)\end{array}$ & $\begin{array}{c}\text { Shear } \\
\text { Correction } \\
\text { Coefficient } \\
\text { ks } \\
\end{array}$ \\
\hline 35RTs & 1,235 & 0.353 & 39.28 & 432,743 & 222,857 & $3,343,240$ & 0.5909 & 732,365 & 112,672 & 4.565 & 2.308 \\
\hline $35 \mathrm{LBs}$ & 1,125 & 0.367 & 37.77 & 393,521 & 206,817 & $3,017,816$ & 0.6189 & 635,860 & 97,825 & 4.746 & 2.245 \\
\hline 19RBs & 1,139 & 0.350 & 37.38 & 399,458 & 204,820 & $3,090,898$ & 0.5850 & 682,891 & 105,060 & 4.526 & 2.322 \\
\hline 19LTs & 1,435 & 0.382 & 39.48 & 500,648 & 268,876 & $3,808,064$ & 0.6495 & 770,861 & 118,594 & 4.940 & 2.179 \\
\hline 17RBs & 1,247 & 0.364 & 38.82 & 436,360 & 228,337 & $3,351,713$ & 0.6128 & 712,033 & 109,544 & 4.707 & 2.258 \\
\hline 17LTs & 1,351 & 0.358 & 38.98 & 473,032 & 245,382 & $3,644,960$ & 0.6008 & 787,308 & 121,124 & 4.630 & 2.285 \\
\hline Mean & $1,1,255$ & 0.362 & 38.62 & 4439,294 & 229,515 & 3,376,115 & 0.6097 & 720,220 & 1110,803 & 4.686 & 2.266 \\
\hline Std. & 120 & 0.012 & 0.85 & 41,560 & 24,380 & 306,679 & 0.0233 & 56,196 & 8,645 & 0.150 & 0.052 \\
\hline COV & 0.10 & 0.03 & 0.02 & 0.09 & 0.11 & 0.09 & 0.04 & 0.08 & 0.08 & 0.03 & 0.02 \\
\hline$+2(\mathrm{Std})$ & 1,495 & 0.386 & 40.31 & 522,414 & 278,274 & $3,989,474$ & 0.656 & 832,611 & 128,094 & 4.985 & 2.369 \\
\hline$-2(\mathrm{Std})$ & 1,015 & 0.339 & 36.92 & 356,174 & 180,756 & $2,762,757$ & 0.563 & 607,828 & 93,512 & 4.386 & 2.163 \\
\hline 5 th $\%$ & 1,129 & 0.350 & 37.48 & 395,005 & 205,319 & $3,036,087$ & 0.586 & 647,618 & 99,634 & 4.536 & 2.196 \\
\hline
\end{tabular}

\begin{tabular}{|c|c|c|c|c|c|c|c|}
\hline \multicolumn{8}{|c|}{ Underlayment (OSB) } \\
\hline Panel No. & $\begin{array}{c}\text { Load/Defl } \\
\text { (lbs/in) }\end{array}$ & $\begin{array}{c}\text { Weighted } \\
\text { Average } \\
\text { Thickness } \\
t_{\text {und }} \\
\text { (in) }\end{array}$ & $\begin{array}{l}\text { Density } \\
\qquad \begin{array}{l}\square \text { und } \\
\text { (pcf) }\end{array}\end{array}$ & $\begin{array}{c}\text { Nominal } \\
\text { Stiffness } \\
\text { El und }_{\text {und }} \\
\left(\text { lbs-in }^{2} / \mathrm{ft}\right)\end{array}$ & $\begin{array}{l}\text { Shear } \\
\text { Stiffness } \\
\text { GA }_{\text {und }} \\
\text { (lbs/ft) }\end{array}$ & $\begin{array}{c}\text { Axial Stiffness } \\
\mathrm{EA}_{\text {und }} \\
(\mathrm{lbs} / \mathrm{ft})\end{array}$ & $\begin{array}{c}\text { Modulus } \\
\text { of } \\
\text { Elasticity } \\
E_{\text {und }} \\
\text { (psi) }\end{array}$ \\
\hline 35RTu & 357 & 0.477 & 38.02 & 105,511 & $1,229,858$ & $3,837,156$ & 670,363 \\
\hline $35 \mathrm{LBu}$ & 412 & 0.486 & 40.16 & 121,766 & $1,317,076$ & $4,109,278$ & 704,971 \\
\hline $19 \mathrm{RBu}$ & 433 & 0.489 & 39.65 & 127,972 & $1,350,880$ & $4,214,746$ & 718,076 \\
\hline $19 \mathrm{LTu}$ & 333 & & 40.32 & 98,418 & $1,263,463$ & $3,942,004$ & 715,200 \\
\hline $17 \mathrm{RBu}$ & 431 & 0.486 & 40.95 & 127,381 & $1,362,796$ & $4,251,925$ & 729,537 \\
\hline $17 \mathrm{LTu}$ & 418 & 0.499 & 38.53 & 123,539 & $1,263,040$ & $3,940,686$ & 657,768 \\
\hline Mean & 397 & 0.483 & 39.61 & 10117,431 & $1,297,852$ & 4,049,299 & 6099,319 \\
\hline Std. & 42 & 0.014 & 1.12 & 12,408 & 53,697 & 167,536 & 28,685 \\
\hline COV & 0.11 & & 0.03 & & 0.04 & 0.04 & 0.04 \\
\hline$+2(\mathrm{Std})$ & 482 & & 41.85 & 142,247 & $1,405,246$ & $4,384,371$ & 756,689 \\
\hline$-2(\mathrm{Std})$ & 313 & & 37.36 & 92,615 & $1,190,458$ & $3,714,228$ & 641,949 \\
\hline 5 th $\%$ & 339 & 0.464 & 38.15 & 100,191 & $1,238,154$ & $3,863,039$ & 660,916 \\
\hline
\end{tabular}

\begin{tabular}{|c|c|c|c|c|c|c|c|c|c|c|}
\hline \multicolumn{5}{|c|}{ Composite Deck (Nail-glued System) } & \multicolumn{6}{|c|}{ Partial Composite Action } \\
\hline Panel No. & $\begin{array}{c}\text { Load/Defl } \\
\text { (Ibs/in) }\end{array}$ & $\begin{array}{l}\text { Maximum } \\
\text { Load } \\
\text { (lbs) }\end{array}$ & $\begin{array}{c}\text { Nominal } \\
\text { Strength } \\
\mathrm{F}_{\mathrm{b}} \mathrm{S}_{\mathrm{c}} \\
\text { (in-lbs/ft) }\end{array}$ & $\begin{array}{c}\text { Adhesive } \\
\text { Shear } \\
\text { Modulus } \\
\mathrm{G}_{\mathrm{ad}} \\
\text { (psi) }\end{array}$ & $\begin{array}{c}\text { Effective Axial } \\
\text { Stiffness of } \\
\text { Underlayment } \\
\text { EA }_{\text {und_eff }} \\
\text { (lbs/ft) }\end{array}$ & $\begin{array}{l}\text { Effective } \\
\text { Bending } \\
\text { Stiffness } \\
\quad \mathrm{EI}_{\mathrm{eff}} \\
\left(\mathrm{lbs}-\mathrm{in}^{2} / \mathrm{ft}\right)\end{array}$ & $\begin{array}{c}\text { Effective } \\
\text { Shear } \\
\text { Stiffness } \\
\mathrm{GA}_{\text {eff }} \\
(\mathrm{lbs} / \mathrm{ft})\end{array}$ & 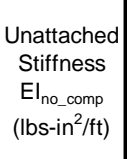 & $\begin{array}{c}\text { Full } \\
\text { Composite } \\
\text { Stiffness } \\
\text { El }_{\text {full_comp }} \\
\left(\text { lbs-in }^{2} / \mathrm{ft}\right)\end{array}$ & $\begin{array}{c}\text { Composite } \\
\text { Factor }\end{array}$ \\
\hline $35 \mathrm{RT}$ & 3,118 & 1,460 & 5,566 & 201 & $1,454,049$ & $1,170,673$ & 362,368 & 538,253 & $1,653,274$ & 0.57 \\
\hline $35 \mathrm{LB}$ & 3,240 & 1,995 & 7,606 & 254 & $1,719,501$ & $1,218,958$ & 372,645 & 515,287 & $1,633,058$ & 0.63 \\
\hline $19 \mathrm{RB}$ & 3,341 & 1,540 & 5,871 & 285 & $1,856,928$ & $1,259,670$ & 380,578 & 527,431 & $1,653,034$ & 0.65 \\
\hline 19LT & 3,742 & 1,935 & 7,377 & 320 & $1,914,013$ & $1,405,141$ & 435,054 & 599,065 & $1,824,799$ & 0.66 \\
\hline $17 \mathrm{RB}$ & 3,477 & 1,750 & 6,672 & 265 & $1,786,718$ & $1,309,627$ & 397,819 & 563,741 & $1,763,271$ & 0.62 \\
\hline $17 \mathrm{LT}$ & 3,582 & 1,615 & 6,157 & 266 & $1,731,900$ & $1,354,553$ & 402,007 & 596,571 & $1,819,057$ & 0.62 \\
\hline Mean & 3,417 & $\overline{~ 1,716}$ & 6,542 & 265 & $1,1,743,852$ & $1,286,437$ & "391,745 & 556,725 & $1,724,416$ & 0.62 \\
\hline Std. & 230 & 216 & 824 & 39 & 160,187 & 87,108 & 25,963 & 35,626 & 88,370 & 0.03 \\
\hline COV & 0.07 & 0.13 & 0.13 & 0.15 & 0.09 & 0.07 & 0.07 & 0.06 & 0.05 & 0.05 \\
\hline$+2(\mathrm{Std})$ & 3,876 & 2,148 & 8,190 & 343 & $2,064,226$ & $1,460,654$ & 443,671 & 627,977 & $1,901,155$ & 0.69 \\
\hline$-2(\mathrm{Std})$ & 2,958 & 1,283 & 4,893 & 187 & $1,423,477$ & $1,112,220$ & 339,819 & 485,473 & $1,547,676$ & 0.56 \\
\hline 5 th \% & 3,148 & 1,480 & 5,643 & 215 & $1,520,412$ & $1,182,744$ & 364,937 & 518,323 & $1,638,052$ & 0.58 \\
\hline
\end{tabular}


Nominal 24” Two-Span Composite Test

\begin{tabular}{|c|c|c|c|c|c|c|c|c|c|c|c|c|c|}
\hline \multicolumn{3}{|c|}{ Corrugated Panels } & \multicolumn{11}{|c|}{ *'non-destructive' flexure test data } \\
\hline $\begin{array}{c}\text { Panel } \\
\text { No. }\end{array}$ & $\begin{array}{l}\text { North Span } \\
\text { Load/Defl } \\
\text { (lbs/in) }\end{array}$ & $\begin{array}{c}\text { South Span } \\
\text { Load/Defl } \\
\text { (Ibs/in) }\end{array}$ & $\begin{array}{c}\text { Average } \\
\text { Load/Defl } \\
\text { (Ibs/in) }\end{array}$ & \begin{tabular}{|c} 
Weighted \\
Average \\
Thickness \\
$\mathrm{T}_{\text {sub }}$ \\
(in)
\end{tabular} & $\begin{array}{l}\text { Density } \\
\square \text { sub } \\
\text { (pcf) }\end{array}$ & $\begin{array}{c}\text { Bending } \\
\text { Stiffness } \\
\text { El }_{\text {sub }} \\
\text { (lbs/ft) }\end{array}$ & $\begin{array}{l}\text { Shear } \\
\text { Stiffness } \\
\text { GA }_{\text {sub }} \\
\left.\text { (lbs-in }{ }^{2} / f t\right)\end{array}$ & $\begin{array}{c}\text { Axial } \\
\text { Stiffness } \\
\text { EA }_{\text {sub }} \\
\text { (lbs/ft) }\end{array}$ & $\begin{array}{c}\text { Moment of } \\
\text { Inertia } \\
\mathrm{I}_{\text {sub }} \\
\left(\mathrm{in}^{4} / \mathrm{ft}\right)\end{array}$ & $\begin{array}{c}\text { Modulus of } \\
\text { Elasticity } \\
\mathrm{E}_{\text {sub }} \\
(\mathrm{psi})\end{array}$ & $\begin{array}{c}\text { Shear } \\
\text { Modulus } \\
\mathrm{G}_{\text {sub }} \\
(\mathrm{psi})\end{array}$ & $\begin{array}{l}\text { Area } \\
A_{\text {sub }} \\
\left(\text { in }^{2} / \mathrm{ft}\right)\end{array}$ & $\begin{array}{c}\text { Shear } \\
\text { Correction } \\
\text { Coefficient } \\
\text { ks }\end{array}$ \\
\hline $06 \mathrm{LB}$ & 2629 & 2800 & 2715 & 0.378 & 37.17 & 413,718 & 220,914 & $3,153,803$ & 0.6412 & 645,175 & 99,258 & 4.888 & 2.196 \\
\hline 06RT & 2936 & 3139 & 3038 & 0.378 & 40.95 & 462,937 & 247,196 & $3,529,007$ & 0.6412 & 721,931 & 111,066 & 4.888 & 2.196 \\
\hline $11 \mathrm{LC}$ & 2470 & 2515 & 2493 & 0.358 & 37.92 & 381,847 & 198,080 & $2,942,328$ & 0.6008 & 635,540 & 97,775 & 4.630 & 2.285 \\
\hline 11RB & 2998 & 3043 & 3021 & 0.373 & 40.69 & 460,932 & 244,356 & $3,523,335$ & 0.6310 & 730,432 & 112,374 & 4.824 & 2.218 \\
\hline $30 \mathrm{LB}$ & 2551 & 2391 & 2471 & 0.376 & 35.46 & 376,727 & 200,583 & $2,874,973$ & 0.6372 & 591,263 & 90,964 & 4.862 & 2.205 \\
\hline $30 \mathrm{RB}$ & 2824 & 3077 & 2950 & 0.375 & 39.47 & 449,870 & 239,181 & $3,435,032$ & 0.6351 & 708,328 & 108,974 & 4.849 & 2.209 \\
\hline Mean & 2,735 & $\overline{2,828}$ & $\overline{2,781}$ & 0.373 & 38.61 & 424,339 & 225,052 & $3,243,080$ & 0.6311 & 672,112 & $\overline{103,402}$ & 4.824 & 2.218 \\
\hline Std. & 216 & 315 & 259 & 0.008 & 2.15 & 39,156 & 21,936 & 293,621 & 0.0153 & 56,204 & 8,647 & 0.098 & 0.034 \\
\hline $\mathrm{COV}$ & 0.08 & 0.11 & 0.09 & 0.02 & 0.06 & 0.09 & 0.10 & 0.09 & 0.02 & 0.08 & 0.08 & 0.02 & 0.02 \\
\hline$+2(\mathrm{Std})$ & 3,167 & 3,457 & 3,300 & 0.388 & 42.90 & 502,651 & 268,924 & $3,830,322$ & 0.662 & 784,519 & 120,695 & 5.019 & 2.286 \\
\hline$-2(\mathrm{Std})$ & 2,303 & 2,198 & 2,263 & 0.357 & 34.32 & 346,026 & 181,179 & $2,655,837$ & 0.600 & 559,704 & 86,109 & 4.628 & 2.151 \\
\hline 5th \% & 2,490 & 2,422 & 2,476 & 0.361 & 35.89 & 378,007 & 198,706 & $2,891,812$ & 0.608 & 602,332 & 92,667 & 4.679 & 2.196 \\
\hline
\end{tabular}

${ }^{*}$ Tested at 22.5" o.c. at north and south spans, with load applied at mid span, load range $=0 \sim 400 \mathrm{lbs}$

\begin{tabular}{|c|c|c|c|c|c|c|}
\hline \multicolumn{7}{|l|}{ Onaeria } \\
\hline $\begin{array}{l}\text { Panel } \\
\text { No. }\end{array}$ & $\begin{array}{c}\text { *Weighted } \\
\text { Average } \\
\text { Thickness } \\
t \\
\text { (in) } \\
\end{array}$ & $\begin{array}{l}\text { *Density } \\
\text { und } \quad(\mathrm{pcf})\end{array}$ & $\begin{array}{c}\text { *Bending } \\
\text { Stiffness } \\
\text { El }_{\text {und }} \\
\left(\mathrm{Ibs}-\mathrm{in}^{2} / \mathrm{ft}\right)\end{array}$ & $\begin{array}{c}\text { Shear } \\
\text { Stiffness } \\
\text { GA }_{\text {und }} \\
\text { (lbs/ft) }\end{array}$ & $\begin{array}{c}\text { Axial } \\
\text { Stiffness } \\
\text { EA } A_{\text {und }} \\
\text { (lbs/ft) }\end{array}$ & $\begin{array}{c}\text { Modulus } \\
\text { of } \\
\text { Elasticity } \\
\mathrm{E}_{\text {und }} \\
(\mathrm{psi}) \\
\end{array}$ \\
\hline $06 \mathrm{LBu}$ & 0.490 & 40.34 & 123,549 & $1,310,020$ & $4,087,263$ & 695,113 \\
\hline 06RTu & 0.475 & 40.26 & 111,584 & $1,292,794$ & $4,033,517$ & 707,635 \\
\hline $11 \mathrm{LCu}$ & 0.479 & 41.23 & 115,061 & $1,300,029$ & $4,056,091$ & 705,653 \\
\hline $11 \mathrm{RBu}$ & 0.481 & 39.35 & 110,582 & $1,250,258$ & $3,900,803$ & 675,815 \\
\hline $30 \mathrm{LBu}$ & 0.472 & 39.62 & 104,577 & $1,248,305$ & $3,894,711$ & 687,626 \\
\hline 30RBu & 0.474 & 40.21 & 113,048 & $1,311,895$ & $4,093,111$ & 719,605 \\
\hline Mean & 0.479 & 40.17 & $\begin{array}{l}113,067 \\
\end{array}$ & $1,285,550$ & $4,010,916$ & 698,574 \\
\hline Std. & 0.007 & 0.65 & 6,234 & 28,940 & 90,294 & 15,648 \\
\hline $\mathrm{COV}$ & & & & & & 0.02 \\
\hline$+2(\mathrm{Std})$ & 0.492 & 41.47 & 125,534 & $1,343,431$ & $4,191,504$ & 729,870 \\
\hline$-2(\mathrm{Std})$ & 0.465 & 38.86 & 100,599 & $1,227,670$ & $3,830,328$ & 667,278 \\
\hline 5th \% & 0.473 & 39.42 & 106,078 & $1,248,793$ & $3,896,234$ & 678,767 \\
\hline
\end{tabular}

*Weighted average values of two panels

Composite Panels

\begin{tabular}{|c|c|c|c|c|c|c|c|c|c|c|c|c|}
\hline & North-Span & South-Span & & & & Partial Con & mposite Action & & & & & \\
\hline $\begin{array}{l}\text { Panel } \\
\text { No. }\end{array}$ & $\begin{array}{c}\text { North Span } \\
\text { Load/Defl } \\
\text { (Ibs/in) }\end{array}$ & $\begin{array}{c}\text { South Span } \\
\text { Load/Defl } \\
\text { (lbs/in) }\end{array}$ & $\begin{array}{c}\text { Average } \\
\text { Load/Defl } \\
\text { (Ibs/in) }\end{array}$ & \begin{tabular}{|} 
Maximum \\
Load \\
$2 \mathrm{P}$ \\
$(\mathrm{lbs})$
\end{tabular} & $\begin{array}{c}\text { Nominal } \\
\text { Strength } \\
\mathrm{F}_{\mathrm{b}} \mathrm{S}_{\mathrm{c}} \\
\text { (in-lbs/ft) }\end{array}$ & $\begin{array}{c}\text { Adhesive } \\
\text { Shear } \\
\text { Modulus } \\
\mathrm{G}_{\mathrm{ad}} \\
(\mathrm{psi})\end{array}$ & $\begin{array}{l}\text { Effective Axial } \\
\text { Stiffness of } \\
\text { Underlayment } \\
\text { EA } A_{\text {und_eff }} \\
\text { (lbs/ft) }\end{array}$ & $\begin{array}{c}\text { Effective } \\
\text { Composite } \\
\text { Stiffness } \\
\text { El }_{\text {eff }} \\
\left(\text { Ibs-in }^{2} / \mathrm{ft}\right)\end{array}$ & $\begin{array}{c}\text { Effective } \\
\text { Shear } \\
\text { Stiffness } \\
\text { GA }_{\text {eff }} \\
(\mathrm{lbs} / \mathrm{ft})\end{array}$ & $\begin{array}{l}\text { Unattached } \\
\text { Stiffness } \\
\text { El }_{\text {no_comp }} \\
\left.\text { (lbs-in }{ }^{2} / \mathrm{ft}\right)\end{array}$ & $\begin{array}{c}\text { Full } \\
\text { Composite } \\
\text { Stiffness } \\
\text { El }_{\text {full_comp }} \\
\left(\text { lbs-in }^{2} / \mathrm{ft}\right)\end{array}$ & $\begin{array}{c}\text { Composite } \\
\text { Factor }\end{array}$ \\
\hline $06 \mathrm{LB}$ & 8907 & 8232 & 8569 & 6,500 & 5,713 & 256 & 713,690 & 918,226 & 263,742 & 537,267 & $1,702,543$ & 0.33 \\
\hline $06 R T$ & 9611 & 8994 & 9302 & 7,600 & 6,680 & 285 & 776,439 & 983,230 & 290,908 & 574,521 & $1,783,284$ & 0.34 \\
\hline $11 \mathrm{LC}$ & 8571 & 7842 & 8207 & 5,900 & 5,186 & 302 & 813,736 & 898,206 & 246,676 & 496,907 & $1,570,462$ & 0.37 \\
\hline $11 \mathrm{RB}$ & 10016 & 9139 & 9578 & 6,920 & 6,082 & 346 & 899,644 & \begin{tabular}{|l|}
$1,032,612$ \\
\end{tabular} & 292,756 & 571,514 & \begin{tabular}{|l|}
$1,762,608$ \\
\end{tabular} & 0.39 \\
\hline $30 \mathrm{LB}$ & 8071 & 7238 & 7655 & 5,840 & 5,133 & 221 & 625,591 & \begin{tabular}{|l|}
809,257 \\
\end{tabular} & 239,359 & 481,304 & \begin{tabular}{|l|}
$1,537,067$ \\
\end{tabular} & 0.31 \\
\hline $30 \mathrm{RB}$ & 7305 & 7205 & 7255 & 6,700 & 5,889 & 73 & 233,218 & 702,448 & 254,522 & 562,918 & $1,756,163$ & 0.12 \\
\hline "Mean & (8,747 & (8,108 & (8,428 & $6,6,577$ & (5,780 & 247 & (677,053 & (890,663 & 264,661 & (537,405 & $1,1,685,355$ & 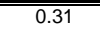 \\
\hline Std. & 995 & 837 & 909 & 661 & 581 & 95 & 236,257 & 119,655 & 22,563 & 39,948 & 105,884 & 0.10 \\
\hline $\mathrm{cov}$ & 0.11 & 0.10 & 0.11 & 0.10 & 0.10 & 0.38 & 0.35 & 0.13 & 0.09 & 0.07 & 0.06 & 0.32 \\
\hline$+2(\mathrm{Std})$ & 10,737 & 9,783 & 10,245 & 7,899 & 6,943 & 438 & $1,149,567$ & $1,129,973$ & 309,787 & 617,302 & $1,897,122$ & 0.51 \\
\hline$-2(\mathrm{Std})$ & 6,757 & 6,434 & 6,610 & 5,254 & 4,618 & 57 & 204,539 & 651,353 & 219,534 & 457,508 & $1,473,587$ & 0.11 \\
\hline 5th $\%$ & 7,497 & 7,213 & 7,355 & 5,855 & 5,146 & 110 & 331,311 & 729,150 & 241,188 & 485,205 & $1,545,416$ & 0.17 \\
\hline
\end{tabular}


Nominal 32” Two-Span Composite Test

\begin{tabular}{|c|c|c|c|c|c|c|c|c|c|c|c|c|c|}
\hline \multicolumn{3}{|c|}{ Corrugated Panels } & \multicolumn{11}{|c|}{ *'non-destructive' flexure test data } \\
\hline $\begin{array}{l}\text { Panel } \\
\text { No. }\end{array}$ & $\begin{array}{l}\text { North Span } \\
\text { Load/Defl } \\
\text { (Ibs/in) }\end{array}$ & $\begin{array}{c}\text { South Span } \\
\text { Load/Defl } \\
\text { (lbs/in) }\end{array}$ & $\begin{array}{c}\text { Average } \\
\text { Load/Defl } \\
\text { (Ibs/in) }\end{array}$ & $\begin{array}{c}\text { Weighted } \\
\text { Average } \\
\text { Thickness } \\
\mathrm{T}_{\text {sub }} \\
\text { (in) }\end{array}$ & $\begin{array}{c}\text { Density } \\
\square \text { sub } \\
\text { (pcf) }\end{array}$ & $\begin{array}{c}\text { Bending } \\
\text { Stiffness } \\
\mathrm{El}_{\text {sub }} \\
\text { (lbs/ft) }\end{array}$ & $\begin{array}{l}\text { Shear } \\
\text { Stiffness } \\
\text { GA }_{\text {sub }} \\
\text { (lbs-in } / \text { ft) }\end{array}$ & $\begin{array}{c}\text { Axial } \\
\text { Stiffness } \\
\text { EA } A_{\text {sub }} \\
\text { (lbs/ft) }\end{array}$ & $\begin{array}{c}\text { Moment of } \\
\text { Inertia } \\
\mathrm{I}_{\text {sub }} \\
\left(\mathrm{in}^{4} / \mathrm{ft}\right)\end{array}$ & $\begin{array}{c}\text { Modulus of } \\
\text { Elasticity } \\
E_{\text {sub }} \\
\text { (psi) }\end{array}$ & $\begin{array}{c}\text { Shear } \\
\text { Modulus } \\
\text { G }_{\text {sub }} \\
\text { (psi) }\end{array}$ & $\begin{array}{l}\text { Area } \\
A_{\text {sub }} \\
\text { (in } / \text { ft) }\end{array}$ & $\begin{array}{c}\text { Shear } \\
\text { Correction } \\
\text { Coefficient } \\
\text { ks }\end{array}$ \\
\hline 17LBs & 1243 & 1120 & 1181 & 0.362 & 37.39 & 413,402 & 215,697 & $3,178,748$ & 0.6088 & 679,020 & 104,465 & 4.681 & 2.267 \\
\hline 17RTs & 1374 & 1374 & 1374 & 0.364 & 39.71 & 480,812 & 251,598 & $3,693,155$ & 0.6128 & 784,569 & 120,703 & 4.707 & 2.258 \\
\hline $19 \mathrm{LBS}$ & 1324 & 1328 & 1326 & 0.391 & 36.63 & 462,143 & 251,423 & $3,497,541$ & 0.6681 & 691,705 & 106,416 & 5.056 & 2.140 \\
\hline 19RTs & 1256 & 1284 & 1270 & 0.352 & 38.98 & 445,245 & 228,962 & $3,441,615$ & 0.5889 & 756,057 & 116,316 & 4.552 & 2.313 \\
\hline 35LTs & 1197 & 1264 & 1231 & 0.360 & 38.64 & 431,036 & 224,247 & $3,317,860$ & 0.6048 & 712,673 & 109,642 & 4.656 & 2.276 \\
\hline $35 \mathrm{RBS}$ & 1264 & 1123 & 1194 & 0.351 & 39.32 & 418,666 & 214,981 & $3,237,844$ & 0.5869 & 713,319 & 109,741 & 4.539 & 2.317 \\
\hline $\begin{array}{l}\text { Mean } \\
\end{array}$ & 1,276 & 1,249 & $\overline{1,263}$ & 0.364 & 38.45 & 441,884 & 231,151 & 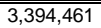 & 0.6117 & $\begin{array}{l}722,891 \\
\end{array}$ & $\begin{array}{l}111,214 \\
\end{array}$ & (4.699 & 2.262 \\
\hline Std. & 63 & 106 & 76 & 0.015 & 1.19 & 26,096 & 16,624 & 189,207 & 0.0296 & 39,994 & 6,153 & 0.188 & 0.064 \\
\hline $\mathrm{COV}$ & 0.05 & 0.08 & 0.06 & 0.04 & 0.03 & 0.06 & 0.07 & 0.06 & 0.05 & 0.06 & 0.06 & 0.04 & 0.03 \\
\hline$+2(\mathrm{Std})$ & 1,402 & 1,460 & 1,414 & 0.393 & 40.83 & 494,077 & 264,399 & $3,772,874$ & 0.671 & 802,878 & 123,519 & 5.075 & 2.391 \\
\hline$-2(\mathrm{Std})$ & 1,150 & 1,037 & 1,111 & 0.334 & 36.06 & 389,691 & 197,903 & $3,016,047$ & 0.553 & 642,903 & 98,908 & 4.322 & 2.133 \\
\hline 5th \% & 1,208 & 1,121 & 1,185 & 0.351 & 36.82 & 414,718 & 215,160 & $3,193,522$ & 0.587 & 682,191 & 104,953 & 4.542 & 2.170 \\
\hline
\end{tabular}

${ }^{*}$ Tested at $30.5 "$ o.c. at north and south spans, with load applied at mid span, load range $=0 \sim 300 \mathrm{lbs}$

\begin{tabular}{|c|c|c|c|c|c|c|}
\hline $\begin{array}{l}\text { Panel } \\
\text { No. }\end{array}$ & $\begin{array}{c}\text { *Weighted } \\
\text { Average } \\
\text { Thickness } \\
t \\
\text { (in) } \\
\end{array}$ & $\begin{array}{c}\text { *Density } \\
\text { —und } \\
\text { (pcf) }\end{array}$ & $\begin{array}{l}\text { *Bending } \\
\text { Stiffness } \\
\text { El }_{\text {und }} \\
\left(\mathrm{lbs}-\mathrm{in}^{2} / \mathrm{ft}\right)\end{array}$ & $\begin{array}{c}\text { Shear } \\
\text { Stiffness } \\
\text { GA }_{\text {und }} \\
\text { (lbs/ft) }\end{array}$ & $\begin{array}{c}\text { Axial } \\
\text { Stiffness } \\
\text { EA }_{\text {und }} \\
\text { (lbs/ft) }\end{array}$ & $\begin{array}{c}\text { Modulus } \\
\text { of } \\
\text { Elasticity } \\
E_{\text {und }} \\
(p s i) \\
\end{array}$ \\
\hline 17LBu & 0.485 & 39.79 & 121,748 & $1,325,614$ & $4,135,917$ & 711,223 \\
\hline 17RTu & 0.483 & 40.86 & 124,677 & $1,354,735$ & $4,226,772$ & 728,962 \\
\hline $19 \mathrm{LBu}$ & 0.479 & 40.69 & 115,876 & $1,310,902$ & $4,090,015$ & 712,240 \\
\hline 19RTu & 0.487 & 40.48 & 128,739 & $1,368,971$ & $4,271,190$ & 731,536 \\
\hline $35 \mathrm{LTu}$ & 0.481 & 40.48 & 118,653 & $1,313,397$ & $4,097,799$ & 710,348 \\
\hline $35 \mathrm{RBu}$ & 0.477 & 41.02 & 122,375 & $1,372,286$ & $4,281,534$ & 747,336 \\
\hline $\begin{array}{l}\text { Mean } \\
\end{array}$ & 0.482 & 40.55 & 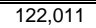 & $\overline{11,340,984}$ & 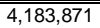 & $\overline{723,608}$ \\
\hline Std. & 0.004 & 0.43 & 4,505 & 27,765 & 86,626 & 14,920 \\
\hline $\mathrm{cov}$ & 0.01 & 0.01 & 0.04 & 0.02 & 0.02 & 0.02 \\
\hline$+2(\mathrm{Std})$ & 0.489 & 41.41 & 131,022 & $1,396,513$ & $4,357,123$ & 753,447 \\
\hline$-2(\mathrm{Std})$ & 0.475 & 39.69 & 113,001 & $1,285,455$ & $4,010,620$ & 693,768 \\
\hline 5th \% & 0.478 & 39.96 & 116,570 & $1,311,526$ & $4,091,961$ & 710,567 \\
\hline
\end{tabular}

Composite Panels

\begin{tabular}{|c|c|c|c|c|c|c|c|c|c|c|c|c|}
\hline & North-Span & South-Span & & & & Partial Con & nposite Action & & & & & \\
\hline $\begin{array}{l}\text { Panel } \\
\text { No. }\end{array}$ & $\begin{array}{c}\text { North Span } \\
\text { Load/Defl } \\
\text { (lbs/in) }\end{array}$ & $\begin{array}{c}\text { South Span } \\
\text { Load/Defl } \\
\text { (lbs/in) }\end{array}$ & $\begin{array}{c}\text { Average } \\
\text { Load/Defl } \\
\text { (lbs/in) }\end{array}$ & \begin{tabular}{|} 
Maximum \\
Load \\
$2 \mathrm{P}$ \\
(lbs)
\end{tabular} & $\begin{array}{c}\text { Nominal } \\
\text { Strength } \\
\mathrm{F}_{\mathrm{b}} \mathrm{S}_{\mathrm{c}} \\
\text { (in-lbs/ft) }\end{array}$ & $\begin{array}{c}\text { Adhesive } \\
\text { Shear } \\
\text { Modulus } \\
\mathrm{G}_{\mathrm{ad}} \\
(\mathrm{psi})\end{array}$ & \begin{tabular}{|c|} 
Effective \\
Axial \\
Stiffness of \\
Underlayment \\
EA $_{\text {und_eff }}$ \\
(lbs/ft)
\end{tabular} & $\begin{array}{c}\text { Effective } \\
\text { Composite } \\
\text { Stiffness } \\
\mathrm{El}_{\text {eff }} \\
\left(\text { lbs-in }^{2} / \mathrm{ft}\right)\end{array}$ & $\begin{array}{c}\text { Effective } \\
\text { Shear } \\
\text { Stiffness } \\
\mathrm{GA}_{\text {eff }} \\
(\mathrm{lbs} / \mathrm{ft})\end{array}$ & $\begin{array}{c}\text { Unattached } \\
\text { Stiffness } \\
\text { EI }_{\text {no_comp }} \\
\text { (lbs-in } / \mathrm{ft})\end{array}$ & $\begin{array}{c}\text { Full } \\
\text { Composite } \\
\text { Stiffness } \\
\text { El }_{\text {full_comp }} \\
\left(\text { lbs-in }^{2} / \mathrm{ft}\right)\end{array}$ & $\begin{array}{c}\text { Composite } \\
\text { Factor }\end{array}$ \\
\hline 17LB & 6,070 & 5,729 & 5899 & 4,370 & 5,206 & 681 & $2,089,014$ & $1,338,523$ & 308,670 & 535,150 & $1,680,608$ & 0.70 \\
\hline $17 \mathrm{RT}$ & 6,775 & 5,680 & 6227 & 5,120 & 6,100 & 524 & $1,837,505$ & $1,388,325$ & 335,935 & 605,489 & $1,862,986$ & 0.62 \\
\hline 19LB & 6,156 & 6,053 & 6104 & 5,010 & 5,969 & 508 & $1,780,194$ & $1,351,443$ & 333,452 & 578,020 & $1,814,026$ & 0.63 \\
\hline 19RT & 6,048 & 5,728 & 5888 & 4,715 & 5,617 & 505 & $1,805,944$ & $1,321,279$ & 314,038 & 573,984 & $1,776,475$ & 0.62 \\
\hline $35 \mathrm{LT}$ & 5,045 & 4,465 & 4755 & 5,330 & 6,350 & 200 & 951,280 & $1,017,466$ & 277,209 & 549,689 & $1,709,724$ & 0.40 \\
\hline $35 \mathrm{RB}$ & 5,333 & 4,738 & 5036 & 4,445 & 5,296 & 283 & $1,243,575$ & $1,100,457$ & 281,859 & 541,041 & $1,688,920$ & 0.49 \\
\hline Mean & $\overline{5,904}$ & $\overline{5,399}$ & $\overline{5,652}$ & $\begin{array}{c}4,832 \\
\end{array}$ & 5,756 & 450 & $\overline{1,617,919}$ & $\overline{1,252,916}$ & 308,527 & $\begin{array}{l}563,896 \\
\end{array}$ & $1,755,457$ & 0.58 \\
\hline Std. & 622 & 638 & 606 & 385 & 458 & 176 & 428,107 & 154,095 & 24,879 & 26,765 & 74,237 & 0.11 \\
\hline $\mathrm{cov}$ & 0.11 & 0.12 & 0.11 & 0.08 & 0.08 & 0.39 & 0.26 & 0.12 & 0.08 & 0.05 & 0.04 & 0.19 \\
\hline$+2(S t d)$ & 7,148 & 6,675 & 6,864 & 5,601 & 6,673 & 803 & $2,474,132$ & $1,561,105$ & 358,285 & 617,425 & $1,903,930$ & 0.80 \\
\hline$-2(\mathrm{Std})$ & 4,661 & 4,123 & 4,439 & 4,062 & 4,840 & 97 & 761,706 & 944,726 & 258,769 & 510,366 & $1,606,983$ & 0.36 \\
\hline 5th \% & 5,117 & 4,533 & 4,825 & 4,389 & 5,229 & 220 & $1,024,354$ & $1,038,214$ & 278,372 & 536,623 & $1,682,686$ & 0.42 \\
\hline
\end{tabular}




\section{Appendix K. Shear Modulus of I-Joist}

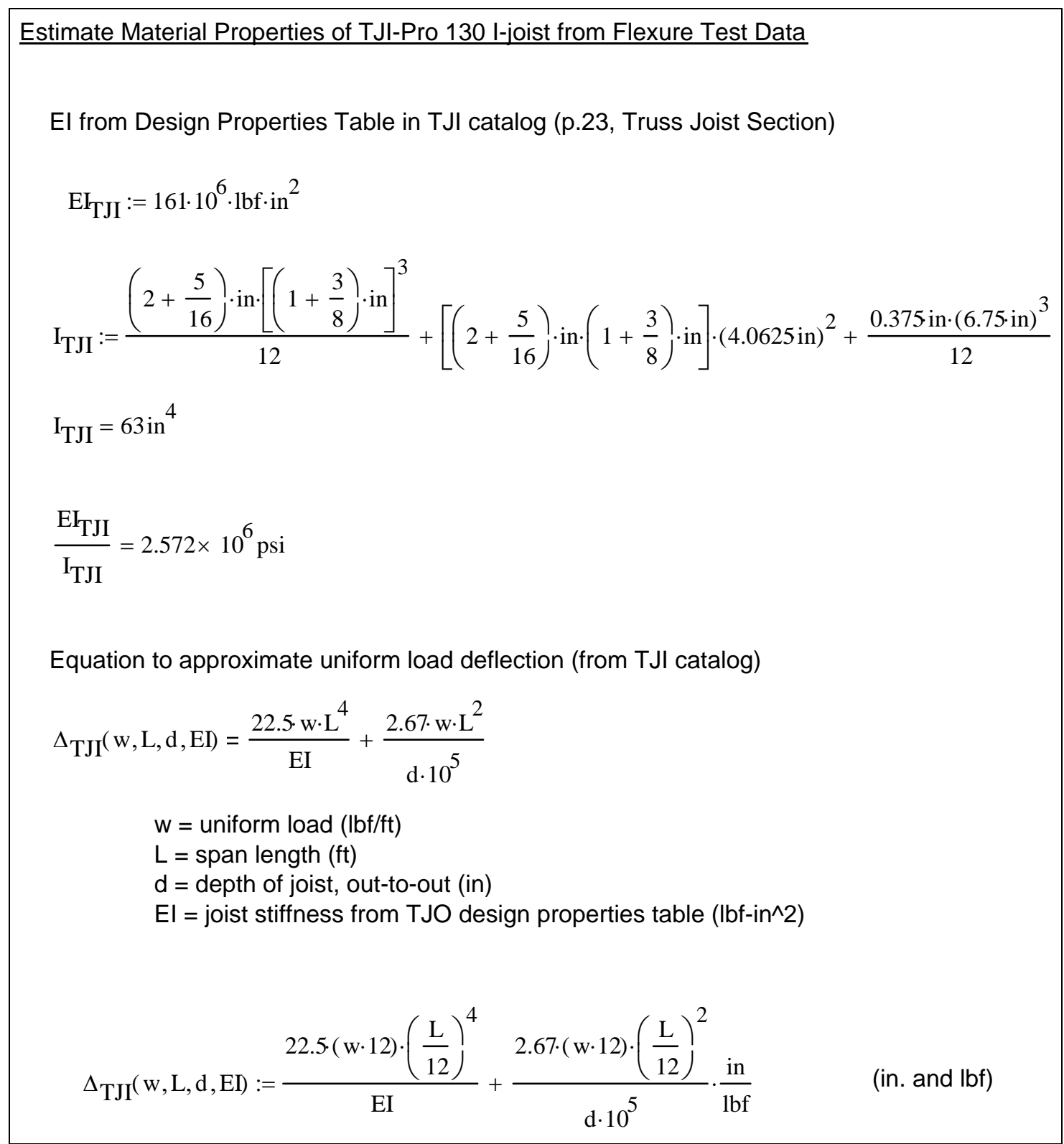


shear deformation of uniformly loaded beam

$2 \cdot \int_{0}^{\frac{L}{2}} \frac{\left(-w \cdot x+\frac{w \cdot L}{2}\right) \cdot \frac{1}{2}}{G \cdot d \cdot t_{w}} d x \rightarrow \frac{1}{8} \cdot w \cdot \frac{L^{2}}{G \cdot d \cdot t_{w}}$

$$
\Delta_{\text {uni }}=\frac{5 \cdot \mathrm{w} \cdot \mathrm{L}^{4}}{384 \mathrm{EI}}+\frac{1}{8} \cdot \frac{\mathrm{w} \cdot \mathrm{L}^{2}}{\mathrm{G} \cdot \mathrm{A}_{\mathrm{S}}}
$$

solve for the implied $\mathrm{G}$ of the $\mathrm{TJI}$ deflection formula

$$
\frac{\mathrm{w} \cdot \mathrm{L}^{2}}{8 \cdot \mathrm{G} \cdot \mathrm{d} \cdot\left(\frac{3}{8} \cdot \mathrm{in}\right)}=\frac{2.67 \cdot(\mathrm{w} \cdot 12) \cdot\left(\frac{\mathrm{L}}{12}\right)^{2}}{\mathrm{~d} \cdot 10^{5}} \cdot \frac{\mathrm{in}}{\mathrm{lbf}}
$$

$\mathrm{G}_{\mathrm{TJI}}:=149813 \mathrm{psi} \quad$ for TJI-130 9-1/2"

$$
\begin{aligned}
& \mathrm{A}_{\text {STJI }}:=\left[(9.5 \cdot \mathrm{in}) \cdot\left(\frac{3}{8} \cdot \mathrm{in}\right)\right] \\
& \mathrm{GA}_{\text {STJI }}:=\mathrm{G}_{\mathrm{TJI}} \cdot \mathrm{A}_{\mathrm{STJI}} \\
& \mathrm{GA}_{\text {STJI }}=533709 \mathrm{lbf}
\end{aligned}
$$




\section{Appendix L. Allowable Moment Estimation for Composite T-Beam}

Allowable Moment of Composite T-beam (with Corrugated Deck System)

$\mathrm{M}_{5 \mathrm{th}}:=11804 \mathrm{lbf} \cdot \mathrm{ft} \quad$ based on $5^{\text {th }}$ percentile value of the test results.

Load factors for residential construction with dead load plus live load:

$$
1.2 \cdot \mathrm{M}_{\mathrm{DL}}+1.6 \cdot \mathrm{M}_{\mathrm{LL}}
$$

Determine an equivalent load factor, LF. Conservatively assume LL/DL ratio approximate infinity

$$
\begin{aligned}
& \mathrm{LF} \cdot\left(\mathrm{M}_{\mathrm{DL}}+\mathrm{M}_{\mathrm{LL}}\right)=1.2 \cdot \mathrm{M}_{\mathrm{DL}}+1.6 \cdot \mathrm{M}_{\mathrm{LL}} \\
& \mathrm{LF}=1.2 \cdot \frac{\mathrm{M}_{\mathrm{DL}}}{\left(\mathrm{M}_{\mathrm{DL}}+\mathrm{M}_{\mathrm{LL}}\right)}+1.6 \cdot \frac{\mathrm{M}_{\mathrm{LL}}}{\left(\mathrm{M}_{\mathrm{DL}}+\mathrm{M}_{\mathrm{LL}}\right)} \\
& \mathrm{LF}=\frac{1.2 \mathrm{M}_{\mathrm{DL}}+1.6 \cdot \mathrm{M}_{\mathrm{LL}}}{\left(\mathrm{M}_{\mathrm{DL}}+\mathrm{M}_{\mathrm{LL}}\right)}
\end{aligned}
$$

take the limit of $M_{L L}->$ infinity

$$
\begin{aligned}
& \lim _{\mathrm{M}_{\mathrm{LL}} \rightarrow \infty} \frac{1.2 \mathrm{M}_{\mathrm{DL}}+1.6 \cdot \mathrm{M}_{\mathrm{LL}}}{\left(\mathrm{M}_{\mathrm{DL}}+\mathrm{M}_{\mathrm{LL}}\right)}=1.6 \\
& \mathrm{LF}:=1.6
\end{aligned}
$$

Determine allowable moment of the composite T-beam:

$$
\phi_{\mathrm{b}} \cdot \lambda \cdot \mathrm{M}_{\mathrm{n}}=\mathrm{LF} \cdot \mathrm{M}_{\mathrm{a}}
$$

let $\mathrm{M}_{\mathrm{n}}=\mathrm{M}_{5 \text { th }}$ and $\mathrm{M}_{\mathrm{a}}=$ allowable moment

$$
\begin{array}{ll}
\mathrm{M}_{\mathrm{a}}:=\frac{\mathrm{M}_{5 \mathrm{th}}}{\frac{\mathrm{LF}}{\left(\phi_{\mathrm{b}} \cdot \lambda\right)}} & \frac{1.6}{(0.85) \cdot(0.8)}=2.353 \quad \text { factor of } \\
\mathrm{M}_{\mathrm{a}}=5017 \mathrm{ft} \cdot \mathrm{lbf} &
\end{array}
$$

